\title{
JEWISH MUSIC \\ IN ITS HISTORICAL \\ DEVELOPMENT
}

\author{
by \\ A.Z. IDELSOHN \\ Professor of Jewish Music \\ Hebrew Union College
}

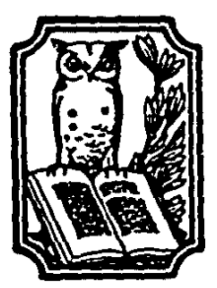

NEW YORK

HENRY HOLT AND COMPANY 
COPYRIGH T, I 929,

BY

HENRY HOLT AND COMPANY, INC.

STADTPIBLIOTHER

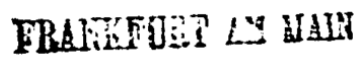

PRINTED IN THE

UNITED STATES OF AMERICA 


\section{PREFACE}

The aim of this book is to give a description and an analysis of the elements and characteristics of Jewish music, in their historical development, from the earliest times of its appearance as a Semitic-Oriental song, throughout the ages and countries. We follow its history as a tonal expression of Judaism and of Jewish life. We try to point out the influence that the foreign music of the environment exerted upon Jewish music, and seek to explain the principles according to which certain foreign elements were incorporated until they became organic parts of the musical body. In this music we find original elements and features, reflecting the spiritual life of the Jewish people.

The book presents the result of the author's research-work in the field of Jewish music during a quarter of a century, of first-hand collecting of Synagogue- and folk-songs in the Oriental and European Jewish communities, and of analyzing these into their elements. The amassed material the author classified, edited and has been publishing in his Thesaurus of Hebrew Oriental Melodies, five of the ten volumes of which have thus far been issued by Benjamin Harz, Berlin, 1922-28. Further, the author made a thorough study of all available old music manuscripts as well as of the vast literature of Synagogue- and folk-music published in both hemispheres-all of which is indispensable to an insight into the spirit of the music and its history. He has correlated all references to music scattered throughout Hebrew literature, from the Bible down to the latest works, in order authentically to assign to music the place that it occupied in Jewish religious and secular life. In 
addition, he found it imperative to. acquaint himself in detail with the music of the many peoples among whom Israel lived or with whom the people came into contact during its 3,500 years of history, because only thus could he draw comparisons with Jewish song.

The book is written not only for technically trained musicians but for the intelligent lay public as well. The student will find technical details, a complete theory and in the notes at the end of the book, a clue to the most important sources; while the layman will gain a knowledge and an understanding of the history, development and character of the music. For clarity, the book is printed in two types: a large one for the nontechnical and a smaller one for the technical sections. All nonEnglish terms are italicized and explained. For both groups of readers the book is liberally illustrated with every type of music discussed and with a table for each comparative study. Almost all the texts of the musical illustrations are either translated or paraphrased in English.

Hebrew transliteration throughout the book follows the system here listed as first in order after each vowel or consonant. The additional possibilities named are employed with the purpose of rendering certain texts as they are pronounced in specific localities:

Vowels:

$\tau=\mathrm{a}$; Ashkenazic, Yemenite and Persian $=$ o.

$i=0$; Lithuanian $=\mathrm{ej}$ or $\mathrm{oj}$.

$q=\mathrm{u}$.

$\cdot=\mathrm{i}$.

$-=\mathrm{a}$.

$*$ e or ey.

$\because=\mathrm{e}$; $\mathrm{e}$.

$:=\mathrm{e}, \mathrm{e}$, or ${ }^{\prime}$. 
Dagesh forte is indicated by the doubling of the letter.

\section{Consonants:}

$$
\begin{aligned}
& x=a \\
& \mathrm{a}=\mathrm{b} \\
& \mathrm{z}=\mathrm{v} \text { or } \mathrm{b} \\
& \text { d, } \mathrm{g}=\mathrm{g} \\
& \text { 7. } \mathrm{T}=\mathrm{d} \\
& \mathrm{r}=\mathrm{h} \\
& \mathrm{l}=\mathrm{w}, \text { Ashkenazic }=\mathrm{v} \\
& i=\mathrm{z} \\
& \Pi=\mathrm{h} . \text { Ashkenazic }=\mathrm{ch} \\
& \Delta=\mathrm{t} \text { or } \mathrm{t} \\
& i=\mathrm{y} \\
& \exists=\mathrm{k} \\
& \mathrm{T}, \mathrm{J}=\mathrm{ch} \text { or } \underline{\mathrm{h}}
\end{aligned}
$$

$$
\begin{aligned}
\partial & =1 \\
0, D & =\mathrm{m} \\
i, J & =\mathrm{n} \\
y, D & =\mathrm{s} \\
y & =\mathrm{a} \text { or } \\
\mathrm{B} & =\mathrm{p} \\
\mathrm{v} & =\mathrm{f}
\end{aligned}
$$

$r, \mathrm{~s}=\mathrm{s}$, Ashkenazic $=\mathrm{tz}$

$p=k ; q ;$.

$7=\mathrm{r}$

$\dot{v}=\operatorname{sh}$ or $\mathbf{s}$

$\pi=\mathrm{t}$

$\pi=$ th or $\underline{t}$, Ashkenazic s.

Biblical names and terms are here given as they occur in the Bible translation issued by the Jewish Publication Society of America, Philadelphia, I917.

Arabic, Syriac, Ukrainian, Ladino and Yiddish texts are transliterated with the one aim of making them pronounceable by the English reader. Technical phonetics is, therefore, not observed. $G$ is to be pronounced like " $\mathrm{dj}$ " and " $\mathrm{zh}$ " like "zsh."

The author wishes to make acknowledgment of the valuable assistance of $\mathrm{A}$. Irma Cohon in the presentation of the material of this book; to express his indebtedness to Professor Samuel S. Cohon for his reading of the manuscript and his helpful suggestions; and to record his gratitude to Dr. Joshua Bloch, chief of the Jewish Division of the Public Library, New York, for his furtherance of this work.

\section{A. Z. IDELSOHN.}





\section{TABLE OF CONTENTS}

\section{PART I}

THE SONG OF THE SYNAGOGUE

CHAPTER

I. A HISTORICAL SURVEY OF RELIGIOUS AND SECULAR MUSIC IN ISRAEL AND ITS NEIGHBORING COUNTRIES THROUGHOUT BIBLICAL AND POST-BIBLICAL AGES UP TO THE DESTRUCTION OF THE SECOND TEMPLE

II. SEMITIC-ORIENTAL SONG. TABLES I, II, AND III . .

III. THE OLDEST UNRHYTHMICAL ELEMENTS OF JEWISH SONG. A: THE MODES OF THE BIBLE-THE TA'AMIM (MUSical NOTATION) OF THE BIBLE. TABLES IV, V, VI, VII, VIII, IX, X, AND XI . . . . • .

IV. THE OLDEST UNRHYTHMICAL ELEMENTS OF JEWISH SONG (CONTINUED). B: THE MODES OF THE PRAYERS. TABLES XII, XIII, XIII ${ }^{2}, \mathrm{XIV}$, AND XV

V. A HISTORICAL SURVEY OF THE SYNAGOGAL SONG AFTER THE DESTRUCTION OF THE SECOND TEMPLE UNTIL THE RISE OF ISLAM ( 70 C.E. - 700 C.E.) . .

VI. THE RISE AND DEVELOPMENT OF THE PRECENTOR AND THE CHAZZAN FROM ANCIENT TIMES UNTIL THE EIGHTH' CENTURY

VII. THE RHYTHMICAL SONG IN THE ORIENTAL AND SEPHARDIC SYNAGOGUE. TABLES XVI, XVII, XVIII, XIX, AND $\mathrm{XX}$

VIII. THE SYNAGOGUE SONG OF THE "ASHKENAZIM." TABLES $\mathrm{XXI}, \mathrm{XXII}, \mathrm{XXIII}, \mathrm{XXIV}, \mathrm{XXV}, \mathrm{XXVI}$. . .

IX. THE SONG OF THE SYNAGOGUE IN EASTERN EUROPE UP TO THE EIGHTEENTH CENTURY. TABLES XXVII AND XXVIII

181

$X$. THE INTRODUCTION OF HARMONY AND POLYPHONY INTO THE SYNAGOGUE IN ITALY BY SALOMON ROSSI vii 
CHAPTER

XI. THE ASHKENAZIC SONG OF THE SYNAGOGUE IN THE SEVENTEENTH AND EIGHTEENTH CENTURIES. TABLE $\mathrm{XXIX}$

XII. THE INFLUENCE OF THE REFORM MOVEMENT ON THE SYNAGOGUE SONG IN THE BEGINNING OF THE NINETEENTH CENTURY

XIII. THE INFLUENCE OF MODERATE-REFORM UPON SYNAGOGUE SONG DURING THE NINETEENTH CENTURY IN CENTRAL AND WESTERN EUROPE. BIBLIOGRAPHY

XIV. "CHAZZANIM" AND "CHAZZANUTH" IN EASTERN EUROPE IN THE NINETEENTH CENTURY

XV. THE SYNAGOGUE SONG IN THE UNITED STATES OF AMERICA

XVI. COLLECTIONS OF AND LITERATURE ON SYNAGOGUE SONG

\section{PART II}

FOLK-SONG

XVII. THE FOLK-SONG OF THE ORIENTAL JEWS. TABLE XXX

XVIII. THE FOLK-SONG OF THE ASHKENAZIM. TABLES XXXI AND XXXII

XIX. THE CHASSIDIC SONG. TABLE XXXIII .

XX. BADCHONIM (MERRY-MAKERS) AND KLEZMORIM (MUSIC-MAKERS). SONG AND SINGERS IN FOLK STYLE. TABLE XXXIV

XXI. ARTISTIC ENDEAVORS . . . . . . . . . . . 461

XXII. THE JEW IN GENERAL MUSIC . $. \quad . \quad . \quad \cdot 47$ I

XXII. HARMONY. TABLE XXXV. . . . . . . . . 478 CONCLUSION . . . . . . . . . . . . . 488

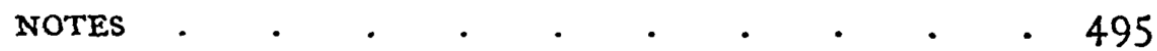

INDEX $. \quad . \quad . \quad . \quad . \quad . \quad . \quad . \quad . \quad 523$ 
TABLES OF THE MUSICAL ILLUSTRATIONS TABLE

I. ARABIC TUNES: (a) SECULAR; (b) RELIGIOUS . . 29

II. JACOBITE CHURCH SONGS: (a) UNRHYTHMICAL; (b) RHYTHMICAL . . . . . . . . 3 I

III. GREEK CHURCH TUNES .

IV. PENTATEUCH: I. Babylonian; 2. PORTUGUESE-AMSTERDAM ; 3. ASHKENAZIC-LITHUANIAN ; 4. ASHKENAZIC; 5. KYRIE ELEISON (3RD TONE GREGORIAN); 6. CARPENTRAS. - COMPARATIVE TABLE OF ACCENTS-MOTIVES IN THE INTONING OF THE PENTATEUCH

v. RUTH: BABYLONIAN-ASHKENAZIC. SONG OF SONGS: LITHUANIAN • .

VI. TUNES FOR THE POETRY OF THE PENTATEUCH: YEMENITE; PORTUGUESE . . . . . .

VIr. PROPHETS: I. YEMENITE-PENTATEUCH; 2. PERSIANSONG OF SONGS; 3. YEMENITE-PROPHETS; 4. BABYLONIAN-PROPHETS; 5. ASHKENAZIC-PROPHETS; 6. ASHKENAZIC-PROPHETS IN EASTERN EUROPE; 7 . ASHKENAZIC CONCLUDING MOTIVE OF THE CHANT OF THE PENTATEUCH . . . . . . .

VIII. LAMENTATIONS: I. BABYLONIAN; 2. PORTUGUESE; 3. ASHKENAZIC; 4. SEPHARDIC-ASHKENAZIC; 5-6. GREGORIAN CHANT .

IX. JOB: I. SEPHARDIC-ORIENTAL; 2. ASHKENAZIC-PENTATEUCH FOR THE HIGH HOLIDAYS

X. PSALMS: (a) SEPHARDIC-ORIENTAL; ASHKENAZIC: I-3; (b) MOROCCAN: 4-8; (c) YEMENITE: 9-14; GREGORIAN: I 5-I 8

62

XI. ESTHER: I. YEMENTTE; 2. BABYLONIAN; 3. ASHKENAZIC

XII. TEFILLA MODE: I. YEMENITE; 2. SYRIAN-ORIENTAL; 3. SEPHARDIC-EUROPEAN; 4. ASHKENAZIC; 5 . GREGORIAN (4TH TONE); 6. GREGORIAN . . ix 
XIII. COMPARATIVE TABLE OF SELICHA MODES: I. PERSIAN;

2. YEMENITE; 3. ASHKENAZIC IN EASTERN EUROPE;

4. BABYLONIAN-SEPHARDIC; 5. SEPHARDIC-ORIENTAL

XIII a. COMPARATIVE TABLE OF VIDDUI MODES: I. YEMENITE;

2. PERSIAN; 3. BABYLONIAN; 4. ASHKENAZIC

XIV. MOGEN OVOS MODE (STEIGER): 1. ASHKENAZIC; 2. SEPHARDIC-ORIENTAL

XV. AHAVOH-RABBOH MODE: I. SEPHARDIC-ORIENTAL;

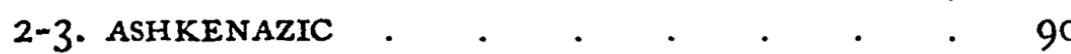

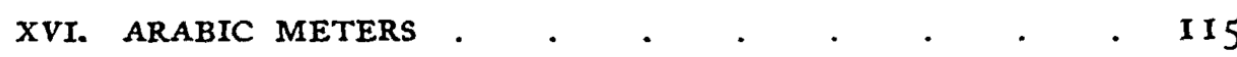

XVII. MELODIES IN THE HAZAĞ METER: (a) YEMENITE;

(b) BABYLONIAN; (c) SEPHARDIC

XVIII. YEMENITE: (a) MELODIES IN THE RAǦAZ METER;

(b) MELODIES IN THE MUTAKARIB METER; (c)

MELODY IN THE KAMIL METER

XIX. SEPHARDIC-ORIENTAL: (a) RHYTHMICAL MUSIC SET TO NON-METRICAL TEXTS; (b) UNRHYTHMICAL MUSIC SET TO METRICAL TEXTS .

XX. "ADONOY BEKOL SHOFAR": I. SEPHARDIC-ORIENTAL;

2. MOROCCAN; 3. ITALIAN; 4. SEPHARDIC-LONDON;

5. CARPENTRAS

XXI. (a) ASHKENAZIC MODES IN MINOR . . . . ${ }_{138}$

XXIr. (b) ASHKENAZIC MODES IN MAJOR . . . . $\quad 145$

XXIII. ASHKENAZIC TUNES FOR INDIVIDUAL PROSE TEXTS: 1 . OLENU; 2. HAMMELECH; 3. OVOS I, OVOS II; 4. KADDISH; 5. VEHAKKOHANIM I, II; 6. KOL NIDRE I-IV .

XXIV. MELODIES OF THE GREGORIAN AND MINNESONG . 163

XXV. ASHKENAZIC TUNES FOR INDIVIDUAL POETICAL TEXTS: OSCHOH EDROSH; EIN AROCH; AAPID NEZER; EDER VEHOD; ESOH DEI; TUMAS TZUROM; SHOFET KOL HOORETZ; ELI TZIYON; MOOZ TZUR; ADDIR HU I, II, III, IV .

XXVI. MOTIVES AND TUNES OF GERMAN RELIGIOUS AND SECULAR FOLK-SONG

XXVII. (a) UKRAINIAN SONG: SYNAGOGAL AV-HORACHMIM MODE; UKRAINIAN MOTIVES IN "DORIAN"; UKRAINIAN MOTIVES IN "DORIAN" ENDING ON THE SECOND. (b) ROUMANIAN SONG 
TABLES OF THE MUSICAL ILLUSTRATIONS TABLE

XXVIII. TABLE OF COMPARATIVE FOLK-SONGS WITH THE YIG-

DAL TUNE: I. SPANISH CANCIO; 2. JEWISH SEPHARDIC FOR TAL; 3. POLISH SONG; 4. ZIONIST HYMN HATIKVA; 5. DORT WO DIE ZEDER; 6. YIGDal; 7. Basque tUNE; 8. Basque tune; 9. SMETANA . . . . . . . . .

XXIX. (a) EN KELOHENU; (b) ETZ CHAYIM • • . 239

XXX. FOLK-SONGS OF THE ORIENTAL JEWS: (a) HEBREW SONGS OF THE BABYLONIAN AND SYRIAC JEWS: BABYLONIAN; SEPHARDIC-SYRIAN; YEMENITE. (b) SPANISH SONGS . $. \quad . \quad . \quad . \quad . \quad . \quad . \quad 372$

XXXI. TUNES OF ASHKENAZIC SONGS IN JUDEO-GERMAN OF THE SEVENTEENTH CENTURY: DER TOD ALS SCHNITTER; BRUDER VEITSTON; ES IST KEIN GRÖSSER FREUD .

XXXII. TUNES OF THE EASTERN ASHKENAZIC FOLK-SONG • 401 XXXIII. CABBALISTIC AND CHASSIDIC SONGS: (a) TUNES IN AHAVOH-RABBOH MODE; (b) TUNES IN MINOR; (c) TUNES IN MAJOR

XXXIV. I. TUNE BY W. EHRENKRANZ; 2. TUNE BY E. ZUNSER XXXV. HARMONY: (a) AHAVOH-RABBOH: I-7; (b) MINOR 8-9; (c) ADONOY-MOLOCH: IO-II. 



\section{FACSIMITES}

ICCENTS: PENTATEUCH (LEVITICUS 22:26-33; $23: 1-7$ ) PaGE ITALIAN MS. I5TH CENTURY . . . . . 36

II. ACCENTS: PROPHETS (I SAMUEL I5: I-6). ITALIAN MS. I5TH CENTURY . . . . . . . . . . 36

III. ACCENTS (JOB 3:2-I4). MS. I3TH CENTURY • $\quad 37$

IV. ReUChlin, DE ACCentibus. PUB. hagenau, I518 . 37

V. SALOMON ROSSI. PUB. VENICE, 1622 . . . . 200

Vi. ISRael Jacobson hymnal. pUb. CASSel, I810 . . 237 


\section{KEY TO INTERPRETATION OF MUSICAL ILLUSTRATIONS}

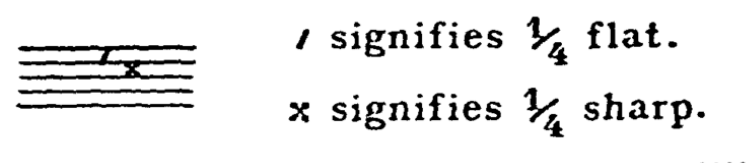

The signs $b$ \# in unrhythmical music: The "accidental" is noted (irrespective of motive divisions) only the first time that it occurs in a continuous series of the same note. Whenever other notes intervene, the note in question either is marked anew or should be understood to have resumed its tone value in the key employed.

Bar-divisions in unrhythmical music indicate motives.They should not be construed to determine accent.

Repeated notes on one syllable, in Oriental song, are not tied to make one prolonged tone, as in modern Occidental song. The Oriental musician or the singer of the old Church song, holds the vowel or consonant of the word sung, while producing a throbbing repetition of the note in question. 
PART I

THE SONG OF THE SYNAGOGUE 



\section{CHAPTER I}

A HISTORICAL SURVEY OF RELIGIOUS AND SECULAR MUSIC IN ISRAEL AND NEIGHBORING COUNTRIES THROUGHOUT BIBLICAL AND POST-BIBLICAL AGES TO THE DESTRUCTION OF THE SECOND TEMPLE.

In surveying the development of music in ancient Israel it is essential to consider the music of Israel's ancient neighbors. In so doing we are enabled to draw a conclusion as to the extent to which Israel's music resembled that of the bordering countries of Palestine, during the period of Israel's development as a nation and thereafter, through the Second Temple until its destruction. From such comparison we likewise gain an idea of the features gradually developed in Israel's music, as an expression of its spiritual evolution. We discover the musical elements and tools held in common with the other ancient cultured peoples, and find how these were reshaped in conformity with Israel's spiritual concepts, and how the resultant music received an original form of expression.

We observe that as the song of the other ancient Oriental peoples, so Israel's music from earliest times was determined by his religious and social life, and the form of that music changed with the changes of Israel's religious attitudes and political conditions.

We turn first to the old Egyptian music. As long as the Egyptian religion and culture were in their flower, music was developed as a tool of expression and drew its significance from its influence upon the sentiments of the gods in the higher regions, the gods in the lower regions, and not less upon the 
evil spirits. The musicians were the priests, male or female, who were also the sacred dancers. Music was regarded as sacred and was credited with its own ETHOs-its divine power. But in the course of ages Egyptian culture outlived itself. When new ideas arose, revolutionizing the old-established ones, the aristocratic party clung desperately to its tradition, and forced the priest-musicians to fascinating expressions which they could no longer draw from the heart of their institution, since it now lacked vital influence.

Though we no longer know Egyptian music because, in the words of the music historian Ambros, we did not have the opportunity of listening to it for even one minute in order to be able to judge its sound, ${ }^{1}$ nevertheless, from our record of the manner of use of the musical instruments we may deduce that at the time of its height, Egyptian religious music had a certain dignity and holiness, inasmuch as those instruments employed were not held conducive to arousing sensuality. Thus, the religious musicians did not use the "profane" Aulos (pipe). Neither did they employ a great number of instruments of percussion, but usually they employed only one drum and one pair of cymbals in an entire religious orchestra. The main instruments were string instruments: the Nabla (different kinds of harps) and the Kithara (different kinds of lyres imported later by Semites). There were further the double-flute which was of an entirely different quality from the single flute or Aulos, and finally the trumpet and the Sistrum-both signal instruments only.

Plato says that the Egyptians accredited their sacred melodies to the goddess Isis. He praises them for their ability to create melodies which had the power to subdue the passions of man and purify his spirit. "This certainly must be the work of god or of a godly man," he exclaims. This might have been the reason that the Egyptians considered their religious melodies 
sacred and would not change them. Neither would they use foreign tunes, as Herodotus, the great Greek historian, states. $\mathrm{He}$ was, therefore, surprised to hear in Egypt a tune famous in Phœnicia, Cyprus and Greece-namely, the lamentation over Linos which the Egyptians called Maneros. ${ }^{2}$

At the beginning of the decay of Egypt, after the period of the Hyksos, we find that the flute was introduced for religious purposes, and that there was a marked increase of percussive instruments as well as of fascinating dancers and singers, as we see from the bas-reliefs representing processions of orchestras, etc., found in the tombs of the Egyptian kings. During the decay, the musicians carefully hid their products, both musical and poetic, allowing no one to see the "books of the songs." According to Pythagoras, who studied in Egypt around the sixth century B.C.E., the protests of the priests against virtuosity were of no avail, because artificiality had to cover the mummy of that great and powerful culture, until it was laid low by Cambyses and later cut off by Alexander. Did Egyptian musical expression die together with its religion? Not entirely; for some of the best human expressions in it were taken over by ISRAEL and GREECE.

The music of the Phonnicians, whose close geographical and ethnological relationship to Israel should lead us to expect many features in common in the music of the two tribes, was nevertheless-according to the description of many Greek authorsin the sharpest contrast with Israel's, at least during the period of the Second Temple. The Phœnicians had the triangular Kinnor which the Greeks borrowed and called Kinura, and the Neval, known to the Greeks as the Sidonian Nabla, and which, according to their tradition, the Egyptians likewise adopted. But the arrangement of the religious orchestra, as well, apparently, as the contents of the music, was of a different nature, for it had an exceedingly sensuous and exciting character. It 
went to the extremity of joy on the one hand, and to the extremity of lamentation (especially for Adonis) on the other, resulting in a boisterous chaos of percussive instruments. Chief in the music of the Phœnician cult-whether for joy or lamentation-was the Abobas (pipe). By this instrument Adonis was lamented, and it therefore became synonymous with Adonis music. The fundamental difference between the music of Israel and Phønicia affords the best proof for the contention that music was always a tool by which ideas were expressed. The fight of Elijah against the Phœnician Baal- and Ishtarcult, which the Phœnician princess Jezebel introduced into Samaria, was one of the bitterest battles prophetic Israel fought. The Biblical description of the barbarous manner of the Baal worshippers: "they danced in halting wise about the altar . . . they cried aloud, and cut themselves after their manner with swords and lances, till the blood gushed out upon them" (I Kings I 8: 26-28), finds its confirmation in the statement of Lucian that at the Spring festivity in honor of Ishtar the noisy and exciting music of the double-pipes, cymbals and drums used so to stimulate the youths to a frenzied craze that they would emasculate themselves. "At the sound of pipes, cymbals and drums, and several other percussive instruments, those emasculated servants of the goddess Ishtar would march through the streets in procession, cut themselves with swords, and lash themselves until blood gushed forth." Isaiah's satire (23: I6) on Tyre, "Take a harp, go about the city, thou harlot long forgotten; make sweet melody, sing many songs, that thou mayest be remembered," finds an explanation in the statement of Horace, who says that "even during the time of the Roman Empire, Phœnician and Syrian female musicians, whose reputation for immorality was known, would be found in the Ambubajarum Collegia.... and in the circus (Roman Arena) offering themselves." 
Music in Assyria and BABYlonia was somewhat similar to that in Egypt. Only few bas-reliefs have been unearthed, presenting musical instruments. On the Ashurakhbal bas-relief a procession of an orchestra is reproduced. ${ }^{3}$ In that orchestra there participate nine boys singing and clapping their hands; three men with big harps, of whom two are dancing; one man playing the double-pipe; one, an oblong harp; four women fingering the big harp; one woman playing the double pipe; one beating a small drum; one man striking the cymbals; six females singing, one of whom presses her cheek and throat with one hand. The composition of that orchestra gives us a clear idea of the character of the music in Assyria. We learn from it that the percussive instruments were of minor importance, and that in employing nine boys' voices and six female singers, stress was laid upon vocal music and sweet singing. Furthermore, there are seven string instruments, only two double-pipes, and no single-pipes at all. Considering that the procession was to meet the king upon his return from battle as a conqueror-and Assyrian kings were always supposed to be victorious-the two small drums and the one cymbal are too modest noise-makers even for our refined taste. This fact indicates a tendency toward refinement of musical expression. And the highly developed hymns and supplications, with their RESPONSIVE form sung by priests and confessors and offerers of sacrifices, which were in use in Babylonia long before Israel came into being, lead us to conclude that the Assyrian music ranks next to the Egyptian as a source out of which Israel drew its best elements of musical forms.

With regard to ancient religious music of the TEMPLE IN JERUSALEM, we have to apply the same words that Ambros did to Egyptian music: ". . . could we listen to it for but one moment!" However, from the composition of the orchestra of the First Temple, we learn that Israel accepted some of the 
arrangements of the religious orchestra used in Egypt at the time of its cultural height. The legend that when Solomon married Pharaoh's daughter she brought with her a thousand varieties of musical instruments ${ }^{4}$ seems to be based upon historical facts, for we find that the instruments employed in the First Temple and the arrangements of its orchestra bore similarity to those in Egypt.

The orchestra of the Temple of Jerusalem consisted of the following instruments: Nevel, the big harp, originally without resonant body; Kinnor, the little lyre or harp, the Semitic form of which was the square, and the Phœnician and Assyrian form of which was mostly triangular. The Kinnor had no resonant body. Both were sTRING instruments. Their difference lay in the number of strings as well as in size, as the Talmud explains. ${ }^{5}$ These two instruments were the most important ones, without which no public religious ceremony could be held. As to the number of their strings we have no definite information. Whether sheminith indicates eight and asor ten strings cannot be proved. ${ }^{6}$ We do know, however, that in Egypt and Assyria the number of the strings of the harps and lyres, etc., varied from three to twenty-two. Neither have investigations been successful in finding out the tonality, the range and pitch, of the string instruments in Israel or Egypt. We are rather more informed of the quality of their tone. The tone of the Kinnor is described in the Bible as "sweet," "tender," "soft"-lyrical. The Kinnor was popular among the more cultured classes in Israel. The tone of the Nevel was naturally stronger because the instrument was larger than the Kinnor, especially after it had received a resonant body. According to Josephus, the Nevel had twelve strings and the Kinnor ten." And from him we know that on the Nevel they used to play with their fingers, whereas for the Kinnor they employed the plectrum. However, it is reported of King 
David that he played the Kinnor with his hand-which means fingers. (I Sam. I6: I6 and 23; I8: 10; 19: 9.)

There were likewise two kinds of wind instruments, one of which was of no musical value, serving only for signaling purposes. To this class belongs (a) the Shofar-ram's-horn (in Assyrian shapparu-wild mountain-goat). ${ }^{8}$ It produces a few tones approximating $\mathrm{c}-\mathrm{g}-\mathrm{c}$, or any other equivalent intervals, e.g., I-5-I, or 5-8-8; I-4-8, and so on. The pitch, naturally, depends on the size of the Shofar and on the construction of its hollow. The instrument lends itself to the production of various rhythmical forms, from long notes to I/32. But it is impossible to produce on it any melody whatsoever. Indeed, the Bible applies the terms "blowing"tekia, meaning long notes, and "shouting"-terua, meaning short notes in staccato or tremulo form, but not nagen-"producing musical tones." It was used chiefly for announcements and signals, not only in secular life, but also in religious ceremonies to call on the god to remind him of his duties to his people, or to wake him from his sleep. To the Shofar was also attributed the magic power of frightening and dispersing evil spirits and gods of the enemies who helped their people in battle. This belief was current among all primitive tribes, and it was, likewise, accepted in Israel, as many Biblical stories and phrases testify. The blowing of the Shofar was even attributed to Yahve himself, in order to frighten his enemies and to gather the scattered remnants of his people to his sanctuary. Thus, Zachariah (9: I4-I 5) says: "And the Lord God will blow the horn. . . . The Lord of Hosts will defend them." Later, after the Second Destruction, the idea of blowing the "Shofar of Redemption" was transferred to the prophet Elijah, who is supposed to announce the coming of the Messiah.

During the latter part of the period of the Second Temple 
two types of Shofaroth were in use: the curved (male) ram'shorn and the straight (female) mountain-goat's horn. The latter form with a gold mouthpiece was used in the Temple on New Year, whereas the first form, with a silver-covered mouthpiece, was used on fast-days. After the destruction of the Temple no luxurious decorations were permitted.

The Shofar is the only instrument that retained its position in the Synagogue throughout the Medieval Ages up to the present day. On New Year's Day the Shofar was blown to remind God of His promise to Abraham, Isaac and Jacob, and especially of Isaac's sacrifice and of the ram that substituted him (Gen. 2I: I3). ${ }^{9}$ Later, Jewish philosophers, such as Saadia (tenth century), tried to interpret the custom of Shofar blowing by giving it a higher human idea, namely, that the sound of the Shofar stirs the heart to awe and reverence, and its purpose, therefore, is to remind us of our duties to God..$^{10}$ In like manner, Maimonides speaks of this custom. ${ }^{11}$

Of all musical instruments, it was the most unmusical of them, the Shofar, that was retained. Because of the religious reasons just mentioned, it was carried into the Synagogue. The term tekia of the Bible and Mishna was in the third century explained as a "long note," whereas concerning the term terua difference of opinion arose as to whether it meant short staccato notes or a tremolo on one sustained note. Finally, in the fourth century Rabbi Abahu in Cæsarea (Palestine) made a compromise that both ways should be used, the staccato (shevarim) and the tremolo (terua), and thus it remained to this day. ${ }^{12}$

(b) The Chatzotzera-TRUMPET seems to have been imported from Egypt, though it was also known to the Assyrians. ${ }^{13}$ The trumpet was made out of silver and was used for signaling purposes (Num. IO: I-IO), for secular and religious functions. Only the priests were entrusted with the 
use of it, as was the custom in Egypt. Chatzotzera and Shofar are, as a rule, quoted together, and for both the terms "tekia" and "terua" are applied. From this we may deduce that their natures were alike. Both were handled by priests and not by Levites-the professional musicians of the Temple-a fact which proves that both served the same function of signaling. Josephus describes the Chatzotzera as being of approximately a cubit's length, its cylinder being somewhat larger than that of the Halil (pipe), its mouthpiece wide and its body expanding into a bell-like ending. ${ }^{14}$ The form of the Chatzotzera is still preserved on the Jewish coins of the later part of the period of the Second Temple, and on the Titus arch in Rome.

As to the number of these two instruments employed in the Temple, we are informed that originally two Chatzotzeroth were ordered (Num. 1.c.), which number remained as a minimum requirement for the Temple service. However, as a maximum, one hundred twenty trumpets might be used. And, indeed, at the dedication of Solomon's Temple, it is reported ( 2 Chron. 5: I2) that this number of trumpets was employed..$^{15}$

The number of Shofaroth was restricted in the Mishna to one for New Year and two for fast-days. ${ }^{18}$

We know of three kinds of musical wind instruments:

(a) Uggav-small pipe or flute. This instrument is not mentioned in the list of the musical instruments used in the Jerusalem Temple. ${ }^{17}$ The only reference to $U$ ggav is in Psalm I 5O, 4. In the later period of the Second Temple it was called Abbrib-hollow reed, ${ }^{18}$ and was identical, at least in name, to the Phœnician Abobas. Tradition reports of an Abbub which had been in the Temple since the time of Moses. It was small and of fine reed, and had a sweet tone. ${ }^{19}$ It was, however, seldom used-only as a solo instrument for interludes "because it slides over softly." 20 Emphasis was laid upon reed instruments which alone produced, according to Jewish taste, a tender 
and sweet tone." The Uggav, it is reported, "was one of the two instruments retained from the First Temple, but when it became defective it could not be mended." ${ }^{22}$ From all of which we learn that the $U g g a v$ was an ancient instrument, once in use in the First Temple; that it had gradually disappeared, so that the last one which survived could not be mended when damaged.

(b) Halil or Chalil-big pipe; in Greek, mono-aulos. Though in ancient Israel the Halil was one of the most popular instruments in secular as well as in religious life, none the less we do not find its name on the list of instruments of the service throughout the First Temple. ${ }^{23}$ Later, at the time of the Second Temple, the Halil was permitted at the service but only on twelve festal days during the year "to increase joy." The number was set from a minimum of two to a maximum of twelve. On Sabbath no playing of the Halil was permissible even at the Temple, because it was not held to be a sacred instrument as the Kinnor and Nevel. ${ }^{24}$ The Halil was also considered by Jews at that time as an exciting instrument, and was used for occasions of extreme joy and gaiety, such as weddings or public processions of the pilgrims with their offerings of the first fruit. ${ }^{25}$ Likewise was it used to express extreme sorrow, as, for example, during funerals, for which occasion even the poorest man had to hire two Halilim-players in order to show his grief over the death of his wife. ${ }^{26}$

The structure of the Halil was similar to that of the Greek Aulos (i.e., with a mouthpiece), and, according to Maimonides, similar to the Arabic Muzmar. ${ }^{27}$ Its tone was sharp and penetrating, like that of the oboe. ${ }^{28}$. The Mishna tells us, in a somewhat exaggerated way, that whenever the Halilim were blown at the Temple their tone carried as far as Jericho. ${ }^{29}$ For that reason the Halil was used for processions, as described by 
Isaiah (30:29), this custom prevailing as late as Mishnaic times.

The fate of the Halil in the Jerusalem Temple was similar to the fate of the Aulos in Greece. Olympus introduced it to Greece about 800 B.C.E. from Asia Minor, but the Greek philosophers opposed it because of its exciting sound and because it was tuned according to the four notes $d^{1} 1 / 2 \# c c^{1} 1 / 2 b b 1 / 2$ a, a tetrachord unfamiliar in Greece. On account of its strangeness (two half-steps and an augmented one) it was called "chromatic"; on account of its sadness, it was called "elegiac." The instrument was debarred from religious music and from the tragedy. But later, to the distress of the philosophers, Agathon, the virtuoso, at the beginning of the fourth century B.C.E., introduced the Aulos and its exciting scale into the tragedy. This scale is the most outstanding one in the TartaricAltaic and Ukrainian songs, and is of much importance also in Jewish music. It remained permanently in Greek music despite the dismay of the philosophers, and created a special type of song called Aolodia, an elegiac song with accompaniment of the Aulos. This scale survived even in the Greek-Catholic song to the present day after the Aulos has vanished and in spite of the strong opposition of the Church Fathers to "chromatic" scales. ${ }^{30}$

Of all the close relationship with the Aulos, we still cannot say with certainty that the Halil had the same scale as the Aulos or what kind of scale it had, because there is no record whatsoever.

(c) Alamoth seems to have been a double-flute. The name bears a similarity to the Greek Elymos which, as Pindar tells us, was produced in Phrygia from a certain kind of wood, and to Phrygia it was originally imported from Assyria. In this case, the name Elymos, too, is possibly of Assyrian origin. It may come from elamu-confronting-usually employed for two 
bodies close together and yet parted, which precisely fits the structure of the double-pipe, as seen on the ancient bas-reliefs and wall-pictures. ${ }^{31}$

The double-pipe, which is always found in the old orchestras in Egypt, Assyria, and Greece, was highly regarded. In the list of instruments of the Jerusalem Temple it is mentioned once (I Chron. I 5:20) as being assigned to the Nevel group. In the lists of the instruments employed in the Second Temple the Alamoth does not appear at all.

About the beginning of the Common Era the name Magrepha (pipe-organ) occurs which, as described in Talmudic literature, was similar to the syrinx and was constructed of a skincovered box into which were fastened ten reeds each with ten holes, each hole being able to produce ten different notes, so that the instrument could produce a thousand notes. The description concludes with the statement that it was used solely for signal purposes: to call the priests and Levites to their duties. Its tone, too, was very strong, so that it was heard as far as Jericho, and it was impossible to hear one talk when the Magrepha played. $^{\mathbf{3 2}}$

It is recorded in the Talmud that there was no water organ (organon hydraulium) at the Temple, because of its sweet and powerful voice which was able to distract attention from the traditional instruments. ${ }^{33}$

The third kind of instruments used in Israel was the PERCussive group. Of the many names mentioned in the Bible, we know with certainty that $T$ of was the little drum, but we are not sure of its exact form. It was the most primitive and popular instrument among the Semitic tribes from ancient times as a rhythm-indicator, and it was used for dances and joyous occasions. In earlier times the tof was used for religious celebrations likewise. King David still employed it at the installation of the ark into Jerusalem (2 Sam. 6:5). Nevertheless, 
despite its being mentioned in the Psalms three times ( $8 \mathrm{r}: 3$; I49: 3 ; 150:4), the drum is not listed among the musical instruments either of the First or of the Second Temple.

The only percussive instrument permainent in the Temple orchestra was the Metziltayim, or as it was called later, Tziltzal -cymbal (derived from the Hebrew term tzalal-to sound). It was constructed of copper, and it had a very strong sound, penetrating "as far as Jericho."

In the time of David and Solomon much stress was supposed to have been laid upon the cymbal and percussive instruments. The chief musician of David, Asaf, was a cymbal player (I Chron. I6:5). David brought a great number of various instruments of percussive character to celebrate the dedication of the sanctuary in Jerusalem, such as Mena'anim and Shalishim. Ezra restored one hundred twenty-eight cymbal players of the Asaf family to their traditional function (Ezra 2:4I; 3: 10). However, in the last century of the Second Temple the percussive instruments were restricted to one cymbal which was used to mark pauses only, but not to participate while the singing and playing were going on. ${ }^{34}$ All of the other kinds disappeared entirely. ${ }^{35}$

Finally we have to mention another signal instrument, the Paamonim (little bells) which were attached to the skirts of the robe of the High Priest. "And the sound thereof shall be heard when he goeth into the holy place before the Lord, and when he cometh out, that he die not" (Exod. 28:35). This custom reminds us of the Egyptian Sistrum which, according to Plutarch, had a double aim: to call the attention of the worshippers to the sacred function in the sanctuary, and to drive away the evil typhon. ${ }^{36}$

Dance-Machol-was considered an integral part of religious ceremonies in ancient Israel. Even in the time of the Kingdom we hear, "David danced before the Lord with all his 
might" (2 Sam. 6: I4). In the Psalms religious dancing is mentioned twice only (Ps. 149:5; I 50:4), and it seems that this custom fell into disuse in the Jerusalem Temple. At least, it is never mentioned in the Bible or in the Talmudic sources. Only at non-devotional public entertainments, such as the celebration of "Water libation" on the festival of Tabernacles, prominent MEN would dance, displaying artistic skill in throwing and catching burning torches. ${ }^{37}$ But the custom of procession around the sanctuary or around the altar was retained in the Temple (Ps. 26:6), especially on the feast of Tabernacles, accompanied with singing, "We beseech Thee, O Lord, save; we beseech Thee, O Lord, make us now to prosper!" concluding with, "Beauty to thee, O Altar," or "To God and to thee, O Altar!" 38

This custom survived in the synagogue in various forms and is still practiced on different occasions up to the present day.

Participation of wOMEN in the Temple choir is nowhere traceable. $^{39}$ The statements recorded in Ezra (2:65) and Nehemiah (7:67) refer to the secular musicians of the noble families who possessed among the 7,337 servants some 200 or 245 male and female musicians. ${ }^{40}$ No reference is made to their being Levites, i.e., of the traditionally sacred cast of musicians. Even the boastful statement of Sennacherib, the Assyrian king, that King Hezekiah of Judah had to send him, as part tribute, male and female musicians, ${ }^{41}$ would refer to secular singers of the court only. The same could be said with regard to the female mourners mentioned in Chronicles $(2,35$ : 25) who were professional public singers for funerals and the like. They still existed in the Mishnaic time. ${ }^{42}$

The Mishna gives the number of the instruments employed in the Temple as follows:

Nevel, minimum two, maximum six.

Kinnor, minimum nine, maximum limitless. 
Cymbal, only one.

Halil, minimum two, maximum twelve.

Thus the total minimum number required for the orchestra was twelve instruments, to which number two Halilim were added on twelve festal days during the year. ${ }^{43}$ Such was the actual composition of the Temple orchestra toward the beginning of the Common Era. Once a year, at the above-mentioned "Water libation," it is reported that all the instruments, "an innumerable mass," would be employed. ${ }^{44}$

We notice that the percussive instruments were reduced to one cymbal, which, as we have mentioned before, was not employed in the music proper, but merely to mark pauses and intermissions. We further learn of the absence of the drum, as well as of the dance and bodily movements and all means by which rhythm is created and marked and without which the rhythm of any music is weakened and diluted. This fact gives us a clue to the understanding of the nature of the music performed at the Temple. We get a full comprehension of it, however, when we learn about the construction of the whole body, the ensemble, i.e., the vocal and instrumental forces.

The chorus had to consist, so the same Mishnaic source reports, of a minimum of twelve adult male-singers, the maximum being limitless. ${ }^{45}$ The singer was admitted to the choir at the age of thirty, and served up to fifty, the age when the decline of the voice began. Before his admittance he had to have a five years' training. ${ }^{46}$ In addition to the twelve adults, boys of the Levites were permitted to participate in the choir, "in order to add sweetness to the song." 47

Thus we see that the choir equaled the number of instruments. Later, the tendency toward the superiority of the vocal music was pronounced by the regulation that for playing the instruments even non-Levites were permitted, whereas for singers Levites alone were admitted. ${ }^{48}$ Furthermore, the 
opinion was pronounced that the importance of music lies in the singing. ${ }^{49}$

The predominance of vocal music naturally grew out of the attitude toward music as a tool for the conveyance of ideas. Vocal music, by its intimate association with words, carried and interpreted thoughts and feelings; while instrumental music, according to Semitic-Oriental conception, serves only as accompaniment and embellishment. On the other hand, the tendency to restrict percussive, stirring and signal instruments, as well as dances and the participation of women, gives evidence of the striving to evade all the forms of pagan worship in use in Phœnicia and in all the countries bordering upon Palestine.

Although Jewish spiritual life sought to elevate the form of its musical expression, it, nevertheless, could not stay the development of virtuosity among its musicians at the Temple. It is recorded that a certain Agades (Hagros) was a virtuoso singer, and that in applying some brilliant tricks he would produce tremolos in Oriental manner which would fascinate the people. He kept his "art" a secret, and did not want to teach it to others. His professionalistic spirit brought down the scorn of the sages. ${ }^{50}$

This is about all that our sources report of the Temple music. There are no descriptions of the tunes retained, nor is there any indication of scales and rhythm employed, such as the Greek philosophers and authors left us. In Israel music was seemingly taught and preserved in oral tradition only, as is the custom in the Orient to the present day. Yet with the scant information at hand, let us try to visualize a musical performance at the Temple service in the last century B.C.E. as it is depicted in the Mishna. ${ }^{51}$

After the priests on duty had recited a benediction, the Ten Commandments, the Shema (Deut. 6:4-9), the priestly benediction (Num. 6:22-26) and three other benedictions, they 
proceeded to the act of the offerings. And after they were through with the arrangement of the sacrifices, one of them sounded the Magrepha (see above) which was the signal for the priests to enter the Temple to prostrate themselves, whereas for the Levites that sound marked the beginning of the musical performance. Two priests took their stand at the altar immediately and started to blow the trumpets tekia-terua-tekia (see above). After this performance, they approached Ben Arza, the cymbal player, and took their stand beside him, one at his right and the other at his left side. Whereupon, at a given sign with a flag by the superintendent, this Levite sounded his cymbal, and all the Levites began to sing a part of the daily Psalm. Whenever they finished a part they stopped, and the priests repeated their blowing of the trumpets and the people present prostrated themselves.

The texts sung by the Levites were not Psalms alone, but also portions of the Pentateuch. ${ }^{.2}$

The description gives us a picture of the service and its musical rendition as conceived by laymen, without indicating whether the instruments accompanied the singers, or whether choir and orchestra worked alternately.

A short time after the destruction of the Temple the entire art of the instrumental music of the Levites fell into oblivion; and two generations later the sages totally lost all technical knowledge and all sense of the reality of that silenced music. They either exhausted themselves in praising the music of the Levites or in homilizing on the musical terminology as well as on the names of the instruments. The vocal music, however, the intonations of the Psalms and the Pentateuch, as well as the recitation of the prayers (see above), was most likely retained and transplanted into the Synagogue, the BethHak'neseth (House of Assembly), an institution established long before the destruction of the Second Temple. We are 
informed that in Jerusalem many synagogues existed, and that even in the Temple court there were synagogues in which priests, Levites, and laymen would worship. ${ }^{53}$

The vocal song of the Temple, like all religious song among the ancient and primitive nations, drew its sap from the folksong, though foreign tunes may have occasionally crept in. These Temple songs-folk-tunes modified and sanctifiedwere in turn copied by the "representatives of the people," the Anshe Maamad, from all parts of the country, who used to be present at the Temple service. ${ }^{54}$ They certainly learned the melodies together with the texts, and would carry them to their homes. Furthermore, many Levites would participate in public services in the synagogues and were naturally chosen to act as precentors or leaders in singing Psalms, portions of the Pentateuch and the Prophets.

The Forms in which the Psalms and prayers were rendered were explained by sages who lived in the first century. Of these, Rabbi Akiba had still witnessed the service in the Temple. From them we learn that three forms of public singing were customary, which were based upon the principle of response. In form A the leader intoned the first half verse, whereupon the congregation repeated it. Then the leader sang each succeeding half-line, the congregation always repeating the same first half-line which thus became a refrain throughout the entire song. This was the form in which ADULTs used to sing the "Hallel" (Ps. I I 3-I I8), and, according to Rabbi Akiba, this form was also employed for the Song of the Sea (Exod. I 5). This form of singing the Hallel is still in use among the Jews in southern Arabia. In form B the leader sang a half-line at a time, and the congregation repeated what he had last sung. This-Rabbi Eliazar, son of Joseph Hagalili, said-was the form in which the children used to be instructed at school. Form $\mathrm{C}$ was responsive in the real sense, i.e., the 
leader would sing the whole first line, whereupon the congregation would respond with the second line of the verse. This was the form, as Rabbi Nehemiah explained, in which the Shema was recited in public; and it is still used by the Babylonian Jews for chanting the Hallel on Passover. ${ }^{\mathrm{ss}}$

We know that the ancient Assyrians and Babylonians had already used the responsive form, notably form A (refrain), in their laudations and supplications. ${ }^{56}$ In ancient Israel, too, that form was popular. Refrains, as Amen, Halleluyah, Hoshianah (Oh, help!), Anenu (Answer us!), etc., were mostly used in public worship. And in accordance with the spiritual development of the people, we can follow a certain development in this form. While in ancient times, the people -in that they were primitive-were able to participate by responding with but one word, as those mentioned above, in later times we find a higher development of the people as shown in their response with phrases, for example, $K i$ leolam Chasdo (Ps. I I 8: I-3; I36).

Besides the responsive form, the UNISON and solo forms were used. To antiphonal singing, i.e., to the alternate singing of balanced groups, we have but few references in the Bible (Deut. 27:2I-26), and it is described in the Mishna. ${ }^{57}$

Thus far we dealt with the SACRED music only. All we can gather about the sEcular music in Israel indicates that it was of the same nature as the music of the neighboring nations in the Near East. As the many references in the Bible to the music performed in secular life testify, Israel enjoyed life through music both vocal and instrumental, and associated music with dance and wine in which men and women participated. The drum and cymbal, the harp and lyre, the small and the big pipe, were used. Rhythm played an important part, and in order to emphasize it, hand-clapping was employed. As a whole, we may say that in its Forms, the secular music was 
similar to the Arabic music still used in Palestine and the Near East.

We learn that toward the beginning of the Common Era Greek song penetrated into Palestine, ${ }^{58}$ and that people of education cultivated a great liking for it, ${ }^{59}$ a fact which aroused the dismay of the pious spiritual leaders. ${ }^{60}$

As already stated above, all the explanations thus far give us no clue as to the ToNality - scales and modes-of ancient Jewish song. We have no reference to its theoretical basis, for so far as we know, there never was written, as in the case of Greek music, a theory of Hebrew music.

There is, however, one authentic source preserved and at our disposal. And this is oral tradition!

Long before the destruction of the national sanctuary in Jerusalem, large Jewish settlements were established throughout the ancient world, from Persia to northwest Africa, and from Arabia to Rome,-settlements which cultivated spiritual values. After the complete ruin of the national center in Palestine, the remnants of Judea were scattered. They were taken into captivity, sold into slavery, and dispersed throughout the Roman Empire as far as the Pyrenean peninsula, the Rhine, and the Danube. They had lost their country, their independence; they had been robbed of their possessions, even of their human rights. But their spirit, their God, could not be taken away from them. Their spiritual values became their only treasure, a recompense for country and independence. And just as they had once defended their country against giants like Assyria, Egypt, Greece, and Rome, so they stood henceforth ready to give their life for their God and their culture-their spiritual creation embodied in a TRADITION! From that tradition we justly draw our information as to the nature of Jewish music and its history.

This musical tradition is preserved in memory and practice 
in various Jewish centers in the East and in the West-centers whose existence continued since the destruction of the Second Temple, and in some instances from even before that event, throughout the ages up to this very day. These centers are:

YEMEN in South Arabia, historically known from preMohammedan times, a community that lived practically in seclusion for thirteen hundred years, and evidence of whose contact with other Jewish settlements we have but scant sources;

BABYLONIA, historically the oldest Jewish settlement, dating from the destruction of the First Temple, never ceasing to exist despite changes of conditions;

Persia, almost as old as the Babylonian community. Syria, North Africa, Italy, and the so-called Sephardim, i.e., the Spanish Jews expelled from Spain in 1492, who, despite dispersion, did preserve their SPanish tradition;

The German Jews, whose settlement in southwestern Germany dates back to the fifth century;

And the Jewish settlement in EAstern Europe, the largest center of all in number, whose tradition comes partly from Germany and partly from the Oriental communities.

The results of our investigations of the traditional song of these communities enable us to construct the features of Jewish song; and the analysis of that tradition reveals to us its elements, its originality, its development, and its growth-in a word-its history. ${ }^{61}$ 
Jewish music is the song of Judaism through the lips of the Jew. It is the tonal expression of Jewish life and development over a period of more than two thousand years. To place that song into its ancient and original setting, we must seek the beginning of the people itself. In so doing, we see that just as the Jew, being of Semitic stock, is a part of the Oriental world, so Jewish music-coming to life in the Near Eastis, generally speaking, of one piece with the music of the Orient. It takes its trend of development through the Semitic race, and retains its Semitic-Oriental characteristics in spite of non-Semitic-Altaic and European-influence. Jewish song achieves its unique qualities through the sentiments and the life of the Jewish people. Its Distinguishing CHARACTERISTics are the result of the spiritual life and struggle of that people.

Hence, in order to recognize the Oriental elements in Jewish song, it is indispensable that we assure ourselves of a common understanding of the basic elements of Semitic-Oriental music. ${ }^{1}$

In the first place, Oriental music-whether. Semitic, Altaic, or Hindu-is based on the modal form.

(a) A MODE (in Arabic and Persian: Makam or Naghana) is composed of a number of motrves (i.e., short music figures or groups of tones) within a certain scale. The motives have different functions. There are beginning and concluding motives, and motives of conjunctive and disjunctive character. The composer operates with the material of these traditional 
folk motives within a certain mode for his creations. His composition is nothing but his arrangement and combination of these limited number of motives. His "freedom" of creation consists further in embellishments and in modulations from one mode to the other. ${ }^{2}$ Sixteen of these modes are most widely known throughout the Near East.

(b) The next element is the emphasis upon orNament. Oriental music is unthinkable in long sustained tones. On the contrary, it is of a vivid tonal character. Either a note is short, or if long, it quavers in a tremolo and is adorned with ornaments.

(c) Oriental music is chiefly UnRHYThmical (in Arabic: Tartil-narrative or recitative). It is mostly rendered by a solo voice with accompaniment of the $U d$, a kind of lyre or mandolin, or Kanun, resembling a guitar. The accompaniment is only a repetition of the melodic line rendered by the singer with some variations. Rhythmical music (in Arabic: Anshada) is used for dancing and bodily movements, and is considered inferior to the unrhythmical Tartil.

(d) The tonality in the Oriental music is based on a quarter-tone system. Thus a scale of an octave has twentyfour steps. The perfect consonance of the octave is known to the Oriental musician by the Arabic term jewab (answer, echo, repetition). However, seldom does the melodic construction show the tendency of the octachordal line, for the folk-tunes are usually built on the tetrachordal or pentachordal range.

As a result of the quarter tones there are a great variety of scales in existence, many of which are rather artificial inventions and subtle combinations which are not used often. The most popular scales are: I. $d^{3 / 2}-e^{3 / 4}-f^{1 / 4}-g^{4 / 4}-a^{3 / 4}-b^{3 / 4}-c^{1 / 4}-d$, which corresponds to the ancient Greek Phrygian (the medieval Dorian): $\mathrm{d}^{1}-\mathrm{e}^{1 / 2}-\mathrm{f}^{1}-\mathrm{g}^{1}$ $a^{1}-b^{1 / 2}-c^{1}-d$; and has the character of minor. II. $e^{3 / 4}-f^{3 / 4}-g^{4 / 4}-$ $a^{3 / 4}-b^{3 / 2}-c^{4 / 4}-d^{3 / 4}-e$, which corresponds to the ancient Greek Dorian 
(the medieval Phrygian): $e^{1 / 2}-\mathrm{f}^{1}-\mathrm{g}^{1}-\mathrm{a}^{1}-\mathrm{b}^{1 / 2}-\mathrm{c}^{1}-\mathrm{d}^{1}-\mathrm{e}$; and is no longer used in modern music. III. $f^{4 / 4}-g^{4 / 4}-a^{2 / 4}-b^{6 / 4}-c^{4 / 4}-$ $d^{3 / 2}-e^{3 / 4}-f$, which is similar to the ancient Greek Lydian with $b$ flat; and has almost the character of major, with the exception of the seventh (e) which is a quarter flat. IV. $d^{2 / 4} e^{6 / 4}-f^{\# / 4}-g^{4 / 3}-a^{3 / 4}-$ $\mathrm{b}^{3 / 4}-\mathrm{c}^{4 / 2}-\mathrm{d}$ is in its first tetrachord $(\mathrm{d}-\mathrm{g})$ similar to the scale of the Aulos (see Chapter I), and corresponds to the Ahavoh-Rabboh scale (Chapter IV): $d^{2 / 4}-e^{6 / 4}-f^{2 / 4}-g^{4 / 4}-a^{2 / 4}-b^{6 / 4}-e^{4 / 4}-d$. On each of these scales several modes are based. ${ }^{3}$

The Oriental musicians have the habit of mixing scales to combination-scales, as for example the mode called "Sabba" which is based on the scale: $d-c-f-g b-a-b b-c-d b-e b-f$, which is merged of scales I and IV. Or some scales receive a different order in the higher octave, as in the case of scale IV, which continues in the octave as follows: $\mathrm{d}-\mathrm{e}-\mathrm{f}-\mathrm{g}$.

Whether or not Jewish music, in its origin, was based on or even affected by a quarter-tone system, we have not sufficient data to prove or disprove. Only these facts are incontrovertible: (I) that the four scales just explained are those on which practically all Jewish song is based; (2) that in the OrIENT the Jews sing in those scales, using the quarter-tone steps of their neighbors, while (3) the Jews of the Occident employ the same scales with steps of the semi-tone system; (4) that despite the resultant variance, Synagogue song remains identical the world over, because these differences in tonality are of sufficiently minor importance not to change the character of the music. Compare the technical differences listed in the preceding paragraph.

(e) The Oriental musicians and laymen are fond of IMprovisation. Even set tunes are largely varied and modified. The improvisation occurs in a certain mode, and the improviser has to operate with the traditional motives therein.

(f) Oriental music is without any harmony. The only beauty the Oriental finds is in the melodic line and in the in- 
tricate ornamentation. Occasionally in unison singing of a group there are fourths or fifths, due solely to the range of the voices, but not to harmonic instincts, because the people sing frequently in seconds or in any other "discord."

(g) Oriental music has retained the FOLK-CHARACTER. Therefore, unlike the art music of Europe, which can be understood by the few only, the song of the Orient is understood by all.

(h) The folk-character is pronounced also in the FORM. Most of the set tunes consist of very short phrases. Only a few have two or three phrases. The most compound form seems to be the Bashraw (Turkish Pashraw), a Rondo form in the scheme $a-b-a-c-a$

(i) Music is never written down, but transmitted ORALLY. Consequently, "EAR"-MARKs were developed by which music is recognized. The entire theory of Oriental music is based upon these "ear"-marks," i.e., signs for musical patterns learned by ear.

All these elements and features are to be found in the religious and secular music of the Mohammedans and of the Oriental Christian churches: the Greek, the Jacobite, the Nestorian, and the Maronite.

"Music" is primarily vocal. Instrumental music, never rising above accompaniment, does not present an art in itself. It is forbidden in Mohammedan and Christian Oriental worship.

Women are excluded from participation in religious music.

This brief description holds true particularly of the SemiticOriental music. It distinguishes itself from the music of the other Oriental races by its preference for the scales cited above and the modes built on them.

In addition, it should be mentioned that minor-scale Iis not considered SAD, nor is major-scale III-considered joy- 
ous. Quite the contrary, the first scale is the basis upon which very joyous tunes are built, while scale III serves for serious music. Moods are rather expressed by the rhythmical construction of the motives. Scale IV is described by the Greek Church musicians as "sad," and is employed for supplications and occasions like funerals; whereas to the Turks the same scale lends itself to the expression of fervent, passionate sentiments. Since music is mainly vocal, its rhythm, when there is any, is not like that of European music divided in small measures such as $3 / 8,3 / 4,2 / 4,4 / 4,6 / 8$, etc., but is derived from the meter of the text. In other words, the metrical text leaves the impress of its meter upon its tune.

As a rule, a tune is constructed according to the length of a stanza of two lines (in Arabic baith), and since most folk-songs are syllabic, each syllable having one note (embellishments are not counted), the number of the time-units of a tune must be equal to the number of the syllables in the stanza. These time-units (in Greek: chronos protos) run from three to thirty-two. There are LONG units, similar to the European whole measure o; HALF unit- $d$; SMALL unit- $d$; and HALF-SMALL unit- $\Lambda$.

In Oriental music provision was also made for the designation of tempo, as slow, vivacious, sad, moderato, soft, and so forth. ${ }^{5}$

Of the account thus far given, the musical examples in the tables I-III will offer sufficient illustration. Table I contains examples of Arabic folk-tunes (a) secular ( $I-6,8)$, popular in Palestine and Syria, (b) religious, of which example 7 is the tune in which the Muezzin calls the people to prayer, beginning with the familiar formula: "Allah is great, there is no God besides Allah and Mohammed is the messenger of Allah. Hasten to prayer, hasten to service!" This musical version is customary in Palestine. It is in unrhythmical MODAL 


\section{TABLE I \\ Arabic Tunes \\ a) Secular}

1. Mode: Bayati

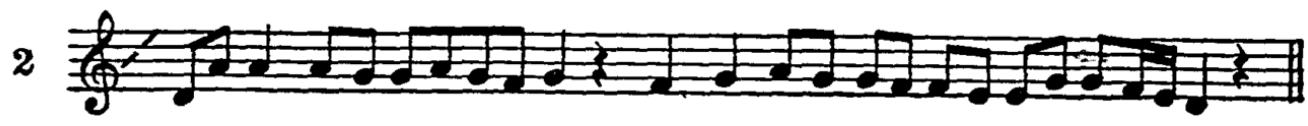

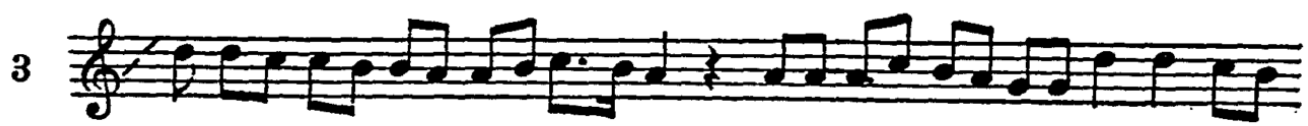

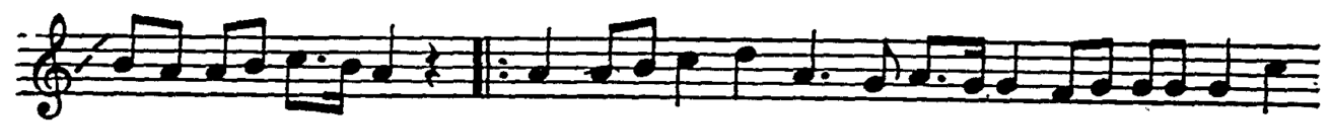

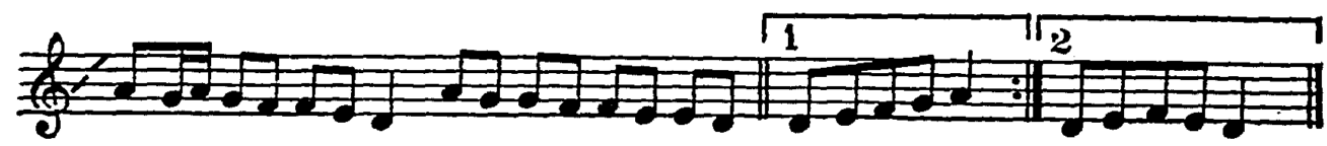

4 Mode. Siga

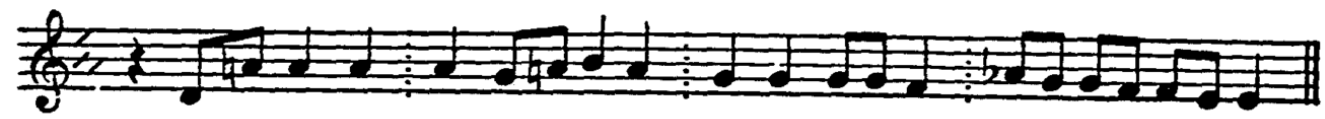

MIode: Sasgar

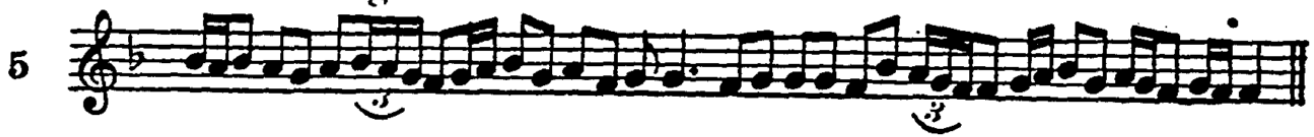

Mode: Nawa

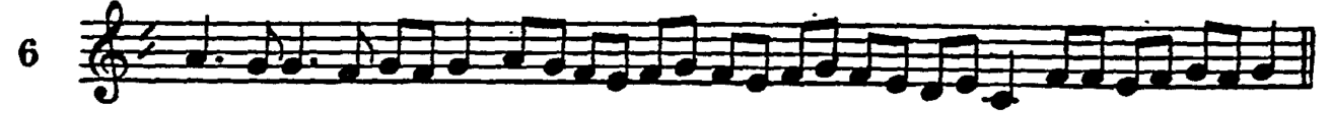



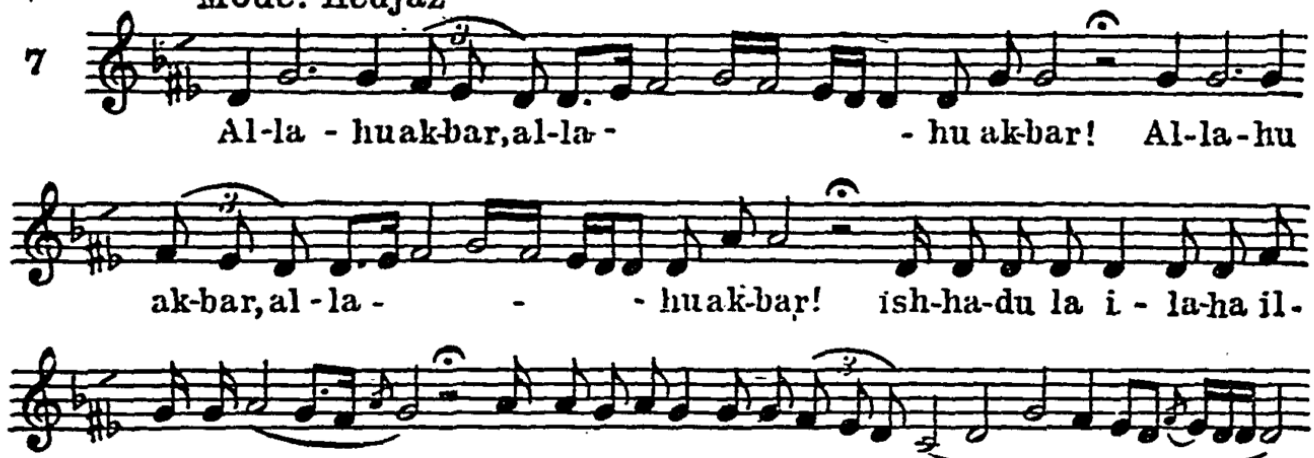

la I-la. lsh-ha-du la i-la-ha il-la l-la.

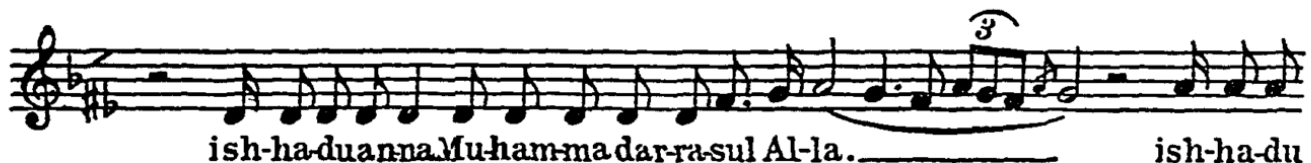
ish-ha-du (3) 位

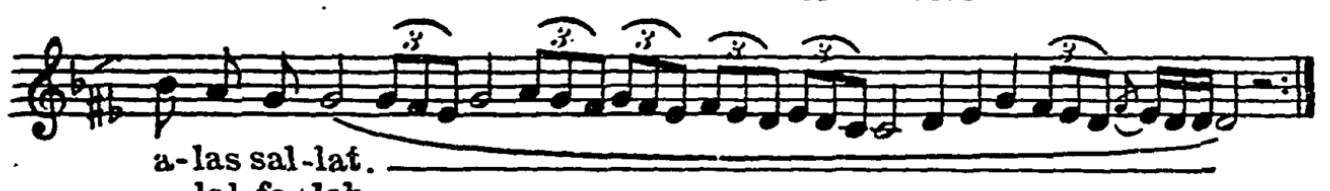

- lal-fa-lah.

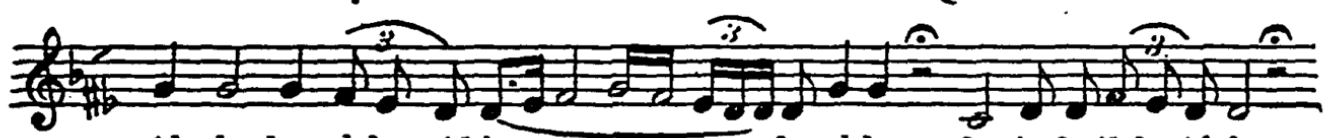
Al-la-hu ak-bar,Al-la-_ - huakbar, la i - la il la Al-la.
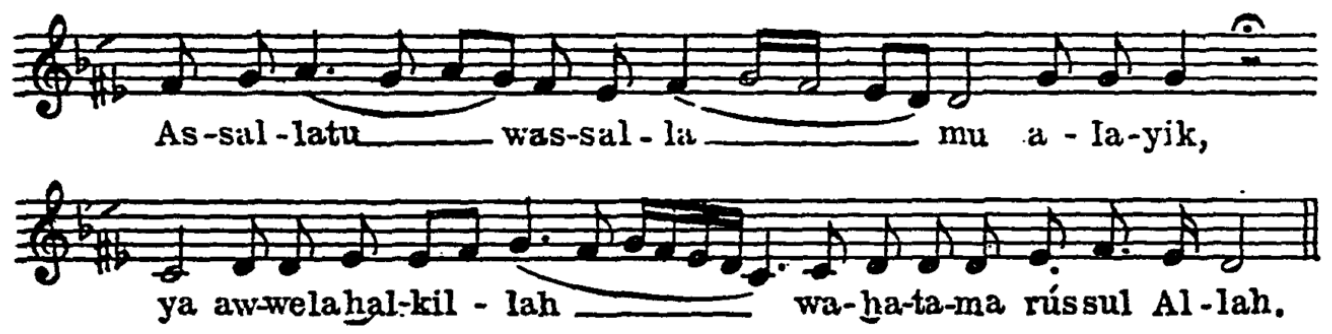

8. 3 Mode: Huseni 1 I 
TABLE II

\section{Jacobite Church-Songs}

\section{a) Unrhythmical}

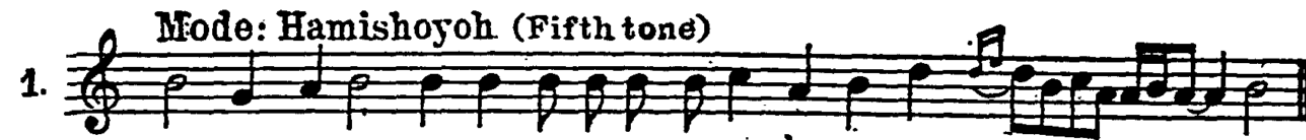

Lo tet-ka-nat ha-to-yo le-me-re-dobur-ho dat - yo - hu - to

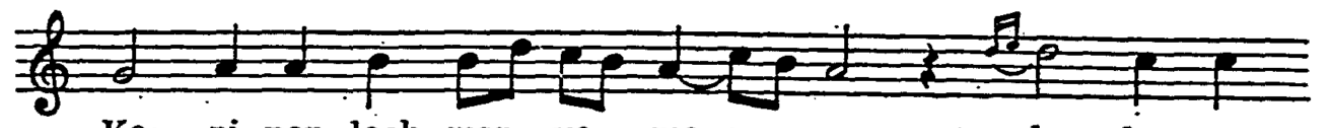

Ko - ri-non loch mor - yo mo - ran;- ... shma bo - u -

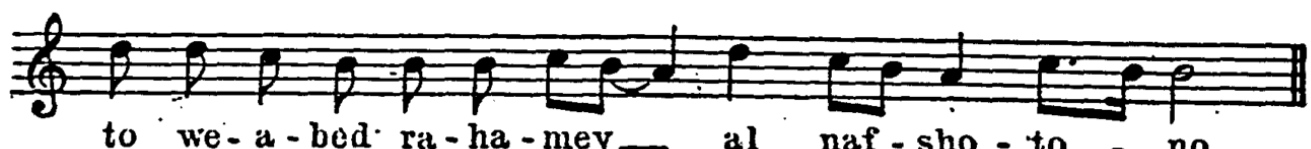

to we-a-bed ra-ha-mey_al naf-sho-to - no.

Mode: sh'titoyoh (Sixth tone)

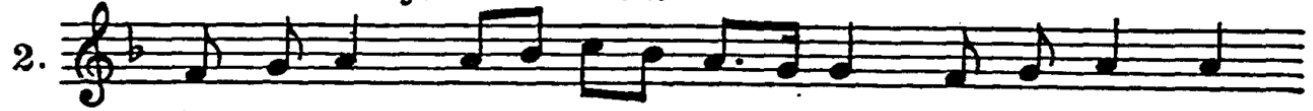

Ko-ri-non mor-yo-. mo-ran, to le-ud-ron,

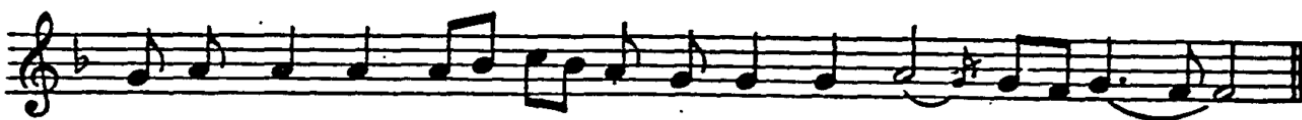

shmabo-u - ton wa - bel ra-ha-mey al. naf - sho-ton._.

Mode: Kadmoyoh (First tone)

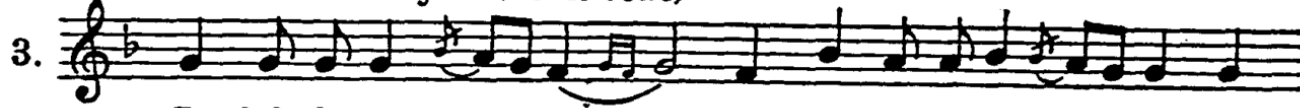

Zo-dek de-ne - he - we_ duch-ro-no le-mar-yam e - me

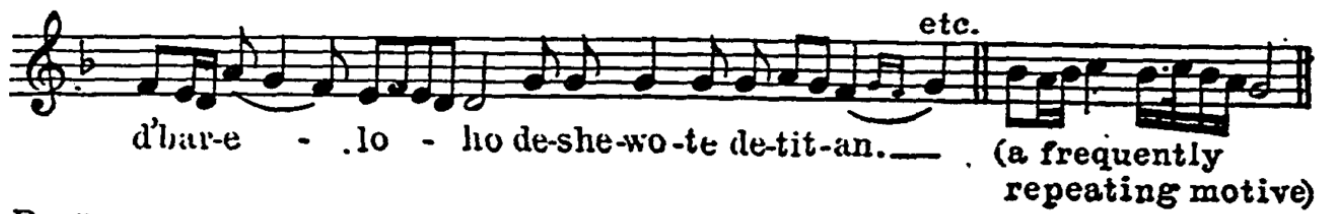
Ps. 91, 1 -

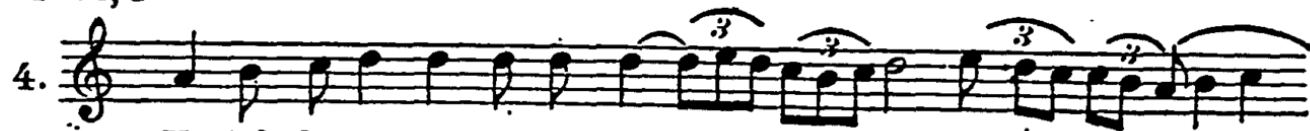

Yo-teb be-se - to- re dam-raty_ mo, ha-ie - lu - ya.

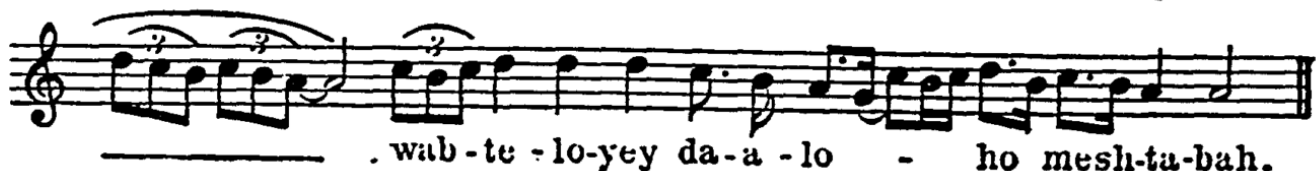


5.
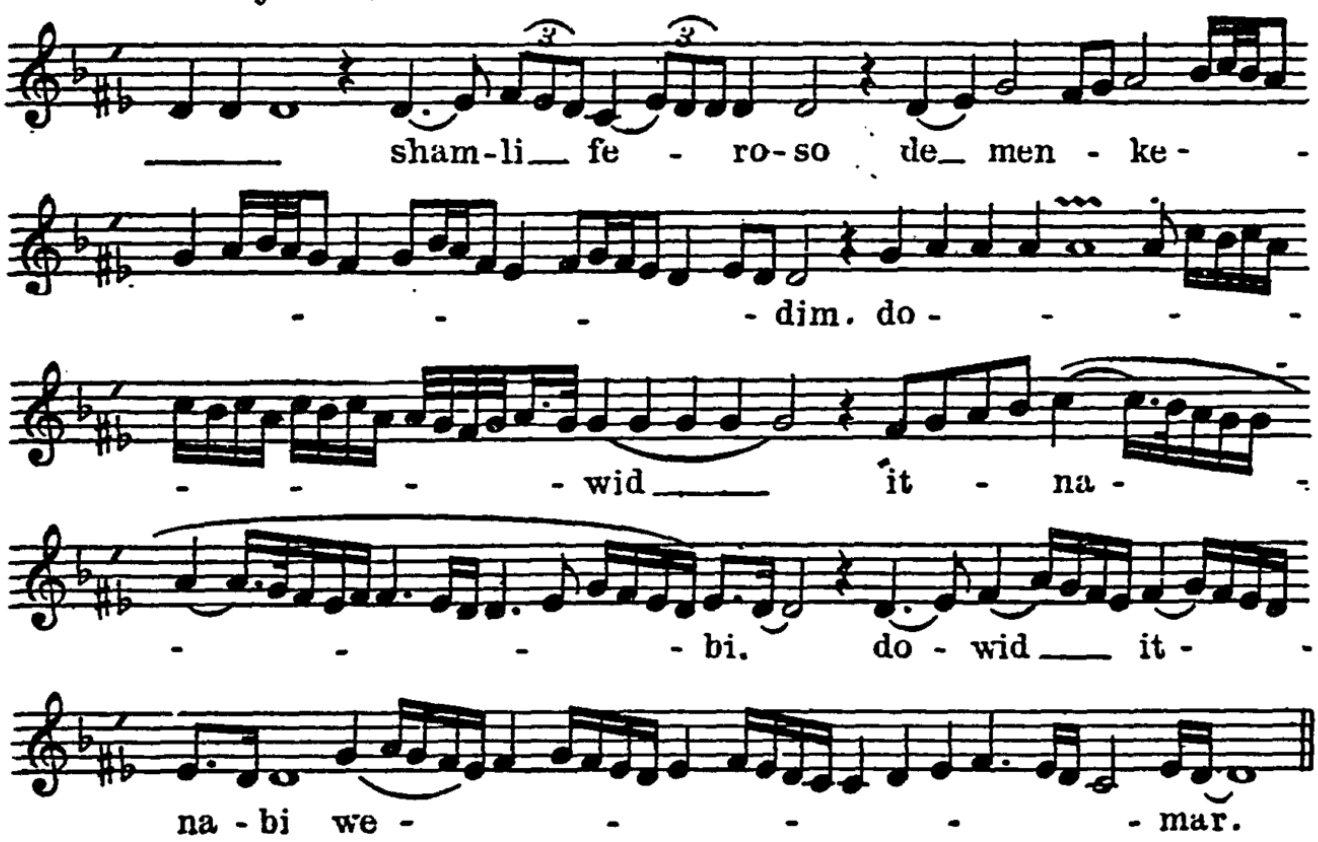

b) Rhythmical
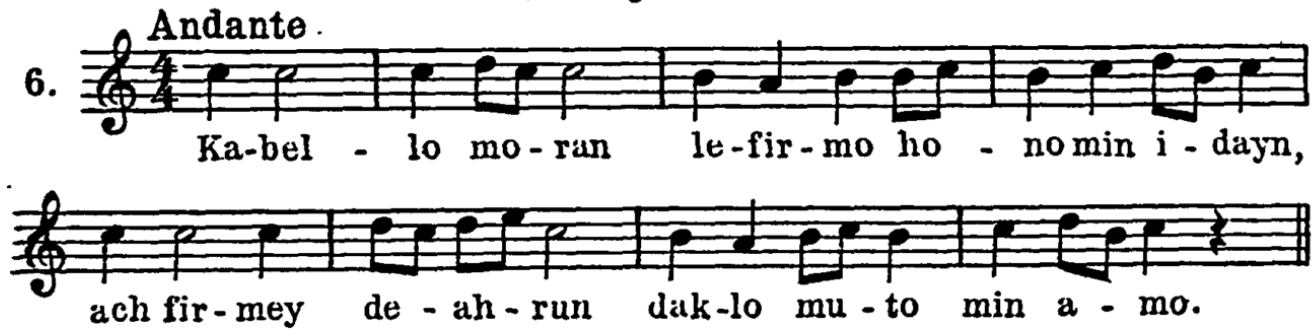

Mode: sh'bioyoh (Seventh tone)

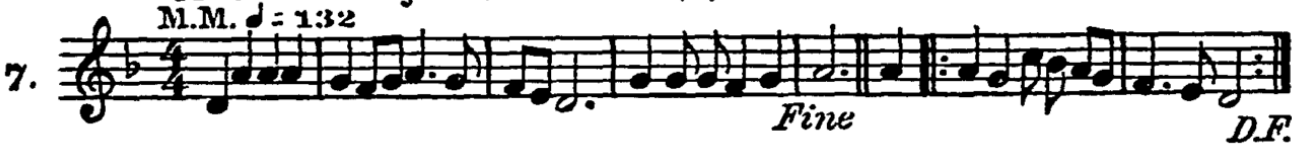

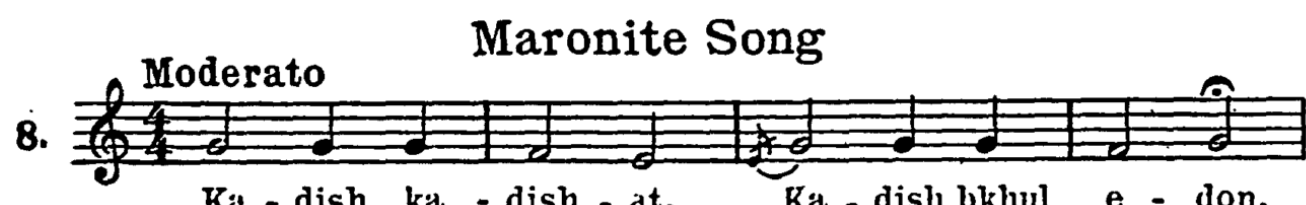

$$
\text { Ka - dish ka - dish - at, Ka - dish bkhul e - don, }
$$

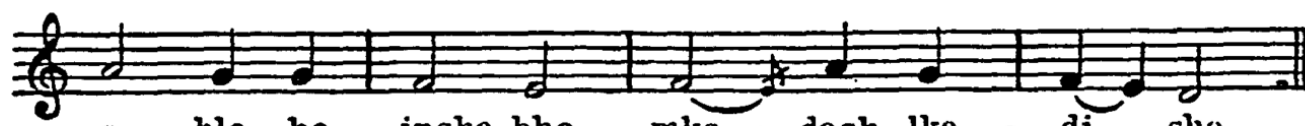

a - blo-ho insha-bho mka - dash lka - di - she. 
TABLE III

Greek Church Tunes

1.

2.2 Sento

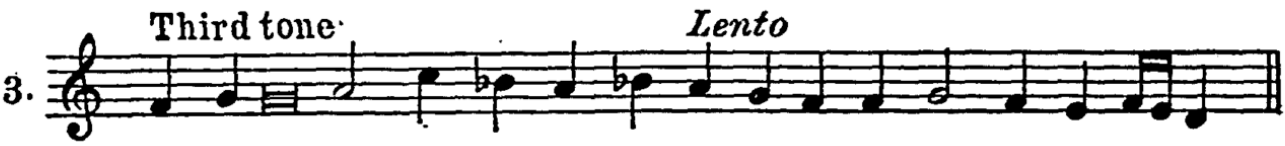

4.2 Fourth tone

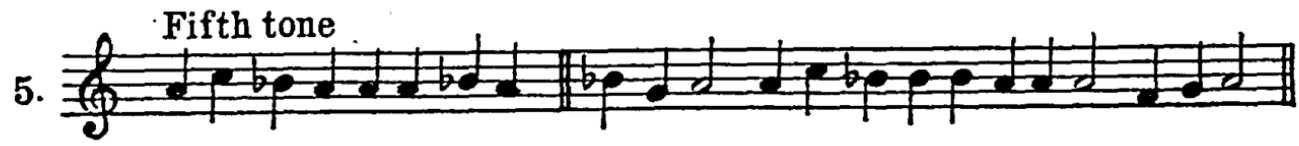

6. Seventh tone

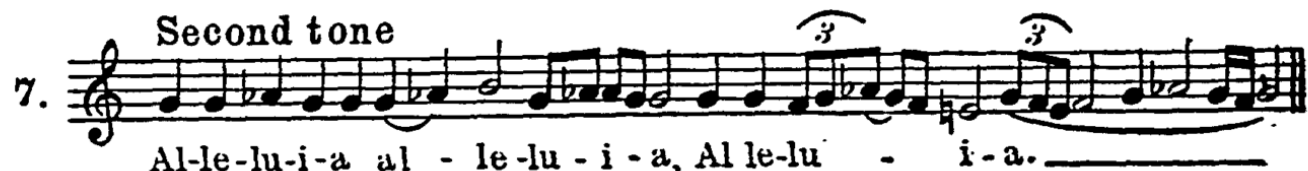
Al-le-lu-i-a al - le-lu - i - a, Al le-lu - i-a.

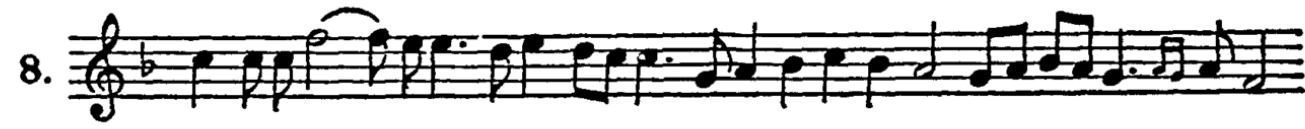

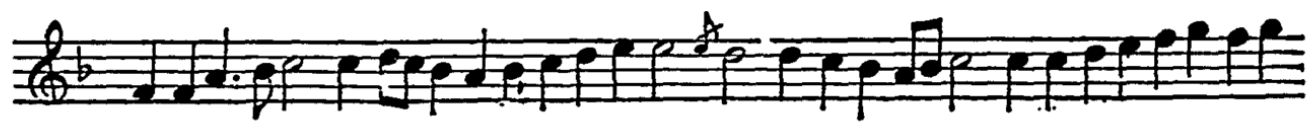

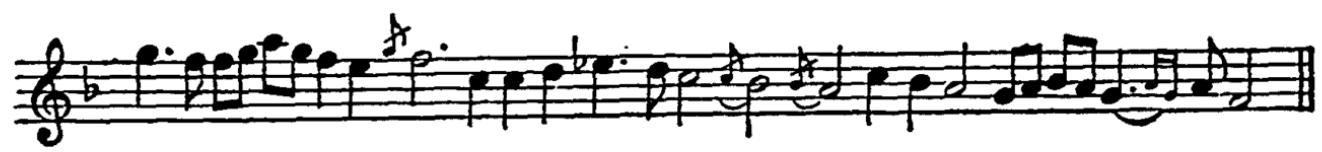


form, in the so-called Makam Hedjaz. The secular tunes are likewise based upon Modes (Makams).

The illustrations are in Bayati (I-3), the most popular Arabic mode; in Siga (4), Sasgar (5), Nawa (6), and Huseni (8), which are also popular throughout Palestine and Syria, as well as in Arabia and Mesopotamia. In No. 7 we recognize motives which repeat themselves with some variations. ${ }^{6}$

Table II gives a selection of religious songs of the SyriacOrthodox Church, called the "Jacobite Church." We see that they have the same scales, forms, and modes as the Arabic song. They are mostly unrhythmical (I-5) in syllabic form (I-4), in free modal form (5); and only part of them indicate strict rhythm similar to European measures (6-8). The last tune (8) is from the Maronite Church of Lebanon, and is used for various texts. The custom of adopting tunes for different texts is general in the Orient.

The Arabic scales and modes used in the Jacobite Church received other names ("first" to "eighth tone"). Example 4 gives a Psalmtune $(9 \mathrm{I}: \mathrm{I})$ in a tetrachordal line, and example 5 is a solo in the Hedjaz-mode, resembling the modal form of table I $(7) .^{7}$

Table III furnishes us with some examples of the Greek Church tunes. They, too, have the same characteristics in scales, modes, forms, as the Mohammedan and the Christian song. We note that 2 and 7 have the "chromatic" scale, or the Hedjaz; I and 3 have scale I; 4 and 5 have scale II; and 6 and 8, scale III. Their form is MODAL, partly syllabic, partly embellished (8). ${ }^{8}$

These illustrations will later serve the purpose of comparative study with the Synagogue song. At present they may enable us to familiarize ourselves with the essential elements of the song of the Near East, the song of that spot which constituted the cradle of the Jewish people. 
CHAPTER III

THE OLDEST UNRHYTHMICAL ELEMENTS OF JEWISH SONG. A: THE MODES OF THE BIBLE.-THE TA'AMIM (MUSICAL NOTATION) OF THE BIBLE.

The public reading of the Bible as performed in ancient times, and as still done in the Orthodox Synagogue, was not according to the manner now employed in the Reform Synagogue (since 1815 ). In the latter it is simply spoken or declaimed without any musical flavor, whereas the manner of reading, according to tradition, is a cantillation, a chanting of the text, a recitation in which music plays a great part. This way of reading the Bible is mentioned in ancient times-at least as far back as the first century. It was not the general manner of public reading, for in the Orient the usual public reading is done in declamation as in the Occident. There may be more flavor in the voice, but it is without musical tone. This usage is true of the Arabs to the present day, whereas the reading of the Koran is done in the same manner as the traditional reading of the Bible. There is, therefore, no foundation for the current notion that the cantillation of the Bible is derived from the Oriental manner of reading in public. It seems rather to indicate that it was introduced in order to arouse the interest of the hearers through the setting of the text to music. The Talmud says that the Bible should be read in public and made understood to the hearers in a mus:cal, sweet tune. And he who reads the Pentateuch without tune shows disregard for it and the vital value of its laws. ${ }^{1}$ A deep understanding can be achieved only by singing the Torah (naturally, in the tradi- 
tional tunes), and "whoever intones the Holy Scriptures in the manner of secular song abuses the Torah." ${ }^{2}$

These statements of the Talmud from the first centuries C.E. prove that the musical performance of the reading of the Bible in public was intentionally instituted. This becomes more evident through observation of the fact that only those bocks of the Bible are provided with tunes the public reading of which was obligatory. These books are: the Pentateuch, the Prophets, Esther, Lamentations, Ruth, Ecclesiastes, Song of Songs, Psalms, and, in some communities, Job; whereas Proverbs,

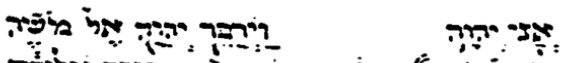

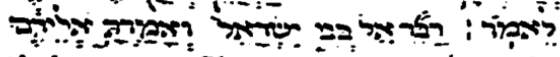

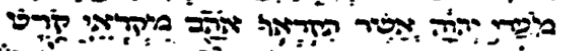

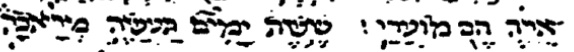

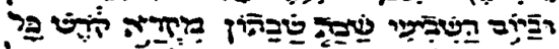

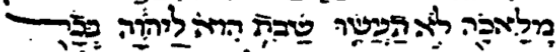

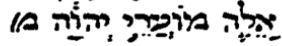

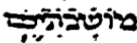

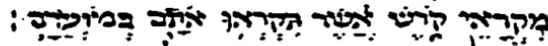

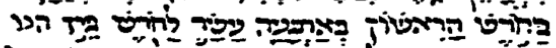

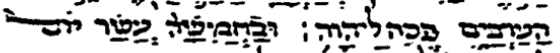

ל-

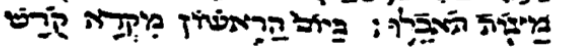

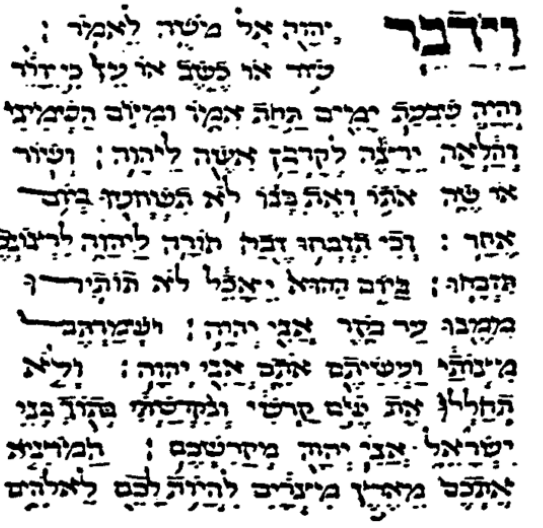

Facsimile 1 .

Accents: Pentateuch (Leviticus 22:26-33; 23:1-7)

Italian MS. 15th Century. Hebrew Union College Library.

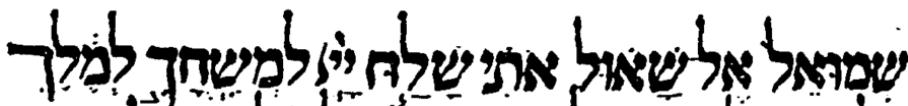

L

רמוּר

7

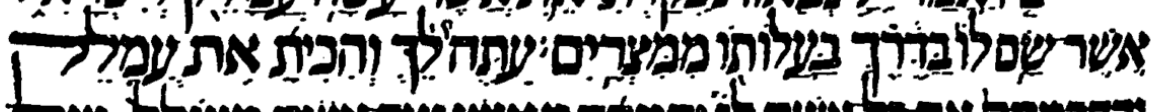

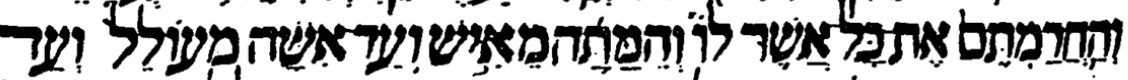

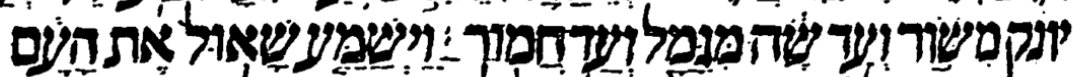

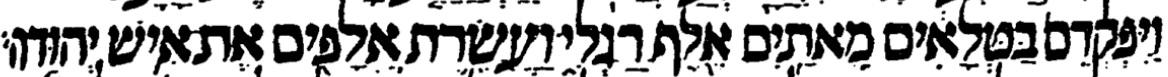

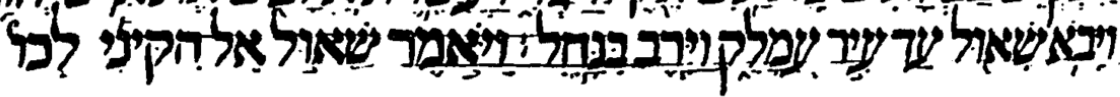

Facsimile 2.

- Accents: Prophets (I Samuel I5: I-6)

Italian MS. I $5^{\text {th }}$ Century. H. U. C. Library. 
:

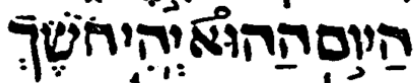
-

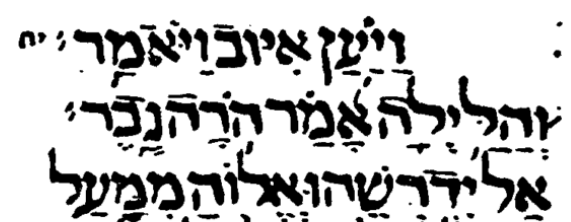

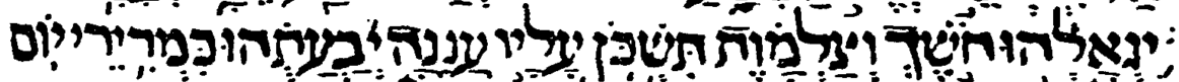

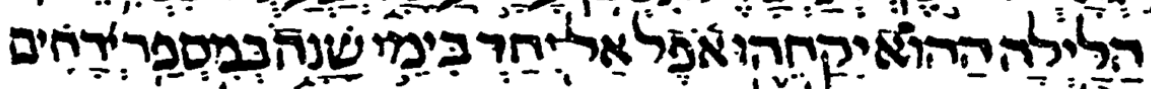

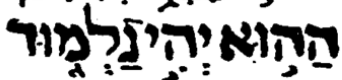

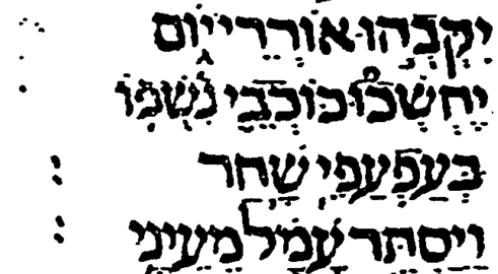

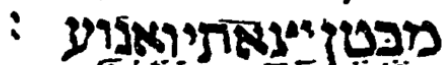

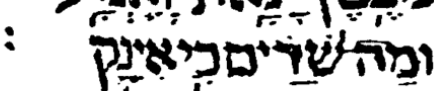

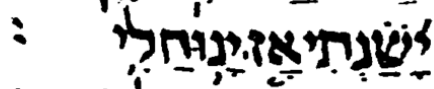

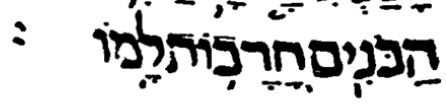

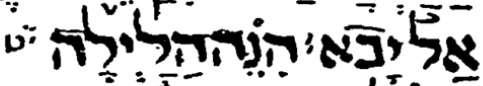

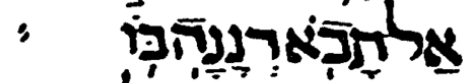

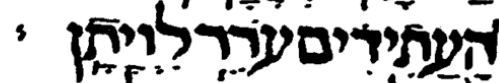

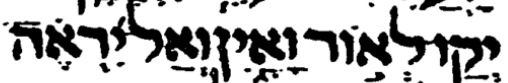

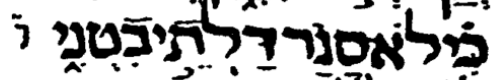
ל" :

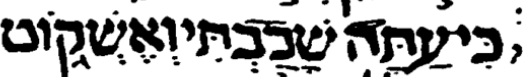

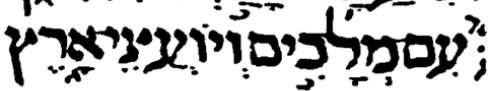

FACSIMILE 3 .

Accents: (Job 3: 2-14)

MS. 1 $3^{\text {th }}$ Century. H. U. C. Library.

Tenor
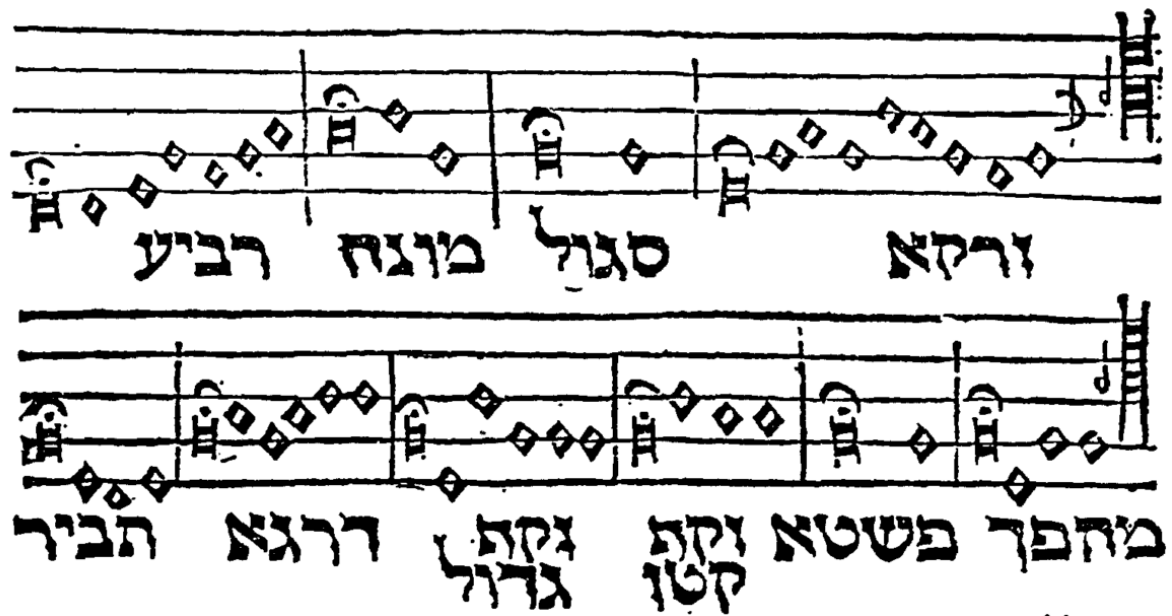

FACSIMILE 4.

$\mathbf{x}$ ii

Reuchlin, De Accentibus. Pub. Hagenau, 15 18. H. U. C. Library. 
Ezra, Nehemiah, and Chronicles have no tunes, because they were not read in the public service.

The obligation to read these books is very old. We know, for instance, that EzRA was the first to introduce the reading of the Pentateuch in public (fifth century B.C.E.). Psalms, as is known, were sung in the Temple in Jerusalem. And we have testimony that the Prophets were read in public service as Haftara-the concluding portion after the reading of the Pentateuch-during the latter part of the existence of the Second Temple, for we know that Jesus was asked to read from the Prophets in the Synagogue service. ${ }^{3}$ The Book of Esther has been read since about the time of the Maccabees ${ }^{4}$; Lamentations, at least since the destruction of the Second Temple; while as to the Song of Songs, Ruth, and Ecclesiastes we have evidence that they were read as far back as the first century. ${ }^{\circ}$ Thus, we see that this ancient usage had its origin in Palestine during the time when the bulk of the Jewish people still lived there.

As proof of the antiquity of the traditional tunes in which the Scriptures are chanted, we cite their Oriental origin. They bear the distinctive marks of the Semitic-Oriental song explained in the second chapter. They have the modal form and character; they are furthermore unrhythmical and are based upon three of the four scales usual in the song of the Semitic Near East.

Though this ancient part of Jewish song has much in common with the song of the East, its motives and consequently its expression distinguish it from the rest of the body of Oriental song.

In the Bible the predominance of the motive is the most outstanding characteristic. The motives of the Biblical modes are regulated in a strict syntactical order. They are arranged not only in disjunctives and conjunctives, as closing or binding 
motives (in Hebrew mafsikim-disjunctives, mesharethimconjunctives), but these two groups are subdivided into primary and secondary disjunctives; motives which express the ending of a complete verse, and those which indicate the conclusion of its parts. Originally, the motives were classified also as to their tonAL, DYNAMICAL (forte or piano), and TIME value (allegro or lento, etc.). There are rules governing the succession of motives into a musical phrase, a melodic line within a certain mode.

But before describing the THEORY of the MOTIVEs, it is necessary to familiarize ourselves with the MODEs, in order to see the practical application of the motives, how by their stratification and musical phrases, specific melodic lines are created which mark the distinctive characteristics of a certain mode.

(a) The Pentateuch Mode is founded upon the scale e-f$\mathrm{g}-\mathrm{a}+\mathrm{b}-\mathrm{c}-\mathrm{d}-\mathrm{e}$ which is identical with the ancient Greek Dorian and with scale II of Oriental music (chapter 2nd). Its chief feature is its tetrachordal basis, for the scale is constituted of two tetrachords: $\mathrm{e}-\mathrm{a}+\mathrm{b}-\mathrm{d}$ in disjunctive form, which means that between the tetrachords there is an interval of a whole step $(a-b)$.

For the better understanding of the nature and development of Jewish song, we give numerous illustrations to assure a clear view of the most essential elements. "The "bars" in the unrhythmical examples do not mark rhythm, but indicate the motives of the modes. This procedure enables us to grasp the way the motives are employed within the modes.

We give an example of the mode of the Pentateuch according to the tradition of the Babylonian Jews (table IV, I). A comparison of this reading with the tradition of the Amsterdam Portuguese community (written down by David Pinna at the end of the seventeenth century ${ }^{6}$ ) proves first: that the two chants are identical, despite the geographical distance between the people who employ them; secondly, that the tonality of the Amsterdam version is remolded according to the European system of half and whole steps, whereas the Babylonian version shows the Oriental tonality of $3 / 4$ steps instead of whole steps, as indicated in table IV, I, (Chapter II). Furthermore, we learn from 


\section{TABLE IV}

Exiod. 18, 1-22

1.

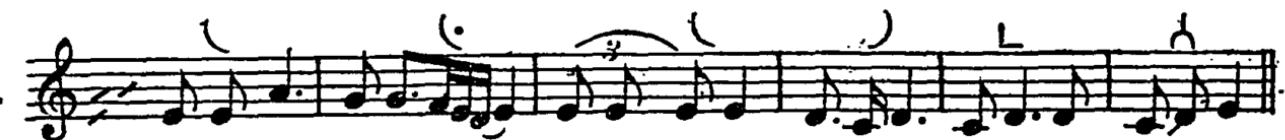

Way-yik-ra mo-she. _ le-cholzik-ne yis-ra-el wa-yo-mer a-le-hem.
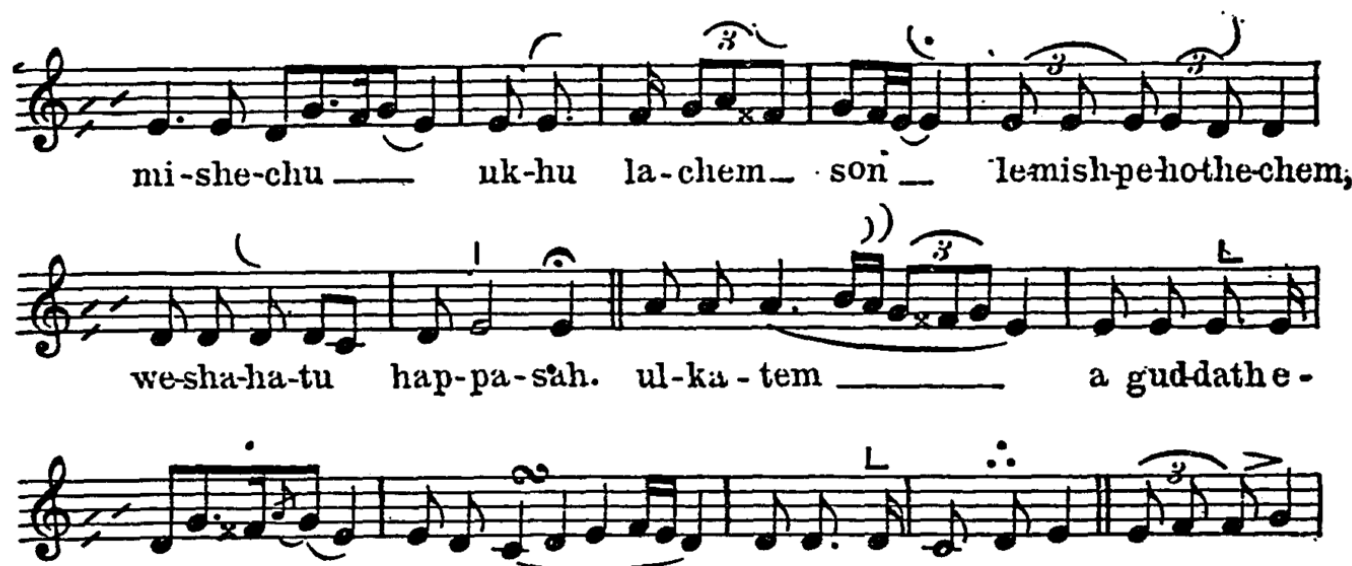

zob

utbal-tem

ball-dam a-sher bassaf,we-hig-ga-tem

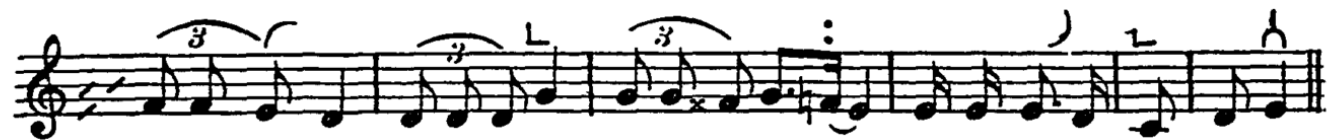

el hammashtzof weel she-te ha-me-zu-zoth min haddama-sher bas-saf.

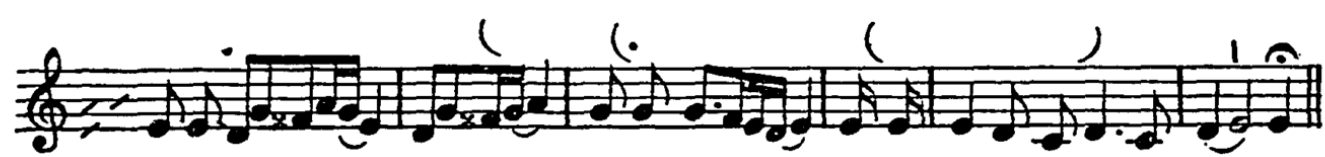

we-at-tem 10

the-se-u

ishmintpe-sahbe-thoad bo-ker.

Genesis 48, 15-16

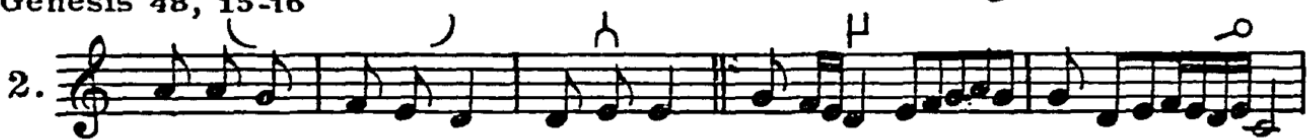

Way-ba-1ech eth yo-sef way-yo-mar. hat-lo-him-a-sher

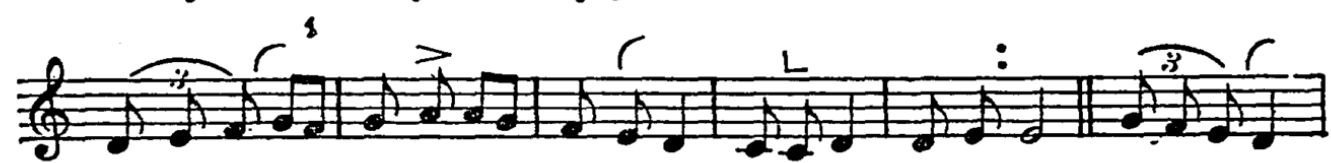

hith-ha-le-chu a-bo-thay le-fo-naw ab-ratham we yisthak. ha-e-lo-him

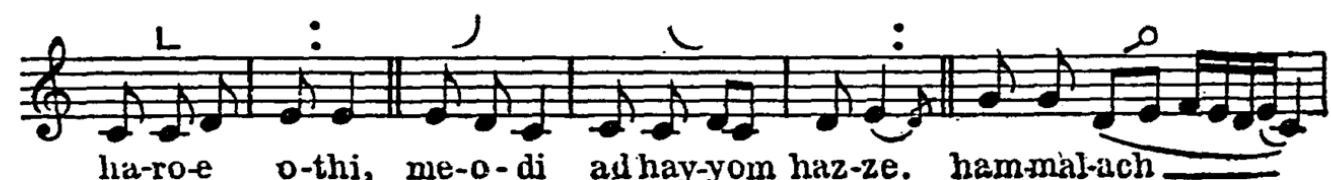



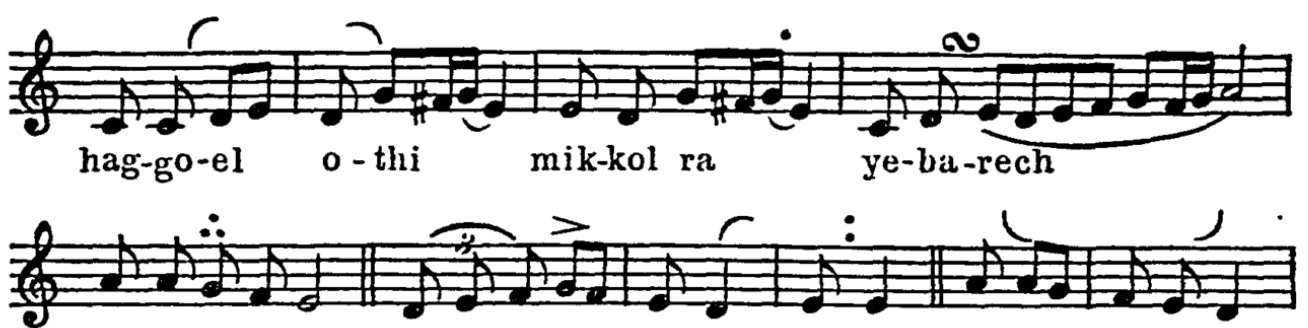
eth ha-ne-a-rim we-yik-ka-re ba-hem she-mi we-shem a-bo-thay

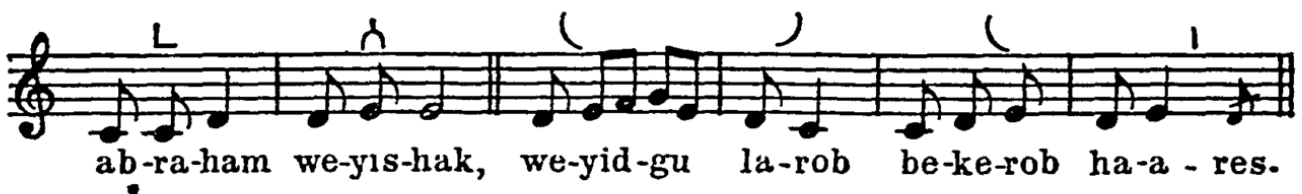

.Song of Songs $1 ; x-2 ; 3,2$

(Ashkenazic-Lithuania)

3

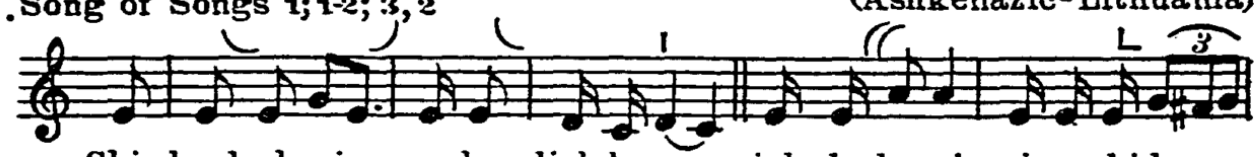

Shir hash-shı-rim a-sher lishto-mu. yish-sho-ke-ni mi-ne-shi-kos.

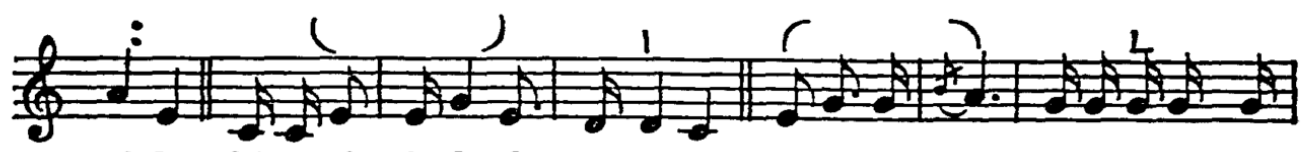

pi-hu, ki to-vim,do-de-cho miy-yo-yim. o-ku-mo no va-a-so-va-voh
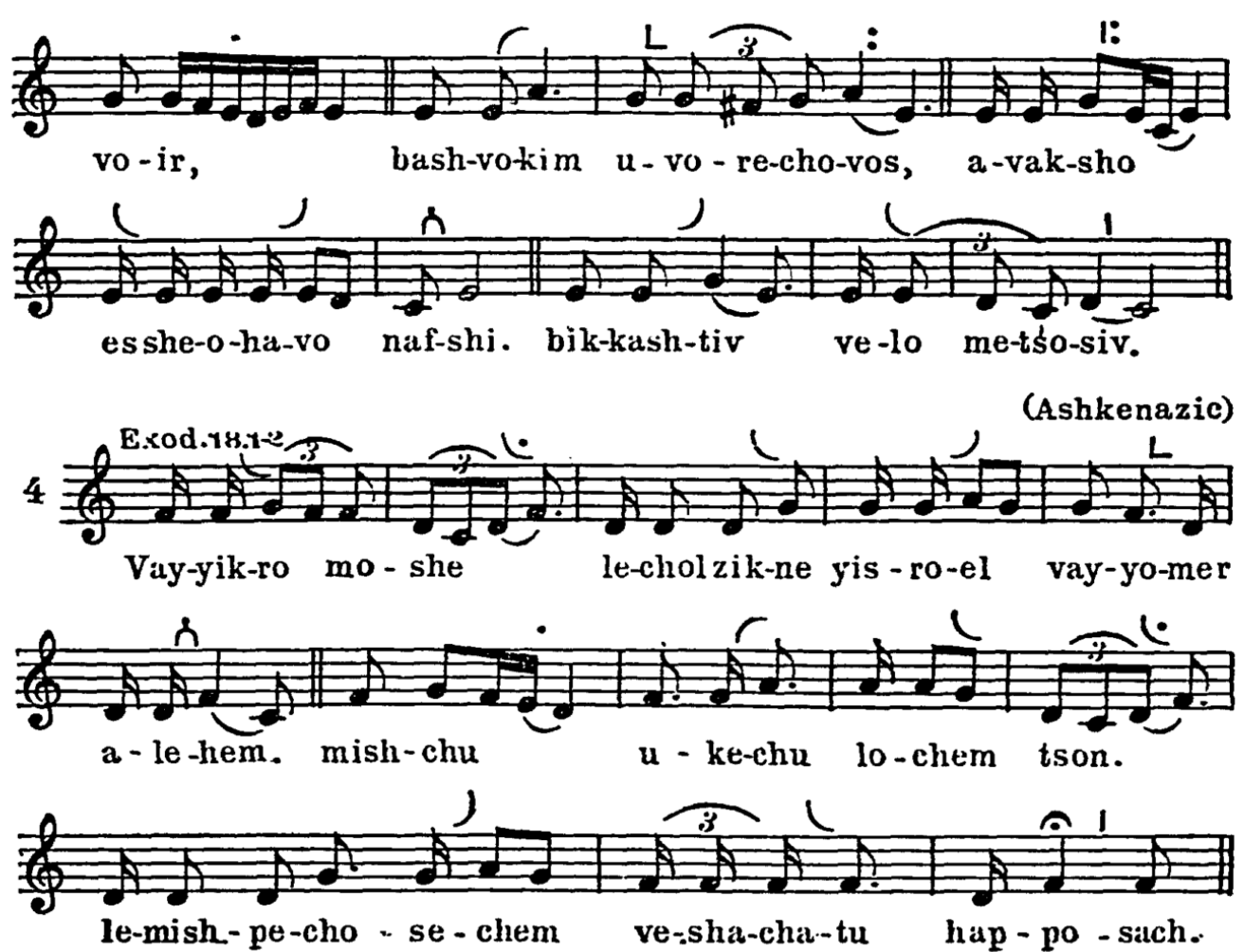

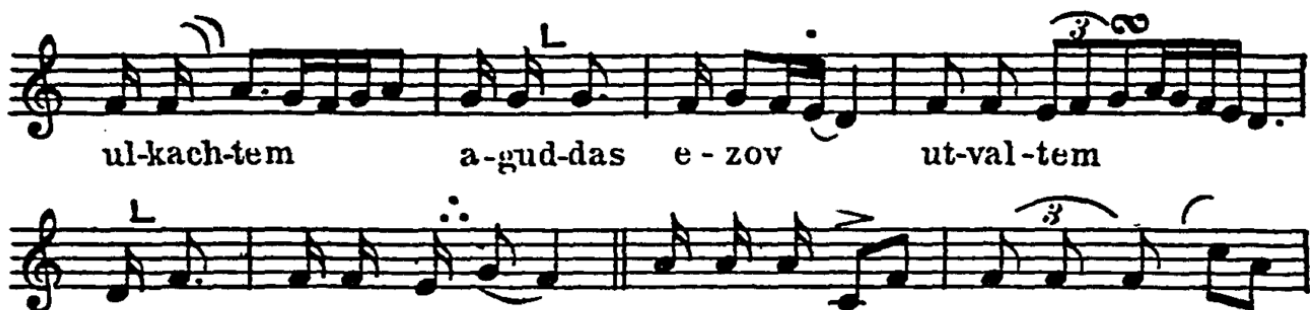

bad-dom a-sher bas-sof, ve-hig-ga-tem el ham-mash-kof

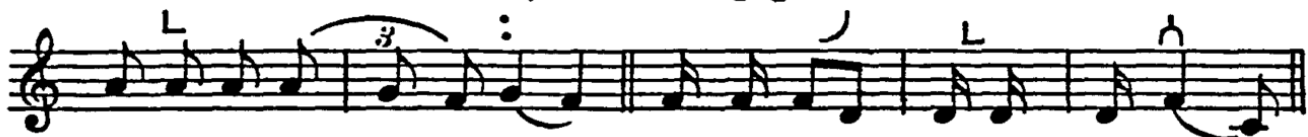
ve-el she-te ham-zu-zos, min-had-dam a-sher bas-saf.

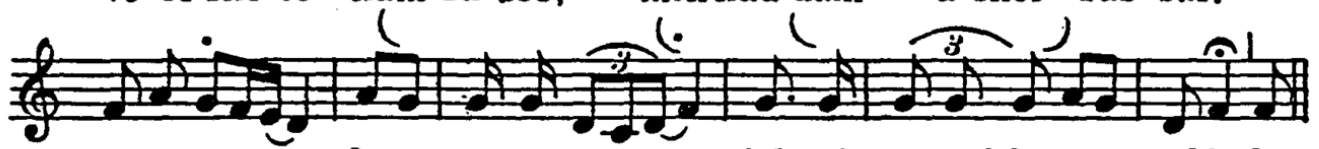

ve-a-tem lo se-tse-u ish mip-pe-sach be-so ad-boker.

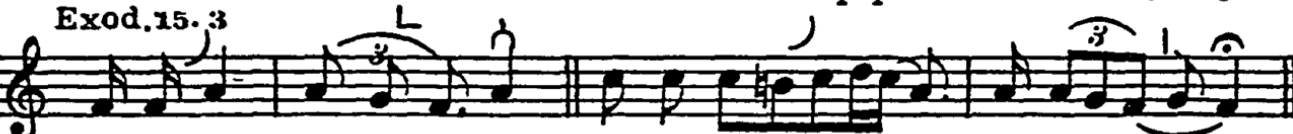

a-do-noy ishmil-chb-moh, at-do-noy shẹ-mo.
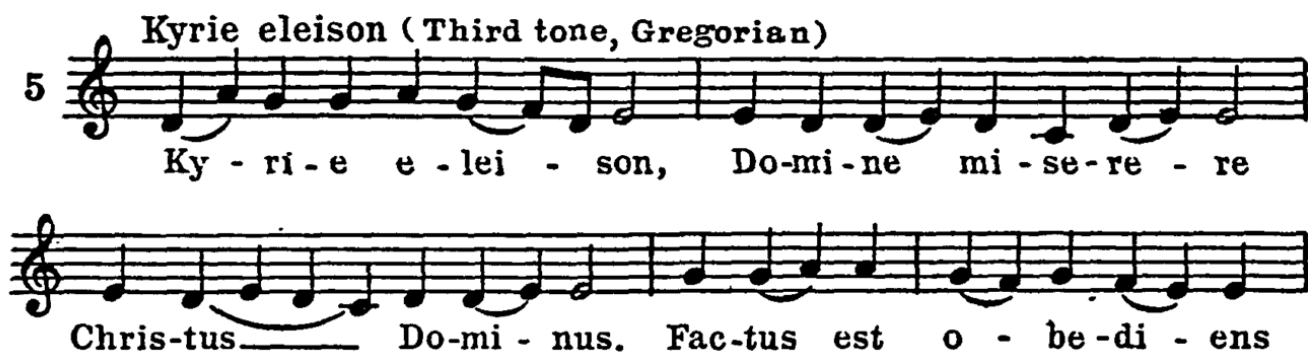

Chris-tus Do-mi - nus. Fac-tus est 0 - be-di - ens
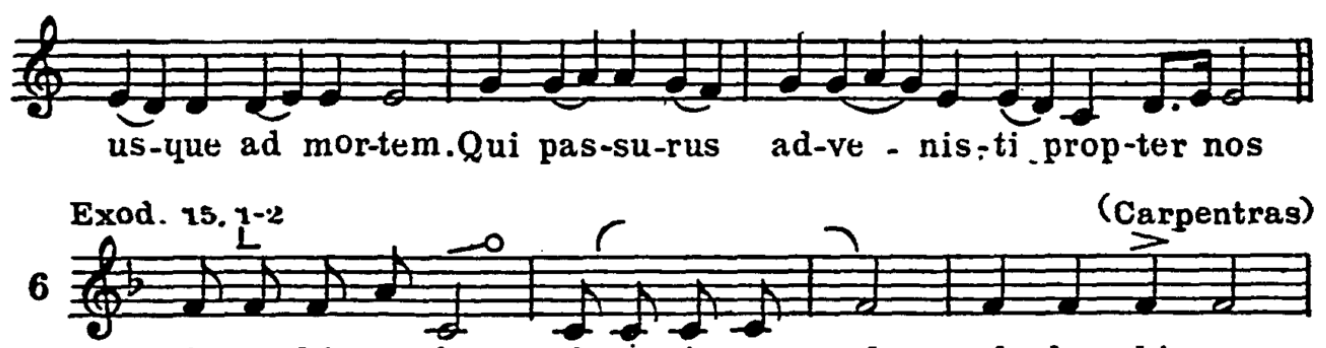

Az ya-shir mo-che ub-ne yis-ra - el eth ha-shi-ra

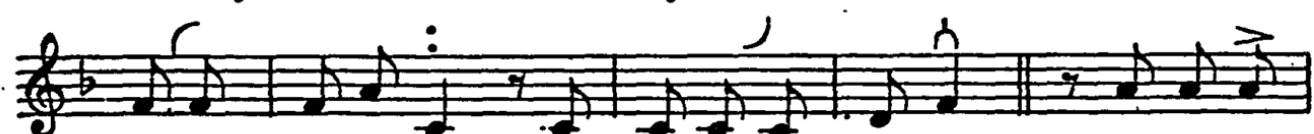

hil-zoth lit-do-nay va-yo-me-ru le-mor a-shi-ra

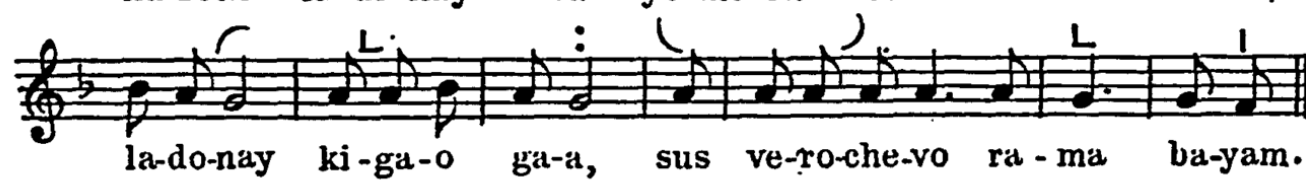


the Amsterdam example that since the seventeenth century no changes in the Pentateuch mode are noticeable.

This mode is common in all Oriental and Italian synagogues with the exception of the Yemenite and Spanish-Oriental. Neither does it occur in the Ashkenazic synagogues.

Example 3 (table IV) shows the same mode used for the Song of Songs by the Ashkenazic communities in Eastern Europe and notably in Lithuania, with the one difference, that through German influence the MAJOR scale was applied and the tonic became $c$ instead of $e$. This procedure of changing the ancient Dorian scale (scale II in Chapter II) to the major is typical in the Ashkenazic song of the Synagogue, and we will witness it repeatedly in the course of our discussions.

Another peculiarity we notice in example 3 is the transfer of the mode from the Pentateuch to the Song of Songs. The transfer of a mode of one text to another text in the Bible is to be found in other cases, as we shall see later.

Of quite different character is the Pentateuch mode of the Ashkenazic communities. Its scale is: $f-g-a^{b}-b-c-d-e-f$, i.e., the Lydian, and it has major character, though several motives are identical with motives of examples I-2, as evidenced by the "Comparative Table" of this mode's motives in their forms in the different communities. In this table we notice that the essential motives of the Babylonian (1), Bokharian (2), Persian (3), Syrian (4), Moroccan (5), Gibraltarian (6), Italian (7), Sephardic in France (8), Sephardic in Amsterdam (9), Sephardic in Egypt and Palestine (10), and the Ashkenazic for Canticles (13) are practically alike. In contrast to these evident similarities, example I I shows the variants in the Ashkenazic tradition. These variants, however, are of no recent date, for their inclusion in the table of motives of the Pentateuch mode printed in 1518 in the Hebrew Grammar of Johann Reuchlin ${ }^{7}$ (see example 12) proves that the mode in this form was already at that time considered traditional by the German Jews.

The Ashkenazic mode is similar to that in use in the Jewish communities in Southern France, in Carpentras and Avignon (example 6). ${ }^{\mathbf{8}}$ Now history tells us that the Ashkenazic tradition is the youngest, that spiritual life in the Jewish settlement in southwestern Germany starts about the ninth or tenth century, and that some of its prominent au- 
44

JEWISH MUSIC

Comparative table of accent motives for the.intoning of the Pentateuch

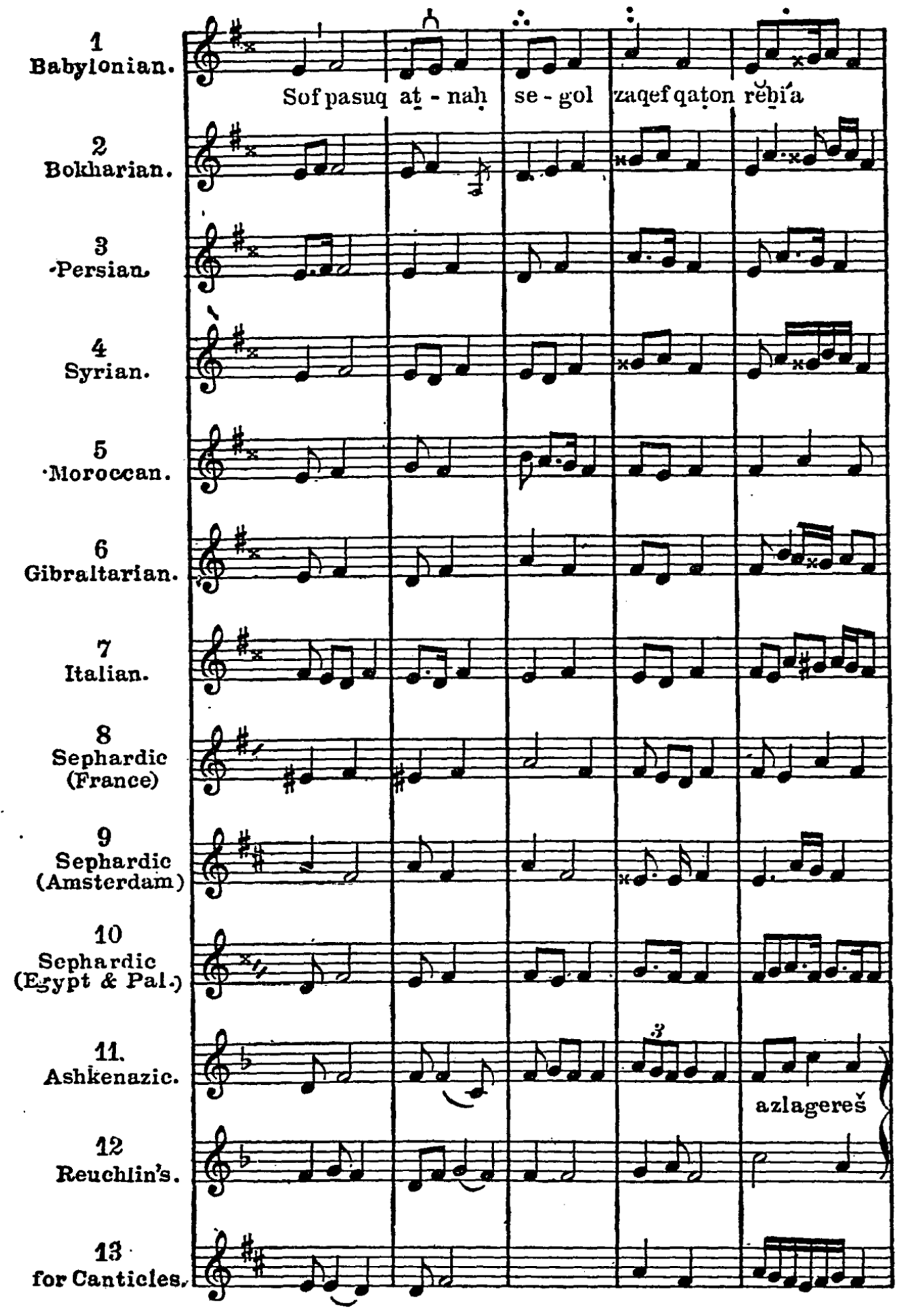

DEF 


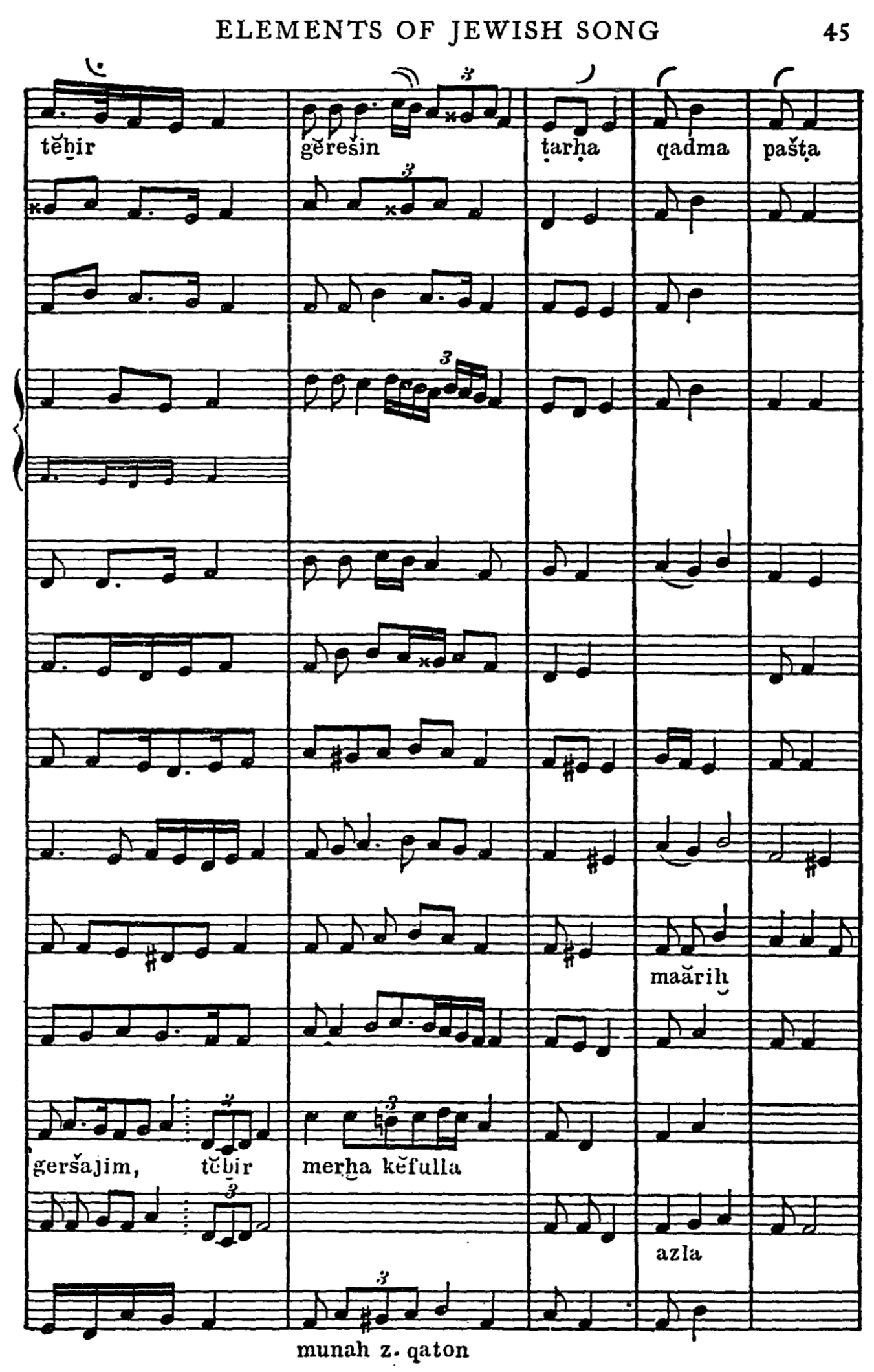




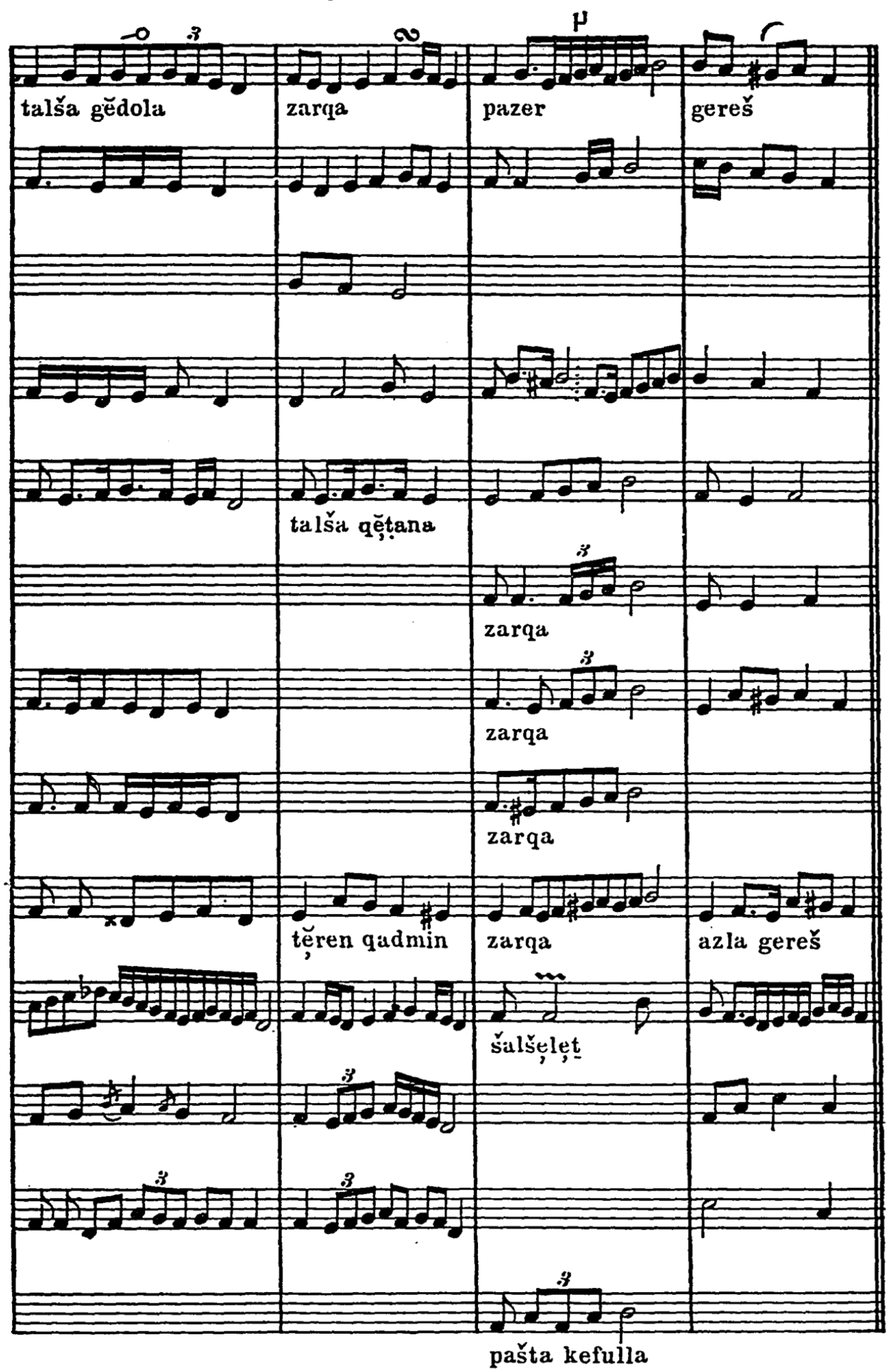


thorities were natives of Southern France or Provence ${ }^{9}$ or of Italy..$^{10}$ These facts may explain why so many similarities between the Ashkenazic (German) and the Southern French and Italian songs of the Synagogue are to be found. In Chapter VIII we shall have some examples of them.

At the same time, much similarity is to be found between the mode of the Pentateuch in its Oriental version and the third Gregorian mode (the ancient Greek Dorian), for which example 5 (Kyrie eleison) may offer evidence. It is quite certain that the Synagogue did not borrow that mode from the Church, since it is the tradition of those communities, which, like the Babylonian, never came into contact with the Roman Church. Quite to the contrary, we know that the Christian Church in the first centuries took over many elements from the Jewish song, as repeatedly testified to by ancient authors and reaffirmed by historians of our day. ${ }^{11}$ The Gregorian song, by establishing for "Plain Chant" the rule of equal time-value for all notes of the chant, robbed the song, which it had borrowed from the Synagogue, of its distinctive features: the unrhythmical, free character of improvisation, and the embellishment, which is the very color of Oriental life.

The mode of the Pentateuch expresses dignity and is elevating in spirit. It has not lost its vitality and elasticity, nor its attractiveness to the Jew of the old school, and if rendered in a proper way, ${ }^{12}$ also to the modern Jew, despite its antiquity.

(b) The mode of RuTH is built on the same scale as that of the Pentateuch, but its motives are of a different nature, for we hear a pronounced lyric strain in them (table V). The comparison between the Babylonian and Ashkenazic versions clearly shows their identity. In the Ashkenazic version we notice the European influence in changing the scale from Dorian to major, by making " $c$ " the tonic instead of " $e$," a change similar to what we saw in the mode of the Pentateuch and the Song of Songs. ${ }^{13}$

(c) Ecclesiastes is chanted in the mode of Ruth in most communities.

Thus far we have discussed the regular mode of the Pentateuch and closely related modes.

(d) For the poetical portrons of the Pentateuch special modes are employed in several communities. These poetical versions are, ac- 


\section{TABLE V}

Ruth

(Babyloniarı-Ashkenazic)
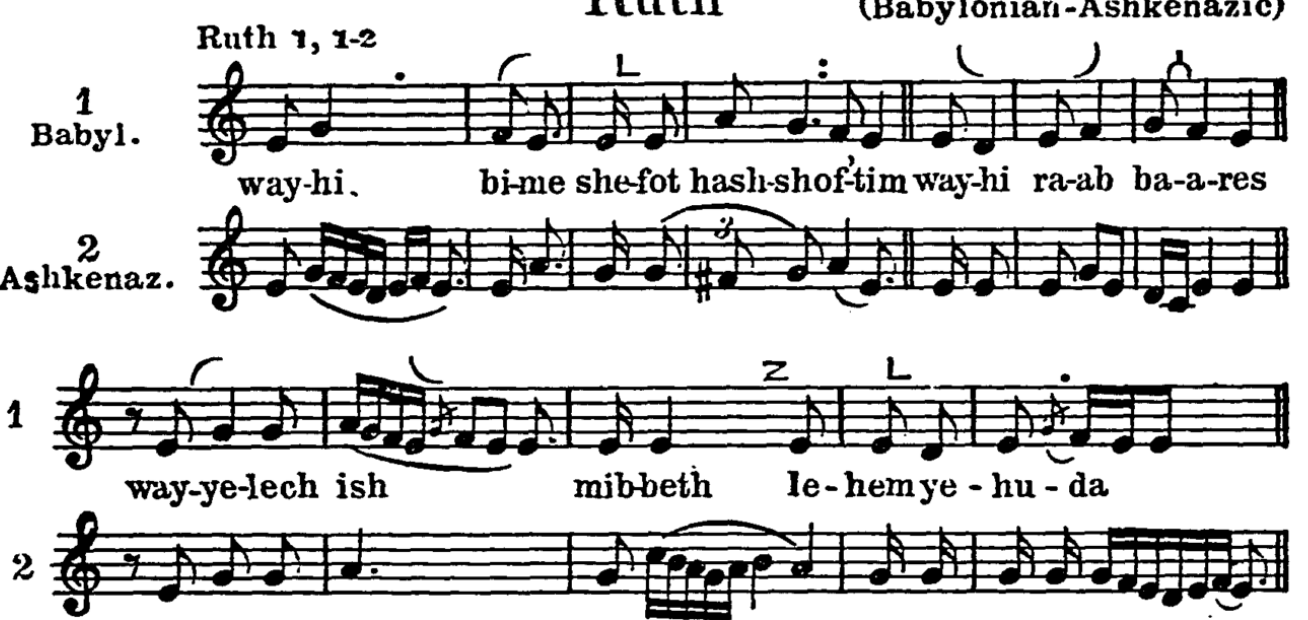

1
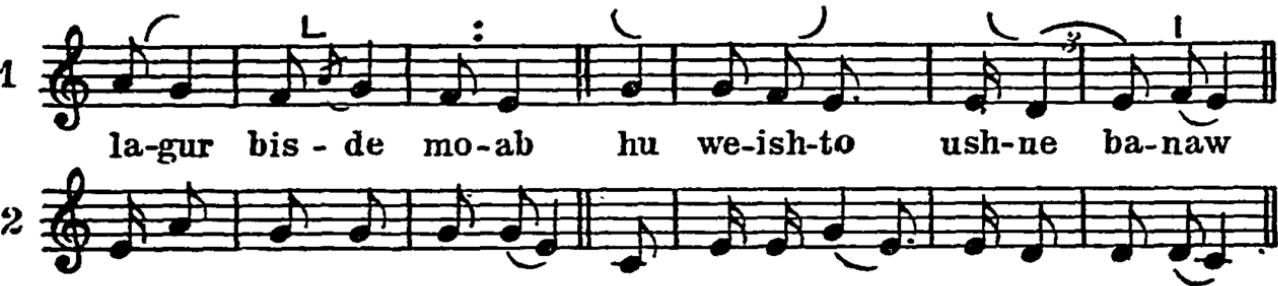

\section{Intonation of the Song of Songs}

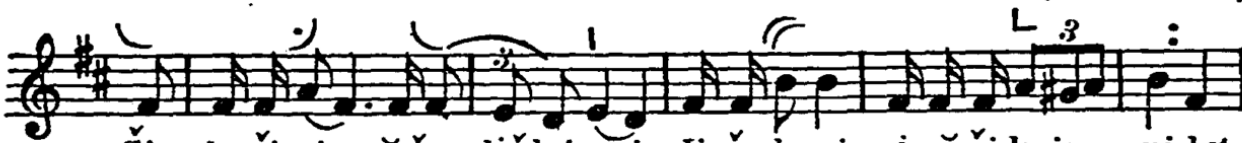
Šir harši-rim ă-šer liš-lej-mej. Ji-šo-ke-ni mi-ně-ši-kejs pi-hu

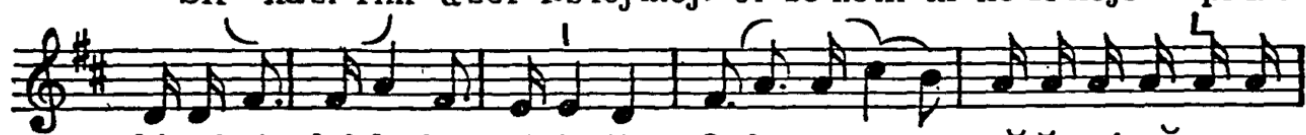

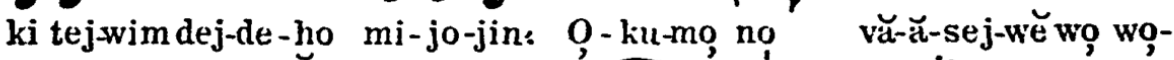

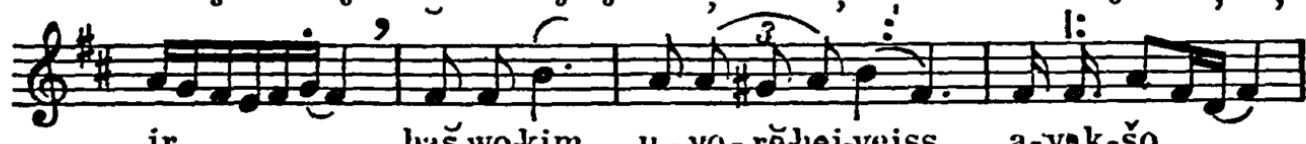

ir baš-wọłkim u-vọ-rę̆łlıj-vejss a-vak-šọ,

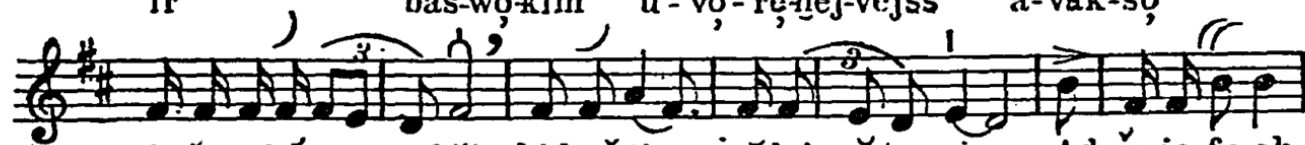

ejs še-o,hă-vo, naf-ši bi-katš-tiv vě-lej mě-tsọsiv. Ad še-jọ-fu-ah̆

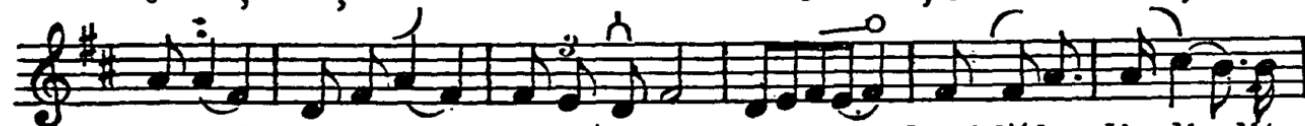

ha-ye-jm ve-no-su ha-tzẹ-lụ-lim sejw, dmej lĕ-họ, dje-dj litz-

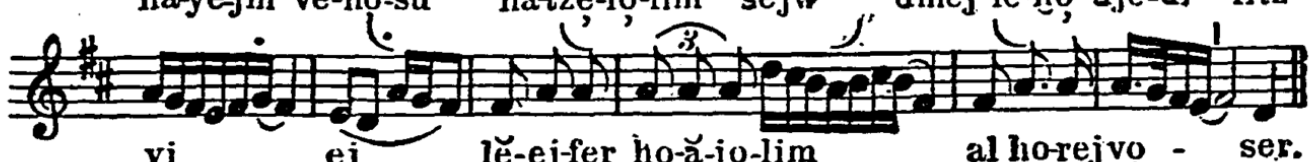

vi

$\mathbf{e j}$

lě-ej-fer ho-ă-jọ-lim

al họejvo - ser. 


\section{TABLE VI \\ Tunes for the Poetry of the Pentateuch}

(Yemenite)
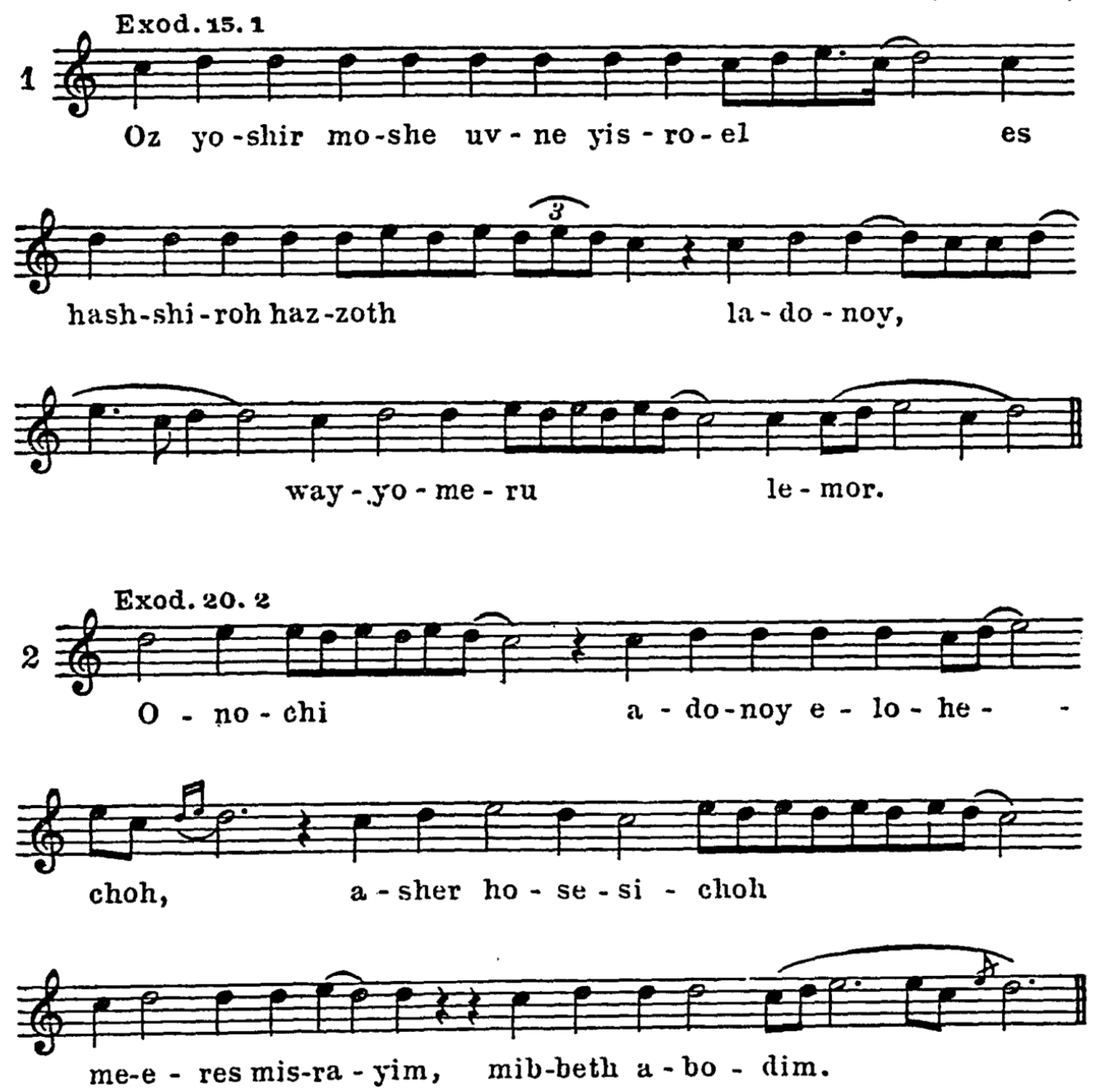

(Portuguese)

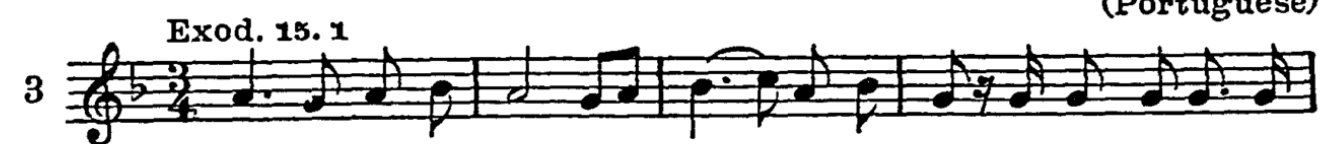
Az ya-shirmo-she uv - ne yis-ra- - l et hash-shi-ra haz-

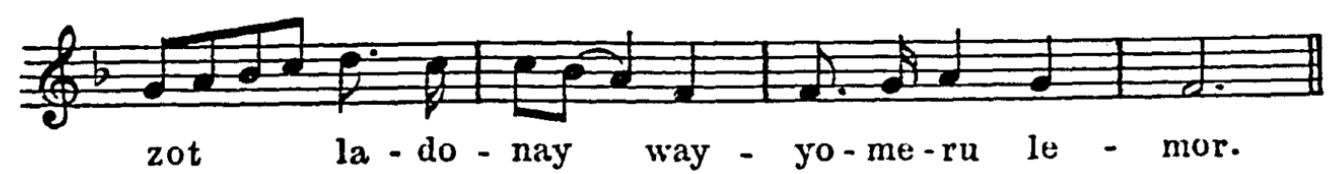


cording to tradition: the Song of the Sea (Exod. I5), the Ten Commandments (Exod. 20:2-17) (Deut. 5:6-18), and the Blessing of Moses (Deut. 33). They are marked by the special way in which they are written in the scroll, the verses being set in this form: $=$ - $=$ called in the Talmud ariach all gabbe levena $=a \overline{l o g}$ (long line) upon a brick (short line), like the structure of a wall. ${ }^{14}$ Deut. 32 is not considered a poem because it is not of a joyous nature and, therefore, it is not written in the poetical form, but the lines are divided in two straight columns, called "log upon $\log ,{ }^{15}=$

The Yemenite and Persian communities have a special tune for the "poems," as given in table VI, I-2. The Moroccan, Italian, Portuguese, and Southern French communities have rhythmical tunes for the Song of the Sea alone. Some of the communities, as the Southern French, have a special tune for the Song of the Sea, for every festival. The best known tune is given in table VI, 3. It reminds one of the second part of example 6 in table IV given for the same text. The tune may be a creation out of the Psalm-mode of which we shall speak later, or even of the Pentateuch mode, according to the FrenchGerman version.

(e) The mode of the Prophets, like the mode of the Pentateuch, is based upon a tetrachordal system, on the scale $d-e-f-g$ plus $a-b-c-d$. This scale is the same as the ancient Greek Phrygian, or the first Gregorian mode or scale I, discussed in Chapter II, and it is identical with the scale of the Arabic mode Bayati (Chapter II). In some instances it is changed to the scale: $d^{1}-e^{1 / 2}-f^{1}-g+$ $g^{1}-a^{1 / 2}-b^{b 1}-c$, the scale of the plagal of the first Gregorian mode, called the second mode (Hypodorian). This is the standard scale in Jewish music, not only in Synagogue song but also in folk-song. Nearly eighty per cent. of all Jewish folk-song is based upon it. This scale expresses what in Hebrew is called hishtapchuth hannefesh-the outpouring of the soul, and it is, therefore, used for the exhortation of the Prophets as well as for Lamentations and for a part of the Psalms, that is, for those emotional texts the contents of which are pleading or fervent. It seems that the Prophetic mode is one of the chief strains in Semitic music, and was even more at home among the Hebrew people in ancient times than later, for the Yemenite and Persian Jews use the Prophetic mode for the Pentateuch also. Although the mode has the 
character of minor, it is, nevertheless, not melancholy because it has a note of hope- of promise. It expresses a fine and tender sentiment, and turns frequently to a bright and even joyous mood. Of course, according to West European and especially Anglo-Saxon feeling, the mode sounds sad, for these peoples prefer the major; and to them any minor tune is melancholy.

The Prophetic mode has been well preserved through the obligatory chanting of a portion of the Prophets-Haftara-after the reading of the Pentateuch. This mode is built of motives just as is the mode of the Pentateuch. See the illustrations in table VII. We recognize in $I$ and 2 the same mode. While the Yemenites use it for the Pentateuch, it was transferred by the Persians to the Song of Songs. A similar procedure we found in the application of the Pentateuchal mode for the Song of Songs by the Ashkenazim in Eastern Europe. In example 3 we see the single tetrachordal range of the Yemenite mode, while in 4-6 we recognize a double tetrachord in a heptachord, which scale corresponds to the Hypodorian mentioned above. Example 6, the East European tradition, is closer to the Yemenite and Persian modes given in $\mathbf{I}-2$.

The Ashkenazim employ a special motive as an ending motive of the reading of the Pentateuch (see 7). This motive leads over to the parallel minor scale, and was apparently invented to lead the reader into the scale of the mode of the Prophets, the chanting of which follows immediately thereafter. Later we shall meet the same motive employed in like capacity in other modes. It is most likely derived from the Ashkenazic athnah motive of the Prophets, as may be clearly seen in example 5 (eved adonoy).

(f) In the scale of the Prophetic mode, there is also the mode of LAMENTATIONs which has the same tetrachordal character, except among the Ashkenazim, with whom the tradition was so modified by European influence as to give special emphasis to the third and fifth tones, a distinctive characteristic of the eight-tone scale.

The lamentative character of the mode of Lamentations is expressed mainly through the melodic line which is short and produces the effect of depression. Especially the verses of the third chapter are short and remind one somehow of the pentameter in which the Greeks wrote lamentations. Though the mode of Lamentations is common to all communities, yet each has peculiarities of its own. For instance, the 


\section{TABLE VII}

\section{Prophets}
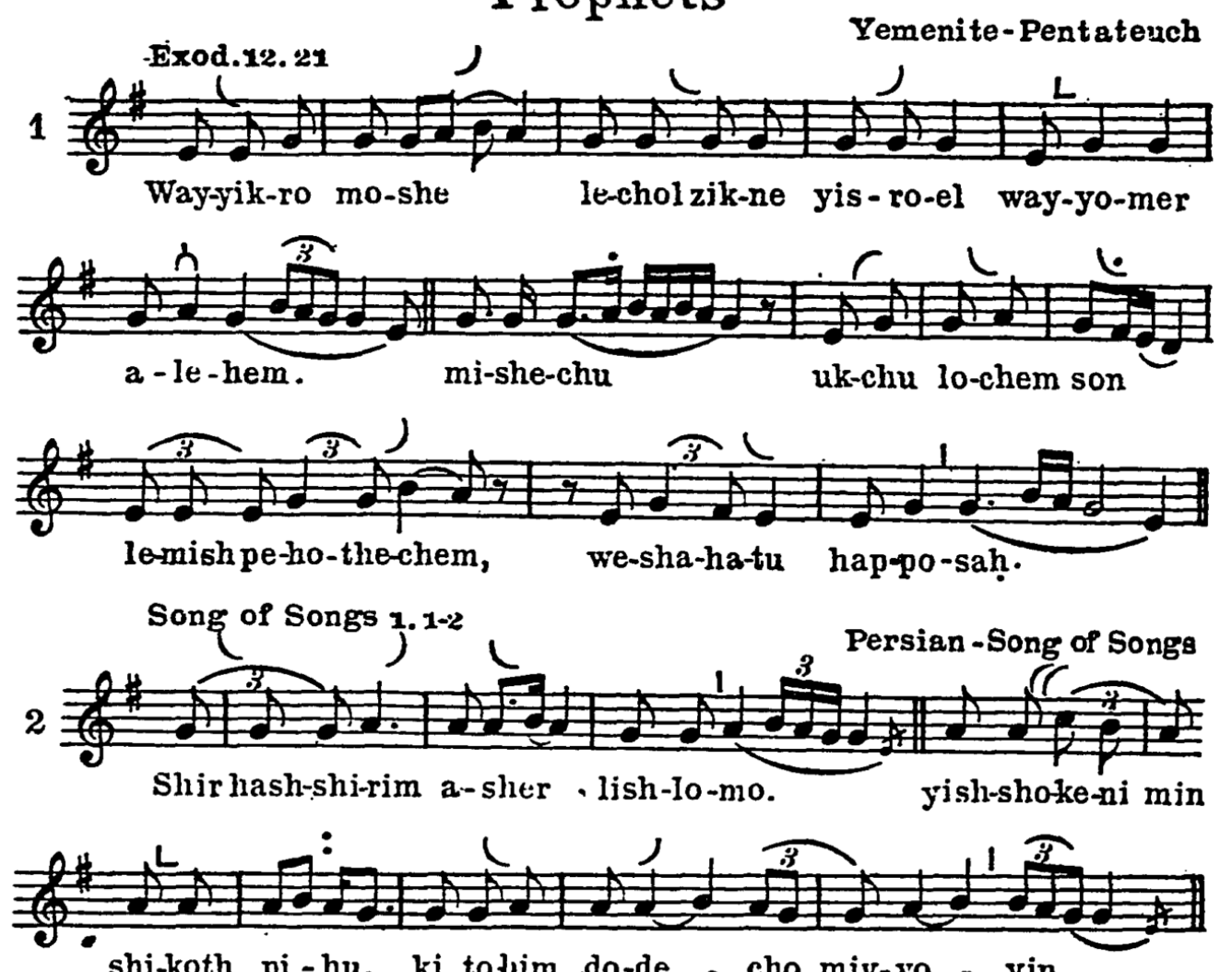

shi-koth pi -hu, ki tolim do-de - cho miy-yo - yin.
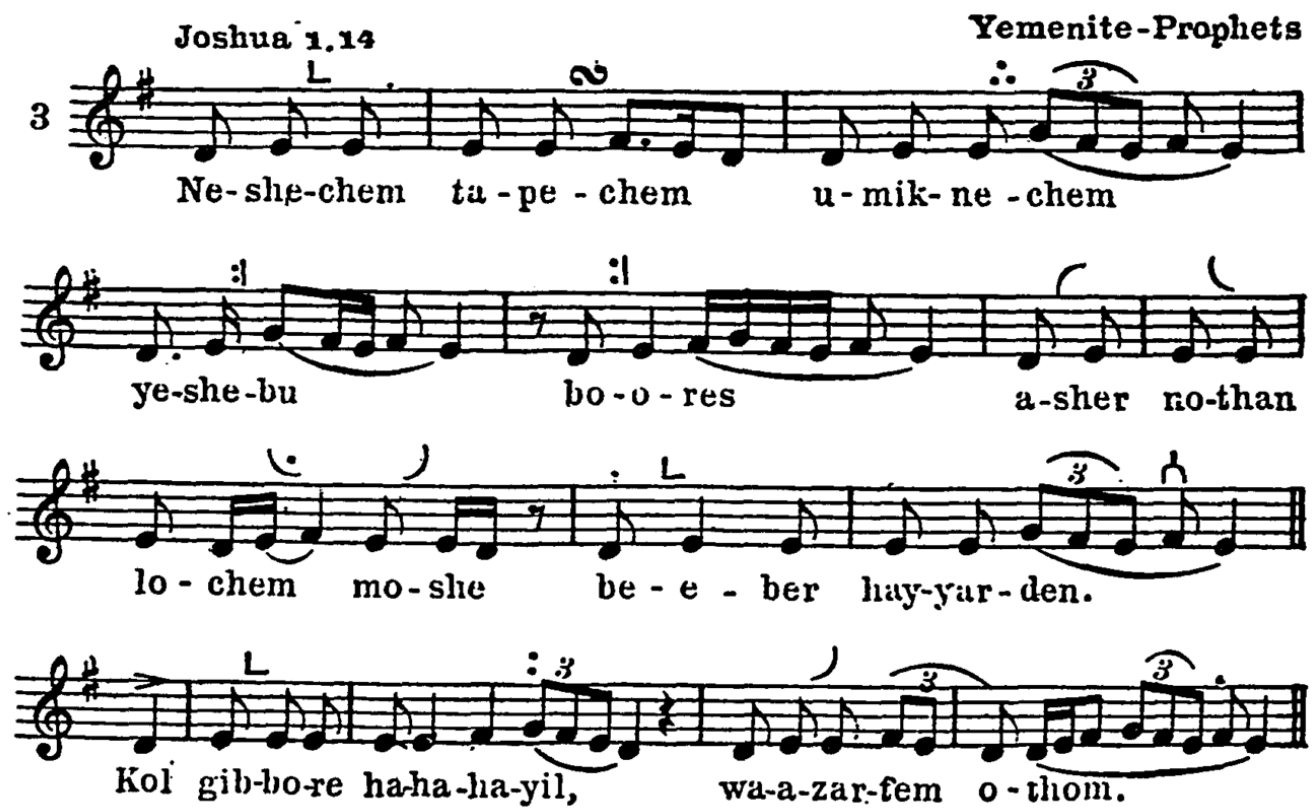
4

Joshua 1. 1-2
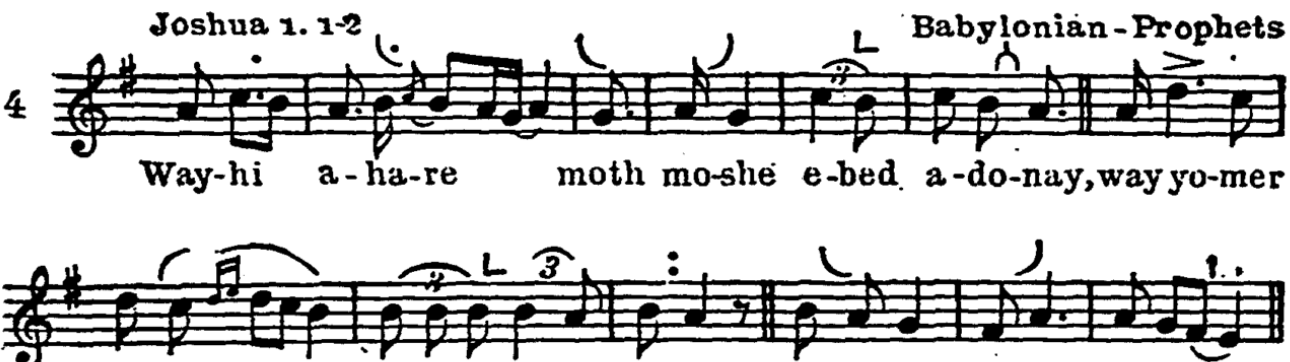

a-do - nay

el. ye-hoshu-a binnun, mesharethmoshe le-mor.
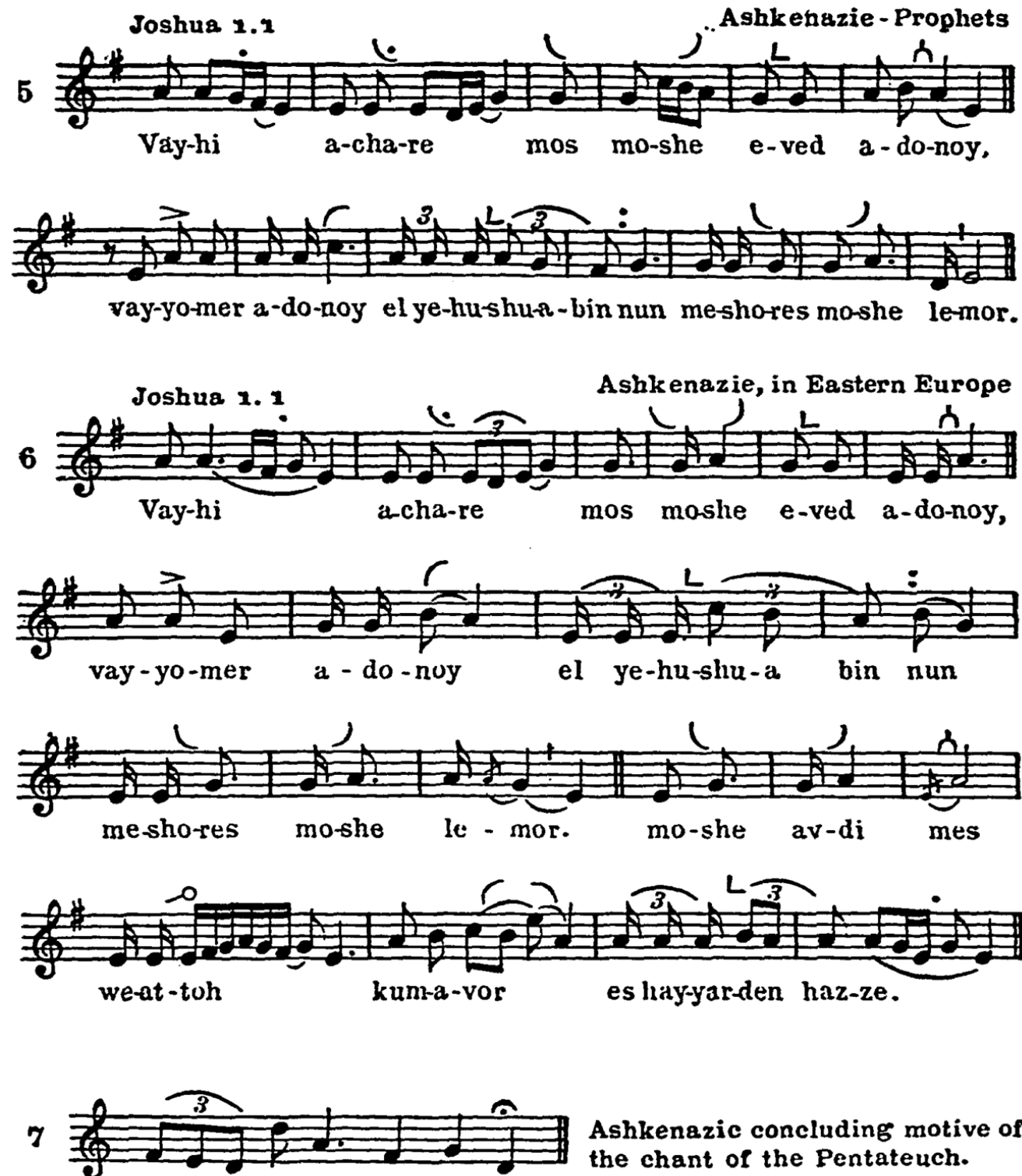

Ashkenazic concluding motive of the chant of the Pentateuch. 


\section{TABIE VIII \\ Lamentations}

Iam. 1.1

1
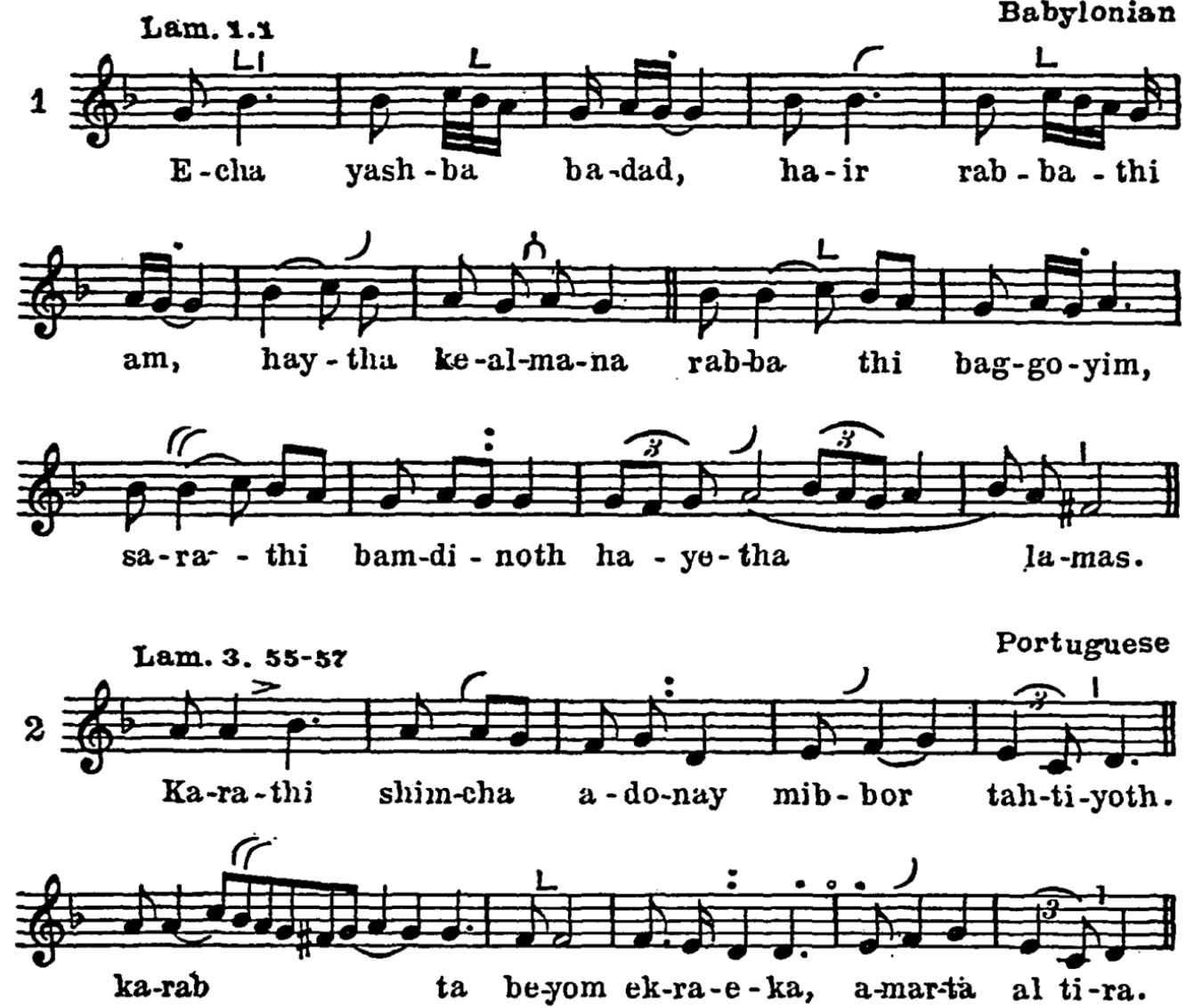

Lam. 1.1

Ashkenazic

3
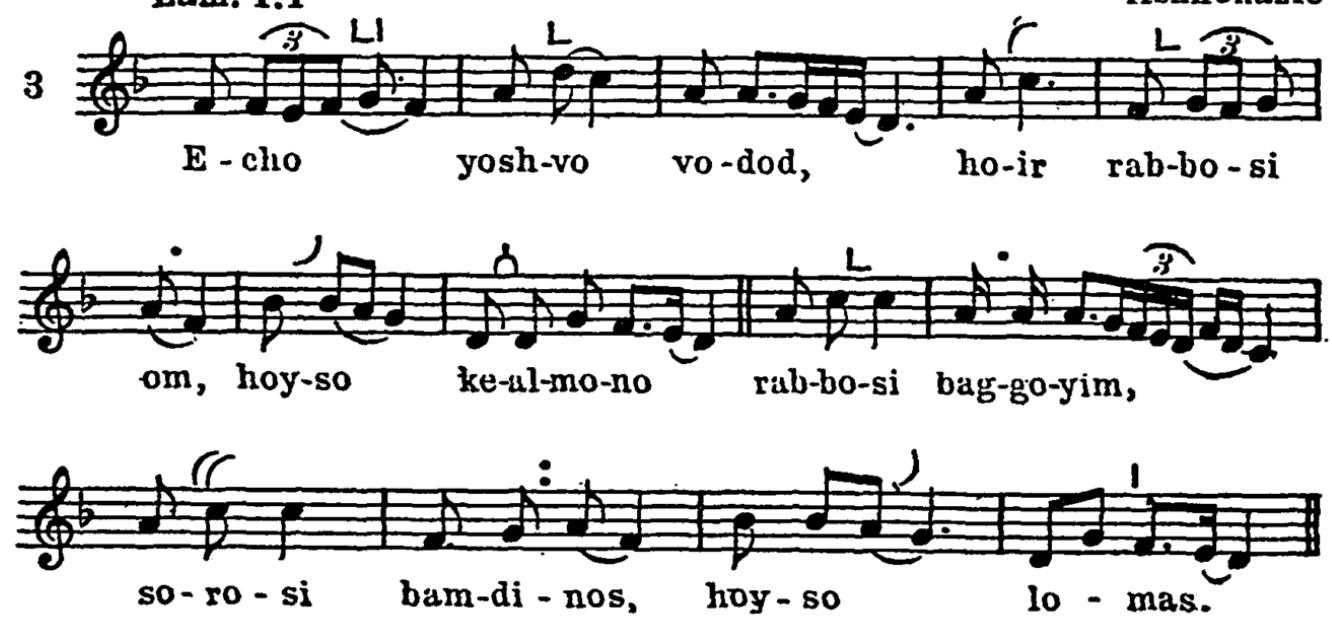
Lam. 5. 1-2

Sephardic

Sephardic-Ashkenazic

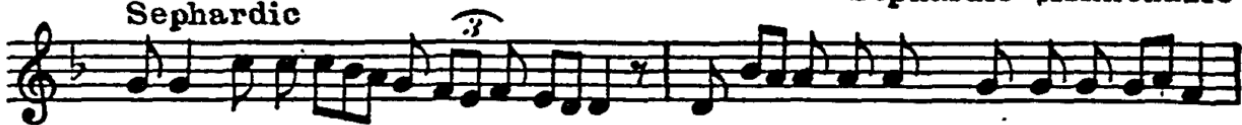

4

Zo-chora-do-nay me ha-ya la-nu hab-bi-ta ur-e ethher-pithe-nu.

Ashkenazic
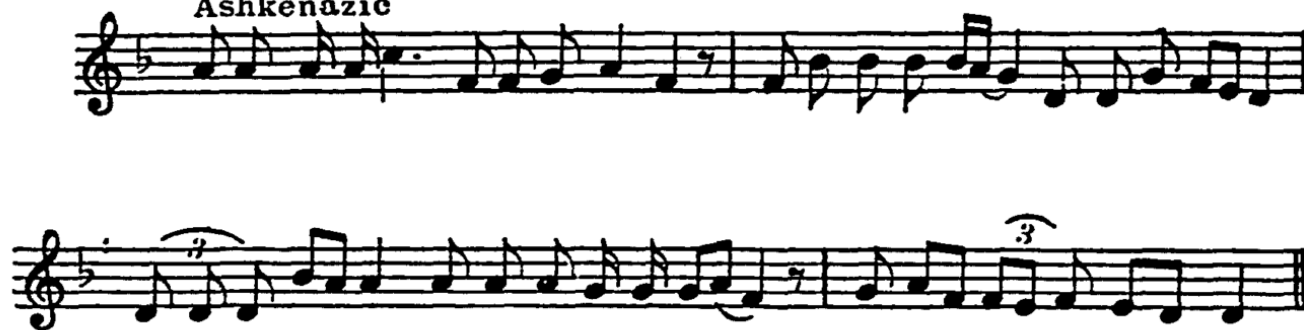
natra-la-the-nu nethef-chale-zo-rim, ba-te-nu le-noch-rin

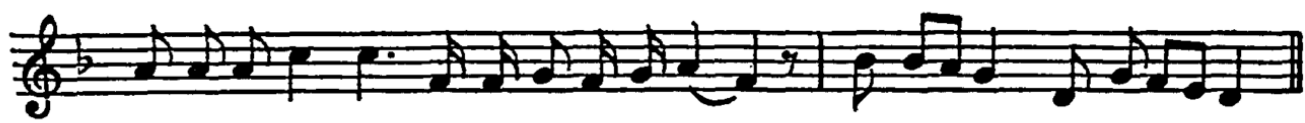

Lam. 4. 16.
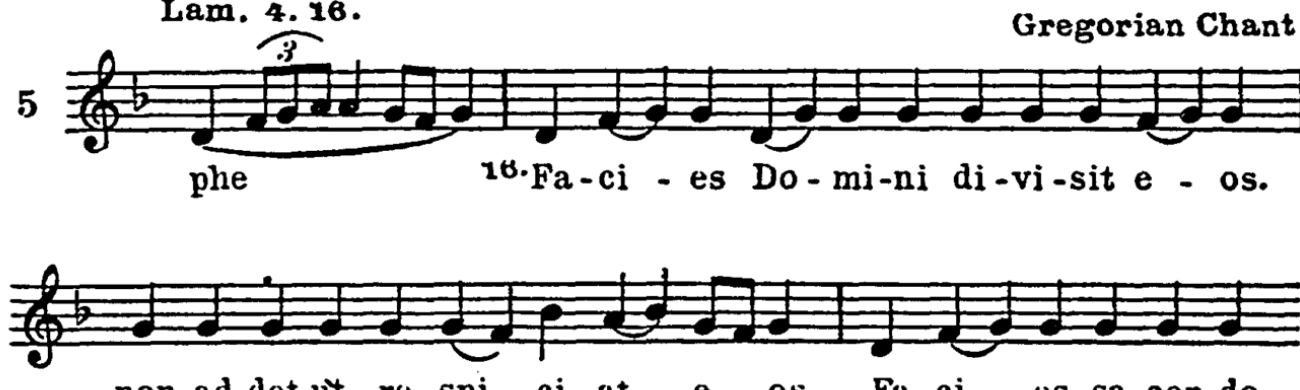

non ad-det ut re-spi - ci-at .e - os. Fal-ci - es sa-cer-do-

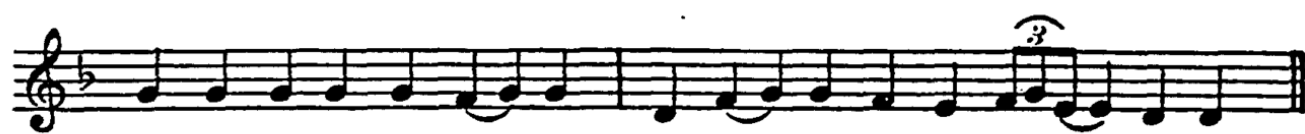

tumnon e-ru-bu-e - runt. e-que se-nummi-ser - ti sunt.
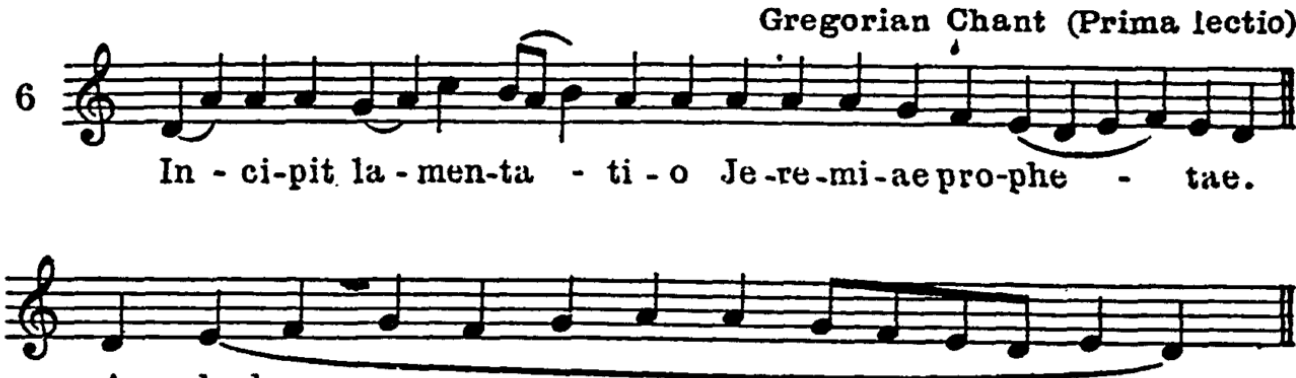

A - leph. 
Babylonian mode has a local concluding motive which is to be found also in the traditional song of the Jacobite Church and in the Song of the Copts in Egypt. ${ }^{16}$ Striking similarity to the mode of Lamentations is to be found in the Gregorian chant. In table VIII we illustrate the Babylonian (I), the Portuguese (2), and the Ashkenazic (3) tradition, and we give a comparative example (Ashkenazic-Sephardic) (4). Further we present two examples of the Gregorian chant for Lamentations, as they are rendered on the night of Easter (5-6). The first is more similar to the Jewish Oriental mode, while the second comes near to the Portuguese and Ashkenazic version, though its scale is that of the first mode (Dorian), and the Jewish scale is based upon the Hypodorian.

The Book of Lamentations is chanted in the Synagogue on the ninth of $A b$, in the evening and in the morning, in commemoration of the destruction of the Temple in Jerusalem.

(g) THE MODE OF Job.

The three books of the Writings, Job, Proverbs, and Psalms, have the peculiar construction of short two-part phrases. Of the reason for this form we are not certain, but it gives the impression that its purpose was to make the verses suitable for public singing and response. In Job, out of 1,070 verses, 1,000 are two-part; 67 have three or four parts; and only three verses have five parts. But these four and five part verses are only in the first two chapters and in the last one, which are in prose, while the verses of the poetic portion of the book from Chapter III to Chapter XLII, 7, are of two parts. Likewise with the Book of Proverbs: out of 915 verses, 870 are twopart; 30 three-part; and only a few in four and five parts. In Psalms, all chapters which were designated for public singing-for unison, or for solo and choral response, or for the antiphonal response of two alternating choirs (see Chapter I) are likewise in two-part verses.

The short two-part form of these books shaped the form of their modes by moulding melodic structure into a two-part period, and for the three-part verses into a three-part period.

The mode of Job is based on the scale $f-g-a-b b$, identical with the Ionian or modified Lydian scale which is a tetrachord. The character of the scale is major in so far as it has a major third; but its tetrachordal form prevents it from being a real major in the modern sense in which the major character is pronounced by the fifth and the 
seventh tones, and the elevating melodic curve to the eighth, the octave. In this ancient Oriental form this scale received a serious and meditative complexion. The same scale is utilized in the Oriental mode called Rehaw, a corruption of the name of the Oriental city Raha, which meant in ancient Assyrian "the West." According to the Arabic tradition, whenever this mode is sung, the angels as well as the devils gather to listen, because it influences the good as well as the evil spirits. ${ }^{17}$

Among the Oriental and Sephardic Jews, Job is read on the ninth of $\mathrm{Ab}$, immediately after Lamentations. Therefore, among these groups its mode has been preserved, while the Ashkenazim-not having this custom-have forgotten the tradition of this mode as the "Job-mode." Instead, they employ it for the reading of the Pentateuch on the High Holidays - a usage in which the Ashkenazim are the exception, as only they have a special mode for the Pentateuch on these days, while all the other communities read it in the same mode as is used during the year. The reason for changing the tune for the High Holidays and for employing especially the Job-mode may be this: The Zohar (a cabbalistic homiletical commentary to the Pentateuch, compiled in Aramaic from old sources of mystical literature in the thirteenth century by Moses de Lion) says (Lev. I6) that while reading on the Day of Atonement the portion Leviticus 16 in which the sudden death of the children of Aaron is mentioned, every one should shed tears, and that whoever expresses his sorrow over the death of the children of Aaron may be sure that his own children will not die during his life. Because of these instructions old editions of the Ashkenazic Machzor (prayer-book including poetical insertions for the entire year), like that of Salonica, 1550, carried a mark on this portion, in order that this text be read in a tune different from the usual one, a tune which expresses complaint and sadness. The search for such a tune led to the mode of Job which had had no function in the Ashkenazic rite and suited these requirements. The Ashkenazim took this mode at first for the reading of the Pentateuch on the Day of Atonement; later they extended its use also to the days of Rosh $\mathrm{Ha}$ shana (New Year). It is interesting to notice that in the ancient communities of Germany, like Frankfort-on-the-Main, only the main portions read from the first scroll are chanted in the Job-mode, while the portions read from the second scroll (the contents of which is a 
description of the sacrifices for these days) are chanted in the usual Pentateuch mode.

The Job mode was utilized by the Ashkenazic Jews also for prayers. We shall find the mode in the supplications (Chapter. IV).

Like the modes of the Pentateuch and Lamentations, the mode of Job has its derivative in the Gregorian chant for Lamentations, according to a manuscript of the thirteenth century. ${ }^{18}$ But this mode is to be found in the Gregorian Graduale in much closer form. In table IX, I, the Job-mode is illustrated according to the SephardicOriental tradition. In some communities local changes of minor importance have crept in. Example 2 gives the Ashkenazic version of the mode. Upon closer study of both examples we find that the Oriental version is the simpler one. It consists of two motives, one ending on the second $(\mathrm{g})$, marking the first part of the period, and the other concluding on the tonic $(f)$ and indicating the ending of the second part of the period and of the whole melodic line. In case the verse has three parts, as in verse four of example I, two parts are intoned by the first part of the musical period, and the third part by its second part. In the Ashkenazic version the same principle is observed. There is, however, a motive which is inserted before the ending motive and which makes a melodic curve to the third. The Ashkenazic is richer in motives than the Oriental. The additional motives were taken over from other modes, from the Pentateuch (for the words: Moshe dabber el aharon ochicho) and from the Prophets (vay'yomer adonoy). The custom of borrowing from other modes is characteristic of the Ashkenazic traditional song-a custom which we shall discuss later at greater length. Example 3 is from the above mentioned manuscript of the thirteenth century, which has more resemblance to the Oriental version, whereas example 4 reminds one more of the Ashkenazic mode, and is commonly used in the Catholic Church. The Job-mode, too, exercised a considerable influence upon the later creations of the Synagogal song.

(h) The modes of the Psalms.

The Book of Psalms has come to be the standard collection of hymns and prayers of the Jewish and Christian faith. It is the fountain from which millions of souls have drawn their inspiration and through which they have voiced their devotion for more than two thousand years. It has provided thousands of religious spirits with a means of 


\section{TABLE IX}

Job

Job $3.3 x$

1

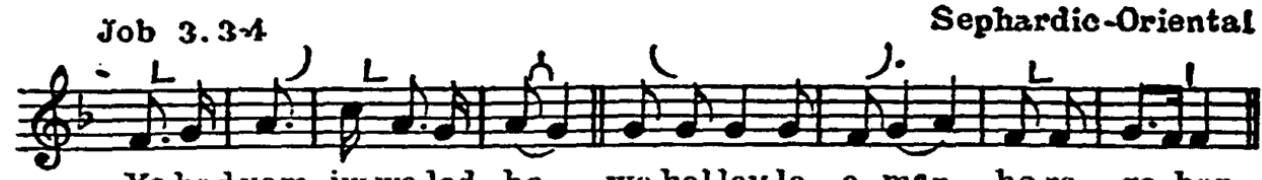
Yo-badyom iw-wa-led bo, we-halłay-la a-mar hora ga-ber..

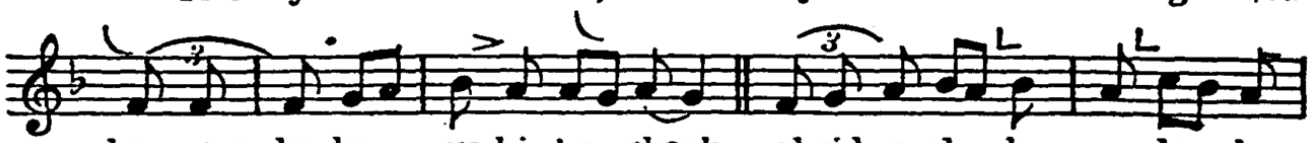
hay-yom ha-hu ye-hi ho-shech, alyid-re-she-hu. e lo-ha

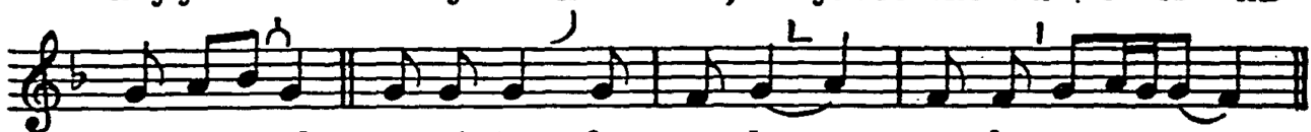
mim-ma - al, we-al to - fa a-law ne-ha-ra.

Leviticus 16. 1-2

Ashkenazic - Pentateuch for the High Holidays

$\left.2 \frac{2}{3}+2\right)$

Vay-dab-ber a-donay el mo-she, a-chate mos she-ne bene a-ha-ron,

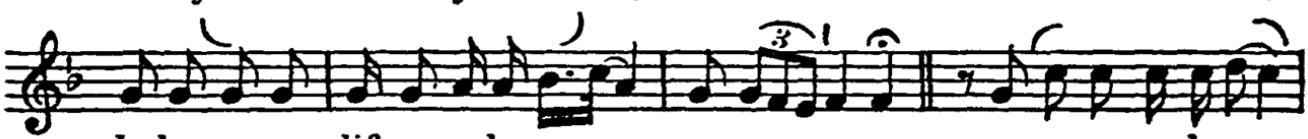
bekor-vo-som lif-ne a-do-noy way-yo-mu-su . way-yo-mera-do-noy

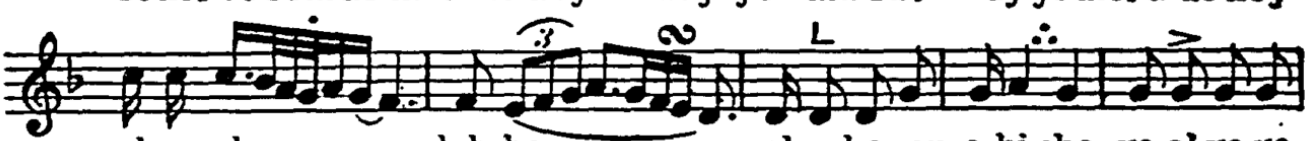
elmo-she, dab-ber

el a-ha-ron o-hi-cho, ve-al yo-vo

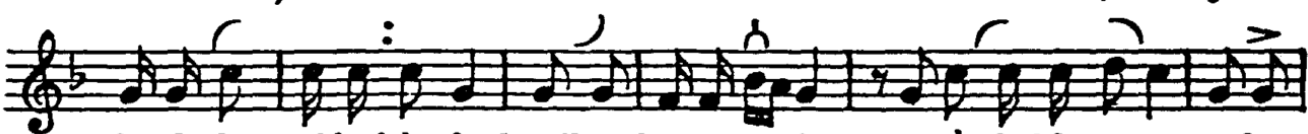
bechol es el hak-kodesh,mibes lap-no-ro-ches, el p'nehakkapo-res_a-sher

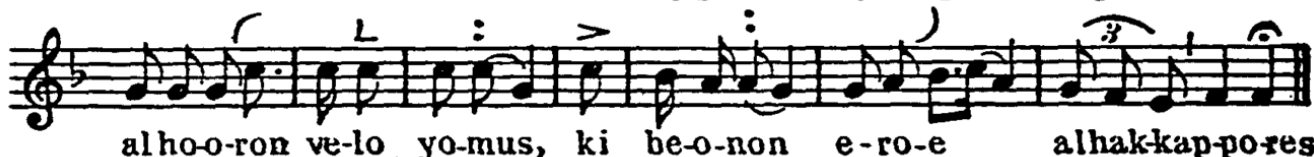
alho-o-ron ve-lo yo-mus, ki be-o-non e-ro-e alhakkap-pores Gregorian

3

Lam. 1

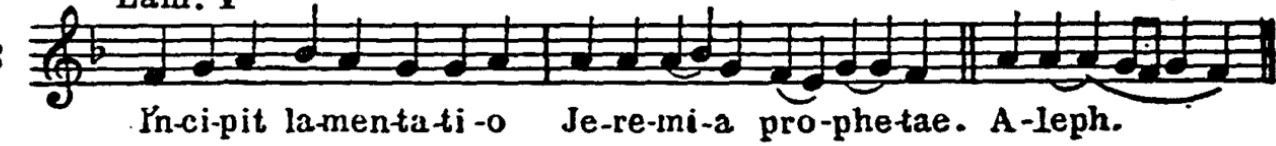

4 Lam.5.1.

Re-cor-da-re Domine,quid ac-ci -de-rit no - bis, in - tu-e-re,

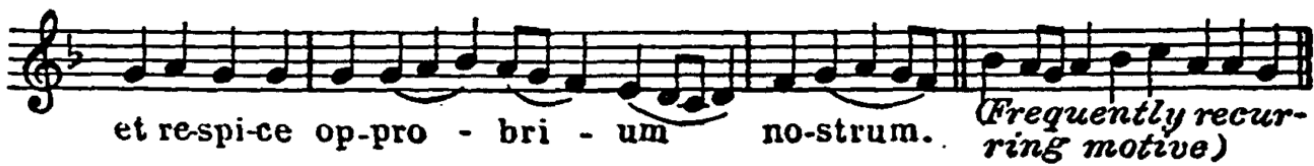


expressing their sentiments to their Creator. So many Jews and Christians, highly gifted and filled with holy devotion, have created wonderful hymns and prayers in the last two thousand years; yet the Psalms still stand supreme. The reason for their power is well explained by many of the Church Fathers; especially by Athanasius, Bishop of Alexandria (295-373). "The Psalms," he says, "embrace the entire human life, express every emotion of the soul, every impulse of the heart. When thy soul yearns for penance and confession, when thy spirit is depressed or joyous, when thou art become master of thy sins or thy sins have overpowered thee, when thy soul is yearning to express its thanks to God, or its pains-for all these, the Psalms completely satisfy our needs." St. Jerome advises a monk "that the Psalter shall be in his hand and he shall learn it by heart." He ordered the nuns in Jerusalem to memorize the Psalms, or leave the convent. Ambrosius gives testimony "that the women sing the Psalter well. And verily its songs are sweet and suitable for every age and sex. . . . It unites the people in the bond of unity, wherever they sing (the Psalms) in unison." 19

For the Jews, it is indeed quite readily understood why the collection of the Psalms was the songster of their faith centuries before the Christian era, and why these Psalms were sung not only at the Temple with the musical apparatus of the Levitical choir and orchestra, described in Chapter I, but also outside of the Temple throughout Palestine and, perhaps, in other countries likewise, forming an integral part of Synagogue worship. When we go through the one hundred fifty Psalms, we see at once the variety not only of their contents but also of their forms.

We spoke already of the predominance of the short two-part verses in the Book of Psalms. But besides this form, the Psalms have also other forms. And it is quite natural that, in accordance with contents and form, different modes were used to intone them. The occasionjoyous or sad, feast or fast day-influenced their musical rendition. And finally, stylistic considerations were decisive. If, for example, a Psalm was used as an introduction to or interlude between prayers in a certain mode, that mode was, as a rule, transferred also to the Psalms-a procedure called by the precentors meinyana-in the same subject or THEME. The musical intonations or modes used for the chanting of the Psalms are based on the Dorian, the Gregorian or 
Hypophrygian, and on the Lydian scale. In table $X$ we give examples of the modes mostly used in the various communities. Group A (I-3) presents modes in Dorian. These modes are common in the Sephardic congregations, whereas in the Ashkenazic tradition (3) they are disappearing, due to the predominance of the major and minor scales. In example I5 a comparison with the Gregorian chant of the Epistles is given. ${ }^{20}$ Group B (4-8) offers examples for modes in Phrygian or Hypophrygian. Some of them have the tetrachordal structure $(4-5, I)$, some the pentachordal line $(6,8)$, and one example (5) is rhythmical $(3 / 8)$, though the rhythm is frequently interrupted to suit the rhythm of the text. We compare these modes with some Gregorian psalmodies, as for example 16 with 4,17 with 7-8. Group C (9-14) is based on the Lydian or Hypolydian scale. The Sephardic-Oriental congregations chant Proverbs 31 : $10-31$ in the same mode as II-I2. The similarity of 18 (Gregorian) with 9-10 (Yemenite and Persian) is apparent.

From the comparative examples thus far given, we learn that the tradition and history of the Catholic Church are justified in claiming that at least a considerable part of its traditional song was adopted from the Synagogue, due to the continuous endeavor of the Church Fathers in the first centuries. At least in Spain it was believed that the Hallelujah tunes were of Jewish origin. Thus Isidor of Sevilla testifies, "Laudes, hoc est Alleluja canere, canticum est Hebraorum""The tunes of Laudations, that is Halleluyah-singing, is of Hebrew origin." 21

From the examples we likewise learn that several modes are common in the various countries, as I Sephardic-Oriental; 3, Ashkenazic; 7, I1, Moroccan; 8, 12, Ashkenazic; 13, Sephardic-Oriental; and I4, Carpentras.

Aside from the modes thus far treated, there are some modes not generally in use, as the mode of Proverbs which book is chanted in Oriental congregations on the Sabbath afternoons between Passover and the Feast of Weeks, but its public reading is not obligatory. The mode is a variation of the Psalm-mode, group A. There is, likewise, a mode for the reading of DanIEL in use in the SephardicOriental congregations only, but it is not used in public services. This mode is based on the Lydian scale. In like manner, we find local modes for some parts of the Bible used by one or the other com- 
a.) Ps.0x.1-2

1

Solo

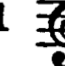

Soln

Congregation

(Sephardic-Oriental)

Yo-sheb be-se - ter el-yon,
Solo

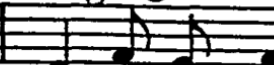

be-sel shad-day yith-lo-nan. Cong.

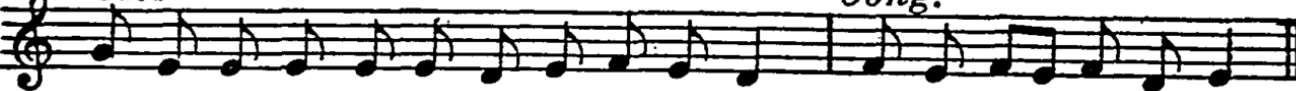

o-mar la -do-nay mah-si um-su-da-thi

e - lo - hay ev - tah bo.

2
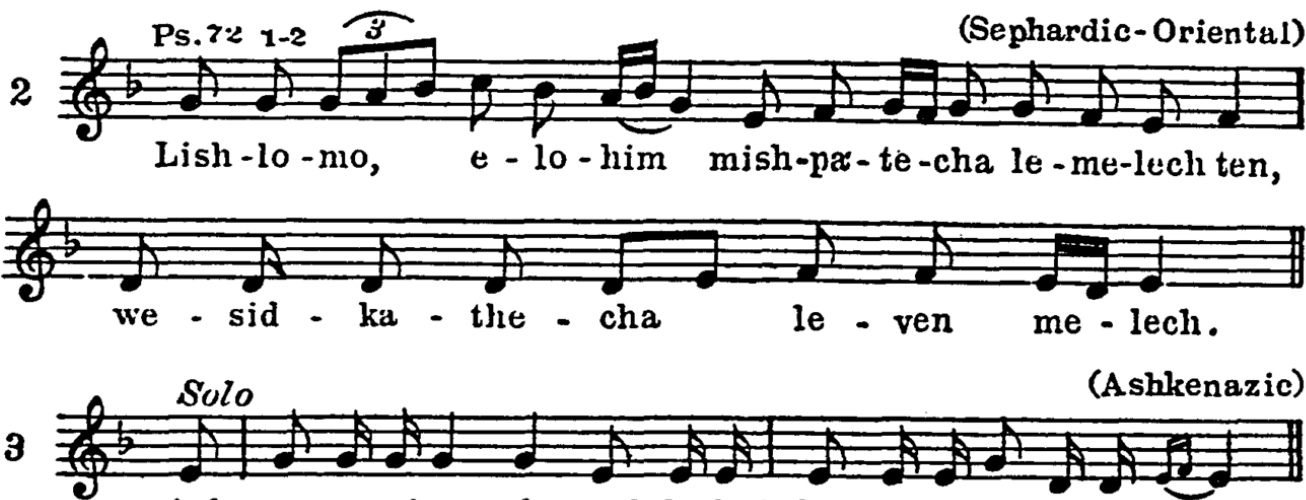

Ash - re se-mi-me do-rech,ha-hol-chim be-so-ras a-do - naty.

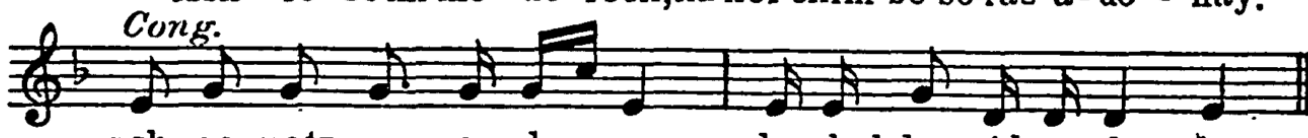

ash-re notz-re e-do-sov, be-chol lev yid-re-shu - hu.

b) Ps. 92. 2-3

4

b) Unison

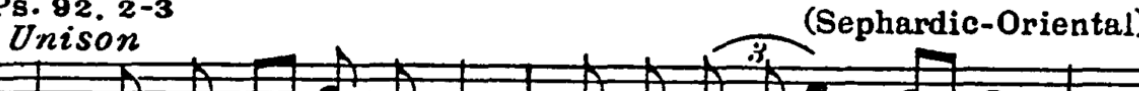

Tob le-ho-doth la-do-nay, ul-zimmerle-shim-cha el-yon.

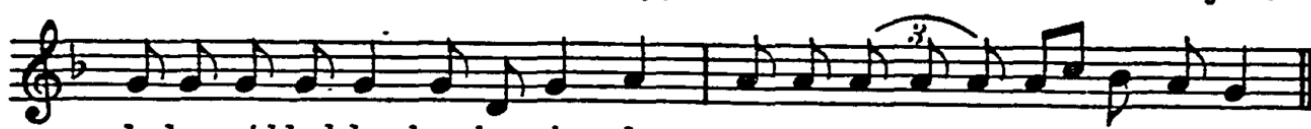

le-haggid bab-bo-ker has de-cha, we-e-mu-na-the-cha bal-le-loth.

Ps.:29. 1-is

Ullison

(Scphardic-O riental)

5
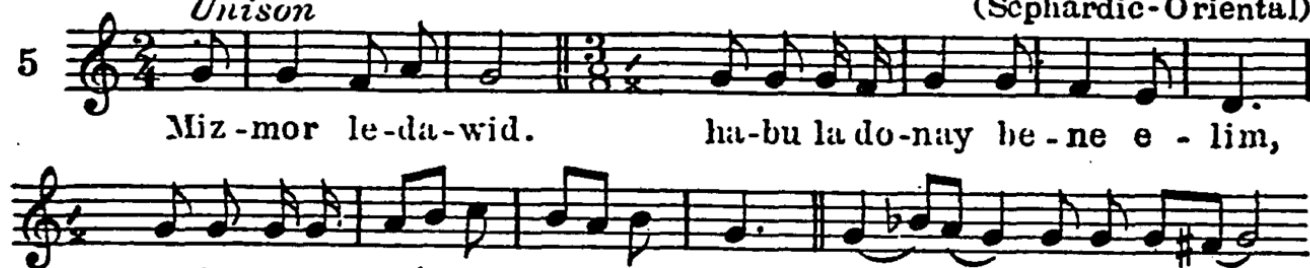

lat-bu la-do - naiy ka - bod wa - oz. kol

a-do-naty

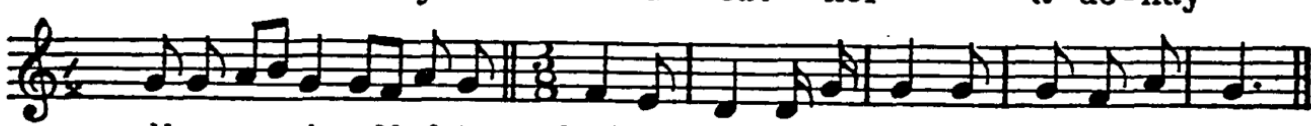

alham-ma-yim,elhak-ka - bodhir -im,a-du-nay al ma-jim rab-jim. 


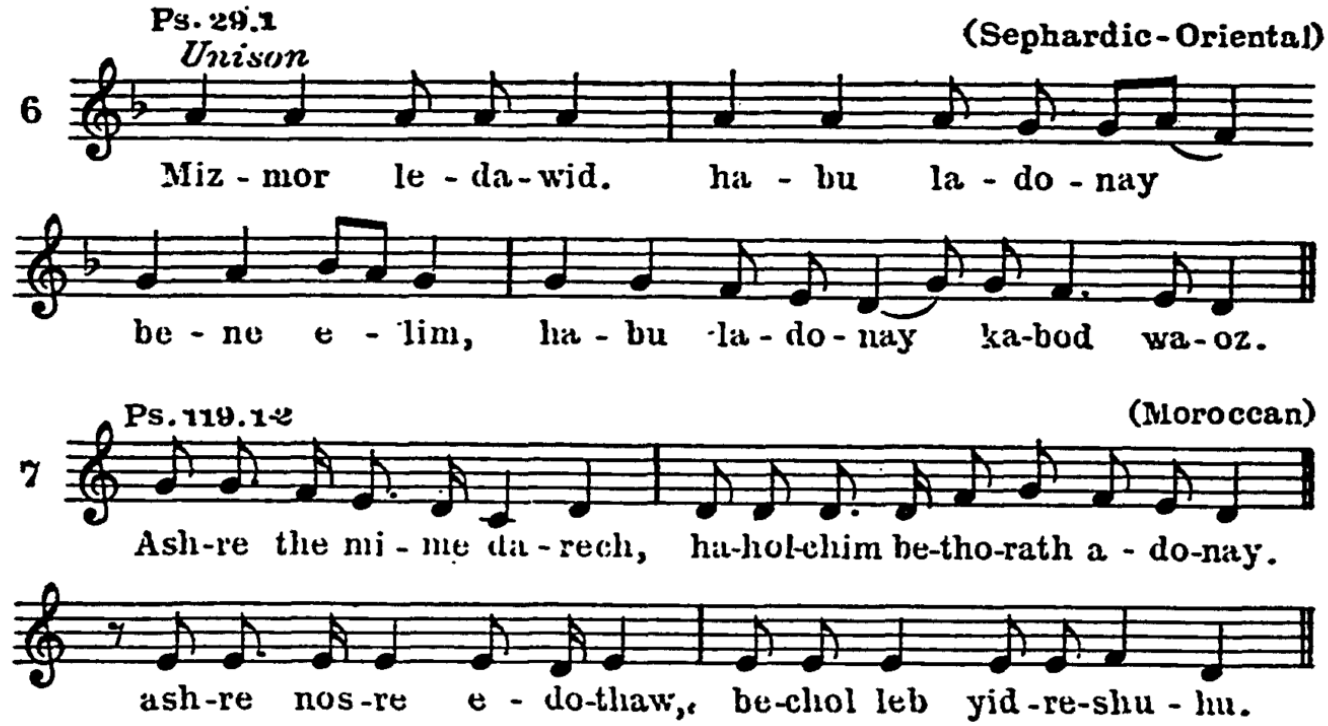

Ps.119.1-2

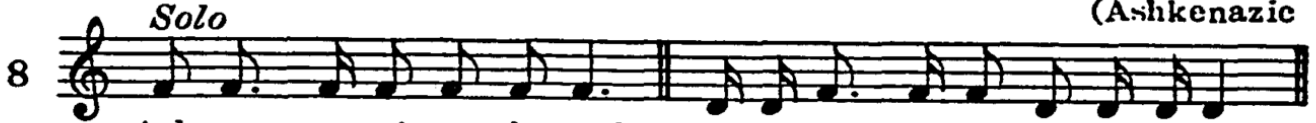

Ash-re se-ni-me do-rech, ha-hul-chim be-so-ras a-do-noy.

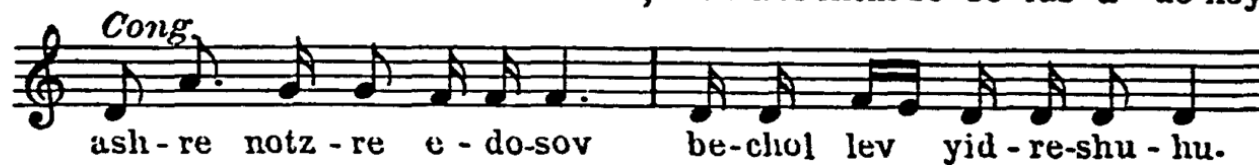

Ps. 81, 1 .

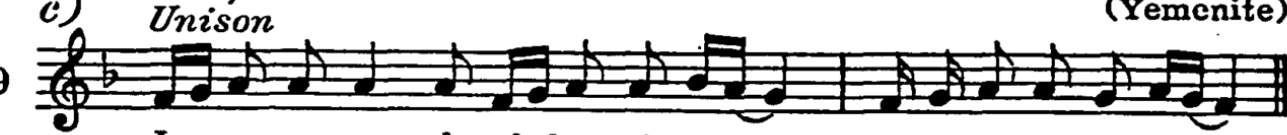

-La-mę-nas-se - ah al hag-git-tit,

mi-ze-mor le-o - sof.

Ps. 81, 1-2.

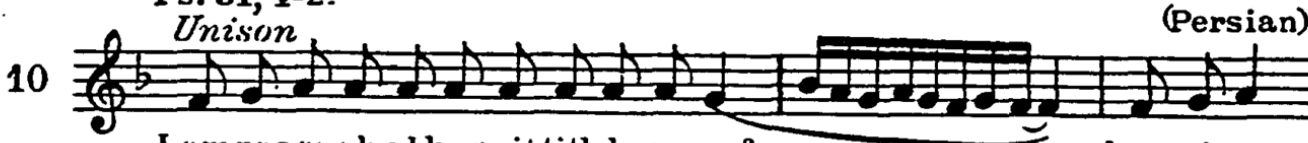

Lamnas-stith al hasisititith le-o - sof.

har-ni-nu

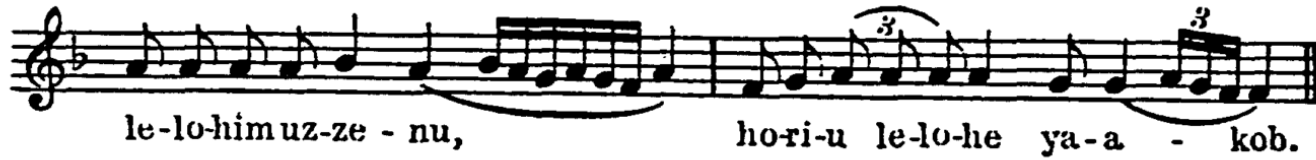

Ps. 42, 1-2

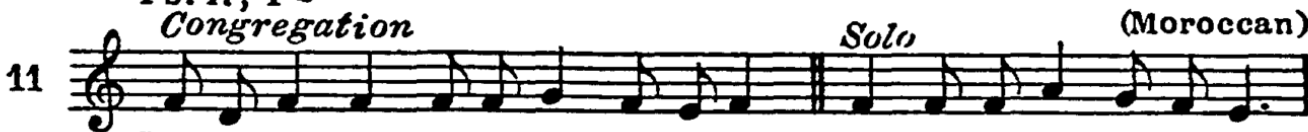

Lamnas-se-ah lib-ne ko-rahmiz-mor. kol ha-ammimtik-u chaf,

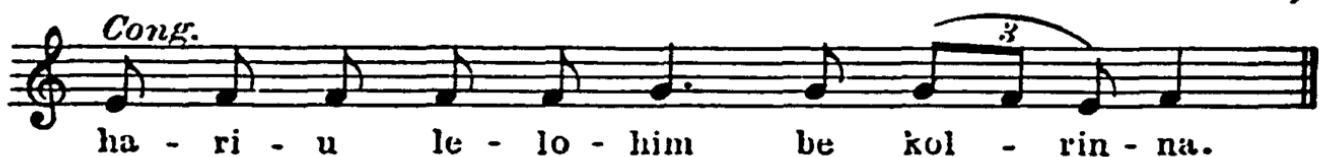


Ps. 21, 1-2

(Ashkenazic)

Solo

12

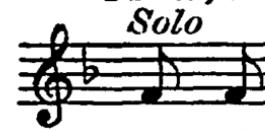

Lam-nats-tse - ah miz-mor le - do - vid

Cong.

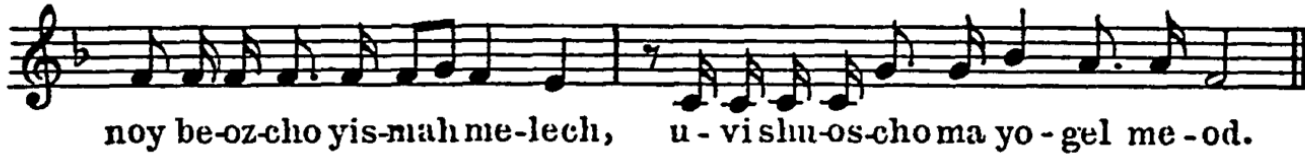

13

Prov. 31, 10-

(Sephardic - Oriental)

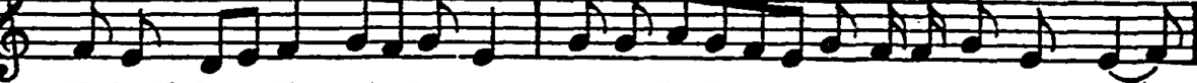

E-sheth ha-yil mi yim-sa, we-ra-hok

rni-nt-ni-nim mich-ra.

14

Ps. 49,1-2

(Carpentras)

采

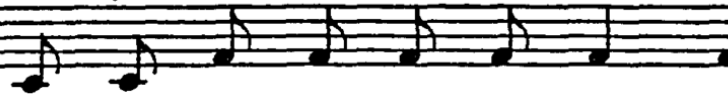

Lam-nas - se - ah lib - ne ko - rah miz - mor.

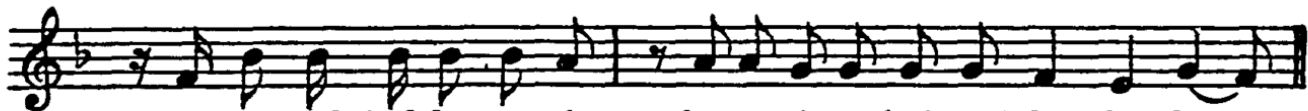

shim-u zoth kol ha-am-im, ha-a-zi-nu kol yosh-be the-bel.

15

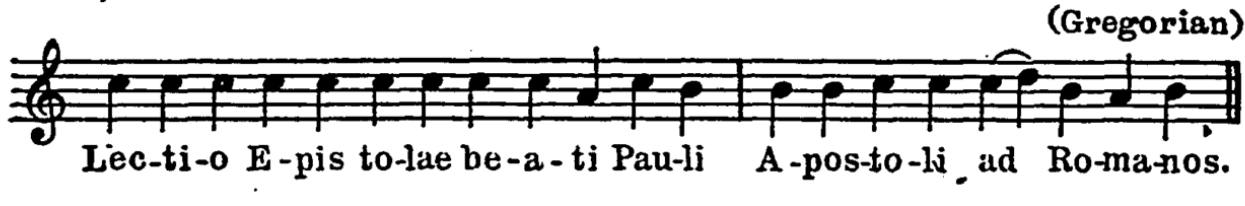

(Gregorian)

16

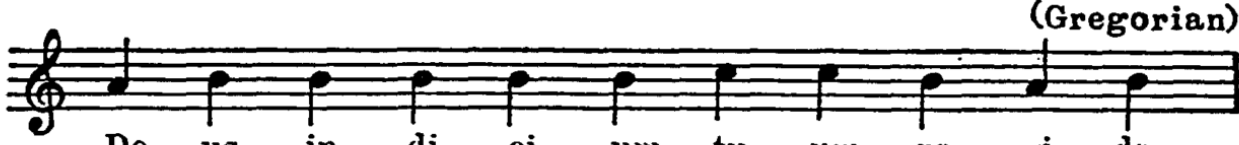

De - us in - di - ci - um tu - um re - gi - da.

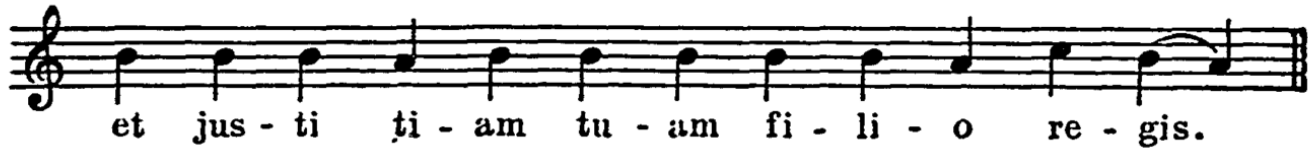

(Gregorian)

17

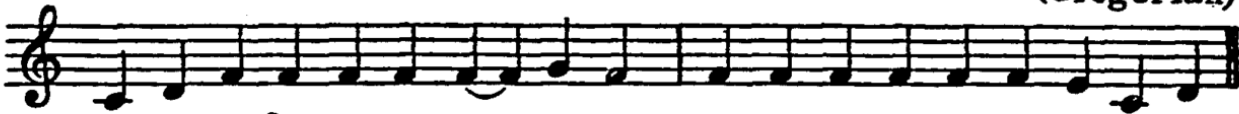

Lau-da-te Do-mi-numde coe-lis; rau-da-te e-um-in ex-cel-sis.
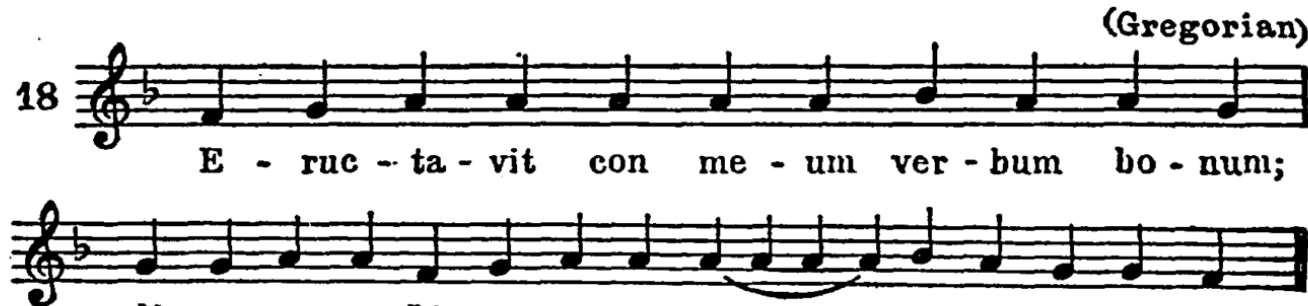

di - co e - go:Lin-gu - a me - a

ca- lia-mus scri-bae. 
munity-modes which have no originality but are derivations of the chief modes presented. ${ }^{22}$

(i) There is a mode which, though developed by one community and, hence, stamped with local characteristics, yet by reason of its influence on the creation of the later songs of that community and the charm it exercised through many centuries, deserves special treatment here. It is the MODE of EsTHER. The Book of Esther has been read in public on the $14^{\text {th }}$ day of Adar since long before the destruction of the Temple (see above), but its reading was very plain-like the reading of a letter or a historical document, which manner the Oriental Jews employ to the present day. The Esthermode in the Orient is, therefore, simple, really only a speaking tone with some elevated points, especially at the half and full stops. Some Orientals employ the Phrygian, others the Dorian, as the examples in table XI, I-2 evidence. The Ashkenazim, however, combined the two modes, and-what is of more significance-introduced into the reading of Esther motives of different modes, such as Pentateuch and Lamentations. The reason for enriching the reading of Esther was that in the reading of this book, the German Jews found opportunity to give vent to their bitterness against their oppressors. They, therefore, interpreted the Megilla (Scroll) of the story of Esther and Mordecai and the struggle of the Jews in Persia as the story of their own life. Their abuse of Haman was but a disguised attack on their contemporary enemies, and an opportunity to mock them, at times even in a vulgar manner. For that reason they drew into the mode popular street tunes, snatches of marches current at different ages in Middle Europe. A more detailed description of these tunes we shall give later when we come to relate the story of the Medieval Ashkenazic song (Chapters XVIII and XX). At present we wish to point out the Ashkenazic Esther mode, the form that was shaped through enrichment by motives of other modes. In example 3 the borrowed motives are marked. The motives 2, 9, 10, are taken from the Lamentations, because the text relates of trouble and affliction; while the motives 7,8 are borrowed from the Pentateuch and are employed whenever the text needs an emphatic expression. The motives 2, 4 and I I were utilized to a great extent as material for tonal creations about which we shall speak later (Chapter VIII).

30 The Táamim (Musical notation) OF the Bible. 


\section{TABLE XI}

Esther

Esther 1.1

Yemenite

1
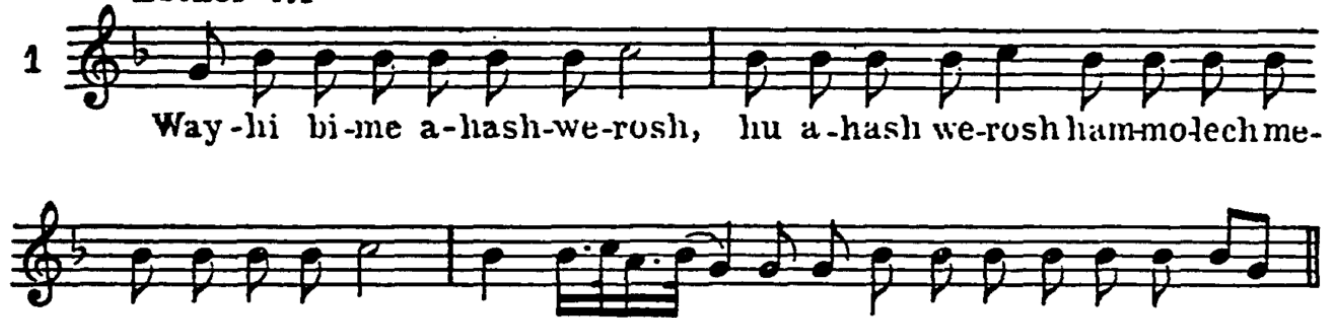

ho-du we-ad kush, shc-bia

we-es-rım u-me-o me-dli-no.

Estḷer 1.1

(Bubylunian)

2

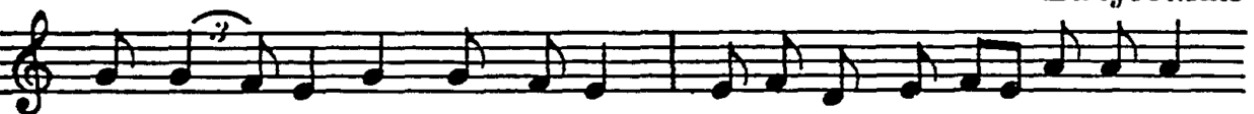

Way-hi bi-me a-hash-we-rosh, hu a-hash-we-rosh ham-motech

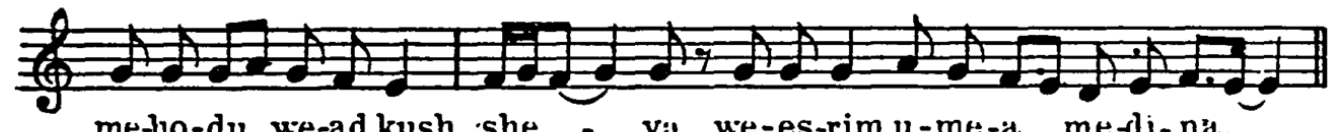

me-ho-du we-ad kush, she - va we-es-rimu-me-a me-di-na.

Esther 1.1

(Ashkenazic)

$\mathbf{3}$
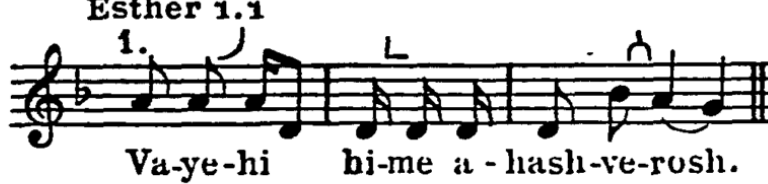

2.(lamentations) -

Va-ye-hi

hi-me a-hash-ve-rush. hu a-hash-ve-rosh,

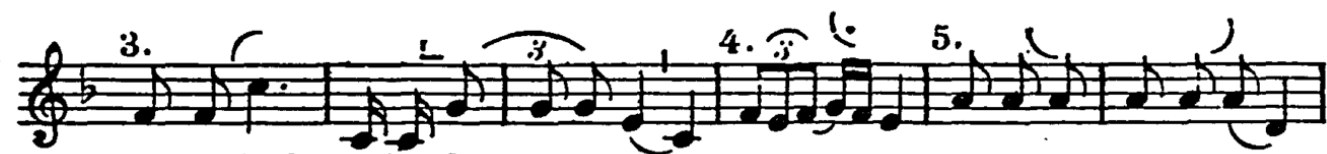

Jian-motech me-ho-du ve-adl kush, she - va ve-es-rim u-ne-u

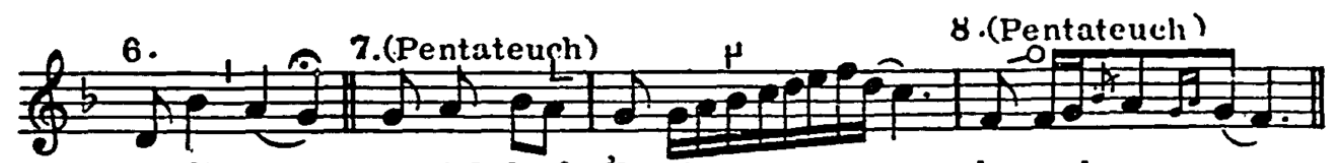

me-di-no. vay-yish-lach s'fo-rim

be-yad.
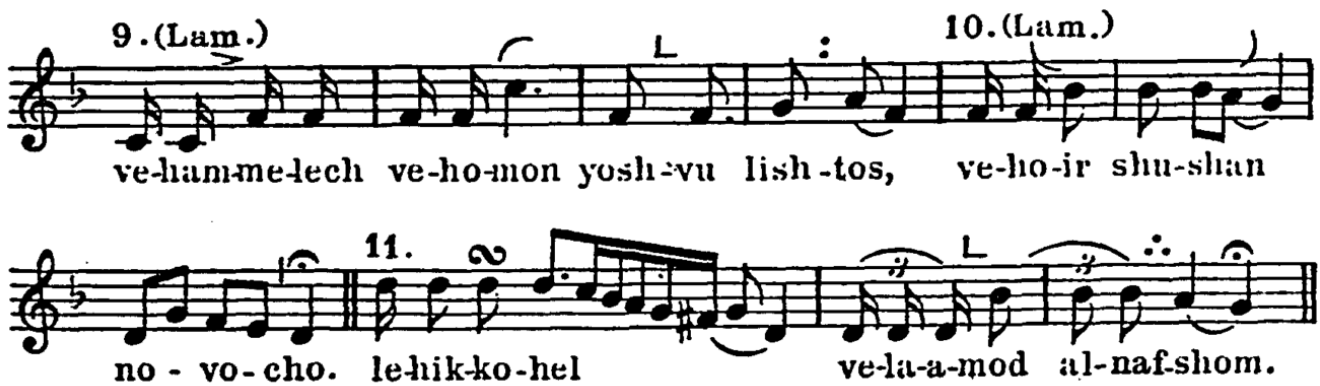
The Biblical intonations preserved in the memory of the people, were transmitted orally from generation to generation. Yet an attempt was made in the early centuries to find a way by which these intonations could be preserved. Similar attempts, as we know, were also made by all the other ancient nations, such as the Indians and the Greeks; and were the beginnings of musical notation, which, after a long development, resulted in the modern system of writing music. The earliest system was the notation of the rise and fall of the voice and the curves made by the voice in producing a motive. These were ear-marks. With the ear-marks the "hand-signs," in Greek cheironomia, made by the teacher or musical leader to indicate the rise and fall of the voice, were developed among the ancient nations. ${ }^{23}$ We notice this custom in ancient Egypt, shown on the wall-pictures of the pyramids. The Talmud gives evidence of the custom of using finger-motions in the air in Palestine and Babylonia in the beginning of the Common Era. ${ }^{24}$ We know that it continued for many centuries, for Palestinian precentors in the eleventh century on their visit to France and Germany still used to make these finger-signs while they were chanting the Pentateuch. ${ }^{25}$ In some countries, like Yemen, the custom is still in vogue. For these movements of the hand descriptive names were invented. For example, the ascending tone was marked by raising the finger. This movement was called Kadmaascending. The falling of the voice was marked by the falling of the finger and was called Tifha-descending. A sustained tone was marked by keeping the hand uplifted and was called Zakef-upright, and so on.

During the Talmudic period only three names were known, marking the beginning, half stops, and end of the verse. In like manner we find among other nations: udata, svarita, and anudata among the Hindus; acutus, circumflex, and gravis among the Greeks; and shesht, kurr, and butu among the Armenians. The names employed by the Jews were kadma-ascending, athnah-resting half-stop, and sofconclusion. Gradually, there developed the system of naming each detail of the nuances marked by voice and hand. But not satisfied with the cheironomia, every nation mentioned above invented WRITTEN sIGNs independently which were IMITATIONS of the HAND-MARKs. And remarkably enough the signs or accents of the three mentioned tonal motions are identical among all the nations. These three ac- 
cents are constructed of the diagonal line in various positions. Thus pashta or acutus is a diagonal line upward $(\cdot)$ and tifha or gravis the same line placed downward $(\cdot)$, while the athnah or circumflex is a combination of the two positions $(a)$. In the accents invented thereafter for further tonal lines filling out between beginning ( $\mathrm{kadma}$ ) and half-stop (athnah) or end (sof), the point was introduced in addition to the line. The development continued for several centuries until the system received its finishing touches in Tiberias and was introduced in the Bible in the ninth century as a means by which the Scripture should be chanted. However, the use of an accented Bible for public reading in the service was not permitted. For this purpose only the original Scroll without vocalization or accents had to be used.

Two systems of accents were employed in the Bible, one for twentyone books and the other for the three books: Psalms, Proverbs, and Job. The first system has thirty accents, ${ }^{26}$ the second only twelve. The reason for the large number of the first is accounted for by the various syntactical forms occurring in the twenty-one books, for which musical interpretations were provided through the various tonal nuances; whereas the three books mentioned above have mostly the short two-part sentences, as has already been explained.

The first man known to furnish the Bible with a complete system of accents was Aaron ben Asher, in Tiberias, of the ninth century. His manuscript became the standard code, though a second scholar, Ben $\mathrm{Naftali}$, prepared another code with some variations. Ben Asher also wrote a treatise, describing the tonal value of the accent-marks. In Babylonia, too, attempts were made to invent a system of accents, but they did not prove successful.

The so-called Tiberian system, on examination, will be found to have a great deal in common with the Greek prosodia, which came to be known about the second century, C.E., ${ }^{27}$ and especially with the neumes-system of the Byzantines and Armenians in the forms that it took on in the ninth century. ${ }^{28}$ Aside from the identical figures, the classification and valuation of the accents are alike. ${ }^{29}$ Like the GreekByzantine accents, so also the Jewish, are divided into con- and disjunctives. Furthermore, they are classified in tonoi-Hebrew rum, marking tonal value, chronoi-shehiya, marking time value, pneumata-gova, specifying dynamic value. ${ }^{30}$ 
The Hebrew accents agree with the Greek system in their general outlines, but not in detail. The reason for the variance is, apparently, that the Jewish scholars had to adjust the accents to the traditional modes of the Bible. In their anxiety to preserve the modes, they made use of this system as the only musical notation which existed at that time. While the Byzantian system was adopted by the Latin Church and later developed more and more into a notation of intervals and steps (by Guido of Arezzo, 995-1050), the Hebrew system remained in its ninth century form. Our modern system of writing music, we know, is still incapable of expressing many nuances regarding tonality (less than half-tones) and many time and dynamic features. In that primitive system of the Biblical ta $a^{\text {samim, or }}$ neginoth (notes, tunes) we must, therefore, expect but poor indication of even the most elementary and basic musical values. And, indeed, the accents indicate small patterns with their approximate intervals but they show neither notes nor exact intervals. Only for those who know the mode and its motives and characteristics do the accents serve their purpose. They are rather reminders of the motives. The fact that the same accents are set for all the twenty-one books, irrespective of the different modes, proves that they are only primitive remindingsigns of the rising and falling of a tune. They indicate neither scale nor rhythm, neither tonality nor tempo, neither intervals nor steps. Even at the time when they were introduced, people who did not know the modes beforehand could learn nothing from this system. This is another proof that the Biblical modes were popular among the scattered communities long before the accents were introduced.

We give here a list of the accents and their classification, according to the oldest sources: ${ }^{31}$ 
I. Tonoi:
A. Disjunctives

Figures and names:

*Zarka-segol-Scatterer

- Rebia-Square

LI Legarme-Disjunctive-rester

- Tifha-Hand-breadth

- Tebir-Broken

- Kadma-Preceder

I Silluk-Cessation

- Sof pasuk-Period

II. Chronoi:

Figures and names:

$<$ Yethib-Staying

A Ethnachta-Rester

: is Zakéf-Raising

III. Pneumata:

Figures and names:

a" Paze,-Dispersed

" Tarsa (gereshin)-Expulsion

Of later date:

Shalsheleth-Chain

B. Conjunctives

Figures and names:

¿Shofar mehuppach-Reversed horn

ऽ Shofar Munach-Resting horn

× Agala-Round

- Maarich-Lengthener

s Darga-Steps

We gain a clear idea of the loose relationship between the motives and accent signs upon examining the COMPARATIVE TABLE. The comparative table of the Pentateuch mode shows how inexactly the names of the accent signs describe the impression made by the music for which they stand. But the same table gives evidence of the close relation between the motives of the various traditions, though some of these communities, due to their geographical situation and their political condition, never, 
or very seldom, came into contact with one another. Some of these communities, on the other hand, never stood under the influence of the Roman Catholic Church, and yet several modes are found in both Synagogue and Church. Both this uniformity of tradition and the independence of Church influence prompt us to adopt the opinion that the Biblical modes treated thus far, are of an ancient age, probably preceding the expulsion of the Jewish people from Palestine, and older than the Christian Church. They are the remainder of the JewishPalestinian folk tunes, representing the Jewish branch of the Semitic-Oriental song. ${ }^{32}$ 


\section{CHAPTER IV}

THE OLDEST UNRHYTHMICAL ELEMENTS OF JEWISH SONG.

(CONTINUED) B: THE MODES OF THE PRAYERS.

Simultaneously with laudation and adoration, Israel likewise cultivated supplication. The Bible contains a considerable number of prayers composed by outstanding men and women in Israel (Chapter VI). The Psalter is not merely a book of songs and praises. An appreciable part, approximately onethird of it, is supplication and petition. This fact justifies the conclusion that prayers, like songs and laudations, were chanted in the Temple service in Jerusalem. The popular refrain Hoshiannah-"Oh, help!" indicates prayer.

At first supplications in public were voiced only in time of need and distress. But gradually, in the later period of the Second Temple, these occasional prayers developed into a set ritual, performed at certain times with certain stipulated texts in a certain order.

The Mishna reports the texts and order of the daily ritual used at the Temple. It consisted of reciting the Ten Commandments, which was later replaced by the Shema, the Song of the Sea, and the priestly benedictions. ${ }^{1}$ All of these selections were taken from the Pentateuch. As introductions to these readings, benedictions were composed based on verses from the Prophets and the Writings. And in addition Psalms were chanted.

Identical in content and spirit, as well as in style and form, with the prayers of the Bible, were those composed by prominent rabbis during the Talmudic period and accepted into the ritual for daily service and for feast-and fast-days. Up to the 
end of the seventh century the ritual was continuously enriched. Its parts fall into several classifications: Tefilla (prayer), Hallel (laudation), Techinna, Tachanun (petition), Selicha (intercession for pardon), Viddui (confession), Kina (lamentation), and Zemiroth (hymns).

By reason of their sources, we should be led to expect that the musical rendition of the prayers was taken over from the Biblical modes, together with the texts. And in fact, we do find the modes of the Bible reechoed in the modes of the prayers, though with variation and additions of motives. We shall examine the main modes used in the service.

\section{(I) THE TEFILLA MODE, OR ADONOY-MOLOCH STEIGER}

This mode is originally derived from the Pentateuch mode, carried along with the Pentateuch texts which constituted the chief parts of the Tefilla. The scale is the Hypodorian, instead of the Dorian as in the Pentateuch mode, and the melodic line has the tetrachordal form. In table XII we furnish examples: (I) is the Yemenite mode for daily service, whereas examples (2) and (3) illustrate the Tefilla mode which the Oriental and European Sephardim use for the High Holidays only. (5) offers a similar chant of the Gregorian song in the "fourth tone." In the Ashkenazic, example (4) we recognize the European influence (as in the case of the Pentateuch mode in Chapter III), by the addition of two steps below the tonic (a-g), through which change the scale becomes identical with that of the Gregorian Mixolydian mode. Consequently the modern Ashkenazic cantors designate as mixolydian the mode originally called Adonoy-Moloch Steiger after the first text (Psalm 93) in the order of the Friday evening service, for which it is used. ${ }^{2}$ During the medieval period many variations in scale and motives, as well as in modulations, were developed by the Ashkenazic cantors, the nature of which we shall discuss in Chapter VIII in detail. In example (6) a Gregorian chant is given for Daniel (Prophetice XIIae in officio matutino), which has striking similarity especially to the Ashkenazic mode of the Tefilla.

The Tefilla mode in its Oriental setting, as we saw, has striking similarity to the Gregorian fourth mode. The latter is described as 
having a soulful, almost dreamy, character, suitable for devout prayer. ${ }^{8}$ It expresses profound emotion and yet solemnity and is used for various prayers and texts which voice an optimistic and sound view of life. Therefore in the Sephardic-Oriental and Occidental communities, the Tefilla on the High Holidays is chanted in this mode mostly. The Ashkenazic communities use it for the introductory selections of Sabbath and for a great part of the morning service on Sabbath and for Holiday prayers.

\section{(2) THE SELICHA MODE}

The Selicha, that is intercession for pardon, Techinna-emotional outbursts of repentance, Bakkasha-intense pleading for a definite boon, and Kina-lamentation, are the expression of the soul in its distress. As is generally known, Israel's prayers are not exclusively in the singular form; they are not prayers for individuals only, but prayers for the household of Israel. The same needs, hopes, wishes, and ideals motivate the entire community. The individual is a part of the community. He does not stand by himself; he could not exist by himself. He is incorporated into the community, and is influenced by the moral strength of the community. At the same time-although in the plural-Israel's prayers interpret the life of the individual. To be aware that a whole community has the same wishes and hopes as he has and shares the same troubles and distress, is in itself a consolation for the individual.

The four types of penance mentioned, although their roots reach to a very early period of antiquity, received their important place in Israel's service after the destruction of the Second Temple (Chapter VI). With the increase of pain and the persecutions inflicted not only upon him as a man and a Jew, but especially upon his convictions and ideals-in a word, upon his Judaism, these four types of penance multiplied. As did no other people or creed, Israel created lamentations over the destruction of religious institutions and the burnings of religious books, because these books held the contents of his life, and these institutions were the backbone of his existence.

Selicha, Techinna, Bakkasha, and Kina sound the vibrations of Israel's tortured soul; they are the reflection of its inmost despair and longing. Yet they do not end in complete despair, for in every supplication or lamentation there is a bright note of hope in a better fu- 
TABLE XII

Tefilla Mode

(Yemenite)
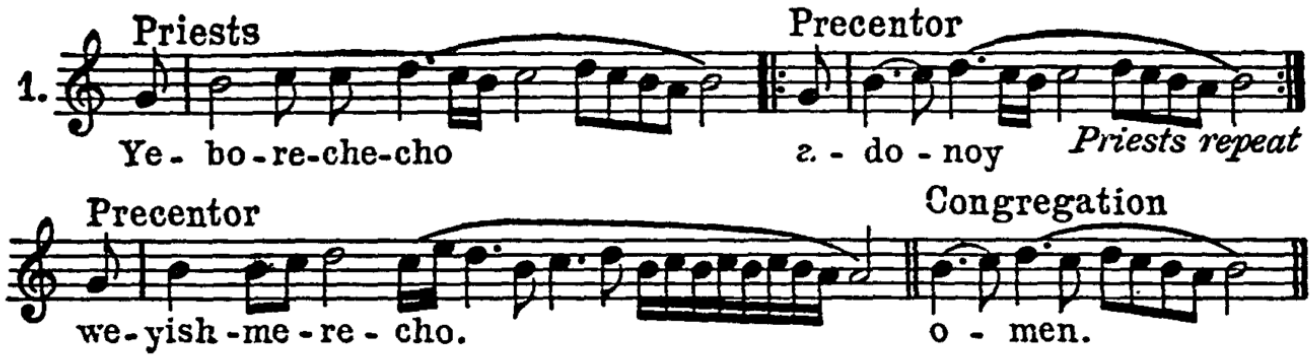

we-yish - me - re - cho.

(Syriac - Oriental)
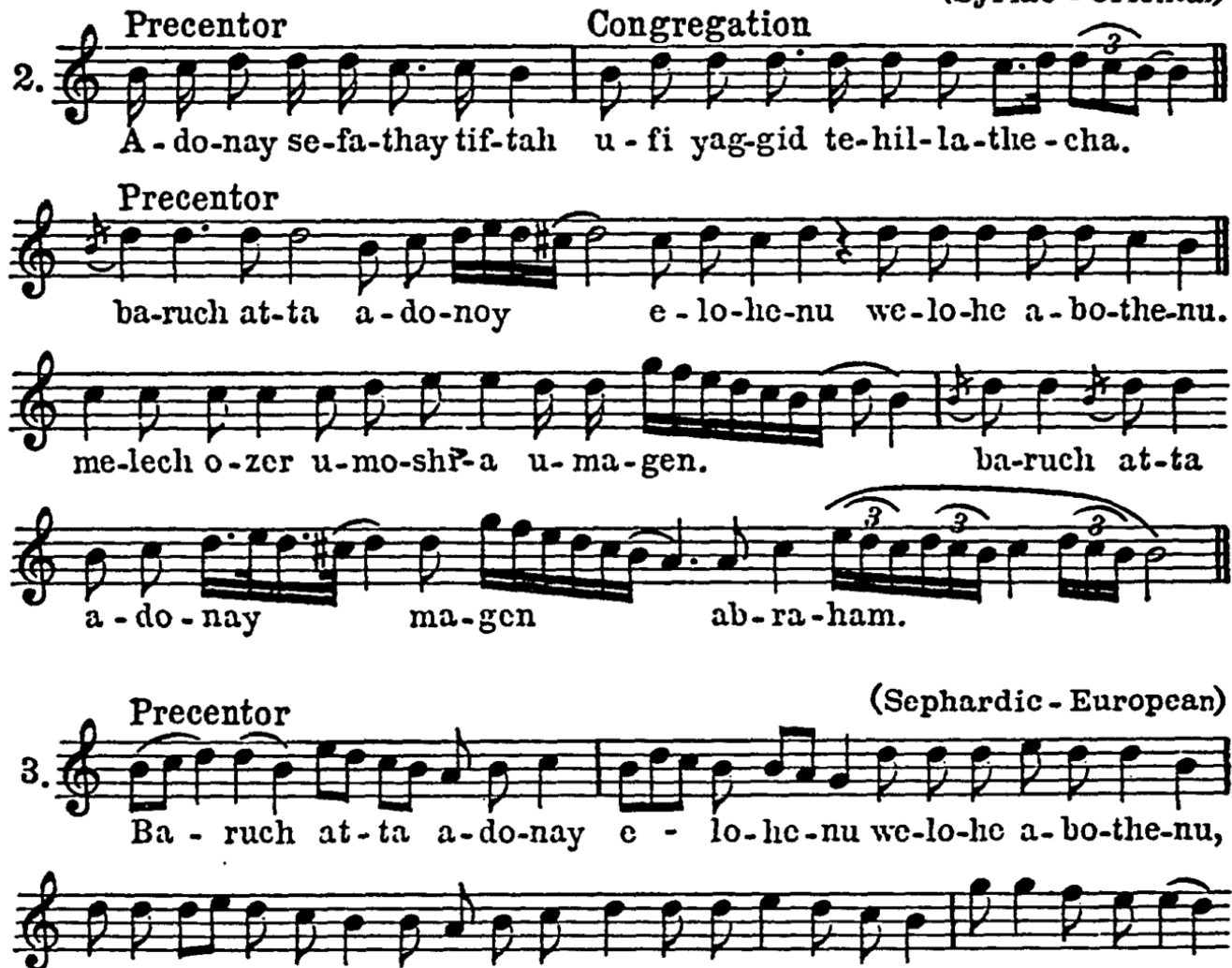

e-lo-he ab-ra-ham,e-lo-he yits-hakve-lo-he ya-a-kob, ha-cl hag-ga-dol
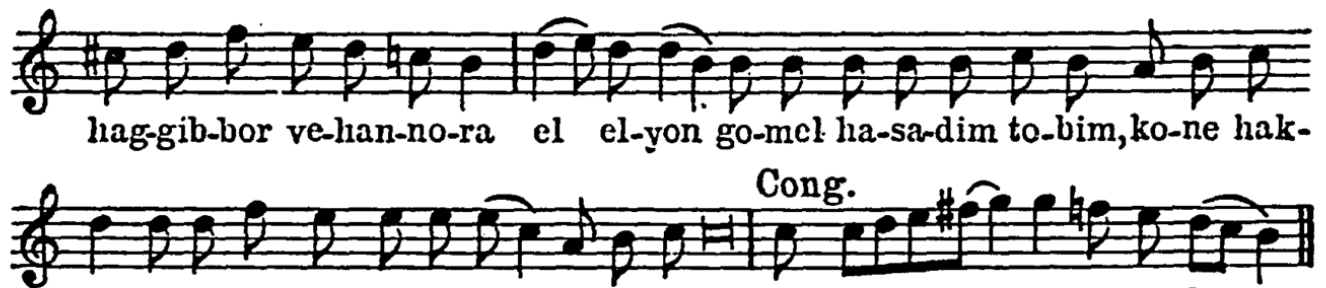

kol ve-zo-cher has-de a-both $u-m e-b i . .$. she-mo be-a-ha-ba. 
Ps. 93

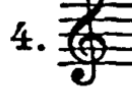

A- do-noy mo-loch ge-us lo-vesh, lo-vesh a-do-noy
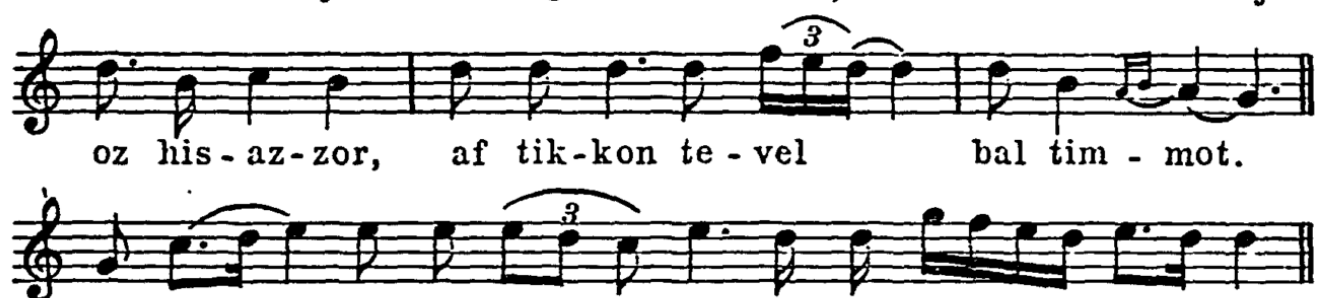
no-chon kis-a-cho me-oz me-o-lom o - to...

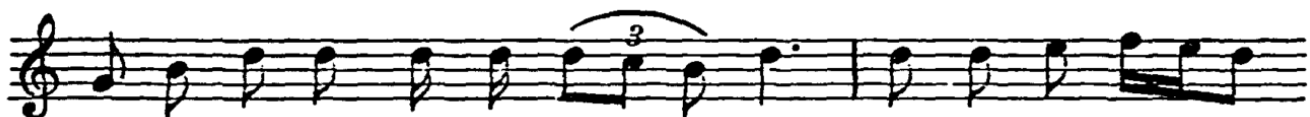

e - do-se-cho ne-em-nu ne-od le-ve-se-cho

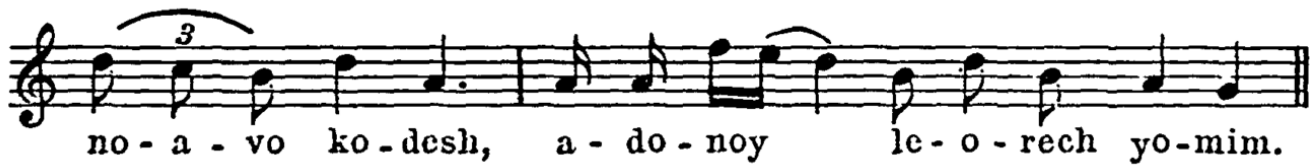

(Gregorian $4^{\text {th }}$ tonc)

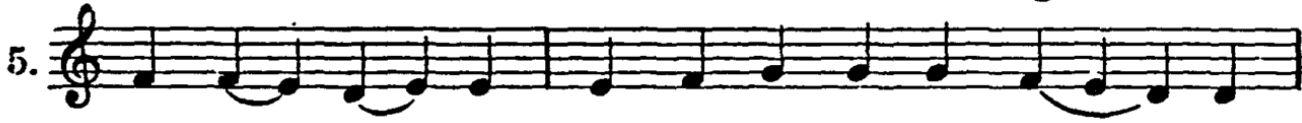
....quid fa - ci - am, qui-a do-mi-nus me - us

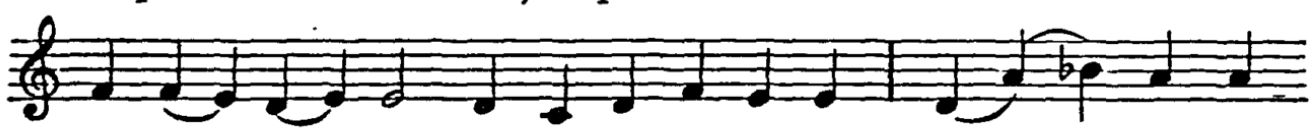

au fert a me vi-li-ca-ti-o-nem, fo- de-re

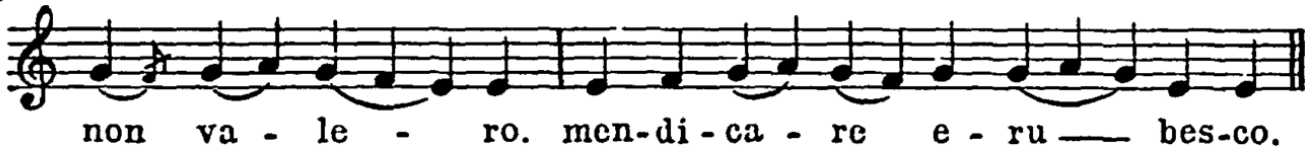

Daniel 3.1.

(Gregorian)

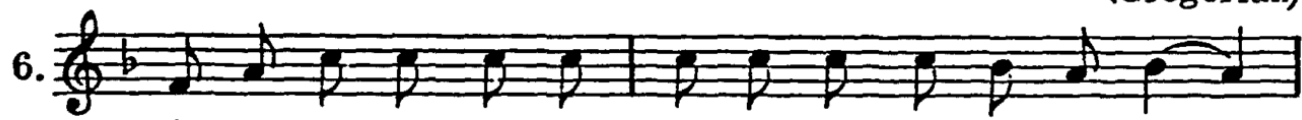
In $\mathrm{di}-\mathrm{e}-\mathrm{bus}$ il-lis na-bu-cho-do-no-sor rex

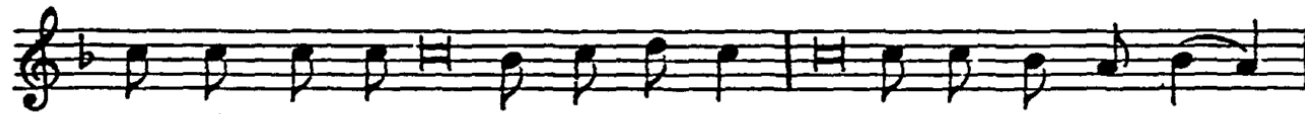
fc-cit sta-tu-am...sc-xo-gin-ta..... cu-bi - to - rum sex ....

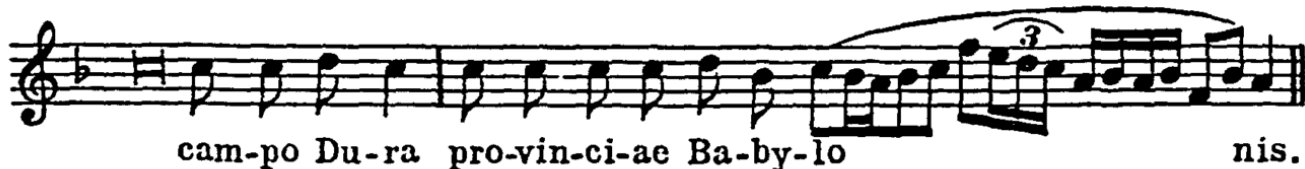


ture; there is the repeated voicing of the lovingkindness of the Almighty. It is quite natural, therefore, that these types of supplications should be expressed in the modes of the Prophets and the Psalms. We find these modes, which we call Selicha modes, in all the communities of the Diaspora-their importance depending upon the economic and political conditions of the respective localities. In those communities which enjoy freedom and equal rights, the Selicha modes are diminished in number, but in those communities which suffer from oppression, these modes are the most outstanding in the service and their usage is extended even over the prayer-texts-the Tefilla. Thus the Selicha becomes the measure by which we can estimate the well-being of the different communities. The Italian and German Jews, who had a rich Selicha literature and, consequently, a great number of Selicha modes and tunes, have gradually abandoned them with the increase of their emancipation since the middle of the nineteenth century. The Spanish Jews, who, while living in Spain, had a small Selicha liturgy, developed it to a great extent in the Orient after their expul. sion from Spain. The Polish and Ukrainian Jews took over the Ger. man Selicha and increased it after the pogroms in 1648-166o. But the community richest in Selicha modes is the Persian, because of its sufferings for many centuries from the fanatic and brutal Shiites, the predominant Mohammedan sect in Persia.

The Selicha-and-Kina mode is founded, as stated above, upon the Prophetic mode, and it is strongly influenced by the Psalms (table X B) and by Lamentations (table VIII, 8). Table XIII, I-4 gives a comparison of the Selicha mode in its Persian, Yemenite, Ashkenazic (Eastern Europe), and Babylonian versions. $\mathrm{I}-3$ have the same text (of the High Holidays), whereas 4 is set to another text. The mode in this table is presented in the form used on High Holidays with the ending on the fourth $c$, whereas on other occasions the mode ends on tonic $\mathrm{g}$, as shown by examples $5-6$. In this mode the melodic line seldom rises above the sixth, the melody dwells upon the third (XIII, 9), and modulates to the fourth. In the Eastern Ashkenazic version (3) the third is frequently elevated to a major, by which procedure the step between second and third becomes augmented, thus creating the scale of the Ahavoh-Rabboh mode. (See further on Hedjaz, Chapter II.)

The Ashkenazim in addition utilized motives of the Prophetic 
mode, such as the motive of athnah and kadma veazla, as evidenced in example 7,2-3. The athnah motive was taken over for the concluding of the Pentateuch mode (Chapter III a). The various phases of the Selicha mode created by the Ashkenazim, we shall treat in Chapter VIII. The responsive forms of the Psalms were likewise carried over to the Tefilla and Selicha (table XII, I-3; XIII, 8-9).

\section{(3) THE VIDDUI MODE}

We have already mentioned the Viddui, the confession, as a part of the penitential prayers. Its mode, however, is a derivation from the Job mode, that is, it has the major tetrachord as its foundation. This fact is significant of the characteristics of Synagogue song, which expresses sentiments and pain, desires and longings, wishes and hope in minor. But as soon as it strives to express or confess truth, it turns to the emphatic sound of the major third. It matters not whether that truth be the proclamation of the Almighty's glory or the self-humiliating declaration of our own sins; for one of Judaism's chief features is its staunch adherence to and fearless proclamation of the truth, however painful to personal vanity that truth may be. Therefore, Synagogue song expresses confession in the emphatic manner of the major scale. Table XIIIa gives a comparison of the Yemenite, Persian, Babylonian and Ashkenazic versions of the Viddui-mode, which evidences the similarity between them. The Persian version shows an inclination to the parallel minor, because of the influence of the Selicha mode in that song, as stated above.

The mode does not rise above the fifth or sixth, so that the melodic line never climbs up to the octave. Consequently, it lacks the energetic ascent of the seventh step, the tone leading to the eighth. In consequence thereof, the mode acquired a sternness and dignity of character.

\section{(4) THE MOGEN-OVOS MODE}

This mode, though it can be traced in the song of other countries, received its development primarily in the song of the Ashkenazim. Its name is derived from the prayer Mogen-Ovos-a summary of the seven benedictions of the Amida-composed in the third century in Babylonia for the benefit of the late comers to the Friday evening service, to enable them to hear, at least, the essentials of the service. 


\section{TABLE XIII \\ Comparative Table of Selicha Modes}
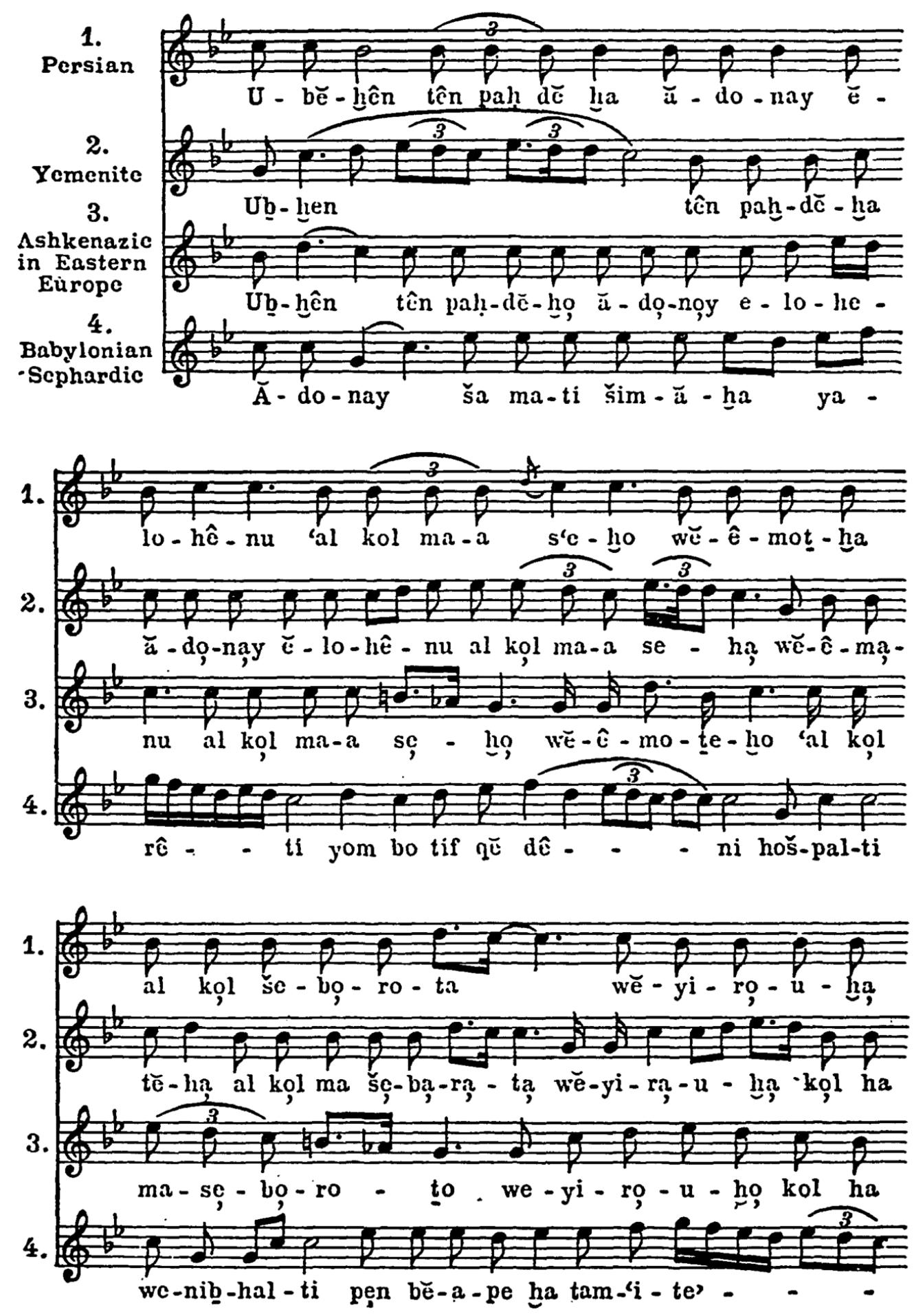

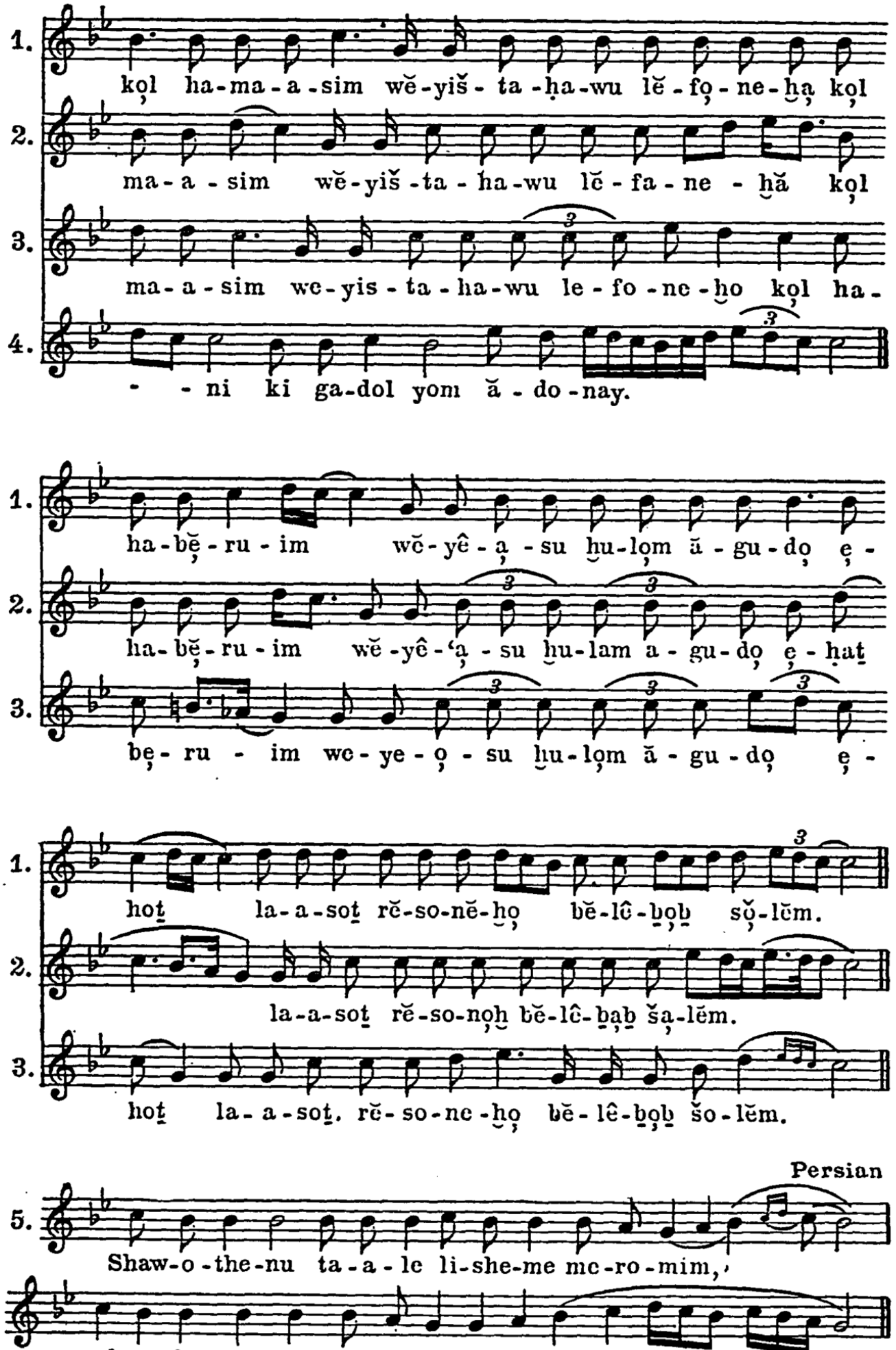

cl me-lech yo-shev al kis-se ra-cha-mim. 


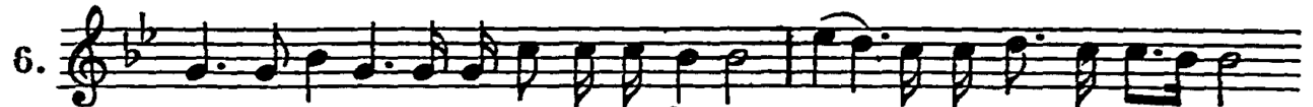

Shma ko-le-nu a- do-noy e- la-he-nu, chus ve- ra-chemo-le - nu,

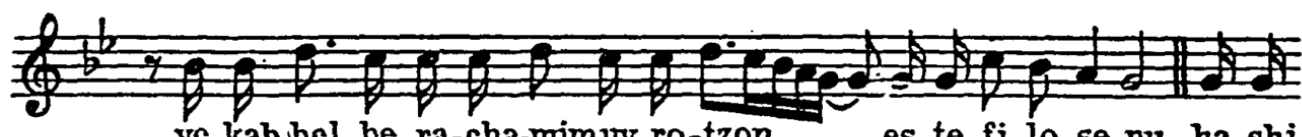

va-kab-bel be-ra-cha-mimuv-ro-tzon

es te-fi-lo-se-nu. ha-shi-

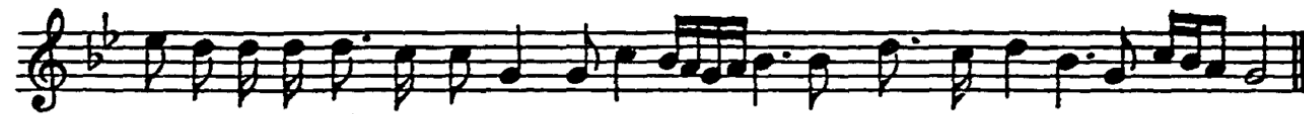

ve-nu a-do-noy e- le-choh ve-no-shu-voh, chad-desh yo-me-nu ke-ke-dem.
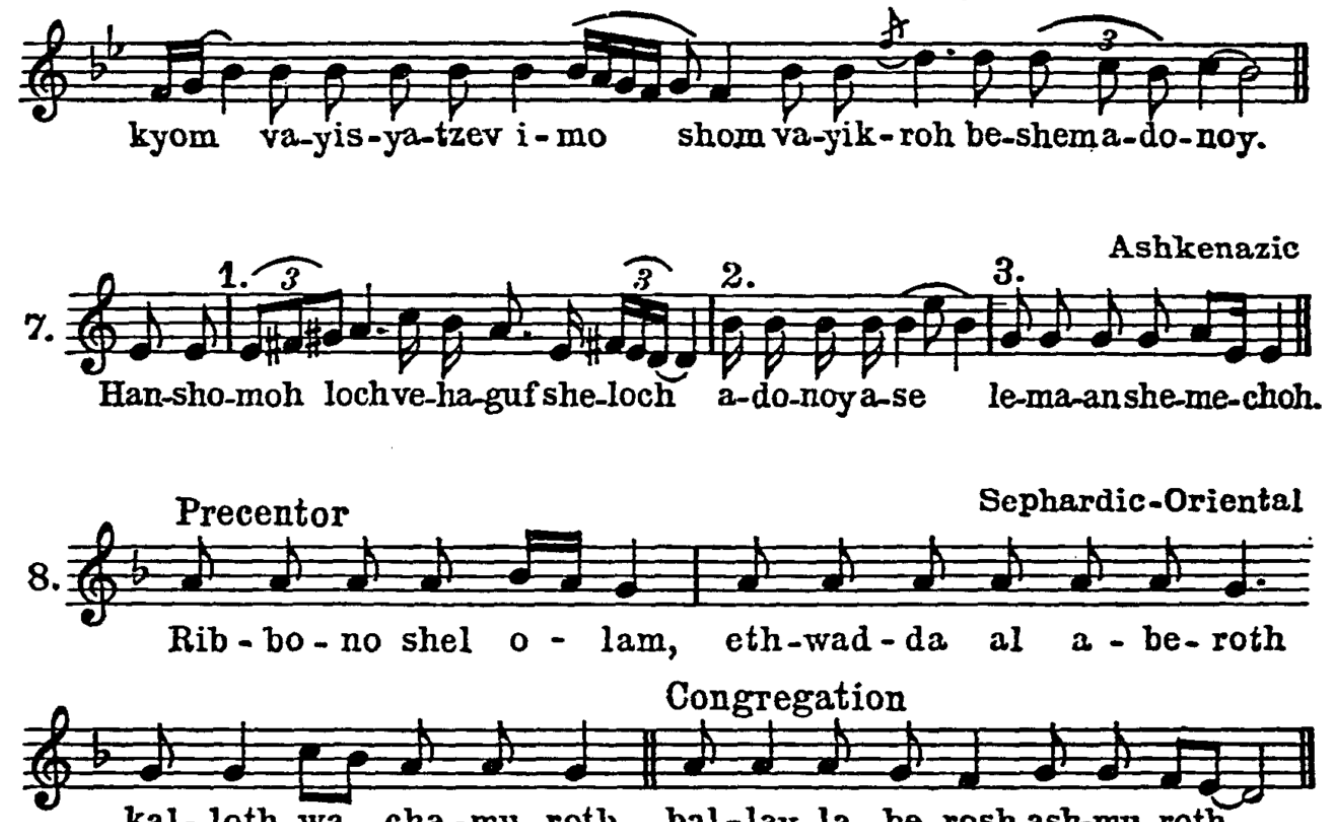

kal-loth wa-cha-mu-roth bal-lay-la be-rosh ash-mu-roth.

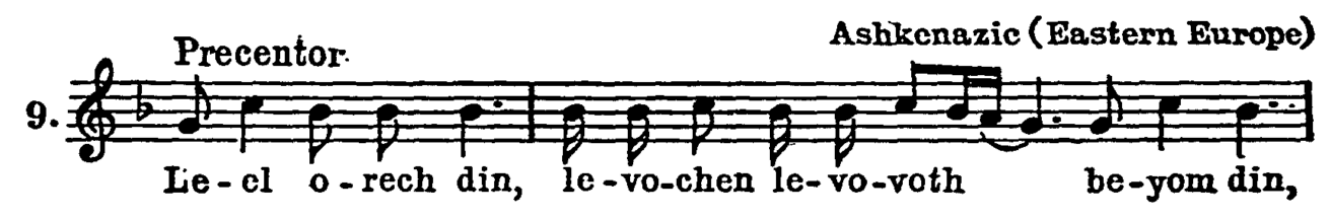

Congregation
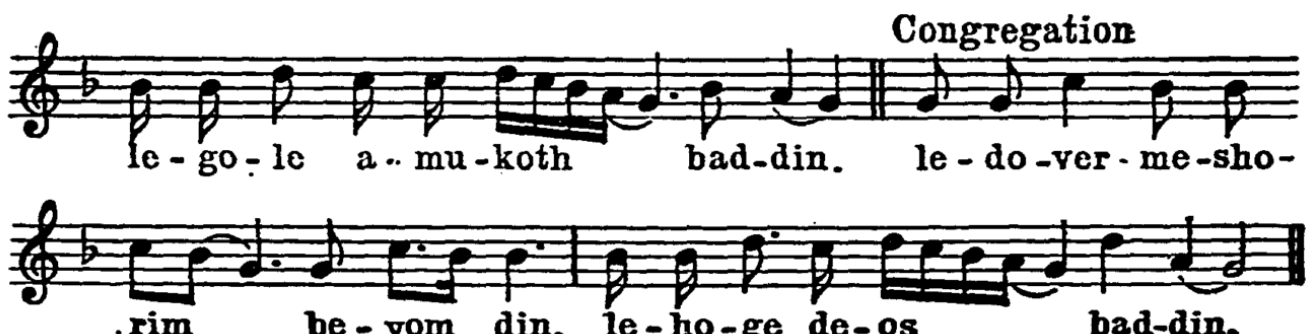

bad-din. 
TABLE XIII

Comparative Table of Viddui Modes
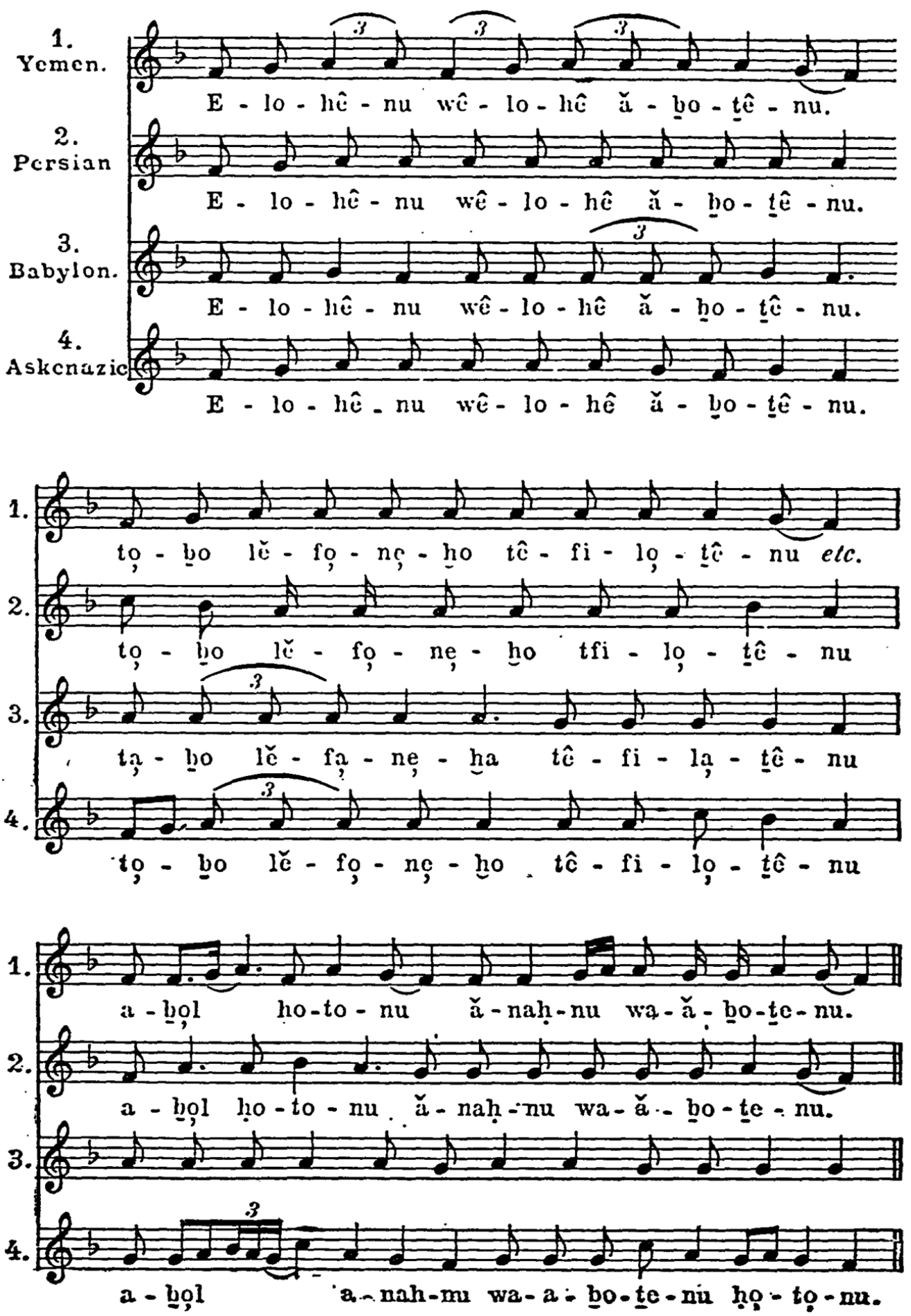

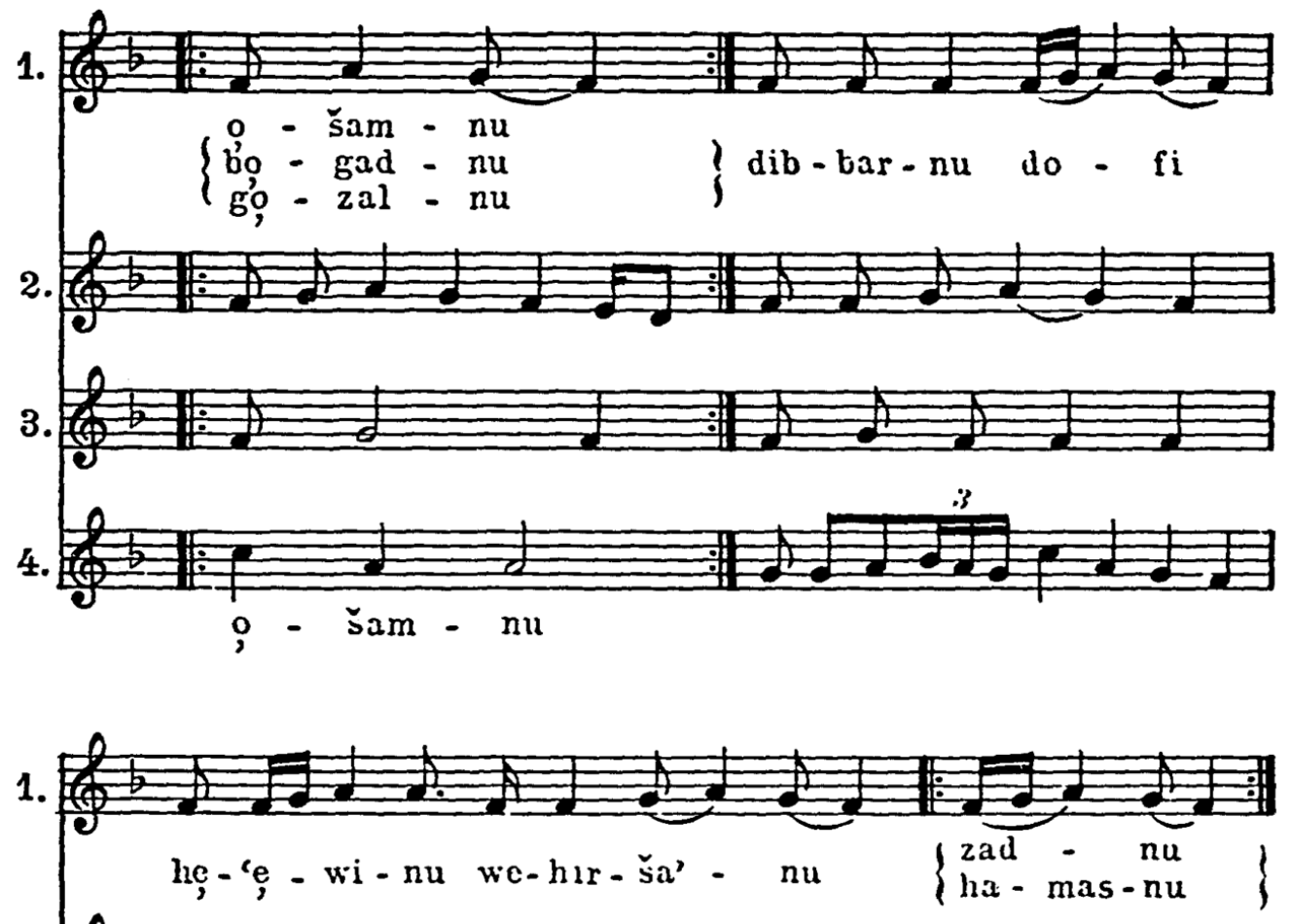

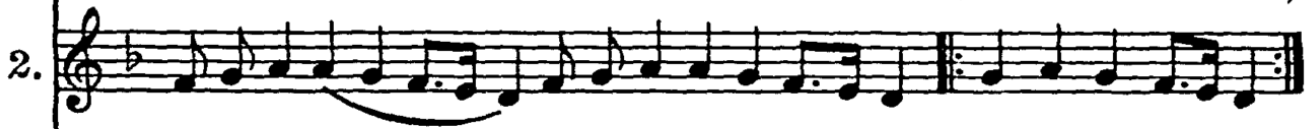

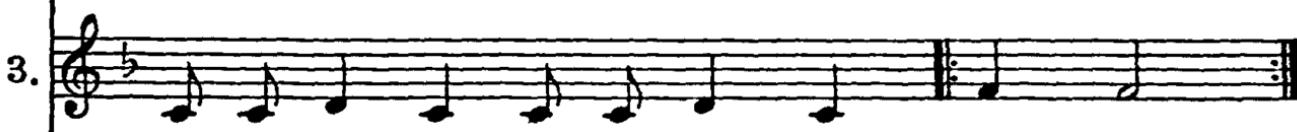

4.
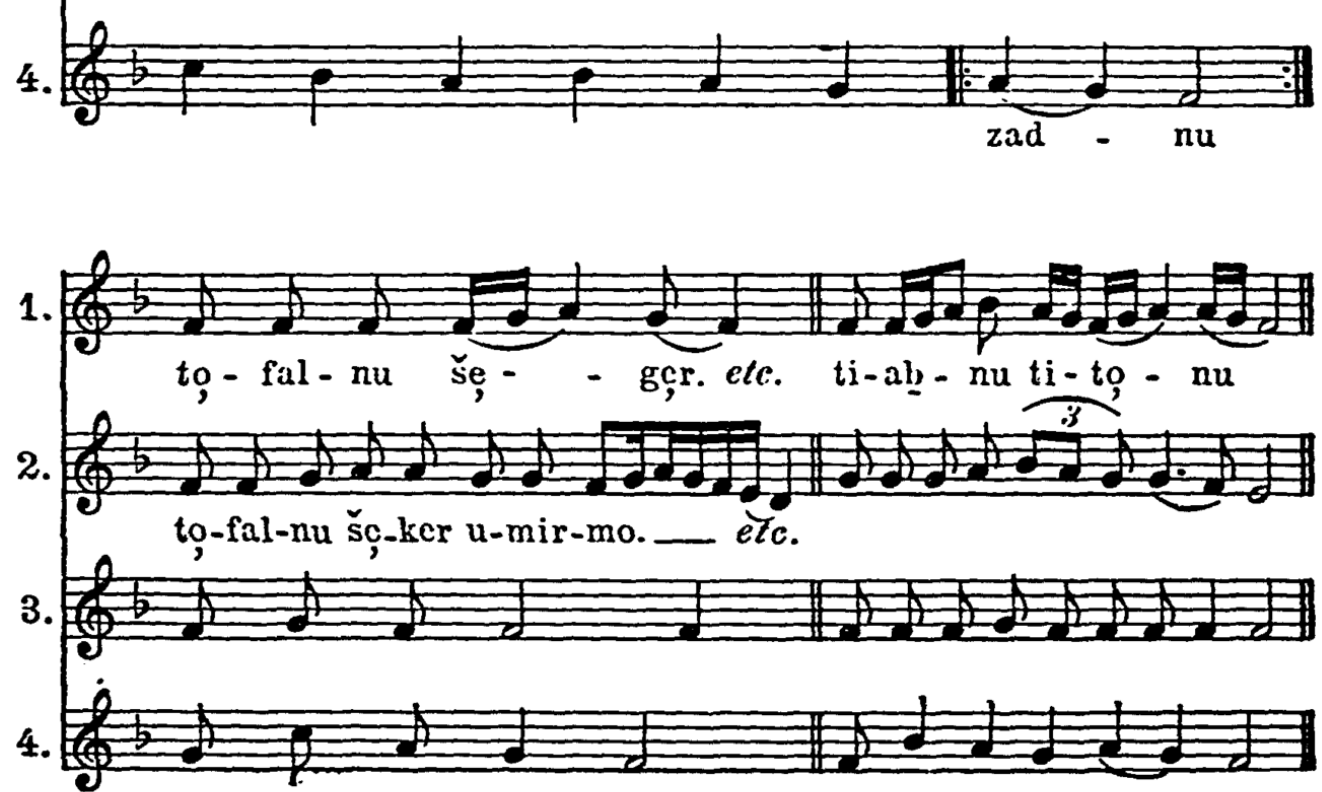
For the same purpose Vaychullu (Gen. 2: I-3) was repeated. ${ }^{4}$ In the eleventh century it was customary to chant Vaychullu and MogenOvos in a "fine and long tune." 5

This mode in its Ashkenazic version is founded on the minor scale. As to the characteristics of the mode, we mention first its pentachordal form, for the melodic line ascends to the fifth which is predominant in the mode. Furthermore, there is noticeable an inclination toward the third, i.e., the parallel major. The ending occurs on the fifth, employing the ending motive (sof pasuk) of the Prophetic mode.

The Mogen-Ovos is identical in many features to the Bayat-Huseni mode of the Arabic song. (See table I.) It has a tender and lyrical strain, and became, therefore, the basis for many Jewish folk tunes of religious and secular character, as we shall see later in Chapter XVIII. In table XIV, I-2, the Ashkenazic version of the Mogen-Ovos mode is given. Example 3 illustrates the Sephardic-Oriental version. The latter differs from the Ashkenazic mode in some basic features, for it has the tetrachordal form and the fourth $(\mathrm{g})$ as the dominating tone on which note it ends. The Orientals call that form Bayat-Nawa (see table I); in Greek music it was called Hyperphrygian.

We mentioned above (Chapter III) that the closing motive of the Mogen-Ovos mode was taken from the mode of the Prophets. On examination, we find that the mode as a whole is a derivation from the Prophetic and Pentateuchal modes. We see it best in XIV, example 2 , in which the motives $1,3,4,5,6$, are to be found in both modes (compare table IV), while the motives 7,8 , are from the Prophets only. Motive 2 is a sequence of 1 . The Oriental version (example 3), however, does not show this relationship.

Motive I is related to rebia-oriental; 2, to Pent. gereshin; 3, to tebir-orient., and Pent. gershayim-Ashken.; 4, to rebia Pent. and Proph.-Ashken.; 5, to telisha, Pent.; 6, to darga and tebir, Pent. and Proph.

\section{(5) THE AHAVOH-RABBOH MODE}

The prayer-modes thus far treated show connections with the Biblical modes. They either are a derivation from them or have at least absorbed some motives of these modes. They have to be considered originally Jewish, even though their scales are to be found in the music of the classic and Oriental nations, for, as we have empha- 


\section{TABLE XIV \\ Mogen-Ovos Mode (Steiger)}

Gen. 2. 1.3

(Ashkenazic)
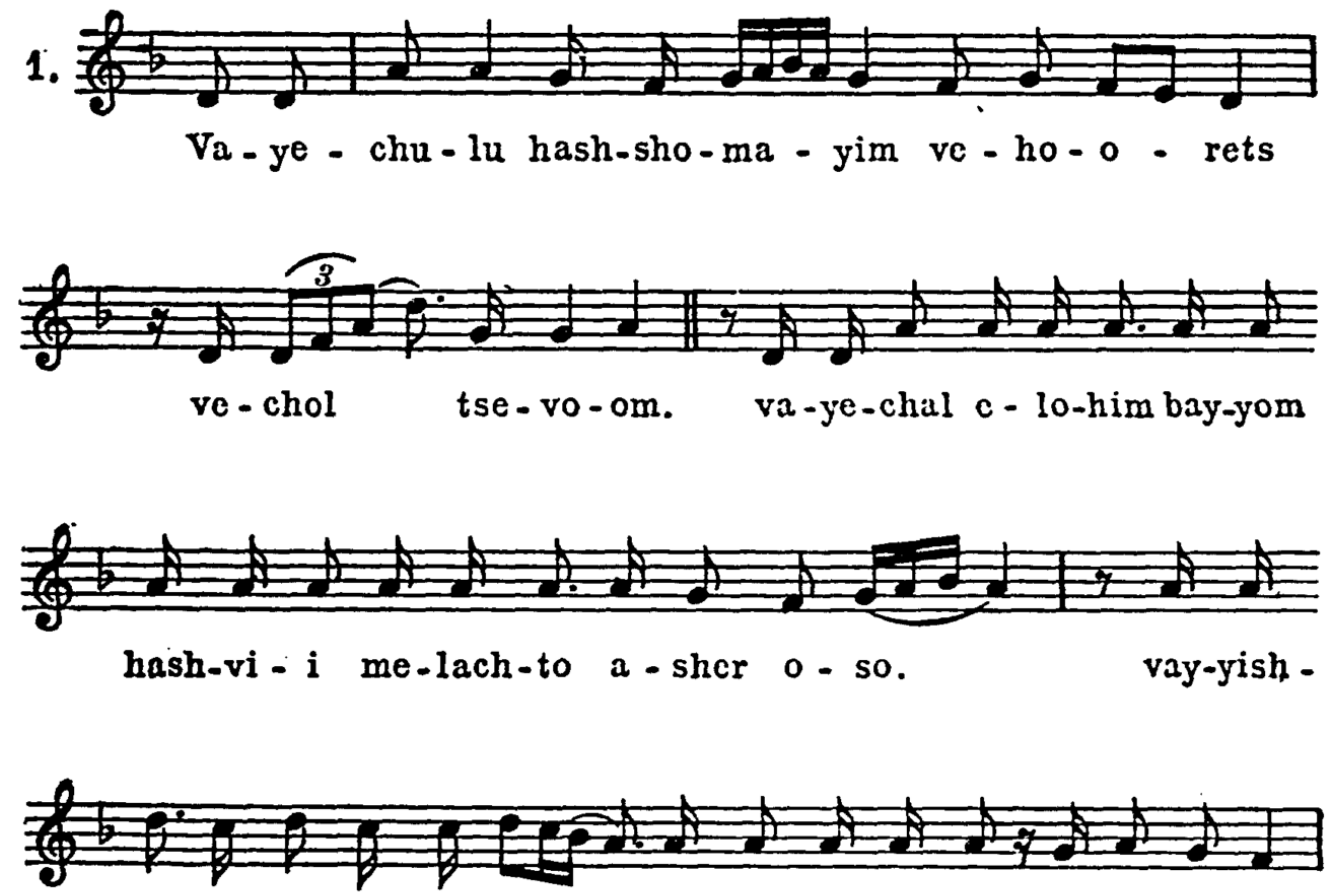

bos bay-yom hash vi-i mik-kol me-lach-to a-sher o-so.

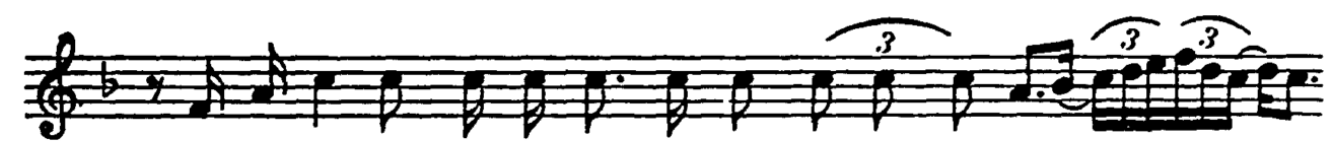
va-ye-vo-rcch e-lo-him es fom ha-she-vi-i

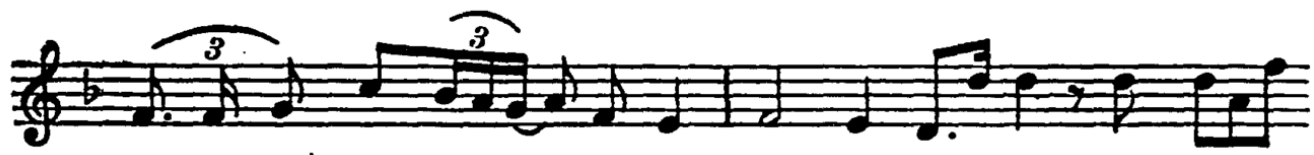
va-ye-kad-desh o-so. $k i$ vo sho-vas mik-kol

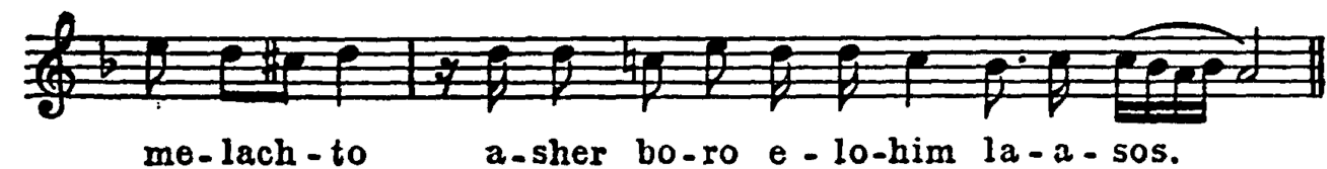

$$
\text { me-lach-to a-sher bo-ro e-lo-him la-a-sos. }
$$


Moderato

(Ashkenazic)
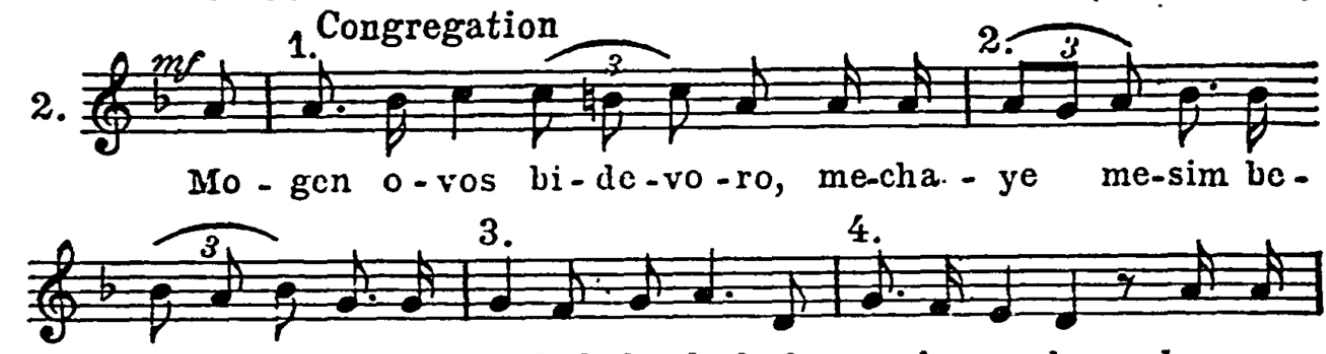

ma-a-mo-ro, ho-el hak-ko-dosh she-en ko-mo-hu, ham-me-

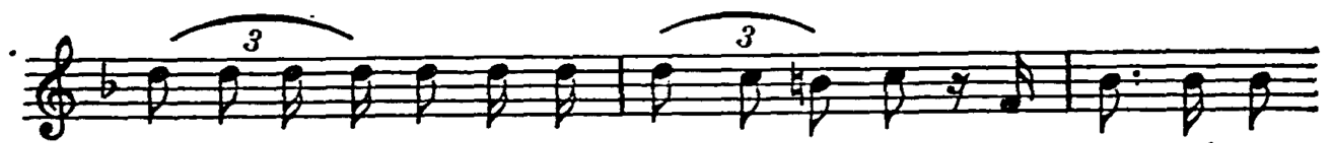

ni -ah le-am-mo be-yom shab-bas kod-sho, ki - vom ró-tso

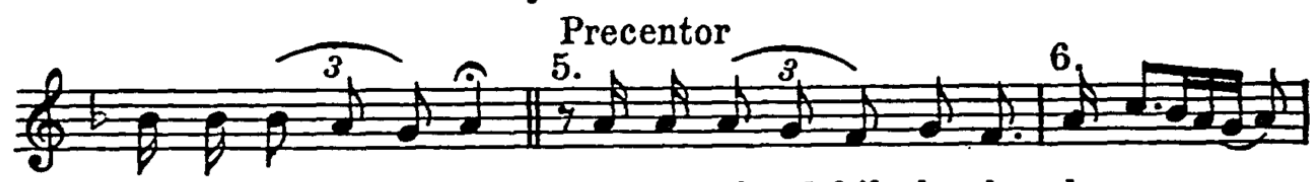

lc-ho-ni-ah lo-hem... u-mc-ni-ach bik-du-sho le-am

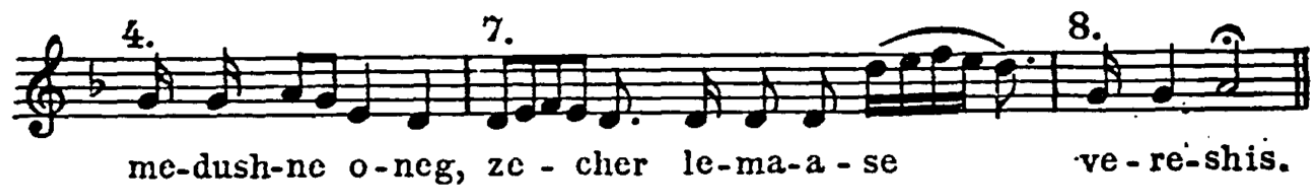

Gen. 2. $1-3$

(Sephardic-Oriental)

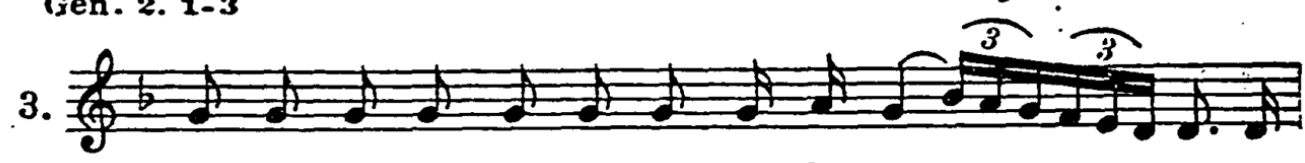

Way-chu-lu hash-sha-ma-yim we-ha-a

res we -

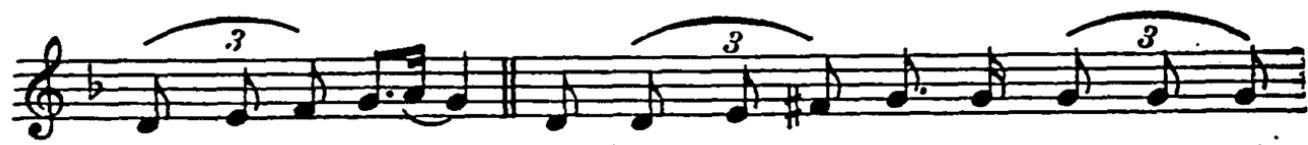

'choi se-ba-am way-chal e - lo-him bay-yom hash-bi -

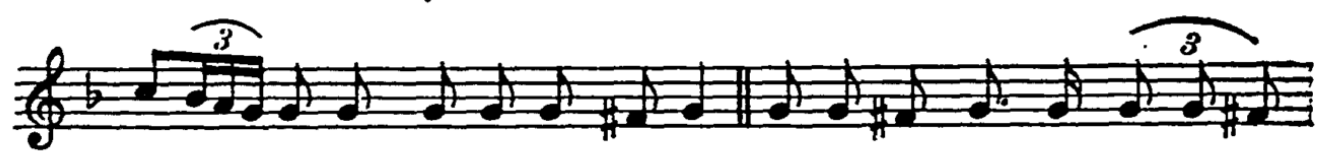

i me-lach-to a-sher a-sa. ki bo sha-bath mik-kol me-lach-

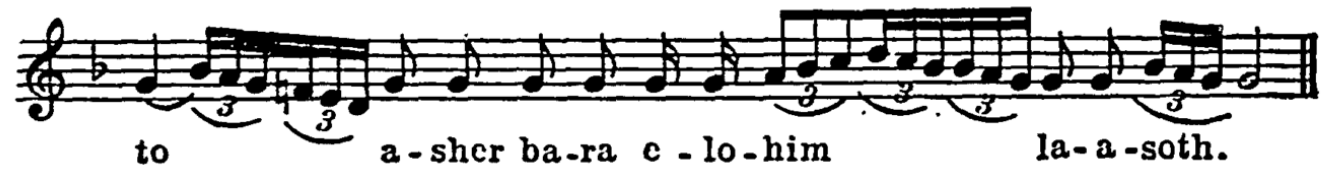


sized several times, the originality of a national music is not dependent upon an original scale, but upon original motives and melodic curves which above all express the characteristics of a nation, a group, or a people. At the same time, one particular mode or Steiger-the socalled Ahavoh-Rabboh-must be especially considered. It is not to be met with in the Biblical modes.

The mode is based on the tetrachords $e-f-g \#-a+b-c-d-e$, or their equivalent steps in other notes. The augmented second step of this scale does Nor exist in the scales of the Biblical modes and of their derivations in the prayer-modes. It is the same scale which Olympus was supposed to have introduced into Greece about 800 B.C.E., with the Aulos and which innovation, as we have seen, aroused strong opposition in Greece. (See Chapter II.)

If we investigate the traditional songs of the various communities, we find the interesting fact that this mode is not at home in all of them. Proceeding geographically, we find that the Yemenite, Persian, Babylonian, Moroccan, Italian, Portuguese, and Western German communities do not use this mode at all, while those communities which are living in environments that are or were predominantly Tartaric-Altaic use it very much; for example, in Egypt, in Palestine, in Syria, in Asia Minor, on the Balkan, in Hungary, Roumania, in Ukraine, and Volhynia. Going further north to Poland, Lithuania and Northern Germany, we find that the usage of this mode diminishes gradually.

The fact that this mode is not used for the Bible and the ancient prayers nor in the ancient communities in the Near East for the prayers or for the old piyyut, created in the period 800-1000 C.E., leads us to the opinion that this mode was originally unknown to the Jewish people, and that only later was it adopted as a result of the influx of the Mongolian and Tartarian tribes into Asia Minor, Syria, Palestine, and Egypt, as well as on the Balkan, beginning with the thirteenth century. With the expansion of the Tartars in Southern Russia, reaching as far west as Hungary, their song was carried with them and nestled itself in the fertile soil of the receptive Jewish soul. Whether or not the Chazarian proselytes on the Caspian Sea sang in the same mode we are not certain. However, being a Tartaric tribe, they probably did so. Thus after they amalgamated with the Jews, they may have transmitted to the latter their characteristic racial song. 
Be that as it may, this mode came to be much liked by the Jews of the countries mentioned above, so that it became a real channel of Jewish expression, especially for moods of excitement, for the stirring passion of pain, of love, and faith in God. The more the Jewish people in those countries were persecuted for their religion, the more passionate became their expression of love for it. For such intense sentiments they adopted this Tartaric Oriental mode, full of fire and romanticism.

For certain parts of the prayers on Sabbaths and Festivals, but foremost on the High Holidays, the Ahavoh-Rabboh mode is employed in those countries. Especially in Ukraine and Volhynia it became the vehicle of tense emotion. We can perceive the power of this mode only when we study the compositions of the chazzanim in Eastern Europe of the eighteenth and nineteenth centuries.

The name Ahavoh-Rabboh is derived from a prayer in the morning ritual, with which, on the Sabbath, the precentor usually introduces this mode into the service. Out of this mode were created a number of rhythmical melodies not only for religious but also for secular purposes about which we shall speak in the sections on Folk-song (Chapters XVII-XX).

The characteristic of this mode may be gathered from table $X V$. Example I is Sephardic-Oriental from the Musaf Kedusha on Sabbaths and Festivals, which is sung responsively. Example 2 is Ashkenazic from Eastern Europe. Its text is likewise from the Sabbath Musaf service. In both examples we find the same features. The

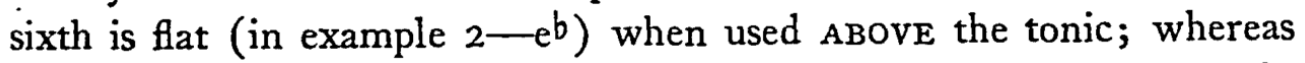
when BELOw the tonic, it is natural. The same peculiarity we saw in the scale of Hedjaz and the Greek "second" tone (see Chapter II). The resting points of the motives are: the fourth, the seventh below the tonic, the third, and the tonic. The descending line from the seventh above to the seventh below the tonic is a chief feature and appears as a rule before the end. Example 3 furnishes an illustration of the same mode when used for the expression of tense emotion. It climbs in tetrachordal curves, first to the fourth, then it changes to Ahavoh-Rabboh on the fourth, and from there it modulates to the fifth according to the same scale, whereupon it turns back to the original tonic, using the same motives in tetrachordal curves. But here we touch the modulation of Jewish song, a subject which we shall 
treat in detail in Chapter XXIII. At present it is our aim to familiarize ourselves with the elementary characteristics of this mode.

There are some modes branched off from the Ahavoh-Rabboh. These are of much later date and of local significance. We, therefore, defer discussion of them to Chapter IX.

These are the oldest elements of the modes of the prayers preserved in the Jewish communities. They are mostly derived from the modes of the Bible: the Tefilla mode from the Pentateuch mode, the Selicha and Mogen-Ovos from the modes of the Prophets, Lamentations, and Psalms, and the Viddui mode from the Job and group C of the Psalms modes. Both Biblical and prayer modes constitute the oldest, the most genuine and the most Oriental-Semitic part of Jewish music, upon which the later creations were based. 


\section{TABLE XV}

\section{Ahavoh-Rabboh Mode}

(Sephardic-Oriental)
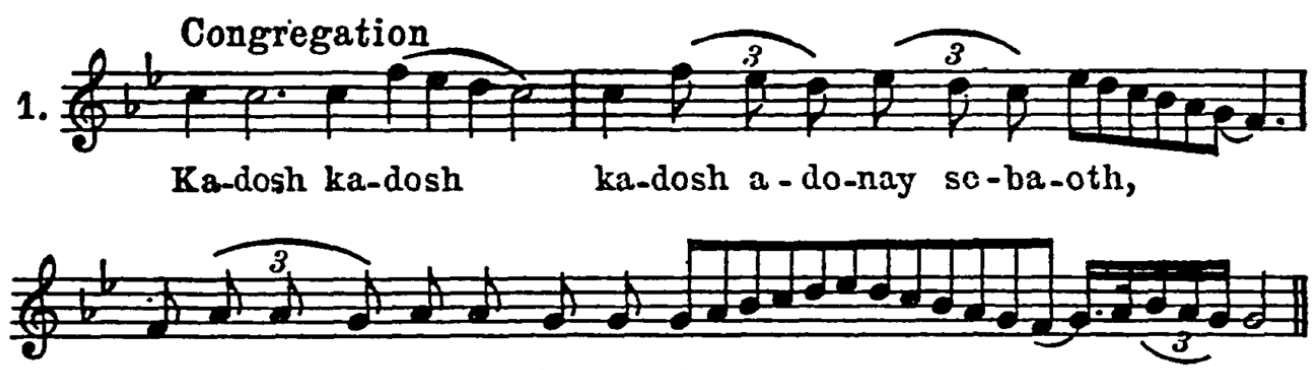

me-lo chol ha-a-res ke-vo-do.

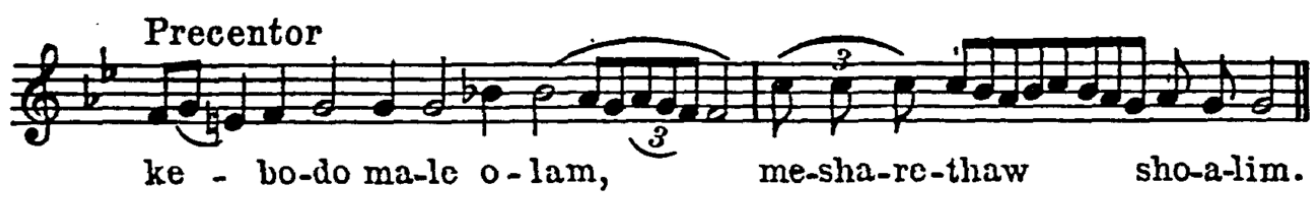

Congregation

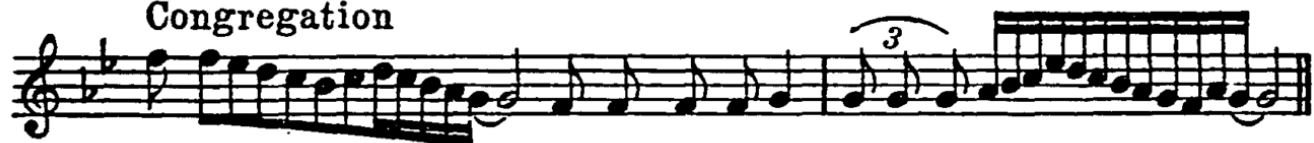

ay-ye

me-kom ke-bo-do. le-ha-ri-so.
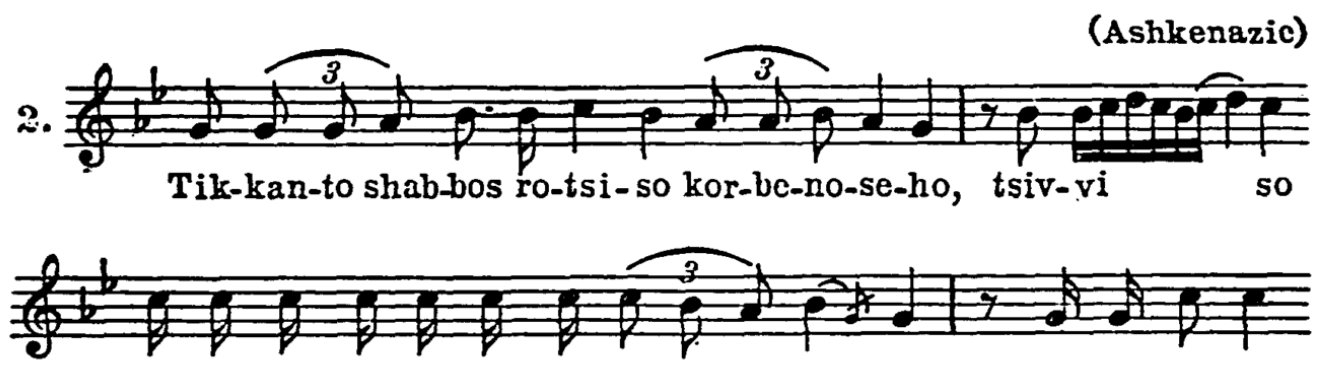

pe-ru-she-ho im sid-du-re ne-so-che-ho, me-an-ge-ho
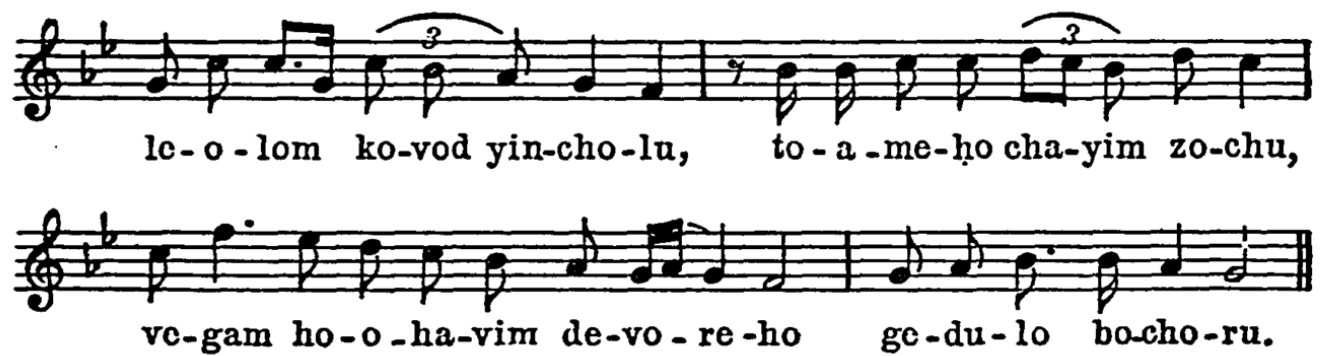

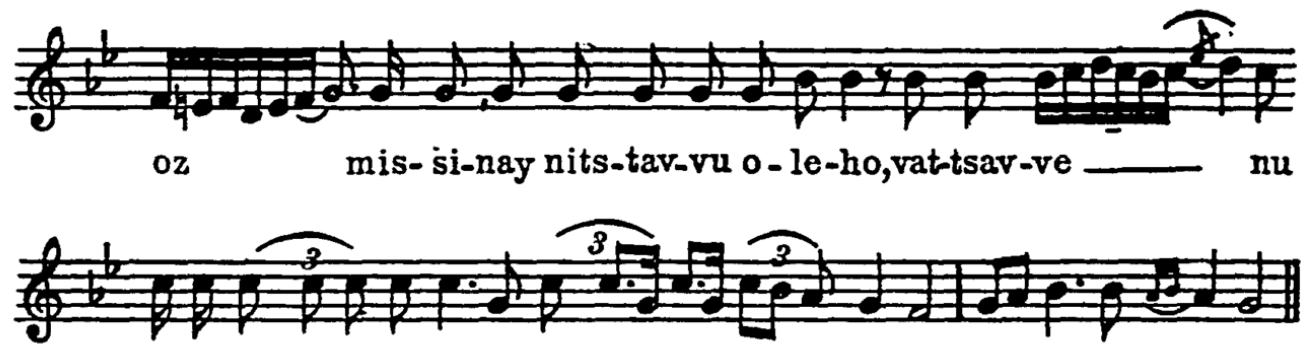

a-do-nay e-lo-he-nu le-hak-riv bo kor-ban mu-saf shab-bosko - ro-uy.

(Ashkenazic)
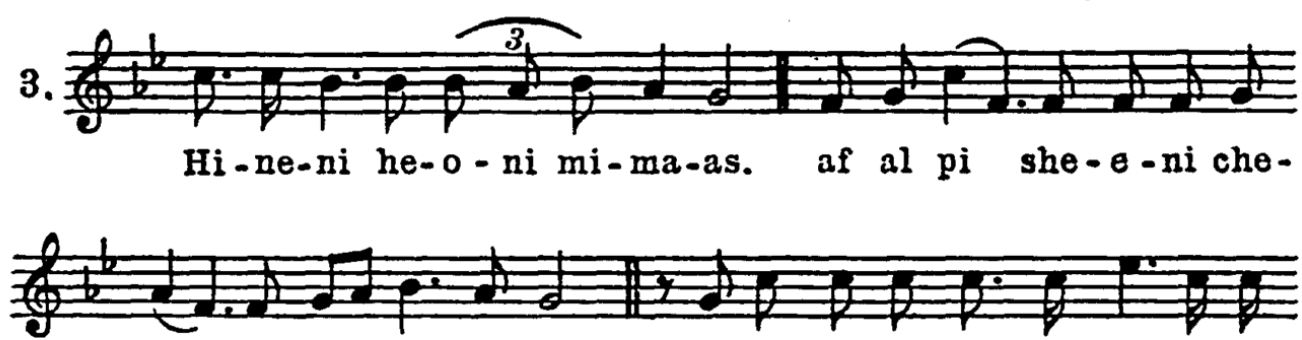

day ve-ho-gun le-chach. lo-chen a-vak kesh mim-cho, e-lo -

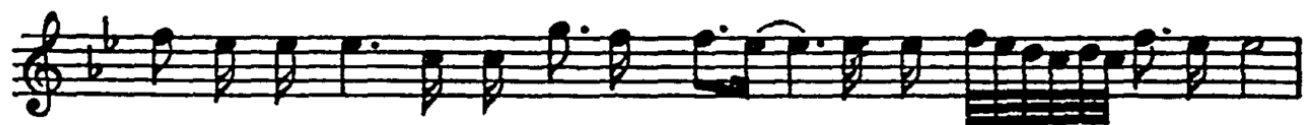

lhe av-ro-hom, e-10-he yits-chok ve-10-he ya-a-kov,

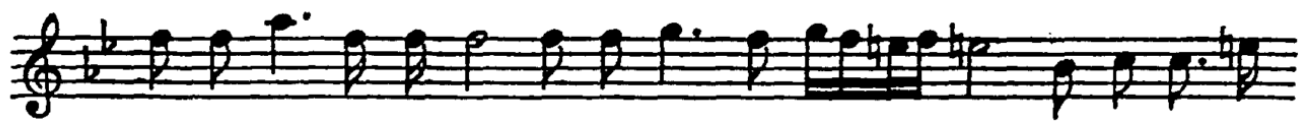

a-do-noy, a-do-noy, el ra-chum ve-chan - nun, e-lo-he yis-

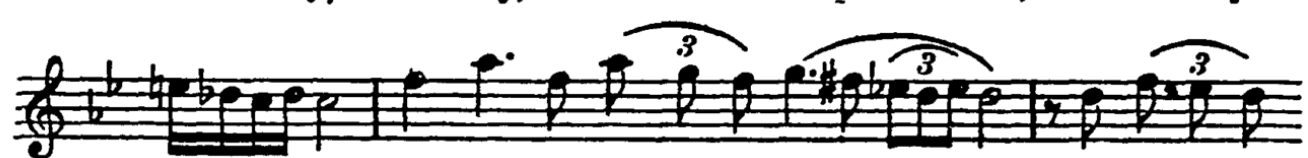

ro - ol. shad-day o-yom ve-no-ro,

he-ye no mats-

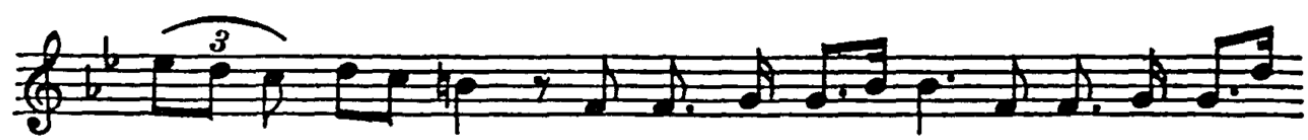

li - ach dar - ki a-shèr o-no - chi ho-lech vo-o -

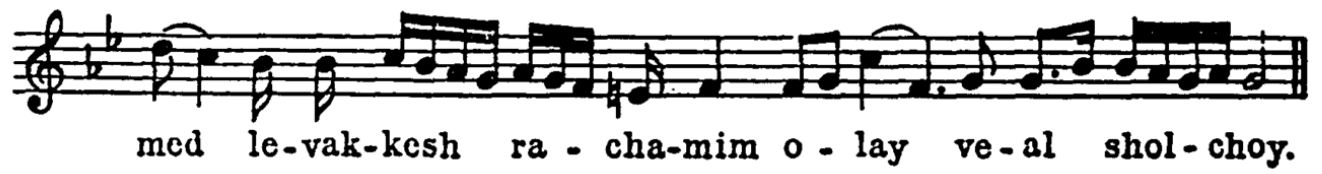




\section{CHAPTER V}

A HISTORICAL SURVEY OF THE SYNAGOGUE SONG AFTER THE DESTRUCTION OF THE SECOND TEMPLE UNTIL THE RISE OF THE ISLAM (7O C.E.-7OO C.E.).

In the first centuries after the destruction of the Temple in Jerusalem and after the failure of the last attempt of the Jews to regain their independence in Palestine, it seemed that music was doomed to be silenced forever among the Jewish people. Already before the Destruction, secular music was considered a bad influence upon the people. ${ }^{1}$ Greek song especially was regarded harmful, ${ }^{2}$ and the spiritual leaders tried to fight against it by urging the people to sing religious songs at festivities. ${ }^{3}$ This attitude grew out of religiousethical considerations. For example, among the transgressions of the apostate "Acher" (Elisha ben Abuyah) was counted his continuous singing of Greek songs. People who had musical ability and sweet voices were exhorted to make a pilgrimage to Jerusalem, there to join in the singing of sacred songs; and he who did not offer his talent for holy service was doomed to divine punishment. It is related of a certain Naboth who went regularly to Jerusalem to perform his songs in public, that because he refused to do so once, he was punished. ${ }^{4}$ The challenge of the sages to all singers was this: "If you have a sweet voice, glorify God with the gift $\mathrm{He}$ bestowed upon you, chant the Shema, and lead the people in prayer." " They went to the extreme in saying that profane songs of love and lust are sufficient cause to destroy the world, and that Israel's religious songs save it. ${ }^{\circ}$ Whenever God hears Israel's song $\mathrm{He}$ calls the Heavenly host to listen. ${ }^{7}$ 
But after the Destruction, all instrumental music, even for religious purposes, was prohibited, as a sign of national mourning over the Temple. The attitude, "Rejoice not, $\mathrm{O}$ Israel, unto exultation, like the peoples" (Hos. 9: I), ${ }^{8}$ became prevalent. Hence national mourning strengthened that antagonism to secular music which existed already before the Destruction.

That antagonism cannot be credited to the exaggeration of moralists only. If a great man like Abba Areka (Rab), at the beginning of the third century, was of the opinion that "an ear which listens to (secular) music shall be torn out," though he himself was a fine singer and one of the greatest liturgists, then there must have been something in the current songs to justify that statement. Nor was he the only one to issue protests against "music." A generation later Raba said, "Music in a house must bring that house to destruction," and his colleague Rab Joseph expressed the opinion that "if men sing and women respond, the result is licentiousness, but if women sing and men respond, the end is like a flame in hatcheled flax." 9

The clue to the attitude here reported we find in the condition of secular and pagan music of a decadent civilization about the beginning of the Common Era. Greek art and culture, which had become international, degenerated to mere virtuosity, empty of any ideal. Hence, Greek music became a means by which to stimulate voluptuousness. It became synonymous with obscenity and was chiefly used for carnal purposes at frivolous occasions. No wonder then that Judaism opposed "profane" music.

But in this regard Judaism was not unique. Christianity, too, fought the heathen music bitterly. We read in the writings of Clement of Alexandria: ${ }^{10}$

"Let revelry keep away from our national entertainers, and foolish virgins, too, that revel in intemperance. For revelry 
is an inebriating pipe, the chain of an amatory bridge, that is, of sorrow. And let love, and intoxication, and senseless passions, be removed from our choir. Burlesque singing is the boon companion of drunkenness. A night spent over drink invites drunkenness, rouses lust, and is audacious in deeds of shame. For if people occupy their time with pipes, and psalteries, and choirs, and dances, and Egyptian clapping of hands, and such disorderly frivolities, they become quite immodest and intractable, beat on cymbals and drums, and make a noise on instruments of delusion; for plainly such a banquet, as seems to me, is a theatre of drunkenness. . . . Let the pipe be resigned to the shepherds, and the flute to the superstitious who are engrossed in idolatry. For, in truth, such instruments are to be banished from the temperate banquet, being more suitable to beasts than men, and the more irrational portion of mankind. For we have heard of stags being charmed by the pipe, and seduced by music into the toils, when hunted by the huntsmen. And when mares are being covered, a tune is played on the flute-a nuptial song, as it were. And every improper sight and sound, to speak in a word, and every shameful sensation of licentiousness-which, in truth, is privation of sensation-must by all means be excluded: and we must be on our guard against whatever pleasure titillates eye and ear, and effeminates. For the various spells of the broken strains and plaintive numbers of the Carian muse corrupt men's morals, drawing to perturbation of mind, by the licentious and mischievous art of music.

“. . . 'Praise Him on the chords and organ.' Our body $\mathrm{He}$ calls an organ, and its nerves are the strings, by which it has received harmonious tension, and when struck by the Spirit, it gives forth human voices. 'Praise Him on the clashing cymbals.' He calls the tongue the cymbal of the mouth which resounds with the pulsation of the lips. Therefore $\mathrm{He}$ cried 
to humanity, 'Let every breath praise the Lord,' because $\mathrm{He}$ cares for every breathing thing which $\mathrm{He}$ hath made. For man is truly a pacific instrument; while other instruments, if you investigate, you will find to be warlike, inflaming to lusts, or kindling up amours, or rousing wrath.

"In their wars, therefore, the Etruscans use the trumpet, the Arcadians the pipe, the Sicilians the pectides, the Cretans the lyre, the Lacedæmonians the flute, the Thracians the horn, the Egyptians the drum, and the Arabians the cymbal. The one instrument of peace, the Word alone by which we honor God, is what we employ. We no longer employ the ancient psaltery, and trumpet, and timbrel, and flute, which those expert in war and contemners of the fear of God were wont to make use of also in the choruses at their festive assemblies, that by such strains they might raise their dejected minds. . . .

"Further, among the ancient Greeks, in their banquets over the brimming cups, a song was sung called a skolion, after the manner of the Hebrew psalms, all together raising the pæan with the voice, and sometimes also taking turns in the song while they drank healths round; while those that were more musical than the rest sang to the lyre. But let amatory songs be banished far away, and let our songs be hymns to God. 'Let them praise,' it is said, 'His name in the dance, and let them play to Him on the timbrel and psaltery.' And what is the choir which plays? The Spirit will show thee: 'Let His praise be in the congregation (church) of the saints; let them be joyful in their King.' And again he adds, 'The Lord will take pleasure in His people.' For temperate harmonies are to be admitted; but we are to banish as far as possible from our robust mind those liquid harmonies, which, through pernicious arts in the modulations of tones, train to effeminacy and scurrility. But grave and modest strains say farewell to the turbulence of drunkenness. Chromatic harmonies are, 
therefore, to be abandoned to immodest revels, and to florid and meretricious music."

The effort succeeded. Within a short time no instrument was used in any Christian service. ${ }^{11}$ The Greek art music was abolished not only from religious but also from secular life, and, with the addition of a few simple sentences of common prayers, the Book of Psalms became the standard prayerbook in the Church.

Hence, Synagogue and Church adopted the tendency toward striking simplicity in text and music. Of the elaborate Temple music the Synagogue retained only the chants in Palestinian folk-modes, which remain to the present day, for Bible and prayers (as explained in Chapters III and IV). All customs regarding heathen worship, such as instruments and bodily motions (dances), vanished. When Athanasius found the congregation in Milet accompanying song in the church with handclapping and bodily motions, he became very much upset. This is proof that at his time (fourth century) all traces of heathen and Greek art had perished from the Church. ${ }^{12}$

The strict order of the Church Fathers that only one instrument should be employed, i.e., the human voice, has been observed in the Syriac, the Jacobite, the Nestorian, and the Greek churches to the present day. So also the Synagogue did not use any instrument in the service up to $18 \mathrm{IO}$, in which year the organ was introduced in the first Reform Temple in Seesen, Germany (see further Chapter XII). The reason for abolishing instrumental music from the Church was the ethical concept of that day that instrumental music led to licentiousness. Therefore, in those countries in which the conception of ethics changed regarding the use of instruments in worship, the prohibition was annulled. In the Synagogue, on the other hand, the prohibition had a national motive, the idea being that no musical instrument be used in the Synagogue 
until the restoration of the Temple when the Levitical music would be revived. In addition, the playing of musical instruments on Sabbaths and festivals was regarded a desecration (see Chapter I). Later, from the time the organ became permanent in the (Catholic) Church (twelfth or thirteenth century), the view was entertained that the organ had become a "Christian" instrument (more in detail in Chapter XII). From this attitude we may deduce that the Jewish sages did not consider the instruments as such, harmful, but rather the music performed on them. A proof of their insight and sound judgment regarding music, we find in the episode related about Rab Huna, who in his zeal, prohibited all secular music in the Jewish community in Babylonia. The prohibition caused the suspension of festivities and social affairs, resulting in a complete paralysis of social and commercial life. It brought about a crisis in the market, for without music nobody cared to arrange festivities, and there was in consequence no sale of products. Becoming aware of the danger of the execution of the decree, Rab Hisda cancelled the extreme ruling. ${ }^{13}$ Nonetheless, restrictions were made as to the occasions appropriate for instrumental music and the degree to which they should be used. Thus, instruments were forbidden, not only on Sabbaths and festivals but also on week days; they were permitted only at joyous celebrations, such as weddings. And even then, to prevent over-indulgence in hilarity, a dish would be thrown and broken in front of the bride and groom to remind them of the destruction of the Temple (in the spirit of the phrase of Psalm I36:6, "If I set not Jerusalem above my chiefest joy"). ${ }^{14}$ It is told of some prominent sages in the Talmudi period that as soon as they noticed that the gaiety at the wedding was becoming extravagant, they would suddenly break the most costly dishes in order to shock the guests and thus tone down the joy. Likewise, in order to turn the minds of the 
hilarious guests to seriousness, they would start singing a responsive song, the subject of which was death and the earnestness of life..$^{15}$

The restrictions applied to everybody, regardless of social standing. Therefore, even the Exilarch Mar Ukba, who in his love for music made extensive use of it in his home, was rebuked by the spiritual leaders, who dispatched a special delegation to him to remind him of the restriction. ${ }^{16}$

No wonder, therefore, that the song in the first centuries was simple, and that only religious song was tolerated and cultivated. The music served only to interpret the text; it was consequently limited in its form, and after becoming closely associated with particular texts, it was cut off from further development. Solo recitation, like the Arabic Tartil (see Chapter II, c), excluded rhythmical development, and the strict adherence to the interpretation of the word caused a certain stagnation in the music.

But what seemed impossible in the Bible was permissible in the prayers. There the Jew found a free field for creative song. Out of elements of the Biblical modes new modes were formed, as we have seen in Chapter IV. Indeed, at first the principle of subduing the music to the text, keeping it a mere interpretation of the words, as we find it in the Biblical modes, continued in the prayer modes. But soon the very purpose of prayer defeated this restriction, for the purpose of reading the Bible was INSTRUCTION, whereas the aim of prayer was INSPIRATION. In texts of instructive nature tunes must be subordinate to the text, while for the outpouring of the heart in prayer-texts musical embellishments offer added power of interpretation, and the solo-recitative insures freedom for the expression of rising devotion. Much stress was laid also upon unison congregational singing "in one tone, with one mouth and in one tune." ${ }^{17}$ The prayer-modes were, as we saw in 
Chapter IV, as a rule unrhythmical, and in the form of unison or responsive singing. There was a syllabic rhythm, based on the accentuated words. Indeed, there was no stimulus to the creation of strict rhythm, such as bodily motions or instruments of rhythmical nature or metrical texts.

This condition obtained not only in the Synagogue but in the Church as well. Not two centuries passed before Christian spiritual leaders in the Orient became conscious of a feeling of stagnation. The completeness of the Psalms that "express all the different sentiments of the human heart in every mood," ${ }^{18}$ did not prevent the natural human longing for innovation. Therefore, when Bardaisan of Edessa (1 50-222) wrote one hundred fifty hymns in the form of the one hundred fifty Psalms to be used as interludes between the Psalms and not as substitutes for them, his verses were accepted with great enthusiasm in the Syriac Church. They became popular throughout the whole Orient, and remained so for about a century and a half, not because they were superior to the Psalms but because they were an innovation, a change. The Christian Church, tiring of its simplicity, began to long for intricate tools of poetical and musical expression, especially after it succeeded in becoming the state-religion of the Eastern Roman Empire. Therefore, when the greatest Syriac Church poet, Ephraim of Nisibis (406-473), started creating his poetry, it spread rapidly throughout the Old World, and was translated into all the languages of the various converts to Christianity. Bardaisan had been accused by Ephraim because he had adapted secular folk tunes for his one hundred fifty imitations of the Psalms, but Ephraim followed in the same practice. His poetry he based on meters of a certain number of accented syllables to the line, for the musical rendition of which rhythmical tunes were required. ${ }^{19}$ This was the first step toward 
metrical poetry and rhythmical music in the Oriental Church, yet the poetry was still far from being in strict meter.

Inspired by the spirit of Ephraim, toward the end of the fifth century, a Jew of Homs in Syria, who had been converted to the Greek Church and had renamed himself Romanos, became the greatest of the Greek Church poets, by composing for his adopted creed one thousand poems of different forms. The new music for this new Greek poetry, too, was not in strict rhythm, as the examples, furnished in the tables II and III, will prove.

In Jewish worship, also, a general craving for new expression gradually came to be felt. In the fifth and sixth centuries poems based on "verbal" meters were created. The meters were formed according to a certain number of words, three or four words to a line, a scheme already employed in several parts of the Bible. ${ }^{20}$ Yet no special music for those poems is recorded. We do not know whether at that time they caused any innovation in the traditional song, for at present they, too, are chanted in the modes of the prayer-texts of old. Only when sung in unison or in responsive form the music of these poems shows a marked syllabic rhythm (Chapter IV).

During the sixth and seventh centuries, the Jews created no new forms in poetry and music. In those periods of persecution, as in all times of distress, the Jew found the modal form, the free outpouring of his troubled soul and aching heart, the most appealing and consoling song. Until around 700 C.E., he cultivated the Selicha and Tachnun modes, the supplicational and petitional song. From the time that the Jews in the above-mentioned countries were permitted to breathe again, i.e., after the rise of Islam and its conquest in the Near East, they interested themselves in new artistic forms in poetry and music created by their new neighbors, the Arabs, and began adding to their song metered verse and rhythmical music. 
RISE AND DEVELOPMENT OF THE PRECENTOR AND THE CHAZZAN FROM ANCIENT TIMES UNTIL THE EIGHTH CENTURY.

The history of Synagogue song and its development cannot be fully understood without the consideration of the functionaries who were the bearers and preservers of this treasury of folksong, and who became the creators of that song throughout the medieval ages. A traditional song is unthinkable without professional executors. It cannot be abandoned to the good will and memory of the community. Furthermore, the song, inasmuch as it is closely connected with the text of the ritual, was surely determined by the precentor or by the priest, who, already in ancient times, recited the prayers to and for the community.

The ancient nations, such as the Assyrians, Babylonians and Egyptians, many centuries before the establishment of worship in Israel, had an organized service with responsive prayers in which the priest functioned as reader and precentor; and the priestly choir and, occasionally, also the public participated with responses, very similar to the forms which, as we explained, were in practice in ancient Israel. ${ }^{1}$ Yet there is one important principle which differentiates the Jewish worship from that of these ancient peoples. In the latter, it was the priest, who simultaneously with his offering of the sacrifices, acted as precentor. He recited the prayers and was the only mediator between the people and their God. In Judaism the idea became prevalent, through the influence of the Prophets, that God is near to everybody, and that everybody is worthy 
of approaching Him. Yahveh is "Our Father" occurs first in Isaiah $(63: 16 ; 64: 7)$, and "Our Father in Heaven" became a common expression in Palestine about the beginning of the Christian Era. ${ }^{2}$ The relation between God and Israel, as between father and children, entitled everybody to pray to God without priestly mediation. But as the people had not sufficient education to express their wishes, usually a prominent man- "one of the people"-used to be the intercessor. It is an interesting and important phenomenon in the history of Judaism that from the very beginning the spokesmen were men of the people. Sometimes even women were chosen to pray for the people; but we seldom find that the people chose a professional priest to pray for them. The latter occasionally prayed while sacrificing, but he never prayed for the people merely as an expression of human need in time of distress.

Such a spokesman was called in ancient times in Hebrew mithpallel-lead oneself to pray. He became the intercessor for the people because he was recognized as one endowed with the rare power of praying. This is a unique Hebrew expression. The act of precentorship which would usually call for a transitive verb, in this instance employs the reflexive.

With the further development of the institution of worship as a regular daily ritual, there arose in the last centuries before the Common Era the need of having a person to recite the very simple and short forms of prayers and laudations used at that time. At the Temple in Jerusalem, as we have already seen (Chapter I), this function was exclusively in the hands of the priests and Levites; but in the houses of worship, in the Synagogues, the office was occupied by a layman, the precentor, at that time called shaliach-tsibur-the messenger of the community. It was an office of honor. It was a distinction to be chosen by the elders of the Synagogue for this function. Naturally, the man selected was well versed in the prayers and 
their meanings. After reciting the first benedictions, the precentor had to improvise prayers according to the need of the hour, and then to close with the final benedictions during which the community listened silently and participated only with short responses, the form of which has already been explained in Chapter I. The progress of education increasingly enabled larger numbers of the community to function as precentors. Moreover, we find that the people visiting from other communities were honored with this function. Since everybody participated in the service, and everybody might be the precentor provided only that he knew the texts, and since even visitors could come to any synagogue and without any preparation chant the prayers, we conclude that the modes of the prayers were generally known and of a popular character, that is, folk-song. And not only were the modes generally known, but even in the way the prayers were offered, there was uniformity, at least in Palestine. Hence, special notice is taken of an exception. It is reported that the community in Jericho had the local tradition of reciting the Shema in unison, thus differing from the general custom which held to the responsive form.

The reading of the Bible, too, was in the hands of the precentor. Though we know that Ezra was the first to arrange the public recitation of the Pentateuch, yet the urgent advice given by a Palestinian authority not to read the Bible without singing, dates from the third century C.E. Therefore, the reader had to be familiar with the text of the Scriptures, with all its traditional variants as well as with its musical rendition, the traditional modes. The knowledge of the Scriptures grew to the extent that almost every congregant was able to read from the Pentateuch and the Prophets, whereas for the parts less in use, such as the "five scrolls," a scholarly man, a scribe (sofer), had to be sought. However, for the reading of the Pentateuch and 
Prophets the custom developed that the congregants would be called upon to chant a portion, while the community reader (koré) was there only to help out in case the layman made a mistake. This custom lasted for centuries and is still prevalent in Yemen. This is historical proof of the widespread familiarity with the ancient traditional modes, of their simplicity and of their folk-character.

The list of prominent precentors did not cease with the Bible. Names of famous mithpallelim throughout the ages have been preserved in honor and esteem, men who distinguished themselves not only as scholars, but primarily by their ethical and democratic personality. ${ }^{3}$ They enriched the Jewish ritual with wonderful prayers which they improvised in moments of inspiration. This custom of improvising prayers continued throughout the Talmudic period until about five hundred C.E. The most striking of these products of momentary inspiration were preserved. They spread among the people and became popular.

In the course of time, the collection of prayers grew into a ritual, preserved by memory, inasmuch as the writing of prayers was prohibited. ${ }^{4}$ Therefore, it became a hard task for the precentor to memorize the ritual and to recite the prayers according to their order. For this reason, two assistants to the precentor were ordered, and it soon became a rule that no precentor should function unless he had at least one assistant. $^{5}$ The task of the assistants was originally that of prompters. Gradually that post developed into that of a musical assistant. The two tomechim or mesayim, as the assistants were called, did not only help the precentor occasionally as reminders, but aided him in singing all the prayers. Although the writing of the prayers was later permitted (seventh century) and the assistants therefore became superfluous, the institution none the less continued and became the nucleus of 
the synagogal choir-singers. The first statements of the existence of assistants go back to the third century. ${ }^{\circ}$

The qualifications required of an honorary precentor were fixed in the second century by Rabbi Judah ben Illai in Palestine. It was the general opinion that though scholars and prominent men were present, only men familiar with the prayers and qualified for precentorship should be invited to officiate. Rabbi Judah described the one who could meet the requirements to be " "a man who has heavy family obligations, who has not enough to meet them, who has to struggle for a livelihood, but who none the less keeps his house clean (above reproach), who has an attractive appearance, is humble, pleasant to and liked by people, who has a sweet voice and musical ability, who is well versed in the Scriptures, capable of preaching, conversant with the Halaka (Law) and Jewish folklore (Agada), and who knows all the prayers and benedictions by heart." The possesson of a sweet voice, however, was regarded the most essential requirement. It was even considered as a heavenly gift bestowed upon the person through which to inspire the people to devotion. ${ }^{s}$

Much stress was laid upon the good pronunciation and distinct articulation of the precentor. Therefore, people with certain defects of speech were not allowed to function. ${ }^{9}$ A proper and clean garment was likewise required..$^{10}$ Physical deficiencies, such as blindness or deformities, were no cause of objection. ${ }^{11}$

As indication of reverence and humility in worship, the sages insisted that the precentor should stand on a lower level than the other worshippers, as the psalmist prays, "Out of the depths I cry to Thee" (Ps. I30: I). Therefore, the platform from which the precentor officiated was lower than the floor of the synagogue. ${ }^{12}$ This custom has been retained in many synagogues. Only for the reading of the Scriptures was there a 
Bema (elevated platform) in the center of the synagogue. ${ }^{13}$

Persecution and oppression changed the face of the Jewish world. In Palestine the severity of the Eastern Roman Empire was followed by that of the Christian Church. In Babylonia, the fanatical Magi caste, which controlled the Persian Rulers, laid its heavy hand upon the Jew also. Old centers of Jewish culture were ruined. The sages were killed in part and in part dispersed, and the continuation of study was interrupted, so that a short time after the conclusion of the Talmud, ignorance was prevalent in many of the communities in which, some generations before, Jewish wisdom and knowledge had flourished. No wonder that in the course of time there was scarcely a man to be found in some communities who was able to officiate as honorary precentor; and the need of a professional shaliachtzibbur became more and more urgent.

Later, another development tended toward professionalizing the post of precentor. The simple style of the ancient prayers continued, as we have already seen, until the sixth century, when attempts. were made to introduce more intricate poetical forms. After Islam's conquest, the metrical poetry called piyyut was created. This piyyut stimulated the creation of intricate music, both rhythmical and modal, the rendition of which required more musical talent than did the simple modes in use before. It necessitated rather professional singers who should devote themselves to studying and cultivating both the new texts and their tunes-a task which was impossible for the lay-precentor. Thus, on the one hand, ignorance, and on the other, the new artistic demands, created the professional precentor who received the name chazzan. ${ }^{14}$

This name is an old one transferred from the secular post of government officer, later care-taker (beadle) of the court of law or of communal affairs in general. Etymologically, chazzan is derived from the stem chazah-to oversee. In the last 
period of the second Temple, care-takers or beadles in general were called chazzanim. After the fall of the Temple and the collapse of political independence, the communal functions of chazzanim melted away; and only the Synagogue retained the chazzan as a beadle. Little by little, there was relegated to him the recitation of minor parts of the service. Yet, during the Talmudic period, the chazzan was never permitted to function as precentor or reader of the Bible in the public service, unless he was a learned man, conversant with the prayers, and might, like everyone else, be thus distinguished. But the time of distress in the sixth and seventh centuries compelled many communities, for lack of able men, to entrust the chazzanbeadle with the function of precentorship, inasmuch as he was always present in the synagogue. $\mathrm{He}$ was first permitted to read the weekly portions of the Pentateuch and Prophets and translate them into the vernacular, the Aramaic idiom spoken in Palestine and Babylonia at that time. For some time a distinction was drawn between the function of reading the Bible and that of leading in prayer. And still in the ninth century the partaking of the chazzan in the prayer was of a subordinate character. ${ }^{15}$

At the same time chazzanim reached an honored position and climbed high in popular esteem by merit of their personality and knowledge. Already toward the end of the first century, the chazzan Rabbi Zenon was recorded as having been an important personage in the court of Rabban Gamaliel in Jamnia. ${ }^{16}$ At times, a special benediction was inserted for the chazzan as one of the distinguished men in the community. ${ }^{17} \mathrm{~A}$ prominent chazzan was often compared to an angel, as he faced the congregation with the Scripture in his hand. ${ }^{18}$ These utterances and many others prove that the advance of the chazzan from beadle to precentor was due not exclusively to emergency, but also to the virtues of some of the leading chazzanim. 
Small congregations were only too glad to acquire a man who could occupy all the religious offices. In the eighth and ninth centuries, for lack of adults suitable for the post, congregations were compelled to entrust youths of seventeen or eighteen with the office of precentor. Amran Gaon, the author of the oldest ritual (siddur) known, in the ninth century, decided that in case of emergency even boys of thirteen should be permitted to assume this office. ${ }^{19}$

Early in the Talmudic period the service was divided between two officers. One was invited to recite the Shema including the benedictions connected with it. $\mathrm{He}$ as a rule used to sit among the congregants. After he was through, another man was invited to stand up before the pulpit facing the direction of Jerusalem to recite the prayer proper, i.e., the Amida (seven benedictions on Sabbaths and holidays, and eighteen on week days). On Sabbaths and Festivals the first precentor recited the morning-prayer (Shachrith), and the second the additional-prayer (Musaf). ${ }^{20}$ The office of the second precentor was regarded superior to that of the first. ${ }^{21}$ This custom has survived to the present day, and has influenced the song, in so much as the music of Musaf is greater in quantity and more elaborate than that of Shachrith.

The professional chazzan, even after he became the permanent precentor, could never replace the honorary precentor. The latter never vanished altogether from the Synagogue. Throughout the medieval ages and in some places down to our time, at special occasions, on fast days and High Holidays, prominent men of high ethical standing, rabbis or laymen, functioned as spokesmen and intercessors for their people. Concerning the outstanding of these we shall speak later (Chapters VIII and IX).

Together with the Psalms and parts of the Jewish ritual, the early Christians transplanted the institution of the precentor 
from the Synagogue into the Church. ${ }^{22}$ Just as in the Synagogue so also in the Church the solo recitation of the precentor became the chief part of the service. Similarly, the responsive form used in the Temple and Synagogue was adopted by the Church, especially short refrains such as Amen, Hallelujah, Hosanna. The singer was called cantor, præcentor, pronunciator psalmi ${ }^{23}$ Originally, in the Church, too, there was the reader (lektor) and the singer (cantor). The latter did not officiate in the Mass. As in the Synagogue so also in the Church an elevated stand was erected for the lektor from which place he read the Scriptures. However, gradually the precentor gave way to the choir; the choral and antiphonal song replaced the solo recitation. Thus, the precentor has vanished completely in some churches, and in some churches his rôle has been reduced to an insignificant function $;^{24}$ whereas in the Synagogue, the precentor preserved his importance in the service. 


\section{CHAPTER VII}

THE RHYTHMICAL SONG IN THE ORIENTAL AND SEPHARDIC SYNAGOGUE.

Music developed in two parallel lines: one accompanying bodily motions, such as marching, laboring, and dancing, for which it had to mark strict rhythm; and the other, the recitative or mode, independent of bodily motions, serving only as an interpretation of text. We find both types in the music of all nations, cultured and primitive. Some peoples, notably the Orientals, such as Hindus, Tartars, Arabs, and Jews, considered the free music, the modes, superior to the rhythmical; while Northern European nations developed the rhythmical music to a high degree, neglecting altogether the modal type. Though we do not know the state of the folk-song of the Northern European peoples before the eleventh century, we see clearly, beginning with that period and afterwards, the tendency to rhythmize even the unrhythmical modes. As an illustration we have the Gregorian chant, originally unrhythmical, taken partly from Jewish-Oriental song and partly from other Levantine sources, gradually reworked according to the taste of the European peoples through the moulding of it into some rhythmical forms, and finally through the use of its elements as themes for rhythmical art music. In the first centuries of their conversion to Christianity, these peoples, greatly influenced by the Gregorian chant, retained the modal forms for the songs that they created ${ }^{1}$ but gradually they emancipated themselves from the Catholic Church chant and started creating, in accord with their nature, the Northern European 
music. Even at so small a distance south as Southern Italy and Spain, not to speak of the Southern Slavs (Ukrainians, Bulgarians, Serbians), likewise, modern Greece, we find the free modal form more and more predominant. The folk-singers of these localities are able to improvise according to a certain modal scheme, while this ability is unthinkable in a Northern folk-singer. This phenomenon is due to the continuous large Semitic-Oriental influx that these countries received for many centuries.

From the psychological point of view it is questionable whether the rhythmical form is better suited to express the emotions of our soul than is the modal form. Rhythm leads inevitably to a fixed succession of measured tones, to a firm structure-to a stable logical expression of a sentiment-to melody. The hard encrusted mould of melody in which none of the tones can be changed is a means of preserving a sentiment. It may serve rather to reawaken a mood to which the composer gave a musical expression. It lacks the spontaneity of the improvisation of the modal form. "The continuous mechanical, pendular motion of rhythmical music was always annoying to the people. Although it was appropriate for marching and riding, yet at no time was it suited to and liked for expressive vocal music. Therefore the recitative is the beginning and the end of all genuine song, from the Psalmody of the Hebrews to the Gregorian chant, and from the Greeks to Richard Wagner." This statement is by Franz M. Boehme, an authority on German folk-song. ${ }^{2}$

Fixed forms of worship were considered by the Jewish sages of old a constraint upon the free stream of our sentiments. Thus they say: Do not make your prayers a fixed form, for he whose prayer is routine, can never attain the pulsating emotion of genuine supplication. ${ }^{3}$ Free, improvised prayers, such as were customary in Jewish worship (Chapter V), without (in) 
artistic forms of meter and rhyme, could not but be intoned in free, improvised modal music. This circumstance and the general Oriental inclination to unrhythmical song explain the predominance of the modal form in the Synagogue; while the complete absence of rhythmical music was, as we saw in Chapter I, due to the abolition of bodily movements and percussive instruments from the service.

The lack of the rhythmical element, though that element was accounted inferior, was certainly intuitively felt by the people all along. But as in so many similar circumstances in history, there was needed a stimulus from without to help the inner longing to express itself. Though already prior to the Arabic invasion attempts were made to compose prayers and hymns in certain metrical forms (Chapter V), yet, due either to lack of a model or to lack of inspiration, those efforts fell like sterile seed.

The Arabs, as a Semitic-Oriental people, were not differentiated from the Jews in their preference for modal music. Yet at the same time they developed secular rhythmical music for those of their poems which were accompanied by bodily motions. This poetry and this music made a great impression upon the Jews. The influence was enhanced by the political freedom which the Jewish people received from the same source. Gradually the Arabic type of verse and music was introduced not only into Jewish secular life but also into the Synagogue, so that by the tenth century we find poetry in Arabic meter together with Arabic melodies in the Synagogal service in Babylonia, Syria, Morocco, and Spain. Hence, rhythmical song among the Jews of the Orient became synonymous with Arabic music from that time on until the present day. An exception to this tendency to fall under the influence of rhythm, we find in the Yemenite Jews, who, though living in Arabic environment, accepted very few Arabic melodies. 
They seldom employ rhythmical music in their Synagogue song, altogether about nine tunes. They recite even those poems in the ritual which are based upon Arabic meter in the same traditional modes employed for the ancient prayers. On the other hand, in their home-songs (though these are religious in content) they have a rich treasury of melodies in strict rhythm, because these are accompanied by handclapping, dancing, and the beating of rhythm on little drums (Chapter XVII). This description holds also for the song of the Persian Jews. ${ }^{4}$

In the Eastern and Balkan countries, which remained under Christian influence and had but little or no contact with Arabic culture, the poetry continued to develop in the forms used prior to the Arabic era, namely in meters based on the number of words or accented syllables. (See Chapter V.) The highest development this type of poetry attained was in the compositions of Eleazar Kallir, who in all likelihood lived in Palestine or Syria in the eighth or ninth century. His poetry was carried over to Italy and Germany where it became a model and was imitated in form and style by local poets. (See Chapter VIII.)

Arabic meter-so Arabic tradition claims-sprang from the rhythm of bodily motions, such as the pendular beating of the blacksmith and the trot of the horse and the camel. ${ }^{5}$ Arabic philosophers and grammarians, however, coined names for the meter derived from grammatical terminology: such as $m u-f a-i-$ lun, fa-u-lun, fa-i-la-tun, etc. These terms were confusing, because, when correctly pronounced, their accents did not correspond to those of the verses that they designated. Hence, they conveyed the idea that it was the NUMBER of their syllables that determined the type of poetic form. The musicians, however, or the poets who were at the same time musicians, instinctively abided by the MUSICAL time value of the meter and 
cultivated those meters which lend themselves to strict time, while the other intricate meters were neglected.

Table XVI presents the musical formulæ of those meters with strict time: I. Hazağ U_- L. This foot has the first chronos (timeunit), a half syllable followed by three syllables, the last being prolonged. For Hazağ meter, the foot occurs twice. In case it occurs three times, the meter is called Wafir. The foot is called "Mŭfâ-î-lun." Its musical value is given in table XVI, I. The musical rhythm of the meter can be rendered in 4/4 measure.

2. Rağaz $\mathbf{U}_{-} \mathbf{U}_{-}$, repeated three times: mŭs-tāf-ĭ-lūn. This meter takes on the triplet character and is rendered in 6/8. (XVI, 2), having the character of the Greek iambic meter (twice).

3. Mutákarib U $\perp$ repeated four times: fă-ü-lūn. Its musical rhythm is $3 / 8$, and has, likewise, the triplet character. (XVI, 3.)

4. Ramal is a compound meter of $\perp U_{-\infty}$, which occurs twice, and

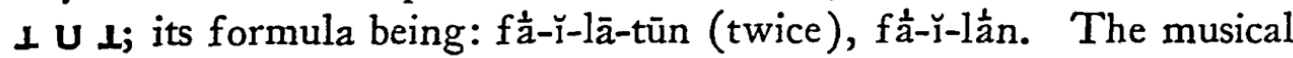
rendition of this meter, however, is in 2/4. (XVI, 4.)

5. Tawil is likewise a compound meter of --1 , which occurs twice and _-_-; its formula being: fā-ū-lùn (twice) and mū-fā-î-lūn. The musical measure is $4 / 4$. (XVI, 5.)

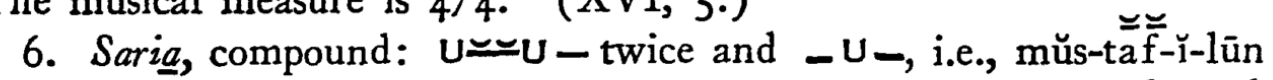
twice and $f \bar{a}-\bar{l}-1 \bar{u} n$. The difference between the Ra⿳̆冖az formula and that of Saria lies in dividing the second time-unit (the syllable $t \bar{a} f$ ) into two halves (ta-f), while the musical value of the unit remains the same as before. (XVI, 6.)

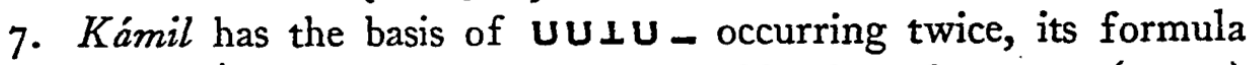
being mŭ-tă-fă-i-lūn. This meter is a combination of anapæst ( $\left.U_{-} U_{-}\right)$ and iambus (U-). Yet its musical rendition is in $4 / 4$. (XVI, 7.)

8. Basit is a compound meter of $\cup \cup \cup_{-}$and $\cup_{-} U_{-}$, using the terms mŭs-tăf-ı̆-lūn, fă- -1 -lūn in a different time value than in the previous meters. This meter must be rendered in the musical scheme of $5 / 8$ 4/8. (XVI, 8.)

Of these meters it was chiefly the first five that were adopted and used in Hebrew poetry, while of the others but little use could be made, because the Hebrew language does not lend itself to their forms. Even these five meters were frequently 


\section{TABLE XVI \\ Arabic Meters}

Hazağ $u_{-}-\dot{1}, u_{-}-1$

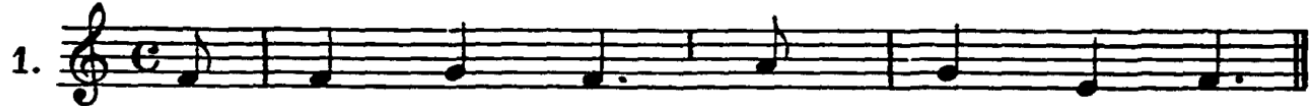

me - fa- ' $i$ - lun, me - fa- $i$ - lun.

Rağaz $\cup-\cup \perp, u-\cup \perp, \cup-\cup \perp$.

2.

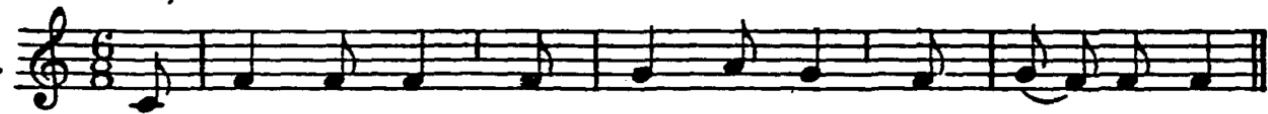

mus - taf - ' $\mathrm{i}-\mathrm{lun}$, mus - taf-' $\mathrm{i}-\mathrm{lun}$, mus - taf - $i \mathrm{i}-$ lun.

Mutákarib u_ı, $\cup_{-\perp,} \cup_{-} \perp, \cup_{-} \perp$.

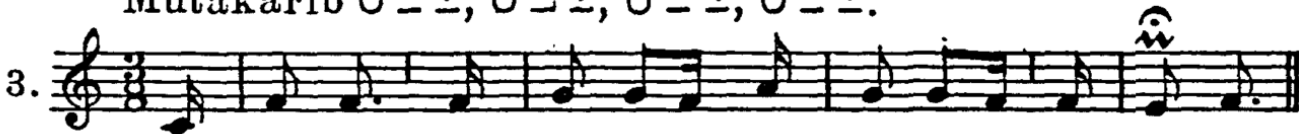

$f a-' u-l u n, f a-' u-l u n, f a-' u-l u i n, ' f a-' u-l u n$.

Ramal $\perp \cup \ldots-, \perp \cup \ldots, \perp \cup \perp$.

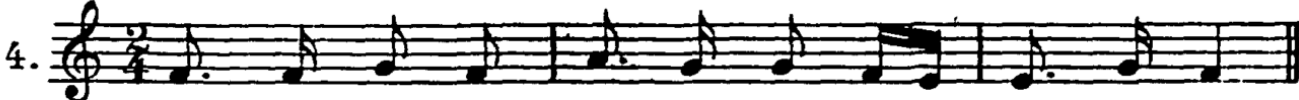

$f a-' i-l a-t u n, f a-c i-l a-t u n, f a-{ }^{\prime} i-l a n$.

Tawíl - - 1, - - - , - - , - - .

5.

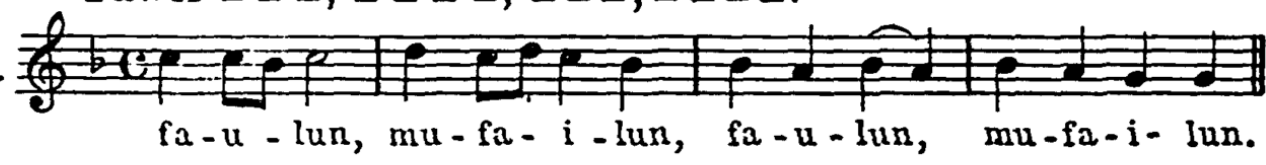

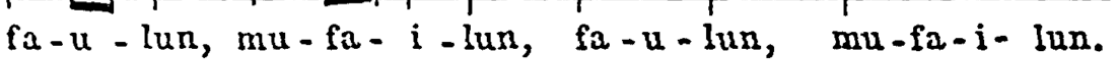

6.

Saria $v=u_{-}, u_{-}=u_{-}, u_{-}$.

6.

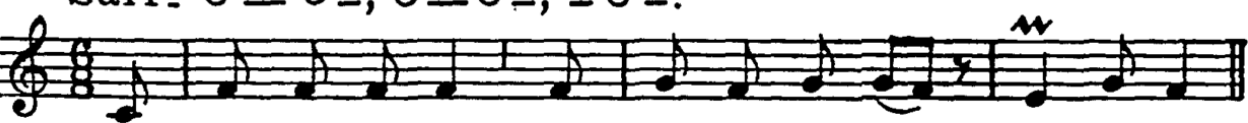

mus - ta - fe-'i - lun, mus - ta - fe-'i - lun, fa-'i - lun.

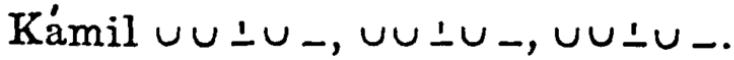

7. $m u-t a-f a-b i-l u-n e, m u-t a-f a-i-l u-n e, m u-t a-f a-i-l u n$.

Basit $\cup \cup \cup_{-}, \cup \cup-, \cup \cup \cup \cup_{-}, \cup \cup \cup_{-}$.

8. mus-taf-i -lun, fa-i-lun, mus-taf-i $i$-lun, fa-i $i$ - lun. 
altered to facilitate their application to Hebrew. The Hazağ meter (and Wafir) became the most popular one in Hebrew poetry, and it was the poetry in this meter most often selected for music. Many melodies in the Hazağ meter are retained in the Oriental Synagogue and we give in table XVII a few of the most popular tunes known in the Oriental and Sephardic ritual. The time of the tunes in the illustrations Nos. I, 2, 6, 7, 9, IO, I I, I2, I4, I 5, I6 corresponds exactly to the Hazağ meter of the poems, whereas in Nos. $3,4,8,13$ the TIME of the music bears no relation to the strictly Haza ğ meter of the poems. The poem in 5 is in the Wafir meter. Nos. 5 and 8 have the same text, yet the melodies are based upon different rhythms. Especially the poem in I (the famous hymn Adon olam) is set to innumerable melodies of various rhythms. The same is true of the text of 14-I6 (the famous hymn Lechoh dodi), a poem which received about two thousand musical settings. Table XVIII furnishes melodies to the well-known hymn Yigdal.

From the illustrations Nos. I-3 we see that the poem which holds strictly to Rağaz-meter (altered) is set to music unrelated in time. Likewise, the Mutakarib meter of 4 and 5 is ignored in the musical setting, as is the Kamil-meter of No. 6.

From these examples we learn that only melodies for poems in Hazağ bear the impress of its meter, and even there, in only a few cases; while in the case of melodies set to poems of other meters, no relation between the meter of the text and the rhythm of the music is traceable. Moreover, we find that PROSE texts are set to RHYTHMICAL music, as the illustrations in table XIX evidence. No. I is set to the Kaddish, No. 2 to Hashkivenu (a prayer in the evening service), No. 3 to Psalm 29, and No. 4 to a Selicha with alphabetical acrostic and wORD-meter (two words to the line). In this connection we 


\section{TABIE XVII \\ Melodies in the Hazağ meter}

a) Yemenite

1.

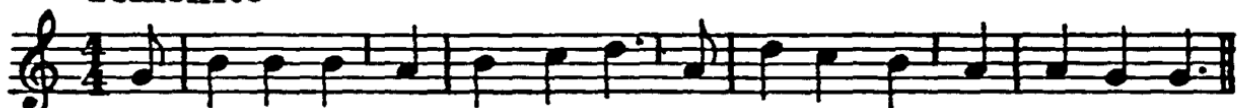

A -don o-lom, a-sher mo-lach, be - te-rem kol ye-sir nib-roh.

2.

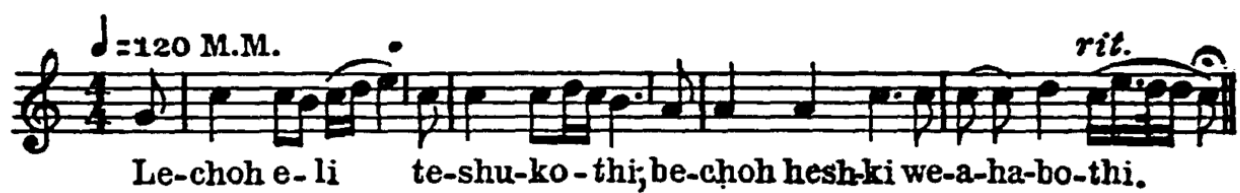

Le-choh e-li te-shu-ko-thi; be-choh hesh-ki we-a-ha-bo-thi.

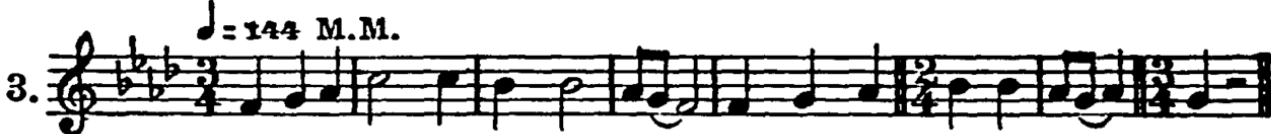

She-e el-yon be-kol eb-yon we-shaw-o - thi al yib - ze.
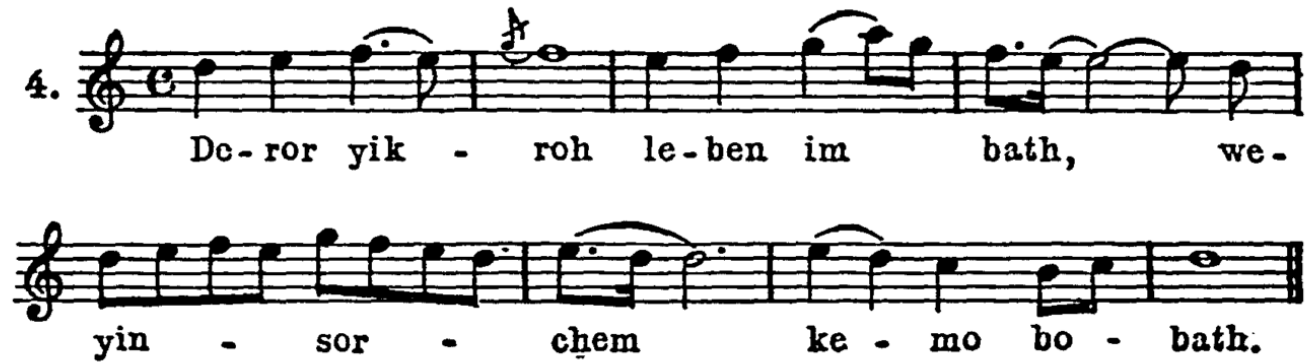

b) Babylonian
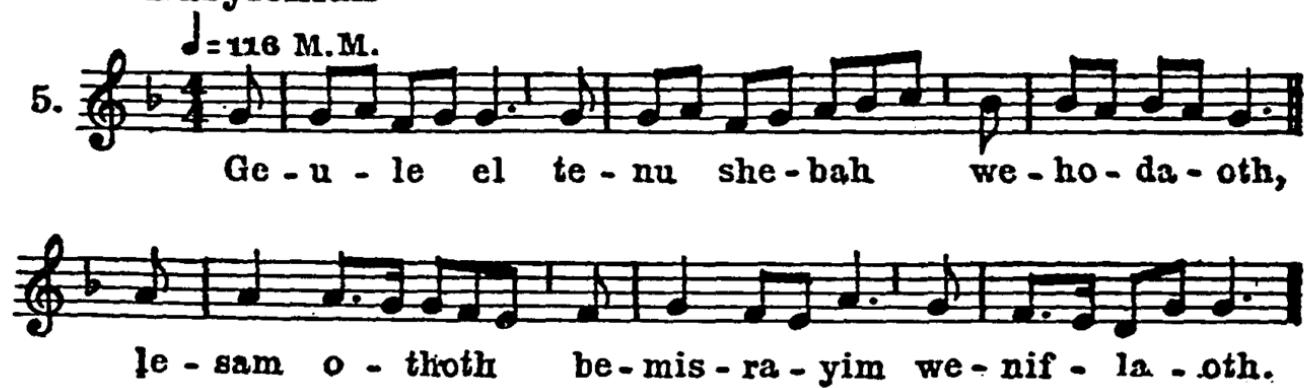
6.

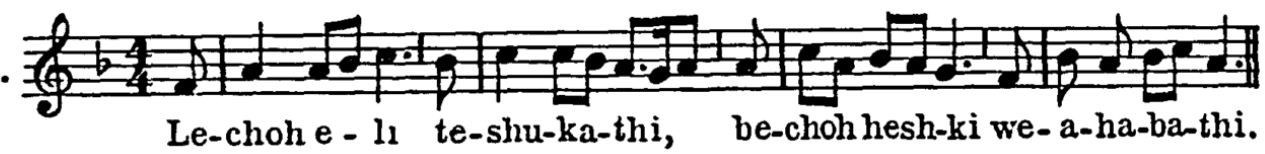

7.

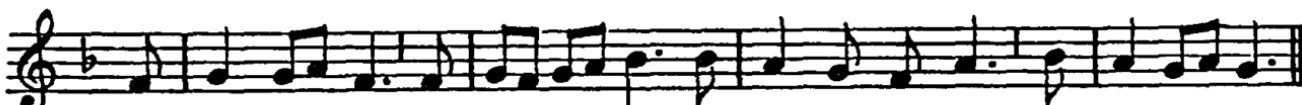
ke-me-lech at le-fa-ne-nu, ye-ba-re-che-chah e-lo-he-nu.

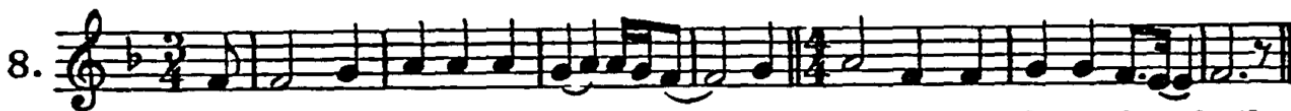
Dc-ror yik-ra lc-ben im bath we-yin-sor-chemke-moba-bath.

c) Sephardic

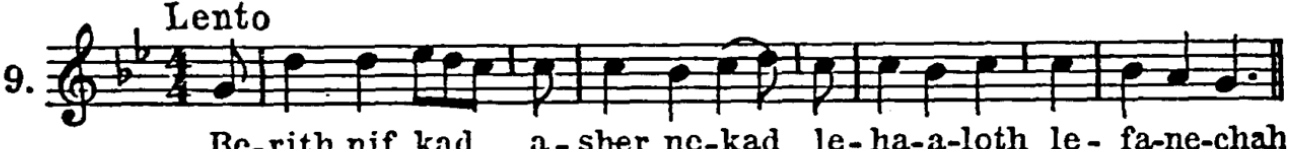

Be-rith nif kad a-sher nc-kad le-ha-a-loth le-fa-ne-chah
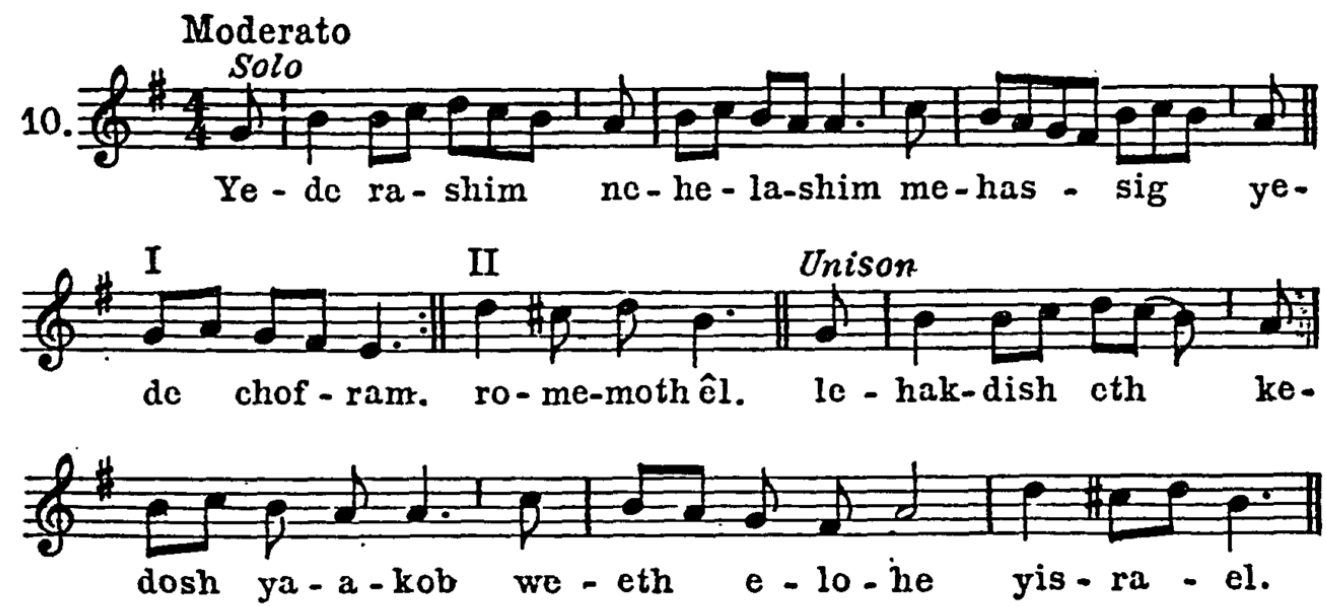
Sephardic-

Ye-de ra-shim ne-he-la-shim me-has-sig ye-de chof-ram.

12.

Sephardi

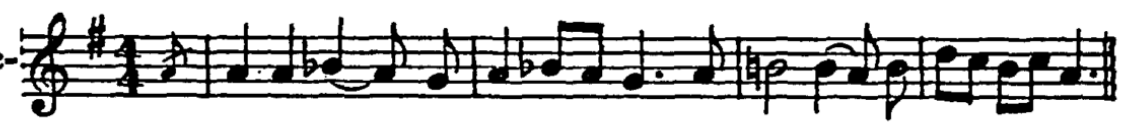

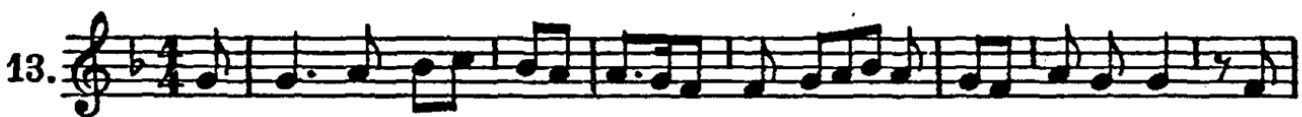
A - zam-mer bish - ba - hin
le-me-al go pi-the-hin de-

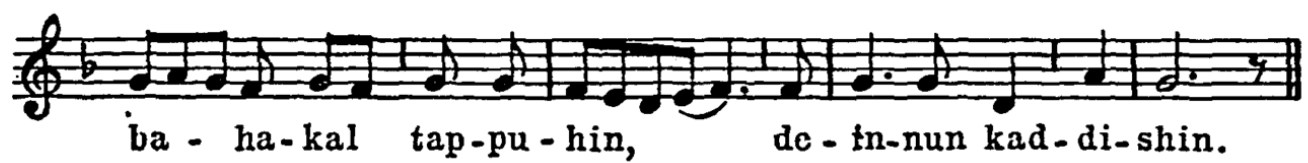

14.

Sephardic

Oriental

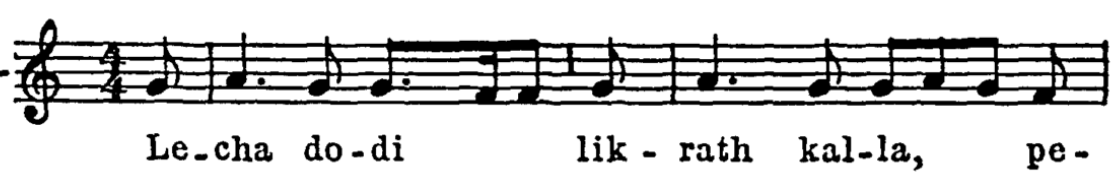

Scphardic- $\begin{aligned} & 15 . \\ & \text { Italian }\end{aligned}$

Italian

16.

Sephardic-

Amsterdam

14.

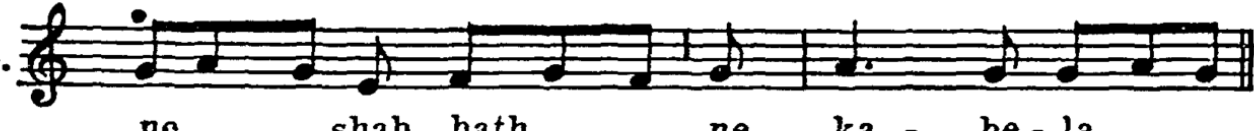

ne

shab - bath

ne - ka - be - la.

15

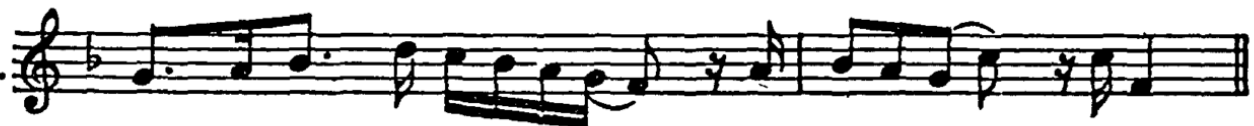

16

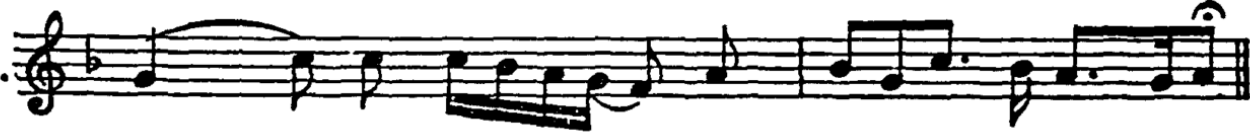




\section{TABLE XVIII \\ a) Melodies in the Rağaz meter}

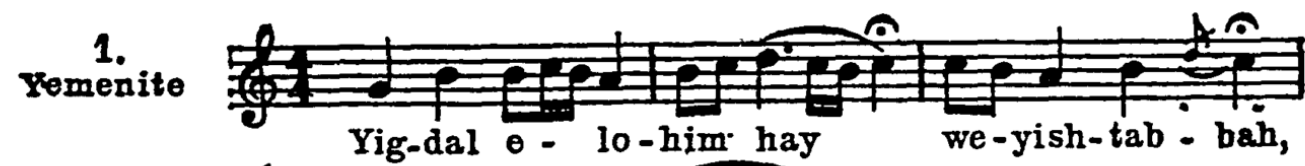

Babylonian

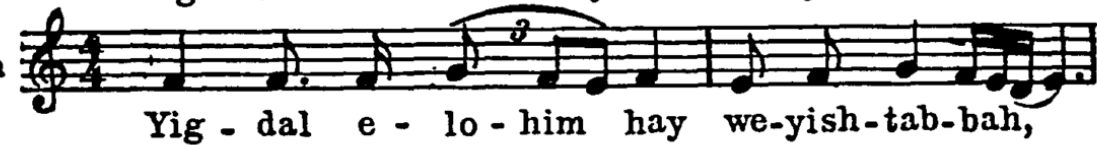

3. Sephardic

Oriental

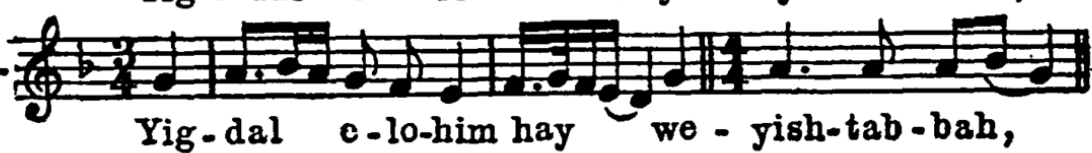

1.

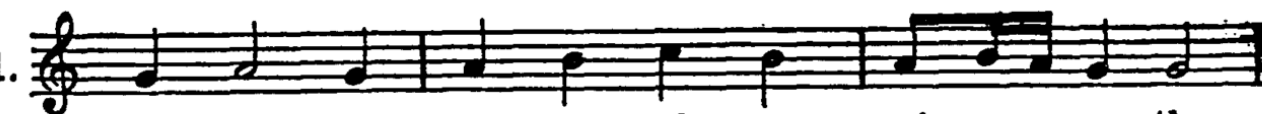

nim - sa we - en eth el me - si - u - tho.

2.

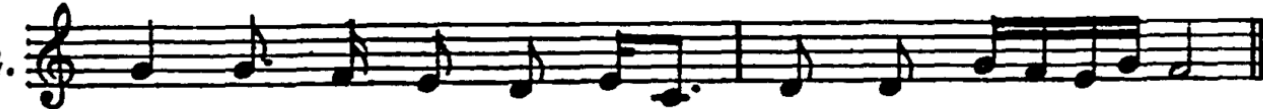

nim - sa we - en eth el me - si - u - tho.

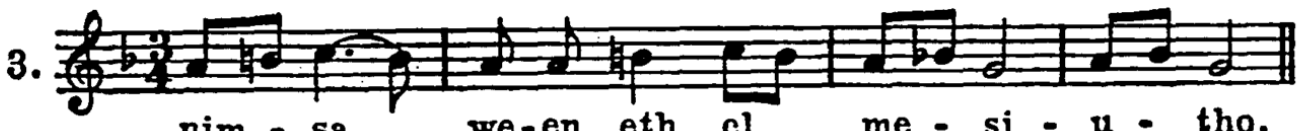

nim - sa we-en eth cl me - si - u - tho.

b) Melodies in the Mutakarib meter

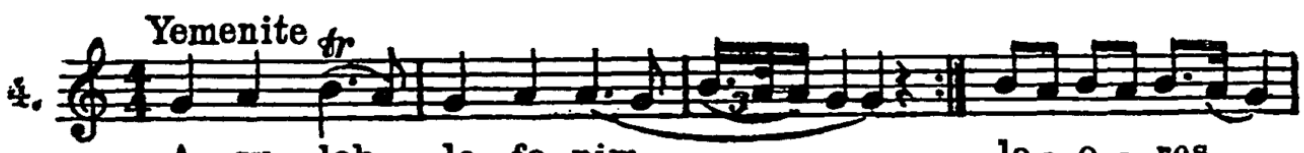

A-su - loh le-fo-nim

$10-0$ - res

be-chis-se

a - ro-both.

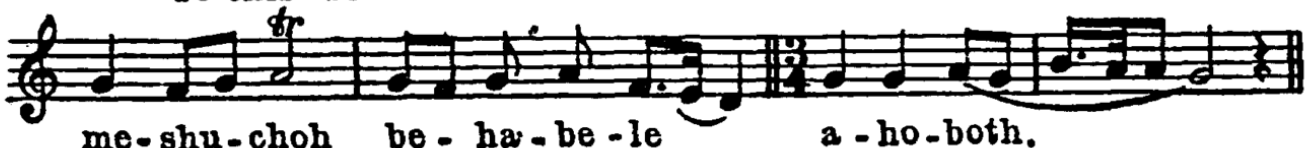

me-shu-choh be-ha-be-le

a - ho-both.

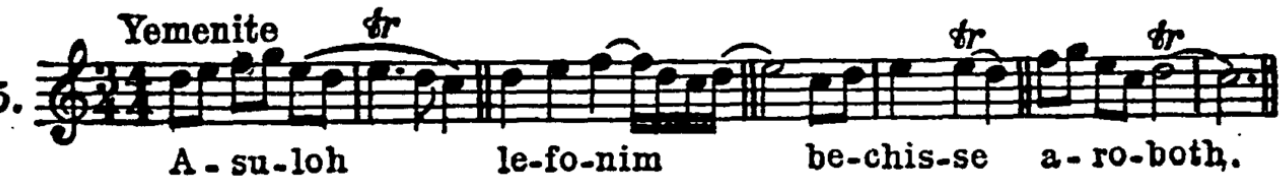

Persian

c) Melody in the Kamil meter

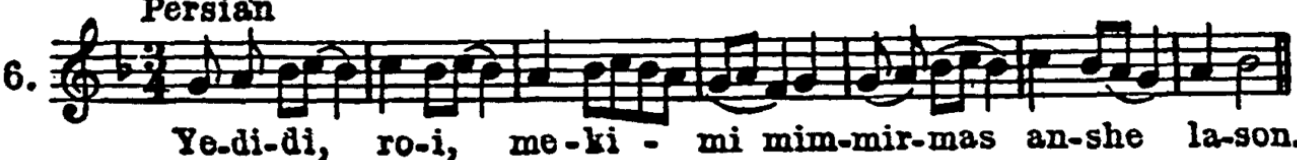




\section{TABLE XIX}

a) Rhythmical music set to unmetrical texts

Sephardic-Oriental

Andante

1. Yith-gad-dal we-yith kad - dash she-me

rab - ba.etc.

Andante

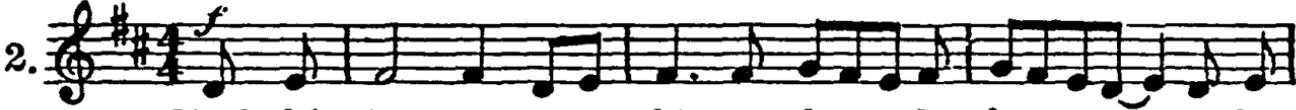
Hash-ki - bc-nu a - bi-nu lc - sha-lom we-ha-

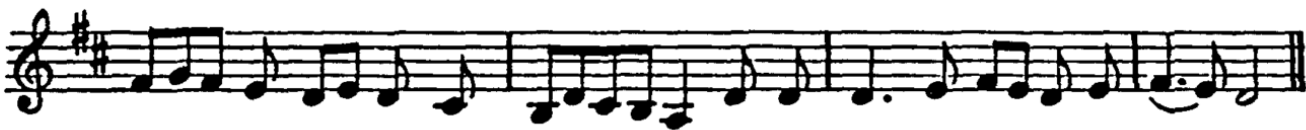

a - mi-de-nu mal ke - nu le-ha-yim to-bimu-le-sha-lom.

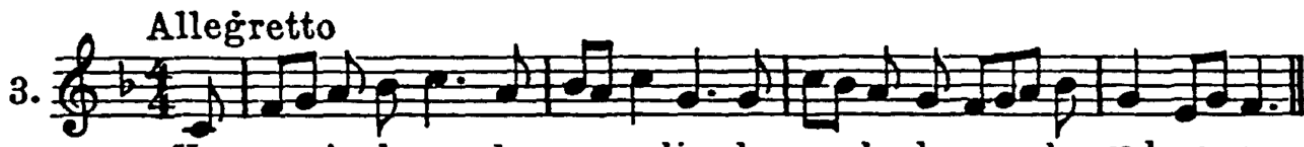

Ha - vu la-da-nay be-ne-e-lim, ha-vu la-do-nay ka-vod wa_oz.

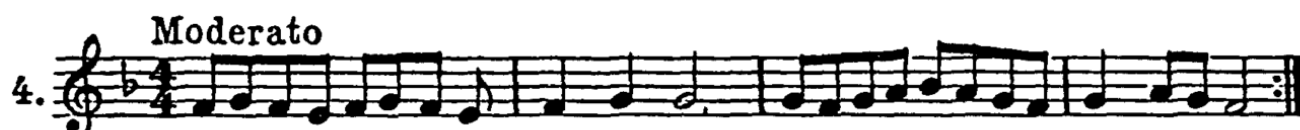

A - don ha-se-li-hoth, bo - hen le-ba-both.

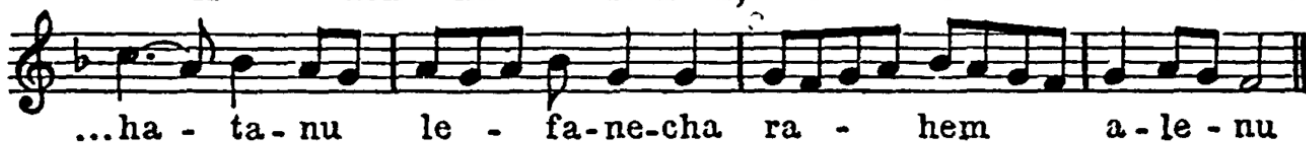

b) Unrhythmical music set to metrical text

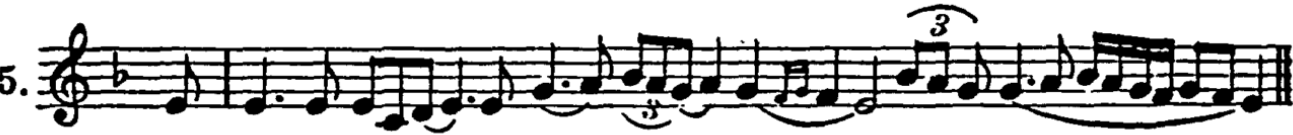

She-fal ru-ach, she-fal be - rech we-ko-ma.

ctc.
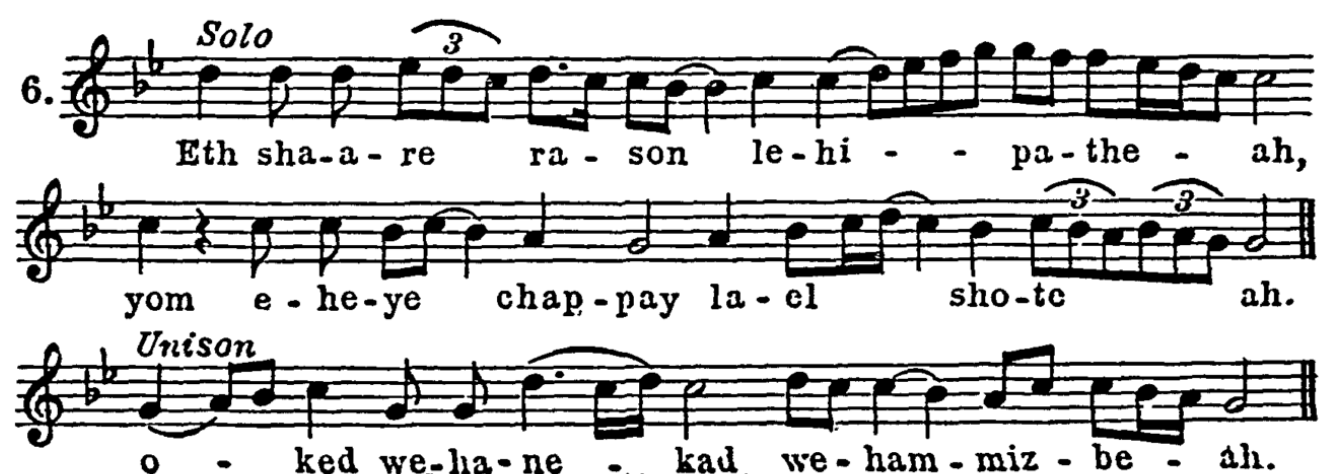


\section{TABLE XX \\ Adonay bekol shofar}

Sephardic-Oriental
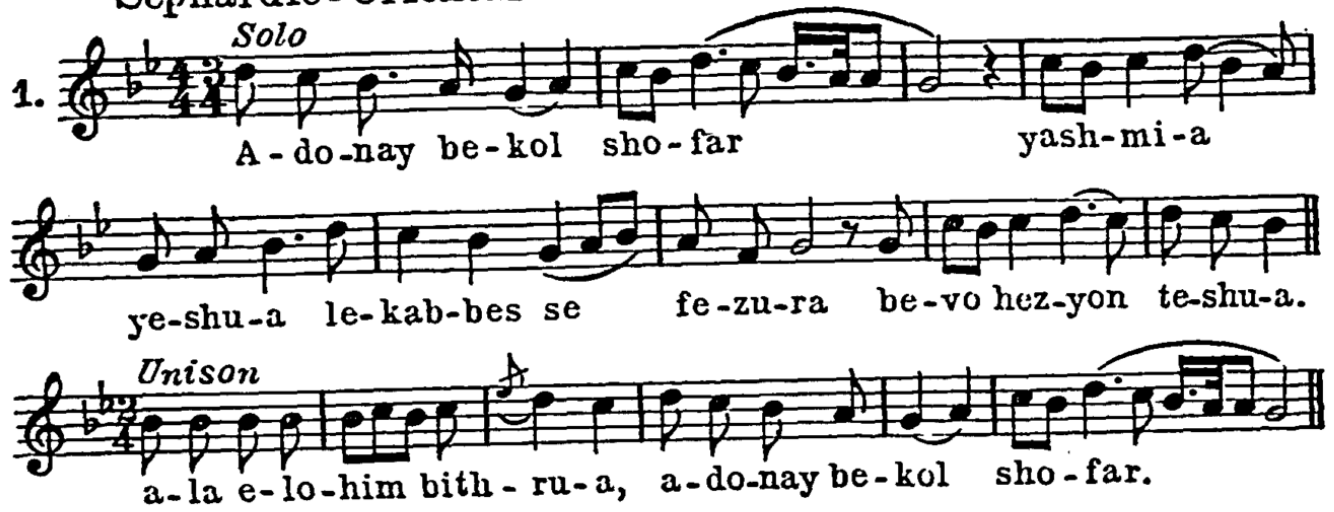

Moroccan
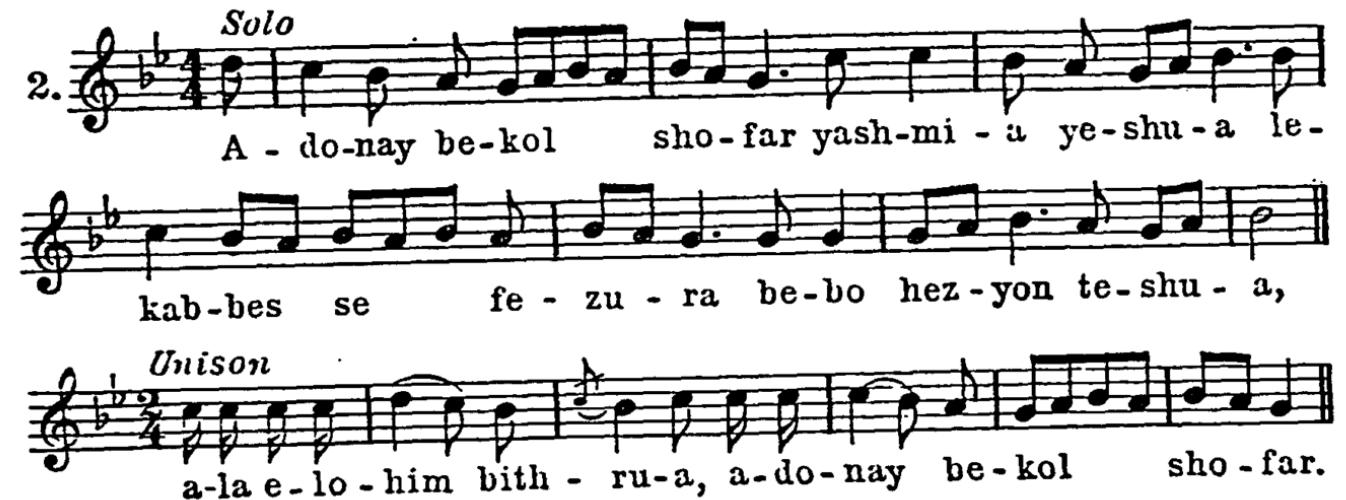

Italian
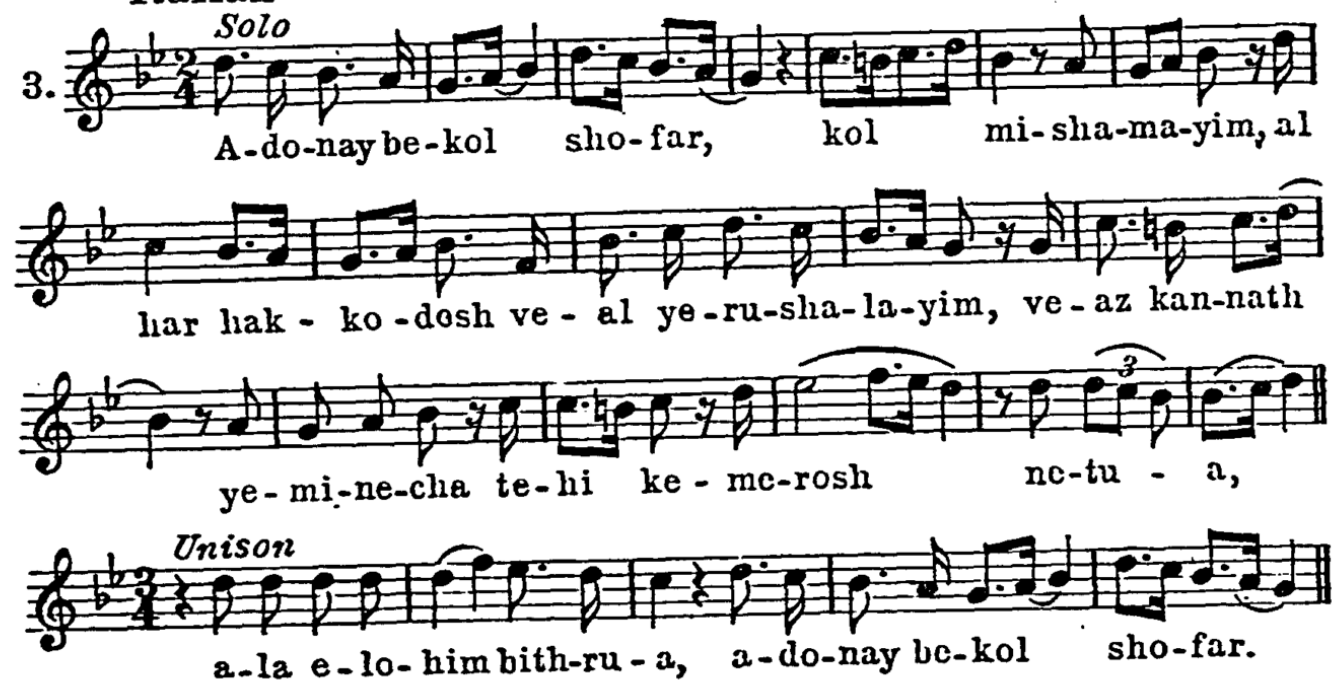
Sephardic-London

4. एक A - do-nay be-kol sho-far yash - mi - a ye -

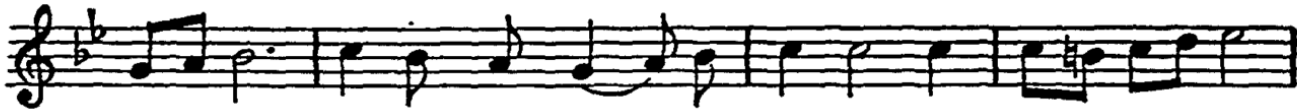
shu-a le-kab-bets se fe-zu-ra be-vo hez-yon

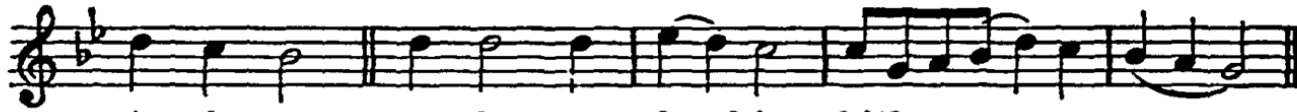

te-shu-a. a-la e-lo-him-bith - ru-a.
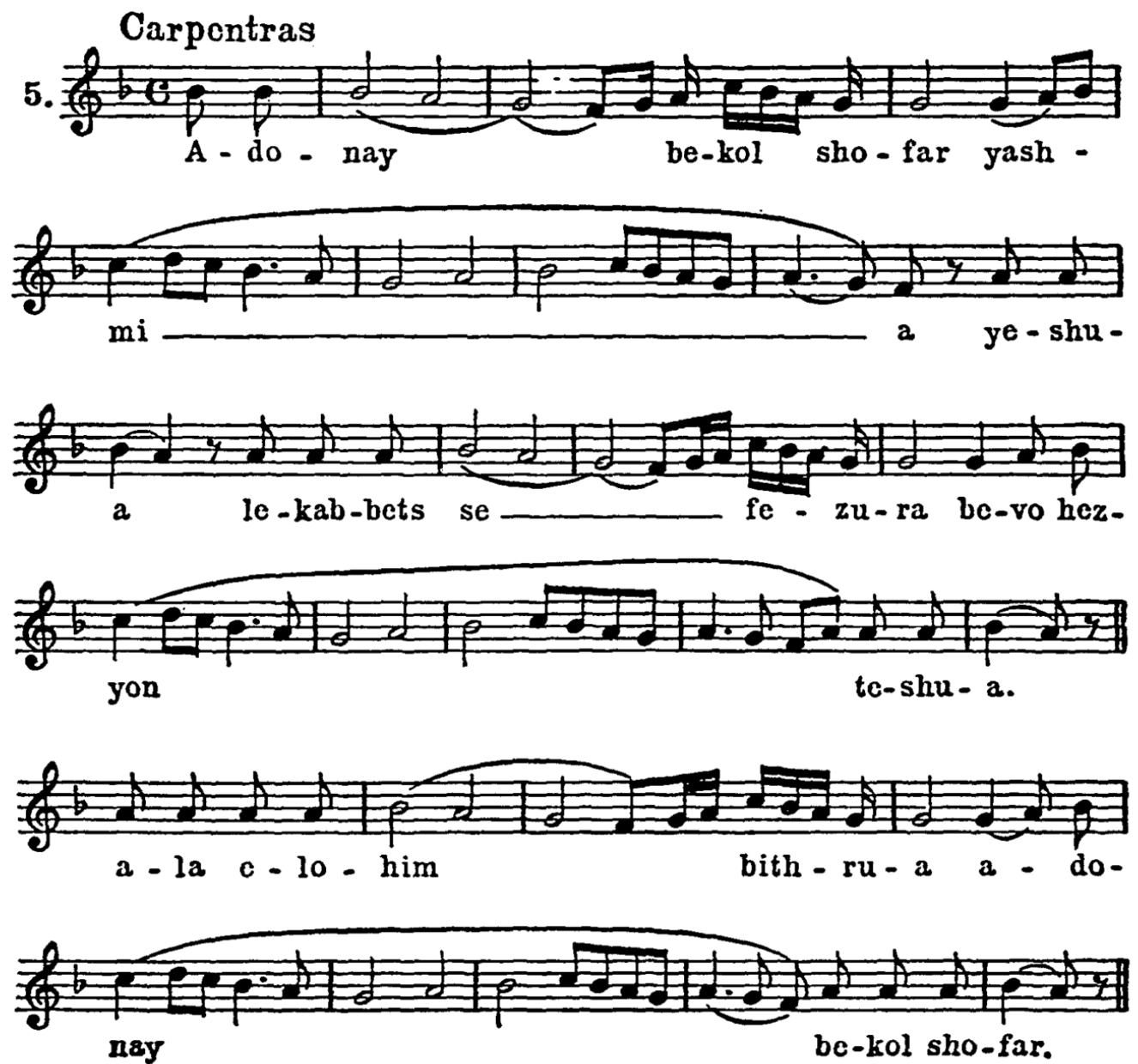
may refer back to table VI, 3, where the "Song of the Sea" is illustrated, set to rhythmical tune, based upon the Pentateuch mode.

It is therefore quite obvious that the Arabic meter, though it opened the way for rhythmical music in the Synagogue, did not remain the only moulding and determining creative power of rhythmical song. Rhythmical music, once established in the Synagogue, gained more and more ground; and rooted itself in Jewish song. It emancipated itself from the metrical impress of the poetry. It was Arabic tunes which were first adopted for the Hebrew poems based upon Arabic meters. This very procedure of adopting tunes, originally set to OTHER texts, developed in the people an appreciation of the Musical value of the melodies, apart from the text. There arose an esteem for music not merely as a tonal interpretation or echo of a certain text, but as a human expression independent of any text. Thus music attained in the eyes of the people a place equal to that of the text. Soon a melody was no longer adopted for a text, but on the contrary, a text was set to a popular melody and sometimes even, especially, composed for it. In this wise, the music became of greater importance than the text. Frequently poets would be inspired by a certain melody to write a poem according to its rhythm; others would adjust their verses to favorite tunes then in vogue, even when the poetical meter did not exactly fit the musical rhythm. There were many instances of attractive tunes originally for secular texts to which some rabbis, in their zeal to prevent the people's singing words of doubtful morals, would supply substitute texts of religious content, imitating the meter and even the sounds of the vowels of the secular texts. ${ }^{6}$

The chief factor in supplying rhythmical music and metrical poetry was the chazzan. His was the task to fascinate his congregation with new material. The week-day services, be- 
cause of the brief time that could be allowed them, permitted no poetical and musical embellishments. On Sabbaths and holidays on the other hand, when the people were free from work, it was the task of the chazzan to entertain them and to display his twofold art of poet and singer. Most of the chazzanim, from the tenth down to the fourteenth centuries, were like the "bards," the Arabic "singers" (Shuar), the French Trobadors, and the German Minnesinger, poetmusicians.

Gradually the traditional unrhythmical modes ceased to hold first place in the hearts of the people, who became interested mainly in singing, which now became synonymous with rhythmical song. A twelfth-century observer states ${ }^{7}$ that the prayers were recited by the precentor only, but that as soon as he started the Chazzanya (the chazzanic art, i.e., poetry and its music), the entire congregation joined in loud singing. Similar testimony reaches us from several authors before and after that time. So Yehuda Charizi, a Sephardic scholar and poet, who visited Mossul (Mesopotamia) at the beginning of the thirteenth century, leaves a satiric description of the "art" of the chazzan there, counting all his grammatical mistakes in the prayers as well as in his poetry; relating how the chazzan, self-satisfied with his artistic performance, exhausted himself and the congregation and wasted the time through his "art," so that no time was left for the ritual proper. When Charizi called the attention of the chazzan and his adherents to the mischief, they declared that his poetry and his music were more important than the prayers themselves. ${ }^{8}$

An opposition to this exaggerated emphasis on the poetry was inevitable. In fact, already early in the eleventh century we hear the opinion of great men like Hay Gaon (himself a poet), Isaac Alfasi, and Jehuda of Barcelona ${ }^{9}$ against too much use of poetry and Arabic melodies in the Synagogue. The op- 
position increased more and more, so that Maimonides was extremely antagonistic to all poetry and "music." ${ }^{10}$ The most that the opposition could effect was a check upon the poetry, to prevent its gaining a permanent upper hand in the service. Numerous poems and their tunes remain in the Synagogue to the present day. Among a vast number of aspiring poets there arose in Spain some very gifted ones: Solomon ibn Gabirol, Jehuda Halevi, who in theory opposed the Arabic meter, ${ }^{11}$ Moses and Abraham ben Ezra in the eleventh and twelfth centuries. They enriched Synagogal poetry with their deep religious spirit, some of their hymns reaching a height equal to that of the Psalms. And even as late as the sixteenth century some poets in Northern Palestine: Isaac Luria, Solomon Alkabetz, and Israel Najara were successful in making worthy contributions to Synagogal poetry. Najara was both poet and singer (chazzan). For some of his poems he composed his own melodies, but most of them were written according to the rhythm of popular Arabic, Turkish, and Spanish tunes. He was the last Synagogal poet (Chapter XVII), writing in Hebrew.

On the other hand, we see that rhythmical music not only did not displace modal music, but also lost out to its older sister, for the settings of even many metrical poems were intoned according to traditional modes or to Arabic Makams in free modal form. Aside from the above-mentioned Yemenite and Persian communities, even the Sephardic and Syrian communities sing poems based upon strict meter in free modes. The Synagogue song in Syria (Aleppo, Damascus) was Arabized more than that of other Mohammedan countries; and yet in these very Syrian communities, not only were the Biblical and Prayer-modes carefully preserved, but more than that, even metrical poems were interpreted in the genuine SemiticOriental modal form. Two illustrations of unrhythmical music 
set to metrical poems may suffice. The one (5) is a poem by the above-mentioned Solomon ibn Gabirol Shefal berech, which is founded upon the Wafir meter (altered). Its musical setting, however, is in the Tefilla mode (Chapter IV). The second (6) is a poem known in the Sephardic-Oriental ritual (Eth Shaare ratzon), of the twelfth century, in the Rağaz meter, while its music is in the Selicha mode (Chapter IV). In like manner we find many modal unrhythmical chants in the Oriental and even in the Italian tradition, which were molded in the Northern European communities of the Sephardim into rhythmical tunes, most likely influenced by the style and spirit of Northern European music.

The custom of adopting tunes from local Arabic or other music made a breach in the unity of Synagogue song, for until the rise of the piyyut (poetry) the traditional modes prevailed in the worship of all communities in the Diaspora. But since poets arose in various localities who composed poems, they selected local tunes for their products, or composed tunes in the style of the music of the people of their environment.

Nonetheless we find a number of tunes common in the various Sephardic communities in the East and the West, though with some variations. Table XX illustrates one of these common tunes for the poem Adonay bekol shofar. Whether these common tunes originated in the Orient and from there were carried by chazzanim to the scattered Sephardic congregations, or originated in Spain before the expulsion in 1492 , it is impossible to find out with certainty. At any rate nothing proves that these rhythmical tunes are Jewish creations, for though they have the general Semitic-Oriental features, they have no specific Jewish characteristics. No elements of Biblical modes are traceable in them, as in the earlier Ashkenazic tunes, which we shall treat in Chapter VIII. It is only in the SELECTION of the tunes that the Jewish spirit mani- 
fested itself, in choosing tunes based primarily on the minor and Dorian scales, expressing tender warmth and a calm dignity. We note no harshness; and we find but very few tunes in the Hedjaz mode. In the phlegmatic Orient, the Synagogue song of the Sephardic-Oriental communities remained stagnant in the last three centuries. Only the Italian Jews were stirred by the Italian Renaissance to renewed activity and creation. And this, indeed, for a short time only (Chapter $\mathrm{X})$, leaving their attempt to be continued by the youngest and strongest of all Jewish groups-the Ashkenazim. 


\section{CHAPTER VIII}

THE SYNAGOGUE SONG OF THE “ASHKENAZIM"

Ashkenazim are Jews living in Western, Central, and Eastern Europe and those Jews in America, Africa, Asia, and Australia who are descendants of them. Originally, only German Jews were called Ashkenazim (Ashkenaz: Gen. I0: 3 was considered Germany). ${ }^{2}$ The oldest Jewish settlement in Germany was in the Southwestern part, on the banks of the Rhine and Main. At the time of Charlemagne there already existed several Jewish communities in the German districts of his Empire. According to tradition, Charlemagne settled the Italian Kalonymos family in Mayence in the eighth century. ${ }^{2}$ He likewise imported a Jewish sage from Bagdad, Rabbi Machir, and placed him in Narbonne, Southern France. ${ }^{3}$ From that time on Jewish learning and tradition were transplanted into France and Germany. The Kalonymos family had a tradition that its ancestors came from Palestine and descended from Simeon Happakoli (who had phrased the eighteen Benedictions for Rabbi Gamaliel in Jamnia c. Ioo C.E.)." Similarly, another Rabbinical family in Southern Italy (Oria) preserved the tradition that its ancestors came to Italy from Jerusalem. Among the members of that family were poets and liturgists of importance. ${ }^{5}$ During the tenth and eleventh centuries the immigration of rabbis of the Orient into France and Germany, and from Italy into Germany, was considerable. These carried with them their Oriental traditions, which became the basis of the religious practices in both Germany and France. Thus "previous to rooo C.E. almost no difference 
existed between the Old French and the Old German rituals, because both were founded upon the Amram ritual." ' great commentator Rashi of the eleventh century says that "all our (religious) customs are according to Babylonian tradition." ? The same may be assumed with regard to the status of the Synagogue song, for, as we saw, the Biblical and prayer modes of the Ashkenazim are essentially the same as those of the Oriental communities. However, the close relations between the Jews and Gentiles in early centuries and especially during the reign of Charlemagne and his son Louis the Pious brought about a cultural reciprocity in which at first the Jews were more frequently those to exert the influence than those to be influenced. We learn this fact from the campaign which Bishop Agobard of Lion in his letters to Louis the Pious started in 825 against the Jewish influence upon the Christians, which in his opinion endangered the Christian faith. He complains that the Jews teach the Christians the principles of their religion; that Christians attend Jewish services and prefer the blessings and prayers of the Jewish rabbis; that Christians attend Jewish meals on Sabbaths and that Christian women rest on Sabbaths ${ }^{8}$ and work on Sundays; that Christians openly declare that they would like to have a lawgiver such as the Jews have; and that Christians have the audacity to announce that the Jewish religion is the only true one. In view of this fact, Agobard demanded that a prohibition should be issued to the effect that no Christian man or woman should attend Jewish services, nor observe the Sabbath, nor participate in Jewish festal meals, and that Christian people should stay away from the Jews. He demanded from the Emperor that he send out orders to all the bishops and priests in the Empire urging them to exert the utmost energy that with united effort the menace be removed from the Church. ${ }^{9}$

Judging from the zealous tone in which Agobard's letters 
are written, we may deduce that the Jewish influence was strongly felt; gradually penetrated into the mind of the clergy, and bore fruit. From that time on restrictions against the relations between Jews and Christians were issued, or old ones dating from the fourth to the seventh centuries were renewed, and at the same time the civil and human rights of the Jews were reduced until the Jews were declared strangers and dangerous individuals.

Of the song of the Germans, there are reports from the fourth century. Armianus Mercelinus (330 C.E.) calls their song whistling, squeaking, or a sound like that of wheels. In like manner Emperor Julianus (356-360) described the German song. ${ }^{10}$ And John Diaconus in the seventh century says that the Gauls and Germans are of all European peoples the most industrious in their study of art (Gregorian) song; but despite all their effort, they are the least capable of performing it, because of their barbarous state, their lack of ability to grasp it precisely, and their vulgar loud voices hoarse from drinking. They always mingle into the art song elements of their own folk-song. Their singing resembles the rumbling of a loaded wagon running down the slope of a hill. ${ }^{11}$ Charlemagne was the first prince who tried to cultivate art singing among his people, for which purpose he brought music teachers from Rome who established the singing schools in St. Gallen and Metz, both of which became centers for fostering and cultivating Gregorian chant and for developing music in Germany. Charlemagne issued the order in 789 that the people should be instructed to sing the Doxology, and Louis II in 856 urged the people to participate in responsive singing. Hence, on various religious and secular occasions and at daily occupations, the people intoned the Kyrie eleison in tunes improvised of Gregorian and folk elements, or they indulged in what was called Jubilations, i.e., protracted improvised singing without words, on the last 
syllable of "Halleluja." In 799 a decree was issued warning the people not to corrupt the Church-song. ${ }^{12}$ Such was the beginning of the creation of German and Gallic music, a combination of Gregorian chant and folk-song, out of which the song of the Troubadours and Minnesinger sprang, about the eleventh century.

Thus we see that prior to the tenth century the standard of music in France and Germany was still low. It is, indeed, no wonder that in the early centuries the Jews exerted an influence upon their Gentile neighbors, for their cultural standard was infinitely higher than that of the latter. We hear that about that time Christian clergy studied Jewish literature and Hebrew, and were instructed by Jews in the principles of Judaism as well as in the song of the Synagogue. Against this practice Archbishop Odo issued a prohibition in I 197..$^{13}$ Also from the Jewish side there arose opposition, in the twelfth century, against the exchange of Synagogue and Church melodies or hymns. ${ }^{14}$ A Jew was forbidden to teach a priest or a gentile layman a tune of the Synagogue. In like manner, it was strictly forbidden to let a Christian nurse sing to a Jewish child a Church song lullaby. ${ }^{15}$ We learn from the same source that Jews used to study Christian liturgical books and to sing from them. ${ }^{16}$ We hear also that Rabbi Simeon the Great in the eleventh century adopted a hymn for himself, the tune of "Magdala," which he was taught in his dream and which was supposed to be similar to the song of the angels. ${ }^{17}$ On the other hand, we hear that even in the fifteenth century Christians and even dukes with their courts used to attend services in the Synagogue. ${ }^{18}$ From these facts we see that restrictions and prohibitions, crusades and persecutions could not stop the reciprocal relation which persisted between Jew and Christian from the ninth down to the seventeenth century. Joseph Hahn, a rabbi and cantor in Frankfort in the seventeenth cen- 
tury, complained that Jews adopt Christian tunes for their Sabbath home songs and justify their act with the excuse that the Christians had borrowed these tunes from the Temple of Jerusalem. ${ }^{19}$

In view of all evidences presented, it is quite natural that motives of German folk or sacred songs crept into the song of the Synagogue in Germany. Especially since and during the development of the Minnesong (eleventh-fourteenth centuries), in which art Jews took part (see below), it was inevitable that German music should leave its impress upon the song of the Jew, that the Jew's spirit should be imbued with the musical scale and style of his surrounding.

With regard to scale we have pointed out on several occasions the German influence in re-shaping it, as in the case of the Pentateuch, Ruth, Song of Songs, and Tefilla modes (Chapters III-IV). Likewise, German music affected the reshaping of the tetrachordal form of the mode of Lamentations into a melodic line in which the third and fifth are pronounced (Chapter III). The influence went much deeper; it touched the very marrow of Jewish song. As already mentioned, German elements penetrated into the Semitic-Oriental song of the Jews and, by amalgamating with it, became an organic part of it. Thus a new type of music was created in the course of time, a Judeo-German song, which became the genuine expression of the German Jew. Here for the first time since the Hellenistic period two conflicting elements met and were merged and moulded into one. In such cases, the stronger element usually gains supremacy. Here, both being powerful, gave birth to a new creation: the unique "Ashkenazic song," while the Oriental Synagogue, continuing to draw musical nourishment from Semitic-Oriental sources, was spared a similar clash.

The Oriental rabbis who settled in Germany, coming via 
Italy and France, were also precentors, chazzanim, and paytanim (poets). For example, there were Kalonymos and his son Meshullam from Italy and Simon bar-Abbun from France. Kallir's poetry (Chapter VII) was introduced into Germany and served as a model in style and meter for new creations. Almost all the rabbis in the period of the tenth-fourteenth centuries composed poems and hymns for the Synagogue and functioned as precentors either permanently or, at least, on feast and fast days. They would create or adapt tunes for their poetry in a FolK-Manner, that is instinctively. Some of these tunes would gain popularity and spread throughout the German congregations; others, of less attraction, would fall into oblivion. The popular tunes, as a rule, would conquer the heart of the Jew by reason of the preponderant proportion of the Jewish over the German elements of which they were composed. In very rare cases pure German tunes without any Jewish flavor became popular in the Synagogue, at least in the earlier period mentioned. As soon as a tune succeeded in becoming popular, it would be imitated; and generally other texts would be written according to its rhythm-a procedure customary in the Occident as well as in the Orient. ${ }^{20}$ As a result of this practice, the Synagogue, like the Church, has infinitely more poems and texts than tunes.

Aside from the tunes of metrical texts, i.e., of poetry, the Ashkenazim created special tunes for several prose-texts of the old prayers. In the Oriental Synagogue, these prayers were and still are chanted in the traditional modes (Chapter IV). Indeed, in the Ashkenazic Synagogue, too, these texts are chanted in the same modes in the daily service. However, for religious reasons the idea was conceived by the Ashkenazic rabbis, to express the significance of every holy day by distinctive tunes, and to consecrate special melodies to each occasion in order to create the distinctive atmosphere for that day. 
To achieve that aim the regular daily prayers were set to special tunes or modes for various distinguished days, with the aim of giving tonal expression to the underlying idea of the day by a LEADING MOTIVE or mode or tune assigned to it. Thus, the leading motives for New Year express reverence and awe for the Day of Judgment; those for the Day of Atonement-pleading and contrition; those for the Three Festivals - joy and hope, liberty, exultation and thanksgiving; those for the Day of Destruction express mourning; and so on. Upon entering the house of worship on one of these days, the Jew was inspired by the dominating mode or melody which reminded him of the purpose of the day.

Of course, it is impossible and futile to pass judgment as to whether these tunes are capable of calling forth in our days the ideas and sentiments they are supposed to express, since so many centuries have passed from the time of their creation, and inasmuch as they have become traditional to the Ashkenazim, deeply rooted in their soul and associated with religious sentiments in general and with the holy days in particular. The fact that only these out of many tunes became traditional and popular would point to their combination of Jewish and German material as the reason for their preservation. Those tunes were selected which appealed to the German-Jewish taste. They were singled out of a multitude of tunes which the rabbis-chazzanim throughout the centuries attempted to introduce into the Synagogue.

The idea of special modes and tunes for prayers in prose to be used on holidays is not an original Ashkenazic one, for the Oriental Synagogue, too, practices the same custom. The Yemenites have a special mode for the High Holidays, which is a variation of the Selicha-mode (table XIII); the Sephardim use the Tefilla-mode for the High Holidays only and possess several tunes for various festivals, as pointed out in Chapter 
VII. However, none of the communities succeeded in creating a new musical genre of "special tunes" as did the Ashkenazim. These tunes were sanctified and were called "sacred melodies" or scarbove-a corruption of the Latin sacra. They were also called Missinai-tunes, which means "received by Moses on Mt. Sinai. ${ }^{21}$ The birth-place of these Missinai-tunes was Southwestern Germany in the old communities of Worms, Mayence, Speyer, and the Rhineland, those places which were for several centuries the center of Judaism, and from which Talmudic Judaism was spread throughout Central and Eastern Europe. There was the cradle of the so-called Ashkenazic ritual, and there lived those sages who were also poets and chazzanim.

In Chapters III and IV we have treated those Biblical and prayer-modes common in the Ashkenazic as well as in the Oriental and Sephardic tradition and we have pointed out the changes the Ashkenazim introduced into them. Therefore we shall deal here with the part of Synagogue song which the Ashkenazim created. On examination we find that this musical material can be classified in (I) Modes, (IIa) in set tunes partially rhythmical and partially unrhythmical, and (IIb) in rhythmical melodies. We shall make an attempt to explain their elements and characteristics and the time of their composition.

Early Hebrew literature makes but scanty reference to its authors. Seldom is mention made of the name of the writer, and more rarely of the incidents of his life. It seems that Jewish sages did not consider it very important to acquaint the public with their personal affairs. From the eighth or ninth century on, the custom arose for poets to weave their names into their poems in acrostics. In the melodies there is no hope of finding any names, because Synagogue music was preserved by 
memory, and only beginning with the sixteenth century were attempts made to write it down (Chapter XVI).

However, if there is no prospect of discovering the names of the composers, there is a way of finding out the time that the songs were created, taking into consideration their style and the elements out of which they were composed. This we can achieve by means of comparison and analysis.

\section{Modes or Steiger in Minor (Table XXI)}

a. In character and form these Ashkenazic modes or Steiger, as they were called, ${ }^{22}$ are similar to the old Oriental modes. They are constituted of a group of motives, and are used in free fluid form for the intonation of certain texts. We differentiate modes as follows:

Mode I (XXI) is founded upon the Prophetic and Mogen-Ovos modes, and it is used for the evening service of the Three Festivals, including the Hakafoth (procession) service of Simchath Torah (Rejoicing in the Torah). It has five motives; 1,2 , and 4 are from the Mogen-Ovos mode (table XIV, 1-2); 3 , in its beginning is from Mogen-Ovos, while the ending is derived from the Prophetic modethe athnach-motive-and 5 is taken from the sof pasuk-motive of the same mode.

(2) The Tal-and Geshem (dew and rain) mode is closely related to I, and consequently to Mogen-Ovos. It has practically all the motives of $\mathrm{I}$, and it has two motives (4-5) in addition.

(3) The mode for SabBath Mincha (afternoon) service is likewise related to I and 2. It has besides, the tebir-motive from Esther (3) and the zarka-segol motive from the Prophets (4-5). These last three motives are very much in use in the Ashkenazic modes and tunes, and we shall meet them often in the course of our discussion.

(4) The Tefilla mode for the High Holidays has motives I, 3, and 4 , found in the modes already explained, and is derived from the Prophetic-mode, from which source also 5 (darga-motive) is taken, 


\section{TABLE XXI}

\section{Ashkenazic Modes in Minor}
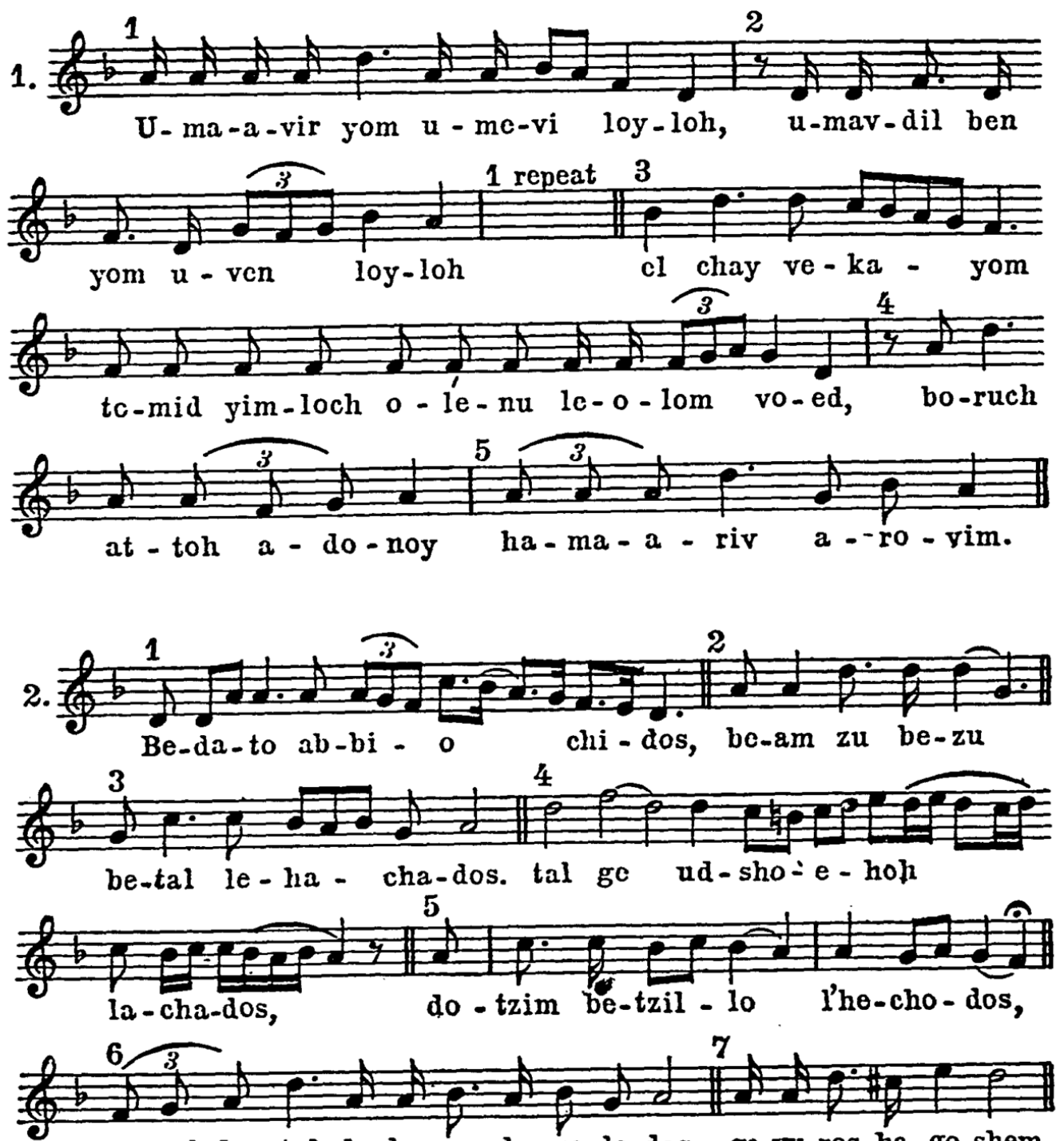
os yal-dus tal le-ho-gen le-so-lo-dos. ge-ru-ros ha-go-shem.

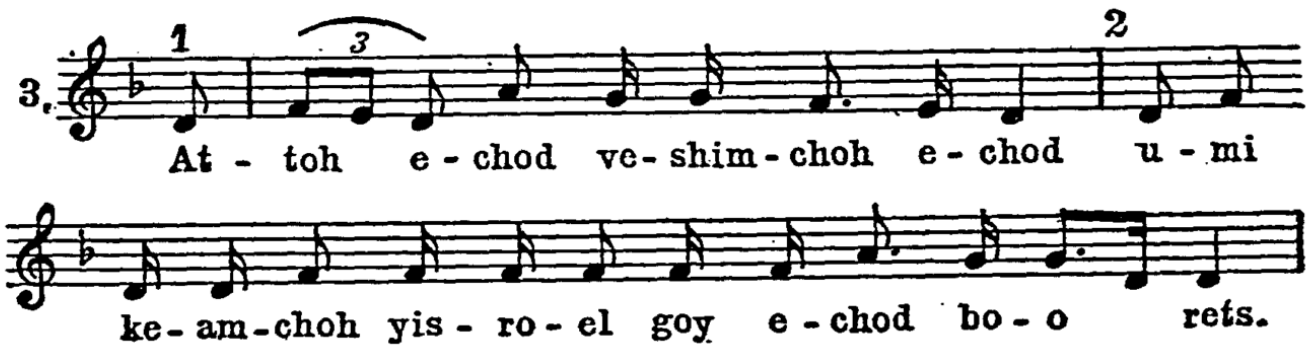




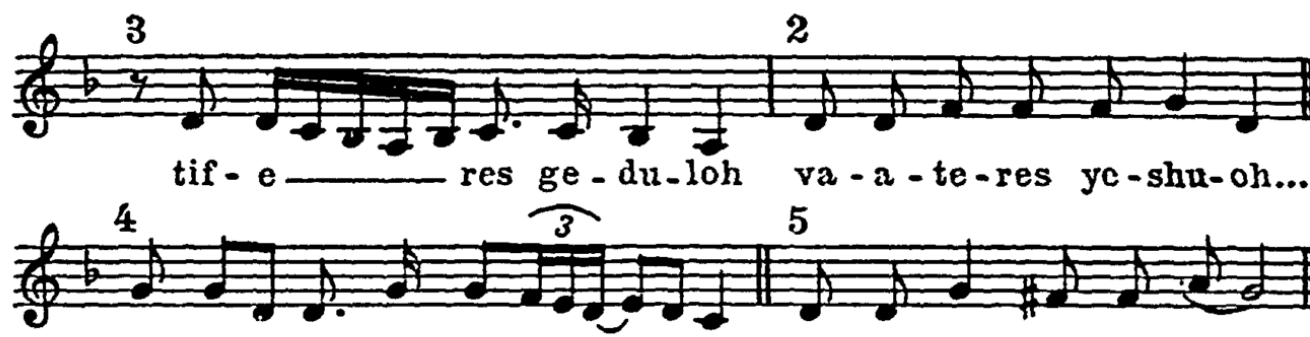

yak-di-shu she-me - - choh...me-ka-desh ha-sha-bos.
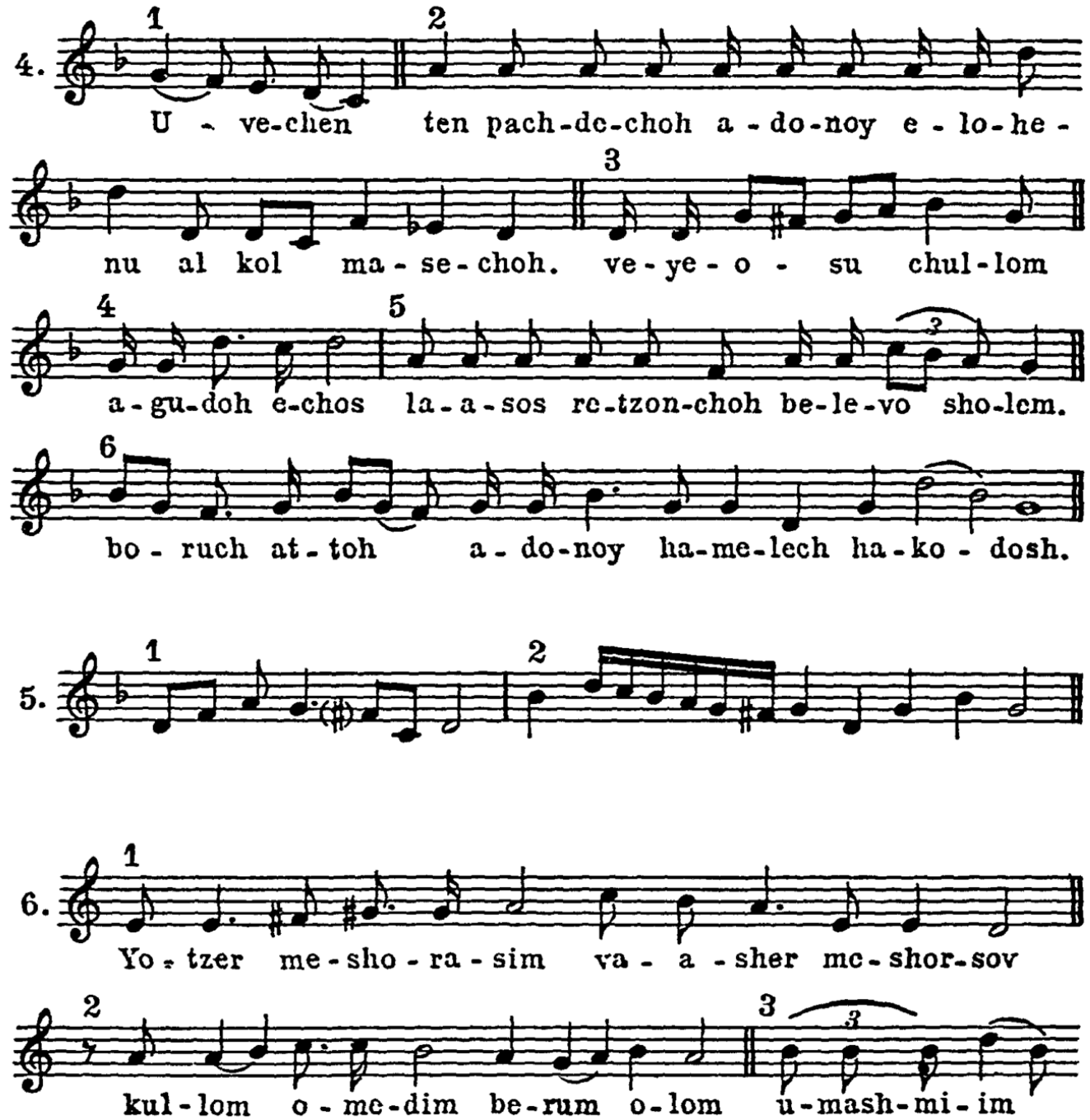

4

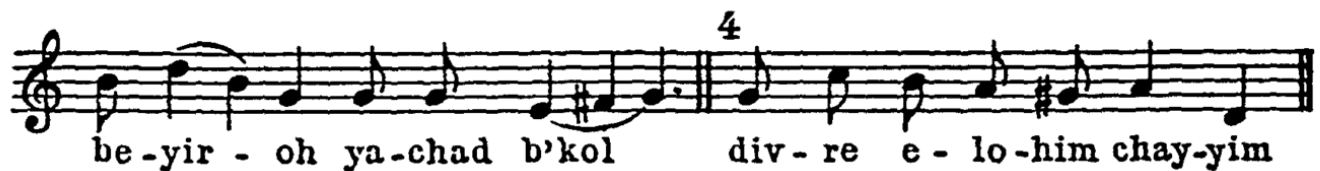



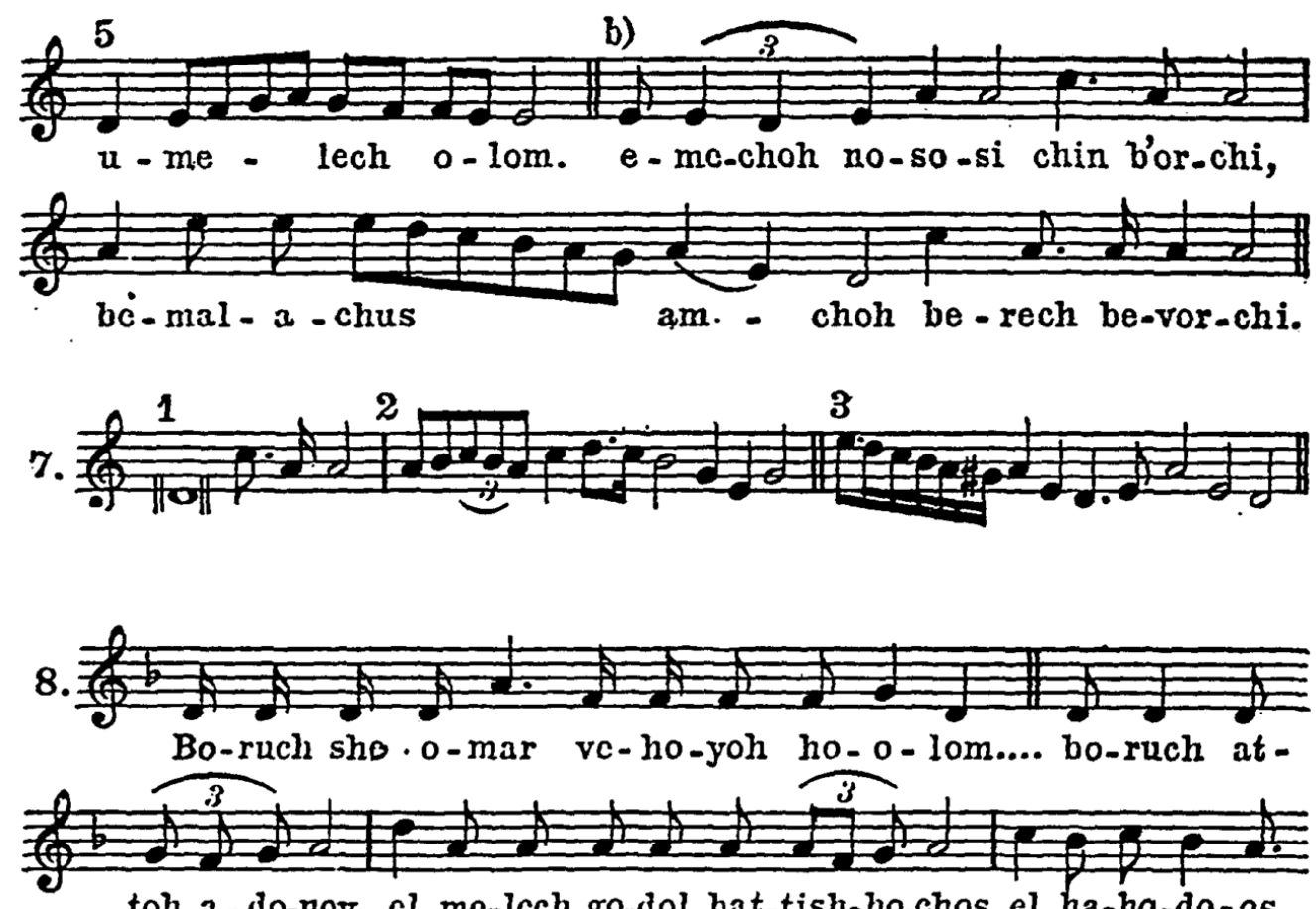
toh a-do-noy, cl mc-lcch go-dol bat-tish-bo-chos, el ha-ha-do-os,
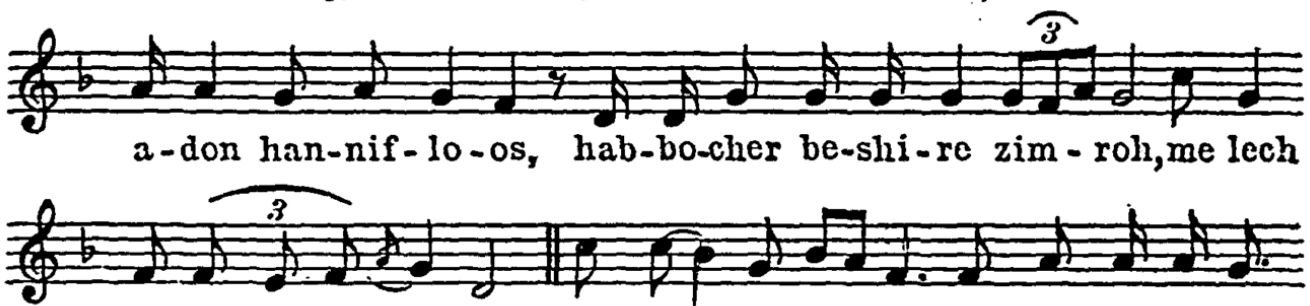
cl chey ho-o - lo-mim...kul-lom a - hu-vim, kul-lom be-ru-rim,

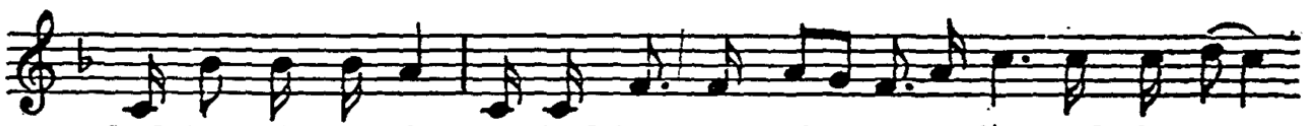
kul-lom gib-bo-rim...vc-chul-lom pos-chim es pi-hem bik-du-shoh

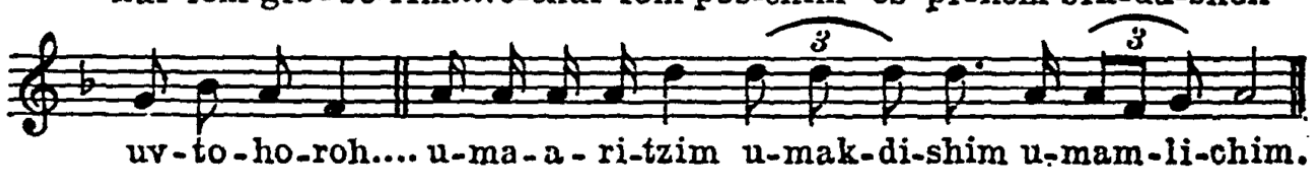

L. SÄNGER

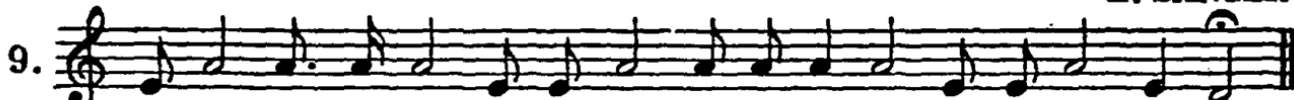
She-ma yis-ro-el a-do-noy e-lo-he-nu, a-do-noy e-chod.

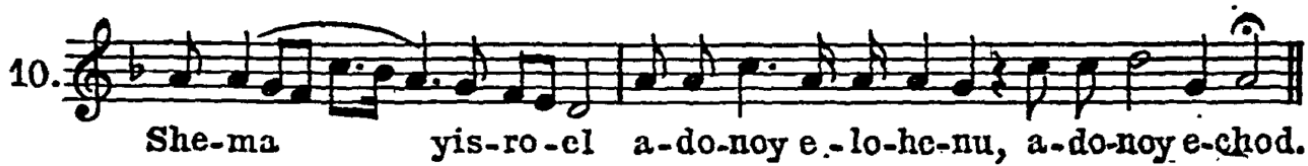



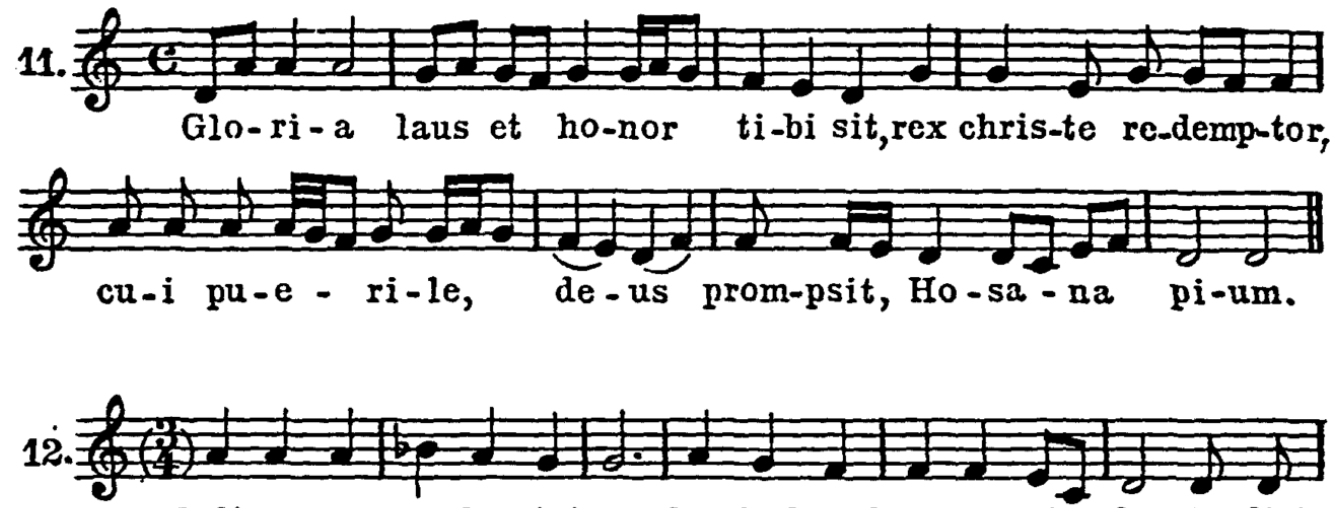

Golt von a - ra-bye ist gut, Daz darb auch nc-man stra-fen Swe-lich

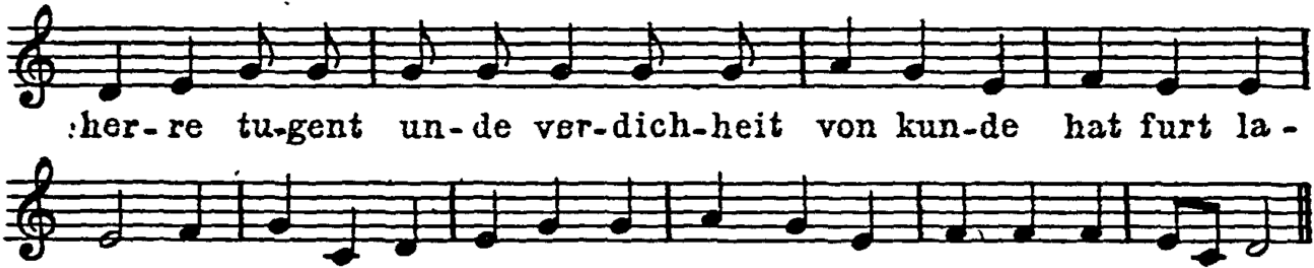
sen.Kant ich in by na-monich wolte in schcl-ten daz iz klvu-ge.

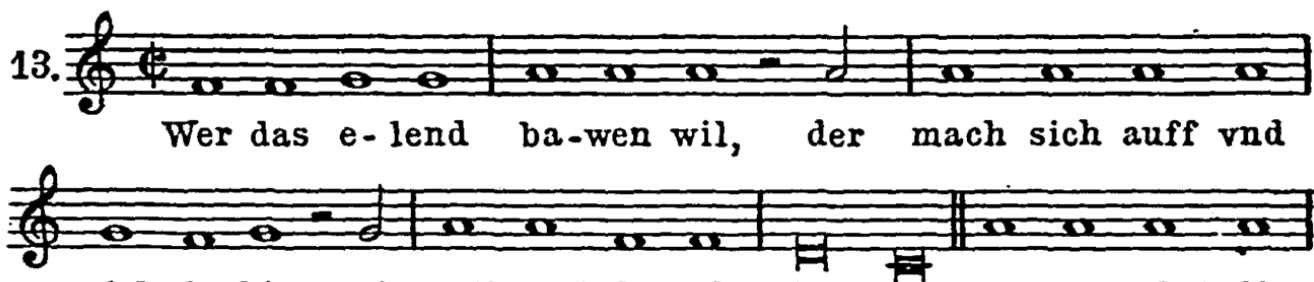

zich da-hin, wol auff sant Ja-cobs stras-se, Zwey par schuh die
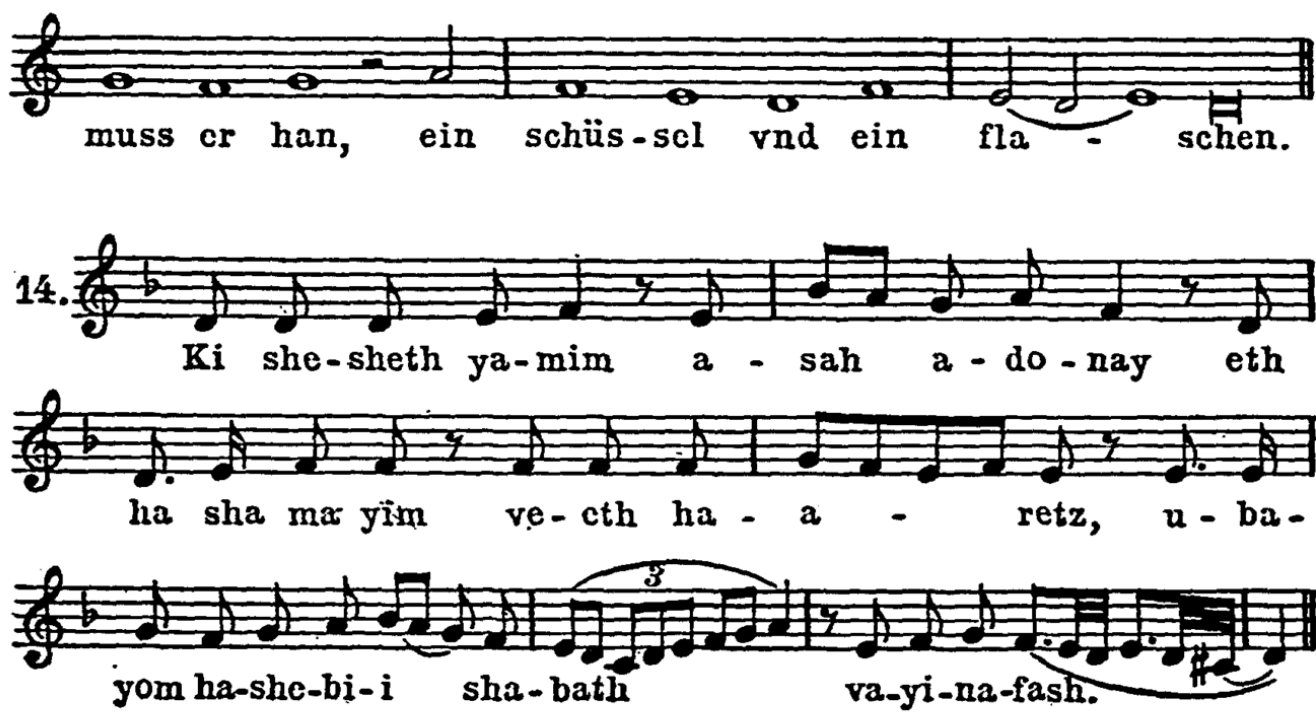
while 2 is somewhat of a variation of (I) (motive 4) or (2) (motive 6). The concluding motive (6) is found also in the Selicha-mode (XIII, 6).

(5) The Yotzer mode for the Three Festivals is composed of the concluding-motive of the Prophetic (I) and that of the Esther-mode. (2)..$^{23}$

(6) The Yotzer mode for the High Holidays is constructed out of the same motives as utilized in 5 plus the darga-tebir motives of the Pentateuch mode (3). 5 is a variation of (I), 5 .

(7) The Tefilla mode for the Three Festivals is likewise composed of the same material: Motive 2 resembles (6), 3; motive 3, is a fusion of (6), 4, (6), I, and (5); 2 is employed as a concluding motive. Motive $I$ is a condensation of (3), 4-5. A similar motive (6) (b) we find in a song of the fourteenth century on the birth of Jesus (XXII, I0)..$^{24}$

(8) The Yotzer mode for weekdays and Sabbaths is a variation of (I) -3 , or vice-versa, and, at any rate, a variation of the Mogen-Ovos mode.

(9) The tune for Shema for Sabbath has the concluding motive of (7), while (10) the tune for "Shema" for the High Holidays has been worked out from (2), or directly from the Mogen-Ovos mode.

The eight modes and the two tunes treated have all a minor character, being chiefly constructed out of the Prophetic, Esther, Selicha, and Mogen-Ovos modes, with but a few motives from the Pentateuch mode. No German elements are to be found in these creations.

Of interest in this connection is the existence of similar tunes (not modes) in the earliest song of the Catholic Church in Germany.

Example I I (Gloria) is sung on Palm Sunday during the procession. ${ }^{25}$ Its close resemblance to the Arabic Bayati-tunes (table $I, 2-8$ ) is obvious.

Example 12 is from the "Minnesong," composed by Meister Gervelyn (thirteenth century), ${ }^{28}$ and it is identical to the 
"Gloria" cited. Example I 3 is the so-called St. Jacob's-tune, used for the pilgrimage to the grave of that saint in Campostella (Spain) in the sixteenth century. ${ }^{27}$ These examples of Semitic-Oriental elements in the old German religious and secular song are not to be taken as mere incidents, but as a continuous influence which came from two sources: first, from the Judeo-Moorish source in Germany and Spain. Tunes like that of St. Jacob, the German pilgrims evidently learned while in Spain. We know that after the Christianization of Spain and expulsion of a number of Moors and Jews, a great many of them embraced Christianity and remained in the country. Their tunes were set to Spanish texts of a religious or secular nature, ${ }^{28}$ which spread over France and Germany. The other source of Semitic-Oriental influence came through the crusaders to Palestine, who brought back tunes which they had picked up while in the East. Already in Chapter IV, 4 (table XIV, 3) we showed that the Mogen-Ovos mode, upon which the greater part of all these songs is based, is also found in the Oriental Synagogue. In XXI, I4, we offer an example for that mode from the Italian Synagogue ${ }^{29}$ which, likewise, proves that there are common musical elements between the Italian and the German Synagogue song.

\section{Modes or Steiger in Major (Table XXII)}

Of modes with major character the Ashkenazim possess but two. In example I the Oriental Tefilla mode (see table XII, 4 ) is still retained. 2 illustrates the Adonoy-moloch mode (Chapter IV, I) as it was used for Friday evening in Germany in the eighteenth century, and 3 , another form of the Tefillamode (example I), presents the Psalm-mode used for the introduction to the Friday-evening service. Its equivalent we find in the Gregorian 5th mode (example 4), which has the same 
text (p. 95) as has 3, and is called invitatorium (invitation for prayer, because the Psalm starts, "Oh, come let us sing"). This example is taken from a MS. from I640. However, this Psalm-tune was already in use in the Church in the eleventh century. ${ }^{30}$ That the Ashkenazim did not borrow that mode from the Church is proved by its genuine Jewish source for which example 5 from the Yemenite Synagogue song gives evidence. Here, the concluding motive shows that this Adonoymoloch mode was originally based upon the Dorian scale and remained so in the Yemenite tradition as well as in the MS. of the eleventh century of Gregorian song $(4,6),{ }^{31}$ while later, through the influence of the German inclination toward Major, both in the Synagogue and Church tradition, the scale of the mode was changed to major, i.e., two tones below the tonic of the ancient Dorian. ${ }^{\mathbf{3 2}}$

The Friday-evening mode, another form of Adonoy-moloch (example 2), enriched with a special tune or theme, is used also for the evening service of the High Holidays. Example 7 gives the insertion. The first four bars are found in an old hymn by Paulus Diaconus at the court of Charlemagne (lived 720-799) and go back to Gregory I (d. 604). ${ }^{33}$ The motive in the bars $3-4$, as well as the concluding motive, are frequent in the Minnesong, as evidenced in examples $8-9 .^{34}$

\section{Tunes for Individual Texts}

The modes or Steiger thus far treated were composed out of old elements of Jewish-Oriental song, with but very little non-Jewish additions. And it seems that these modes were created in an early age, at a time when German music was still in its infancy, and therefore incapable of exerting an influence to compete with Jewish song, i.e., before or about Iooo C.E. Hebrew literature of the eleventh and twelfth centuries men- 
TABLE XXII

Ashkenazic Modes in Major
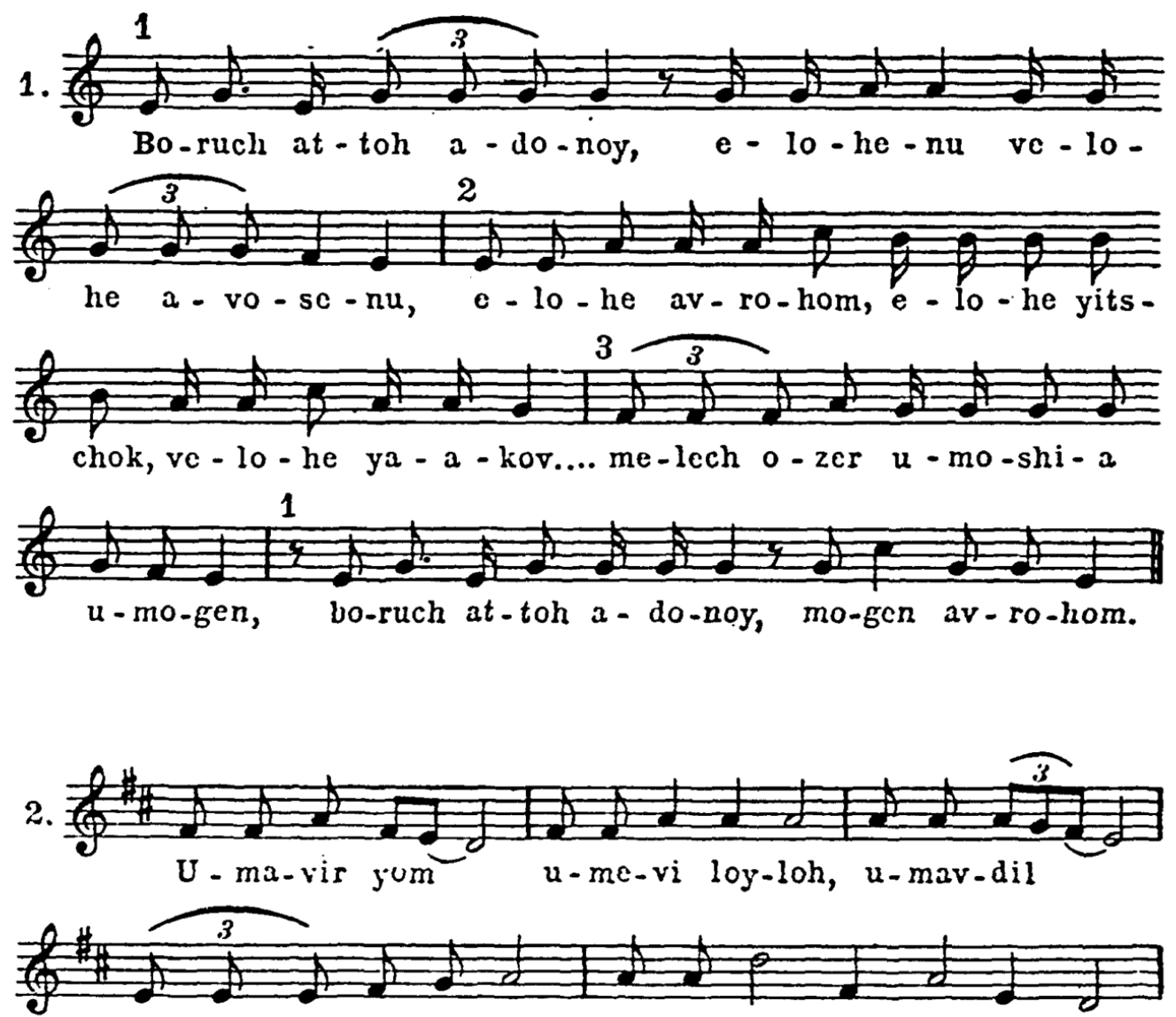
ben yom u-ven loy-loh, a-do-noy tzvo-os she-mo.

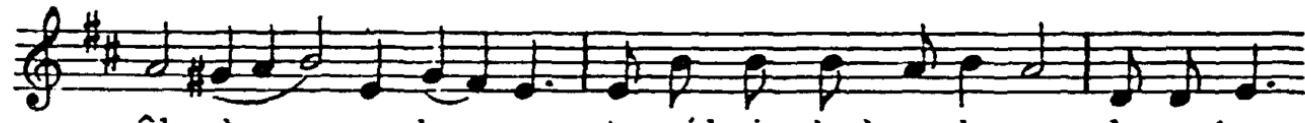

êl chay ve-kily-yom, to-mid yim-loch o-le-nu le-o-lom

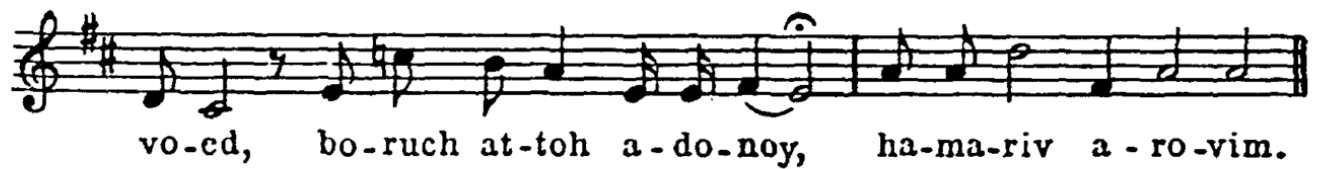

Ps. 85

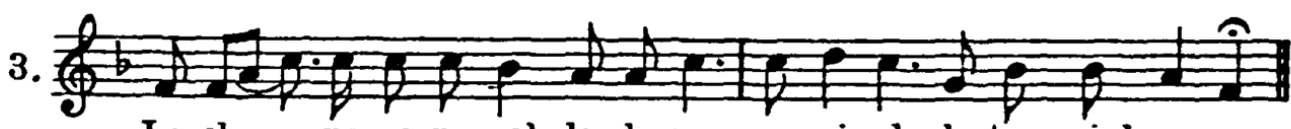
Lo-chu ne-ra-na-noh la-do-noy, no-ri-oh le-tzur yish-e-nu. 


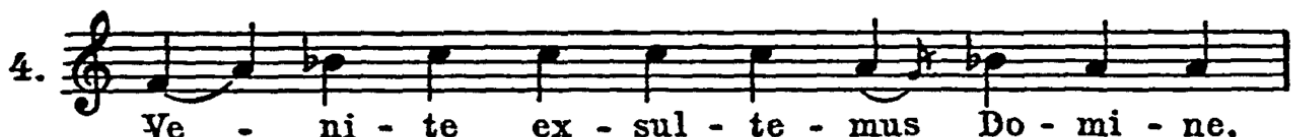
Ve - ni - te ex - sul - te - mus Do - mi - ne,
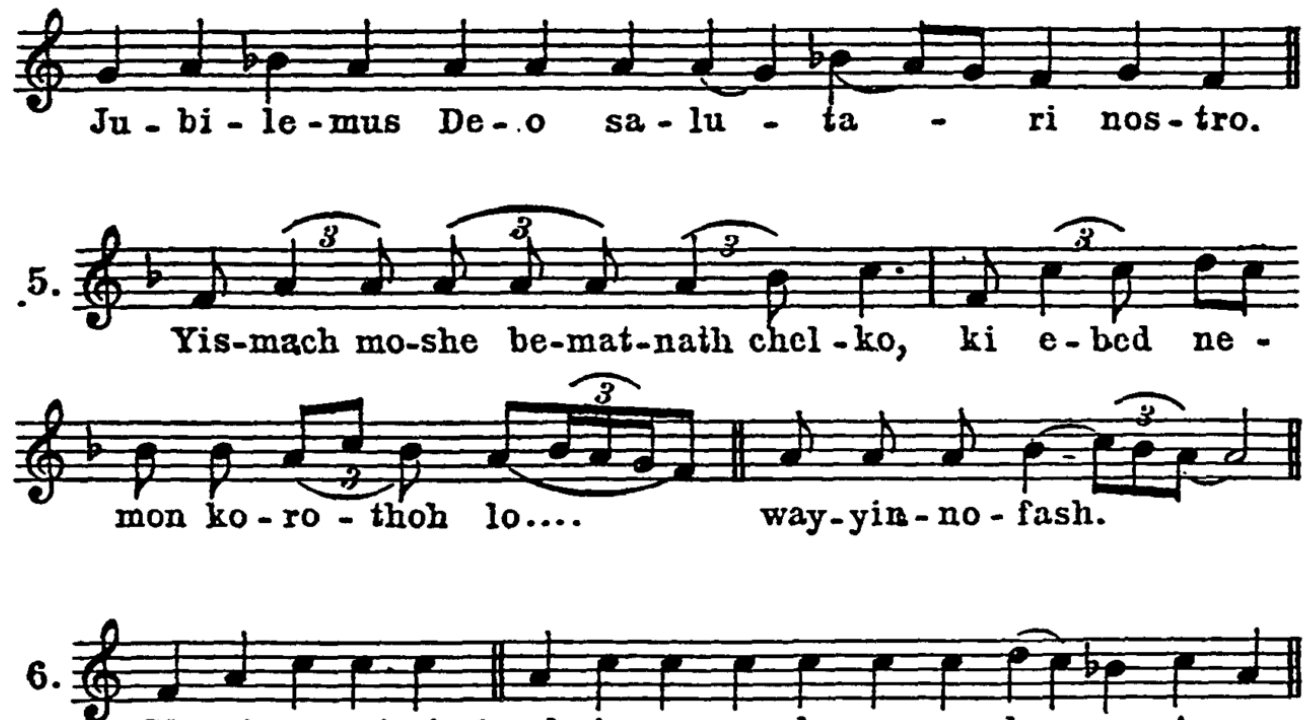

Glo-ri-a pat-ri etc. el in sae-cu-la sac-cu-lo-rum. A-men.

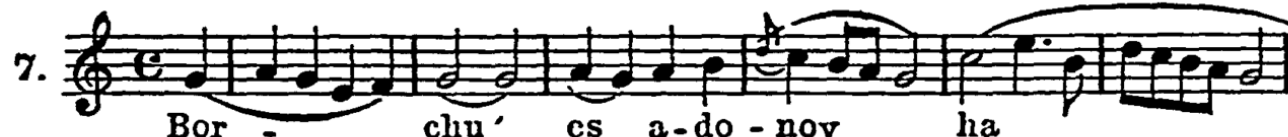
Bor - chu' cs a-do-noy ha

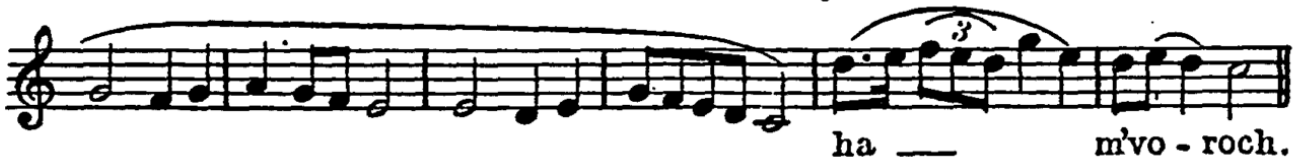

8.
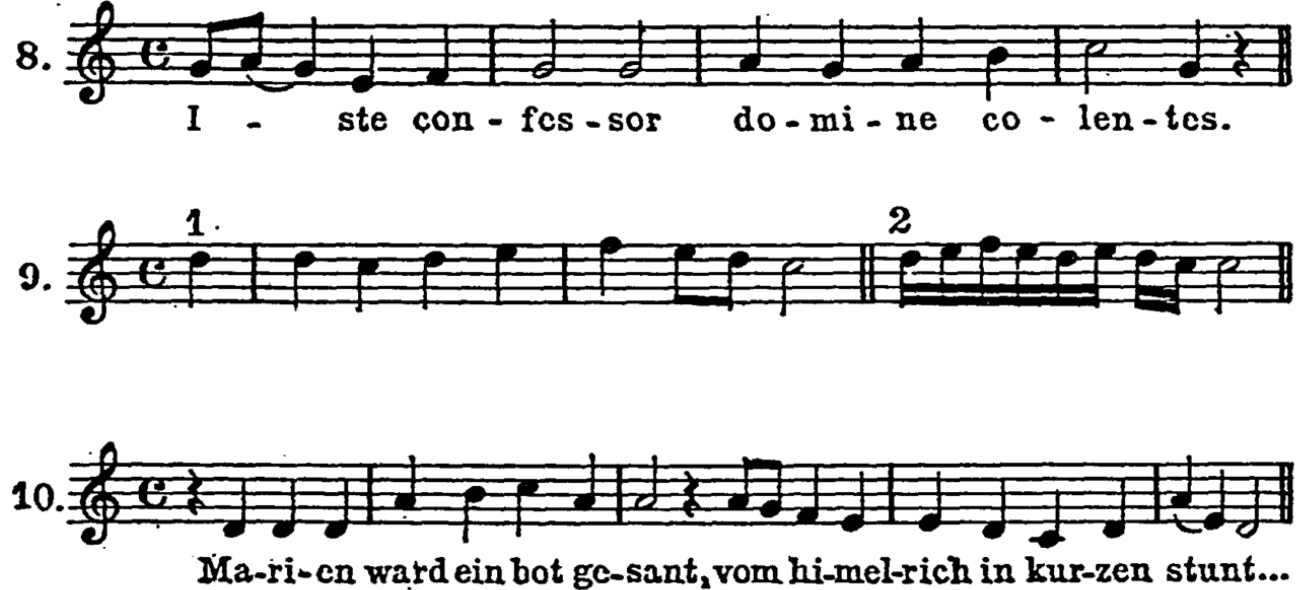
tions already the special modes for the different services for Sabbath and festivals. ${ }^{35}$

The tunes composed for the individual texts in the services of the festivals and chiefly for the High Holidays differ from the modes. In these tunes we find Jewish and German-Gregorian elements fused and molded into forms which were current in the period of the Minnesong, from the eleventh to the fourteenth centuries. In some of these tunes, forms of the "Sequence" and "Jubilation" are traceable. Some of them show the lais form. They repeat two or three times, dividing the texts, though they are in prose, into two or three parts similar to stanzas. However, these parts being prose could not be symmetrical, so that shorter and longer divisions were inevitable, which had to be repeated according to the same tune. This procedure caused variations in the tunes. At times, some of the parts of the tunes repeated had to be sung without words because of shorter texts.

In the employment of the major scale for these tunes, German influence can be recognized. The preference for that scale started with the Minnesong. Indeed, the minor note still retains a considerable place in the tunes, while the Dorian (Greg. Phrygian) scale of the Pentateuch and Tefilla was gradually abandoned, being retained in only a few tunes. Neither was the Ahavoh-Rabboh mode or Hedjaz scale employed. Only later in the seventeenth century was this scale brought to Germany and Central Europe by the Eastern chazzanim (Chapter XI), who introduced variations into these tunes according to the scale of Ahavoh-Rabboh.

(A) The tunes for prose texts composed in the period of the eleverth to the fifteenth centuries are these (table XXIII):

I. Olenu (Adoration). The text was originally composed in the third century in Babylonia for Musaf (additional service) of the High Holidays. The singing of that text became cus- 


\section{TABLE XXIII}

Ashkenazic tunes for individual prose texts

\section{Olenu}

1
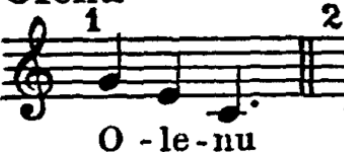

O - le - nu
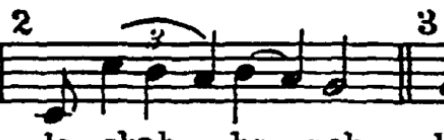

\section{3}

A. BEER,17̈65(?)

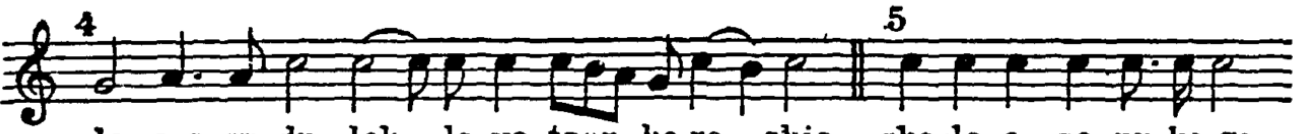

lo-ses ge-du-loh le-yo-tzer be-re - shis, she-lo o-so-nu ke-go-
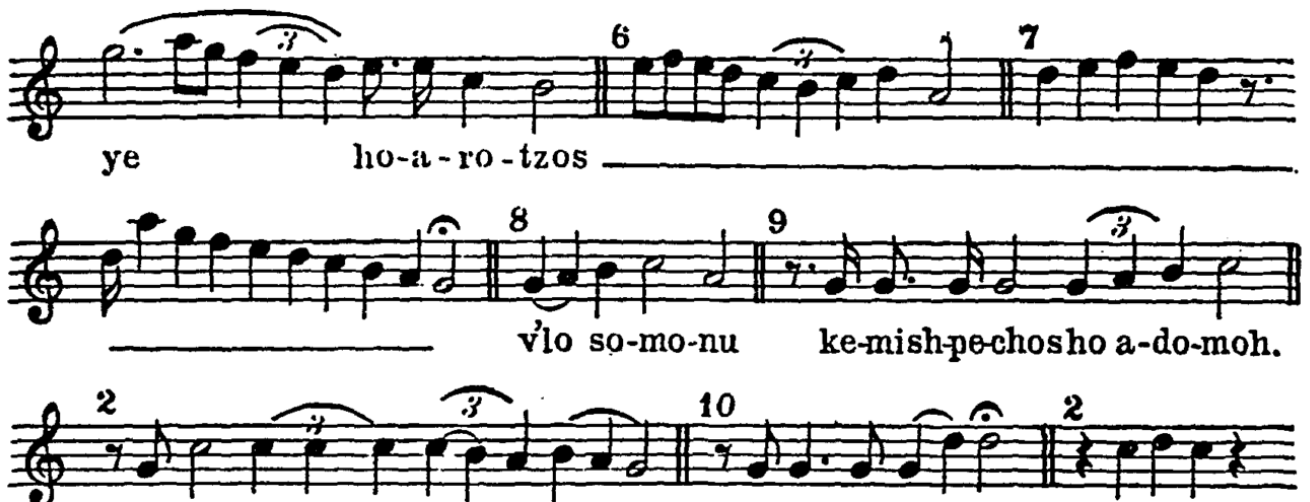

she-lo som chel-ke-nu ko-hem

ve-go-ro-le - nu
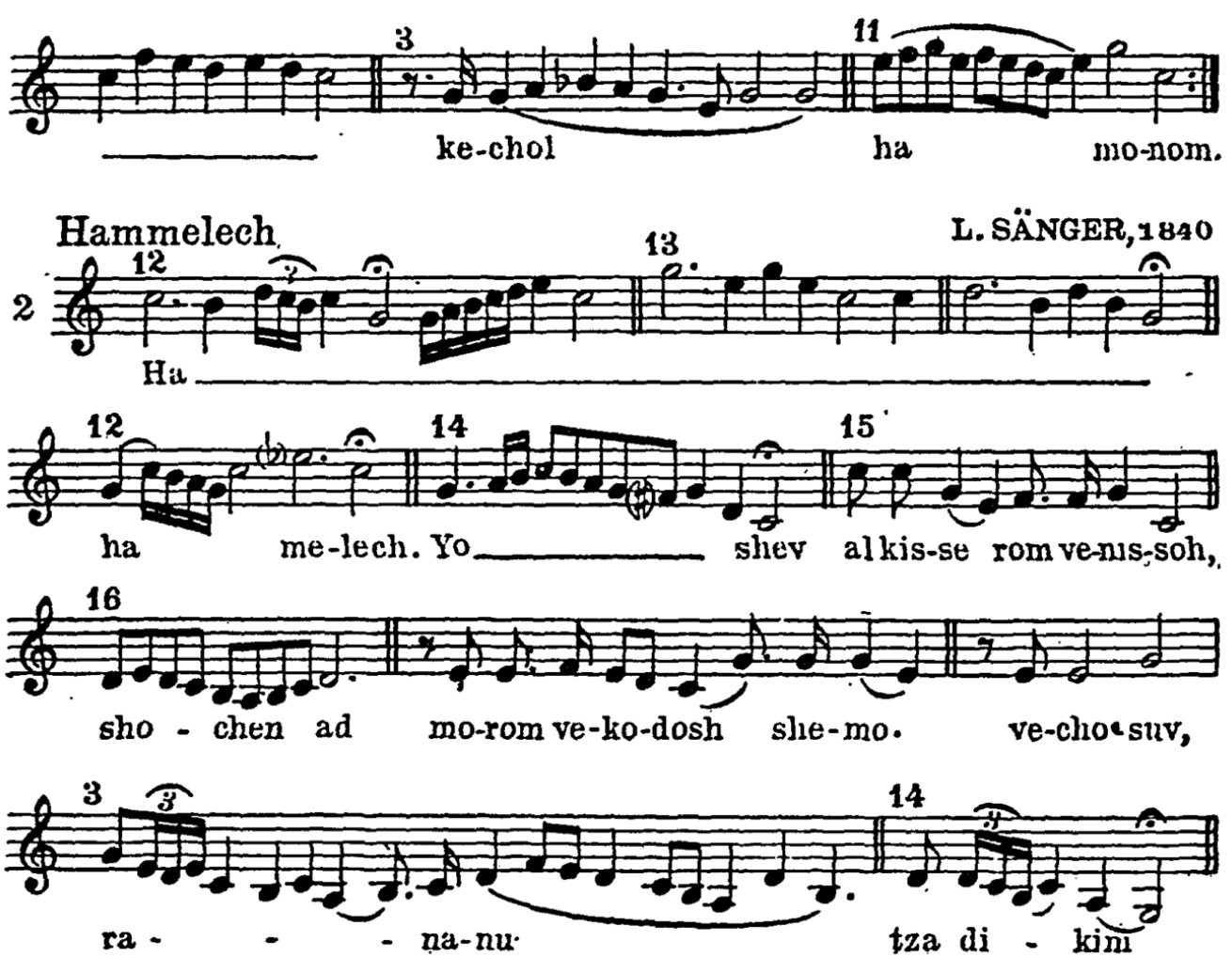

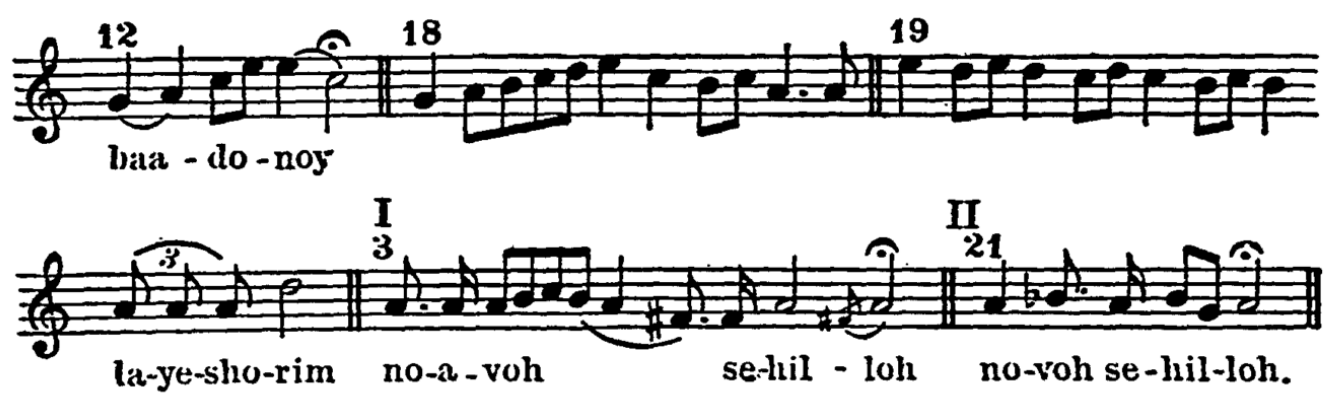

3 Ovos 1 2. bo-ruch at -toh ado-noy 1) ใ.

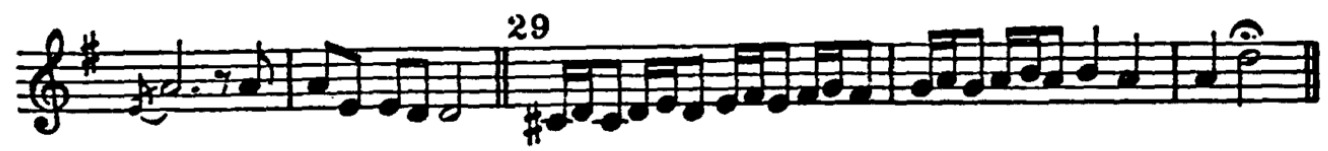

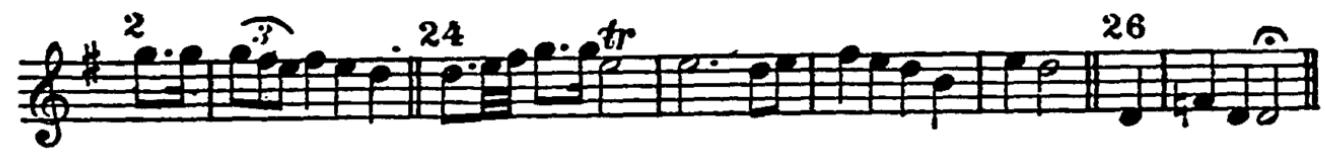
7.3. 

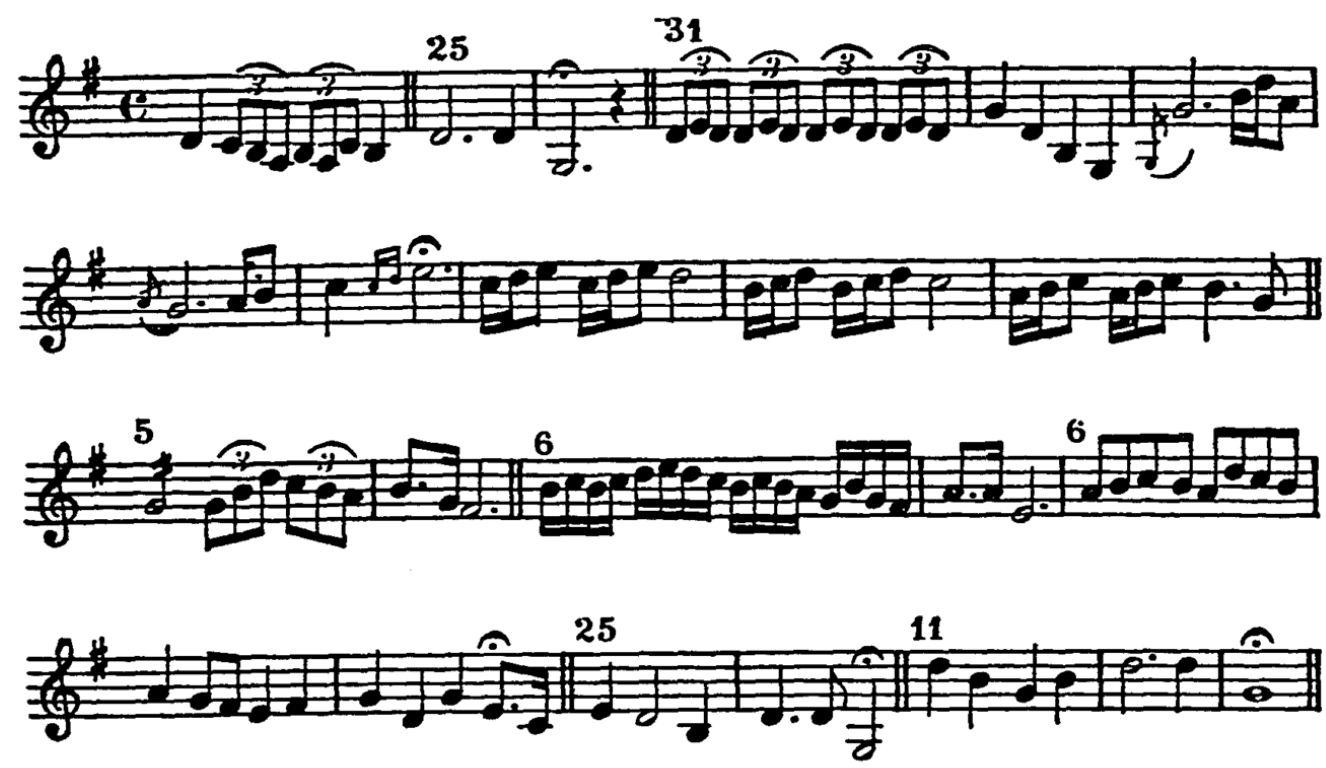

Ovos II

L.SÄNGER, 1840
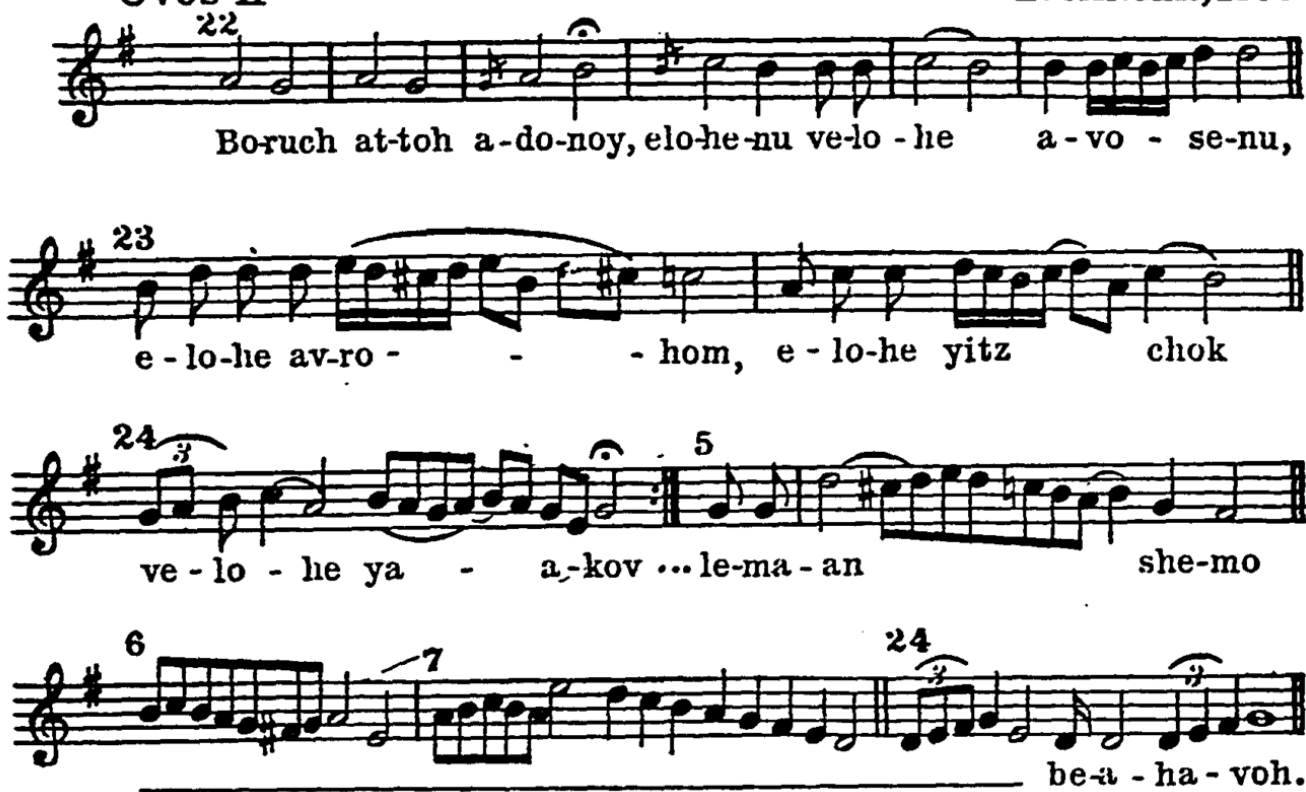

Ovos III

J. M. ABELOV, 1820 (?)

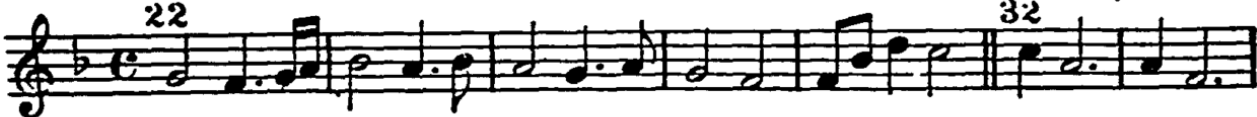

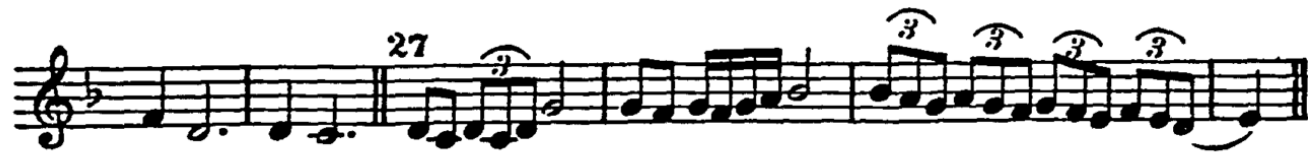



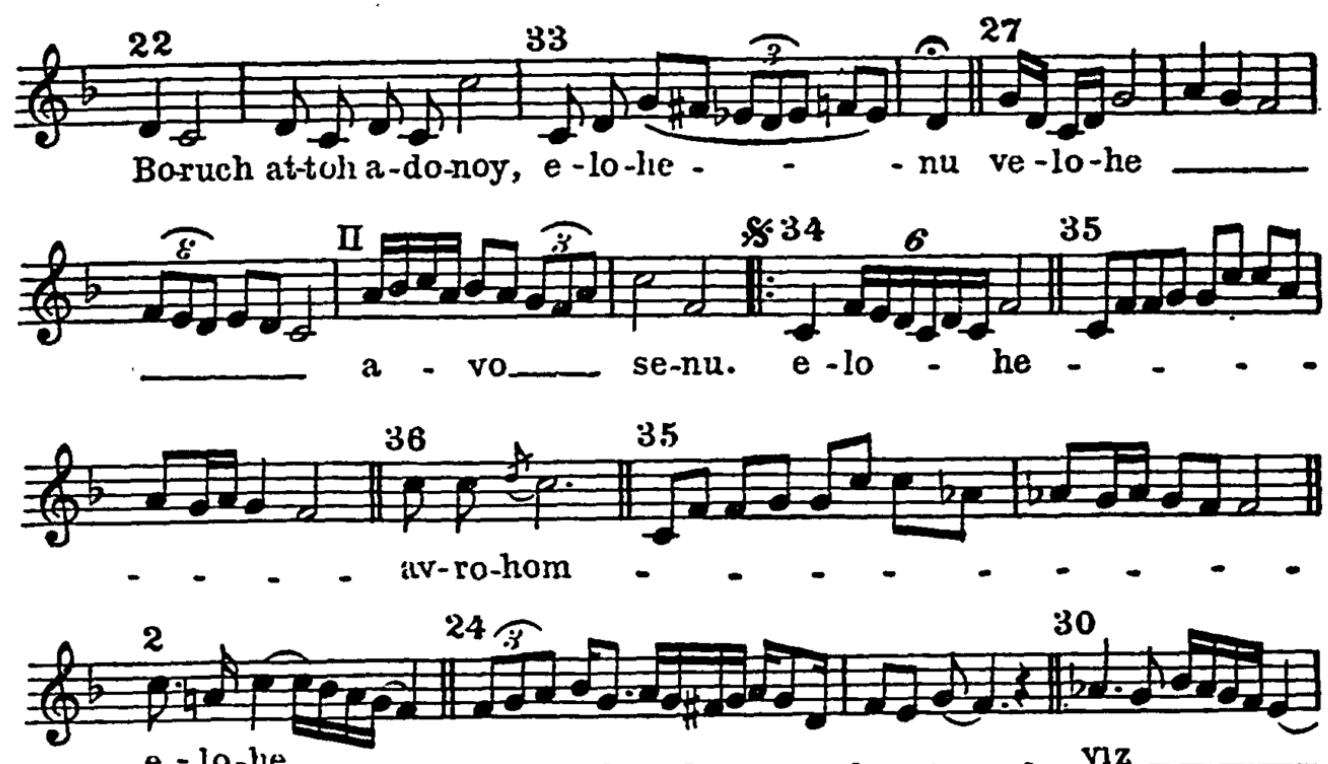
e - lo-he

\section{I $\pi$ II}
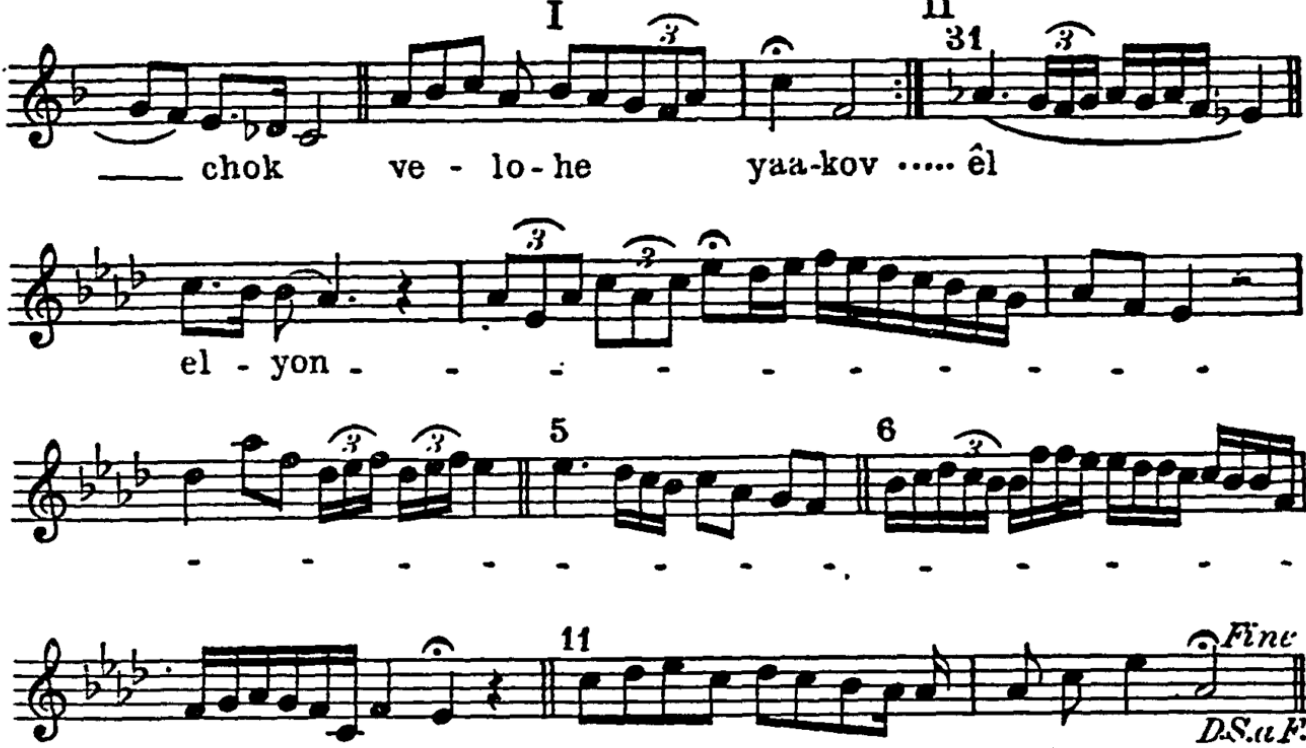

go - mel cha-so-dim to-vim.
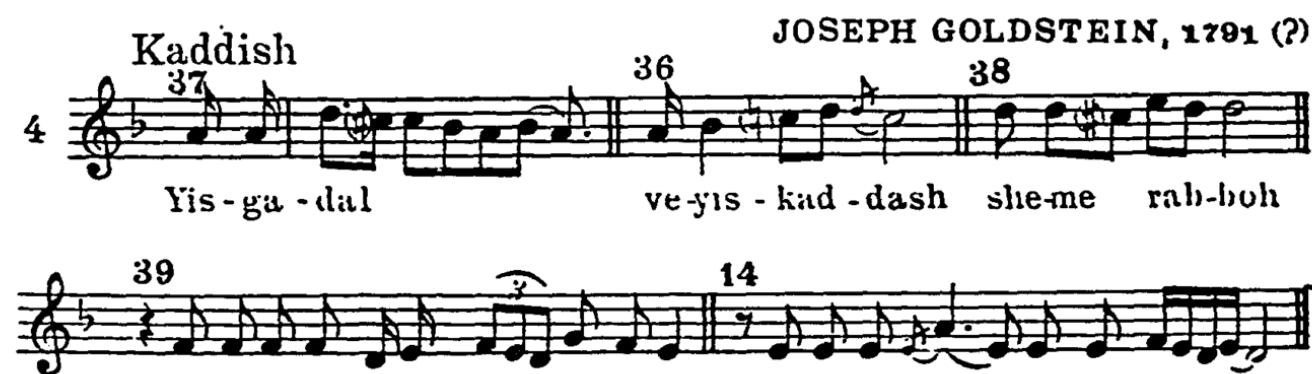
be-o-le-mohdi-ve - roh chir-u-se ve-ya-me lich mal-chu-st, 


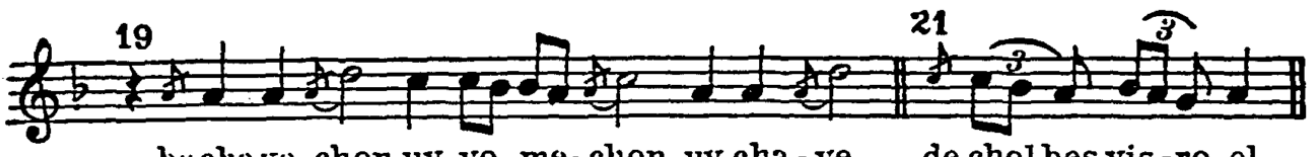

bechafe-chon uv-yo-me-clion uv-cha-ye de-chol bes yis-ro-el
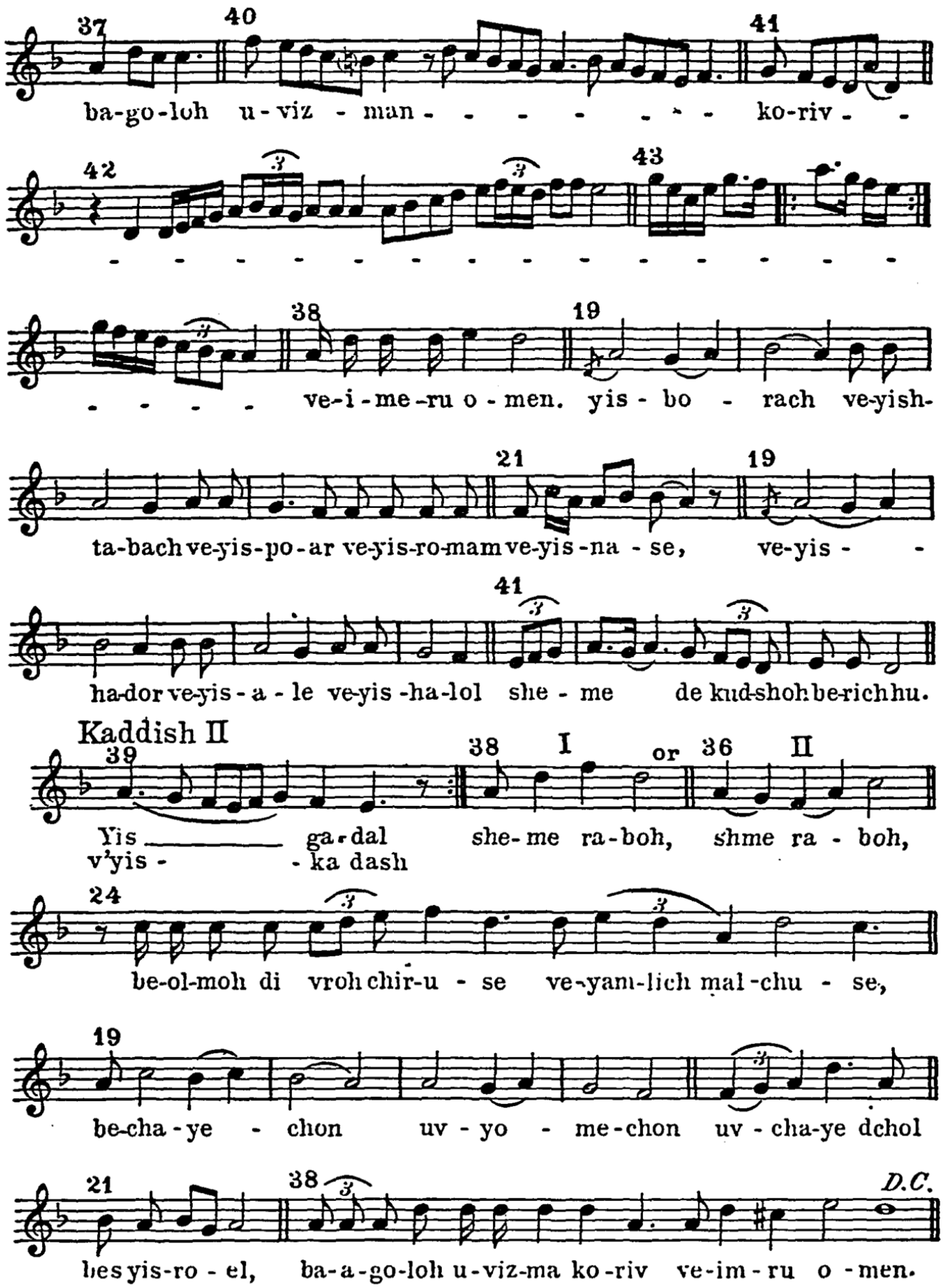
Vehakkohanim I JOSEPH GOLDSTEIN, 12ษ1(?)

5 F⿻ Ve-ha-ko - ha - nim.

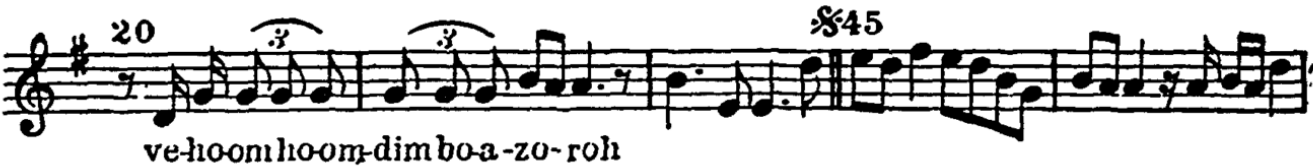

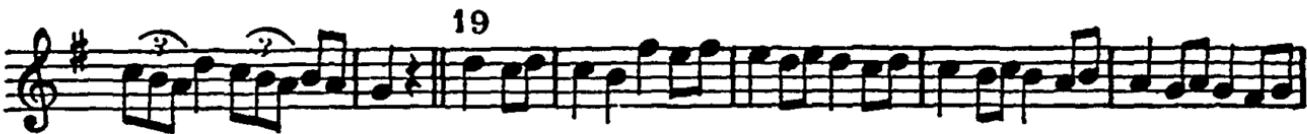

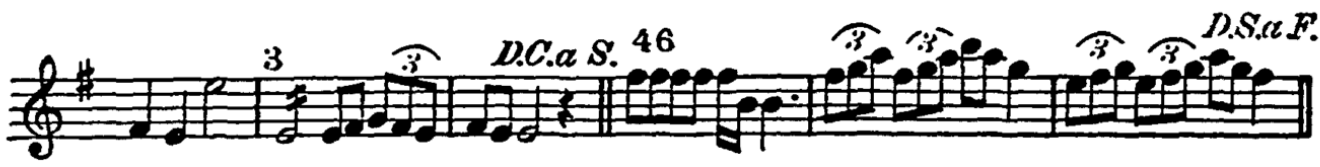

Vehakkohanim II

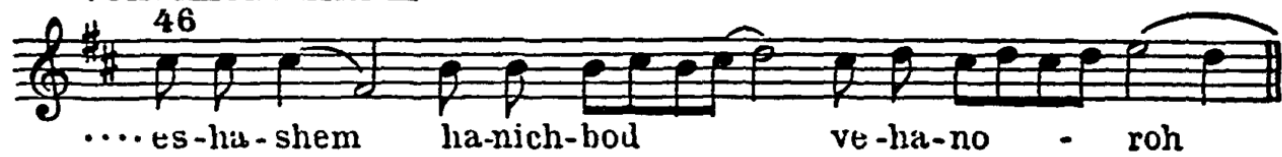

45
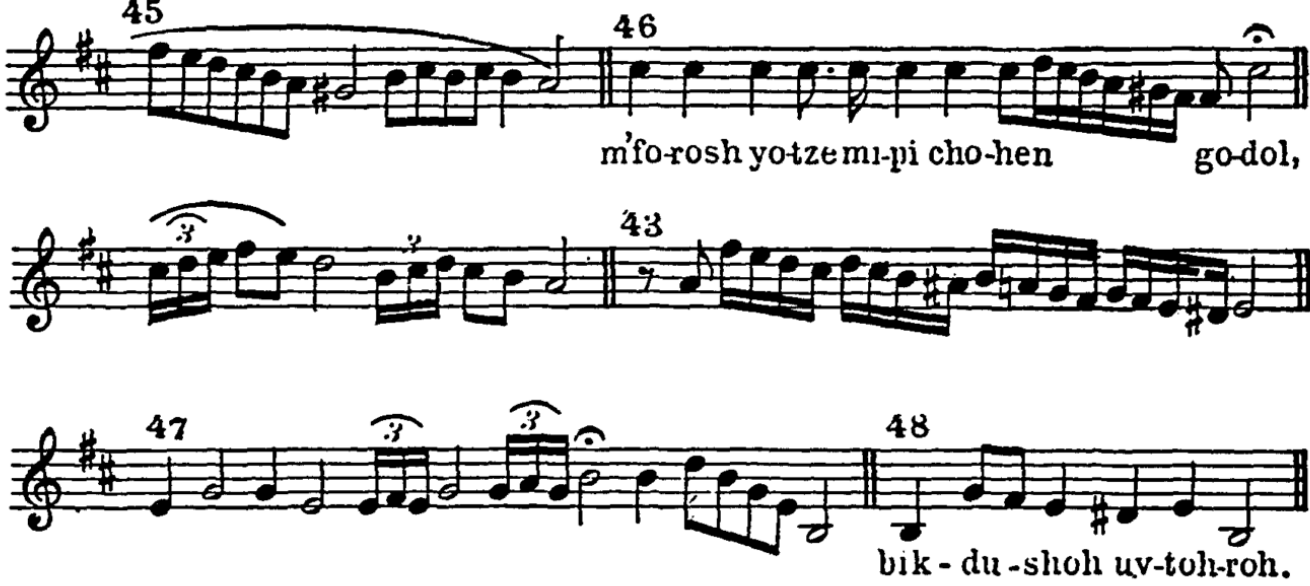

Vehakkohanim III
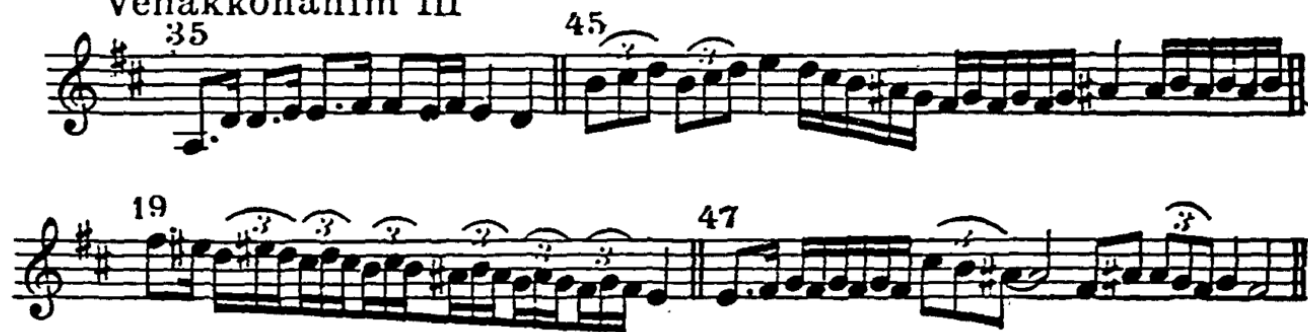
Kol nidré I

A. BEER, 1265 (?)

6 12.

1)

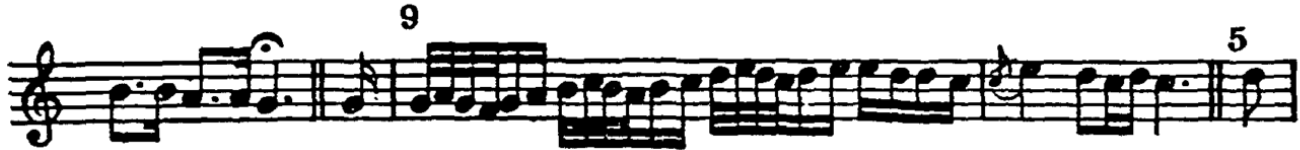

1\%

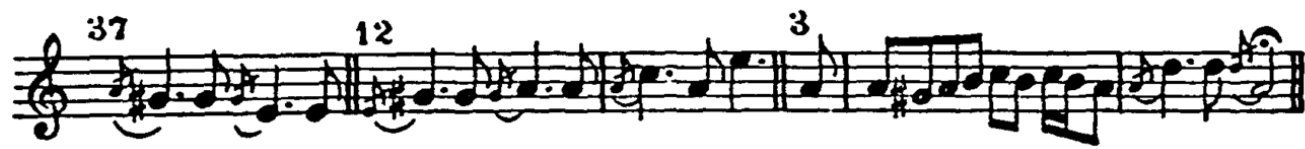

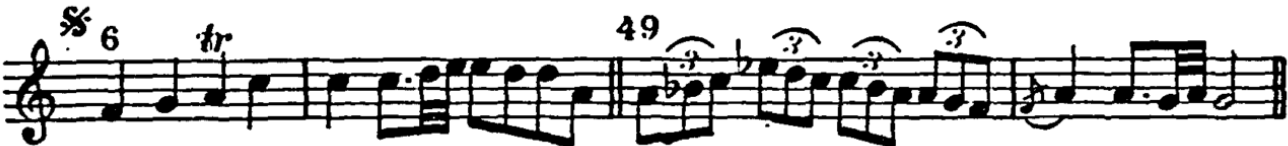

\% 50 of

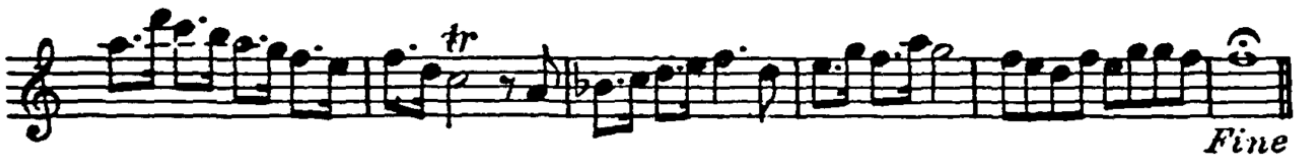

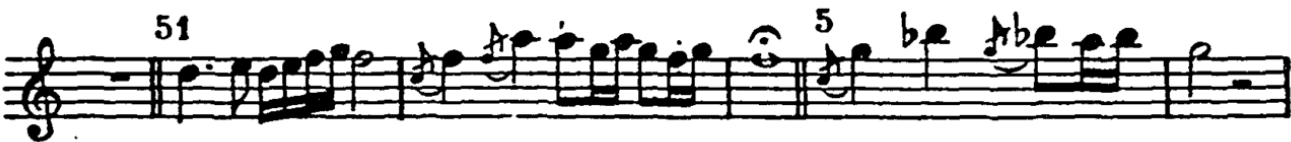

t 

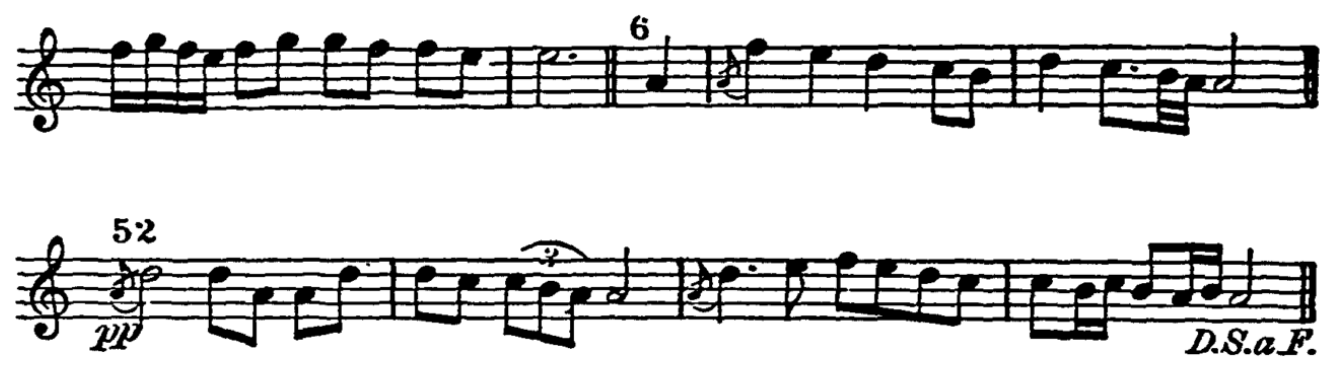

Kol nidré III
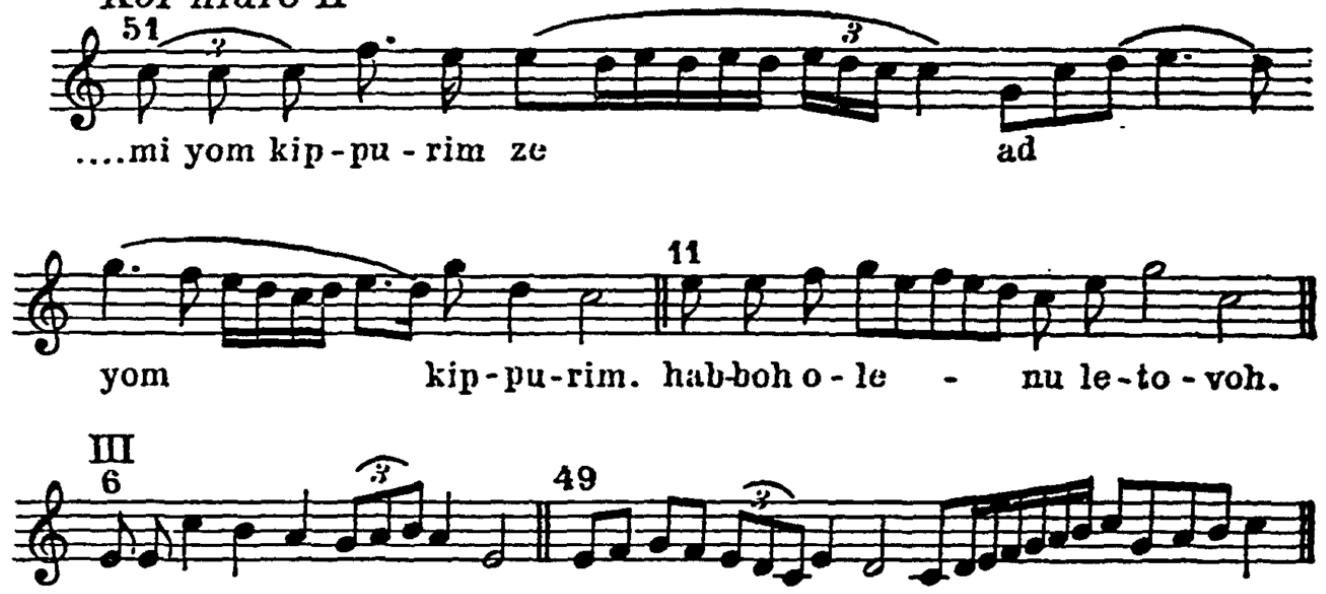

Kol nidré IV

L.LEWANDOWSKI, 1821
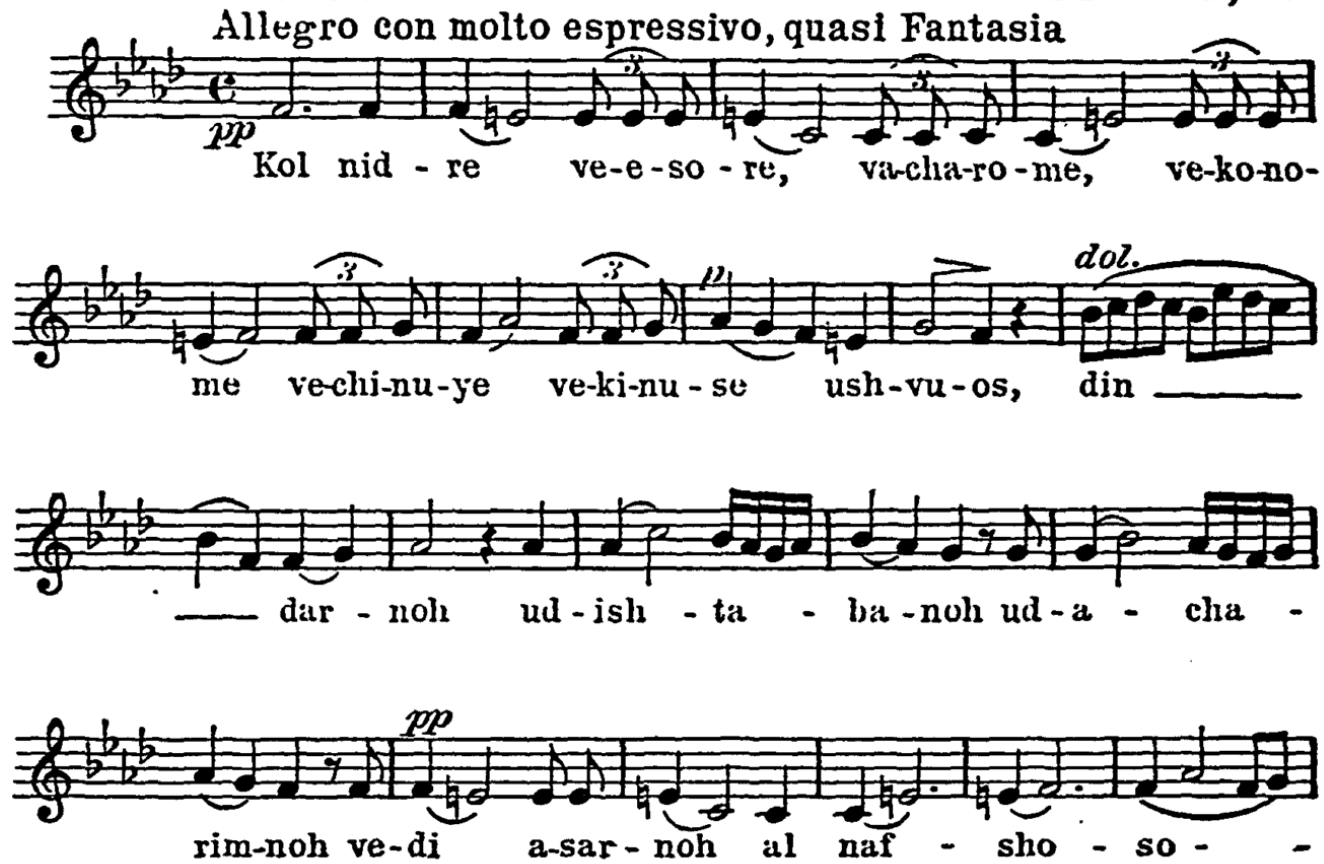

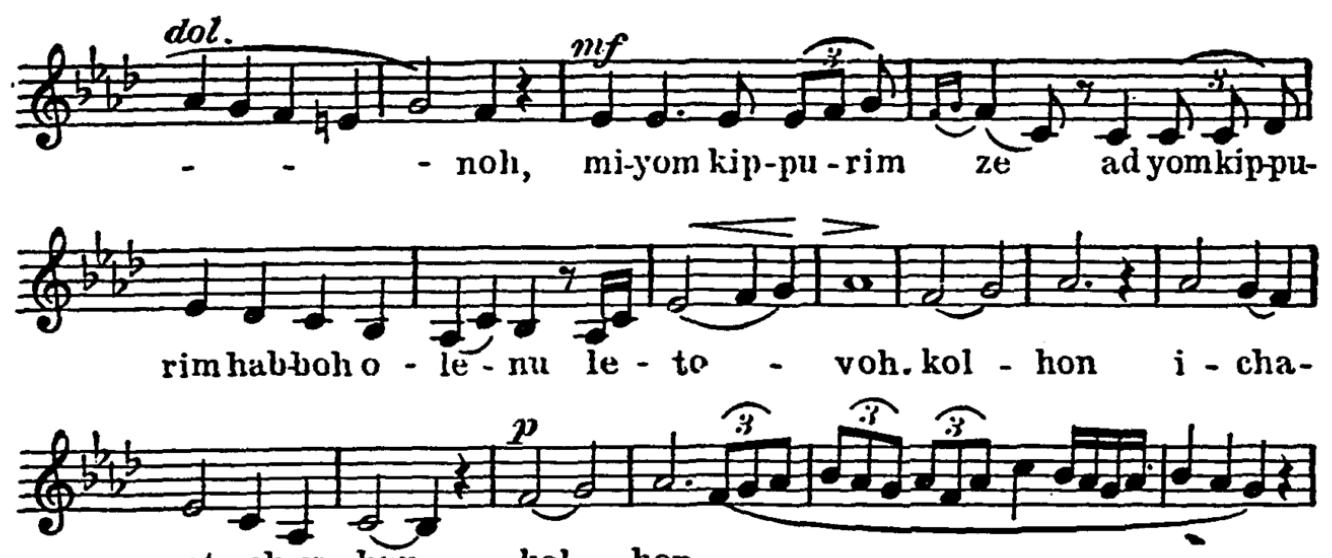

rat-nohve-hun, kol - hon
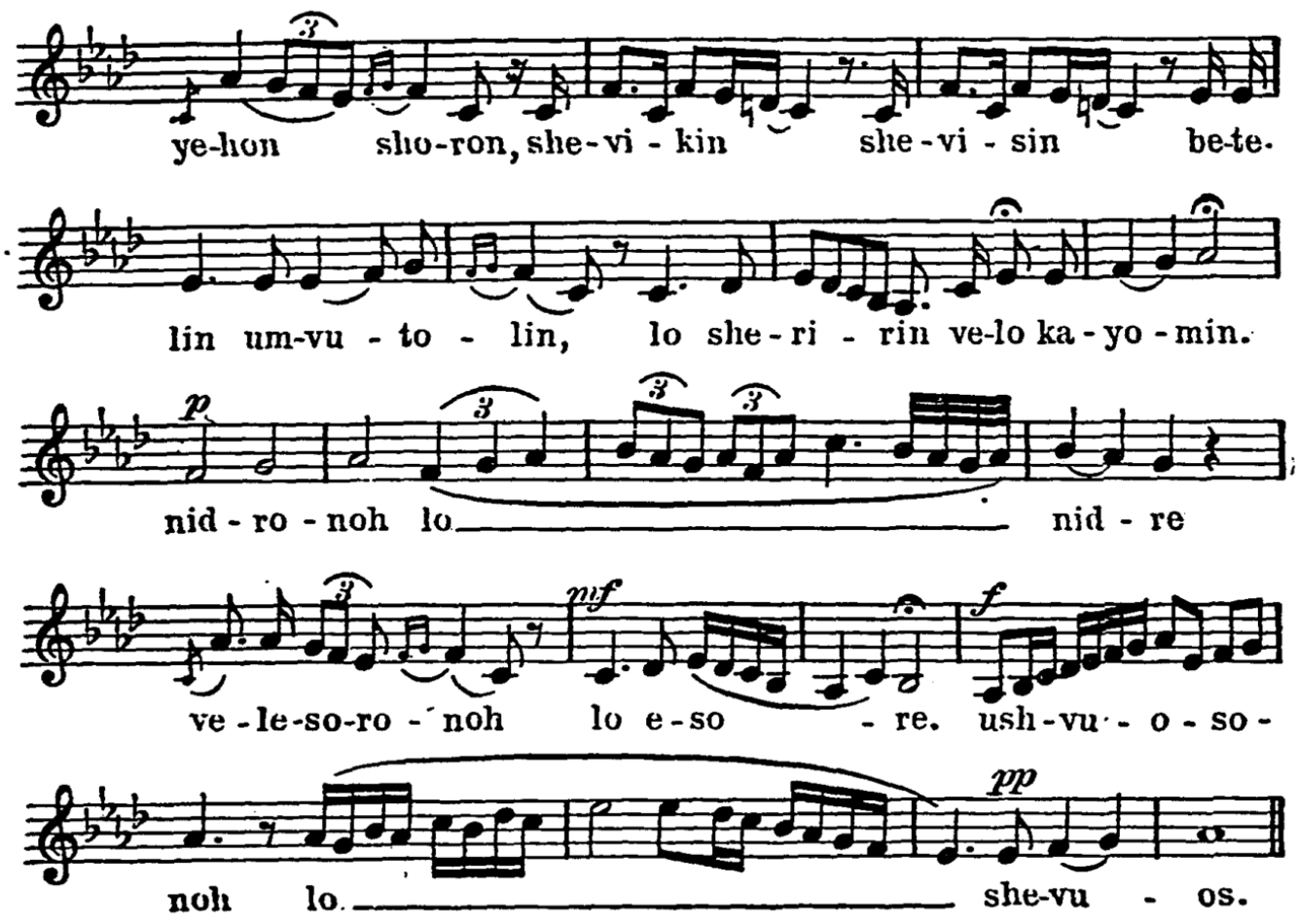

Aldiomus

$\eta$

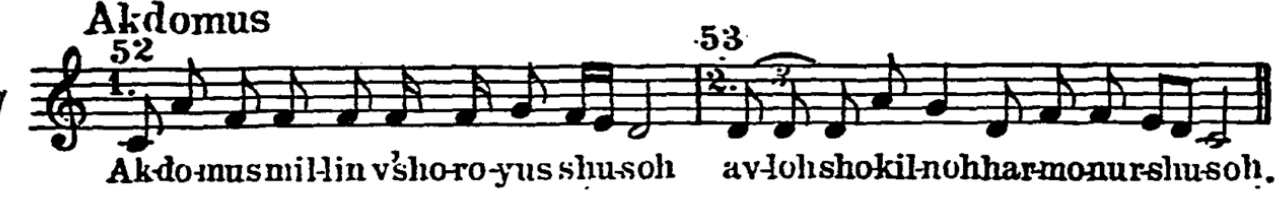

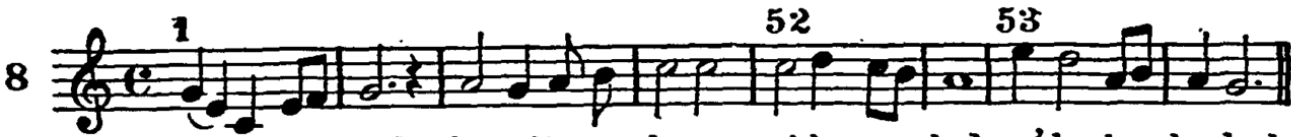
Mi-chomochoh bo-e-lima-do-noy, mi-ko-nochoh ne'dor ba-ko-desh. 
tomary apparently during the first period of the crusades, when Jews were forced to embrace Christianity. They preferred to be burned or killed, singing with exultation the sovereignty of the One Eternal Living God, expressed in the Olenu. It is related that "during the persecution of the Jews of Blois (France) in I I 7 I, when many masters of the Law died as martyrs at the stake, an eye-witness wrote to Rabbi Jacob of Orleans that the death of the saints was accompanied by a weird song resounding through the stillness of the night, causing the Christians who heard it from afar to wonder at the melodious strains, the like of which they had never heard before. It was ascertained afterward that the martyred saints had made use of the Olenu as their dying song." ${ }^{36}$ The cantor Herz Treves of Frankfort (I470-I 550) arranged some verses for the congregation to recite softly while the chazzan sang the Olenu on the High Holidays. ${ }^{37}$

We have the oldest MS. of the tune written down by Ahron Beer, chazzan in Berlin about 1765 , which we give in table XXIII, I, leaving out the embellishments obviously added by the writer. Since then the tune has been written down by several chazzanim of various localities in Europe with different variations, but all versions retained the essential motives to be found in the oldest example cited.

2. Hammelech (The King). The custom to sing this text in the morning service (Shachris) was established by Rabbi Meyer of Rothenburg (Worms, I 2 I 5-I 293).$^{38}$ However, in the communities in the Eastern districts like Regensburg, Nuremberg, etc., the usage was still unknown in $1300 .^{39}$ Only the famous Rabbi and chazzan Jacob Mölin emphasized this custom. According to the description of his disciples he used to start in a low and soft voice, then gradually raise his voice with all force. ${ }^{40}$ A similar description is given by an author of 
the sixteenth century. ${ }^{41}$ In I 700 the tune was employed also for Esther VI, I, a custom which continued until lately. ${ }^{42}$ The reason given for singing the Hammelech was to remind the people that God the King sat in judgment in that hour. The tune in XXIII, 2 is taken from MS. L. Sänger ( $178 \mathrm{I}-1843$ ).

3. Ovos (The Patriarchs, i.e., the first benediction of the Amida, relating the merits of the fathers). Rabbi Meyer of Rothenburg used to chant that text solo in an emphatic tune. ${ }^{43}$ In the seventeenth century the tune for this text was well known and accounted traditional. ${ }^{44}$ We possess a MS. of it written in 1782 by A. Beer, which is given in XXIII, 3, I, with omission of later embellishments. Beer's version contains elements which are to be found in L. Sänger's version XXIII, 3, II, as well as in the Lithuanian version XXIII, 3, III, by Jacob Moshe Abelov of Trocki (I846-I888). The latter contains even ancient motives (like 35 ) not to be found in the two other settings. Besides, the Lithuanian shows Oriental influence in motive 33. It has likewise several modulations of which we shall speak in Chapter XXIII.

4. Kaddish (Sanctification) had several musical settings, of especial importance being one for Sabbaths and one for the Three Festivals. On the High Holidays in Troyes (France) and Mayence (Germany) Kaddish and Borchu were sung according to the tune of the Three Festivals, whereas M. Rothenburg changed that custom and ordered that on the High Holidays Kaddish should be sung in the tune of Sabbath. ${ }^{45}$ In the seventeenth century the tune of Kaddish was like those already named, known as awe-inspiring. ${ }^{46}$ The text was considered very important and therefore it became the chazzan's duty to prolong its singing in order to give the people time to meditate while the tune was sung. ${ }^{47}$ There were, besides, special tunes for the half-Kaddish and for the full-Kaddish, for the Kaddish after the reading of the Pentateuch and for the 
last Kaddish after the service. The most important of them, however, is the tune for the half-Kaddish before Musaf for the High Holidays and its variation for the Dew and Rain prayer. Originally one tune, it was later branched out into two variations. Already the MS. of the eighteenth century bears these two variations. Example XXIII, 4, I, by Joseph Goldstein I79I (omitting later embellishments) illustrates the version for the High Holidays, while XXIII, 4, II, gives the version for Dew and Rain prayer.

5. Vehakohanim in the Avoda (service of the High Priest at the Temple of Jerusalem) in the Musaf of the Day of Atonement was sung to commemorate the service at the Temple in Jerusalem. ${ }^{48}$ The tune is given in XXIII, 5, I, from MS. Goldstein I79r. However, this tune, too, has various versions, as illustrated in XXIII, 5, II, from M. Kohn, I839, and XXIII, 5, III, from A. Beer. ${ }^{50}$ The same tune used to be employed in the eighteenth century also for other texts of the $A v o d a,{ }^{51}$ and is still employed partly for the Musaf Kedusha on the High Holidays and on Hoshanah Rabbah as well as on the festal day on which the solemn character of the Day of Judgment is voiced. Because of its solemnity, the tune.is used also for the poem "Oz shesh meos" on the Feast of Weeks (Shavuoth). ${ }^{52}$

6. Kol-Nidré was recited in the eleventh century three times, beginning in a low and soft voice and gradually at each repetition increasing in volume. ${ }^{53}$ The chazzan Meier ben Yitzchak of Worms, however, used to sing it twice only. ${ }^{54}$ Rabbi Jacob Mölin used to sing the Kol-Nidré text in various tunes, prolonging the singing until night, in order to enable the late comers to hear the content of the text. The Hebrew expression for singing given at that occasion indicates rather "improvisation" than the singing of a set tune. ${ }^{55}$ Rabbi $M$. Jaffa of Prague was the first to mention a set melody tradi- 
tional for Kol-Nidré, known by the chazzanim of his time (sixteenth century). ${ }^{56}$

The Kol-Nidré tune is illustrated in XXIII, 6, I, according to the setting of Ahron Beer, and it is the oldest version in written form. It has the modulation to the sixth in major, instead of the parallel third in major, as is now customary and as is illustrated in XXIII, 6, III (motives 6 and 49). The Kol-Nidré tune, too, has several versions in which other motives are inserted not found in Beer's setting. We give in XXIII, 6, II and III, some of these insertions, of which II is customary in Eastern Europe, while III is found in later versions, especially in the settings of the nineteenth century, as illustrated in 6, IV, in L. Lewandowski's version in his " $\mathrm{Kol}$ Rinnah," No. 107.

In example XXIII, 7, a mode for the Kiddush of the Three Festivals is given, which is used also for the Aramaic poem Akdomus for Shavuoth. This is a variation of the Psalmmode given in table $\mathrm{X}, 9-\mathrm{I} 2$. Out of the same mode a rhythmical tune for Shavuoth was created for the text Mi Chomochoh, as illustrated in example XXIII, 8.

The singing of the "thirteen attributes" on fast days (Exod. 34: 6-7) while reading the portion of the Pentateuch was already customary in the eleventh century, and was sanctioned by Rashi. ${ }^{57}$. The chant is identical to the mode of the Pentateuch for the High Holidays (Chapter III, table IX, 2), and it has much in common with the Sephardic chant for the "thirteen attributes." 58

The chant for Hakkol Yoduchoh at the beginning of Yotzer was already known in the twelfth century. ${ }^{59}$ In Frankfort this text was sung every Sabbath beginning with the "great Sabbath" before Passover, while in Mayence it was started six weeks earlier (Shekalim) and was continued until the Sabbath before Rosh Hashanah. ${ }^{60}$ The tune used to be rendered in re- 
sponsive singing, in which form it is sung in Southern Germany up to the present day. ${ }^{61}$

Borchu, the chazzan Eliezer ben Meshullam "the Great" in Mayence (eleventh century) used to sing at the evening service of the outgoing Sabbath in a long tune. ${ }^{62}$ The custom became permanent for all services. ${ }^{63}$ For each occasion a special tune was invented. The reason given was to give the people an opportunity to gather and to meditate for the service, while the chazzan opened the service with Borchu. In XXII, 7, the tune of Borchu for the High Holidays is given, and in XXII, 8-9, its parallel tunes found in the old Gregorian and the Minnesong.

These tunes are the most outstanding ones set to prose texts mentioned in the medieval Hebrew literature of the Ashkenazic rabbis in the period of the eleventh to the fifteenth centuries, while the authors of the seventeenth century refer to the tunes as traditional, inherited from their forefathers. The purpose of their creation was, as we have seen, a ritualistic and religious one, each individual tune having a specific reason. But the general purpose of them was "to call forth in the hearts of the people awe and devotion, especially on the Day of Judgement." ${ }^{64}$ Thus it was then recognized that music had the power of inspiring the worshippers and calling forth in them sentiments and ideas for which the various festal days were supposed to stand. Therefore, for joyous festivals joyous tunes were invented, while for the High Holidays tunes expressing solemnity and severity were demanded. ${ }^{65}$

In examining the musical elements of the tunes given in table XXIII, we find that these tunes are composed of fifty-two motives. Several of these motives repeat themselves within the same tunes and in various other tunes, while some of the motives occur only once. The motives 3, 5, 19, 24 occur seven times; 2, 37 five times; I I six times; 6 eleven times; 7, I2, 21, 22 four times; 25, 27, 35, 38, 39, 
$45,46,52$ three times; I, 8, 9, I4, 26, 30, 31, 43, 47, 49, 51, 52 repeat themselves twice; whereas $4,10,13,15,16,17,18,20,28$, $29,32,33,34,40,42,44,48,50$ occur but once.

We mentioned above that these tunes were composed out of Biblical and German elements. This we see clearly when we classify the motives cited into (A) Biblical: 2, 3, 4, 5, 6, 13, 21, 24, 27, 35, 39, 51, 52; (B) German: I, 7, 8, 9, 10, I1, I2, I4, 15, I6, I 7, I8, I9, $20,22,23,25,26,28,29,31,32,34,36,40,41,42,43,44,45$, $46,47,48,49,50$; and (C) Slavic Oriental: $30,33,37,3^{8}$.

From this list we gather that thirteen motives are of Biblical origin, four of Slavic, and thirty-five motives are of German origin. In order to establish proof we give in XXIV a selection of motives of Gregorian and Minnesong of the period of the eleventh to the sixteenth centuries, and compare the motives of table XXIII to those in table XXIV as follows: $I-2$ to $I-3 ; 3$ to $7, I ; 4$ to 16,$5 ;$ II to 6 (end); 6 to $4 ; 35$ to $5 ; 37-38$ to $9 ; 39$ to $10 ; 36$ to 10,$12 ; 41$ to Io, $3 ; 44$ to 8 ; 37 to II. The Minnesong influenced even the Pentateuch-mode, as becomes evident by comparison of 13 to 16,4 , and example 12 to 4 in table IV. On the other hand, the song of Heinrich Vrowenlop in XXIV, 13 (the last great Minnesinger, died in 1318) has decidedly Oriental character. This song has striking similarity to the Selicha-chant by Joshua Feinsinger, who lived in Eastern Europe five hundred fifty years later (example 14). Vrowenlop's tune reminds us further of the Arabic song in table $I, 2$.

From the list of motives given above we learn also that those most often repeated are, with exception of ii, of Biblical origin. Example ii is a popular concluding motive in the Minnesong and serves here, too, as such.

There is a type of motive which serves as links or as passages of instrumental character, and was inserted at a later time, most likely in the seventeenth century, influenced by the ars nova. These embellishments are found in abundant quantity in the tune in XXIII, 3, I (compare the motives 28, 29, $3 \mathrm{r}, 42 ; 5,9,15,45)$. Those motives which repeat themselves in the same melody or occur in various tunes may be considered 
TABLE XXIV

Motives of the Gregorian and Minnesong

1

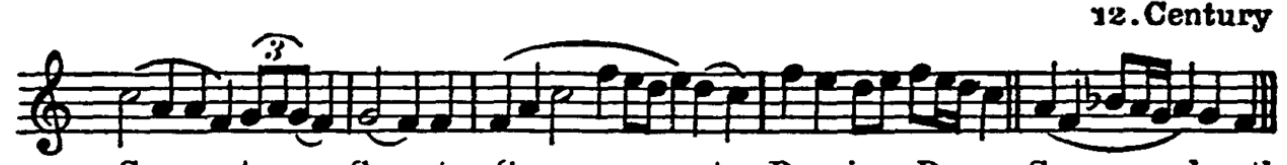
San-ctus, Sanctus, San ctuspominusDe-us Sa - baoth.

2
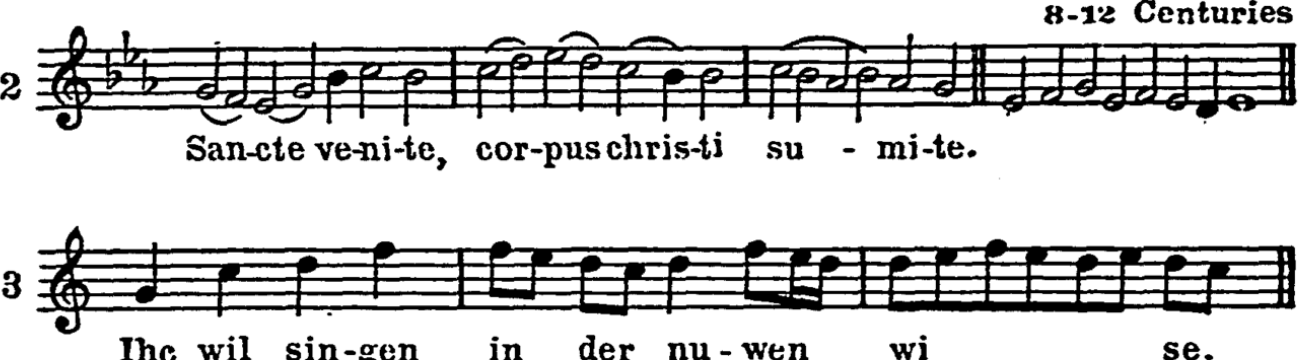

Ihc wil sin-gen in der nu-wen wi se.

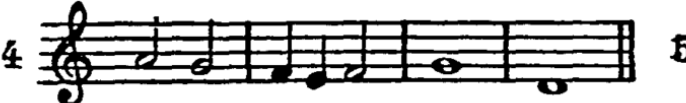

$5+2$

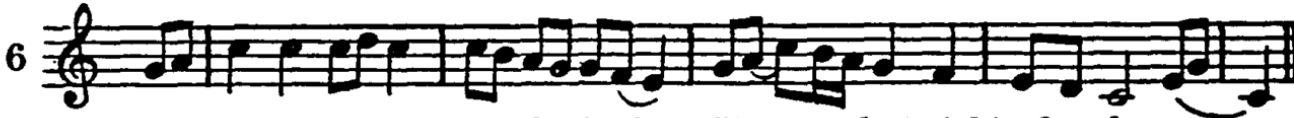
:.... von gol-de daz er di-cke iach, Sie hetnichtschandenmeye.
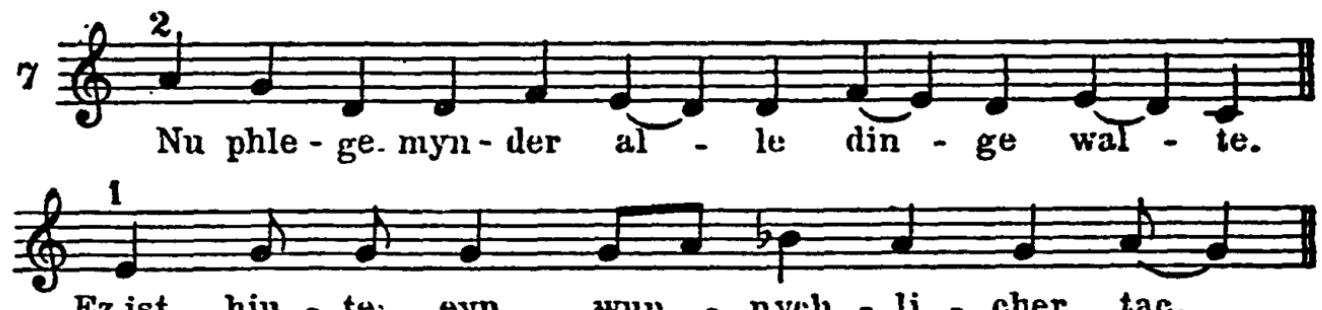

Ez ist hiu - te eyn wan - nych - li - cher tac.

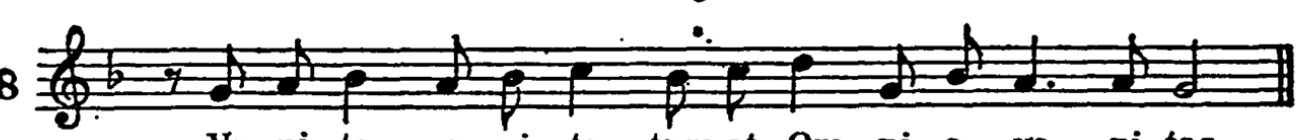

Vị-ni-te, va-nj-til-tum et $O m-n i-a$ va-ni-tas.

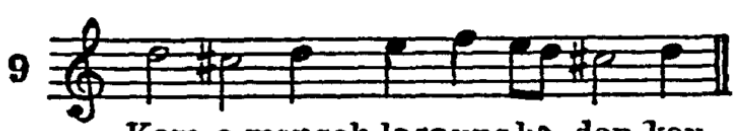

10

Kom, o mensch, lass uns be-den-ken.

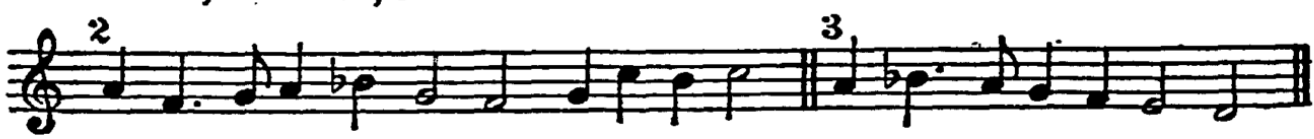


11

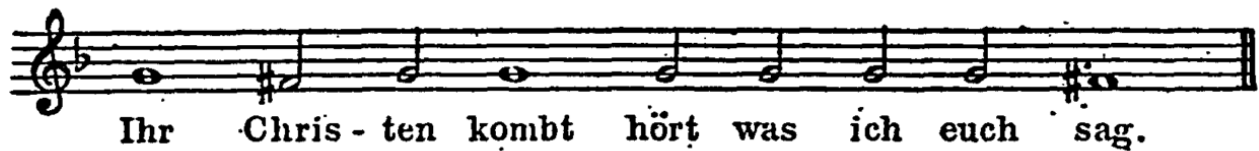

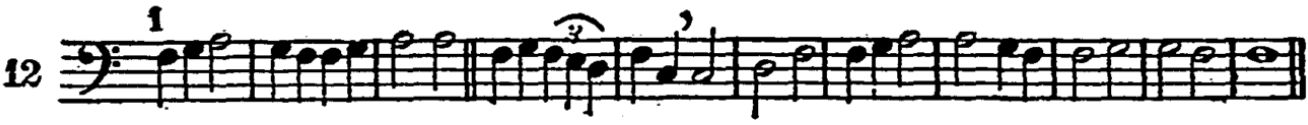

HEINRICH VROWENLOP, d.1318

13

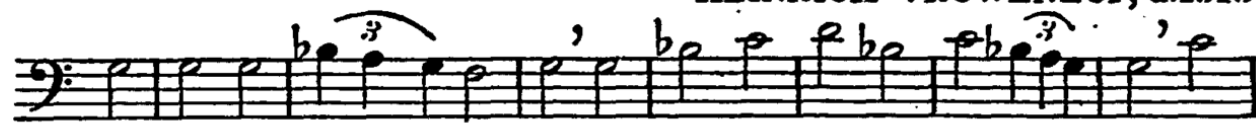

Swa sich die tu-gent ir biv-tet. Dakomt sie mit vur-mez-zen heit.Der

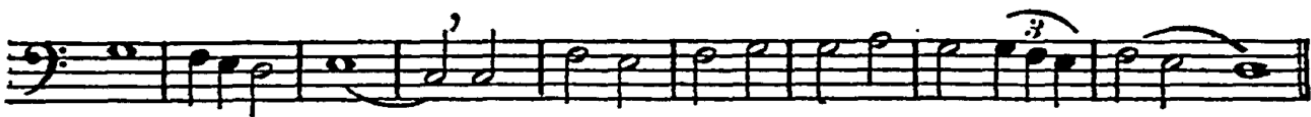
sel - den kleyt. Treit sie myt ir vil gar am vu -der - scheit. JOSHUA FEINSINGER, 1838-182\%

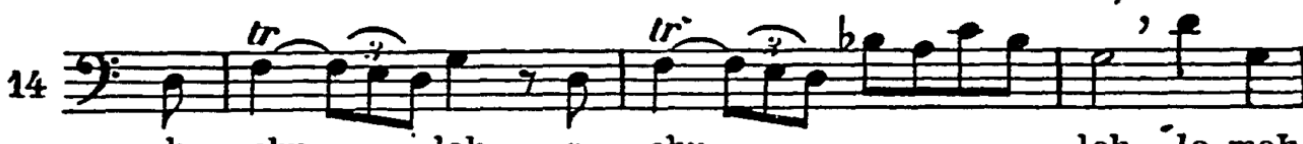
she - chu - loh a-chu - - - loh 'lo-moh

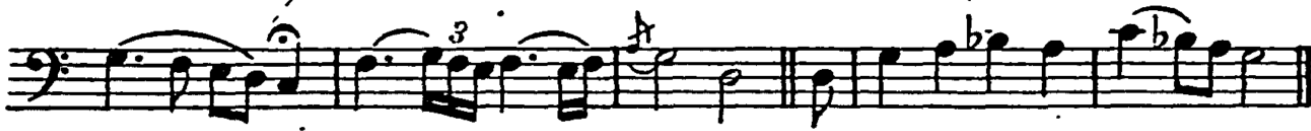
Siv - ki, lo - moh $s i v=k i$

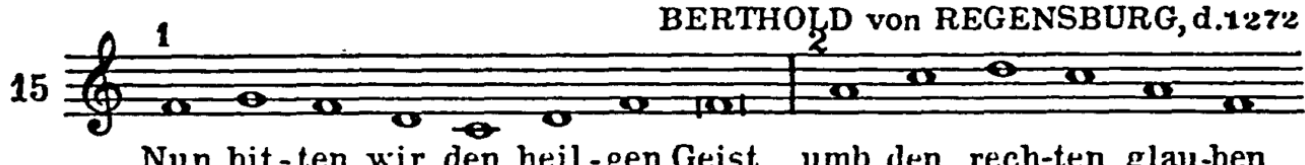

Nun bit-ten wir den heil-gen Geist umb den rech-ten glau-ben

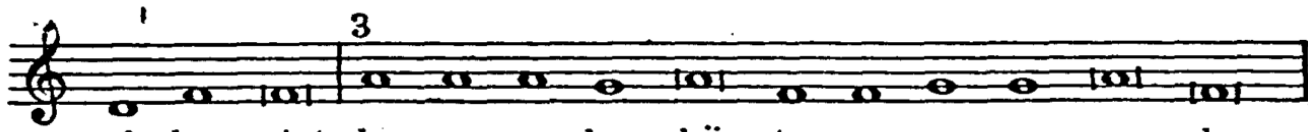

al-ler-meist, das er uns be - hii - te an un-serm en - de

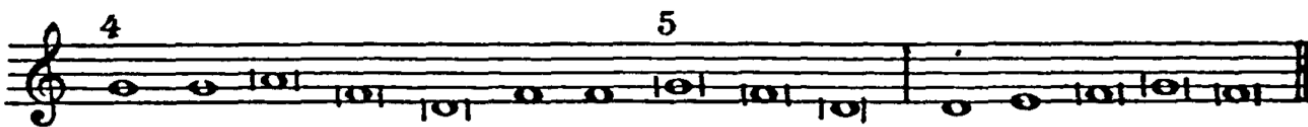

wenn wirheim-farn aus die-sem e - len-de, hy-ri-e e-lei-son.
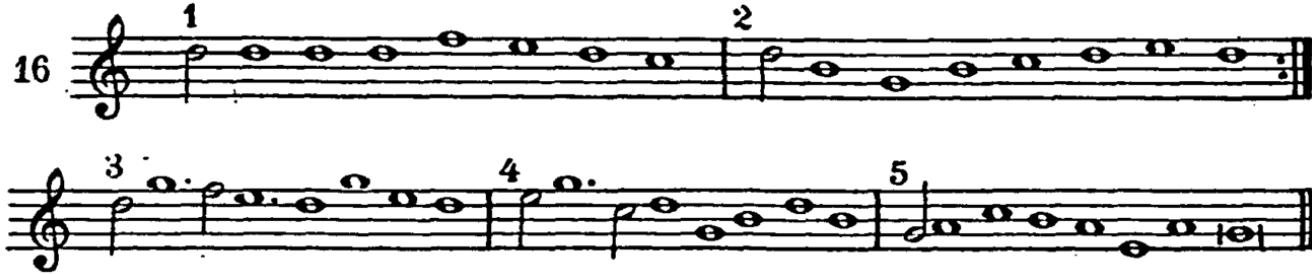
the basic elements, the heart of the tunes. They resisted during the centuries all sorts of styles and yielded only to some reshaping. We meet them in the innumerable settings of the last two centuries, now in the barock style of the eighteenth century, now in the classical style of the first part of the nineteenth century, or in the Slavic-Oriental flavor of the Eastern chazzanuth. We find them shaped in the lyric-sentimental German Lied-style of the romantic school in the middle of the nineteenth century, and a half-century later set in the elaborate form of the dramatic style for chorus and organ plus orchestra.

The other motives employed in these tunes are transmutable, or only of temporary value, in order to satisfy the taste of the age. Some of them, however, were retained, while others gave way to other motives in "fashion," as products of a new musical style.

The tunes of XXIII are highly regarded in the Orthodox Synagogue and are still sung with reverence in Central and Western as well as in Eastern Europe. They still bear the imprint of loose modal form, in which the predominance of the motive is apparent. In them the characteristic freedom of the modes is retained, for they offer free play to the singer for improvisation, in changing the motives or modifying them.

(B) Of the tunes with poetical texts from the same and later periods we give a selection in table XXV:

I. Oschoh edrosh, a poem based on the meter of four words to the line and four double lines to the stanza, by Simon bar Abbun (eleventh century). The tune and form of rendition are described in the fifteenth century. ${ }^{60}$ The poem was repeatedly imitated in meter and form, and its tunes were adapted to these imitations.

2. Emechoh nososi, by Meshullam ben Kalonymos (tenth century). This "sweet and beautiful tune" was known already 


\section{TABLE XXV}

Ashkenazic tunes for individual poetical texts
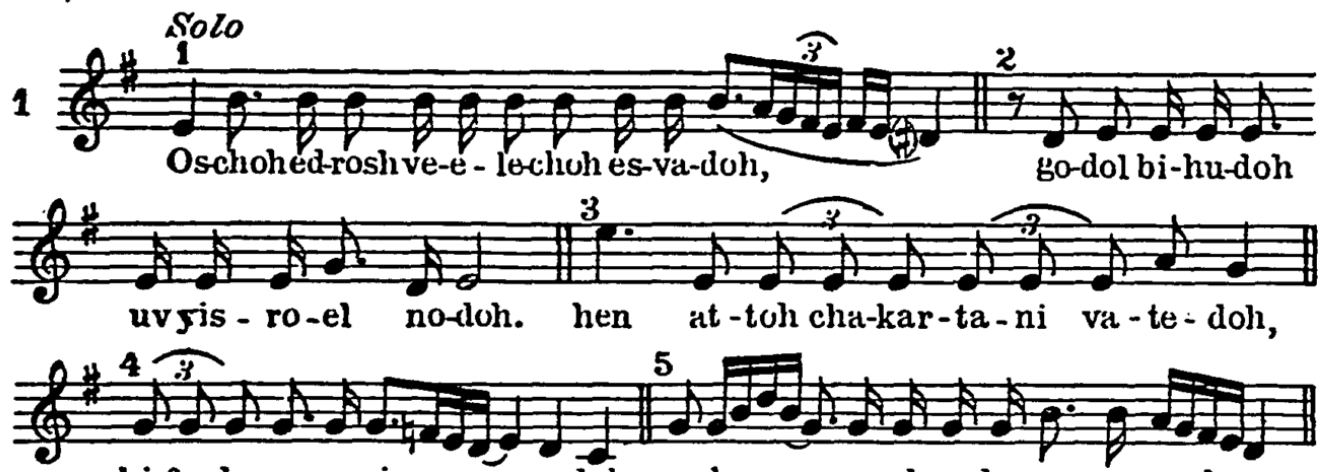

ki forsho-ay ậ-ni

e-dolı. e-da

a-vol a-shemim a - nach-nu Solo and Congregation
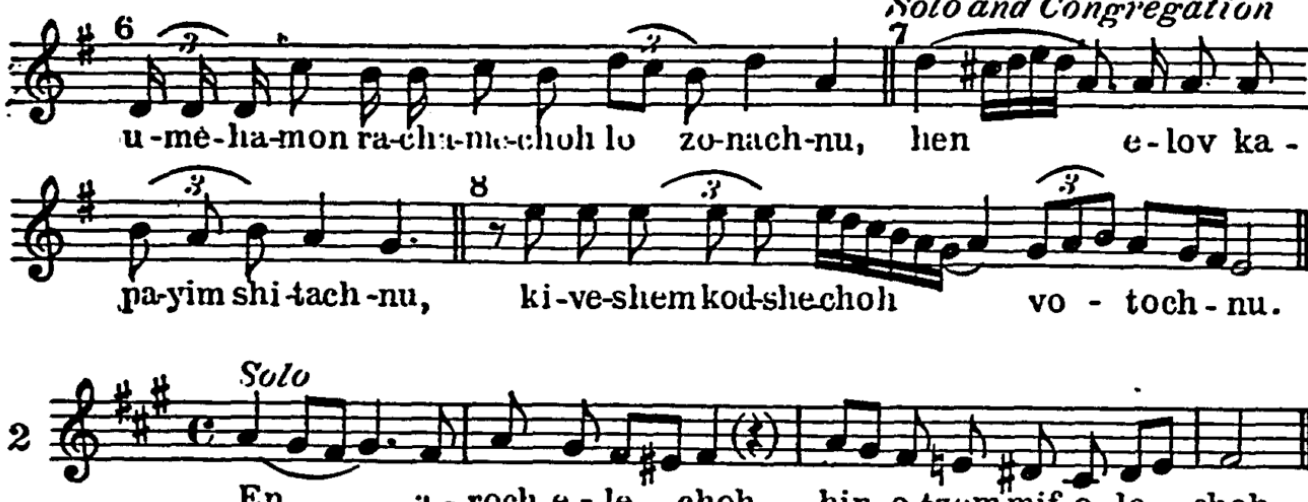

En a - roch $e-l e-c h o h$

bin o-tzemmif-o-le - choh.

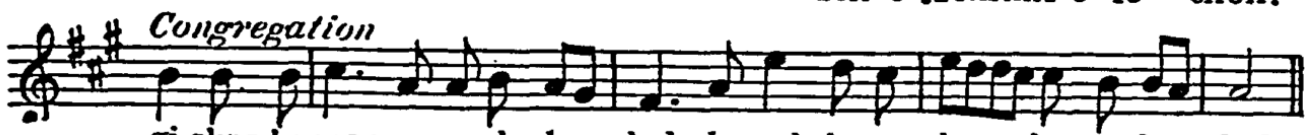

gi-shas liatmon me-ya-cha-le - choh, derosh le-gä-ber cha-yo-le - choh.
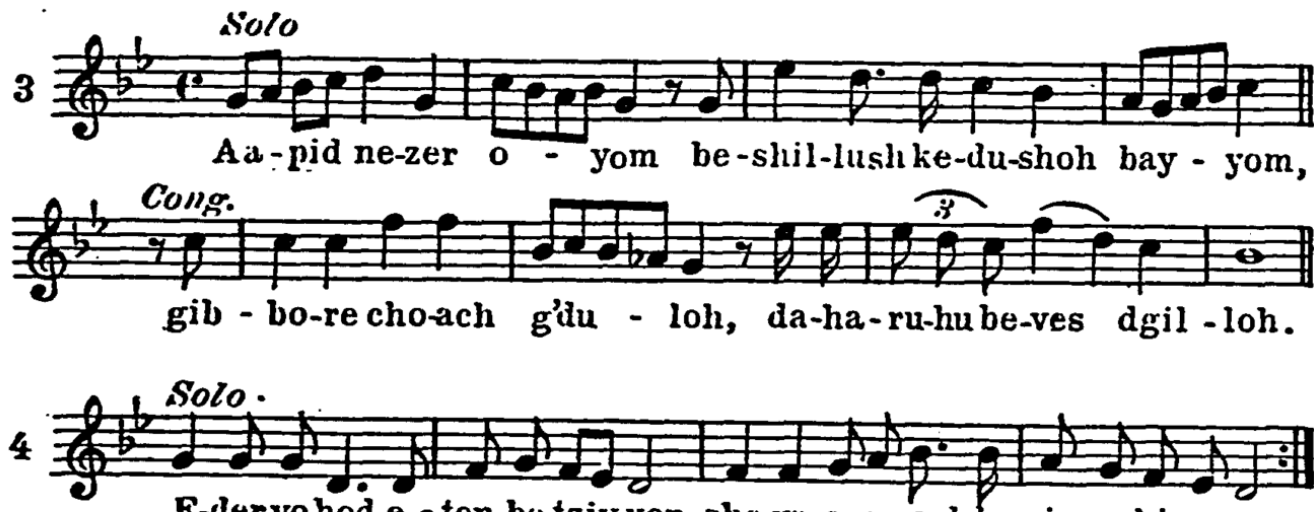

E-dervohod e - ten be-tziv-yon, she-va e-e-roch be-niv ve-hi-go-yon.

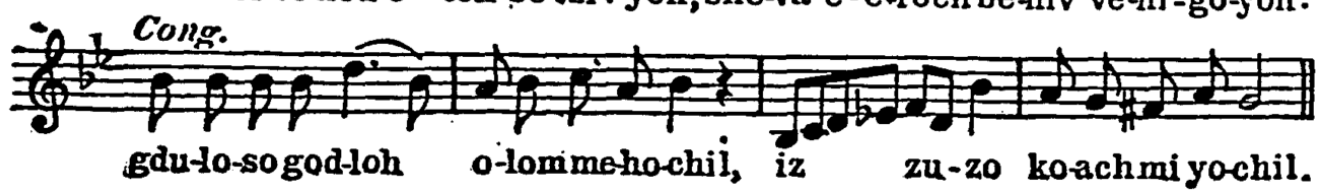




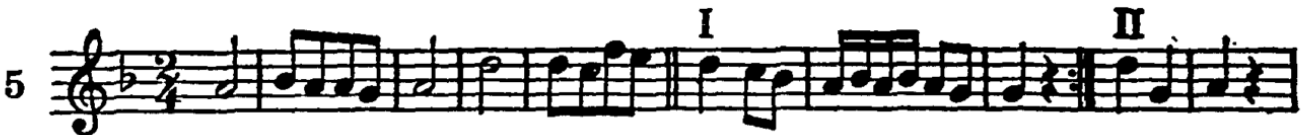
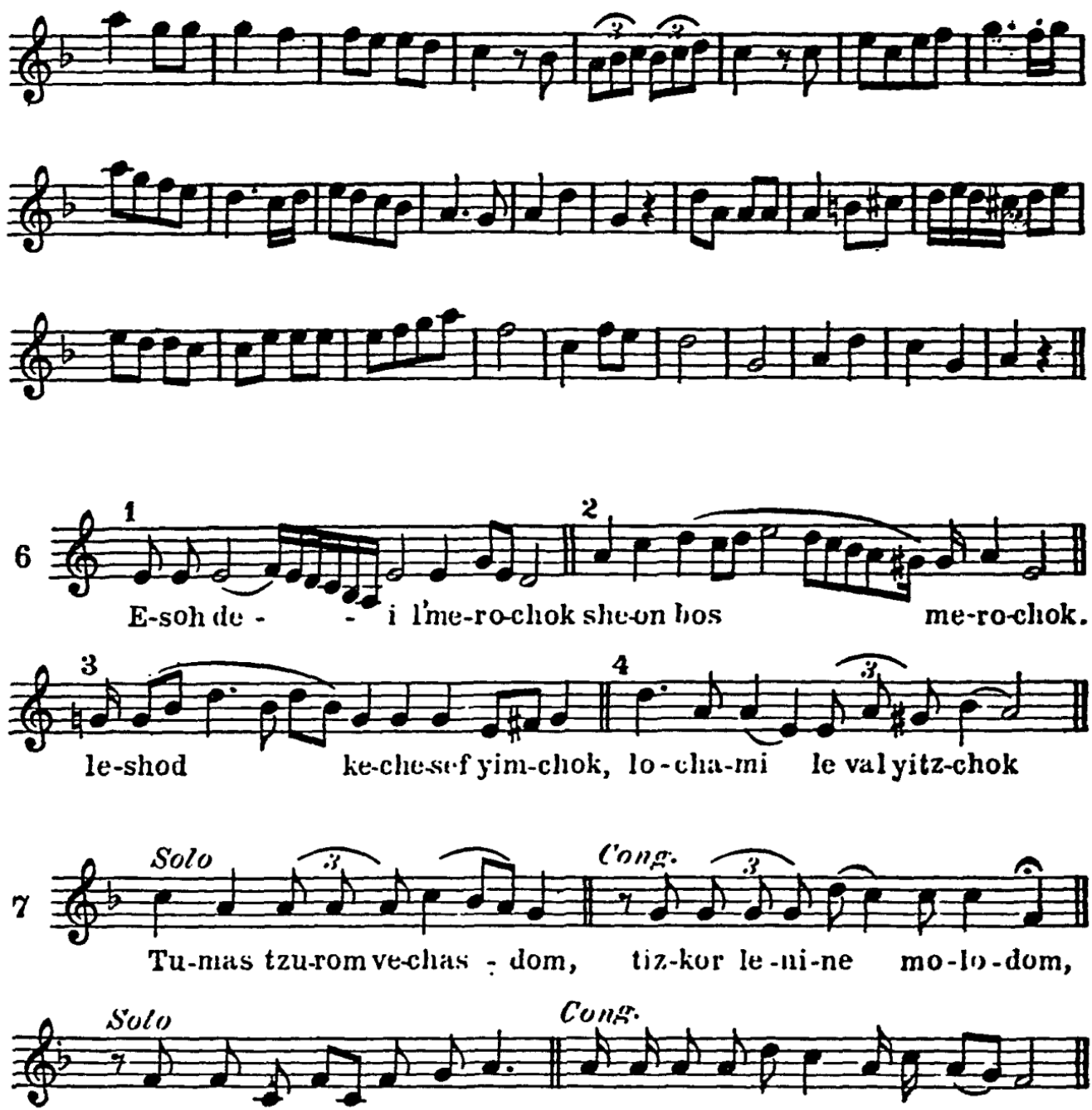

shiv-tom be-ge maf-chi-lom, she-fu-timbe-ro-a ma-a - bo-dom.
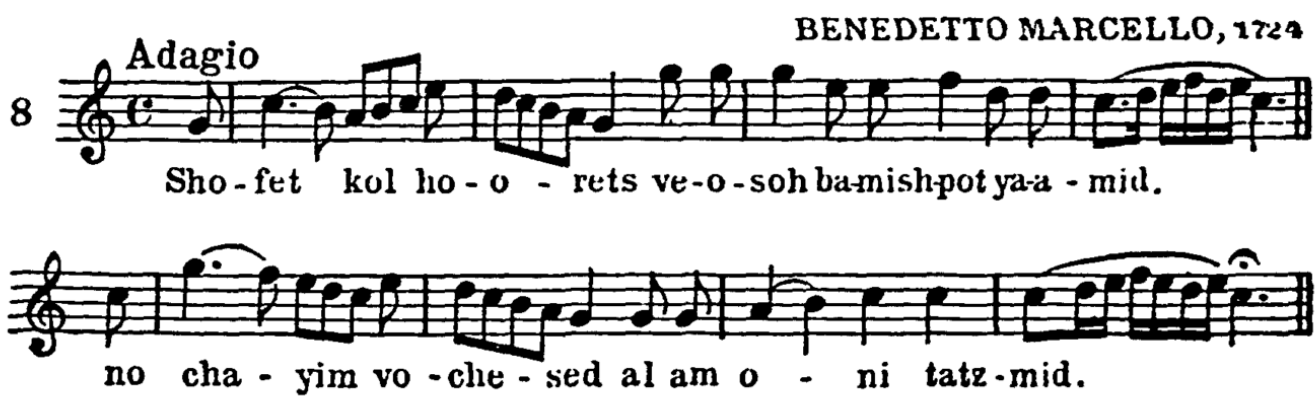

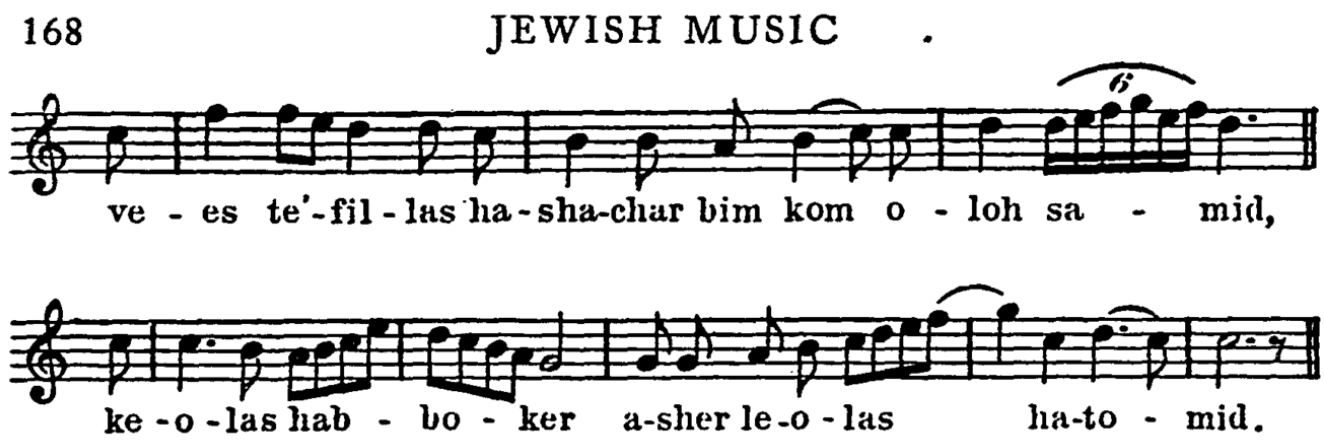

9
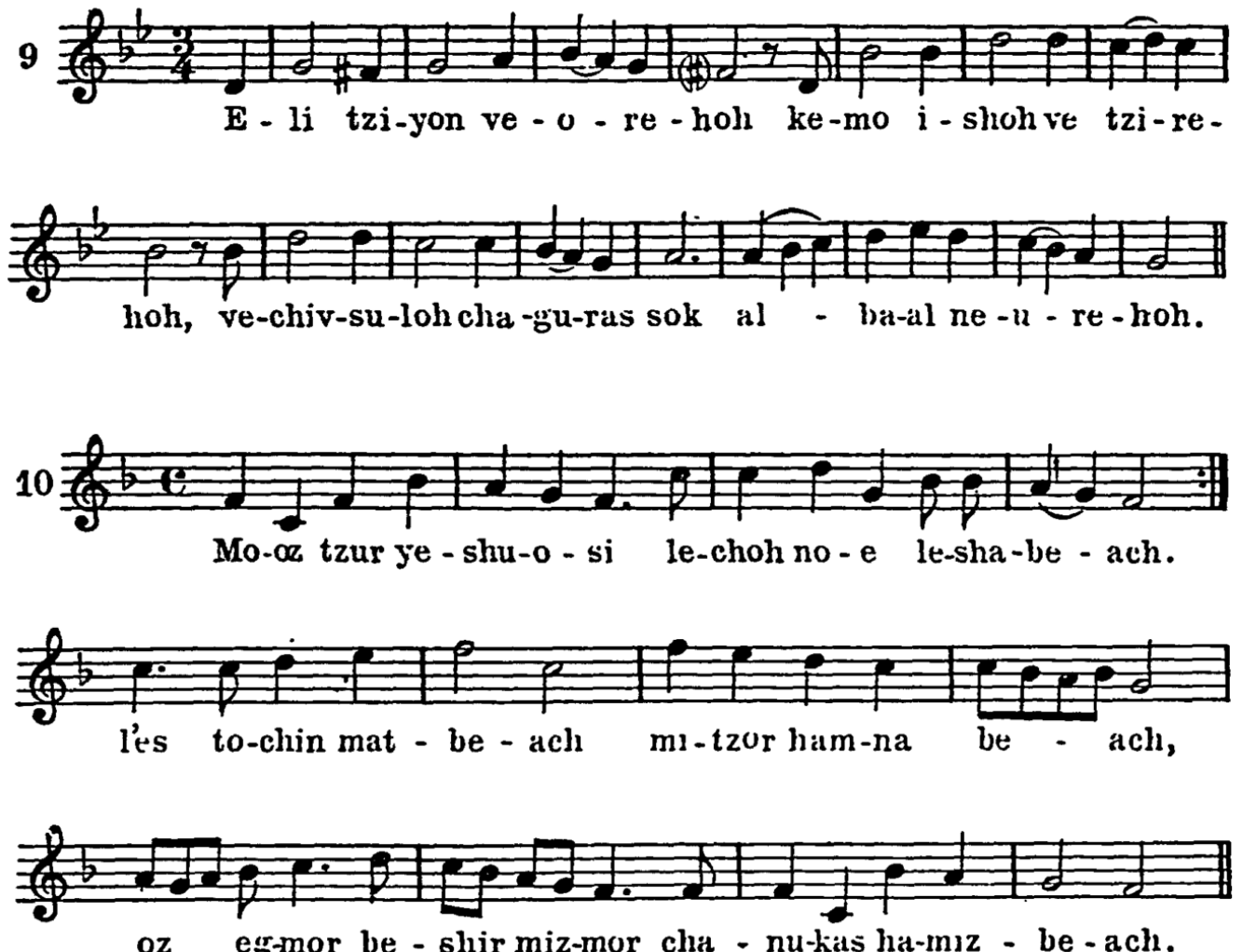

Addir hu

1644
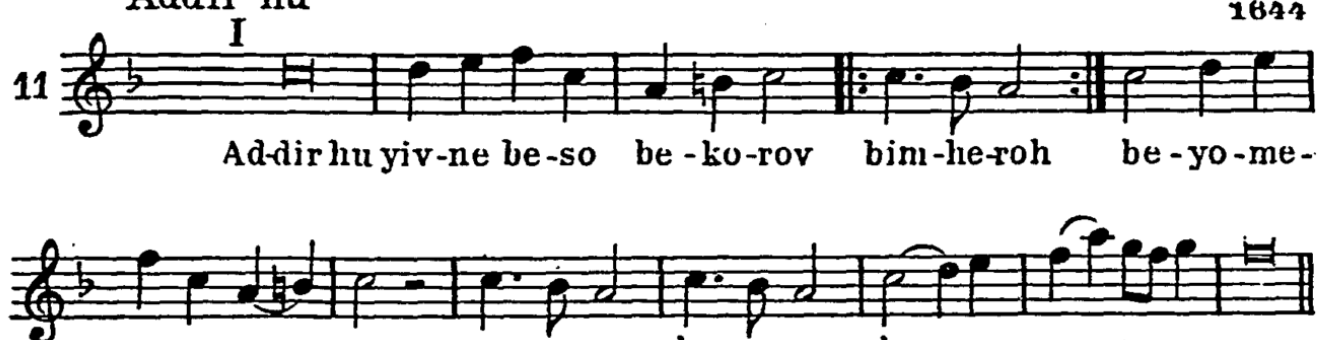

nu be-ko - rov,

el be-ne, b'ne be-ne, b'ne bes-choh be-ko-rov. 

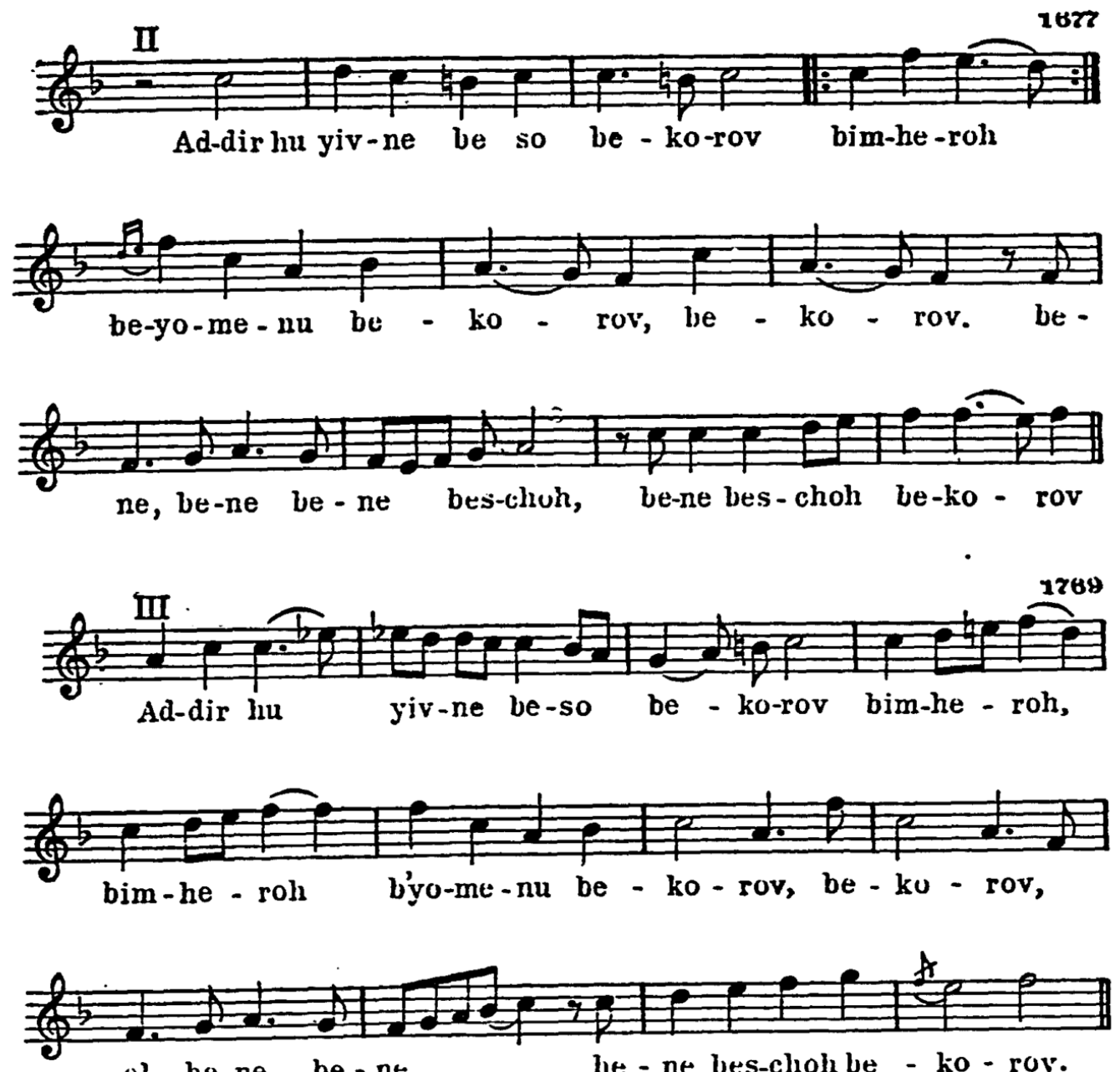

el be-ne, be-nt

be - ne bes-choh be - ko - rov.
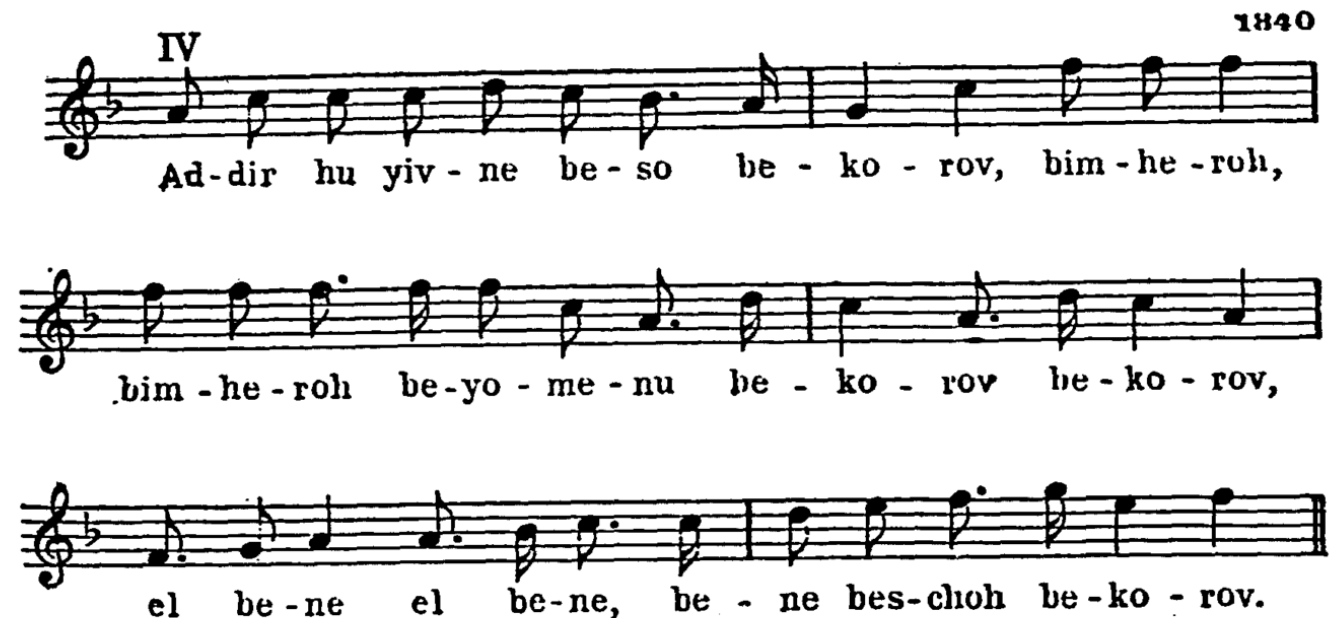

el be-ne el be-ne, be - ne bes-clioh be-ko - rov. 
in the fourteenth century. ${ }^{67}$ The tune was also adopted for other poems, like Osisi by Simon bar Abbun, and Yoreisi by Yekuthiel ben Moshe of Speyer (eleventh century). It was likewise used for the Neila Kaddish (concluding service on the Day of Atonement) and for Ochiloh loel. (Compare XXI, 6, b.)

3. Aapid, by Eleazar Kallir, three words to the line and two double lines to the stanza. The tune was famous in the fourteenth century, and Jacob Mölin Maharil adopted it for other poems of similar meter. The tune is rendered in responsive form. For the same text there are two tunes traditional in different congregations. These tunes are employed also for other poems $(X X V, 2-3)$. Both are identical in rhythm (c), form (responsive) and length (eight bars). They are alike based on minor and modulate to the parallel major.

4. Eder vohod, four words to the line, by the above mentioned S. bar Abbun. This tune too was adopted for several poems. It resembles the Ledovid boruch tune. ${ }^{68}$

5. This is a tune used for various poems. The example is taken from MS. Goldstein (I79I).

6. Esoh déi, three words to the line, by Kallir. The tune consists of four parts, has no strict rhythm, and is used also for other texts, such as Boruch sheomar. In the Italian song of the Synagogue the tune is used for another text. ${ }^{69}$

7. Akeda (dealing with the sacrifice of Isaac), three words to the line and four lines to the stanza. The tune was customary in the fourteenth century, and was referred to by Maharil as the Akeda-tune, because it was used for all the poems with the same content and meter. The author of the poem in example 7 is Benjamin ben Yerach. ${ }^{70}$

8. This is of special interest inasmuch as it was known at the beginning of the eighteenth century as traditional even 
in the Ashkenazic congregation in Venice, and is one of the twelve Jewish tunes chosen by Benedetto Marcello as themes for his Psalms (Chapter X). The tune in example 8 was copied from Marcello's work Esto poetico armonico, No. $2 \mathrm{I}^{71}$ This tune is also found in the German Protestant song in two forms, given in table XXVI, 3-4. Example 3 is similar to Marcello's version, while 4 is the version now used in the Synagogue, and is a composition by M. Vulpius of $1609 .^{72}$ The poem is by Solomon of France (eleventh century).

9. This is the elegy Eli tziyon sung on the Day of Destruction. The same tune is found in the German-Catholic Church as one of the "fast songs" printed in I642, given in table XXVI, $5 .^{73}$ On the other hand, the tune is found as a Spanish Folksong of the seventeenth century, illustrated in $\mathrm{XXVI}, 6,{ }^{74}$ as well as a Czecho-Slovakian folk-song (XXVI, 7).$^{75}$ Thus this tune was popular simultaneously in Spain, Germany, and Bohemia. However, its character indicates that it originated in Spain, whence it was in all likelihood carried to Central and Eastern Europe by pilgrims; and was picked up by Jewish singers likewise. We find many such "travelling" melodies in the medieval age. ${ }^{78}$

IO. Mooz tsur is the well-known Chanukah hymn. Its typical German characteristics are obvious, and we become more convinced of its German origin by comparing the tune with the themes in XXVI, 8, 9. No. 8 is the well-known chorale by Martin Luther Nun freut Euch Ihr lieben Christen, for which text he adopted the tune of an old German folksong: So weiss ich eins was mich erfreut, das plumlein auff preyter heyde. ${ }^{77}$ From this chorale only the first four and the last two bars are to be found in the Mooz tsur, while the middle part (bars 5-8) has a reminiscence of the battle-song called the Benzenauer which was composed in 1504 and became very popular throughout Germany. ${ }^{88}$ In XXVI, 9, the 


\section{TABLE XXVI}

Motives and tunes of German religious and secular Folksong

1

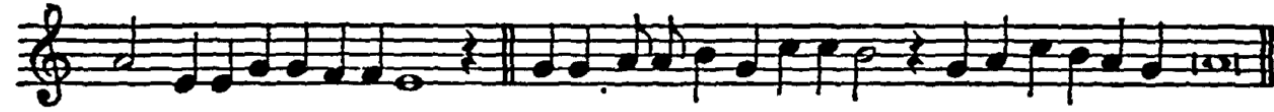
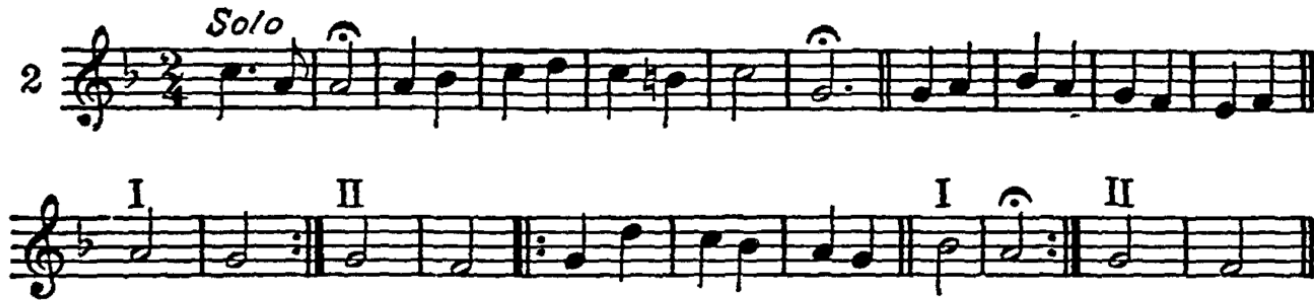

3
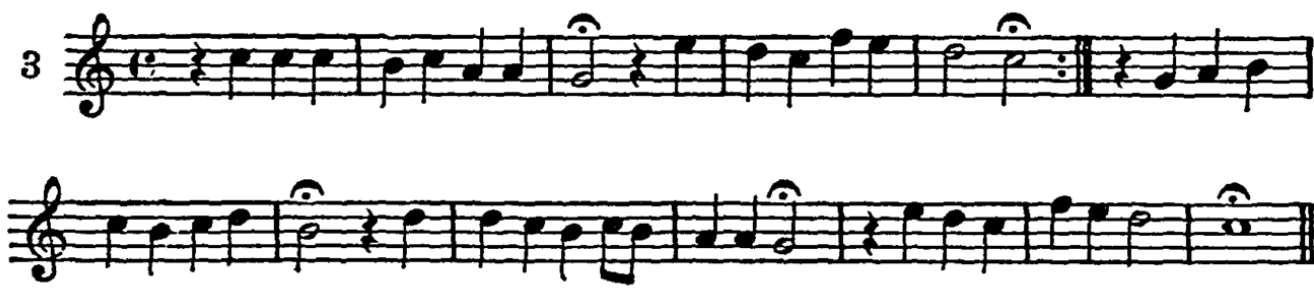

4

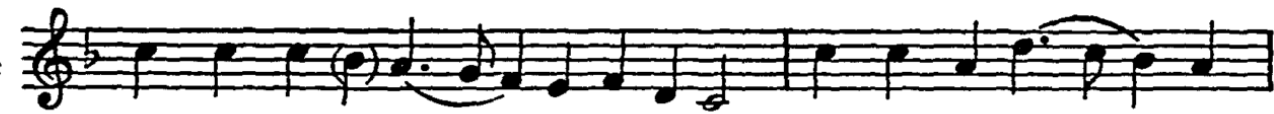

Lobt Gott den Herrn iln Hei-denall, lobt Gott vonHer - zen -
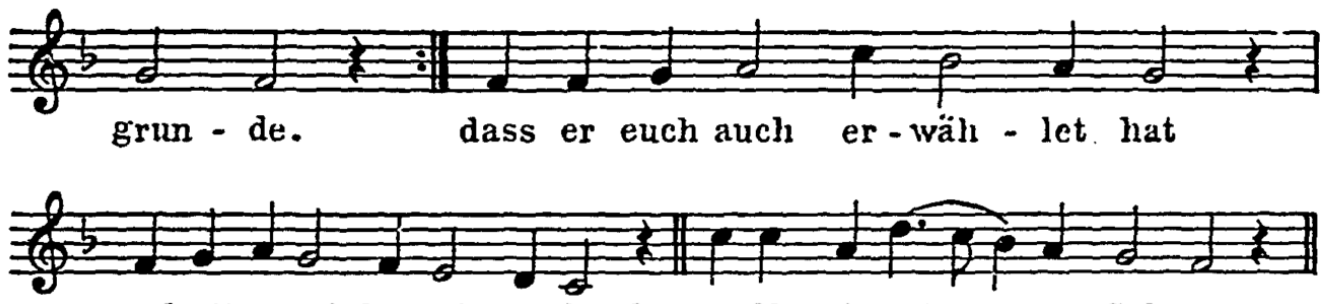
undmit ge-tei -let sei - ne Gnad inChristo sei - nem Soh-ne.

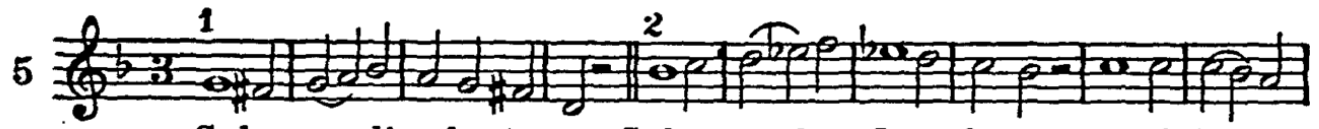
Sałuemundi salu-ta-re, Sa-lue sa-łue Je-sucha-re, cru-ci tu-ae

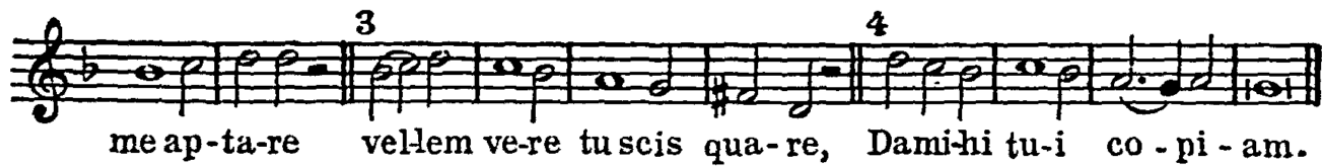


Aiñhara

6
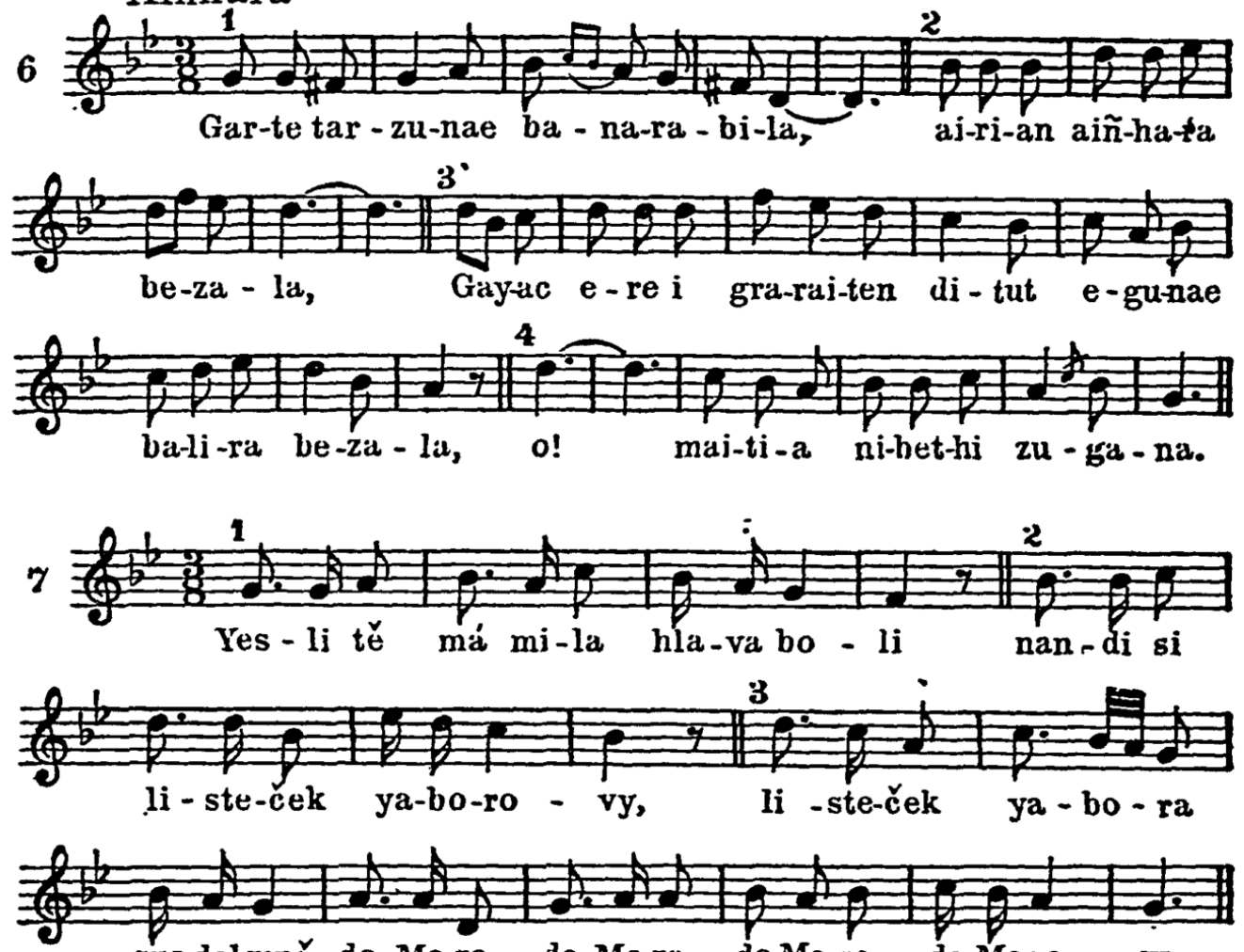
spardel mně do Mo-ra, do Mo-ra, do Mo-ra, do Mo-ra - vy.

8

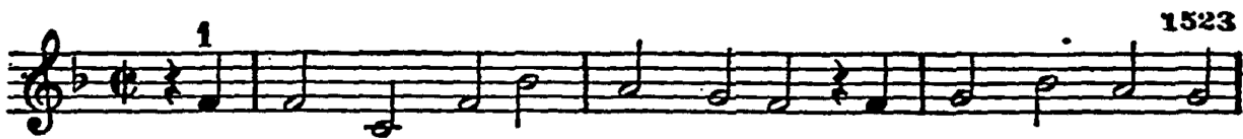

Nun freut euch lie-ben Chris-ten gmein und lasst uns fròh-lich

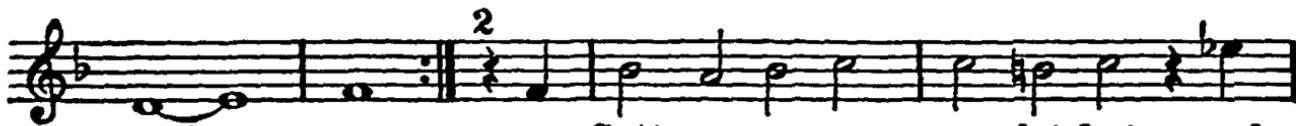

sprin - gen. was Gott an uns ge - wen-det hat und

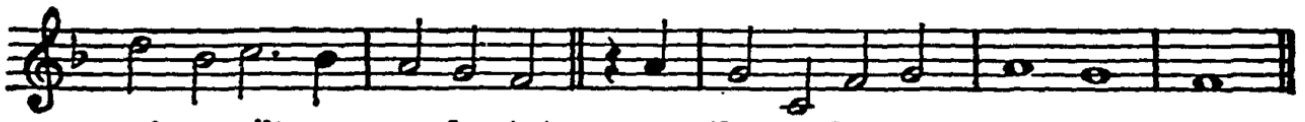

sei-nensüs-se wunder-tat, gar theuerhaters er-wor - ben.

1504

9

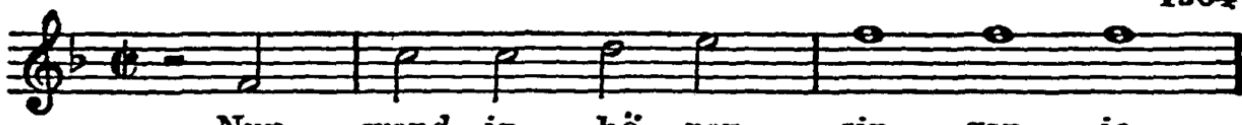

Nun wend ir hö - ren sin - gen ie -

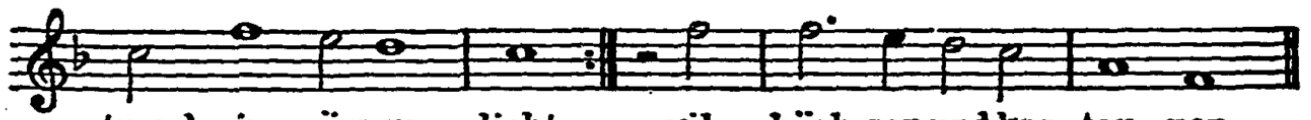

tzund ein nüw ge - dicht. vil büch-senundkar-tau-nen. 
part of the song similar to Mooz tsur is given. The two German songs penetrated into the Ghetto, and were fused in the mind of some Jewish singer into one tune and used for the joyous theme of the victory of the Maccabees. It was first sung at the home-service of the kindling the Chanukah lights, and was later introduced into the Synagogue. The poem, however, was sung long before the invention of the present tune, and it had another melody in $1450 .^{79}$ In 1606 we hear of an imitation of this poem to be sung in the same melody, ${ }^{80}$ while in Venice the Ashkenazim sang the poem to another tune, which, too, Marcello selected for his Psalms: No. $15{ }^{81}$

II. This is the well-known tune for Addir hu for the Seder service on the first two nights of Passover, and it was, likewise, carried over from the home into the Synagogue. This tune underwent several variations until it received its present shape. We have its oldest form printed in I644 in the Hagada published by J. S. Rittangel (ii, I), a second form in 1677 by the convert F. A. Christian in his Hagada "Zevach Pesach" (ii, II), and a third version printed by another convert (Gottfried Selig) in I769 (ii, III). In the last-named, the JewishGerman translation is added: "Allmächtiger Gott, nun bau dein Tempel, Schiera! (Oh, praise!), also schier (a German wordplay on the Hebrew word meaning speedily) und also bald, in unsern Tagen, Schiera! Yau (yea) Schiera! Nun bau, nun bau, deinen Tempel, Schiera." The song is called Baugesang, i.e., the song of the rebuilding of the Temple. ${ }^{82}$

This tune found its way even to the Southern French Jews. The Bavarian version (in MS.) by M. Kohn has still retained the form of the seventeenth century (ii, IV). Its characteristics are decidedly German, though no identical German tune has yet been found. There are many with some of its motives and features, as for example "Maria's cradlesong" of 1544, or the "Song of the Pilgrims" of $15377^{83}$ 
Apart from the comparison of Jewish and German tunes offered, we give some more parallel tunes of the German-Catholic song in table XXVI, such as $\mathrm{I}$, which is similar to XXV, 4 . The German melody was printed in 1619 and an older setting of it is known from $1582 .{ }^{84}$ In like manner do we find for XXV, 7, a parallel in XXVI, $2 .{ }^{85}$

Jewish elements, we find only in example XXV, 5, in which the concluding motive is derived from the sof-passuk of the Prophetic mode, while I and 6 have the flavor of the Biblical modes. Thus, in the group of tunes for poetical texts we notice that the Jewish element is almost abandoned, that the rhythmical element became the basis, and that in most cases the tunes are either in toto or in their main features and elements adoptions from that period of German religious and secular folk-song.

The reasons for the stagnation of the musical creation of the Jews in Germany in the later period of the medieval era are manifold. Of first importance is the desperate social position into which the Jews were forced since the thirteenth century. German music was enriched through the Minnesinger, the Meistersinger, and, beginning with the sixteenth century, through the Protestant movement which strengthened German song and brought about the birth of German poetry and music. At the same time Jewish culture, the product of a small, oppressed, and disfranchised dwindling and scattered minority, declined, impoverished by reason of cruel persecutions and brutal expulsions from century-old settlements to Eastern Europe, to Italy, and the Balkan. The German neighbors, at first inferior culturally, became superior; and the Jews, crushed in body and spirit, were influenced by the song of their oppressors. The song of the Synagogue in Germany, beginning at least with the sixteenth century, became Germanized. All musical 
material that originated in that period has typical German characteristics with but little Jewish flavor.

This fact may give us a clue to the reason for the attitude of the spiritual leaders in Germany toward the tunes "newly" introduced into the Synagogue. With the beginning of the sixteenth century complaints were levelled against chazzanim for abandoning the old sanctified tunes inherited from the fathers, tunes which gave tonal expression to the religious thoughts. The above cited chazzan Herz Treves inveighs against the new chazzanim who neglected the traditional functions of the precentor and the study of Jewish lore, who centered their interest in displaying their singing and their art, employing tunes which had no relation to the prayer texts. They further embellished the poem with elaborate music, and did not pay attention to the prayers proper. The chazzanim chose to officiate only during the Musaf service because that service offered them the opportunity to display their art, and they considered the officiating at the Mincha service beneath their dignity. This change took place at the same time when in Central Europe the ars nova began its inroad from Italy into Germany. ${ }^{86}$ On the other hand, the Protestant movement abolished the Gregorian chant about the same time and replaced it with the German folk-song.

The introduction of new songs into the Synagogue aroused opposition by reason of the innovation. But a more fundamental, if less obvious, cause for the antagonism was something in the very nature of the new tunes that was displeasing to the Jewish spirit, while in the old tunes there was something that spoke to the Jewish sentiment. Of that "something" we become aware on examining the two types of songs. The older elements explained in I, II and III (A) still bear Jewish Semitic features in that they consist, to a considerable part, of Jewish motives and retain to a certain degree the modal form; 
while the "new" type, i.e., the tunes for the poetical texts treated in III (B), comprise adaptations and imitations of German folk-tunes. No wonder that in these melodies the people felt sentiments expressed which were not their own. And the Jew in medieval Germany certainly had sentiments different from those of his persecutors. Even the hopes which the Jews had placed in the liberal Protestants turned into disappointment, for the attitude of the latter toward Jews was by no means better than that of the Catholic Church.

For a long time the new tunes were tolerated by the rabbis. They remained secondary and inferior to the Biblical and prayer modes as well as to the Missinai tunes, namely, groups I, II and III (A). These groups of songs were adopted by all Ashkenazim and were retained also by the Ashkenazic settlers in the East; the "new" tunes in group III (B) remained mostly within the borders of Germany and did not survive in the East, in all likelihood on account of their German character.

In the Catholic Church an effort was made, beginning with Gregory I (d., 604) and continuing to the present time, to preserve the traditional song of the Church and to keep away vulgar secular tunes. In the Synagogue no laws or orders were issued to that end; the Jew being guided merely by his instinct. As long as his Jewish consciousness was strong, wherever he developed his spiritual culture and lived accordingly, his religious song was Jewish.

As stated at the opening of this chapter, at the period of the flourishing of Jewish culture in Germany, the rabbis paid much attention to the ritual of the Synagogue. The last prominent rabbi who rendered great service to the Synagogue song was Jacob Levi Mölin, called Maharil (born in Mayence c. I356, and died in Worms in 1427). He found it his joy and considered it his high duty to be precentor on festivals, fast days, 
and High Holidays. By means of this office he could render service to his people, elevate their spirits and arouse devotion in them by his inspiring rendition of the prayers and songs. He used to travel to many communities in Germany, and in every place he officiated. The Maharil was the greatest rabbinical authority of his time, at least in German countries; and therefore his word was accepted as law all over the country. His opinion was that the communities should hold fast to their traditional customs and melodies. When in the fourteenth century the decay in the spiritual life of German Jewry began, the Maharil, through his exalted personality, saved the integrity of the Synagogal ritual and music by sanctioning the old tunes. The following legendary incident told about him illustrates his attitude toward the sanctity of traditional melodies. While officiating once on the High Holidays in Regensburg, without being informed of the local customs, he changed a tune and used a hymn not used there. In the same year his daughter died; and he considered the blow a punishment for his violation of a local custom. Many of his settings of poems and prayers, as mentioned above, remain traditional to the present day.

In spite of the care the Maharil exercised in Synagogue song, the high spirit of the Ashkenazic service was affected during the atrocious persecutions of the fifteenth and sixteenth centuries, in which period many ancient communities were molested and partly expelled. The German Jew, hated and enslaved during the week, wanted to be refreshed on Sabbath and on the festivals by attractive popular songs which would make him forget his dire position. Hence, the less cultivated people urged the chazzanim to satisfy their desires despite the protest of the rabbis. These people mingled all the week with gentiles in business, and returning home to the Ghetto on Sabbaths, they would demand that the chazzan sing the tunes 
from the outside world for religious texts, to the greatest dismay of the more highly educated Jews. ${ }^{87}$

In many cases, ethics and morality declined in Jewish life in that period and lowered the standards also of religious life. More than once it happened that the service was interrupted by quarrels, and that the chazzan was attacked while officiating even on Rosh Hashanah and the Day of Atonement and was removed from the pulpit by police. ${ }^{88}$ These same chaotic conditions were prevalent at the same time in the Catholic Church. $^{89}$

The repeated expulsions of Jews naturally produced an unsettled community life, which resulted in many congregations not engaging permanent chazzanim. Consequently, the chazzanim used to wander from city to city giving concerts, guestservices, without finding a permanent engagement. This abnormal condition developed the type of the wandering chazzan, with all the bad habits of the wanderer. These, in addition to the artistic strain, gave the chazzan a minstrel-like character, resembling that of the wandering Italian musicians of that time who overran Central Europe.

Partly as a consequence of political and cultural circumstances and partly influenced by the above-mentioned wandering music-makers, the chazzan, as stated above, abandoned all functions connected with his office (Chapter VI), and confined himself to his music, constructing dazzling tunes in order to capture the attention of the mob. To put an end to this demoralization, at the request of the old community of Bamberg, Rabbi Moses Minz wrote detailed regulations for the chazzan: how he should behave in the synagogue while officiating, what garment he should wear while in the synagogue, how he should conduct himself with members of his congregation, and that he should always be concerned about the dignity of his sacred office. ${ }^{90}$ 
However, in those communities which were fortunate enough to escape the brutality of the raging Christian clergy and mob, the dignity and continuity of tradition were maintained. Consequently, their "minhag" (custom) became the standard for other communities which, after having been ruined by the "holy" crusades or other mob outrages, tried to re-establish their religious practices. Therefore, in places like Frankfort, Prague, Mayence, and Worms much stress was laid upon the dignity of the service and upon the quality of the chazzanim. And, indeed, we meet in those communities chazzanim of high rabbinic learning and ethical standard. Thus, an author of the seventeenth century, Joseph Hahn, states that his grandfather, Isaac Hahn, was appointed chazzan in Frankfort not because of his sweet voice but on account of his piety. ${ }^{91}$

From the evidence presented in this chapter, we conclude that the Synagogue song of the so-called Ashkenazim was well established at the end of the sixteenth or at the beginning of the seventeenth century, and that, with the exception of typical German tunes, the Ashkenazic song created in Southwestern Germany spread all over Central and Eastern Europe. 


\section{CHAPTER IX}

THE SONG OF THE SYNAGOGUE IN EASTERN EUROPE TO THE EIGHTEENTH CENTURY.

The thirteenth-century Hebrew poet, Immanuel of Rome, gives in the fifteenth part of his work Machbaroth a very exact description of a chazzan. He recounts that he was travelling with a rich man and met several people, each bewailing his condition. Among them was a chazzan who bitterly complained about his distress and poverty. In response to the question whether he would agree to exchange his lot with that of Immanuel's rich companion, the chazzan immediately assented with joy; but when he was informed that he would have to give also his voice for the voice of the rich man, he grew indignant and spurned the bargain, because through his voice he conquered the heart of the people. This characteristic picture of the chazzan at the time of Immanuel in the thirteenth century would even better suit the chazzan-artist of the seventeenth and eighteenth centuries in Eastern Europe where the chazzan reached the highest degree as artist, casting from himself all those tasks historically associated with his office which drew him down to the station of beadle and servitor of the community.

Only in Eastern Europe did conditions favor the chazzan's making himself solely an artist. The Jewish population in Eastern Europe, especially in Poland, Ukrainia, and Lithuania, has increased during the past three centuries to a phenomenal number. Living in concentrated masses in an environment of a 
very low cultural standard, the Jews developed an original spiritual life; and Judaism found a resting place safe from every influence from without. Being of a people with pronounced musical abilities and inclinations, the Jew hungered for music; and for lack of such performances as the gentile world enjoyed, the Jew sought to satisfy his craving by his own means. Inasmuch as Jewish life was concentrated in the Synagogue, and music meant only sacred music (that is concerned with worship), it was a mere consequence that the chazzan was urged to satisfy the longing for music, that he became the artist, the supplier of tunes, and that the services came to be viewed by the community as musical performances. Even in small places where the chazzan was still burdened not only with his traditional offices which had been transplanted from Germany, but also with the work of shechitah (ritual slaughtering), the demand was made of him to supply music. In the big communities where the chazzan was released from all his other offices and devoted himself to music only, he was honored with the title "city chazzan" (Stadt-chazzan). These chazzanim created a special brand of Synagogue music which the German Jews called Polnisch.

In the first place, let us note the component elements of Eastern European Jewry. The earliest Jewish settlers in the southeastern countries were Oriental Jews from Persia and the Caucasus, were remainders of the Jewish Greek colonies around the Black Sea or came from Crimea; were to a certain extent also Tartaric Chazars who had become proselytes and who after the fall of their empire were spread among and intermingled with the Jewish population. The language of the Jewish settlers was either Tartaric or Slavic, which tongues persisted till the fourteenth century. Only through the German immigrants from the fourteenth century on was the spoken language changed into the German dialect of those 
immigrants. This determining influence was due not to preponderant numbers, but to the immigrants' superiority by reason of the Jewish culture which they brought, and which made them teachers and spiritual leaders of the native Jews.

From the newcomers, the older inhabitants learned also the traditional songs. Now it is to be taken for granted, although no descriptions of examples remain, that, before the German immigration, the Eastern European Jews had a Synagogue song for their service, and that it was probably Oriental. While they neglected their tunes in favor of those of the newcomers, they retained the decidedly Oriental strain of their music, and this they introduced into the Ashkenazic Synagogue song. We saw in the previous chapter that in the preceding centuries the Ashkenazic Synagogue song had been Germanized to a degree that jeopardized not only its distinctive Jewishness but its very existence. In Eastern Europe, on the other hand, the everrenewed Oriental sap penetrated also into the song. Hence, Eastern Europe Orientalized the Ashkenazic traditional Synagogue song, both in its elements and in its forms, by freeing it of the fixed mold of European melody, and developing again the unfettered improvisation of the modes. In this improvisation (in Yiddish, Sogachts), lay the chief power of the chazzanim. Through it, they developed an admirable and distinctive art which surpasses the improvisation of even the Oriental singers, for they created a unique coloratura with an unmatched elasticity and complexity of fine tonal groups and curves-a coloratura of dazzling intricacy and brilliance, of soaring fantasy, of sharp-witted finesse. That type of coloratura is to be found neither in the greatest Arabic and Turkish singers, whose coloratura is too sentimental and vapid, nor in the best coloratura work of Italian music, which is too artificial and rather of instrumental than vocal character. The coloratura in the Eastern European chazzanuth is like the soul in the 
body; without it, that chazzanuth loses its vitality, its charm, its fascination (Chapter II).

An attempt has been made to explain the coloratura and ornamentation in the Eastern European chazzanuth as the product of Talmudic pilpul, of the shrewd intricate dialectics which influenced sentiment as well as logic. But the opinion is a superficial one, for the period of identical pilpulistic character which flourished in Southwestern Germany in the earlier medieval times (the so-called period of the sages or Tossafists in Lorain) produced a chazzanuth which shows not the slightest similarity to the involved nature of that of the Eastern Europeans, but-quite to the contrary-is, as we saw, of a very simple style. On the other hand, the ornamental style which distinguished Eastern European chazzanuth, we find also in the Arabic and Turkish music, as well as in the Ukrainian folk-song and in the Gipsies' instrumental music. Yet these peoples have no Talmud.

In order intelligently to point out the originality of the Eastern European song of the Synagogue and the features distinguishing it from the Ukrainian folk-song prevailing in the South Russian districts from Volhynia through Ukrainia, Podolia, and Bessarabia down to the shores of the Black Sea, we shall have to analyze the characteristic elements of that song. In like manner, we shall proceed with the Roumanian folk-song, current also in Bessarabia and in parts of Hungary. With the aid of the painstaking investigations into and collections of these folk-songs that have been published in recent years, we are enabled to gain a clear insight into the matter.

The Ukrainian folk-song is composed of two types, the unrhythmical fluid recitative, which is supposed to be the older type, and the rhythmical tunes for dancing. The unrhythmical song is based entirely upon the scale: $d^{1}-e^{1 / 2}-f^{9 / 2}-g^{\# 1 / 2}-a^{1}-b^{1 / 2}-c$, the fourth tone 
being an augmented second. The scale has seven tones only, i.e., a heptachord, and is, according to the Ukrainian Musicologist Philaret Kolessa, the (Gregorian) Dorian mode with the augmented fourth. ${ }^{2}$ However, a group of songs ends on the second of that scale, namely on "e." In this case the scale is identical with the Hedjaz scale or scale IV (Chapter II). But Kolessa insists that nonetheless the scale remains the same Dorian. ${ }^{2}$ Kolessa explains that this PECULIARrTY is at home in the folk-song of the districts of Poltava and Charkov and is characteristic of the older elements of Ukrainian and Southern Slavic folk-songs. ${ }^{3}$ The augmented step he considers as an Oriental influence. Furthermore, he states the fact that there is a tendency toward the neutral third, which at times impresses one as major, at times as minor. We noticed a similar fact in the Semitic Oriental song (Chapter II, III). The Ukrainian folk-song is cultivated orally by the blind singers (Kobsari) who accompany themselves on string instruments. The song is improvisation on traditional motives, and Kolessa furnishes a multitude of variations on one and the same theme, improvised by various singers, or by one singer at different times. The accompaniment is usually applied as a short pre- and postlude, which ends with a chord of tonic and fifth, the third being employed only in rare cases.

It is quite apparent that since the Ukrainian song is a mixture of Slavic-Tartaric and Semitic-Oriental elements (and Kolessa is of the same opinion), ${ }^{5}$ it therefore has much in common with Jewish song. Yet in many basic features they differ. In the first place the main scale in the Ukrainian, the above-mentioned "Dorian," is not to be found in the TRADITIONAL song of the Synagogue. The Eastern European chazzanim apply it to a few prayers and call it the $M i$-sheberach or Av-horachamim-Steiger. In table XXVII I-2 we give Ukrainian and Jewish examples in this scale. Likewise, we furnish some examples of the Ukrainian song with the ending on the second XXVII $5-7 \cdot^{\circ}$

From these illustrations we gain an idea of the Ukrainian modal songs. They have mostly only one motive, varied and embellished. The examples $1,3,4,5,6,7$, are motives which serve as basis for many songs. We learn also the close relation between the type of song ending on the second and the Ahavoh-Rabboh mode explained in Chapter IV. Yet we see unmistakably the original features of 


\section{TABLE XXVII \\ a) Ukrainian Song:}
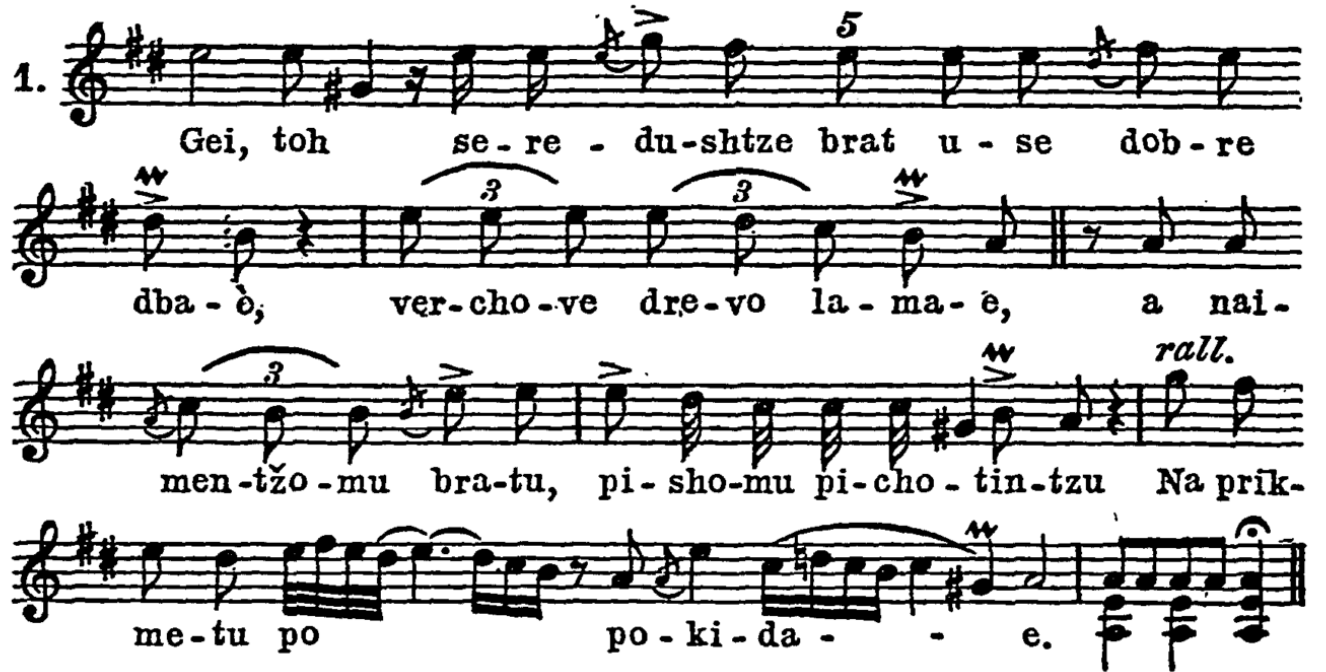

Synagogal Av-horachmim Mode

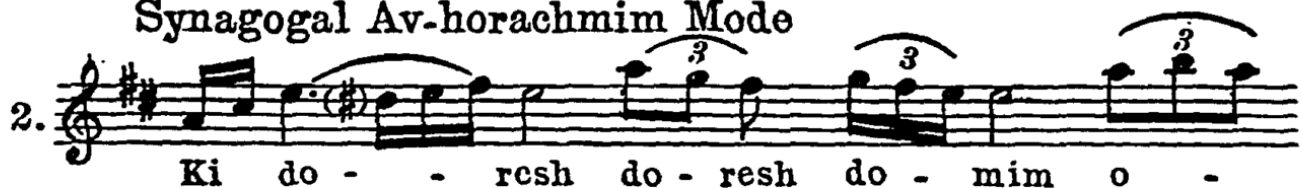

$\mathrm{Ki}$ do - $-\mathrm{rcsh}$ do - resh do $-\operatorname{mim} 0$ -
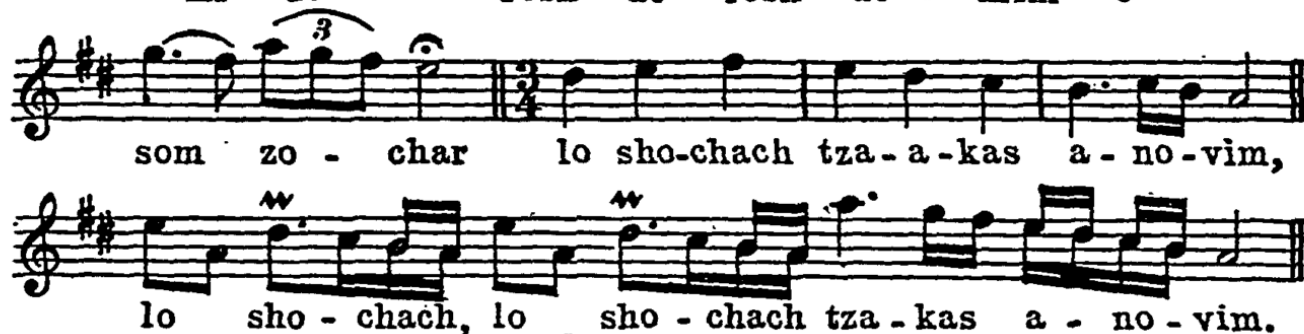

Ukrainian Motives in Dorian
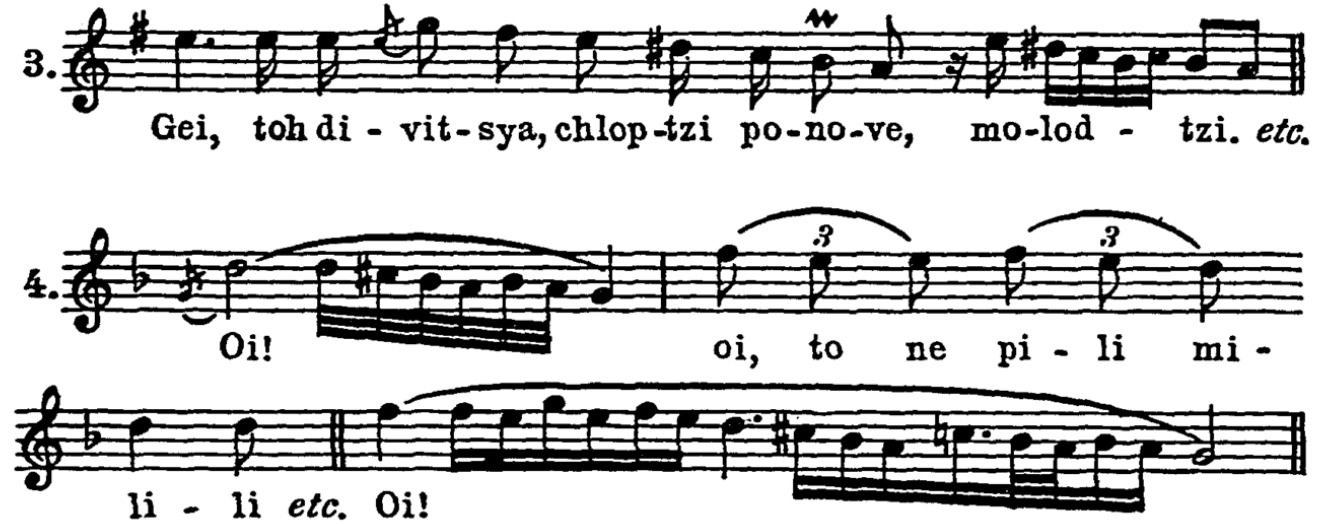
Ukrainian Motives in Dorian,ending on the second

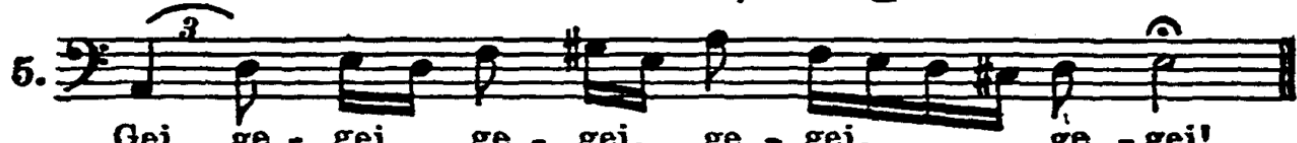

Gei, ge-gei, ge.-gei, ge - gei, ge = gei!

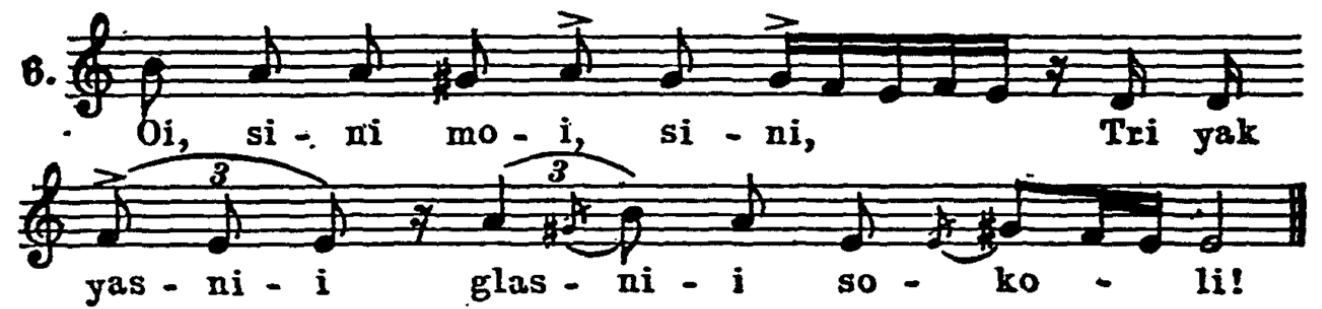

7. b) Roumanian Song
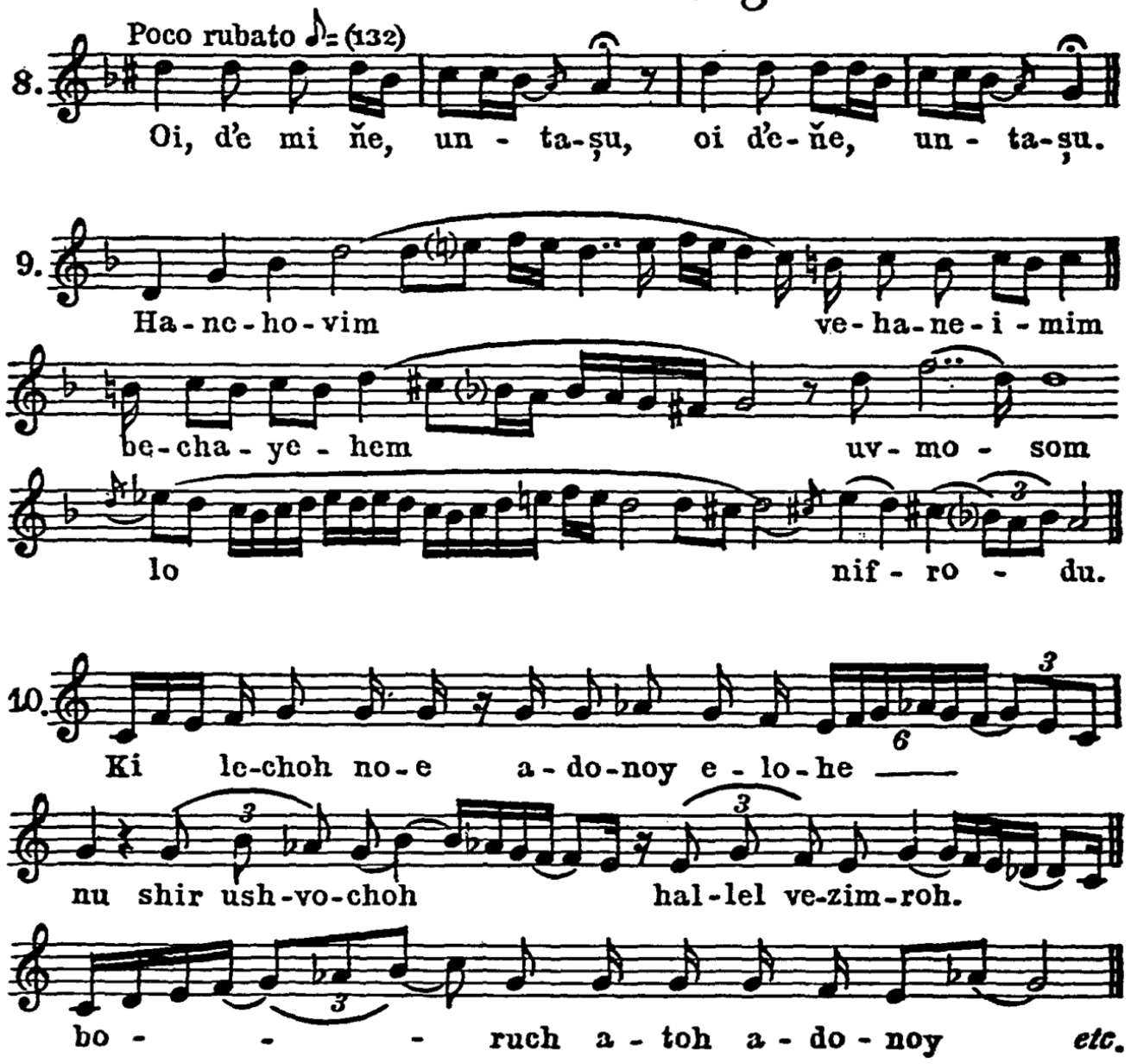
11. 123 Jewish 3 3 $=2$. Jowish

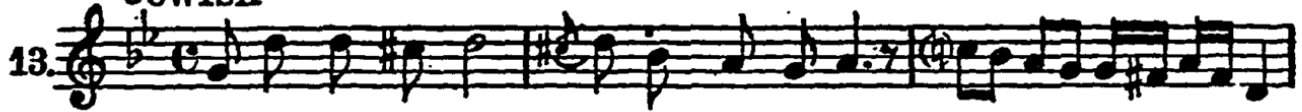
Ad-dir bim-lu-choh, bo-chur kah-lo-choh, gdu-dov yom-ru lo,
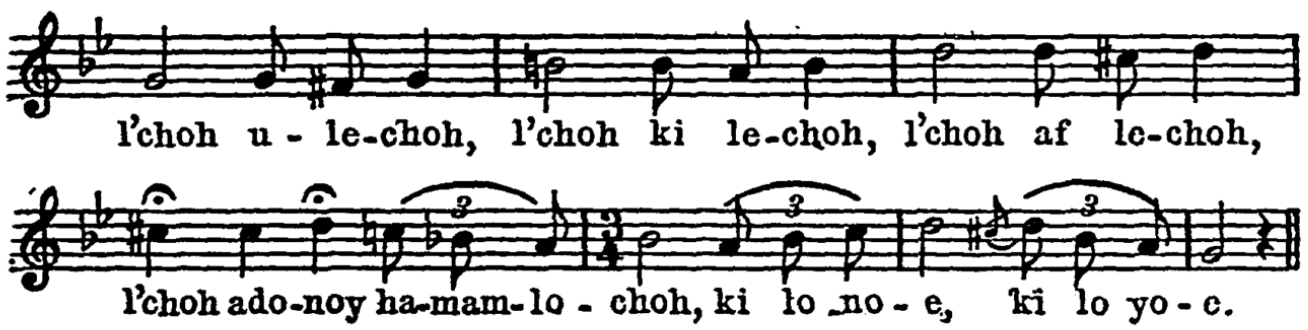

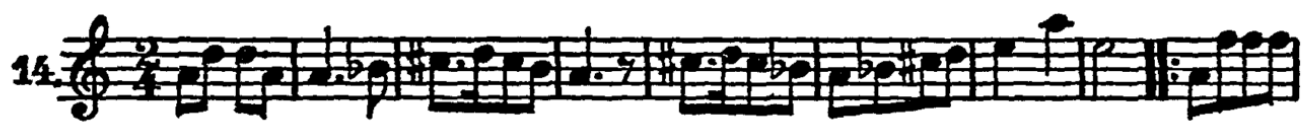

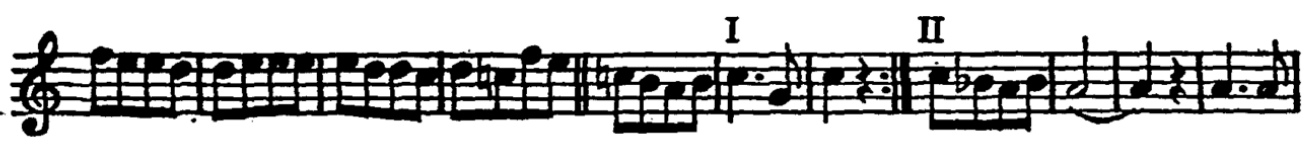
12 30 (singers) 林 
Roumanian

15.
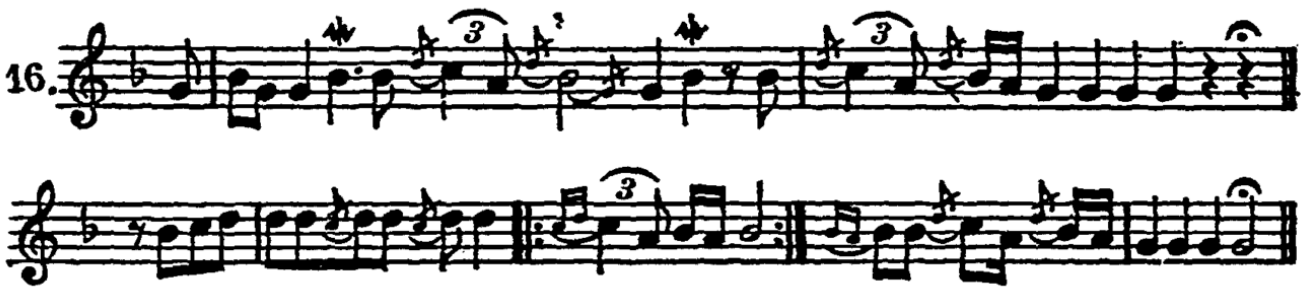

Jewish
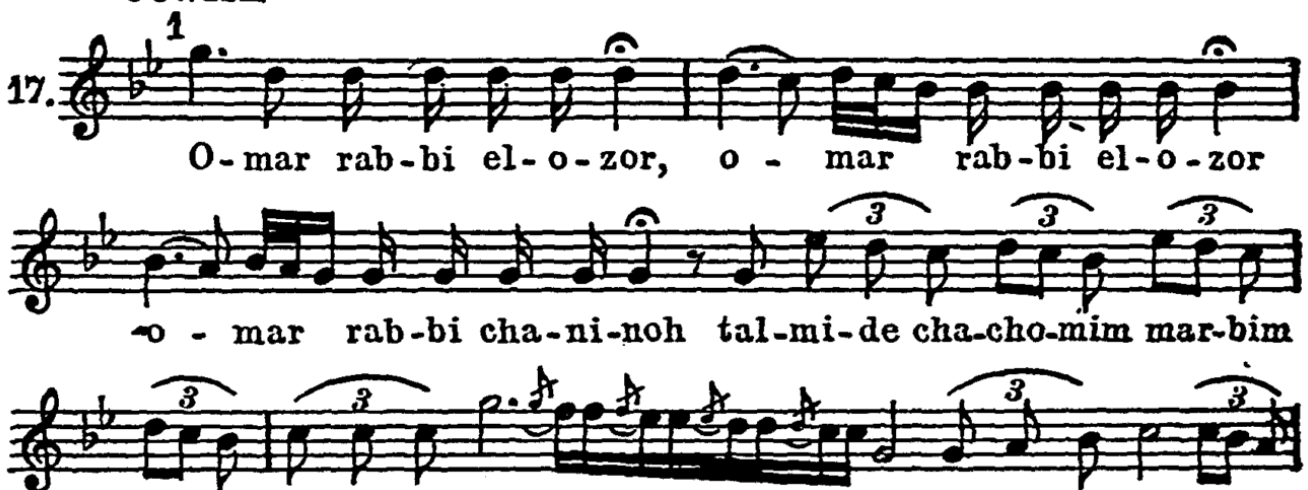
sho-lom,mar-bim sho-lom bo 0-lom, mar-bim sha-lom bo-0 -

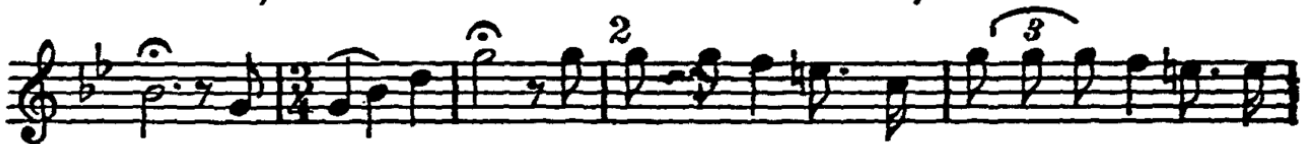
lom. she - ne - e-mar: ve-chol bo-na-yich lim-mu-de a-do-noy ve.

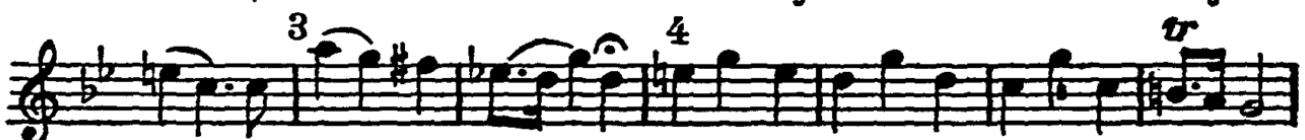
rav she-lom bo-no-yich al tik-ri bo-no-yich,e-loh bô-no-yich,

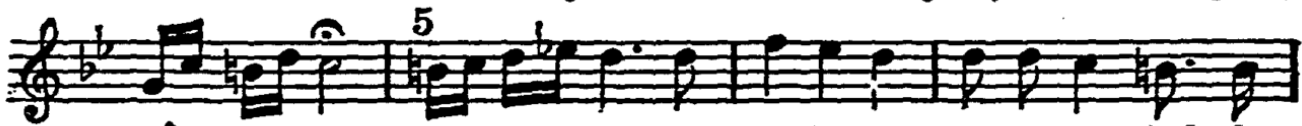
bô - no-yich. sho-lom rav le - o-ha-ve so-ro-se-choh, leo-ha-ve

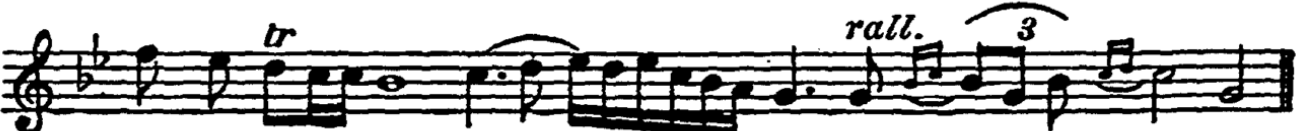
lom be-che -lech shal voh be - ar-m'no-so-yich. 
each, through a comparison of illustrations given in table $\mathrm{XV}$ with those of table XXVII. Distinctive of the Ahavoh-Rabboh mode is its modulation-possibilities to several other modes and to the same mode on other scales, for which table $X V, 3$ furnishes an example. This characteristic is lacking in the Ukrainian Song. Also the melodic curves within the mode differ, for the dwelling upon the third, the gradual ascending of the melodic line, the predominance of the fourth and the seventh below the tonic are Jewish traits missing in the Ukrainian mode, the melodic structure of which is, according to Kolessa's statement, throughout of a descending character. ${ }^{7}$ The Jewish mode is rather similar to the Arabic Hedjaz, as we have seen in Chapter II.

Roumanian folk-song has been investigated and published by Béla Bartók. ${ }^{8} \mathrm{He}$ is of the opinion that "the old Maramures style, the Hora lunga, was taken over from the Ukrainian." ${ }^{9}$ We offer example 8 from his collection. The tune, in its scale and features, is similar to the Ukrainian examples in table XXVII. This type is called in the Roumanian Song "plaintive songs of the old people." 10 "These songs are here and there much embellished in parlando" style.

In addition to the already mentioned example 2 of $A v$-horachamim, we give another one of the same mode by Weintraub (No. 9) in MS. in the Ukrainian scale ending on the second. This example shows relationship to the examples 1,3 , and 4. However, the example presents only one phrase of the composition and should be considered only a modulation, for in the following development of the selection variations and modulation to other scales and modes lend it a rather minor and Hedjaz character.

There are those who maintain that the East European. chazzanuth was influenced by the Gipsy's music. True, a certain similarity grows out of their common Oriental origins. Gipsy music is based chiefly on the so-called Gipsy scale which is similar to the Ahavoh-Rabboh mode, with the difference that this mode has the combination of the tetrachord $\mathrm{e}-\mathrm{f}-\mathrm{g} \#-\mathrm{a}$ and $\mathrm{b}-\mathrm{c}-\mathrm{d}-\mathrm{e}$, which means Hedjaz scale (Chapter II), while the Gipsy scale is the combination of two tetrachords with augmented steps, the second and the sixth step being augmented. This scale is used by Tartars and Turks and is called HedjazKar. ${ }^{11}$ Gipsy music also is based upon the mode form and upon the principle of improvisation.

But a thorough analysis proves the difference between Gipsy and 
Jewish music. These two types express two diametrically opposed worlds. Gipsy music voices nothing but primitive wild passions: the content of the Gipsy's life-quite remote from the doctrines and sentiments of Judaism. The great gentile musician, Franz Liszt, succeeded in penetrating into Israel's spirit, and in his remarkable work on the Gipsies and their music in Hungary, he draws a clear line of demarcation between the Jew and the Gipsy. ${ }^{12}$ Example 10-a recitative by Dovidl Brod (Chapter XIV) -may serve as illustration of the way this Gipsy scale was employed in the Synagogue. ${ }^{13}$ In the same scale we have example 14, a MS. from Amsterdam written about 180o. This tune was carried over by "Polish" chazzanim into Central and Western European Synagogues. In example 14 we notice also the part of the "singers" (i.e., the choir, assisting the cantor), which consists of the unison humming of a tone at the end of a phrase -a form taken over from the Ukrainian singers. ${ }^{14}$ Despite the scale, the two examples have nothing in common with Gipsy tunes.

On the other hand, the relationship between the Roumanian song and the Jewish becomes evident through an examination of examples II and 12. The latter is also from Amsterdam. Both are in the Ukrainian Dorian. Of the same origin is No. 13, a song for the Seder meal on Passover evening. This tune found its way to Copenhagen, where A. P. Berggreen incorporated it in the tenth volume of his collection of folksongs. ${ }^{15}$ The tune shows the typical Ukrainian and Roumanian manner of inconstant tonality, with the fourth (c) alternately sharp and natural; and the third alternately flat and natural. ${ }^{16}$

In the examples $15-16$ a Roumanian style is given which has similarity to the Jewish style for meditation and study (Lern-steiger), illustrated in No. I7. In this case as in the previous examples, though we recognize the common Oriental basis in both types, we are aware that different aims and sentiments animate them. Here, too, the Jewish version is by far richer in motives, in range; is deeper in conception and expression as well as in modulation. Starting in minor on $g$ ( 1 ) it makes a turn (in 2) to major on $f$, then (in 3 ) to Hedjaz on the fifth (d), which is followed by a modulation to the fourth (c) in major, from which it turns to the original scale in $g$ minor. However, this manner can no longer be considered "folk-song," yet neither can it be taken as "art-song," at least not conscious art, for 
the executors, the chazzanim, did not know of any theory of music and modulation. Not even classic European theory suggests methods of modulation such as the one just analyzed. The Jewish song, however, developed original ways of modulation, which we shall treat in detail further on (Chapter XXIII). ${ }^{17}$

An essential consideration in East European chazzanuth is the voice of the chazzan. Like other Orientals, the Jew has preferred what he called a sweet voice, which meant to him a lyric tenor with nasal quality, rather than the powerful voice of a heroic tenor, baritone, or bass. At best, the heroic voice was designated as the "roar of the lion," whereas a lyric tenor usually had all the qualities required to move the heart of the Jew, by its natural sweetness and by its facile execution of the most ornamental coloratura, which art was called Kelim (instruments, implements). This lyric quality the Jew loved in instruments, the violin becoming his favorite. Singing he termed han-im (to sweeten), and King David he called nëim zemiroth, he who sweetened the songs (compare the Greek melos). As a matter of fact, the great chazzanim, with the exception of very few, were teinors; or, if baritones, they "tenorized" their voices.

As we already explained, the chazzan had to satisfy the popular desire for music-for a music which should express the sentiments of the Jew, interpret his ideals, his wishes, and his hopes as a Jew, give tonal expression to his pains and sorrows, release him from the weight of his heavy burden as an oppressed and disfranchised human being, and interpret that glorious past from the Exodus from Egypt to the Fall of the Temple. The Jew demanded that the chazzan, through his music, make him forget his actual life, and that he elevate him on the wings of his tunes into a fantastic paradisaical world, affording him a foretaste of the Messianic time in the heavenly Jerusalem. The chazzan chose those texts, the contents of 
which indicate all the above-mentioned sentiments. This choice led to a marked differentiation between the Eastern European chazzanuth and the German Ashkenazic. In the latter, as we have seen in Chapter VIII, only those texts were intoned which, for one or the other Hallachic or Cabbalistic reason, called forth Rabbinic demands for musical settings. But the Eastern European chazzanim, in their choice of texts, were guided only by the contents of the lines, which were of a religious, national, and ethical nature. Thanks to this attitude, the chazzanim revived many wonderful poems which had been entirely forgotten during the sixteenth and seventeenth centuries by the Italianized chazzanim in Central Europe, who, influenced by Italian art and German folk-song, had preferred texts of laudation and exultation for their musical settings. It is remarkable to notice that while the Berlin chazzan Beer (Chapter XI) wrote some sixty compositions for Lechoh dodi and $M^{i}$ chomochoh, he has not a single tune for texts like $A v-$ horachamim, Hashkivenu, Umipne Chatoenu, for each of which the Eastern European chazzanim, and especially Kashtan (Chapter XIII), left a multitude of settings. Of course, in order to intone the above-explained types of texts, the chazzan had to understand them, to feel the vibrations of the Jew's heart in reciting them; he had to be saturated with their spirit, life, and history. He had to be brought up in the same atmosphere in which these texts had grown. He not only had to be a talented singer and musician with a feeling heart, but also necessarily had to be steeped in Jewish tradition and folksong. In reality, the majority of the famous chazzanim in Eastern Europe, like those in Germany in the earlier medieval centuries, were of this type.

$\mathrm{Up}$ to the eighteenth century there is available but scanty information of conditions of the Synagogue song in Eastern Europe. Occasionally we hear about restrictions as to the 
number of tunes a chazzan was permitted to sing at services, restrictions either growing out of a consistent effort to prevent waste of time, or due to temporary mourning over renewed persecutions. ${ }^{18}$ At times we find in the responsa of the rabbis decisions regarding the conduct, income, etc., of chazzanim. However, nothing has been preserved depicting the essence of the song itself. For the first time, a record of the Chmelnitzki pogroms in 1648 describes a chazzan Hirsch of Ziviotov, who, through his emotional chanting of the memorial prayer $E l$ Mole Rachamim, moved the Tartars to save three thousand Jews from the hands of the raging Cossacks. ${ }^{19}$ At the end of the seventeenth century, Rabbi Selig Margolis of Kalisch describes that quality in the Eastern chazzanuth which tended to stir the people and move them to tears. ${ }^{20} \mathrm{He}$ claims that the Eastern chazzanim were capable of inspiring the people with their singing much more than the rabbis by their preaching; that it frequently happened that people who did not cry even when their parents died and had no desire to pray, were moved to tears and to repentance through the touching song of the chazzan Baruch of Kalisch. "Such ability," says Margolis, "is possessed by the chazzanim in our country [i.e., Poland] only, whereas in other countries they [the chazzanim] have neither melody nor emotion."

Eastern European chazzanuth has been accused of having a melancholy character, of being a lamentation, a weeping. We have already explained (Chapter II) that the main basis of Semitic and Jewish music is the minor scale which, at a very late date (beginning of the nineteenth century), came to be considered of a melancholy character by the Anglo-Saxons only. Of iar deeper significance is the truth that genuine music is the offspring of profound emotion: of exaltation, pain, or joy. Music produced out of a situation between these poles of the human heart is of banal character, bloodless, watery. 
A music to be understood and to be intelligently analyzed must be approached in the spirit and from the point of view of the people of whom it was born. For genuine music is the tonal expression of the life and struggle of a people or of a group which has created ideals of its own, an outlook of life of its own, as the result of its life, its convictions, its faith. "The musician," says J. G. Frazer, "21 "has done his part as well as the prophet and the thinker in the making of religion. Every faith has its appropriate music, and the difference between the creeds might almost be expressed in musical notation. The interval, for example, which divides the wild revels of Cybele from the stately ritual of the Catholic Church is measured by the gulf which severs the dissonant clash of cymbals and tambourines from the grave harmonies of Palestrina and Handel. A different spirit breathes in the difference of the music."

After the Chmelnitzki pogroms which caused the dispersion of hosts of Jews, the chazzanim who emigrated to Central and Western Europe transplanted their Eastern chazzanuth and fused it with the traditional German-Ashkenazic song. We shall treat this influence in more detail in Chapter XI. 


\section{CHAPTER $\mathrm{X}$}

THE INTRODUCTION OF HARMONY AND POLYPHONY INTO

THE SYNAGOGUE IN ITALY BY SALOMON ROSSI.

Influenced by the Renaissance, the Jews in Italy began to enter musical life, and to contribute toward general European musical creation. Although they were excluded from social circles and were without human rights, some Jewish musicians, nevertheless, were privileged at the court of the art-loving Dukes in Mantua (Guglielmo, I 555-I587, Vicenzo I, I 562I6I2, and Ferdinando, d. I626) in the second half of the sixteenth and the first quarter of the seventeenth centuries. ${ }^{1}$ Among these Jewish musicians, singers, and performers were such as: Abramo dall' Arpa Ebreo, who was employed at the court as singer and actor in I 542-1 566; his sister's son Abramino dall' Arpa in 1566-1587, who was the favorite musician of Duke Guglielmo; Isacchino or Jacchino Massarano, who played the lute, sang soprano, and was instructor in acting and dancing in 1583-1599, whose house the Duke and his court used to visit; Davit da Civita Hebreo, composer, who dedicated his seventeen madrigals for three voices to Duke Ferdinando in $1616 ;{ }^{2}$ Allegro Porto Hebreo, composer. The last named dedicated a collection of songs called Nuove Musiche, to Signora Conte Alfonso da Porzia (Venice I619), and two collections of Madrigali à Cinque Voci he dedicated (Venice 1625) to Emperor Ferdinando II of Austria. ${ }^{3}$

The most gifted and famous Jewish musician at the court of Mantua was Salomon (or Salomone) Rossi. He was a descendant of a prominent family, whose pedigree went back to 196 
the captives of Jerusalem whom Titus brought to Rome. For over forty years (1587-1628) he was composer, singer, and violinist at the ducal court. His sister, Madama Europa, was famous there as a singer and actress; and also his nephew Anselmi Rossi was employed as musician at the court.

Salomon Rossi was prolific. He became one of the greatest composers of canzonets and madrigals, "but his most important works were instrumental, being contained in four books, called Sinfonie e Cagliarde and Sonate." " H. Riemann considers Rossi "doubtless to be the most important representative of the new style in the instrumental field." "He certainly was one of the first cultivators of the 'Trisonata'; and the manner of his conception remained for a long time a model for the simple form of it. His way of writing the Sonata as well as the simple, small Sinfonia (he cultivated) is homophonous throughout, and his inclination to the Florentine reform is obvious. . . He prefers simple forms of the 'Songtype' (Liedform) ... ; for longer selections he employs the Variation form, in thematic unity." 6

Rossi's first publication ( 1589 ) was a collection of nineteen canzonets for three voices, dedicated to Duke Vincenzo I. During the forty years of his activity he published about thirteen works of various types, his last publication ( 1628 ), containing "twenty-five Madrigaletti a due voci, per cantar a doi Soprani, overo Tenori . . O Opera tergadecima." " He was likewise the composer of one number inserted in a religious (Christian) opera "Maddalena." 8

Rossi was highly regarded by his contemporaries and was invited by princes to present concerts at their courts. He enjoyed such high favor with two successive Dukes that he was privileged to dispense (in I606) with the yellow badge that all Jews were ordered to wear at that time. ${ }^{9}$

But what interests us in particular is the fact that Rossi de- 
voted his talent also to the Synagogue. It was toward the end of the sixteenth century that the communities in Venice, Mantua, Ferrara, Padua, and Casale Monferrato, inspired by the Renaissance music, wanted to introduce some modernization into the Service. The greatest protagonist of the idea was the encyclopedic Jewish scholar Leon of Modena. According to his own statement he had a good voice, was a trained musician, and even taught music. ${ }^{10}$ In 1605 he organized in the Italian synagogue in Ferrara a choir of six or eight voices, conducted according to "musical science," i.e., harmony. ${ }^{11}$ But to this innovation there soon arose a strong opposition, which argued that " $j$ oy and song in the Synagogue have been prohibited since the destruction of the Temple. ${ }^{12}$ L. Modena submitted the case to the rabbinical assembly in Venice, and the latter decided in favor of his enterprise. One member of the Assembly, Rabbi Benzion Zarfati, stated that in his youth, when he was studying in Padua, he used to join in singing in the choir in the synagogue. ${ }^{13}$

Rossi manifested his Jewish religious piety in composing Psalms and prayers for the Synagogue. It became his aim, as he relates in his Hebrew dedication, "to glorify and beautify the songs of King David according to the rules of music." These compositions gradually grew into a collection of thirtythree, for choir and soli, for three, four, five, six, seven, and eight parts. They were set to Psalms, Hymns, and prayers for Sabbaths and Festivals, and were performed before they were printed. His friends, and especially Mose Sullam-a rich and prominent man in Mantua-persuaded him to publish this collection of Synagogue songs. M. Sullam and his parents had been Rossi's supporters, who had helped him in his education until his attainment of his high position. Accordingly Rossi published that collection; and, in a preface written in Hebrew, dedicated it to Mose Sullam. ${ }^{14}$ Leon of Modena 
undertook the proofreading of the music and he, too, wrote a preface, or rather an apology, in Hebrew, with the aim of winning over the rabbis, most of whom had opposed the innovation. The collection was printed in Venice in October 1622 and was called Hashirim Asher Lishlomo-the Songs of Solomon, a play on the first verse of the Song of Songs. Only the ParTs were printed (not the complete score) with the text in Hebrew letters running from right to left, while the music runs from left to right. In I877 Samuel Naumbourg, cantor in Paris (Chapter XIII), re-edited Rossi's collection in score and in modern musical transcription, adding a biographical sketch of Rossi, and an evaluation of his creative work. To the Synagogue songs, a collection of Rossi's secular madrigals was added, edited by Vincent d'Indy. ${ }^{15}$

The compositions of Rossi for the Synagogue have not the slightest sound of Jewishness. They are entirely in the Italian Renaissance style, and they have the same spirit as his secular compositions. Naumbourg entertained the opinion that Rossi introduced a cadence in minor in which the Jewish music distinguishes itself from the sacred (Christian) music of his contemporaries. ${ }^{16}$ In fact, about twenty numbers out of the thirty-three have minor character, being based either on a minor or "Dorian" (Gregorian) scale; but they finish either in unison on the tonic or in a major chord on the tonic, as was the custom during the sixteenth century and afterwards throughout the classic period.

Technically, his Synagogal music is much simpler than his secular music. This difference may have been made intentionally, because he was aware that his compositions would be rendered by Jewish laymen, or it may have been due to the then general tendency toward the simplification of Church music.

On the other hand, no traditional modes or motives are to 

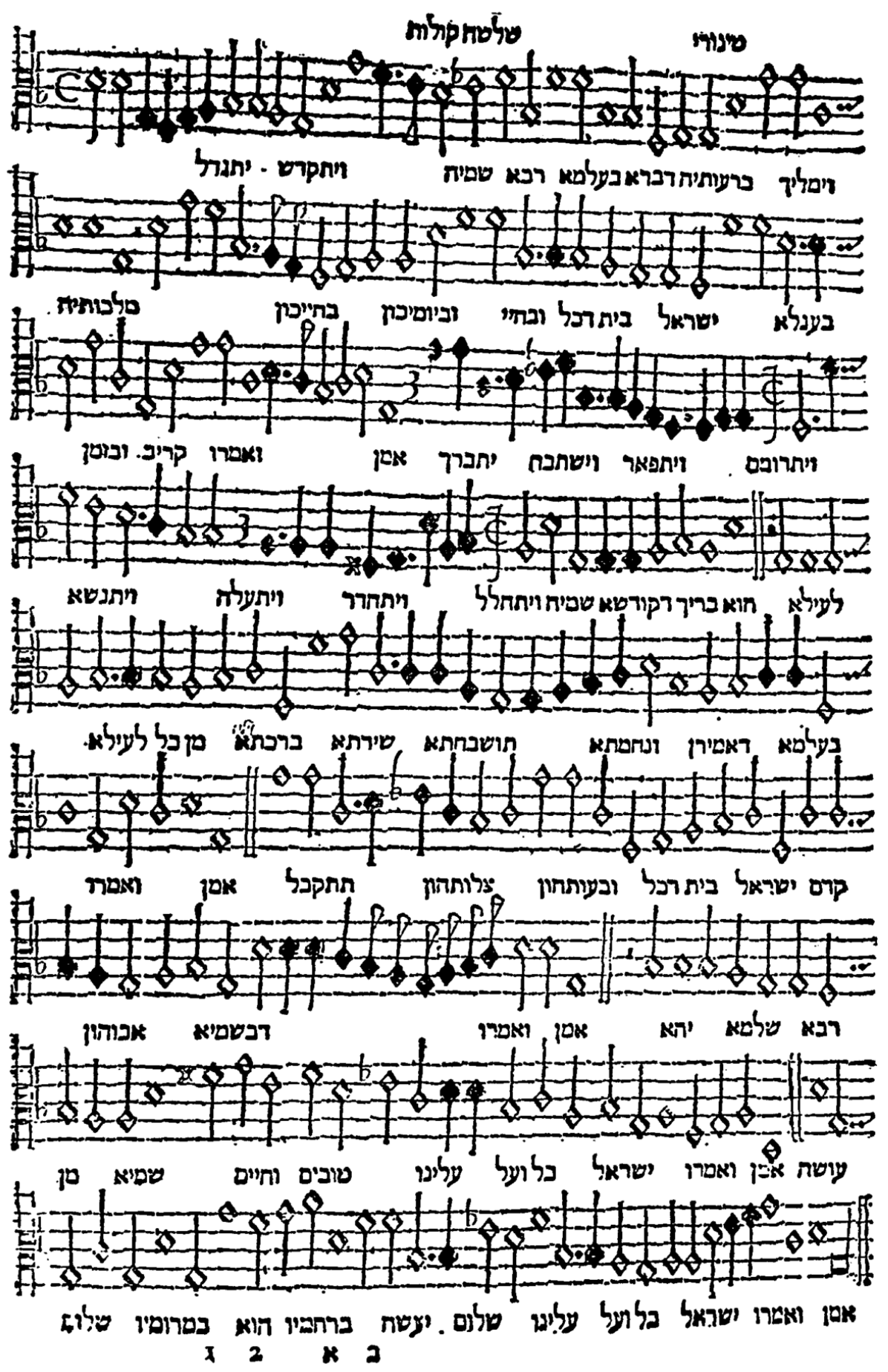

Facsimile 5 .

Salomon Rossi. Pub. Venice, I622; pg. I (Tenore).

H. U. C. Library. 
be found in Rossi's music. Neither did he utilize any traditional melodic line as theme or cantus firmus, as was then customary in Church music.

We do not know exactly how long Rossi's music was sung in the Italian synagogues. At any rate it could not have lasted long, because a few years later, in I630, when Mantua was swept over by war and was captured by Emperor Ferdinando II, I,800 Jews were expelled from the city. The glorious era-an era which illumined their darkness for a short while-ceased for the Jews in Northern Italy with the Austrian régime, and with it all desire for the ars nova was killed in the Jew. He abandoned his ambition to become a co-worker in the Renaissance and the few attempts made toward the introduction of European achievements in music were deserted. Soon Rossi's music was forgotten, and the Italian Synagogue went back to the old traditional song with more zeal than ever. Indeed, when in the same synagogue in Ferrara, in which already one hundred and forty years earlier a choir had sung "new music," someone dared to change the musical setting of the priestly benediction from the tradition, he was excommunicated by the Rabbinate in Ferrara. ${ }^{17}$

Apart from the Jewish musicians thus far discussed, we hear of chazzanim in Italy trained in music, such as Abraham Sagri and his disciple Jacob Finzi, both Ashkenazim officiating in the Ashkenazic congregation in Casale Monferrato. The first compiled a collection of Synagogue tunes according to the Ashkenazic tradition for his disciple Finzi. ${ }^{18}$ The latter, born about $158 \mathrm{I}$, was also scholastically trained, was a fine Hebrew writer, and compiled a Hebrew grammar in verse, in $1605 .^{19}$

Some Jewish scholars of that period occupied themselves with musical science. Noteworthy were Jehuda Moscato and Abraham Porteleone. The latter was a physician and wrote a great deal on Biblical instruments. ${ }^{20} \mathrm{~A}$ certain Jehuda ben 
Jischac made an attempt to translate or rework a theory of music from Italian into Hebrew. The theory is based upon that of Marchettus of Padua, who lived in the early part of the fourteenth century. ${ }^{21}$

At the beginning of the eighteenth century we hear from a Jewish traveller, Abraham Levy of Amsterdam, ${ }^{22}$ that in the great (Levantine) synagogue in Venice a very fine song was cultivated. Though he gives no description of the nature of that song, his comment affords us a clue to the reason why the Italian composer Benedetto Marcello took about a dozen traditional tunes from the Sephardic and the Ashkenazic synagogues in Venice and used them as themes in his fifty Psalms which he published in $1724-27 .^{23}$ The synagogue must have had a reputation among the Christian musicians in Venice. However, with the exception of Shofet kol hooretz (Chapter VIII), the tunes chosen by Marcello have no bearing on Jewish tradition, but seem to be ADOPTED tunes, even the above-named exception being (as we have seen in Chapter VIII, table XXV, 8 and XXVI, 3-4) of German origin.

As stated above, no trace was left of Rossi's attempt to introduce polyphonic song, according to the ars nova, into the Synagogue song. As proof of the Italian Synagogue's adherence to tradition, we have: Libro dei canti d'Israele, Antichi Canti Liturgici del Rito degli Ebrei Spagnoli, collected and published by Federigo Consolo, a renowed Jewish violinist (born in Ancona I84I, died in Florence 1906). He devoted himself to the study of the Synagogue song of the Jews in Livorno. These were descendants of the Spanish fugitives that had settled there after 1492. Though he claimed that the song he presented in his collection was the Sephardic tradition, it is in reality the Northern Italian tradition. The song shows Levantine as well as Ashkenazic influence (Chapter VIII); and several of the tunes are imitations or adoptions from the 
Italian song of the seventeenth or eighteenth centuries. However, a considerable part of the tunes is common among the Sephardim in the Orient as well as in Europe, as it was pointed out in Chapters III, IV, and VII.

The material presented by Consolo contains neither harmony nor polyphony. It has partly the unrhythmical, partly the rhythmical, form; is partly for solo and partly for solo with congregational response, or unison, with a strong Oriental flavor.

Thus we see that Rossi's songs vanished entirely from the Italian Synagogue. But they did exert an influence, by arousing interest in elaborate music in another country, Germany. Indirectly, Rossi's efforts influenced the communities in Central Europe through the introduction of the Italian style, choral singing in parts or in octaves, and even instrumental music into the Synagogue in the seventeenth and eighteenth centuries. 


\section{CHAPTER XI}

THE ASHKENAZIC SONG OF THE SYNAGOGUE IN THE SEVENTEENTH AND EIGHTEENTH CENTURIES.

At the beginning of the sixteenth century a new spirit penetrated into the GHetro, and aroused the artistic temperament of the chazzanim. It seems that the new flame of life-the Renaissance coming from Italy and spreading northward-cast its sparks into the dark corners of the Ghetto (Chapter VIII). We find an echo of the movement of that time in the Cabbalistic rabbi and cantor in Frankfurt am Main, Rabbi Herz Treves, I470-I 550, who bitterly complains against the new movement and the strange attitude that the chazzanim took toward their holy function: "They have ceased to be writers of Torah, Tefillin, Megilloth; nor do they care for the correct grammatical reading nor for the meaning of the prayers-only for their songs, without regard for the real sense of the words. They neglect the traditional tunes of their ancestors." 1 Gradually there arose the interesting phenomenon that the chazzanim devoted themselves more and more to music, and began to consider all other communal functions as burdens. Hence their effort to free themselves from these tasks! From Italy travelling singers and musicians overran Northern Europe, spreading their new art. Italian music came to be the synonym for music in general. ${ }^{2}$ Under the spell of these minstrels, the chazzanim, too, abandoned all their other functions, devoted themselves to music, and started travelling from community to community to perform their concert-services. The meshorer or chorister is the product of and largely the creation of those 
Renaissance chazzanim. In Germany, despite all the orthodox attitude, we find that the opposition to that Renaissance influence on the Synagogue music was much less pronounced; and some communities were even more favorably disposed toward it than those in Italy itself. While Italy saw the fight between Leon of Modena and the majority of the rabbis over the introduction of "music" into the Synagogue, Prague equipped its new synagogue (built in 1594 by Mordecai Meisel) with an organ and a special orchestra organized to play and to accompany different songs including Lechoh dodi on Friday evening, which number was elaborated into a concert of more than an hour's length. ${ }^{3}$ The same concerts were held in almost all the nine synagogues of Prague, including the "Alt-NeuSchul" in which a new portable organ, built by a Jewish organ builder, Rabbi Maier Mahler, was installed in $1716 .{ }^{4}$ There is a report of instrumental music in the synagogues around the beginning of the eighteenth century in the communities of Nikolsburg, Offenbach, Fürth, etc. ${ }^{5}$

The somewhat strange phenomenon of employing elaborate instrumental music in the Synagogue for the Friday-evening service had two reasons. The one was called forth by the Cabbalistic movement which started with Isaac Luria (I 534-I 572). He laid much stress upon receiving the Sabbath with music for which purpose he inspired his disciples to compose special songs. ${ }^{6}$ Soon that custom spread all over Europe, so that with the beginning of the seventeenth century the custom was established. "The Sabbath is received with great joy and with pleasant songs and hymns; and in several communities, choral singing with string and wind instruments is employed. The reason for it is that the Sabbath should be received with joy; and the divine Shekinah dwells among us only when we are joyous." " The other cause was the influence from without. At that time it became customary in the Protestant Church in 
Germany to play instrumental selections, or to render choral singing with instrumental accompaniment on Sundays before the service. This performance was called religious Concert or "Cantata," and it is continued to the present time. ${ }^{8}$

Indeed, the employing of instrumental music at religious celebrations, as the dedication of a Synagogue or a Scroll and at weddings was customary throughout the medieval time. Jacob Segal Mölin "Maharil" already used instrumental music for the procession of the wedding ceremony in Mayence. ${ }^{9}$ The instrumentalists were Jews. In almost every community there were Jewish musicians who, united into a band, used to travel throughout the country playing music before the gentiles at various occasions. For their trade they needed special permission from the governmental authorities, for which privilege they had to pay heavy taxes. ${ }^{10}$ The rabbis gave them permission to mingle with the Christians and to play even at Christian festivities, considering their performances professional labor only. ${ }^{11}$ The Jewish musicians were naturally acquainted with German and Church music ${ }^{12}$ and would play that music occasionally in the Ghetto, and even at religious celebrations. On the other hand, they used to compose music of their own. ${ }^{13}$ We hear of the Jewish musician Woelfin von Locham who wrote thirty-six songs, the text and music in polyphonic style c. 1450 , for his wife Barbara to whom he dedicated that collection in Hebrew lines. ${ }^{14}$ The MS. is considered one of the most important sources of old German music. Some of the Jewish musical productions of the sixteenth century, especially the "Jewish dance music," was retained. However, they are rather caricatures of Jewish music. ${ }^{15}$ (More in Chapter XX.)

The Jewish musicians volunteered to play every Friday evening for about an hour in several congregations throughout the seventeenth and eighteenth centuries. In Prague the custom continued in all the nine synagogues until I793, when the 
custom was abolished because the musicians used to continue their music even after sunset. Likewise, instrumental music was prohibited at wedding ceremonies in the Synagogue. Even in Livorno in Italy instrumental music before Friday evening service was introduced in the eighteenth century, and its performance was restricted to Jewish musicians. ${ }^{16}$

It is quite natural that the chazzanim learned from the Jewish musicians the reading of music and the playing of instruments. In Prague there were at the same time musically trained chazzanim, like Lipman Katz Popper (d. I649 or I 655) "who was a master on several instruments and a brilliant improvisor," according to the poem-eulogy of him, written in Judeo-German. ${ }^{17}$ We hear of Jewish instrumentalists and secular singers who were related to chazzanim, such as Süsskind of Offenbach, the son-in-law of the chazzan Salman in Frankfort. Süsskind used to travel with his cast concertizing at the beginning of the eighteenth century (I 7I4). His son was the tragically famous "Jud Süss Oppenheimer." 18

Despite the antagonism toward the ars nova introduced by the chazzanim in the sixteenth and seventeenth centuries and the opposition to the choir which it created and required, the latter innovation became an established organization in almost every congregation or community. At the beginning of the eighteenth century, we find from Prague to Amsterdam "community or kahal singers" consisting of a bass and a "discant" or "singer," that is a soprano or falsetto. These men were sustained by the congregations, and together with the chazzanim received the nickname keleichomos (instruments of robbery)an abbreviation of chazzan, meshorer, singer. ${ }^{10}$ In Amsterdam choir singing was introduced in 1700 , and at the same time also in Hamburg. ${ }^{20}$ In Frankfort, ${ }^{21}$ about I7I4, the institution of a choir was considered a long established one. In Prague, every synagogue had its choral society of volunteers, ${ }^{22}$ aside 
from the employed singers. Among the first institutions of the newly established community in Berlin ( 1671 ), we find that of community singers, for whose admission the Jewish community had to obtain special residence permits from the government in 1697. It seems that a permit for the bass alone was procurable, so that the other singers' residence in Berlin was illegal. ${ }^{23}$ Even in small communities the people were enthusiastic over having a choir. One such example is Prosnitz, ${ }^{24}$ Moravia, which became a center for Jewish singers and song in the first half of the eighteenth century and from which prominent Jewish composers came forth, as we shall see later. A similar attitude we find in Hildesheim ${ }^{25}$ in Western Germany, which like Prosnitz served as the cradle for a considerable number of Jewish musicians. In other communities that innovation was barely tolerated, so that any severe calamity, in the form of persecutions or restrictions, brought among the first orders for repentance laid upon the community by the spiritual leaders, the prohibition of "Synagogue singing" which meant the ars nova of the chazzanim. We meet such orders of repentance in different countries at the same time, as for example in Selz and Brisk, both in Lithuania (Chapter IX), and in Worms ${ }^{26}$ and Hamburg. ${ }^{27}$ Even in Eastern Europe, in Podolia and Galicia, the institution of choristers was established at the time of Israel Baal Shem-tob. ${ }^{28}$

Concerning the origins, uses, and abuses of the new style of song introduced by the chazzanim, we have two sources of information: on the one hand, the caricature drawn by rabbis of the seventeenth and eighteenth centuries; on the other hand, the music manuscripts of the chazzanim themselves. "The custom of the chazzanim in our generation is to invent tunes, and to transfer tunes from the secular to the sacred. They know not how to read the Torah, because the congregations prefer to have chazzanim show off with sweet voices and fine 
singing. Every Saturday the number of new tunes increases -tunes which we knew not before." ${ }^{29}$ In the same vein write the two chazzanim: Yehudah Leb ben Moses ${ }^{30}$ in his pamphlet "Shire Yehudah," and Solomon Lifshitz, cantor in Metz. Both testify that the chazzanim used to take tunes from the theatre or the dance hall and use them for the service. Other chazzanim were accused of taking tunes from the Catholic Church. Peculiarly enough, to the question of borrowed melodies Rabbi- Joel Sirkas responded ${ }^{32}$ that there was no objection whatever so long as the tunes had not been used for the Christian service, by which judgment he pronounced non-Jewish tunes permissible. Menahem de Lonzano ${ }^{33}$ was of the same opinion, while Rabbi Joseph Hahn opposed strongly. ${ }^{34}$ A serious complaint was that the chazzanim introduced their own or borrowed compositions for those prayers which had never before been sung, and that they neglected both the traditional tunes and the principal parts of the ritual. "The chazzanim run through the main prayers with such rapidity that even the swiftest horse could not follow them; while on the Kaddish or Psalm tunes they spend so much effort and time that the annoyed congregants begin to converse." ${ }^{35}$

Considering the fact that some of the traditional tunes as those for Kol-Nidré, Olenu, or Borchu, were also very long drawn out, and that nevertheless no protests were uttered against these by the rabbis, we must conclude that the reason for the complaints was not only the prolongation of the service, but the introduction of new tunes for prayers, the especial emphasis of which was not sanctioned by the necessities of the ritual. While they did not hesitate to spend over an hour in singing Boruch Sheomar, ${ }^{36}$ since to that usage they ascribed a cabbalistic or mystic connotation, they violently opposed the new tunes of the chazzanim, which had no other purpose than a musical one. 
The invasion of the ars nova into the Synagogue and the custom of adopting or imitating secular music were paralleled by the same procedure in the Church. In I700 a clergyman, Erdman Neumeister of Weissenfels, published Cantatas for the Church in the form and style of the secular Cantatas with Arias in the style of the Italian opera. The texts to these he did not take from the Bible and prayers, but he wrote them himself. In his preface he stated that there is no difference between the style of the Cantata for religious purposes and the operatic style. "Neumeister's innovation caused the last barrier between the secular and sacred to be abolished." ${ }^{37}$ Since that attempt was made, every Cantor and Church musician considered it his task to compose or compile a collection of sacred songs for the entire cycle of the year, based upon the operatic Aria-style. Hence, the Church melody lost its original characteristics, and resembled the operatic melody. ${ }^{38}$

This innovation aroused a strong antagonism, especially on the part of the "Pietists," as Butstedt ( $\mathrm{I} 7 \mathrm{r} 7$ ) and Joachim Meyer (I726). ${ }^{89}$ Not only in the Protestant Church, but in the Catholic Church, likewise, secular music penetrated, and even to a larger extent than into the Protestant. ${ }^{40}$ Tunes were introduced with coloratura, vulgar in spirit, arias and minuets, which belong to the theatre. Notably, the collection Tochter Zion ( $174 \mathrm{I}$ ) was considered detrimental to tradition with regard to both text and music. ${ }^{41}$

This condition continued throughout the eighteenth century. In a collection of 1778 we read that "the artistic singers in their ambition to show their art and to entertain the public with new tunes, forget the difference between the sacred place and the profane. Therefore, we hear in the sanctuary concerts, symphonies, and arias which belong in the dance hall and in the theatre. They call forth in the heart of the congregation profane sentiments instead of religious." ${ }^{42}$ On the other hand, 
complaints were heard that "the old traditional Church-song is dull, heavy and sad, and has a plaintive character, and does not appeal to the 'modern' listener who is accustomed to exciting symphonies." 43

The borrowing of secular folk-tunes for the Church was an old custom. But in the earlier times the secular folk-song was in its spirit and its musical elements closer to the Gregorian Song. According to W. Bäumker, there was hardly any difference between a secular and a Church tune, ${ }^{44}$ whereas in the later period, especially in the seventeenth and eighteenth centuries, the folk-song and the secular music took another course and influenced the Church-song to the extent that it departed from the traditional chorale style, and adopted the secular style. ${ }^{45}$

Thus, we see that the Church lived through the same struggle as did the Synagogue. To the Church, however, the innovation meant a secularization only of its sacred spirit, while to the Jew it meant much more. It not only secularized Jewish worship, but in addition it Europeanized and Germanized the Jewish song and, simultaneously, also the Jewish sentiments. The European music in the seventeenth century was completely emancipated from the remnants of Orientalism and antiquity, dropping all those scales and melodic forms borrowed from Asia and Greece, and was confined to Major and Minor, founded on harmony. Harmony, a pure European expression of music, created a new type of melodic line, a "harmonic melody," i.e., a melody developed out of harmonic principles, with tonic third, fifth, and octave as predominant tones, and the modulation to dominant and subdominant as the scope of the melodic curve. These harmonic principles were applied even for old preharmonic melodies, accordingly remodeled, i.e., modernized. The same procedure we see also regarding the modernization of the Synagogue songs in the eighteenth cen- 
tury, as far as the material retained serves. All the tunes and selections composed at that time are influenced by harmonic principles and by the Italian-German style. We look in vain for some Jewish features. With the exception of those pieces adopted from the East, called "Polish," which, as mentioned above, were introduced by Eastern European chazzanim and were based upon the minor or the Ahavoh-Rabboh mode, no distinction can be discovered between those "Jewish" compositions and German or Italian instrumental or vocal selections for secular or even "sacred" purposes prevalent in the eighteenth century.

Chazzanuth in Central Europe seems to have gone through the same development in the seventeenth and eighteenth centuries as did the Synagogue song in the Orient in the eleventh and twelfth centuries-in that period when the piyyut was at its height. Here, as well as there, we see the inclination of the chazzanim to neglect traditional folk-song and to elevate the Synagogue music to the realm of art; and here, as well as there, the result was either a reaction or a complete failure. First, the artistic flavor caused the people to cease to understand the song, although they favored it as a novelty and as art; and secondly, inasmuch as the art demanded professional singers to devote themselves to it, it excluded laymen entirely. Hence, the traditional occupancy of the position of precentor by rabbis and prominent men was, by reason of the new art, impossible. Therefore, precentorship gradually became a matter of sweet voices rather than of religious spirits. The best account in caricature has been preserved in a pamphlet of the beginning of the seventeenth century. ${ }^{46}$

If until the seventeenth century Germany had supplied Eastern Europe with rabbis and chazzanim, the one transplanting thither Ashkenazic Jewish learning, and the other Ashkenazic traditional songs and customs, that rôle was no 
longer hers after the massacres of Chmelnitzki (I648-60), which caused the Polish and Ukrainian Jews to leave their dwelling place and to migrate westward. In the course of a very short time, the Polish influx colored the character of many a Central European congregation; or, in some instances, separate Polish congregations were established. Toward the end of the seventeenth century, Rabbi Selig Margolis of Kalish complains against those rabbis, religious teachers, and chazzanim who, for the sake of material returns, left their native places and migrated to the wealthy German communities. Not approving of such actions, he travelled instead to the Holy Land. ${ }^{47}$ In fact, we find around the same time in Germany, Holland, and even Italy, many rabbis and cantors of Polish origin. Especially a famous chazzan Jokele of Rzeszow of Poland made a furor through his tremendous voice and wonderful singing. We find him now in Prague ${ }^{48}$ as chazzan, and later (in I7I5) in Metz, where, while he was officiating on the feast of Shabuoth, a terrible calamity occurred at the Synagogue, fatal to many worshippers. ${ }^{49}$ A great many of the Ashkenazic chazzanim in Amsterdam were from Poland, as for example Michael ben Nathan of Lublin, who was the first to introduce choral singing of bass and "singer" into the Amsterdam synagogue (officiated I700-I7I2), causing heated contention in the synagogue over this innovation. ${ }^{50} \mathrm{We}$ find similar examples in many other communities such as Fürth. ${ }^{81}$ Those East European chazzanim introduced the Polish style of singing into Central European synagogues, until their type of song became so much a part of chazzanuth that even the German chazzanim were obliged to give it to their congregations.

The eighteenth-century manuscripts of Synagogue song betray a striking monotony of style and texts. The Jewish singers adopted that peculiar barock style which flourished so widely in 
the seventeenth and eighteenth centuries. Altogether neglecting the fluid Oriental recitative chanting, they developed the rhythmical melodic form, utilizing the minuetto, andante, allegretto, aria, rondo, polonaise, preludio, adagio, Siciliano, and Waldhorn. The texts selected to be intoned were of hymn or laudatory character, such as Lechoh dodi, Psalm 95, Mi chomocho, Kaddish, El hahodo-os, El odon, Kedushah, Ashre, Hodu, Ono, Hallel; on the High Festivals much stress was laid upon Mechalkel chayim, Hayom haras olom, etc. And we never find an attempt of one of the composers to choose for his musical creation a text other than those habitually sung. Because of this dull conformity to routine, we find in the manuscripts innumerable tunes for one and the same text.

In form and character, the tunes were rather instrumental than vocal-and this for two reasons. In the first place, the Jewish singers had no opportunity to listen to vocal music since they had no access to Christian society functions or Church programs and services, while they did hear the instrumental music played mostly in the open air by travelling musicians or military bands. In the second place, the vivacious Jewish spirit preferred the more sprightly music, especially of string and wind instruments. Although the tunes are written for the cantor and the two singers (bass and discant), yet we never find harmony in the manuscripts, that is the three voices do not carry three individual parts sung simultaneously, and thus provide opportunity to achieve harmonic combinations; but the manuscripts are throughout of one melodic line, separated alternately for the various voices. We do not know whether this is an abbreviated method of indicating only the melodic line, while the accompaniments were primitively extemporized; or whether the music was sung merely in one part or in unison. Only in the later manuscripts of the end of the eighteenth and the beginning of the nineteenth century do we meet with the at- 
tempt to write three different voices simultaneously in harmony -naturally, in poor harmony.

The education of the chazzan both in Jewish knowledge and in music was the same three hundred years ago as it still is in Eastern Europe. The before-mentioned Solomon Lifshitz leaves us a description of his own education in the second half of the seventeenth century. He studied at the Yeshivah of David Oppenheim in Nikolsburg, where he learned shechitah. Chazzanuth he acquired from his father, Moses Lifshitz, chazzan in Fürth (1652-I73I). He became chazzan and shochet and religious teacher in a little place. Gradually advancing, he secured a better position where he abandoned shechitah and teaching, and devoted himself to his chazzanuth. In about I 709, he became the official community cantor in Prague. This position he could not retain. He resigned and went to Frankfort. In I715, he became the cantor in Metz, where he died in 1758 . He had been fortunate in having a father a chazzan with whom he could study, for usually the singers had to serve chazzanim from their childhood, travelling and suffering with them from place to place, without the possibility of having any general education. In the chazzanuth-brief, the agreement between the community of Hildesheim and the chazzan Yosef of Bicksheim, of 1780 , paragraph eight provides that the chazzan must keep one "singer" at his own expense, and that in case the chazzan has another singer called "bass," the community would pay the bass one-half of his salary, that is onehalf taler a week, and the various households would supply him with food. ${ }^{52}$ This type of condition continued at least in Eastern Europe till late in the nineteenth century. In his memoirs, Elkan Cohen (born in Hungary 1806), son of Lipman Bass, writes that in his twelfth year he was stolen by a chazzan and brought to the chazzan Yisroel in Prosnitz, who travelled over Moravia, Bohemia, Galicia, and Prussia. On 
his travels he came to Budapest, where the famous chazzan of that time, Dovidl Brod (Chapter XIV), who had been newly appointed, accepted him as a "singer" under these conditions: "I know that you are a drong (a special chazzanic term meaning IOG, applied to those with an unmusical, wooden voice); but if one wants to sing, he should not be frightened. You can remain with me. I will supply you with DAYs (the privilege of eating regularly with specified families-one for each of the seven days of the week-throughout the year). Wages, I do not give; but at weddings and festal meals you can have a collection plate, the proceeds of which you will have to divide with the discant (falsetto singer). On Chanukah and Purim you may go from house to house with the bass, and share with him what you thus gather. Erev Yom Kippur, when it is customary for the meshorerim to be posted in the Schul, you will receive many donations." ${ }^{53}$ The essential requirement for a "singer" was not only a good voice, but also a good memory, since the chazzanim for the most part could not read music, or, if they could, then only with great difficulty. Hence, they were dependent upon the memory of the singers for the retaining of their tunes or the obtaining of new ones. For this reason, a "singer" with a great repertoire in his head was very desirable and much sought after. And for the same reason, a "singer" could not remain long with the same cantor, because after handing over the entire treasury of tunes obtained from some other chazzan, he was a useless and empty shell, and was compelled to go further and start anew with the dissemination of his treasures. With the growth of musical knowledge, it rested with the "singers" to compose or to copy tunes and to present them to the chazzanim. We possess many manuscripts of those singers, some of them inscribed with dedications to chazzanim. Toward the end of the eighteenth century, we find even "singers" who supplied chazzanim with compositions for 
remuneration. After a long period of travelling from one community to the other, "singers" (meshorerim) might succeed in obtaining the position of chazzan. Their title was usually Hamshorer Hagodol - the great "singer." Some of them always retained the title bass; while many of them, never succeeding in obtaining a cantorship, remained "singers" all their lives. The previously quoted Solomon Lifshitz traces the musical knowledge of the cantors in Prague in the seventeenth century from some of their epitaphs, e.g., I668, Jacob the son of Peretz "in the wisdom of music he was the chief of all singers"; Lipman Poppers (died I656) was "a virtuoso on all string and wind instruments" (on him there was a poem written in Yiddish; it was printed by Wagenseil in his book Sota, I674, p. 3; see Chapter XX); David, son of Jacob Futralmacher, I 724, "who could play on different instruments, was a singer, and one of the music scholars."

The following are some of the composers and singers of the Synagogue in the eighteenth century.

Ahron Beer was born in Bamberg, Bavaria, in I738. He became chazzan for a short while in Paderborn, and was appointed chazzan in Berlin in 1765 . Through his fine tenor voice and attractive singing he gained fame in Berlin; and his picture is still preserved in the art museum there. He was one of the first chazzanim who obtained some musical knowledge. As a result, he was able to write music and even to compose.

During the long period of his activity (died I82I) he gathered compositions of all his contemporaries in a large collection of over twelve hundred numbers, marked with the dates of the compositions and, in most cases, with the names of the composers. He included also traditional songs. Of chief interest in the volume we find the oldest form of Kol Nidré dated I720, and another variation of it marked 1783; Ovos for the High Festivals; Olenu, Omnom Ken, Al horishonim, 
Hodu for Succoth; Kaddish for Neila, and Vechach hoyoh omer using the tune of Vehakohanim. Since these traditional songs show no difference from their present form, we may assume that the traditional songs were already fixed in the seventeenth century. There is a Kaddish for Neila and for the last day of Pessach by Rabbi Michael Chosid, who was rabbi in Berlin I7I4-I 728 (Chapter VIII).

Ahron Beer prepared a collection of songs in $16 / 0$ size probably for his own use at services. It is in his own hand, neatly written, and bound in leather, with an illuminated title page in Hebrew. Written in I79I, it includes 447 numbers, arranged for the entire cycle of the year, for fifty-three Sabbaths, for each day of the festivals and semi-festivals. On the title page Beer wrote a preface significant for the conditions of the Synagogue song of the eighteenth century. There he states, for instance, that the reason for his arrangement of special songs for every Saturday and feast day of the year was to prevent the members of the congregation from grasping the tunes, and thus to make it impossible for them to sing with the cantor. His intention was that a tune be sung once a year only, for "if a person hear a tune but once a year, it will be impossible for him to sing with the cantor during the service, and therefore he will not be able to confuse the chazzan. It has become a plague to the chazzanim to have the members of the congregation join the song." The tunes throughout the book are all for single voice, sometimes marked "singer" or "bass." The names of the prayers are given above the tunes, but there is no indication of apportionment of the text to the phrases and notes of the melody.

The texts used are for Saturday: Lechoh dodi, Hisorari, Veahavos'cho, Malchus'cho, Mechalkel chayim, Kaddish, El hahodoos; for holidays: Hamelech hamromom, Tisborach tzurenu, Hodu, Ono, Al zos shibchu, Berachi dodi for Passover, Akdomus for Shabuoth, Or ponecho 
for Sabbath Shekalim, a Shir Hashirim Kaddish, and a Ruth Kaddish. Some traditional tunes are utilized as, e.g., Akdomus, Sefira Lechoh dodi, ${ }^{54}$ Kinos Lechoh dodi for Friday evening before Tisha be-av and in the same tune $A v$ harachamim for the Saturday before Tisha be-av. For Rosh Hashanah there are Melech elyon, Ovinu malkenu, Eder vohod, Siluk Kedushah, Ase lema-an shmecho, Veye-esoyu, Heye im pifiyos, Hayom haras olom, Psalm 150, Hayom teamezenu; for Yom Kippur: Yaaleh, Vidui, Ki onu Amecho, Veal chatoim, More chatoim, Imru lelohim, Amitze Shechokim, Eso dei, Veoviso sehilo, Ho-oches, Vechach hoyo omer, Vechach hoyo moneh, Ashre ayin. This constitutes the complete list of texts for which so large a variety (447 numbers) of tunes was composed. The songs are for cantor and singer, and include no recitatives and only a few traditional tunes.

As mentioned above, this collection incorporates material of many other composers whose music was either well known or found special grace in the eyes of Beer. Due to this use by Beer, some names of Jewish composers with their creations were preserved. Thus, we make the acquaintance of a certain Moshe $P_{A N}$ to whom Beer always gives the title RABBI, and from whom he incorporated 144 selections in the last named collection. Pan's compositions show considerable musical talent and originality; and it seems that many other composers (also Beer himself) imitated him. Up to the present time, it has been virtually impossible to identify this $\mathrm{Pan}$ with any degree of certainty. However, by tracing his daughter (who was married to the chazzan Meier Coblentz in Offenbach near Frankfort) who died in 1814 and on whose tombstone the father is named Hameshorer Hagodol Rabbi Moshe Pan without the addition of the usual zal (for departed persons) we can assume that he was still alive at that time. The name of Pan is the Jewish pronunciation of the place Peine near Hildesheim. In the archive of Hildesheim several Moshe Peines are named as citizens.

Ten numbers are marked Mi-haschaz be-Berlin, probably referring to the predecessor of Beer, Leb Chazzan (1736-1758). One number is by Yitzchok, chazzan in Glogow, who was the teacher of Israel Lovy (v. below). Fifty numbers are marked $M S c h B$ and $R Y C h$, both abbreviations which probably mean Mishër-besori (relative of mine) and Rabbi Yitzchok Chazzan in Glogow, the same just mentioned. 
Twelve numbers are marked Leon Singer, the composer. of the famous "Leoni" Yigdal. His real name was Meier Leon. In I766 he was appointed singer in the newly rebuilt Duke's Place Synagogue in London on an annual salary of $£_{40}$ sterling. His sweet voice and wonderful singing attracted a great attendance of even gentiles. James Piccioto says in his "Sketches": " ${ }^{55}$ "Meier Leon the humble chorister rose to be Leoni the opera singer. He possessed a tuneful head, and he composed light and sacred melody. He adapted some Synagogue airs to Church hymns, but he preserved strictly his religion, declining to appear on the stage on Friday nights and Festivals." Nevertheless the Board of the synagogue did not hesitate in $\mathbf{I} 772$ to reduce his salary to $\AA_{32}$ sterling. Hence, he left the synagogue and became a stage singer. "But his appearance on the Boards was a failure merely because he had not the slightest conception of the histrionic art." After a time, he turned back to the Synagogue choir. There he composed tunes especially for the High Festivals which "used to be sung in the English Synagogue until the advent of the foreign chazzanim in I8I4-I8I5." "The writer of the hymn which is sung to the tune 'Leoni' was Thomas Olivers, a Welshman who was born in I $725 \ldots$ became a Wesleyan minister in 1753, and died in I799. One day ... Oliver went to the synagogue where he heard a tune which so completely enraptured him that he resolved to have it sung in Christian congregations; and he therefore wrote for this purpose an hymn 'The God of Abraham, Praise.' It was published in 1772 and became so popular that eight editions had to be published in less than two years, and it had reached the thirtieth edition in I799. A writer on hymnology relates how the son of an old minister once said: 'I remember my father told me, during a conference in Wesley's time, Thomas Olivers, one of the preachers, came down to him, and unfolding a manuscript, said: "Look at this. 
I have rendered it from the Hebrew, giving it as far as I could a Christian character, and I have called on LeONI THE JEW, WHO HAS GIVEN ME A SYNAGOGUE MELODY TO SUIT IT; HERE IS THE TUNE, AND IT IS TO BE CALLED 'LeONI.' "' I read the composition and it was that now well-known grand imitation of Israel's ancient hymns- "The God of Abraham, Praise." ' " s6 When in 1787 the Ashkenazic congregation in Kingston, Jamaica, built a new synagogue and asked the Ashkenazic congregation in London to recommend to it a reader, Leon took that position and settled in Kingston, where he died in 1800 .

The Yigdal tune can be considered a compilation of an old folk-motive which is prevalent both in Jewish, Spanish-Basque as well as in Slavic song, as proved in Table XXVIII. We find the same melodic line in $\mathrm{r}$, a Spanish cancion; ${ }^{57}$, in the Jewish-Spanish prayer for Dew; 3 , in a Polish Song; ${ }^{58} 7-8$, in the folk-song of the Basques; ${ }^{59} 9$, in the symphony Moravia by Smetana; 4 , in the Zionist hymn Hatikva and 5 , in the Zionist song (in German) Dort wo die Zeder.

YeKel Singer of Prague, called also "Yekel Bass" or J. Lehman, lived at the end of the eighteenth century. $\mathrm{He}$ was a productive composer, and much of his work remains to us in manuscript form. His songs became popular with the chazzanim in Germany. He seems to have had little knowledge of Hebrew. His orthography is faulty to the point of the comic.

MS. No. 28 A: I and 2 is inscribed with the following dedication written in Hebrew letters: "Meinen herzlichen Gruss an Hameshorer hagodol Rabbi Meir Schaz. Ich werde bald das Vergnïgen haben, persönlish aufzuwarten. Dann von allem, so viel Sie wollen. Dieses nur in Eil. Ihr Freund, Yekel." MS. No. 28 C: I and 2 he dedicates: "Meinem Freund Abele Wachenheimer gewidmet mit der Bitte nicht weiter zu geben. Yekel Singer." This was the way that the "singers" used to 


\section{TABLE XXVIII}

Table of Folks-songs

Compared with the Yigdal tune

1.

Spanish cancio Pedrcll II 186

2.

Jewish Sephardic for Tal

3.

Polish, Collection Noskowski p.218

4.

Zionist Hymn Hatikva

5.

Dort wo die Zeder

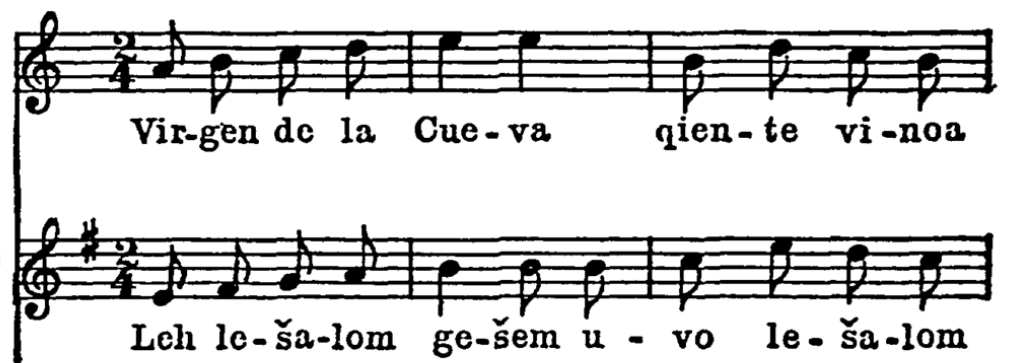

Yigdal

\%.

Basque

8.

Basque

9.

Smetana
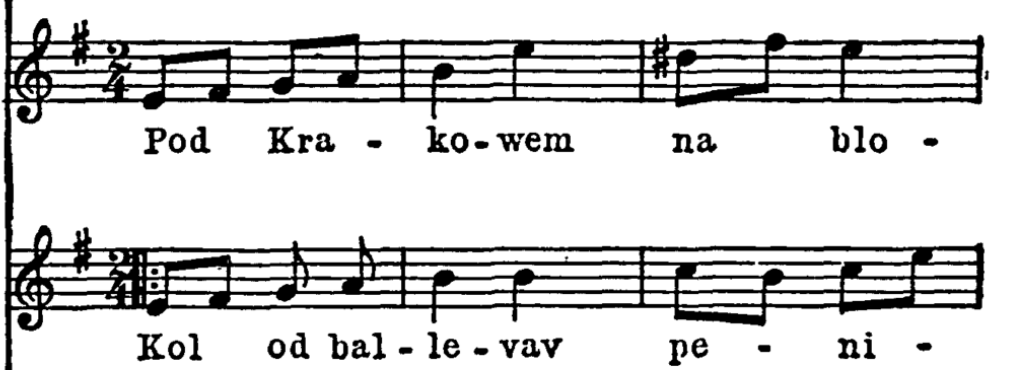

(
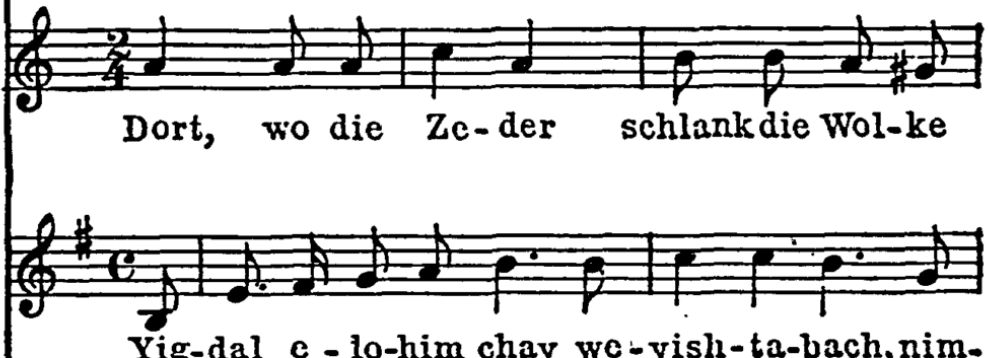

Yig-dal e - lo-him chay we-yish-ta-bach, nim-
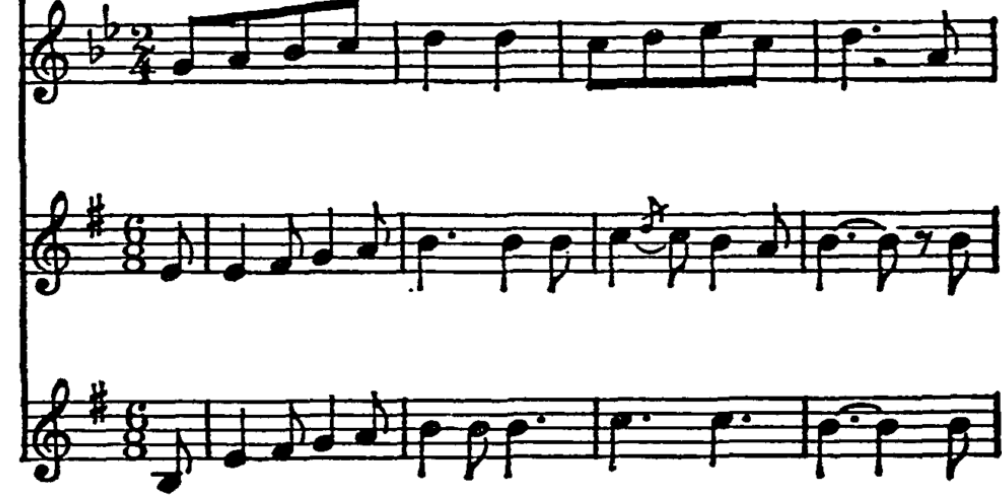


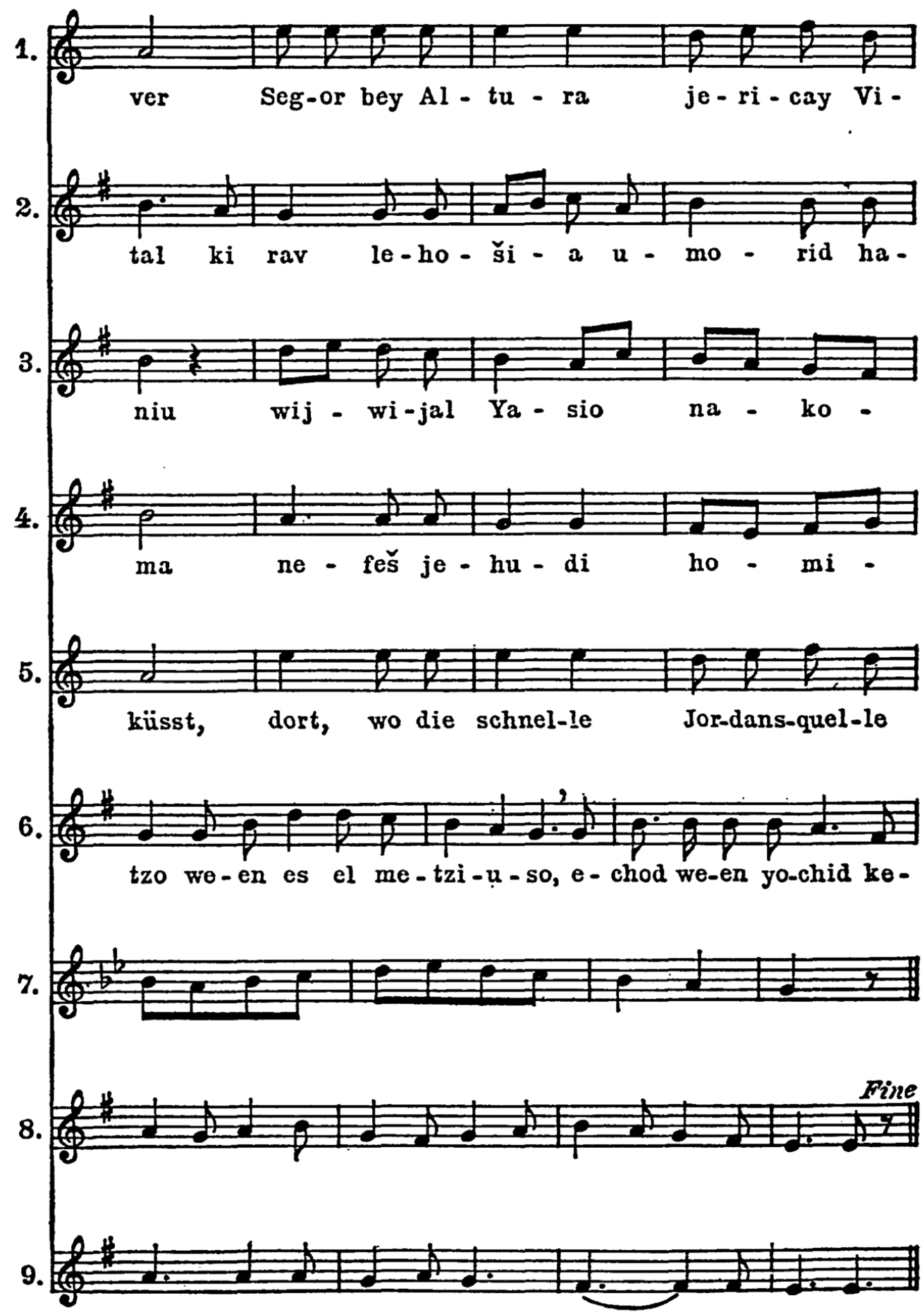




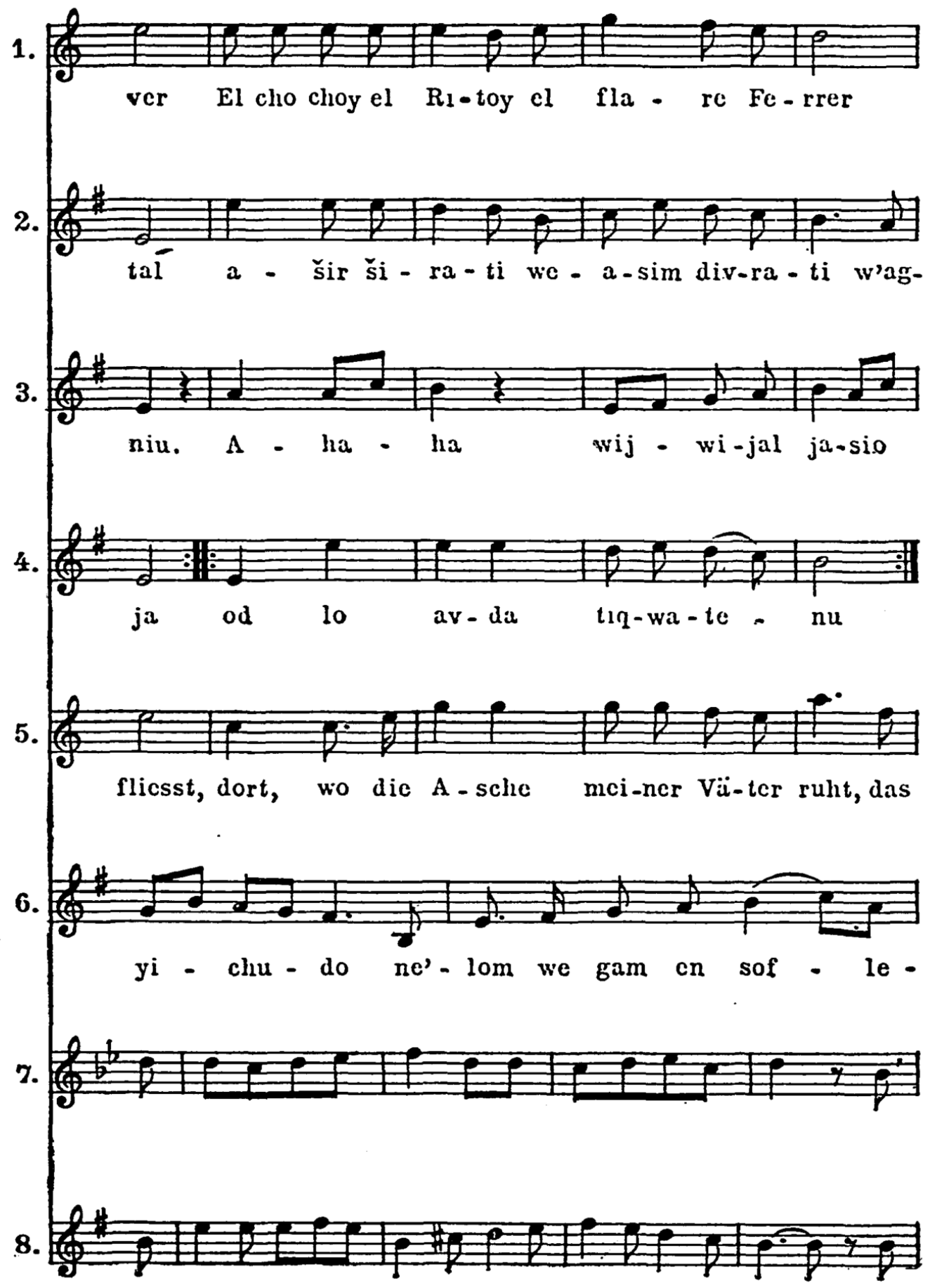




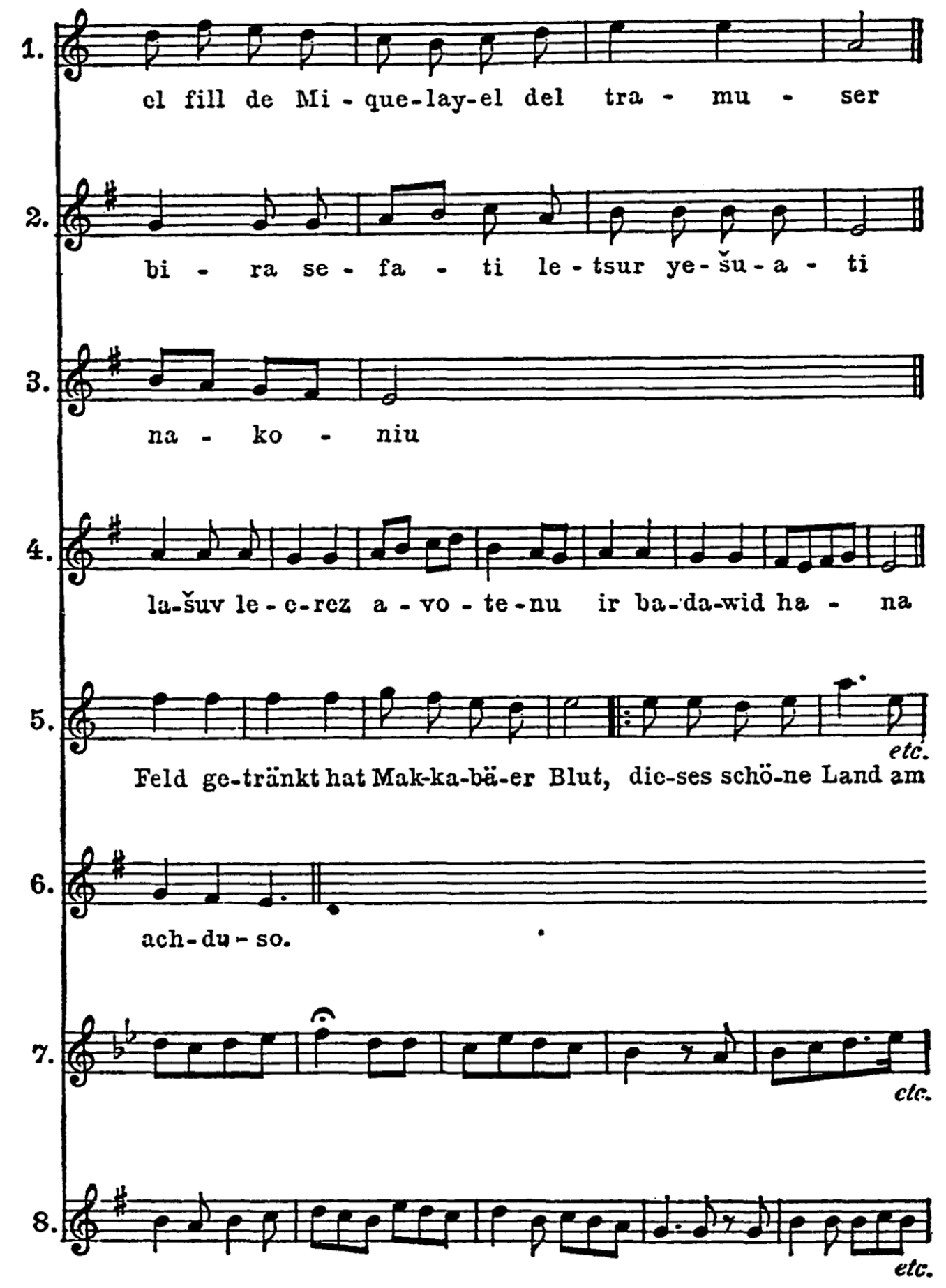


introduce themselves to the chazzanim, presenting them with their compositions to show their ability.

Abraham Singer of Prosnitz, father of the famous John Braham. (The latter's name was formed by dropping the " $A$ " of Abraham. This son was co-editor with Nathan of the collection of Hebrew melodies under their joint names, I8I5). Singer lived in London, where he died about I 780.

Another manuscript, No. I96, by L. M. MAYER, chazzan in Aarhus Denmark, written around I825, has a tune for Kol Nidré (No. 25) which is entirely different from the usual Kol Nidré, being based on the mode of the Psalm recitative according to Ashkenazic tradition.

One of the outstanding Synagogue singers toward the end of the eighteenth and the beginning of the nineteenth century was IsRaEL Lovy-born in Schottland near Danzig (I 773). His parents came from Poland. While he was still in his childhood, his parents settled in Glogow, where he became meshorer to Yitzchok Glogow, whose compositions are included in Ahron Beer's MS.-(v. above). Equipped with unusual quality of voice and musical talent as well as intelligence, the young Israel Lovy became very popular. In accord with the custom of that time, he organized a group of singers, with which he started a tour throughout Central Europe, giving Synagogal concerts.

In 1798 he came, in the course of his tour, to Fürth in which community the post of chazzan was vacant. He made a deep impression with his singing, and was elected chazzan there. (His predecessor was Isaac of Prosnitz, I782-I 795.) In the eighteenth century that community was one of the most prosperous in Germany, and very fond of music. Already in the beginning of that century it had maintained a choir of four singers; and, on special occasions, had increased it to ten. ${ }^{60} \mathrm{Be}-$ cause of their pleasure in being entertained with music, the 
Jews of Fürth secured residence permits for a troup of Jewish musicians, making them legal "community officials." Chanukah and Purim were celebrated with great pomp. Indeed, the head of the community found it necessary to issue a prohibition against the engaging of more than three musicians for entertainments. In Fürth, the first Jewish Songster with musical scores was published under the name of Simchias Hannefesh by Rabbi Elchonon Henle Kirchhain, containing thirteen songs in Yiddish for Sabbath and festal days (Chapter XVIII). It was printed by a Jewish press. In Fürth, Lovy continued his education and studied with eagerness piano, violin, and violoncello, as well as the classic music of Mozart and Haydn. At the same time he attained facility in the Italian and French languages, the latter of which became and remained his vernacular to the end of his days. Here he began to call himself Lowy. He achieved a mastery of Hebrew literature. However, his outstanding strength was his phenomenal voice. $\mathrm{He}$ soon became a concert singer, especially of Haydn's and Mozart's compositions; and was invited by the Duke (later king) of Bavaria, Maximilian Joseph, to sing the tenor part in Haydn's "Creation" at a court concert. Lowy also received special permission, for the first time in the history of Germany, to give public concerts in Nürnberg, a place where a Jew was not allowed to stay over night and was permitted to enter only when accompanied by a Christian woman. ${ }^{61}$ In I799 Lowy, accompanied by two singers, gave a concert in Nürnberg, after which the local paper Friedens-und-Kriegs Courier, No. 67, March 20, I799, carried the announcement: "The three singers, especially Mr. Lowy, who gave the 'musi- cal academy' on the seventeenth, in the Bitterholz, thank the public for the great applause and kindly reception; and herewith make acknowledgment of the courtesy extended them." The concert he repeated annually for six years, until he left 
Fürth in I806. Among the chazzanim, he became famous as Israel Glogow and later as Reb Yisroel Fürth. The Hebrew Union College Library possesses in MS., No. 65, a collection of fifty-six items by Lowy from his Fürth period. In those tunes he shows no originality, but walks rather in the path of his colleagues, in the style of the eighteenth century. Although he was accounted well acquainted with the vocal music of Haydn and Mozart, this knowledge had no influence upon his chazzanic creations. They are, throughout, instrumental in character, and require considerable technique not only for a singer but even for an instrumentalist.

In I 806 Lowy left Fürth with the intention of going to the metropolis of the Europe of that time-to Paris. However, since he progressed by the old method of concert-touring, he was kept in Mayence as chazzan for three years, and in Strassburg for eight. Finally in 1818 he succeeded in reaching the goal of his travel, Paris, where he gave concerts of secular music, and where he soon became famous in musical circles as a great singer. Attempts were made to inveigle him into stage appearances. We do not know what it was, but something held him back from that step. At that time the Jewish community in Paris, which had received official recognition in I79I, attempted to complete its organization; to that end, planned the building of a great Synagogue, and introduced some reforms in the service. Therefore in 1818 , the community engaged Lowy as cantor and regenerator of the Synagogue service. In 1822 the synagogue on Rue Notre Dame de Nazarite was dedicated. There Lowy organized a choir in four parts, for which he composed a service for the entire year. Thus he was really the first to have introduced a modern four part choir.

Lowy here became Lovy, in conformity with French pronunciation. 
Lovy's voice was baritone-bass from lower $F$, while in the high range it had tenor timbre and reached the highest notes.

$\mathrm{He}$ died in 1832 . After his death, all his reform endeavors melted away. However, many of his tunes became popular not only in Paris but also as far as Poland; and one of them was adopted by Goldfaden in his opera Shulamith (Chapter XX). Some of them were published by Naumbourg in his Synagogal work; and a selection of them, with his biography, was printed by his family under the name Chants $R e$ ligieux, Paris, I852. To the chazzanim in Germany he was known as Israel Glogow, Israel Fürth, Israel Mayence, and Israel Strassburg; and they used to sing his songs written in those cities-all of which were composed in the old style of the eighteenth century. But after he had settled in Paris, he disappeared from the chazzanic world. His reform attempts made no impression on the chazzanim, as they left no trace upon the course of modernization of the Synagogue Song in the beginning of the nineteenth century. Although he was endowed with all the gifts required for a reformer, this rôle was accorded not to him but to Sulzer in Vienna, to Naumbourg in Paris, and to Lewandowski in Berlin. The explanation may be found in the fact that Lovy was an extremist, as we see from his compositions, whose effort was to break with the past and tradition and to introduce entirely new tunes-an effort in line with the general attempt to do away with the old Jewish life and create an entirely new Jew and Judaism.

Another prominent chazzan belongs to the eighteenth century, although his activity lasted to the middle of the nineteenth century. He is Sholom Friede, chazzan in Amsterdam, born in that city in 1783 . He officiated for some time in Utrecht. In I 809 he was appointed first chazzan in Amsterdam. Concerning the pompous ceremony of his installation (interesting because indicative of the important position that 
the chazzan occupied at that time), the archive of the Ashkenazic community there provides a detailed description. He had a fine taste for music. His numerous collections are retained in the Hebrew Union College library (in MSS., Nos. 17, 34, $35,39,40,42,69,-)$ containing in all about two hundred numbers, in the style of the eighteenth century. He had a love for the Polish-Jewish songs; and due to that fact, we are in possession of the early Polish chazzanuth and of tunes in Chassidic style. He died in Amsterdam in 1854.

Joseph S. Goldstein-Bass of Oberlauringen bei Schweinfurth am Main-wrote a collection of Synagogal songs (probably toward the end of the eighteenth century), consisting of tunes in the usual style; and, in addition, several recitatives for the High Festivals in the traditional modes. This is the first and only written music of that particular style, and it demonstrates that the recitative of the eighteenth century is in no way different from the recitative of East European chazzanuth, for Goldstein, by his own testimony, was of German origin. In $18: 3$ he became the bass of Moshe Raff, chazzan in Jebenhausen in Bavaria, to whom he presented his collection and whom "he taught the tunes by playing them on the violin," according to the statement of the son of Raff (providing us with another sidelight on the relationship of Bass, "singer," and chazzan of those days).

From a glance over the entire field, one should not infer that the chazzanim entirely abolished the traditional tunes and recitatives. Quite to the contrary, parallel to the new and free Synagogue compositions, the traditional modes were preserved -and usually very carefully, as we see in the traditional chazzanuth of Southern Germany, copied by S. Naumbourg in I840, according to the singing of the chazzan of München, Loew Sänger (I78I-I843) (Chapter XIII). Those recita- 
tives, inasmuch as they had certainly been in tradition for many generations, give us a grasp of the state of the recitative of the earlier centuries. They have not the elaborate chazzanic flavor of the recitatives of the above-mentioned Goldstein, for they are much simpler. The chazzanim of the eighteenth century, with the exception of Israel Lovy, did not make any effort to reform the recitative. Their only innovation was the introduction of measured melodies-tunes in the style of the eighteenth century, through the use of which they contributed toward the Europeanization of the Synagogue song. 


\section{CHAPTER XII}

THE INFLUENCE OF THE REFORM MOVEMENT ON THE SYNAGOGUE SONG IN THE BEGINNING OF THE NINETEENTH CENTURY.

One of the best proofs that ideas and ideals influence music, creating new melodic lines, as well as changing the taste for music, is the reform movement in Jewry at the end of the eighteenth and at the beginning of the nineteenth century. As long as the Jews lived in the belief that their stay in the Diaspora was compulsory Golus-"exile," that they belonged to and would return to Palestine, they instinctively preserved the Semitic-Oriental element in themselves and in their cultural creations.

So also in their music! Even the attempts of the chazzanim in the eighteenth century to introduce "European" music into the Synagogue were without any intention to abolish the Semitic-Oriental element of the Synagogue song, and without any desire to supplant it by European music in order to Europeanize the Jewish taste. Their activity was but the attempt to satisfy the hunger for music of both singers and public; and to achieve their goal they were compelled not to be selective in the choice of musical material. Despite the opposition of the spiritual leaders and spirited Jews, they gave to the masses what they liked, namely, the music heard in the Christian environment.

But the Golus-viewpoint of the Jew sustained a shock by the flare of the new spirit aroused in Europe at the end of the eighteenth century by the Revolution in Paris and by the philo- 
sophical schools in Germany. Free-thinking, irreligiosity, enthusiastic belief in humanity, made some Europeanized and free-thinking Jews here and there in Central Europe believe that the source of their misery as Jews lay in their seclusion from general modern European culture and in their adherence to an ancient Asiatic religion, a religious culture the humanism of which those neo-humanists could not see. A bitter hatred arose in their hearts against Judaism and Jewish customs. The same ritual which, a half-century before, had had the power to inspire their ancestors became obnoxious to them. Those extremely modernized Jews who with Heine considered Judaism "a calamity," which had no justification for existence, deserted their faith and their people and went over to the Christian Church, thinking thus to become complete human beings and full-blooded citizens of their country, Germany or France. Others, whose Jewish consciousness was stronger, could not take this step; and therefore came upon the idea to reform their Judaism, by which they meant to cut away exotic, Semitic-Oriental parts, and retain only that part of Judaism which was of a general religious and ethical nature. ${ }^{1}$ The idea was so to remodel Judaism that it should not be a stumbling block by reason of its Orientalism and Medievalism, that it should be as easy to observe as is Christianity, that, furthermore, the modern Jew should not be offended by its strangeness and should be attracted by its European exterior.

It is significant to notice that this first "practical" reform attempt was made not by rabbis but by laymen. Against it the rabbis conducted a fight for many years; and not until a generation later did some rabbis of prominence become reformers.

The Jewish movement for reform was called forth by the general struggle in Europe for social emancipation and justice and for freedom of thought. Who more than the Jew was deprived of social, yea, human, rights? Who more than he 
suffered from medieval prejudices and barbarism? And who more than he was craving for light and enlightenment, for the abolition of customs and practices founded on inhuman conceptions? The amount of cruelty and injustice, abuse and degradation, slavery and brutality, he experienced from his Christian environment in that long dark period of eighteen centuries accumulated in his heart until it burst forth at the touch of that explosive element which spread all over Europe, and shattered all "traditional" institutions, social and individual, religious and secular. Indeed, religion received the brunt of the attack. Religious practices, and especially the ritual, became subject to criticism and reform. In the Church, there had arisen opposition against the dead Latin language, unknown to the people, and an effort was made to substitute instead the vernacular of the respective countries. That change caused fights in the Church. There were cases where the priests were progressive and intoned the prayers in German, while the public, being conservative, responded in Latin, and vice versa.

The same fight raged regarding the music, as told in Chapter XI. The progressives claimed that the old traditional song did not appeal to them any longer, while the conservative elements denounced the reformers in that "they started to intone the Mass in the brilliant style of the opera in order to cover the emptiness in their hearts, caused by lack of religiosity, and that they started using all kinds of effects to stimulate the senses." 2 The antagonism resulted at times in a tumultuous and bloody riot, such as the sad incident in the Church of Ruedesheim in 1787 . When the new German songs were introduced into the service, against the opposition of the public, the Archduke sent soldiers and guns into the Church, causing the death of thirty people. ${ }^{3}$

Quietly building behind the chaos of the crude public fight were the two spirits-Henry Purcell (I658-1695) in England 
and Johann Sebastian Bach (r685-I750) in Germany-who created the new forms which became the foundation of Protestant Church music in both countries.

A similar striving toward the reform of Synagogue worship started in Jewry. The first to make an attempt toward reform were, as mentioned above, laymen. They, as practical men, facing the problems of life, felt the severity of the social problems of the Jew more intensely than the rabbis, who in that time generally lived apart from social life, secluded in the realm of study. The first reforms were chiefly directed toward social and practical aspects of religion. The first protagonist of reform was David Friedlander in Berlin, a wealthy merchant and an intellectual. He made the attempt to translate the prayerbook from the Hebrew into German ( 1787 ). But being such an extremist as even to propose an affiliation with Christianity minus the belief in Jesus (see note I), he found no following.

The first successful reformer of the Synagogue ritual was Israel Jacobson (I768-1828), a rich and influential merchant who, with the aid of the French government in Westphalia, made it his aim to reform the ritual as well as to reorganize the religious education of the Jews in Germany. In Seesen (Westphalia) he established in r80r a boys' school for elementary knowledge and trade; and he repeated the venture in Cassel in I808. There he arranged a children's service into which he introduced hymns, the tunes of which he took from the Protestant chorales. To these tunes he set Hebrew texts, and printed a collection of chorales with the notes running from right to left (Cassel, I8IO).4 In Seesen, in I810, he erected on the grounds of the boys' school the first Reform Temple in Europe, in which he installed an organ and for which he arranged the ritual as well as the music. He provided the Temple with a bell which, according to Christian 
custom, should announce the time of prayer. Jacobson's program for the service was this: Alongside of the Hebrew texts of the prayers, which at the beginning he did not touch, he introduced German hymns to the tunes of Christian chorales. $\mathrm{He}$ abolished the chanting of the Pentateuch and Prophets according to traditional modes as well as the unrhythmical prayer modes, and together with these he discarded the chazzan. $\mathrm{He}$ himself read the service without any chant, according to the manner of reading the Bible text and prayers in the Protestant Church. He introduced the sermon in pure German-he himself preaching in his Temple. He brought to his Temple the gown of the Church. He also introduced the confirmation of boys and girls (I8II).

In 1815 he settled in Berlin, where he opened a Temple in his private home, which was of short duration, for it was closed by the Prussian government in the same year on the ground that according to the law only one house of Jewish worship was permitted in Berlin.

However, utilizing the occasion of the renovation of the Synagogue in Berlin, Jacob Herz Beer, the father of the composer Meyerbeer, opened a Temple in his private home, according to Jacobson's program. The music was arranged by his son, who, as he himself stated, opposed the using of an organ in the Jewish service. ${ }^{5}$ In order to attract a greater audience, to whom a service without a chazzan was unthinkable, Beer was constrained to engage a chazzan. Whether or not from intent, he chose a chazzan without a voice but with some modern culture, Asher Lion (I776-1863), who later became the successor of Ahron Beer (Chapter XI). In Beer's Temple the first Jewish preachers officiated, such as Zunz, the promoter of the "Science of Judaism," and Israel Eduard Kley.

After the completion of the renovation of the old Synagogue, built in I714, Beer was forced by the government to 
I.

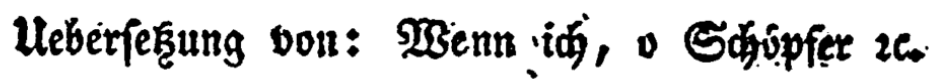
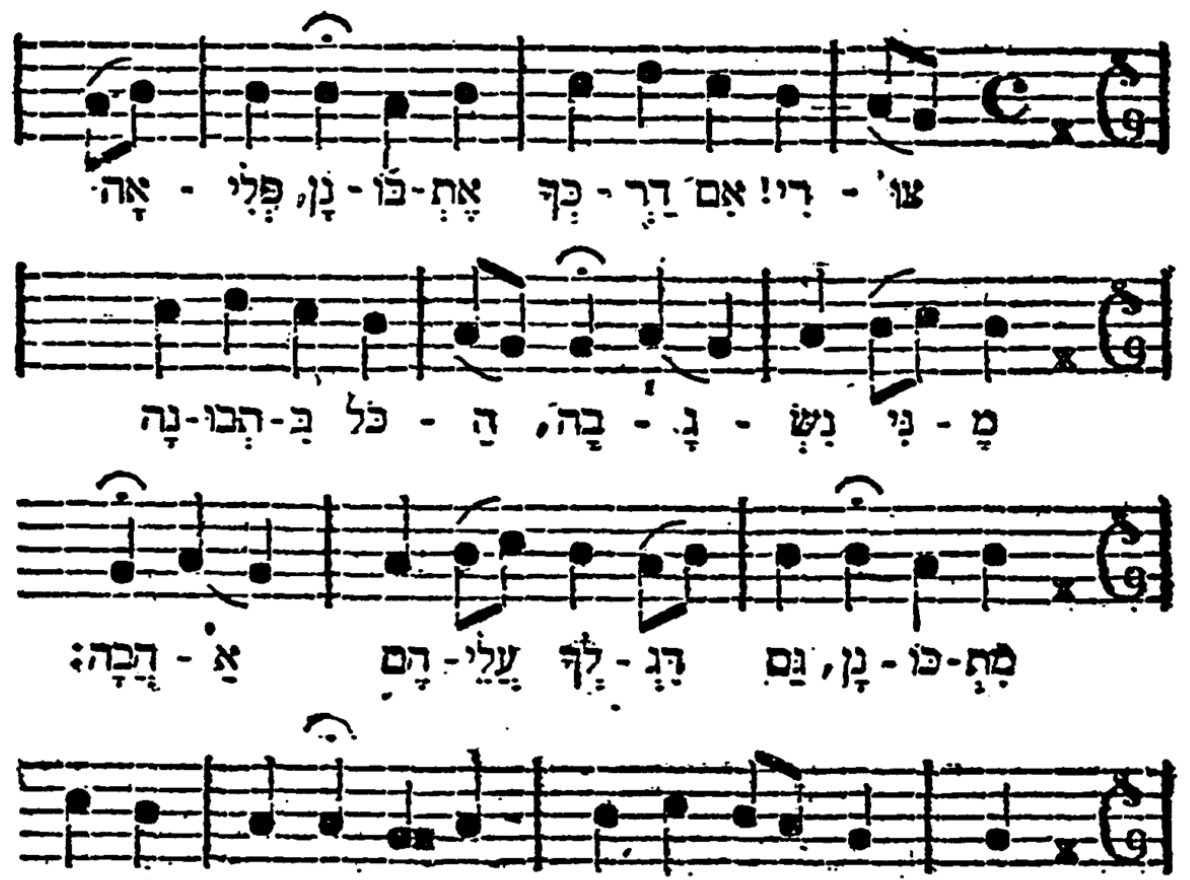

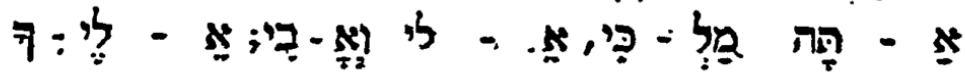

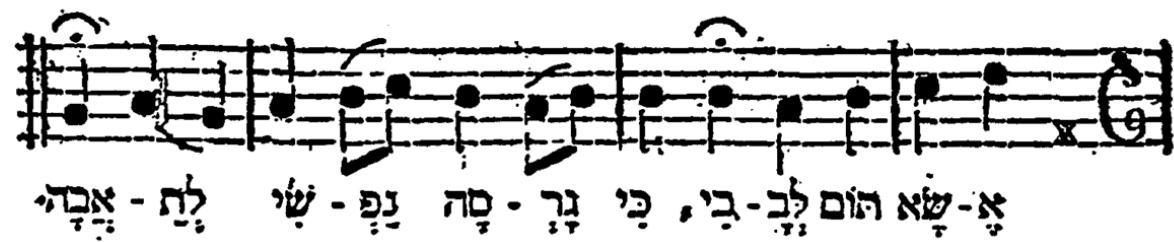

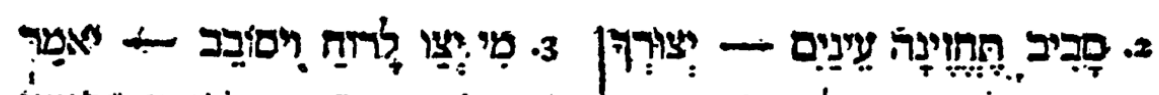

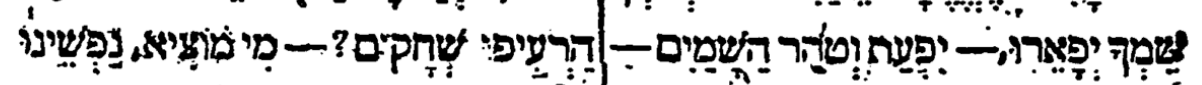

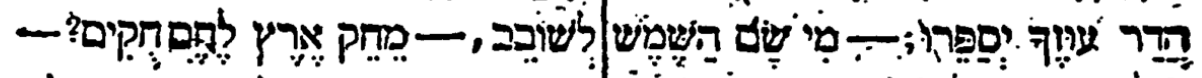

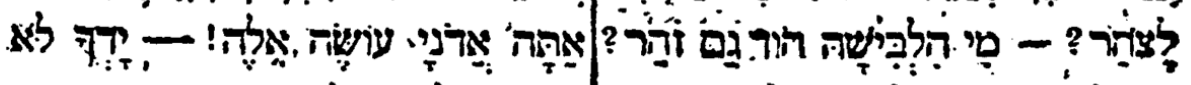
-

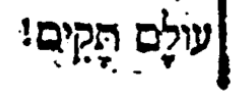

Facsimile 6.

Israel Jacobson Hymnal. Pub. Cassel, r8 1о. No. 1. 
close his Temple and thus the reform attempts in Berlin were suppressed until I 842, when the Reform Society was founded which built the Temple existing to the present day.

But even in Jacobson's Temple in Seesen its leaders had to yield to the demand of the public and engaged the chazzan Hirsch Goldberg (1807-1893) in 1833. He served there until I 842 and was then appointed chazzan in Brunswick. Together with Julius Freudenthal (Brunswick I805-I 874), Dukal musician, he modernized the Synagogue song and published in I843 a collection of songs for solo and small choir in two parts. $^{6}$ To this songster Freudenthal contributed several tunes and, especially his famous tune for En Kelohenu, which he had composed in $184 \mathrm{I}^{7}$ This tune has the typical German melodic line, and in its first part resembles a German melody of 1774 (No. I) (see table XXIX), which was reworked in I8 I9 and in 1844 (No. 3 ) and published in $1844 .^{\circ}$

It is of interest to state the fact that the School in Seesen educated its own musical director who also became the organist of the Temple, the first Jewish organist in the first Reform Temple. This was Gerson Rosenstein (I790-I85I). In 1849 he published a collection of 106 "chorales," melodies to the song-texts in use at the school. These "chorales" have the genuine German chorale style. He compiled also a collection of traditional tunes for the Temple service (Hamburg, I 852) for solo and unison singing. The songster contains sixty-three numbers, twenty-seven of Ashkenazic and fourteen of Sephardic origin. The reason for the inclusion of the latter we shall explain later. The other tunes are new compositions. ${ }^{9}$

Jacobson's program was accepted as a foundation by the "Tempel Verein," founded in Hamburg in I8I7 through the initiative of I. E. Kley. The latter brought along a collection of hymns used in Beer's Temple in Berlin, and introduced them in Hamburg. Kley published Religious songs for Israel- 


\section{TABLE XXIX \\ En Kelohenu}

1.

1774

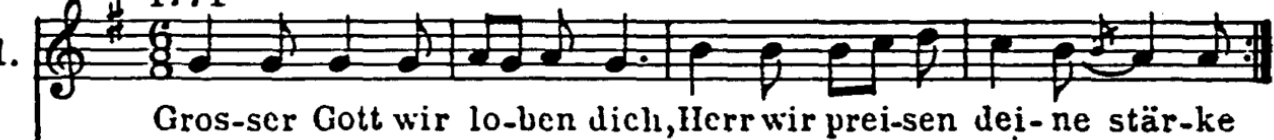

Gros-ser Gott wir lo-ben dich, Herr wir prei-sen dei-ne stär-ke

2. 1819

3.

1844

(e)

4

of 1843

.

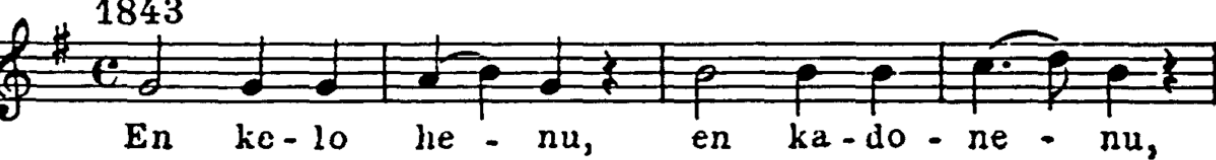

1.

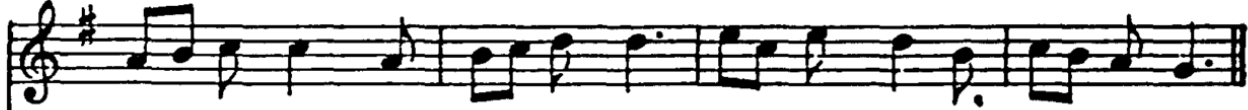

Wic du warst vor al-lcr Zeit, So bleibst du in E-wig-keit.

2 .

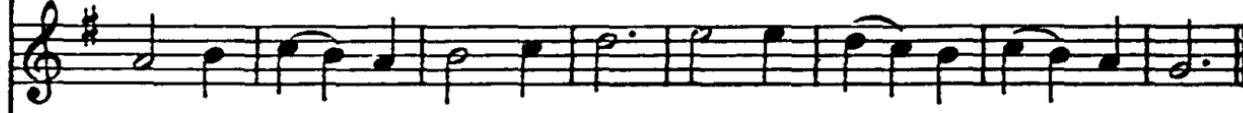

3 .

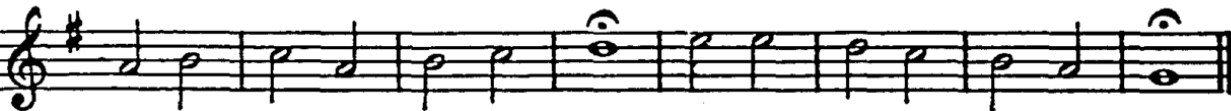

4.

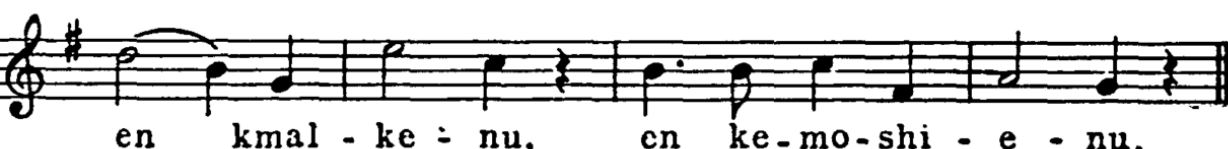

Etz Chayim

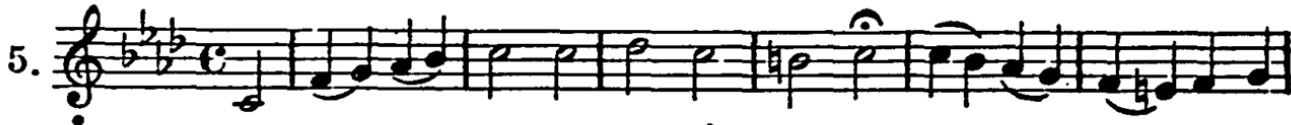
Etz cha-yim hi la-ma-ch'zl-kim boh ve-som-che-hoh mu-

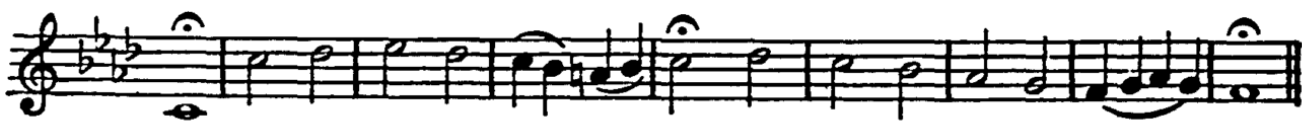

shor, dro-che-hoh dar.che no - am v'chol n'si-ro - sc-hoh sho - lom. 
ites in German, in I8I8, which became the nucleus for the "Hamburg Hymnal" published in $1845 .^{10}$

The suppliers of music for the Temple were mostly Christian musicians: Bethuel, who was the first organist at the Temple (I818-I828), contributed nineteen chorales; I. H. G. Stoewing; A. G. Methfessel; J. A. G. Heinroth; Lütgert; F. J. Groenland; Demuth; Schinck; Schwenke, and others. Ferdinand Hiller, a Jewish convert to Christianity, contributed some chorales. Likewise Jewish laymen like M. Levy and the chairman of the Temple, Isaak Seckl Frankel, contributed thirteen tunes to German texts. The latter was also a member of the committee to compose a new prayerbook for the Reform congregation, which was published in 1819 and dedicated with high esteem and appreciation to Israel Jacobson. The organ was a gift of Salomon Heine, the uncle of the poet Heine. A boys' choir in two parts was trained. Following the intention to abolish all "ugliness of medievalism," although originally it was planned not to employ a chazzan at all, ${ }^{11}$ a Portuguese, David Meldola (born in Amsterdam in 1780; died in Hamburg in 186r), was engaged. He had very little musical ability, but was preferred on account of his Portuguese pronunciation of the Hebrew which was regarded by Kley nearest to the scientific. ${ }^{12}$

D. Meldola introduced Portuguese tunes into the Temple. In doing so, the Ashkenazic chazzanuth was naturally done away with. The Bible was read without chanting. Only in I 879 did the then appointed Cantor of the Temple, M. Henle (1850-1925), reintroduce the chanting according to the Biblical modes; and in 1909 he reintroduced the Ashkenazic pronunciation. ${ }^{13}$ In $1846 \mathrm{Kley}$ published the melodies to the Israelitish Songbook, containing ninety-nine tunes to German texts. In style and character these tunes are similar to the tunes published by G. Rosenstein. 
On special occasions a mixed choir of volunteers would sing German music in four parts. In the preface to his collection, Kley promised to publish those songs, but did not carry out his intention. A collection of these songs was compiled in 1827 by Methfessel and M. Haarbleicher, in which the $E_{t z}$ Chayim melody is contained (table XXIX). This melody seems to be a rearrangement of the Portuguese Tal tune (table XXVIII ${ }^{2}$ ). The same melody was printed later by Goldberg and Rosenstein in their above-mentioned collections. In 1833 another collection in part-singing was arranged by I. F. Schwenke, the organist of the Temple. Both remained in MS. All these "chorales" were lately abolished by the present cantor L. Kornitzer; and, according to his statement, "Jewish" music was introduced instead. ${ }^{14}$

Following Jacobson's reform, several other German "chorale" books for Israelites were compiled, such as the Songster for Israelites in Wuertemberg in I836, in four parts, arranged for all the Sabbaths and festivals of the year (397 numbers). In each hymn the contents of the weekly portion of the Pentateuch, or the underlying idea of the Festival, is expressed. The music is entirely Christian. Another collection was published by Joseph Johlson in Frankfort for the Jewish educational institution "Philantropin." This Israelitish Songbook, published in 1840 (second edition in 1842 ), contains among its IO2 melodies many popular Protestant chorales, such as No. I6a, introduced by I. Jacobson in his songbook printed in I 8 Io. This "chorale" J. S. Bach, for example, utilized four times in his St. Matthew (Nos. 23, 53, 63, 72), in his Christmas Oratorio, Nos. 5, 64, etc. The tune was composed by Hans Leo Hassler in $160{ }^{15}$

Likewise No. 9b and No. 4I, found in Jacobson's Songbook, is the famous Protestant chorale utilized by Bach in St. Matthew, No. $3 \mathrm{I}$; in his Christmas Oratorio, Nos. I2, 60. This 
melody is of Christian origin with Latin text dating back to I $539 .^{16}$

In the matter of adoption from Christian sources Kley was more careful, for he did not adopt popular Christian melodies, but had, according to his statement in the preface, seventy out of ninety-nine tunes especially composed for the texts he submitted to the musicians.

The radical reform introduced by Jacobson and carried out in the Hamburg Temple called forth a stormy opposition throughout Central European Jewry. Many prominent rabbis of that time announced their disapproval of the German prayers and hymns, of the changing of the traditional texts, of the abolition of the traditional Missinay modes of the Bible, of the introduction of the organ, and of the singing of mixed choirs. ${ }^{17}$ That fight continued for many years, and in I845 at the rabbinical conference in Frankfort, after a long debate, the young reform rabbis, such as Holdheim, Abraham Geiger, Salomon, Samuel Adler, etc., adopted the resolution that the employment of the organ in the Synagogue even on Sabbaths and holy days is not only permissible but also advisable, and that making music by playing instruments on Sabbaths and holidays in homes should be recommended from a spiritualreligious standpoint. ${ }^{18}$ Geiger was of those who considered the chant of the Bible of no validity, since it was, to his opinion, a later, post-Biblical innovation. ${ }^{19}$

The Reformers, notably the rabbis, apart from their endeavor to emancipate the Jew and make him a modern European human being by stripping off all the medieval and Oriental elements still clinging to him, were deeply interested in retaining the youth which started to drift away from their peo-ple and culture and to become absorbed by the Christian environment. In their honest effort, they wanted to reconstruct Judaism and to beautify it according to the model they had 
before them. The Jewish youth found delight in Christian forms of worship and religion. Hence, the Reform leaders adopted all those forms and customs of the Church which seemed to them to be in harmony with what they considered to be Prophetic Judaism, completely neglecting all post-Biblical culture, ignoring the result of over two thousand years of Jewish spiritual and social life and creation and the sentiments developed from them. The craving for assimilation roused a dislike for old music, which nevertheless in some places retained its pristine beauty. Around that time an English Christian traveller, speaking of the characteristic old Synagogue song, says: "It has often excited our wonder that in the principal capitals of Europe, wherever there is a Synagogue we have generally found a vocal performer or two who sang in the Italian manner and in exquisite taste ... so it was in Paris, Amsterdam, Milan, Venice, Rome, Naples, and we have had instances at home of exquisite Hebrew singing in our own country (England). ${ }^{20}$

At first, the radical reformers found but a few adherents in Germany: a group in Leipzig which organized, in I 820, a service similar to that of Hamburg, a group in Frankfort, and later, in 1842 , one in Berlin. The bulk of German Jews at that time was still saturated with Jewish tradition and consciousness, so that the few ultra-reformers in every community could arouse interest only in some minor modernization of the ritual and the music. Soon, in almost every community, a battle began between the radical elements and the Orthodox-a fight which led to a division of the communities into Progressive and Conservative congregations. But even the Progressive group did not go so far as did the Temple in Hamburg. The Progressive congregations adopted from Hamburg the singing of German chorales in Protestant style, the mixed choir, and the organ; while, on principle, they retained the 
chazzan and the traditional tunes. Throughout Europe not a single congregation became entirely Reform according to the program of Jacobson. Every community in Central Europe, notably in Germany, is still divided into Orthodox and Progressive or "Organ" congregations.

Almost all the composers for those Progressive synagogues in the first part of the nineteenth century were Christians. Their musical creations are naturally German music in the Church style. Even in arranging Jewish traditional tunes, they employed European structure and German modulation (Chapter XXIII). The solo part of the chazzan, the unrhythmical chant, did not receive any attention; it remained in its eighteenth-century form and frequently became stale and lifeless. This remainder of the old Semitic-Oriental song was tolerated only for the sake of those members who still belonged to the older generation and who, through education and habit, considered a service without chazzanuth as unJewish. The opinion of the young progressive element was that, inasmuch as they were good Germans, this type of nonGerman song had no place in their worship, and should be abolished sooner or later. ${ }^{21}$

From the history of European music we know that through the gigantic classic creations of the eighteenth and the first quarter of the nineteenth centuries the style of and the taste for music were entirely changed. This change, of course, influenced the Jews also. Without radical reform attempts, the Synagogue would have felt the change of taste and would have immediately produced songs in the classic style, but also in accord with the Jewish traditional genius of Synagogue song. This would have fused Jewish elements with classical to new musical forms. But, with the abolition of the entire Jewish song, the Jewish spirit was simultaneously forced out.

As we survey the musical creations of the ultra-reform 
movement of the first half of the nineteenth century, we see that its leaders failed to sense the truth so well expressed by J. G. Frazer in his above-quoted statement (Chapter IX): "Every faith has its appropriate music, and the difference between the creeds might almost be expressed in musical notation. . . . For we cannot doubt that this, the most ultimate and affecting of all the arts, has done much to create as well as to express the religious emotions, thus modifying more or less deeply the fabric of belief to which at first it seems only to minister."

Even more applicable is this statement to the Jews, as a religious, historical and racial group with pronounced original spiritual and intellectual features. They cannot but have a musical expression of their own! Verily, Jacobson and his adherents in Europe and America did not realize this truth.

From the historical point of view it should be recorded that Joseph PerL was the first to establish a modern service in Austria, and, like Israel Jacobson in Seesen, he erected a House of Worship in Tarnopol (Galicia) at his own expense in 1819 with choir, called "Tempel für geregelten Gottesdienst." 


\section{CHAPTER XIII}

THE INFLUENCE OF MODERATE REFORM UPON SYNAGOGUE SONG DURING THE NINETEENTH CENTURY IN CENTRAL AND WESTERN EUROPE.

\section{Salomon Sulzer (I804-1890)}

Judaism in Germany was too strong, too deep-rooted, Jewish sentiment too full of vitality and of desires for life, the SemiticOriental elements in the Jew still too virile to succumb to the ultra-reform movement, to submit to the Europeanization and Germanization of the Jewish soul. Therefore, UltraReform had no direct success. But indirectly it aroused the desire for modernization, for the purification of the vessels of the sanctuary from the rust of ages. It drew the attention of Israel's intellectual spirits to the need of a thorough investigation of the inherited treasures, in order to learn their nature and their manner of development in the past, and to determine which of their elements are essential to Judaism and should be retained and which had value only for the past and should be relegated to the sacred archives. That scientific and philosophical movement embraced all the intellectual spirits in Israel regardless of their practical attitude toward tradition, and it directly influenced the Synagogue song.

Around the beginning of the nineteenth century, some members of the newly established Jewish community in Vienna (organized in 1790) sought the introduction of the Reform Service of the Hamburg Temple, to which end they elected one of the prominent leaders of the Reform movement, Isaac Noah Mannheimer, as principal of the religious school and preacher 
and erected a Temple in 1826 . The old chazzan who had also been religious teacher and minister, Koppel Markbreiter ${ }^{1}$ (in Vienna from 1792), was found incompetent to undertake a modernization of the music; and, therefore, Christian musicians were employed from I8I2-among them also the Jew Ignaz Moscheles, who composed for the Vienna synagogue's celebration of $18 \mathrm{I} 4$, but who later embraced Christianity. ${ }^{2}$ In this connection, because it is significant for the attitude of the Reform Jews in their relation to Christianity, we digress a moment to note that the Hamburg Temple invited the Christianized Felix Mendelssohn in 1844 to compose for the twenty-fifth anniversary of the Temple, which invitation he at first accepted but later declined. Likewise, Beethoven was asked by the Vienna community to compose a cantata on the occasion of the dedication of the new temple in $1826 .^{3}$ Mannheimer was the son of a well-known chazzan, Noah Mannheimer. ${ }^{4}$ The son inherited from his father some musical and chazzanic appreciation and understanding. He therefore considered the old Markbreiter incapable. In truth, he would have preferred to abolish the office entirely, as his general attitude toward reform was a radical one, and his aim was to introduce the Jacobson-Hamburg program (see further in Sulzer's statement). Yet the majority of the congregation in Vienna, rooted still in the tradition of the past, for most of them were from the Hungarian and Slavic countries of the Austrian Monarchy, opposed him. Probably the conservative Catholic atmosphere of Vienna, in contradistinction to the liberal Protestant atmosphere in Northern Germany, may have contributed to the conservatism of the Jews. Consequently Mannheimer, despite his personal views, was constrained to make far-reaching compromises with conservatism, as he himself admitted in his letters. Among his compromises was the engagement of a chazzan. 
And here it happened that the chazzan whom the Vienna community engaged was a genius-Salomon Sulzer. Had he been a mediocrity, the result would have been-as in so many other communities-that Christian composers would have provided chorales and German music, while the chazzan continued his stale recitative. Sulzer was in every aspect quite unique in the chazzanic caste. The son of a rich and intelligent family of manufacturers, he was through accidental circumstances directed to the service of the Synagogue. In the recklessness of early boyhood, he had fallen into the river, and was thought drowned. His mother, frantically summoning all possible aid, vowed to devote him to a sacred career if he would be saved. His instructor in chazzanuth was the chazzan in his native place, Hohenems: Salomon Eichberg ( $1786-$ 1880). Eichberg had been a "singer" under Israel Lovy in Fürth (Chapter XI), and probably instructed his disciple Sulzer in the traditional song of Southern Germany as well as in the compositions of Israel Lovy. Aside from this, Sulzer had a modern general and musical education. He was gifted with a phenomenal voice, a Baritone-Tenor, and a fiery temperament. No wonder that his appearance in Vienna at the newly built Temple caused a sensation.

The policy of the leaders of the Vienna community-and in this Mannheimer concurred-was to maintain the unity of its members, and therefore to avoid every extreme reform which might cause a split such as had occurred in Germany. The young Sulzer instinctively felt "in the first place, it behooves us to fight the opinion that the regeneration of the service can be materialized only by an entire break with the past, by abolishing all traditional and inherited, historicallyevolved liturgy. To limit the entire service to a German hymn before and after the sermon, to give a certificate of divorce to tradition, was the intention of those who instigated 
the ill-fated reform in Hamburg and Berlin. . . . But to me it appeared that the confusion of the Synagogue service resulted from the need of only a RESTORATION which should remain on historical ground; and that we might find out the original noble forms to which we should anchor, developing them in artistic style. The old generation should recognize the familiar and endeared element, while the young generation should be educated to the appreciation of it. Jewish liturgy must satisfy the musical demands while remaining Jewish; and it should not be necessary to sacrifice the Jewish characteristics to artistic forms. The principle was to unite the heart of the fathers with that of the children, and to win ambitious youth for the sentiments of the old generation. ... Among the most beautiful memories of my life, I count that moment in which the truth of my conviction completely captured the great and noble nature of the preacher MANNHEIMER, whose ideal for a long time had been that radical reform of Hamburg and Berlin; and in which he frankly confessed that the way which I had opened was the one and only possible avenue to the goal." This is the program which Sulzer worked out, as presented in his own words in his Denkschrift, Vienna, I 876.

In order to give the complete program of Sulzer, we have to add another statement of his which will throw much light on his real attitude. He says: "The old tunes and singing modes which became national should be improved, selected, and adjusted to the rules of art. But also new musical creations should not be avoided; and for that purpose, great heroes of music stood helpfully at my side, such as SEYFriEd, ScHuBERT, FISCHhOF, and others (all Christians)..$^{5}$ The traditional part of the music they left entirely to me, but their contribution was very essential to the beautifying of the Synagogue song; and therefore part of the success which the Vienna 
ritual earned is to be accredited to them." In his preface to Schir Zion, I, written in 1838, he says: "I set it as my duty ... to consider, as far as possible, the traditional tunes bequeathed to us, to cleanse the ancient and dignified type from the later accretions of tasteless embellishments, to bring them back to the original (?) * purity, and to reconstruct them in accordance with the text and with the rules of harmony. For obvious reasons, this could be more easily achieved with the songs of the festivals-especially with those of the High Holidays-than with the Sabbath service, because for the latter (particularly for the Friday evening service) there were frequently employed profane tunes which desecrated the holiness of the service ... whereas the songs of the High Festivals have an inwardness and depth, a gripping and moving power, which they have preserved through the centuries."

Worthy of note is Sulzer's attitude toward the traditional modes of the Friday evening and Sabbath services. His habit of disavowing these modes he shared with most of the chazzanim; who-as a result-adopted all foreign types of music in preference to their own. The fact is that for Friday evening and Sabbath there are dignified traditional modes of no less value than those for the holidays (Chapter VIII). The reason for the neglect lies probably in the circumstance that the traditional Sabbath tunes are not rhythmical but are MODES only, and could easily have been misjudged by those lacking appreciation of non-rhythmical music.

After weighing these quotations of Sulzer's, expressing his underlying ideals and principles in regard to the reformation of the Synagogue song, let us analyze the result of his work given in his Schir Zion, ${ }^{6}$ and estimate his achievements. Although his purpose was the artistic re-creation of the traditional

\footnotetext{
* It is doubtful just what Sulzer could have meant by "original" and by what standards he could have judged. Hence I add the question mark.
} 
songs, the two volumes of his services prove to be not this RE-CREATION but only a RE-SHAPING. Traditional tunes remained to him a product of the past, to be retained for the sake of the sanctity associated with them through the generations, and not as a living body pregnant with new artistic forms, a treasury of musical atoms sentient with the power of new life. He did not recognize the Jewish musical inheritance as an echo of the living Jewish soul. To him it was merely a body of song that had somehow become national and as such was sacred to the Jew. This same attitude he showed in regard to the Hebrew language. To him it was not the question of HIs desire and sentiments but those of the PEOPLE's. He thought himself to have outgrown such sentiment. His moderateness in reform was, therefore, not the result of his innermost feeling but the consequence of conditions. Thus he says in the preface of the Schir Zion, II, written in I865: "Especial attention did I pay to the old tunes of the Nestor 'Maharil' (Chapter VIII) which I repeatedly took as a basis for my compositions, in that I excluded everything which could detract from the musical dignity. . . . Likewise, I considered those congregations which had introduced the organ as the musical basis for their services, so that the work (Schir Zion), starting from existing conditions, linking with the old, and proceeding by the evolution of creation, moves toward the new. It performs a mediatory mission between the past and the future."

From this statement we may conclude that Sulzer did not consider moderate reform as a goal in itself, but only as a bridge from the old to the new. Hence, we can understand his apparent shifting of position when, after fifty years of struggle for moderation, he pleaded (in his above-mentioned Denkschrift) for the introduction of the organ in his Temple, for the diminution of the Hebrew text in the prayers, and for 
the inclusion of hymns in the vernacular, "even though," he says, "I appreciate and venerate the sacred sounds of the holy tongue in which our ancestors expressed their joy and pain." He further urged the abolition of the chanting of the Pentateuch, the adoption of the three-year cycle of Torah-reading, and the introduction of the modern declamation-a plea which he laid before the Synods of Leipzig and Augsburg in 1869-70. And lastly he made a strong appeal against allowing chazzanim to improvise, insisting that everything that the chazzan sings should be fixed. Finally, he strongly opposed participation in the functions of the service by the congregation in unison or by the individual members of it. We see here that, in reality, Sulzer had in mind the program of the Hamburg Temple; but for practical purposes he preferred to start slowly -very slowly in his reform attempts.

It is most interesting to notice in the movements of Judaism that, while on the one hand the extreme Hamburg reform, having gone too far away, started moving back, gradually reintroducing Hebrew prayers, until finally in 1879 it again adopted the chanting of the Pentateuch (Chapter XII), on the other hand those who moved gradually, still hold as their goal and still strive toward that which the extremists discovered to be suicidal. We see this process now in Europe: reform and assimilative elements turning back after becoming aware of a dangerous abyss before them, while the orthodox elements-unwarned by the experience of the others-are still blindly driving with full power toward the fatal extremity. There appears to be the same pendular movement in America. Indeed, it seems that the entire history of Judaism is of this character.

Sulzer's attitude toward music must be viewed in the light of the almost universal misconception of music's source. The notion tenaciously persists that music is an art obtained and 
developed APART from daily life, that the musical creative power is a "gift of the heavens" and not an outgrowth of the earthy soil of environment, a product of the struggle of life, of history. It refuses to recognize music as an aggregation of the echoes, of the breathings, of the troubled or of the overjoyed hearts of a long line of generations, as accumulated tones inherited from ancestors, and buried and hidden in the hearts of the children-sounds which cannot be comprehended by hearts which are unattuned. So long as men blind themselves to the true roots of song, any understanding of music will remain unattainable. Until we realize that Music as such, without a nourishing soil, does not and cannot spring to life, until we see that MUSicians in the abstract, without concrete derivation, do not and cannot exist, all our efforts to appreciate music-and especially Jewish music-will be in vain.

Sulzer's preparation in Jewishness and his impressions of Jewish life were very meagre. He did not drink from the deep and rich wells of Jewish traditional life, because his native community was small and far removed from Jewish centers. The spirit there was the usual spirit of decay to the point of caricature, a drifting away from Judaism toward European culture. How then can we expect Jewish music to be an instinctive, natural, living power in his heart-a part of his soul? And yet he was surely inspired, full of enthusiasm for Jewish ideas-at least, the Prophetic ideas. A sacred fire burned in his heart, the light and warmth of which inflamed all his hearers. Of him, the great musician and creator, Franz Liszt, in his famous work "The Gipsies" ? says: "Only once we witnessed what a real Judaic art could be if the Israelites would have poured out their suppressed passions and sentiments and revealed the glow of their fire in the art forms of their Asiatic genius, in its full pomp and fantasy and dreamsthat hot fire which they kept so carefully hidden and they 
covered with ashes that it should appear cold. In Vienna we knew the famous tenor Sulzer, who served in capacity of precentor in the synagogue, and whose reputation is so outstanding. For moments we could penetrate into his real soul and recognize the secret doctrines of the fathers. . . . We went to his synagogue in order to hear him. Seldom were we so deeply stirred by emotion as on that evening, so shaken that our soul was entirely given to meditation and to participation in the service." This quoted thought of the gentile was the standard opinion of all the gentiles who heard Sulzer. To them, his song and singing were something foreign, un-German, and even un-European. The same opinion was shared even by assimilated Jews whose Jewish sentiments had dwindled to a minimum, while Jews from the Ghetto-untouched by foreign influence-were overwhelmed by his powerful and sweet voice and inspiring rendition, but were unaffected by the Jewishness of Sulzer. To them, he was a wonderful singer only. They considered his music galchish (Church style) and by no means Jewish.

Sulzer's music affords but another proof of the general phenomenon which we may observe in regard to the identifying of the music of a foreign people. Music, the originality of which has so dwindled that it would not be recognized as their own even by its own people, is yet by another people considered foreign. Not by its faithfulness to its own tradition is a national music judged by a stranger, but by its unlikeness to that to which he is accustomed. For example, the Oriental pieces by Rimsky-Korsakow, the Oriental parts in Ä̈da by Verdi or in Samson and Delilah by Saint-Saëns, would hardly be recognized by Orientals as their own music. The Oriental flavor of them is as thin as a drop of wine in a cask of water.

Sulzer did not know what Jewish music was, but he did instinctively feel or he deduced the fact from the general 
character of Jewish traditional tunes that the manner of Jewish musical expression was a different one from that of the German. Therefore we find a very peculiar phenomenon, at least in his Schir Zion, that somehow there are avoided the specifically German melodic lines and curves, not only in His creations but even in the creations of all his German collaborators. We know that at least a third of Schir Zion, I (most of the choral numbers) is the work of Germans. ${ }^{8}$ Many of these numbers became famous and popular. The Jew does not recognize their German character, although he does sense something foreign if not specifically German. All the choral part of Schir Zion is rooted in the classical Church music, especially the choral responsa that have the typical Catholic character, e.g.: $28,66,67,75,99,222,272,478,545,548$. The specifically Catholic marks have been consistently avoided. And yet the Jew considered this creation non-Jewish, while the Christians felt it foreign to them, and therefore counted it Jewish. It has the character of a careful attempt to express something original, something different from Germanism and the Church. We cannot credit Sulzer with making this attempt consciously, for in his GERMAn songs for Jews he is quite a good German (see Dudaim, II, pp. 27-32), while only in his compositions for Hebrew texts does he avoid these German characteristics.

Sulzer's positive contributions may be chiefly outlined under the following divisions: (I) His form of expression distinguishes itself by a brevity and conciseness similar to the ancient Hebrew style. (2) No lyrical melodies of playful character occur, his melodic line always being serious and dignified. (3) He was the first to base the Synagogue song on classical harmony and style. (4) He further introduced the regular four part singing, consisting of boys (soprano and alto) and men (tenor and bass). In this innovation, however, the abovementioned Israel Lovy preceded him by inaugurating four part 
singing in the newly built Temple in Paris in 1822 . Until that time, the Synagogue choir ("singers" or meshorerim) consisted of a soprano or an alto and a bass, who together with the chazzan made a trio (Chapter XI). (5) He overemphasized the phase of exultation and holiness in the Synagogue song, neglecting the no less important emotional strain, the sentimental note in Jewish song, an important feature in Semitic-Oriental music. Due to the lack of that element Sulzer's music and style makes an exalted but cold impression upon the pious orthodox Jew, though in a few pieces he touches the deepest Jewish emotions, as in No. 236 Veseerav, or No. 381 Meloch. However, these themes he adopted from Polish chazzanim and gave them an artistic touch.

His opinion was that "harmony is a cheerful art" (preface to Schir Zion, II), and that sadness cuts off the wings of the spirit, and Israel's martyrdom, to his mind, prevented the creation of a musical art (l.c.).

It seems that Sulzer's caution against the introduction of Germanism greatly aided his popularity. His new music was not so goyish as the typical German chorales of the Hamburg Temple. But this alone would not have been sufficient to make him so popular, and so firmly to establish him as an authority all over the world. There was a more striking power in him; and this was his great, almost unique, talent as singer. It was not so much the Music which convinced the people, as the manner and the marvelous beauty of rendition which fascinated and bewitched them. A mania spread among the chazzanim to sing à la Sulzer, to dress à la Sulzer, to wear their hair à la Sulzer, to cough à la Sulzer. For the first time in Jewish history in the Exile did a cantor become so famous, so honored by kings and princes, by artists and musicians, by magnates of wealth, and by academies of art. For a half century he not only reigned over the entire caste of chazzanim, but held the 
veneration of the entire modern rabbinic and scholarly world, esteemed by it as the authority and genius of Israel's song. Hundreds and hundreds of chazzanim were his pupils. They sang in his choir or received some instruction from him or were his attentive auditors. From I 835 till I 876 practically every modern Synagogue in Central Europe as well as in Eastern Europe reorganized its music according to Sulzer's service.

Judging from Sulzer's own statement quoted above, that his aim was to retain the traditional tunes, giving them artistic forms, and to introduce new creations, we should be led to believe that in his music we should find traditional tunes preserved and new creations based upon and in the spirit of those traditional tunes, thus building a continued creation of Jewish music in new forms. But such belief is dissipated as soon as we peruse his Schir Zion. Indeed, he did preserve the traditional tunes; and though he abolished all their chazzanic flavor and abbreviated them, he at the same time also improved them artistically. We do find, indeed, recitatives based on the traditional modes, as the following numbers will prove: (The numbers are according to the second Edition.) 39, 42, 44, 63-69, 80, 82, 85-92, ro9, I35-I4I, I43-I47, I 54, I 58-I6r, $165-169,294,373$. He was the first to pay attention to the value of the Biblical modes: of the Pentateuch (29-30, I08, 340, 34I), Esther (5 I I-529), Lamentations (549-566). Similarly based upon the traditional modes are the recitatives, or solos, with choruses in the form of responses, or vocal accompaniment: 43 , I IO, I 57, I63, 236, 238, 245-253, 254257,27 I, 277-279, 296, 300, 336, 344, 347, 348, 350-357, $36 \mathrm{I}, 365,366-367,38 \mathrm{I}, 384,387,388,390,39 \mathrm{I}, 447,450$, $458,545-567,572,574$. Sulzer composed short choruses in minor with Jewish flavor: I62, I79, 205-2 I I, 2 I4, 22 I, 289$29 \mathrm{I}, 295,385,396,397,4 \mathrm{I} 3,462,479-48 \mathrm{I}, 563,567,575-$ 578 ; yet they have rather the character of responses than com- 
positions complete in themselves. Not a single tune that he created anew has a genuine Jewish character. In none of his compositions is there to be found a Jewish motive employed and evolved. While the modal structure and loose recitative character of Jewish song presented some difficulties for modern compositions, nevertheless Jewish musicians many centuries before Sulzer had succeeded in utilizing motives of these modes for new creations (Chapter VIII); the Jews of Eastern Europe developed their folksong from these modes (Chapters XVIII-XIX); and the Eastern European chazzanim built most of their tunes from the same material (Chapter XIV). Most of Sulzer's compositions in MAJOR are not to be distinguished by any special Jewish flavor from those of his Christian collaborators. He was praised for introducing the recitative of the oratorio, that is, a musical reading more nearly approaching speaking than singing. But also herein he was more imitator than creator. The recitative style in its oratorio form is the original Jewish Psalmodic recitative with the elimination of the melisma at the end of every sentence. ${ }^{9}$ Here as in many other cases, Sulzer's complete ignorance of the elements, types, and forms of Jewish music led him to imitate imitations instead of drawing directly from the source. $\mathrm{He}$ did not know that the recitative form is traditional among the Oriental Jews as well as among the Portuguese. He did not understand the Semitic-Oriental character of the Jew-despite the conviction of gentiles that he was the embodiment and symbol of the ancient Hebrews-an opinion which was strengthened by his typical Semitic complexion and features. He did not feel the Eastern European chazzanuth, in spite of the fact that he tried to learn it in order to satisfy his hearers, and that he tried even to imitate it in several recitatives incorporated in his Schir Zion. ${ }^{10}$ In his above-mentioned preface to his Schir Zion, II, he says: "I paid attention to even the Polish song, 
i.e., the traditional modes of the Jews in Eastern Europe, in so far as it presented real individual characteristics, seeking to utilize it in its original features, and to set it in musical forms." But he could not sufficiently digest and assimilate that chazzanuth to be able to think and feel in its language; and it always remained apart from his spirit. His nature, like that of most of the Central European partially assimilated Jews, retained a German-Catholic attitude, with a gloomy subconscious leaning toward the ideals and inheritance that they called JUDAISM.

But one improvement of far-reaching significance Sulzer brought into the Synagogue, which contribution alone would have made his name unforgettable in history; and this is Dignity-dignity of the song and dignity of the sINGER. Toward the end of the eighteenth century, the song had become decadent to the point of caricature; it was an imitation of every low type of vapid secular music, and it had in consequence lost all power to inspire any devotion and to elevate the spirit. It had taken on the character of provincial entertainments, while the singers had degenerated to the level of minstrels. In his casting aside all the musical products of the eighteenth century and in his introduction of the pseudoChurch and classical style with powerful harmony, Sulzer restored to Synagogue music its tone of dignity. He himself became the symbol of a chazzan of high artistic and social standing. He urged his pupils to equip themselves with elementary education, thus to raise their standard and lend them dignity. He even demanded that the chazzan, or "Cantor" as Sulzer chose to be called, ${ }^{11}$ be acknowledged the equal of the rabbi. In this attempt, of course, he never succeeded. Indeed, his insistent demand for the same degree of credit for himself as that paid to Rabbi Mannheimer by A. Jellinek, called down upon him the rebuff of the president of the Vienna 
Community; and he was officially suspended from his office for three months. Only his tremendous popularity among the members of the community protected him from severe consequences. $^{12}$

\section{Maier Kohn (I802-I875); Samuel Naumbourg (I 8 I 5-I 880 )}

The old stock of German Jewry, deep-rooted in South and Southwestern German countries from the days of Charlemagne, survived in Bavaria, Württemberg, Hessen, and Baden, despite terrible persecutions lasting through a period of eight hundred years. Those Jews retained their distinctive Jewish tradition-a tradition imprinted with blood and fire. Their conservatism, in the course of time, had taken on the color of Catholic Germanism. They remained almost untouched by the winds of Reform. Yet in the capital of Bavaria, Munich, a new community was formed at the beginning of the nineteenth century, after an interval of almost four hundred years from the time that the old Munich community had been partly killed, partly driven out. That new community had some members who had somehow been slightly brushed by the breeze of Reform coming from afar. They demanded therefore some modernization in the service of the Synagogue newly built in 1826 . But since the appointed chazzan, Loew Sänger (I78I-I843), was of the old type of the German chazzanim of the eighteenth century, the Board of the Congregation decided to appoint a special music committee with the purpose of organizing a choir and introducing some innovations in the Synagogue song. In I832, such a choral society was formed. It consisted of music lovers from among the members of the congregation, and also of boys; and it was placed under the leadership of Maier Kohn. 
Kohn was a teacher of religion, who had charge of a boarding school and who claimed to have a musical strain. In reality his knowledge of music was equivalent to nothing, consisting only of the ability to read a simple melody with the aid of a violin. He lacked the knowledge of even the simplest rudiments of music. He seemed to have only one virtue, and this was a strong ambition to work for the benefit of the Synagogue. He knew traditional chazzanuth by inheritance; and he was very eager to become choir leader and SECOND cantorsecond, because he had no voice. It must be noted that his co-laborers were not greater musical geniuses than he. There was David Hessel, the son of the Rabbi in Munich, who contributed a few melodies from an obscure source, one of which, "Yigdal," became famous and reached Sulzer in Vienna. Even as far as Berlin and in many communities in Bavaria, it is sung to the present day. Another associate in the work was Wimmelbacher, who later became cantor and choir master in Aix la Chapelle, and in about 1842 assumed a similar post in Bernburg in Anhalt. One by the name of Neuburger and still others contributed tunes for Kohn's choir. Among the choristers was SAmuel Naumbourg, who also gave one number.

At that time the custom became general to follow the plan, first introduced by Israel Jacobson in the Seesen Temple in I 8 IO and standardized in the Hamburg Temple, of employing gentile musicians to supply music for the Synagogue. For this procedure there were two reasons: in the first place, the Jewish musicians had no modern musical training and did not know a thing about harmony; and in the second place, the aim was to replace the Jewish Asiatic tunes with German European melodies which alone were considered capable of arousing devotion. Matters went so far that Synagogue music was considered good music, if it had the approval of a gentile musician. In every synagogue the song was composed of two 
elements, of the "musical" part, that is, compositions by gentiles or, if by Jews, at least true imitations of gentile music; and of chazzanuth - the insinuation being that chazzanuth was not included in Music. That opinion still persists in certain groups all over the world, whether in Central or Eastern Europe, whether in America or Palestine. Maier Kohn, becoming aware that he could not get along without gentile help, engaged a few German musicians in Munich, who harmonized Jewish tunes and added compositions of their own.

All the material that he collected was arranged and set in order by a certain musician, Ett, and published in Munich in I 839, a year before Sulzer published his Schir Zion, I. In comparison with the musical value of the Schir Zion, the music of Maier Kohn's publication is very poor. But in the chazzanic numbers, he presented very important material from the Southern German traditional tunes of the Jews. Moreover, Kohn promised a second collection containing only chazzanuth without any Music for the entire cycle of the year. And he really prepared the manuscript for it; but unfortunately he never succeeded in interesting anyone to publish it, likely because it was chazzanuth and not Music. His work, as the first attempt at a moderate-reform service, met with favorable reception in Germany, and answered a need at least until another work of similar intention superseded it-a work of much higher musical and artistic value and of more extensive chazzanic elementsthe work of SAmUel NaUmbourg.

Naumbourg was a descendant of a three-century-old chazzanic family in Germany, saturated with Southern Ashkenazic chazzanuth and gifted with musical talent and with intelligence. In Munich he received a musical training, and after being choir-master in Strassburg with a then famous chazzan LoEwe, he came to Paris warmly recommended to Jacques Fromental Halévy, in i 843. Halévy was the son of a 
Parisian chazzan and teacher, originating in Fürth in Bavaria. ${ }^{13}$ He took interest in the Jewish communal life and was a member of the Consistoire Israelite. After the death of Israel Lovy (1832), the Paris community remained without a chaz$z a n$, probably for lack of interest in religious life. The reforms that Lovy had introduced vanished, and confusion came into its own again. Naumbourg bent his efforts toward becoming first chazzan and reorganizer of the service. The reactionary atmosphere in Paris at that time helped him a great deal to achieve his goal. Religious officers were then considered governmental officers; and the French government started paying much attention to the religious life of the denominations. So Naumbourg presented to the government a memorandum in which he explained the state of the Jewish worship and the necessity of its reorganization; and since his program bore the endorsement of Halévy, it found ready ears in the Departments of Cults and Education. Naumbourg received the order to work out a Jewish musical service; and, thus favored by the government and Halévy, he procured the appointment to the post of first chazzan in I 845 .

In an astonishingly short time, considering the hugeness of the task, he fulfilled the governmental order; and by 1847 he succeeded in compiling and publishing his great work in two big volumes, under the name Z Zmiroth Y YSRAEL, containing the complete service for the entire cycle of the year, arranged for chazzan and choir, and partly provided with organ accompaniment. In Naumbourg's work, we find for the first time a musical task of high artistic rank, achieved by Jewish musicians only. Aside from his own compositions, he incorporated several tunes by his predecessor Israel Lovy. Furthermore, he succeeded in interesting Halévy in composing some items, one of which, Min Hametzar (Ps. I I8), became very famous. He included also some compositions of other 
Jewish composers. He even received permission from Meyerbeer to adapt a Christmas Carol composed by him, for $U v^{\text {nucho }}$ Yomar. $^{14}$ But the most striking part in Naumbourg's work is his adherence to South German chazzanuth of which he embodied a considerable quantity. Although, as already said, he himself knew that chazzanuth to perfection, he nevertheless for some reason or other preferred to follow the version of it he had written while in Munich from the singing of the abovementioned Loew Sänger. ${ }^{15}$ Another important feature in Naumbourg's work is that among his compositions we find, for the first time in modern services, creations of new Jewish tunes based upon old material. Although these are few in number, they yet give expression to Naumbourg's noteworthy attitude and sentiment toward Jewish music. The traditional elements occupy about half of Naumbourg's work. Though his talent was inferior to that of Sulzer, his harmony conservative and at times dull, he succeeded in creating some impressive pieces, such as No. I79 Veseerav, No. 233 Berosh Hashonoh, No. 269 Onnoh tovo.

In regard to Naumbourg's style in his un-Jewish creations for the Synagogue, a word should be said. He was influenced by the art music then current in Paris. From the time of the Revolution, Paris increasingly became the metropolis of civilized Europe-in music as well as in other things. Especially was it the center of Grand Opera. Everyone with musical talent from Italy and Germany went to Paris. Italian, German and French music were accumulated and amalgamated in that center. Different styles intermingled, but Grand Opera predominated. Every branch of music, even sacred song, was influenced by that operatic style. Music became synonymous with OPERA. Hence the operatic flavor in Naumbourg's compositions! And hence also the Parisian music-style mixture in his melodies-that style-mixture which, by reason of its limit- 
less possibilities and his skillful utilization of it, had made Meyerbeer so victorious over all other composers, so successful and great in HIs time-that Parisian mixture against which Wagner as well as Liszt battled. ${ }^{16}$ This style gave to Naumbourg's work some international features, and helped it to become widely known, much liked and used. ${ }^{17}$

Aside from his activity as regenerator, he made historical investigations in Jewish music, on which subject he published a long essay as an introduction to his collection of popularized Synagogal tunes which he called Agudath Schirim (1874). ${ }^{18}$ It was the first attempt made to present, along historical lines, the features of Jewish traditional song, and hence it still has the historical value of an initial attempt. In the Agudath Schirim he brought together Ashkenazic traditional tunes as well as Portuguese, and added the cantillation of the Pentateuch according to those traditions.

Finally, we must treat his edition of the collection of Synagogue compositions of SALOMON Rossi, originally published in Venice, 1622-those compositions which Salomon Rossi had written for the modernized service in Italy and which, in spite of all the efforts of Leon of Modena, met with no success. The original publication was of separate parts only, and not in score. Baron de Rothschild collected the scattered parts and entrusted them to Naumbourg for publication. In I 877 Naumbourg brought out the work under the name Schir Haschirim Asher Lischlomo. Despite all the book's blunders, due probably to Naumbourg's ignorance of the history of music and his inability to read old musical prints, or due-according to Birnbaum's opinion-to lack of accuracy, we nevertheless have to be thankful for his publication of Rossi's songs, for if they have no practical value for Jewish music, they have historical value as music by a Jew. The distinguished scholar, Heyman SteinTHAL, made this importance clear when, in his essay on Jewish 
music, he said: "Let our descendants, the future generation, know all that our ancestors sang, be it even of foreign origin. Let the future generations know the participation of our ancestors in general culture and its influence upon them." ${ }^{19}$ Naumbourg, through this publication of Rossi's songs, awakened the interest of chazzanim in historical research in a deeper understanding of the tradition. He called their attention back to the past, and caused them to broaden their horizon and to see the truth that Synagogue song did not begin with Sulzer, all before him having been tohu vavohu, but that Jewish musical activity dated back centuries, perhaps thousands of years.

\section{Hirsch Weintraub (I8I I-I882)}

Already in the seventeenth and the beginning of the eighteenth centuries, famous Eastern chazzanim are cited in literature. But nothing of their products has survived. The first chazzan whose compositions were written down and preserved is Salomon Kashtan (born in $178 \mathrm{I}$ in old Constantine, and died in 1829). His was the greatest voice of his time. His coloratura, according to the testimony of his contemporaries, was inimitable even by instruments. He was, at the same time, a man of profound religious devotion and piety, and of a great knowledge of Hebrew literature. Although officially chazzan in the famous community of Dubno, he used to travel from city to city throughout Lithuania, Poland, Hungary, and Prussia, all the year round; and his function as city chazzan of Dubno he fulfilled only three days of the year-Rosh Hashanah and Yom Kippur. His art of performance was overwhelming, and nobody could resist being moved to tears when he intoned those tunes which express pain. He could, on a simple Shabbos, create the atmosphere of Yom Kippur, and in the following moment rouse the whole congregation 
from deep melancholy to the mood of dance. As composer, he established a school, an original style in Eastern chazzanuth which may rightly be designated as the finest. The cradle of the earlier Eastern chazzanuth was Volhynia, whence came two styles: one was the style of Kashtan, which found its recognition in the Northwestern communities; and the other which turned to the South, and was developed and spread by the famous chazzan Bezalel in Odessa and by his pupils. Although both have the same elements and forms and are mostly based on the Ahavoh-Rabboh Steiger, Kashtan's style has more depth of thought and dignity, while Bezalel's is more lyric and sweet and ingratiating. Of the innumerable pupils of Kashtan, we shall name the two most prominent: his brother Nochum Leb, chazzan in Berditchev, who-although not possessing Kashtan's heroic voice-had, as composer and Talmudist, the same qualifications; and it is rather impossible to know which of the compositions belong to the one brother and which to the other, because the two men had the same style. Both died in the same month, in November $1829 .{ }^{20}$

The second pupil was Kashtan's son Hirsch Weintraub, who became his successor in Dubno, but left his native country while still young, and-as his father before him-traveled throughout Austria and Prussia giving service-concerts. $\mathrm{He}$ had not the vocal qualities of his father, but he inherited his coloratura and his creative talent. His meeting with Sulzer, the first model of a Europeanized chazzan, and the influence of the European classic music with which he gained acquaintance through his artistic playing on the violin, made him decide to abandon his native country and to establish his permanent home in Germany, where he became chazzan in Königsberg. After a deep and thorough study of the theory of music and the classics, he reworked his father's compositions in order to give them a more European form. At the same time, he composed services 
in the modern style which had been created by Sulzer. Indisputably dignified and genuine as are these compositions from the general musical point of view, they have nothing Jewish in them, and they clearly indicate that this style had been merely adopted by Weintraub in order that he might become MODERN, a quality which to him apparently meant un-Jewish. The compositions, therefore, lack the warmth of life; they have no soul. When the composer creates, he intones the emotions of his heart; and, in embodying these echoes in tonal creations, he breathes into them the warmth of his life. But when a composer seeks to imitate creations born of another spirit, he can only shape figures but never endow them with living souls. He cannot acquire another's soul. This truth we see in Weintraub's compositions. While his un-Jewish creations are soulless, and were, therefore, scarcely ever used in any congregation, his Jewish compositions-whether his own or reworkings of his father's-found an enthusiastic reception, and were sung and imitated by numberless chazzanim throughout the nineteenth century. And this, despite Weintraub's comment in the preface to his work wherein he says, with reference to his father's compositions: "They should be considered rather as antiquities. I have transcribed them for those Jewish precentors who are trained in and are familiar with the ancient spirit . . . with coloratura and embellishment, as they are especially tolerated and demanded in Oriental song." Indeed, Weintraub combined a deep Jewish feeling and enthusiasm for the high ideals of Judaism, in the light of a genuine Jewish tradition and education, with European culture. Therefore he succeeded in creating a style in Eastern chazzanuth that had high musical value. He created a special form for the formless fantastic improvisation. He utilized classic harmony for the Orientalized Eastern chazzanuth, which achievement appeared to be impossible till his time. $\mathrm{He}$ 
showed his great genius in intoning one and the same text in different settings. He composed about forty tunes for the text Hashkivenu (evening prayer) and the same number for $A v$ Horachamim (a supplication), thirty-seven for Veshomru (Exod. 31: 16-I7), ten for Yehi Rotzon (the benediction for the new moon), about the same number for Umip'ne Chatoenu, etc. In 1859, he published a collection of his Synagogue compositions-the greater number in un-Jewish style which were ignored entirely-the minor part, Jewish, which made him popular and saved his work from oblivion. But the greater part of his compositions, hundreds of numbers of Jewish character which he neglected, evidently considering them not modern enough, and in which are buried wonderful musical jewels, remained in manuscript, and are in the possession of the Hebrew Union College Library. In his effort to employ classic harmony to Jewish modes, he created an original system of harmonization, which we call Jewish harmony. We shall treat this subject in detail in Chapter XXIII.

\section{Louis Lewandowski (I $82 \mathrm{I}-\mathrm{I} 894$ )}

Lewandowski originally came from the province of Posen, that Polish district which, although taken by Frederick II as the Prussian part in the division of Poland at the end of the eighteenth century, nevertheless remained Polish in its character. Its Jews, too, remained Polish Jews in life, tradition, and custom. Lewandowski, a villager from the little settlement Wreschen, son of poor parents, entered the city of Berlin at the age of thirteen. After bitter struggles, he became a singerl under the chazzan Asher Lion (Chapter XII), who continued the chazzanuth of the eighteenth century. The young Lewandowski's desire for musical training opened his way to a member of the Mendelssohn family, who, although 
no longer a Jew, still preserved sympathy for poor Jewish youths longing for light and education. Mendelssohn, who himself was musically inclined and who was proud of having the famous Felix Mendelssohn as his cousin, became the boy's patron and supporter. In this way Lewandowski received a thorough musical education, and dreamed of becoming a second Mendelssohn. His first attempt at composition received a prize at the Sing-Akademie in Berlin. Thus the lad of sixteen faced a great future in general music, and might have shared the lot of many other Jewish musicians, of drifting away from their Judaism and Jewishness and drowning in the general stream of European culture. But a serious nervous disorder made an end to all his dreams. For a few years he was unable to continue his musical studies at all. $\mathrm{He}$ had to relinquish his scholarship at the Academy, and for a while it seemed that he would be forced to abandon his entire musical career. However, the urgent necessity of sustaining himself compelled him, after a partial recovery, to start upon some musical activity. Although his strength was insufficient to recommence work along the lines of general music, he counted it sufficient for participation in the work of Synagogue music.

The Jewish Community of Berlin, the cradle of Reform, was swept by the spirit of reaction after the government forcibly closed the Beer Temple in I8I7 (Chapter XII). Asher Lion, the chazzan of the Reform Temple, upon his appointment as chazzan of the Community Synagogue, became a reactionary, reintroducing the old eighteenth-century chazzanuth with SINGERL and bass, which style he continued until 1836 . In general, the eighteenth-century style lasted in many communities till about the middle of the nineteenth century. Thus, for instance, in Dessau, the birthplace of Mendelssohn, the service was conducted in the same way as in the centuries preceding. The same situation obtained in different communities of central 
and northern Germany. In 1838 the young and talented Hirsch Weintraub came to Berlin on his Synagogue concert tour. He had started from Dubno, as mentioned above, and with his quartet gave a few service concerts in private homes. These aroused such enthusiasm in the city that he was invited to officiate at the Community Synagogue. Lewandowski describes in the most attractive manner that event which caused the reformation of the service in Berlin. ${ }^{21}$ Thus Weintraub was the cause of the first enduring musical reform in the Berlin synagogue; and he opened the door to the new possibilities of Lewandowski. Weintraub's quartet was wonderfully trained. As Prelude and Introduction, he played violin solos. Then his choir sANG instrumental quartets by Mozart and Haydn with an exactness and perfection that called forth the profoundest appreciation of gentile musicians. Thereafter he recited the prayers with responsive accompaniment of his quartet in a perfect harmonic style and with deep Jewish feeling. The profound Jewish music voiced in Weintraub's recitatives, he inherited from his father, Salomon Kashtan, and expressed in fine musical style. Weintraub's appearance in Berlin was like a sudden illumination in the darkness. He convinced both the ultra-reform elements and the ultra-orthodox elements of the possibility of having music modern in form and really traditional in character. And a general demand arose among the members to have the same kind of service. But the greatest influence-a sort of hypnotic power-Weintraub exerted upon the young Lewandowski. It was the first time that Lewandowski, as he himself stated, heard real Jewish music molded in rich-sounding classic harmonic form. And it was the first time that he heard Synagogue singers performing European music in a most satisfactory manner. This influence struck deep root in Lewandowski's spirit, slumbering on in his heart 
until one day it brought forth musical blossoms which later delighted hundreds of congregations.

In the meanwhile, the chazzan Asher Lion faced the demand of the Berlin community to reorganize his Synagogue song. Lion was rooted in the rococo style. His musical ability extended as far as the deciphering of the tones of a tune on a piano (this with great difficulty and with but one finger); but they were insufficient for the distinguishing of the rhythm of the melody. He was placed in a very critical situation. However, his greatest strength lay in his cleverness. He determined to act in accord with the custom of the chazzanim of the rococo age, that is, to capture Weintraub's quartet, believing that in enticing Weintraub's singers, he would eo ipso come into possession of Weintraub's music. He did, indeed, succeed in winning the tenor Mirkin, who later became cantor in Copenhagen. But, alas, the tenor knew his part only, without having any idea of the leading melody of the soprano, nor any notion of the cantor solos or the bass part. Thus, the problem remained as unsolved as before. The only information that Lion could obtain from the tenor was that Weintraub utilized Sulzer's music which was still at that time unpublished, and that Weintraub had obtained from Sulzer his service in manuscript. Lion now demanded of his committee the procuring of Sulzer's music, trusting that that aim was an unattainable one, so that his problem, if not solved, would thus be removed, and he would be allowed to return to his good old rococo. But soon the old man had to experience the worst. After the short space of Two years, a copy of Sulzer's manuscript arrived in Berlin. Lion was faced with Hamlet's problem: To BE OR NOT то BE. Sulzer's scores were written in the unheard-of system of the four clefs: Soprano, Alto, Tenor, Bass, while for poor Lion, with the exception of the treble, clefs were nonexistent. However, he relied upon his cleverness; and started 
training singers, reading all parts as if in the treble clef. Aside from this dilemma, he had his difficulty with the community bass, the seventy-year-old Kasper, who never in his life had seen music notes, but who had inherited his art of singing bass from his predecessors of many generations, which art consisted of certain instrumental intervals or passages of an imitation of the melody in the octave or of the producing of a single sound in his deep register, just "in order to bring forth a sentiment of devotion in the congregation, that the members may HEAR and FEAR." Lion's singers could not find any taste, either melodic or harmonic, in what Lion extracted from Sulzer's score; and the tenor, enticed by Weintraub, who boasted that he was a great musician, entered into discussion with Lion as to the exactness of his reading. After a considerable time wasted in hard struggle, without any results, while the entire community waited impatiently for the new music, Lion decided to turn in his distress to his former SINGERL who, as he was told, had studied Music. In a most confidential interview, he asked his SINGERL to help him with that most peculiar musical manuscript, and probably promised to reward himeven financially. Young Lewandowski, sickly and without employment as he was, took over the job willingly. His first task was to transfer the parts from their distinctive clefs to the treble, in order that Lion might read them; his second, to help Lion drill the choir. The singers, who conducted themselves most impudently toward Lion, were overwhelmed by the young Lewandowski's stupendous musical knowledge, seeing that he read the parts without any assistance from an instrument. Even the intractable rococo bass was deeply impressed by the musical superiority of the SINGERL. Thus Lewandowski became master of the situation; and wisely enough left old Lion as titular choir-master. Things went along smoothly, and soon the choir was sufficiently trained to present its first per- 
formance at a Friday evening service. This was in 1840 . The rendition met with the approval of the members of the Board and of the Congregation. In connection with the first performance of one of the selections of the new music, Lewandowski tells this amusing episode, indicative of the musical education of the higher class of Jews in Berlin at that time. Lewandowski had trained the choir in a selection of Sulzer's, written in fugue or canon form. After the service, a member of the Board, a rich Kommerzienrath, most ambitious to exhibit his musical knowledge, gave his criticism of the rendition of the music by saying that, while on the whole the performance was good, in the one item just mentioned, the singers lost themselves and could not keep together; whereupon Lewandowski, realizing the futility of explanation, answered: "Oh, yes, you are right; but I trust that they will improve in the course of time."

Lion, seeing that without Lewandowski he would be lost, graciously permitted Lewandowski to train the choir; and in most confidential manner, granted Lewandowski the honor of teaching him some of those solos of Sulzer's which were combined with choral work. Lewandowski, although still very young, was intelligent enough to perceive that a new world of activity was opening before him. The Berlin community was in the process of rapid growth, and it was obvious that it was soon to become the leading Jewish community in Prussia. In the same year (1840), Lewandowski was appointed singing teacher at the Jewish Free School, and he made up his mind to devote himself to the development of music in the Jewish institutions in Berlin, in which position he remained for over fifty years, climbing slowly higher and higher from step to step, until he conquered not only the German synagogues, but also those beyond Germany's boundaries.

In view of the difference in the circumstances of their labors, 
we may account Lewandowski's personal accomplishment greater than Sulzer's. The latter started his career with complete power, as first cantor and official reorganizer of the Synagogue service. His influence and authority were established from the very beginning, created by his position and strengthened by his great talent as singing artist; while Lewandowski started with practically no position, with no office, with no fame, and with no attracting art-merely as a poor young musical aspirant. He was just the chazzan's assistant-his indispensable right hand, while to the community he still remained the poor SINGERL. No wonder, therefore, that for many years he was not noticed at all.

Indeed, his position was an entirely new one in the history of the Synagogue, for there had never been such an office as that of a choir-master. The leader had been the chazzan-had to be the chazzan even if he had no voice. So we had voiceless, silent chazzanim, the latest of whom was Nissi BELzER (Chapter XIV).

Fortune did not seem to favor Lewandowski in his young years. In I 845, he succeeded in publishing a song (always a great event in the life of a young composer); but because the text expressed political ideas too free for the reactionary Prussian government, the publication was confiscated, and Lewandowski was placed in a dangerous situation. For fully thirty years Lewandowski remained unnoticed, hidden, of no importance - a choral leader and singing teacher. He published a few little songsters for the Public School, written in the routine German Lied-style; and a few numbers for piano and voice which remained unnoticed. For many years his repertoire at the Synagogue consisted of Sulzer's music, he himself not daring to compose anything. In 1845, the community in Berlin, tired of its voiceless chazian Lion, appointed Abraham Jacob Lichtenstein, then chazzan in Stettin. 
Lichtenstein (I 806-I 880) was gifted with a most wonderful dramatic tenor voice of phenomenal power and brilliancy, with a bewitching art of performance, and with an Italian temperament. He was a pious and warm-hearted Jew, and master of traditional chazzamuth. In comparison with his contemporary chazzanim, he was accounted musically trained. He played the violin in the symphony orchestra, and used to sing tenor parts in oratorio, under the leadership of Karl Loewe. It was he who called the attention of Max Bruch to Jewish traditional tunes, as a result of which interest, Bruch-according to his cwn statement-composed his Kol Nidré. ${ }^{22}$

At that time every chazzan of importance had his own style of service and his own melodies. So with Lichtenstein! But he lacked knowledge of one important essential-harmony! Since there was established a four part choir in Berlin, it was necessary to arrange his chazzanuth for four part choir-a task which Lewandowski undertook.

With that work began Lewandowski's real activity. Lichtenstein's chazzanuth became to Lewandowski the model and symbol of chazzanuth. He studied it; he arranged it; he remodelled it in the course of years, until his spirit was saturated with it. It became so much a part of him that he considered Lichtenstein's chazzanuth as his own. For twenty-five years Lewandowski worked on Lichtenstein's chazzanuth, until the material acquired a new form-the form bestowed by Lewandowski's genius. And in publishing that chazzanuth in his work Kol Rinnah Utefillah, Lewandowski did not mention even the name of Lichtenstein, apparently believing that this music was or had become His. Only by means of Lichtenstein's own manuscripts do we recognize the origin. Lewandowski had no fund of traditional song nor of Synagogue song-Polish or Southern German. Aside from Lichtenstein's chazzanuth, Lewandowski used to obtain Eastern European chazzanuth 
from innumerable chazzanim passing through Berlin. He had the inclination, the love, and the instinct for Eastern European chazzanuth, as he himself states, which was bequeathed to him by his birthplace.

The most outstanding talent in Lewandowski was his tasteful and skillful re-shaping in modern forms of old material. His recitatives and solos for the Synagogue song have the wonderful quality of being suitable for and easily rendered by any voice of fair quality. His recitatives and solos, even the traditional tunes, are not merely well preserved, as in the manner of Sulzer, but they are creations molten anew. His greatest strength in that branch is the cantabile, in the region between tune and recitative, in the free-flowing Jewish solo-singing, in minor. He created and developed a noble warm-breathing style of Jewish melody, purged of the tangled fungous growth of sentimentality. As examples, we have all those numbers in minor or in the Ahavoh-Rabboh mode, found in quantity in his above-mentioned Kol Rinnah and in his principal work Todah Wesimrah. No sadness is expressed in them, but a sweet lyric strain inspiring hope and life-that distinguishing characteristic of the real Jewish minor melody. And not only in his solos but also in his choir pieces, Lewandowski created real Jewish selections which will remain marvelous jewels in the treasury of Jewish song. We name such choruses as Hallelujah (Todah Wesimrah, II, No. 202), L'Dovid Boruch (o.c., I, No. 9r), Zocharti Loch (o.c., II, No. 198). In his style and harmony, Lewandowski was entirely under Mendelssohn's influence. His solo as well as choral style follow the path of Mendelssohn's oratorio. He was saturated with Mendelssohn's art to the extent that he unconsciously utilized some of his master's themes, as, for example, Enosh K'chotzir Yomov (o.c., II, No. 34), from the first duet in Elijah, "Zion spreads her hands." Greatly amazed must we ever be by the fact that 
at the same time we find in Lewandowski's music a real German element, a slavish imitation of the German folk-song and Liedform. Lewandowski, the Polish Jew, was so far Germanized as not to be able to distinguish between conscious and instinctive imitation. Those texts which had no traditional tunes or did not express a plea or sorrow but were rather of hymnal or laudatory character were open to GENERAL interpretation. The conception was and still is current among certain Jewish musicians that JEwISH means the expression of pain and sorrow, and that Jewish tonal expression cannot be used for joyous texts. These must be intoned by the music of the joyous nations; that is, it must be German or English. To Lewandowski it was German. All his L'choh Dodi tunes, his Psalm tunes, especially No. 92, his music for the removal and replacing of the Torah, all his laudations, are based either on German folk-song or on oratorio. There is one thing which Lewandowski carefully avoided, and this is CHURCH style. There is no taint in his music of either the Catholic or the Protestant Church. We do not find any hymn or chorale that tastes of the Protestant Church. With the exception of one number, No. 196 (Seu Sheorim), which he adopted from a Christian composer, from the new service in Dresden in $1840,{ }^{23}$ and which he published in his Todah Wesimrah, II, No. 196, we know of no non-Jewish composition in Lewandowski's Synagogue works. As proof of Lewandowski's fine talent and skill in reshaping and developing high type music out of old primitive themes, his composition Weye'esoyu (ibid., II, No. I93) may serve. He utilized two themes of two tunes composed for that text by Ahron Beer (Chapter XI). Those two tunes probably used to be sung by Beer's successor, Lion, and Lewandowski as his sINGERL, undoubtedly sang them for many years until their themes were engraven in his memory. 
All his achievements in the realm of Synagogue song were the fruit of the last two decades of his life, for, as already said, his early activity was that of interpreter of Sulzer's music. In I 855, after fifteen years of activity, Lewandowski, together with Lichtenstein, then about thirty years in office, was sent to Sulzer to be instructed and advised. So powerful and authoritative was Sulzer even in Berlin! It is understandable that under such circumstances Lewandowski had no chance to introduce any of his own compositions. Indeed, he says in his preface to Todah Wesimrah that his compositions were hidden in his desk for many years before they were performed. It required great self-restraint to suppress his ambitions to have his own works heard, rare equanimity to await a propitious time, and never-flagging alertness to grasp the opportunity to introduce them. That opportunity came to him in I864 with the building of the new Oranienburgerstrasse Temple, which was equipped with an organ and for which a modified service was arranged by Geiger and Joel. As long as he had acted as choir-master in the old orthodox community synagogue on Heidereuterstrasse, two obstacles had prevented the presenting of his own compositions: the first was Sulzer's music; the second, Lichtenstein's chazzanuth. The new Temple offered him the opportunity of creating an entire service with organ accompaniment-a task until then never undertaken. Sulzer's music was unsuited, since it was arranged for the orthodox prayerbook and was without organ accompaniment. Therefore, Lewandowski's creative activity really begins with 1864. It is interesting to note how little he was valued at that time for his true significance in Jewish life. In I865, at the celebration of his twenty-fifth anniversary as music teacher in the Jewish Free School and the Jewish Teachers' Seminary, Zunz, upon whom as principal of the 
Seminary fell the obligation of delivering the address of the celebration, could find no other merit to praise in Lewandowski than that of faithfulness to his office and his family. ${ }^{24}$

In the meanwhile the Berlin community not only grew in membership but became a European center for Jewish culture and education in general as well as for music. Numerous young Jewish musicians pilgrimed to Berlin to study-many of them with the object of becoming cantors. They turned to Lewandowski for instruction and help. Thus gradually Lewandowski became a trainer and advisor of chazzanim. It was for the aid of these pupils that the already described solos were created.

How unshakable Sulzer's authority was we may see from the fact that Lewandowski did not dare to begin his publication with his four part compositions; but he started with a new branchnot cultivated by Sulzer ${ }^{25}$ - that of popular easily executed Synagogue music written in solos and duets, especially designed for those small congregations which were not in position to employ a trained four part choir. His aim was to provide a complete service for the entire year, its recitative part for the cantor, popularized choral parts, and congregational songs. None of these three classes of Synagogue song had at that time been cultivated. The recitative was still either overgrown with tangled flourishes of Eastern chazzanuth, as we find it in the third part of Weintraub's work, or it was of the style that Sulzer had introduced in his first volume. And even Naumbourg, who at times gave a Jewish recitative natural and simple and at the same time artistically purified, had not provided for the entire service. It was therefore Lewandowski who first fully understood the importance of the recitative in the modern Jewish service, and supplied the ritual of the entire year with a natural singable recitative based mostly on traditional Jewish modes. 
He was first to recognize how the entirely foreign form of the Catholic Church song, introduced by Sulzer, froze the warmth of Jewish sentiment, and silenced the congregation, precluding its participation in the singing. But, although wellintentioned, he failed to solve this latter problem; for he introduced, instead, the German folk-song for congregational singing, which, while well received in Northern German communities, had a decidedly assimilative influence in that it Germanized the sentiments of the Jews. Lewandowski's blunder here, as we already mentioned, grew out of the prevalent opinion that choral parts could be created by non-Jews out of nonJewish material-an opinion which Lewandowski expressed in his preface to Kol Rinnah. Furthermore, despite all his opposition to the Church style of Sulzer, he was so far influenced by Sulzer that he imitated his responsive style-a style which has remained standard in our modern services of both ultrareform and moderate-reform. Lewandowski's statement, in his above-mentioned preface, that there was no congregational singing, is true only with respect to Eastern European and Northern German communities, for the old Southern and Western congregations had always had responsive congregational singing which dated far back to the earlier medieval times, and was the continuation of the Oriental, Italian, and Spanish-Portuguese service. This group participation was one of the principal features of Jewish worship since Bible times. Lewandowski, not knowing the history of Jewish worship, and being acquainted with the Eastern European service only, considered this contribution of congregational song his innovation.

The appearance of his Kol Rinnah in I87I caused a sensation in the chazzanic circle. It was the first time that a complete service for Sabbath and festivals, with detailed recitatives for the entire text of the prayers, had appeared-a work which enabled every young man of fair musical ability and voice to 
master the liturgical and traditional Chazzanuth in a modern form. The Kol Rinnah became the most popular reference book for the average chazzan. It developed a certain type of cantors who were called Kol Rinnah cantors. The appeal of the book to what we called the second grade chazzanim, casts no aspersions on the work, but is accounted for by the fact that chazzanim with attractive voices and fine power of musical execution preferred the intricate flourishes of Weintraub and his like and the high, sounding phrases of Sulzer, which afforded opportunity for the demonstration of their artistic gifts and powers. Because of its provision for congregational responsa and congregational choir singing, the Kol Rinnah maintained its position even after the publication of Moritz Deutsch's Vorbeterschule, which, in respect to its recitatives, was of a higher quality, and even after the publication of Abraham Baer's Baal Tefillah, which gave a.very rich variety of traditional and chazzanic recitatives of the Polish as well as of the Ashkenazic rite. The Kol Rinnah brought Lewandowski popularity; while his Todah Wesimrah (two volumes, Berlin, I876-1882) for four part choir and cantor solos with congregational singing, established his fame as Synagogue composer. Most of the tunes of that latter publication had been utilized in the $\mathrm{Kol}$ Rinnah in the simple form already described. The singability and the freshness as well as the elaborate musical form of the choir parts, and last but not least the German lied-style, made them so beloved by the Jewish congregations in Germany. Lewandowski developed the choral part in the Synagogue song to a greater degree than did Sulzer. He gave to the organ a specific rôle. Soon Sulzer was dispossessed, and Lewandowski became dominant. Not only in the synagogues with organ did he hold sway, but also in those without, for with the intention of serving the synagogues without organs, Lewandowski had composed the choral parts for a cappella rendition, without put- 
ting into the organ any artistic part of the composition. As he himself states in his preface to the work, the organ was simply a support to the voices of the choir. With the publication of Todah Wesimrah, Lewandowski climbed to the summit of his path. He attained the pinnacle. He became the recognized genius of Synagogue song; he was honored by the Jewish communities in Germany as well as by the German government, which rewarded him with medals and titles. He was elected honorary president of the Cantors' Association. He was made chief choral master of all the synagogues of Berlin, in which only his music was to be heard. It is not pleasant to reflect on the tyranny with which he ruled over the dominion thus finally acquired, the harshness with which he crushed or the shrewdness with which he excluded possible rising rivals. The long struggle which would have softened a greater soul, profiting such as came for his protection, his guidance and assistance, left him only the determination to hold fast to the hardwon glory. By a system of rotation of chazzanim in the Berlin temples, he prevented any one from gaining sufficient popularity to detract from his own supreme position. Men with voices of too promising a quality, he found means of sending to other cities. The sceptre had long eluded him. He wielded it now with despotism.

Among Lewandowski's German compositions, his Eighteen Psalms for chorus and soli gained wide use even in the Protestant Churches in Germany. They are in the genuine oratorio and Lied-form, but have not the slightest sound of Jewishness. On the other hand, his arrangement of traditional themes for organ, piano, and violin may be accounted a pleasing contribution toward the popularization of Jewish song.

Lewandowski was the youngest of the line of those who may be termed moderate or temperate regenerators of the Synagogue song; and he was the most capable as composer, and the 
nearest to Eastern European Jewish song. He, more than the others of Western Europe, gave proof of the possibility of the re-creation of Synagogue song, and of its adjustability to modern musical forms.

\section{Israel Meyer Japhet (I8I8-I892)}

Though Japhet was connected with the ultra-orthodox tendency of Rabbi S. R. Hirsch in Frankfort, for whose service he wrote his music, nevertheless, as a Synagogue composer, he belongs to the moderate-reform. Indeed, when we look into his music, we may even come to the conclusion that his style was similar to that of the ultra-reform of Germany. In his preface to collection I, Japhet emphasizes the great value of traditional tunes, and emphatically opposes the Reform endeavor to introduce Catholic Church music. But the fact is that with the exception of nine (9) numbers (i.e., 5, 9, I 5, 29, $30,37,40,57,58)$-a few selections in which he utilizes traditional tunes-his composition is based on the secular German Lied-style and even on the Protestant hymn. He, like the Christian Protestant and the Jewish Reform composer, cultivated the laudatory part of the service. For example, he offers for Lechoh Dodi twelve different settings-these constituting one-fourth of his entire work. Likewise, does he provide Psalm 92 and the removing and the returning of the Scrolls, with various tunes. And therefore does this statement in his preface sound ridiculous: "The author tried to give the traditional tunes as well as his own compositions the impress of chazzanuth, the character of which is entirely different from that of the Church song, for the aim of the latter is to develop solemnity and esthetic sentiments in the minds of the hearers, and to lift them to a higher region where they may be forgetful of the earth beneath, whereas the Synagogue song comes from 
within, filled with emotion and inwardness, with yearning after and joy in the presence of God, thus combining heaven and earth." Yet he offers not a single song of petition and supplication expressive of either the joy of the Jewish spirit or the depths of its yearnings. He further says that he paid attention to the chazzan's part of the service; but he did not provide a single recitative in any of the traditional modes, his solos for chazzan being rhythmical numbers in modern form. We look in vain for settings for some of those wonderful texts of the traditional prayers. It is true that he was handicapped by the ultra-orthodox restriction against the insertion of music into the service (Tefillah) proper because of "distraction of the mind." For that reason, according to his own statement, he did not compose music for Kedushah, Shema Yisroel, Veshomru, Borchu, Mi Chomocho, etc. He had opportunity for music in only the introductory and concluding parts of the service. But the restriction could not have prevented his composing these permitted parts in genuine Jewish style. All in all, from the musical point of view, Japhet was as German as any composer of the German Reform temples, though-it must be statedhe did avoid the Catholic style. In this connection, it is interesting to note that, in his recommendation of the second collection of Japhet, the before-mentioned I. Moscheles says that he gives preference to the traditional material of the collection rather than to the NEW compositions.

These works, despite their earnest intention to preserve tradition, to modify and modernize it, yea, even to attempt to create new tunes out of the old material, did in reality cultivate only a part of the traditional modes-chiefly the so-called Mogen-Ovos and Ahavoh-Rabboh modes, neglecting all the others. Especially the Adonoy-Moloch mode, which constitutes a considerable part of Synagogue song, was (since Sulzer) 
transferred to major. Only Weintraub paid attention to it in its original form, in so far as he gave at least his father's composition in that mode, which Weintraub mistakenly designated "mixolydian." It is really a pity that that lyrical and delightful mode was either ignored or assimilated with the European major, simply as a result of ignorance, and in spite of the emphatic warning given by men like Lachmann and Friedmann in their works mentioned below. In like manner the Biblical modes were neglected in their original form; and, in modern forms, no one except Emanuel Kirschner ${ }^{26}$ attempted to utilize them.

Moderate-reform song developed the rhythmical music, and made it predominant in the Synagogue service. The modal form of recitative chanting, on the other hand, was gradually reduced, in some places to a minimum; but it was not entirely abolished. This trend was not determined by the use of the organ. We find the same conditions in the Synagogues with, and in those without, organs. The moderate-reform Synagogue did not completely cast aside that Jewish Oriental form of singing, as did the ultra-reform.

The music-from the point of view of its Jewishness-shows no difference by reason of the presence or absence of organ obligato. There is no more Jewishness in the service by Mombach and Hast in England, though they are without organ, nor even in the service of the ultra-orthodox of Frankfort by Japhet than there is in those of Lewandowski and especially of Kirschner, though in these the organ work forms an integral part of the music.

Moderate-reform can hardly be viewed as a unit, since its manifold shadings range from a leaning toward conservatism to a drifting toward the opposite extreme. Even so, the song - from Weintraub's father or Boruch Schorr to Japhet and Mombach-runs a far reach in the scale of Jewishness. Yet 
one thing is common to all-one thing unites them; and this is the positive conviction that the essentials in traditional songs should be preserved, not merely, as in Sulzer's opinion, as a BRIDGE, but for their distinctive and eternal values to the Jew.

\section{BiBLIOGRAPHY}

A century has passed since the dedication of the Temples in Vienna and Munich, wherein was inaugurated the tendency toward moderate-reform-a tendency which exerted a decided influence upon the Synagogue song. The effort was to modernize and to Europeanize the music, while at the same time retaining the traditional material. To execute that program, a considerable number of talented and cultured musicians labored. Their work was along two lines: first (I), the modernizing and beautifying of Synagogue song for practical use; and second (2), the collecting of traditional tunes and the . investigating of their origins and history. Worthy of mention are:

Group I:

Israel Lovy (Schottland, near Danzig, I773-Paris, I832). (Cantor in Fürth, I799-1806; Mayence, I807-1810; Strassburg, I810-I818; Paris, I 8 I 8-1 832.)

Chants Religieux, Paris, 1862, with biography by his grandson, Eugene Manuel.

Salomon Sulzer (Hohenems, Tyrol, I804-Vienna, 1890). (Cantor in Hohenems, I820-1825; Vienna, I 826-I 88I.)

Schir Zion, I, Vienna, I838-I840; Schir Zion, II, I866. Dudaim, Kleines liturgisches Gesangbuch für Schulen, kleinere Gemeinden und die häusliche Andacht., I and II, Vienna, I86o. 
Schir Zion, I and II, second edition, published by Joseph Sulzer, I905.

Maier Kohn (Schwabach, I802-Munich, I875).

Münchener Synagogengesänge, I-III, Munich, I839.

Samuel Naumbourg (Dennelohe near Ansbach, I815Paris, I880). (Cantor in Paris, I 845-I 880.)

Zemiroth Yisrael, I-II, Paris, I847; Vol. III, I857; Schiré Kodesch, chants religieux, Paris, I864; Agudath Schirim, Recueil de chants religieux et populaires des Israelites des Temps les plus reculés jusqu'à nos jours ... Précédeés d'une étude Historique sur la musique des Hebreux, Paris, 1874.

Hirsch (Alter) Weintraub (Dubno, $18 \mathrm{I}$ I-Königsberg i/P., I882). (Cantor in Dubno, I830-1835; Königsberg, I 838-1 880.)

Schire Beth Adonai-Tempelgesänge, I-II, Leipzig, I859; III, Schire Sch'lomo, Leipzig, I859.

Louis (ELIEZER) LEWANDOWSKI (Wreschen, I $82 \mathrm{I}$-Berlin, 1894). (Choir Leader and Music Teacher in Berlin, I 840-I 894.)

Kol Rinnah Utefillah, Berlin, I87I ; Todah Wesimrah, I, Berlin, I876; II, I882.

Israel Lazarus Mombach (Pfungstadt; 1813-London, I880). (Choir Leader in London, I84I-I 880.)

Ne'im Zemiroth Israel-The Sacred Musical Compositions of Mombach, London, I88I.

Moritz Deutsch (Nikolsburg, I8I8-Breslau, I894). (Disciple of Sulzer, 2nd Cantor with Sulzer in Vienna, I842-1844; in Breslau, I844-1894.)

Breslauer Synagogengesänge, Breslau, I880; Vorbeterschule, Breslau, I87I; Anhang zu Vorbeterschule, 1890, including Nachwort: Der Ritualgesang der Synagoge. 
Max G. Löwenstamm (Trebitsch, I8I4-Munich, I88I). (Disciple of Sulzer, Cantor in Pest, I842-1844; in Munich, I 847-1881.)

S'miroth l'El Chaj-Synagogengesänge, I-IV, Munich, I 882.

IsRael Meyer Japhet (Cassel, I 8 I 8-Frankfort, I892). (Choir Leader and Teacher at the Orthodox Congregation in Frankfort, I853-1892.)

Schire Jeschurun, I, Frankfort, I856; II, I864.

Anton (Ahron Wolf) Berliyn (Amsterdam, I8I7I 870 ). (Composer and conductor.)

Schire Beth Elohim.

Schire Beth Ahron.

Schire Chag Wetoda.

Drei hebreeluwsche Gezangen, for 3 children's voices.

Vier hebreeuwsche Gezangen voor Kinderstemmen.

All published in Amsterdam.

Hirsch Goldberg (Wollstein, Posen, I 807-Braunschweig, 1893). (Cantor in Holzminden and Seesen, I 829-1 842; in Braunschweig, I 842-I893.)

Gesänge für Synagogen, Braunschweig, I 843 .

(Joshua) Osias Abrass (called "Pitzsche"-Pitzele in Yiddish, the "little one," because of his fame as singer while still a child. Berditschev, I 820-Odessa, 1896.) (Disciple of Bezalel Schulsinger, Cantor in Tarnopol, I 840-I 842; Lemberg, I842-I858; Odessa, I858I 884.)

Simrath Yah, Vienna, I874.

Chaim Wasserzug (Schiradz, Poland, 1822-Brighton, 1882). (Cantor in Konin, I840; Novy Dvor, I841I854; Lomza, I854-I859; Wilna, I859-I867; London, I 868-I 882.)

Sefer Schire Mikdash, London, 1878. 
BorUCH SchoRr (Lemberg, I823-1904). (Cantor in Lemberg.)

N'ginoth Boruch Schorr, New York, I906; published by his son, Israel Schorr, Cantor in Brooklyn.

Samuel David (Paris, I836-I895). Musical director at the Jewish Temple in Paris, I872-1895; composer of operas and symphonies, etc. Poal Chayé Adam: Musique Religieuse Ancienne et Moderne en usage dans les Temples consistoriaux Israelites de Paris, Paris, I895. Publication of the Consistoire de Paris.

Jacó Leopold (Leib) Weiss (Neutra, Hungary, I825Warsaw, I889). (Disciple of Sulzer, Cantor in Agram, I850-I; Botschowitz, I853-9; Warsaw, I859-1873; Wilna, I 873-1876.)

Ozar Schire Jeschurun, Vienna, I874; II Ed., I88 I.

Josef Goldstein (Kecskemet, Hungary, I 837 -Vienna, 1899). (Cantor in Neutra, I850, as successor of his father; Neusatz, I852-4; in Vienna, I855-1899.)

Schire Jeschurun, Vienna, I862.

Emile Jonas (Paris, I827-St. Germain, 1905). (Composer of Operettas and Professor at the Conservatoire in Paris.)

Schiroth Israél-Recueil des Chants Hebraiques anciens et modernes exécutés au Temple du rit purtugais des Paris, 1854 .

Jacoв Bachmann (Berditschev, I846-Budapest, I905). (Cantor in Lemberg, I868-I884; Odessa, I884-5; Budapest, I885-I905.)

Schirath Jacob, Petersburg and Moscow, I884.

David Rubin (Gebitsch, I837-Baden near Vienna, 1922).

(Choir Leader in Prague, I860-1912.)

Schire Hechal, Prague, I86o, etc. 
Adolf Grünzweig (Choir Leader in Arad, Hungary, 1829I905).

Sabbath Songs-Mayence, 1863.

Matte Ahron-Mayence, I893.

Marcus Hast (Praga, Warsaw, I840-London, I9II).

(Cantor in London, I87I-I9II.)

Abodath Hakodesh, I-IV, London, r9ro.

Simon Waley (London, I827-1875). Pianist and composer. He composed hymns for Sabbaths and festivals, of which his tune for Adon Olam became popular.

Emanuel Kirschner (Rokinitz, Silesia, 1857-living in Munich, ). Cantor in Berlin, I880- $\mathrm{I}$; in Munich, I88I-I928.)

Tehilloth Le'el Elyon-Synagogengesänge, I-IV, I8971926.

Josef Heller (Szatmar, Hungary, I864-Brünn). Cantor in Kaposvár, I884-1859; Brünn, I889- .) Kol T'hilloh, I-II, Brünn, I905-I4.

Francis Lyon Cohen (Aldershot, 1862; Rabbi in Sydney, Australia) and

B. L. Mosely, in 1889, compiled The Handbook of Synagogue Music, re-edited and re-arranged by $\mathrm{F}$. L. Conen and D. M. Davis as The Voice of Prayer and Praise . . . for the Choir Committee of the Council of the United Synagogue with the Sanction of the Chief Rabbi, London, I899; 2nd edition, 1914. This hymnal for choir and congregational singing contains 3 Io numbers for Synagogue, religious school and home, for the Sabbath, the festivals and for special occasions, according to the Orthodox ritual. The musical material is drawn from traditional sources and from Synagogue composers, such as Sulzer and Naumbourg, but mostly from Mombach, Wasserzug, Hast and Davis. A few 
tunes are adopted from Beethoven and Mendelssohn.

M. Cohen-Linaru (Born in Adrianople-.) (Choir Leader at the Sephardic Temple in Bucharest.)

Thehilloth Israel, I-II, Bucharest, I9ro.

Moritz Henle (Laupheim, I850-Hamburg, 1925). Cantor in Thalheim, I868; Laupheim, I867-1873; Ulm, a/D., I873-I879; Hamburg [Tempelverein], I879-I9I3.)

Many compositions and essays, especially Der Gottesdienstliche Gesang im Hamburger Tempel, r918; in Festschrift, etc., Hamburg, I9I8.

Group II:

Josef Singer (Illinik, Hungary, I84I-Vienna, I9I I).

Die Tonarten des trad. Synagogengessanges, 1886; many essays in various periodicals in German.

ISAAK LACHMANN (Dubno, I838-Hürben, Bavaria, I900). Abodath Israel, I, I899; many essays in German periodicals.

Samuel Naumbourg (See Group I).

Cantiques de Salomon Rossi with introduction, Paris, I876; A gudath Schirim, 1.c., Group I.

Moritz Deutsch (See Group I).

Vorbeterschule. Breslau, I87I; Appendix, I890.

Abraham BaER (Filehne, I834-Gothenburg, I894).

(Cantor in Pakosch, Gothenburg, I857-1894.)

Baal T'fillah, Leipzig, I877.

N. H. Katz (Cantor in Brilon) and L. Talbott (Cantor in Oberlustsadt).

Die traditionellen Synagogen-Gesänge, I-II, Emmerich, I868.

DAvid DE Sola (Portuguese Rabbi, Amsterdam, I796Shadwell, near London, I860) and Emanuel ABRA- 
ham Aguilar (London, I824-1904). (Composer and pianist.)

The Ancient Melodies of the Spanish and Portuguese

Jews, London, I 857; Historical Introduction by David de Sola. Music by Aguilar.

Federico Consolo (Jehiel Nahmani Sefardi) (Ancona, I840-Florence, I906). (Composer and violin virtuoso.)

Sefer Shire Yisrael-Libro dei Canti d'Israelle, antichi canti liturgici, Rito degli Ebrei Spagnoli, Firenze, I89I ; Cenni sull 'origine e sul progresso della musica liturgica, con appendice intorno all 'origine dell 'organo, Firenze, 1897 .

Jules Salomon Crémieu and Mardochee Crémieu.

Chants Hebraïques suivant le rite des communautes Israelites de l'ancien Comtat Venaissin, Aix, 1885.

Aron Friedmann (Schaki, Lithuania, 1855-living in Berlin, ). (Cantor in Berlin, I882-1923.)

Schir Lishlaumau, I90 (Chasonus); Der Synagogale Gesang, eine Studie, Berlin, I904; 2nd edition, I908; Lebensbilder berïhmter Cantoren, Vols. I-III, Berlin, I918-I92I-I927.

Eduard (Asher Ensel) Birnbaum (Cracow, I855Königsberg, i/P., I920). (Cantor in Magdeburg, I872-74; Beuthen, I874-1879; Königsberg, 18791920.)

Jïdische Musiker am Hofe von Mantua von 1 542-1628, Vienna, I893; many essays in various periodicals; collector of musical and historical material.

Francis Lyon Cohen. Author of most of the articles on Jewish music in the Jewish Encyclopedia; several essays in English.

Pinchos Minkowsky (Biela Tzerkow, I859-Boston, 
1924). (Cantor in Kischenew, I878; Cherson, I88084; Odessa, I884; New York, I 884-89; Odessa, I889I920.)

Reshumoth, I, II, III, IV. Hashiloah, Odessa, I 899; Die Entwickelung der synag. Liturgie, Odessa, 1902; Der Sulzerismus, Vienna, I905.

Many articles in Hebrew, German, Yiddish. and Russian (in the Jewish-Russian Encyclopedia).

Abraham Ber Birnbaum (Poltusk, i865-Tschenstichov, I922). (Cantor in Tschenstichov.)

Omonus Hachazonus-The Art of Chazzanuth, Tschenstichov, 1908; Theory of Music, 1902; A Monthly for Chazzanim (4 numbers 1897). Several essays in Hebrew and Yiddish.

Aron Ackermann (I867-I9I2). (Rabbi in Brandenburg.)

"Der Synag. Gesang in seiner historischen Entwickelung," in Winter and Wünsche, Die jüd. Literatur, Vol. III, pp. 477-529.

Hermann Ehrlich (I815-1879). (Cantor in Berkach, near Meiningen.)

Founder and Editor of the magazine Liturgische Zeitschrift, I-IV (I852-55), including essays, historical research, and the publication of traditional songs, etc.

Abraham Blaustein (Riga, I836-Bromberg, I9I4). (Cantor in Gnesen, Bromberg, I874-19r4.)

Founder of the Cantor-Association in Middle Europe in I879, and founder and editor of the weekly Der Jüdische Cantor, I879-I 899 .

JaCoв BAUer (Gr. Pristerst near Czenits, Hungary, I852Vienna, 1926). (Cantor in Szigetwor, 1875-78; Gratz, I878-8I; at the Turkish Temple in Vienna, I 88 I-I 926.) 
Modernizer of the Sephardic Service at the Turkish Temple in Vienna. Friday Evening Service published in cooperation with I. Löwit, Vienna, I889. Editor of the weekly Die Oesterreich-Ungarische Cantoren-Zeitung, I88I-I898, and from I 899 on, under the name Wahrheit.

The second group we shall treat in Chapter XVI. In this chapter we devoted our attention to the practical workers.

Though most of the men listed in Group I certainly made important contributions toward the furtherance of ModerateReform, yet they were rather followers of the real pathfinders and pioneers: Sulzer, Maier Kohn, Naumbourg, Weintraub, and Lewandowski, who merit the individual and detailed treatment accorded them in this chapter. 


\section{CHAPTER XIV}

\section{“Chazzanim" and "Chazzanuth" in EASTERn EURope IN THE NINETEENTH CENTURY.}

While in Central Europe the fight between reform and orthodoxy was in progress in the beginning of the nineteenth century, menacing the very existence of traditional Synagogue music, in Eastern Europe Jewish song unfolded a remarkable creative power, both in Synagogue and folk-song. A long line of inspired chazzanim and talented singers and composers arose in Galicia, Poland, and Lithuania in the course of the nineteenth and the beginning of the twentieth century, until the World War and the subsequent disasters caused the ruin and misery of the present-day East European Jewry.

The Eastern chazzanim of the first half of the nineteenth century can be classified in two groups: (I) those who possessed fine voices combined with marvelous talent of performance, and were at the same time gifted composers, and (2) gifted composers and choir-leaders who had poor or no vocal ability. They were compelled to function as chazzanim, because there was no other post for a musician created in the Synagogue, as we saw in Chapter XIII with regard to Lewandowski.

The chazzanim of the first group created schools of their own not only by their original music but also by their original method of performance. There were those of them who created selections in fixed forms, in tunes; but for the most part they founded their strength upon their free spontaneous song, improvised while conducting the service. As a result of the latter practice, in the course of time, certain motives and 296 
melodic curves, modulations and coloratura passages and embellishments within given modes became distinctive of their chant. And thus an individual style was created, crystallized during a lifelong improvisatory singing. The style of an individual used to be copied by his "singers" and admirers and used to be called motzoh-style of expression. The same procedure is still customary among the Oriental singers as well as among the Ukrainian Kobsari (Chapter IX).

The reason for that procedure is to be found in the fact that the reading and writing of music had been unknown accomplishments to the greatest number of Eastern chazzanim during the first half of the nineteenth century. They had held their compositions in mind, and had trained their "singers" accordingly. It had rested with the singers to remember the compositions improvised by the chazzanim while officiating.

Of type (I), apart from the already mentioned Salomon Kashtan (Chapter XIII), we shall name:

I. Dovidl Brod Strelisker (born in Brody, I783; died in Budapest, I848). He distinguished himself from childhood on with his sweet singing; and, while still a young boy, he was privileged to officiate in the synagogue of his native town. He never received any musical training, neither was he meshorer with any chazzan. Destined originally for the vocation of rabbi, he finally became an accountant and later a merchant. Traveling to various business centers, he volunteered his singing talent in the service of the Synagogue wherever he happened to be. ${ }^{1}$

Through adverse circumstances he lost his fortune and was compelled in I 822 to accept the post of chazzan in Alt-Ofen, to which post he was recommended by his friend Salomon Kashtan. In I 830 he was called to Pest, in which synagogue he officiated until his death in 1848 .

Though no authentic compositions of his have been retained, 
since he could neither write nor read music, his influence upon the chazzanim in Galicia and Hungary was enormous. He was of those chazzanim who, in the course of their activity, created an original style of chazzanuth. His many choristers carried his style with them. This style, as explained in Chapter IX, was mainly based upon the Ahavoh-Rabboh mode and on the Ukrainian-Gipsy scale. In his later years Dovidl Brod made an attempt to acquire the rudiments of music, but he finally realized that it was too late. Dovidl Brod was highly regarded by Sulzer. ${ }^{2}$

2. Bezalel Shulsinger, called Bezalel Odessaer. The place and date of his birth are not known. He was born sometime around 1790 in Galicia or Podolia. In 1826 he was already a renowned chazzan. Soon thereafter he became city chazzan in Odessa, where he stayed until I860, when he left for Jerusalem. He died in the Holy City shortly thereafter.

Bezalel, too, was an autodidact and established a style distinguished by simplicity, inwardness, and grace. Almost all the famous chazzanim of the first half of the nineteenth century were his "singers." Though without any musical knowledge, he composed; and his creations became popular and were written down by his pupils who acquired technical knowledge of music. Due to this circumstance, no claim to authenticity can be made for the manuscripts, though the various writings in circulation show but minor variations.

3. Sender Polatshik, called "Sender Minsker." He was born in Gombin, Poland, in 1786, and he was singer with Nochum Leb Kashtan (brother of Salomon) in Berditschev. He became chazzan in Mir; and, in I822, in Minsk, where he remained until his death in 1869. Sender had a powerful bass-baritone voice, and was likewise without any musical knowledge. His manner of composing was later described by one of his singers. ${ }^{3}$ At moments of inspiration he would 
gather his choristers who were always at his command and would work out his compositions, weaving the theme through the different voices in variations, repeating from the beginning, and with each repetition adding some new phrase, until the piece was completed. Thus, in the course of its creation, the composition was simultaneously rehearsed. It was now the choristers' task to preserve the new selection in their memory; and woe to a chorister if he forgot his part!

Sender opposed the style of Bezalel, the so-called Volhynian chazzanuth, distinguished by its ingratiating motives and its tendency toward embellishments. He created a style noteworthy for its depth and lack of embellishment, if we may judge from the few pieces accredited to him.

4. Joseph Altshul, called "Yoshe Slonimer," was born in Wilna in 1840 . He received some instruction from Chayim Wasserzug (Chapter XIII); he became "singer" with Yeruchom Hakoton in $186 \mathrm{I}-3$; later he was chazzan in some villages in Lithuania; then in Slonim and finally in Horodna, where he died in I908. He had a powerful bass voice and acquired the rudiments of music, so that he was able to read and write music. He was a prolific composer in the folk-tune style, and a great number of his tunes for solo and choir are circulating in MS., some of which became popular among the Eastern chazzanim.

5. We shall select but one more chazzan from the great number belonging to type I, and this is Yoel Dovid Levinsonn, called "Wilnaer Baalhabessil." His father, Hirsch Bochur Levi (I786-I830), was city-chazzan in Wilna (I822-I830), and died young, leaving Yoel Dovid a boy of thirteen (born in 1816 in Libau, Latvia, where his father was then chazzan). Already as a little boy of ten and eleven, he was famous as a wonderful singer; and his father was urged by the public to let the lad officiate in the big synagogue on Saturday services. 
After the sudden death of the father, the boy was selected as his successor. ${ }^{4}$ Soon a rich member of the congregation took him as a son-in-law, and granted him an allowance for his entire life. ${ }^{5}$ So the young Yoel Dovid, who till now had been called Der Yingele (the little lad), now that he was married and affluent, received the pet name Der Baal-habessil (the little member of the community). It was probably the first time in the history of the Synagogue that a talented chazzan was financially independent. The young lad, endowed with genius and fortune, was beloved and venerated by his people to a degree of idolatry. From all over Lithuania lovers of chazzanuth streamed to Wilna in order to hear and see the little Baal-habessil. Apart from his fascinating voice and singing (he had a lyric tenor with a brilliant coloratura), he was also a talented composer. His compositions were of an original charm, of genuine Jewish-oriental sentimentality and in the Jewish folk-tune style, and therefore they became popular. At the age of twenty-three, already ten years in office, Yoel Dovid started studying music with the Polish musician Stanislaus Moniuszko, who in 1839 established himself in Wilna as teacher and organist. ${ }^{6}$ The Baal-habessil, who up to that time lived in the fantastic realm of self-glorification, now became acquainted with European music and musical geniuses of his time. Gradually his chazzanuth became distasteful to him, and his environment too narrow. Upon Moniuszko's suggestion he decided to leave his position and go to Warsaw, at that time a center of music. In Warsaw he was enthusiastically received by the Jews. At the recommendation of Moniuszko, he was invited to give concerts before the Polish public, in which a Polish woman-singer participated. A web of legends is woven about this event. It is said that he was attracted by the gentile woman-singer and was plunged into a gloomy melancholy from which he never recovered. From Warsaw he 
went to Vienna, where he was cordially received by Sulzer, but this meeting proved to be the cause of another terrible shock to him. He had considered himself the greatest chazzan of his time. Suddenly this fantasy was shattered as he listened to the powerful, artistic and overwhelming singing of Sulzer. He felt that his own voice and singing were only those of a child in comparison with those of a hero. At the same time, the passion for the Polish singer unconsciously grew in his heart, until he became aware that it was love-love of a married orthodox Jew for a gentile woman! In his mental derangement which followed he abandoned his musical career and became a penitent.

Hence, he left Vienna, and started on his penitential way, according to the old Jewish fashion, walking from community to community, without speaking to anyone, occupying himself with the study of Talmud only, like the old type of Porush (recluse). Finally his family got hold of him and placed him in the insane asylum in Warsaw, where he died in 1850.

Once, while in Dubno, he was by accident recognized and was persuaded to officiate on a Sabbath. We have a description of that service by Isaak Lachmann, who was present at that service. ${ }^{7}$ He says: ${ }^{8}$ "Never again in my life did I hear such a voice, such a performance, such a holy spirit expressed in worship. I never again in my life heard such a coloratura which seemed living garlands of pearls coming from his mouth and flying in the air of the synagogue. His voice was a lyric tenor-rather weak, for he was greatly worn, and more spirit than body. It was a year before his death. He seemed to stand before the pulpit entranced, oblivious of his environment, swaying in the higher spheres. His singing was without effort. He hardly moved his lips even. It was more an exhalation of soul than a sounding of voice."

He left no pupils nor any school. Only half a dozen of his 
compositions have been retained. Report has it that the manuscripts were burned by his wife when she had heard of his attraction to the Polish woman-singer. ${ }^{9}$

Of the second type of chazzanim we shall mention only a few of the most outstanding, such as:

6. Boruch Karliner, a disciple of "Sender Minsker." He was chazzan in Karlin, later in Pinsk; and he died in Brisk in 1879 on his way back to Bialistok, where he had been appointed chazzan. He was original both as an untamed individual and as a composer. With but little voice and without any musical knowledge, like his master Sender, he would compose when "the spirit came upon him," be that on the street or in the synagogue during the service. He would drill his choir on certain pieces for the services, but suddenly during the service "the spirit" would come upon him, so that he would abandon the tune prepared and start creating a new composition for the text. His choristers were trained to his ways of improvisation, so that they would immediately catch up the theme just invented by Boruch and continue developing it according to his "style," thus creating a new composition to the greatest delight of his congregants, who, knowing their chazzan's ways, immediately felt the new inspiration. Some of his singers were greatly devoted to him, and knowing how to write music, retained several of his compositions. The creations are remarkable for their power and their bold modulations. His chief singer, Nehemia Bass, had the privilege of adding a shtel - a vocal prelude without words, to his master's compositions. Such a privilege was usually accorded the chief singers by their chazzanim. ${ }^{10}$

7. Yeruchom Blindman, called "Yeruchom Hakoton" (the little one). He was born in Bessarabia or in Galicia c. I 798. In 1834 he was already a well-known wandering chazzan. Until $\mathrm{I} 860$ he was chazzan in Kishenev, and in I86I- 
I 877 in Berditschev in the old synagogue. Though in his agreement with the later congregation he had pledged to refrain from touring the country and remain at that post all his life, he nonetheless broke his contract and became chazzan in Tarnopol from 1877 to 1886 . He died at the age of ninetythree. Yeruchom seems to have been a "singer" of Bezalel Odessaer. He acquired later some knowledge of music, even in elementary harmony. His compositions show attempts at harmonic arrangements in four parts. He had in his younger years a high lyric tenor with a limitless falsetto. Many of his compositions are still circulating among the chazzanim. Some of them, especially those in minor, breathe warm Jewish sentiments. They are new creations of the old material of MogenOvos or Selicha-modes. In them Yeruchom created new melodic turns through which the Eastern Jewish folk tune is echoed. His compositions in major are imitations of military music.

8. Nisson Sprvak, called "Nissi Belzer." This most gifted composer for the Eastern Synagogue of the old school was born in 1824 in a little village in Lithuania. As a boy, he sang with Boruch Karliner. Then he wandered south to Yeruchom, whose niece he married, in Bessarabia. Through an accident he lost his voice. Nevertheless, he became chazzan by merit of his remarkable talent as composer and choir-leader. He occupied the post of chazzan in Belz (hence his name Belzer), Yelissavetgrad, Kishinev (1864-1877), and from 1877 on in Berditschev as successor of his uncle Yeruchom (with whom he had been on bad terms), where he remained until his death in 1906. He died in Sadegora, while on a concert tour to the famous chassidic rabbi of that town.

It is remarkable that in Eastern Europe, where so much emphasis was laid upon a beautiful voice, we find chazzanim of great fame who were voiceless. Under West European 
conditions, these men would have probably been Synagogue composers and choir-leaders; but in Eastern Europe until a half-century ago such a position was still unknown. Therefore, they had to be chazzanim. Strangely enough, the public seemed to be willing to listen to such voiceless singers. The unpleasantness of the performance is easily imaginable, but the public felt repaid by the wonderful tunes that those chazzanim composed and rendered by the fine voices of the choir. This phenomenon caused two changes of considerable importance in the Synagogue song: First, taking into consideration their inability to sing solo, these chazzanim limited their solo parts to a minimum. And secondly, in order to cover their vocal deficiencies, they tried to select fine voices for their choirs. Thus, while the chazzan with the beautiful voice often made the prayers merely a tool of his solos, using the choir as a mere accompanying body, these voiceless chazzanim, through sheer emergency, were forced to express the Synagogue song through the choir primarily. The singers, partly as soloists and partly as an ensemble, carried practically the entire service. And the remarkable aspect of this arrangement was that the public seemed never to miss the chazzan. Of Nissi Belzer it is told that after his and his choir's performance of his best compositions before the chassidic rabbi Dovidl of Talno, the rabbi asked him how much his choir cost him, whereupon he answered, "Fifteen hundred rubles per annum!" "Oh, Nissi," responded the rabbi, "you are too economical! Why do you not spend another couple of hundred rubles and engage also a good chazzan?" 11

Out of the school of this voiceless chazzan there arose a great number of chazzanim. Nissi's meshorer was no longer only a helper to the heroic chazzan; but he became, even while still a chorister, an important factor in the service. This was another significant step in the development of Synagogue song. 
Compelled by the circumstances described above, Nissi created a new genre in the Synagogue song, a style which though based upon the principle of chorus, nonetheless gave ample solo-work of the chazzanic type, i.e., the modal form, the execution of which he divided among the choristers. For solo only or for solo with choir accompaniment he never wrote. His pieces are mostly choruses with interspersed solos of considerable length. In Nissi the harmonic sense is much more developed than in Yeruchom. At times he attempted a small canon or fughetta and dared modulations with the boldness of his first teacher, Boruch Karliner.

The reason for his lengthy compositions lies in the fact that he did not write for the average service but for concert-services, for he, being a city-chazzan, had the task of supplying the large Jewish community of Kishinev or Berditschev with "music." As a city-chazzan, he used to officiate on special Sabbaths or feasts and fast days only. These services were regarded as religious concerts which members of different Jewish congregations used to attend usually after they had finished the regular service in their own synagogues. The citychazzan would prepare a musical program, the texts of which were selections from the ritual, though the setting was hardly adaptable to the service, inasmuch as some of these compositions would consume a half hour or more.

Nissi's themes are striking in their genuineness, and his creative power in variations of his themes is refreshing and rich. Strongly influenced by military music, he shows also what seems to be the influence of the opera. In his compositions based upon the Ahavoh-Rabboh mode he strikes the soul of the Jew to its very depth. To a considerable extent he is also influenced by the Ukrainian scale. But what a difference of conception! None of the Ukrainian tunes in folk style could match some of Nissi's creations. Nissi's music shows his striv- 
ing after form; but being without any training in the art of form, he gropes in darkness. At times, he repeats the first theme at the end, but usually, influenced by instrumental military music, he repeats the sections of the compositions in a manner imitative of the rondo. Furthermore, his selection of texts, formless from the musical point of view, and his faithful adherence to their content which he tried to voice, were in themselves barriers to form in his musical settings. In addition, he lacked the sense of economy; he produced a rich treasury of wonderful themes which he lavishly spent without developing them.

We may count Nissi Belzer as the greatest musical genius of Synagogue song that Eastern Europe produced. He stands wholly on Jewish-Oriental ground, gazing at the ExTERIOR of the European palace of music.

His numerous compositions are still in manuscript form, scattered among the Eastern chazzanim in Europe and America. They constitute an integral part of the music of the Orthodox Synagogue.

In the second half of the nineteenth century Eastern Europe was more and more opened to Western European culture; and the large communities started building the modern Synagogue called Chor-Schul, according to the model of the Vienna Temple of Sulzer- of course, without the organ. It was a thorough imitation of Sulzer, even to the dress and long hair of the chazzan. The chor-chazzanim in the first place eliminated the whole East European Synagogue song, and replaced it with Sulzer's service. They tried to abolish embellishments and ornaments because Sulzer did thus, but they lacked Sulzer's tremendous voice and his wonderful execution. Deeper inland in Russia, where the Jews never saw Sulzer or his pupils, but heard and saw only the Eastern European imi- 
tation of him, they found a great similarity between the pseudo-Sulzers and the Russian Greek Catholic priests, who were in their neighborhood and whom they could easily imitate. Hence, the chor-chazzanim received the HONORABLE name of galochim and their song was called galochish, i.e., dressed as priests, and singing in long-extended tones without ornaments, similar to those of the song of that Church. Needless to say, these modern chor-chazzanim could not gain the sympathy of the Jewish public; and the well-built modern synagogues were more visited by gentiles, mostly military officers and their wives, than by the Jews, who preferred the old-fashioned chazzan and even the simple baal-tefillah. A few exceptions there were among these chor-chazzanim, who were equipped with Jewish knowledge and feeling. And they, out of consideration for the taste of the Jewish people, retained in the service some tunes which had real Jewish character.

I. Nisson Blumenthal was the first modernized chazzan in Russia in the first Chor-Schul in Odessa, founded in I840, and called "Brody-Synagogue" because it was organized by the Jewish settlers from Brody. Blumenthal was born in Berditschev in 1805 and was raised in Jassy, Roumania. He was an autodidact in music and in German classic literature; he was a man of fine spirit and taste. He endeavored to raise the musical standard of the Synagogue song by means of a welltrained choir (men and boys) singing in four parts. $\mathrm{He}$ likewise tried to simplify the modal chant of the chazzan, giving it more inwardness rather than acrobatics of vocal technique. Not having any creative ability himself, he used to adapt for Hebrew texts selections of oratorios and sacred music by Handel, Haydn, Cherubini, and Mendelssohn. He had a fine lyric tenor voice, and presented an inspiring interpretation of the Synagogue modes. During the long period of his activity ( $184 \mathrm{I}-\mathrm{I} 892$, he died in 1903 at the age of ninety- 
eight) he exerted a good influence upon his congregation and upon young Jewish musicians by developing in them a finer musical understanding. Especially fortunate was his success in obtaining as choir-leader a man of considerable musical talent and a marvelous choir trainer, and this was:

2. David Nowakowsky. He was born in $\mathrm{I} 848$ in a small village (Malin) in the government of Kiev. From the age of eight he was chorister for ten years in the new Chor-Schul in Berditschev. ${ }^{12}$ In 1870 or 187 I he was appointed choir-leader in the "Brody-Synagogue," at which post he remained for a half-century until his death in I92I.

Nowakowsky is the most Europeanized Synagogue composer in the East. He made a thorough study of harmony and counterpoint, and acquired the technique of the forms of the classic vocal music for choir, notably the oratorio style. His themes he often takes from the traditional modes or tunes; and he displays a fine talent for variation and development. His compositions are mostly of great length and suited rather for religious concerts than for an average service, a manner of composition which, as already explained, is to be found in the Eastern chazzanic creations. This manner of writing was a far cry to Sulzer's music distinguished by its brevity of form and created with the aim of suiting the regular service. Nowakowsky's harmony is likewise of great interest, but we shall treat that in Chaper XXIII.

During his life he published a service for Friday evening and one for the concluding-service (Neila) of the Day of Atonement. The greatest part of his creations remained in manuscript form.

3. Wolf Shestapol, called "Welwele Chersoner," the son of Samuel, chazzan in Odessa, was born c. 1832. He sang with his father and with Bezalel, and became chazzan in Cherson. His congregation sent him to Vienna to be instructed 
by Sulzer. Shestapol was a prolific composer of sweet and ingratiating tunes of but little originality. He was influenced by the Italian opera in Odessa to the extent of adopting themes and snatches of arias. Thus he adopted a part of an aria from La Traviata, No. 6 for Adonoy Zechoronu (Ps. I I5: x2-I8, beginning with the word hashomayim). From there A. Goldfaden took the tune over into his musical play Shulamith (Chapter XX).

Shestapol's choral harmony is poor and of instrumental character. On account of their sweetness and folk-character, his compositions, notably his tunes in minor, became very popular, though they were never printed. He died in 1872, not reaching even the age of forty.

4. Boruch Schorr. The second chazzan of fame that Galicia produced was born in Lemberg in 1823 of a prominent chassidic family. At the age of nine he became a singerl with Bezalel in Odessa; at eleven he sang with Yeruchom; and at thirteen he already conducted services. After officiating in various congregations in Podolia and Roumania, he was appointed chazzan in the great synagogue in Lemberg in 1859 . Though very pious, Schorr was nonetheless touched by European culture. In I 890 he composed an operetta, Samson, which was performed in the Jewish theatre in Lemberg. At the call of the audience Schorr appeared on the stage led by the prima donna. Such conduct was regarded by the orthodox element as undignified for an orthodox chazzan, and Schorr was suspended from his office for one month. Hurt by this rebuke, Schorr went to New York, where he remained for five years. But the Lemberg community was lonesome for its popular chazzan and recalled him to his post which he occupied until the end of his days. He died while officiating on the last day of Passover in 1904.

Schorr's Synagogue compositions for the High Holidays are 
notable for their genuine Jewish motives and melodic structure, for their simplicity and singability. Schorr gave the traditional tunes a pleasant shape, without taking away their unique originality, without trying to Europeanize them. In his responsa he imitates Sulzer, likewise in his use of brief forms, especially in those compositions for the High Holidays published in New York in 1906 by his son Israel Schorr. In this collection many pieces are the work of the latter. Apparently also the son has to a great extent doctored his father's harmony. ${ }^{13}$ Schorr's compositions are almost entirely either in minor or in the Ahavoh-Rabboh mode (in major there are only two, Nos. 142 and I43). He raised six sons as chazzanim. These are officiating in various communities in the Old and the New World.

5. Elieser Gerovitsch is one of the first chazzanim who received a musical education in the conservatory of music in Petersburg. He was born in a village in the government of Kiev in 1844, sang in choirs in Berditschev and Odessa, went later to Petersburg to study music and voice, and occupied the post of chazzan in Rostov on the Don for about twenty-five years. He died in 1913. In 1890 he published a collection of songs for Sabbath, the Three Festivals, and the High Holidays, called Schiré Tefillah. Gerovitsch is a master of counterpoint and of the Church-style which he acquired in the above-mentioned institute. He applied the method of the classic composers to the utilization of traditional tunes as "cantus firmus," around which he created artistic forms. He mastered all the traditional modes of the Synagogue, even the most neglected Adonoy-Moloch mode (in his work, Nos. 2-3) and created out of that mode choral items. He introduced a Persian scale, called Suz-Nak, ${ }^{14}$ into the Synagogue (No. 22), probably influenced by Persian or Tartaric song frequently 
heard in the environment of Rostov. In 1904 Gerovitsch published another collection, called Schiré Zimra.

Gerovitsch, like Nowakowsky, created music which may be designated "Jewish art music," utilizing European technique for Jewish elements.

Southeastern Europe brought forth infinitely more creative Jewish musicians than did the Northern part, apparently because of the inspiration drawn from the Near East which borders the Southeastern districts. Volhynia, Ukraine, Podolia, and Bessarabia were the cradle of the great Jewish singers and composers. Weintraub and his father, Kashtan, too, originated from the South, though the former spent the greatest part of his life in the North (in Koenigsberg-Prussia). From the biographies of chazzanim given in this chapter we notice that the chazzanim of the North (Lithuania) were trained in the South. By almost all the chazzanim, with the exception of Sender Minsker, the South was considered the cradle of chazzanuth. Nonetheless, due to Weintraub's influence, several of his disciples became prominent chazzanim in the Northern districts, in Prussia, Lithuania, and in the Baltic provinces, where they transplanted Weintraub's style and art. The most prominent of these was:

6. BoRUCh Leib Rosowsky, for almost a half-century chazzan in Riga (Latvia). Born in a village near Wilna in I 84 I, he went in I 867 to the then newly established conservatory in Petersburg (founded in 1863 by Anton Rubinstein). In that institute Rosowsky studied for three years. There Tschaikowsky is reported to have been his classmate in composition. ${ }^{15}$ In 1870 he went to Weintraub, and in a short time he absorbed Weintraub's chazzanuth to such an extent that, according to the master's own statement, he rendered it in a more accomplished manner than Weintraub himself. And 
truly, Rosowsky was a wonderful interpreter of Weintraub's art to which he remained faithful all his life. Rosowsky had a well-trained choir; and during his activity in Riga, from I87 I until his death in 1919, he trained many chazzanim and a number of Jewish singers who became prominent on the stage, such as Joseph Schwarz and Jadlowker. In his compositions Rosowsky adhered to the Jewish folk-character. Judging from a collection of his compositions published by his son, Solomon Rosowsky (Chapter XIX) in 1923, he lacked originality and depth.

At the end of the nineteenth century, the spirit of Russian revolutionary endeavors with its concomitant breakdown of the religious traditions and life in the Jewish Ghetto, resulting from the Russian pseudo-European education, robbed chazzanuth of the soil from which it had drawn its nourishment, and reduced it to a virtuosity consisting of powerful voices without any depth of feeling or purpose. The chazzanim of the last generation in Eastern Europe were mostly without any Jewish training, without religious spirit and sentiment. They conducted themselves as professional artists, as religious actors on the stage of the Synagogue whose only purpose was to captivate the mob. They used cheap means, especially dazzling tricks of coloratura combined with powerful tones, and sought to appeal to the sentiment of the Jew through motives which drew tears. It would seem that East European chazzanuth has already reached its end, and belongs to history. After surveying it, we must pay it credit, for-at its best-it was in a sense a new creation and an addition to Synagogue song. Besides the many wonderful and genuinely Jewish tunes that were born of it, its main value and achievement were its bringing back to Jewish song the elements lost in Central European chazzanuth-the Jewish-Oriental strain, in European form. Even on the Missinay melodies and on the traditional modes 
it had its influence, casting out German additions of the Middle Ages and replacing them with Eastern material.

The World War caused the destruction of the Jewish center in Eastern Europe. The spiritual life therein was crushed by brutal force, the survivors of the intellectual group mostly dispersed throughout the Old and the New World. All the spiritual values created in that center in the last two or three centuries, including the Synagogue song, were brought to a standstill. Yet here and there some of those musical refugees try to revive the art they carried with them from the East, and transplant it in the new environment.

7. Samuel Alman, choir leader in the Duke's Place Synagogue in London, is one of these promoters of the Eastern song of the Synagogue. In 1925 he published Synagogue Compositions for Sabbaths and weekdays "in the spirit of Nissi Belzer and Bezalel of Odessa," as he states in his preface. He aims "not to furnish his compositions with foreign forms as the Western chazzanim did . . . not to corrupt the Jewish tunes, but to set them to modern harmony."

Alman was born in 1877 in Podolia. He studied in the conservatory in Odessa and served in the Russian army band. After the pogrom in his home city, Kishinev, he went to London, where he continued his study in the Royal College. There he took to composing operas, but finally returned to the Synagogue song.

Despite his effort to free himself from the style of the Western chazzanuth, he could not escape Sulzer, whose style is deeply impressed in his settings of Lechoh dodi (Nos. I-4), of Kiddush (Nos. I7-19), and of the removing and replacing the Torah (Nos. 28-29, 37-38). Even in the Kedushoh (No. I42) and Mi-sheberach (No. 30) he is decidedly a follower of Sulzer's forms and models. The reason is that these forms of Sulzer had been accepted in the East since the estab- 
lishment of the Chor-Schul in the middle of the nineteenth century, and were gradually adopted also by the orthodox chazzanim. Alman, indeed, followed the chazzanuth of Nissi and Yeruchom (not Bezalel), but without analyzing which elements were Jewish and which foreign. Especially in his compositions in Ahavoh-Rabboh mode, in the Ukrainian "Dorian," and in minor, he follows the folk steps of the two chazzanim mentioned above. He utilizes intricate modern harmony with an abundance of augmented and diminished intervals and chromatic steps and plentiful operatic effects, without considering the appropriateness of these elements for Jewish religious music, or whether they are in keeping with the spirit of Jewish music. Since his music is destined for the English Synagogue and for the conservative ritual, he writes a cappella, substituting at times for the organ the sustained humming chords by the choir, a device originally borrowed from the Ukrainian folk song, as pointed out in Chapter IX.

It remains to be seen what impression this Southeastern Orientalized style will make upon the Occidentalized Synagogue in Western Europe in general and upon the Anglo-Saxonized Synagogue in England in particular, where for almost a century Occidental song has been cultivated and a tradition established by Simon Asher (I84I-I870), L. Mombach (I840I880), and Marcus Hast (I87I-I9II). Asher came from Holland, Mombach from Germany, while Hast was born in Praga, near Warsaw. Hast, the most prominent of the three, received a thorough training in Hebrew literature and in Synagogue song as well as in classic music. In London he became Occidentalized, as shown from his voluminous creative works for Synagogue (Chapter XIII). He composed, also, several oratorios on Biblical and post-Biblical subjects: "Bostanai," "Azariah," "The Death of Moses," "The Fall of Jerusalem," in the style of Handel. He showed skill and ability in these 
works, but no originality, and but slight suggestions of Jewishness. Asher introduced the German-Dutch chazzanuth. However, none of his tunes were published. Mombach's music, with the exception of a few selections which are in Jewish traditional modes, is a fusion of the German and English popular song-style. It became the standard music of the English Synagogue. A collection of his Sacred Musical Compositions was published in I88I (see Chapter XIII). 


\section{CHAPTER XV}

SYNAGOGUE SONG IN THE UNITED STATES OF AMERICA.

The Jewish settlement in the United States is comparatively very young-all in all somewhat more than two centuries. During that period the settlers struggled hard to acclimatize themselves and adapt themselves to the new environment. This adjustment caused them to drop a great part of their inherited conceptions and to abandon manners to which they had been accustomed in their old dwelling places. Such a period of struggle immigrants and new settlers usually have to endure in the first few generations, until they root themselves in the soil of their adopted country. Thus, during the period of acclimatization and adjustment there was no possibility for spiritual creation. Yet, following that period of struggle, forecasts of creations of a new Jewish-we may say American Jewish -type are noticeable. It is from this point of view that the achievements in the field of Synagogue song in America have to be considered. And it is, therefore, not a history of achievements that we can offer here, but rather an insight into its first steps.

Though the first Jewish settlers in the middle of the eighteenth century were of Portuguese stock, nevertheless, as in Europe, that group remained a very small minority, and is now gradually dwindling away. The bulk of the first Jewish settlers in the beginning of the nineteenth century came from Central Europe, especially from the German countries. Medieval prejudice, which weighed heavily upon their shoulders as Jews and which brought about their social and economic handicaps, urged them to leave their homes and emigrate to 
the land of freedom, a land, then, without tradition. Upon their arrival in this country, though engaged in the driving struggle for their existence, they nevertheless found the need and the time to care for their Judaism. And thus, under the greatest handicaps and with the poorest means at their disposal, they tried to organize Jewish religious institutions as best they could. True, their first attempts were modeled after the traditional forms of the religious institutions in which they had been born and raised in the Old World. Thus, the Portuguese Jews established institutions according to the model of Amsterdam and London, and the German Jews according to the model of their respective homes in different parts of Germany; whereas the Bohemians and the Hungarians copied their home institutions with all their medievalisms and their antiquated religious forms which had no cause for existence in this new environment.

The Synagogue song, too, as all other spiritual values, was transplanted into these homes of worship newly sprung up on American soil. That song, as a tonal expression of the long history and martyrdom of Israel during the Dark Ages and as an exalted expression of its high and eternal ideals, had made a deep impression upon the worshippers when properly rendered by the traditional interpreter, the chazzan, if he had devotion and understanding, a sweet voice and the power of presentation. But in the new country there were neither properly prepared spiritual leaders, rabbis, nor well-trained chazzanim. The qualified men preferred rather to stay in their old homes than go out into the New World and do pioneer work. The result was that the newly established synagogues in America were led by unqualified leaders, and the song was vulgarized by untrained and unfit chazzanim. These circumstances brought about a lower standard of Jewish public worship. ${ }^{1}$ 
But even with qualified ministers, the traditional service and song were doomed to but a short life, for new conditions soon robbed the old ritual of its appeal. True to the principle that the song is the tonal expression of ideas and sentiments, of modes of life and the combats of life, the Synagogue song had to undergo changes in order to become once more a genuine expression of that group of Jews which was being remolded under new conditions. So too the Jewish congregations could no longer remain mere continuations of those in the Ghettos of the Old World, for the adjustment and acclimatization of the Jews to their new environment caused a change in their attitude toward life and in their sentiments. The long dark period of oppression was over. In this country of freedom and equality they no longer felt themselves inferior, outlawed strangers, a nation within a nation, in a condition of exile, but full citizens of the country which they began to consider their real home. In addition, they prospered economically, so that for the first time after a period of about two thousand years, the Jew began to regard himself a free man and a citizen, having a home.

If socially and economically the change was fundamental and somewhat sudden, the spiritual change grew and developed gradually in the successive generations born and raised in the atmosphere of Anglo-Saxon culture and American ideas and standards; so that a deep psychological change in the second and third generations was noticeable. Consequently, a part of the Jewish inheritance lost its significance. Numerous religious laws which had been considered for many centuries as fundamental to Judaism on account of the conditions in which the Jews lived-as all ordinances connected with the underlying idea of Israel being in exile and its dwelling place in exile being of only a temporary nature, or laws which had the aim of separating the Jewish people from the hostile environment -were no longer of vital value to the free Americanized Jew. 
This change manifested itself in various attitudes toward the old religious code. First of all, to many people who were pious by nature that part of the code became burdensome. Secondly, other people, iconoclasts by nature, rejected that burden altogether; and some who were indifferent by nature neglected it. And finally, a fourth group, either not conscious of any change in these new conditions or in spite of that change, insisted that not an iota of the religious laws be changed, that every minute injunction must be observed. These people did not realize that, while they believed themselves strictly observant, the undercurrent of American life was stronger than they, and that it was against their own will causing a fundamental change in their attitude. At any rate, the psychological transformation from the second generation on was practically the same in all groups.

And more than in any other cultural sphere that psychological change manifested itself in the Synagogue song, song being a genuine expression of emotions and sentiments. Fundamental changes could be expected here. A handful of men at first-three thousand being the entire population of Jews at the time of the War for Independence-their numbers grew to fifty thousand toward the middle of the nineteenth century. Scattered in small groups throughout the vast country of predominant Anglo-Saxon milieu, imbued by its culture, educated in its schools, carried along by its train of thought, the heart of the young generation from its infancy on vibrated to the sound of Anglo-Saxon song. The Germanized Synagogue song which the Ashkenazic immigrants had brought with them to this country, was thus more and more Occidentalized, and the Oriental-Jewish elements gradually deteriorated to a meaningless exotic chant.

Yet, out of the above-mentioned groups some came forward, unwilling to await the tardy process of circumstance, environ- 
ment, and accident, anxious to adjust their religion to the new condition by abandoning elements which had become obsolete and by reshaping that part which to their mind was fundamental and would meet the needs of the new life-these men came forward and set about to turn their ideas into deeds. The first attempt was made in Charleston in 1824 in the organization of a "Reform Society of Israelites" with the aim "not to overthrow but rebuild, not to destroy but to reform." As a model, that Society took the Hamburg Reform Temple, organized but a few years earlier (Chapter XII). But it was not until I 843 that the entire congregation in Charleston was drawn over to Reform and accepted the organ and prayers and hymns in English texts. Many hymns and tunes, as stated by the editors in the preface of the first prayer-book in English published in 1830 , were taken over from the Christian Church. Later, several chorales from the Hamburg chorale-book were translated into English. A native Charlestonian, the poetess Penina Moise (I797-I880), was the first Jewish woman after many centuries to contribute toward the Synagogue ritual (Chapters VI, VIII). She wrote a number of religious hymns for Jewish schools which have become popular in the Reform service.

At the same time ( 1842 ), a Reform congregation in Baltimore ("Har Sinai") was organized and adopted the Hamburg Temple Prayer-book for its service. In I 845 the "Emanuel" congregation in New York was founded. Within the following two decades several Reform congregations throughout the country were called into being, or Orthodox congregations were transformed into Reform. ${ }^{2}$ The Reform service, with its abbreviated Hebrew texts, its introduction of prayers and hymns in English, and its use of the organ, caused a great technical difficulty in the musical rendition of the service. The historical interpreter of the Synagogue song, the chazzan, could not suf- 
fice. First, most of the cantors were not trained in modern music and in singing with organ accompaniment. Secondly, the song of the chazzan itself, the traditional chant in unrhythmical modes, no longer appealed to the Occidentalized American Reform congregations. And finally, there was no possibility of having a Synagogue choir of Jewish men and boys, since the historical "Singer-guild" (meshorerim) did not obtain in the New World, and the American Reform congregations, like those in Germany, preferred a mixed choir, after the model of the Protestant Church. Thus, other-non-Jewishservices had to be utilized to supply music for the Temple. First, the Church-organist who was available in all places was engaged in the Temple. Jewish organists did not exist at all then, and if there had existed any, there might have arisen the disturbing old problem of a Jew playing an instrument on Sabbaths and holidays. Since only in rare cases could Jewish singers and especially female singers be obtained, the organists were commissioned to engage the Church choristers for the Temple. But the greatest difficulty was brought about by the music itself. Tunes for hymns were adopted from the Church, or, following the procedure of the Hamburg Temple, composed by Christian musicians in the Church style. Anthems and solos, a new item introduced into the Reform service, according to the model of the Protestant Church, were also taken from the Christian sacred music.

This arrangement still did not solve the problem of music for the prayers proper. In the first years of the existence of the Reform congregation there was no other modernized music for the Synagogue on the market but Sulzer's Schir Zion, I, and Naumbourg's Zemiroth Israel. Both these works were based on the Orthodox ritual with Hebrew texts only and without organ accompaniment (Chapter XIII); both were published in large unhandy volumes. All these obstacles made 
it impossible for gentile organists and singers to make extensive use of them. In addition to musical skill, familiarity with the traditional song was essential to adjust it to the new requirements. And in this familiarity the gentile musicians were naturally lacking. The general attitude of the Reform movement was: "Whatever makes us ridiculous before the world as it now is, may be and should be abolished," and, "Whatever tends to the elevation of the divine service, to inspire the heart of the worshipper and to attract him, should be done without any unnecessary delay." 3 Besides, the train of thought and sentiment of the Americanized generation was Occidentalized. It was, therefore, quite natural that the organists set the Jewish prayers to Christian music, without meeting with any objections. Though the transformed congregations retained the chazzan for some time, he, instead of influencing the music, had to yield to the new song-style introduced and conducted by the gentile organists, who now became the creators and shapers of the Synagogue song in the Reform Temples. The rabbi again became the only central figure in the Synagogue. As in olden days, but in Occidentalized form, he became both preacher and precentor. This custom was retained in the Sephardic and Portuguese Synagogues throughout the ages.

There were, however, also a few Jewish musicians who contributed to the upbuilding of the modernized and reformed service in the United States, and mention should be made of the following:

JACOB FRAENKEL (I808-I887), the brother of Carl, who was the brother-in-law of Sulzer (his choir-leader and bass), was appointed chazzan in the congregation Rodeph Sholom in Philadelphia in 1848. He served there for nearly forty years, until his death in 1887 . Of Sulzer's school there was also Alois KaIser (born in Hungary in 1840 and died in I908), who occupied the position of chazzan in Ohev-Sholom, 
Baltimore, from I 866 to I908. SAMUEL WeLsh, born in Prague in 1835, became chazzan in Ahavath Chesed, New York, in I865, but in 1880 he returned to Prague, where he died in rgor. There was also Morriz Goldstein, born in Hungary in 1840 . His father was the well-known chazzan Shmelke, a "singer" with Dovidl Brod (Chapter XIV), who died young in 1849 , leaving behind ten little children. The oldest boy, Joseph, who was eleven at his father's death, became the successor to his father. Later he gained fame as chazzan in Vienna from I 858 to I899. Morriz Goldstein sang under Sulzer and studied music in Vienna. In 1868 he came to New York to accept the position as cantor in the Norko Synagogue. In I88I he was appointed cantor in the Benei Israel Temple in Cincinnati, which position he held until his death in 1906.

The last three of these chazzanim, realizing the need of new music for the American Synagogue, compiled a collection of songs for choir and solo with organ accompaniment, for prayers and Psalms in Hebrew, English, and German. This collection, named Zimrath Yah, was published (New York, I87II886) in four volumes, for Sabbath, the festivals, and other occasions. The music was written partly by the three editors and partly by gentile musicians, or was adapted from different sources. The style is intricate, of operatic character, though at times the intention to adopt the oratorio style is apparent. A striving after virtuosity and effect runs through the organ accompaniment. German in melody and character, the collection contains but few traditional elements. M. Goldstein independently compiled "services" for the Sabbath, the three festivals, and the High Holidays in three volumes (1895), arranged according to the Union Prayer-book. He borrowed compositions from Sulzer, Löwenstamm, Naumbourg, and others, without mentioning their names. Likewise he inserted 
several items by the French musician Amres and others. His music lacks originality and Jewishness, and is in part too theatrical. He also published a collection of hymns, Kol Zimra, with English texts, in I885.

Of Kaiser's activities, we mention his editing for the Conference of American Rabbis the music of the Union Hymnal which was published in 1897 . To this collection, consisting of about one hundred forty-nine items, he contributed about forty tunes. Sixteen tunes of this collection are marked "traditional," though some of them (Nos. I IO, I I8) are not traditional at all. The remainder are modernized to the extent of being robbed of their original flavor. With the exception of two tunes by Sulzer, two by Lewandowski, and one by Kirschner, the bulk of the tunes (C. 88) are adaptations from German, English, and French Christian composers. Of far greater value is Kaiser's cooperation in A Collection of the Principal Melodies of the Synagogue from the Earliest to-the Present, which he, together with William Sparger (cantor of Temple Emanuel, New York), compiled as a "Souvenir of the Jewish Women's Congress held under the auspices of the World's Parliament of Religions," Chicago, I893. In their preface the compilers gave a survey of Jewish Song, summarizing the state of research done until that date. They conclude with a warm appeal "to preserve carefully its inherited characteristics and originality, and plant it again in the Synagogue and home of our people in the only form in which this can be achieved now, namely, in the form of hymns." Probably the compilers were convinced that the unrhythmical modal form in Jewish Song was a matter of the past, and had no longer any place in the Occidentalized Synagogue.-The volume has two parts. Part I contains fifty traditional melodies with accompaniment and English texts; Part II has sixteen modern compositions partly 
based upon traditional themes and partly original compositions. The selection of traditional tunes is well chosen, and some of the original compositions are of significance.

In both collections there is a noticeable tendency to reduce the minor-melody to a minimum and to emphasize the major note, the German melodic line.

Sigmund SChLEsinger is the only Jewish musician whose music gained wide popularity in the Reform Synagogue in America. He was born in Uhlen (Württemberg), Germany, on March I, I835, and received his musical education in Munich. In 1860 he came to America and settled in Mobile, Alabama, in 1863, where he served as organist and choir-leader of congregation Shaarei Shomayim for forty years. He died April 14, 1906. "His funeral received the nature of a public demonstration in Mobile." 4 Schlesinger was one of the first to recognize the need of a musical setting for the Union Prayerbook. He composed six complete services: three for Sabbath evening and morning, one for the three festivals and two for the High Holidays.

Schlesinger's popularity, especially with the non-Jewish choirs and organists of the Reform temples, lies in the fact that his music is entirely Occidental. He omitted all Oriental and medieval Jewish characteristics from the Synagogue Song, such as the modal chant, the minor note. From the treasury of traditional tunes he left only two (Ovos and Kol Nidré) for the High Holidays, and he utilized a few motives for the same occasion. His is the German Protestant style plus operatic flavor. He also adapted several tunes from the Italian opera, the sources of which he sometimes mentions. Whenever he wishes a minor setting, he turns to the eighteenth-century Italian Opera or Church music. His melody is German, vigorous, usually major with dramatic strength, but at times senti- 
mental-Italian. His harmony is simple, frequently shallow; his accompaniment is rather a support for the voices, often without individuality or depth.

Quite different is the music of Edward STARK (I863I918). His father, Joseph Stark, was chazzan in Hohenems and Ichenhausen, and later in New York. From his father, Edward Stark inherited the understanding and knowledge of chazzanuth in Sulzer's style. He was gifted with considerable creative talent, with power and depth of Jewish expression. In 1893 he became cantor of Temple Emanuel in San Francisco, where he served for about twenty years. He composed services for Friday evening, one for Sabbath morning, one for New Year, and one for the Day of Atonement (r909I9I3, New York), and arranged them according to the Union Prayer-book.

His music shows a strong influence of the classic oratorio. He likewise acquired the style of modern harmonization and organ accompaniment. His music for Sabbath contains very few Jewish elements, but his services for the High Holidays are provided with cantor solos in the old modal form and choruses based upon traditional themes. He also provided organ pre- and interludes, utilizing traditional motives. As a whole, his High Holiday service shows unity. of style and spirit, in addition to a considerable amount of Jewish-Oriental flavor. Since his services contain a large number of cantor solos with choir, the cantor or, at least, a soloist to assume the cantor part becomes indispensable. This requirement often presents an impediment in rendering Stark's music in temples which employ a quartet only. A still greater difficulty in using Stark's music lies in the lack of singers capable of rendering the cantor parts with understanding. In Stark's music for the Memorial service we again perceive the depth of the Jewish soul, with its Semitic sensitiveness, with its Jewish clinging to life and to 
faith. His chief merit consists in reintroducing traditional Jewish musical elements into the Reform Synagogue.

Stark arranged the Kol Nidré for a small orchestra; and in some of the selections of his service he uses violin, cello, cornet, trombone, or harp obbligatos, with skill.

Franz WaLd, born in Hungary, sang bass in the choir of Zion Temple in Chicago, and became organist in Bethel congregation. In 1908 he published a Sabbath evening service, and compiled a selection of traditional songs for the High Holidays with (poor) organ accompaniment (in MS.).

M. GraumanN, cantor of the West End Synagogue, New York, composed a Friday evening service, in Sulzer's style, with a few genuine Jewish cantor solos in the Mogen-ovos mode with organ accompaniment.

Apart from these Jewish musicians, a great number of Christians, as a rule organists, composed services for the Reform temples in America, mostly for the Sabbath. Out of the vast publications we furnish here a list of the works which became known.

I. M. Spicker and W. Sparger: Sabbath evening and morning, New York, G. Schirmer, r901. (With contributions by H. Zoelner, W. Mackfarlane, Ottenhofer, Frank vander-Stucken. Seu Sheorim adapted from Gounod's Faust.)

2. Fred E. Kitzinger, organist in Judah Turo Temple in New Orleans. He published four volumes Shiré Yehuda for choir with organ accompaniment according to the old and the new ritual: Vol. I, Sabbath evening and morning, I888; Vol. II, I89I; Vol. III, Sabbath evening and morning for a small choir; Vol. IV he "dedicated to the promoter and lover of song," Dr. I. M. Wise, I 899.

3. Frank T. Fisk, organist in Kansas City. He published a Sabbath evening service in 1899 .

4. James H. Rogers, organist in Euclid Temple, Cleve- 
land, published a Sabbath evening and morning service, G. Schirmer, New York, I912. Rogers uses Jewish traditional tunes as themes for some items; he uses the tune of Berosh Hashonoh of the High Holidays for Veshomru, and employs the Traditional High Holiday Adon Olam tune.

5. Abram Ray Tylor, organist in Detroit in Temple Beth-El, published a Sabbath morning service, Bloch, New York, I9I4.

6. W. G. Owst, organist in Baltimore, published a Sabbath morning service, Oliver Ditson Co., Boston.

7. A. J. Davis, organist in Temple Emanuel, New York, published a Sabbath evening service, Oliver Ditson Co., Boston, $\mathrm{I} 898$.

8. W. H. Neidlinger, organist in Chicago, published a Sabbath evening service, Oliver Ditson Co., Boston.

9. CARL GRImm, organist in the Reading Road Temple, later Plum Street Temple, Cincinnati, published a Sabbath morning service, Church Co., Cincinnati, I916.

Io. Howard Thatcher, organist in the Ohev Sholom Temple, Baltimore, published a Sabbath morning service, Bloch, New York, I9I I Sabbath evening, ibid., I9I3.

i I. Edmond Sereno Endel, organist Eoff Street Temple, Wheeling: Sabbath Morning, "Short and of moderate difficulty," Bloch, New York, I908. 1906.

I2. T. L. KREBs: Sabbath Evening, Bloch, New York,

I3. Arthur Foot, Ozi vesimrath Yah, Boston, I9O2.

I4. Marx HelfEre, Synagogue Songs, New York, I 897.

I5. Arthur Dunham, organist "Sinai Temple," Chicago, published a Sunday Service, Chicago.

In the last few years new attempts have been made in the field of song for the Reform Temple with the aim of introducing ultra-modern harmony and style into the Synagogue. 
We mention here two services composed by American Jews. The one is of special interest for the mere fact that this is the first attempt made by a Jewess to write music for the Synagogue.

Rosalie Hausman: Sabbath Morning Service, Bloch, New York, I924; and

Heniot LEVY, composer in Chicago: Synagogue Hymns and Responses for Sabbath Evening and Morning, Bloch, New York, I926.

\section{Hymnals}

The singing of hymns in English (at first also in German) became an integral part of the Reform service in America. Hence, several collections of hymns were compiled, partly translated from the German Hamburg Songbook, partly original compositions by Jewish and Christian writers. But Hebrew poems of the medieval Synagogal piyyut were also paraphrased in English hymn forms. The musical settings, however, were generally done by Christian musicians or were adopted from German and English hymnal music. The first successful composer of hymns was the non-Jewish organist of Zion Temple, Chicago, Отто Lов. In 1876 he published his Israelitische Temple-Gesänge, consisting of forty hymns for the Sabbath and Holidays. Many of his hymns became popular in the Reform Temples and in the religious schools. Rev. Simon Hecht, Evansville, Indiana, compiled a collection of Jerish Hymns for Sabbath Schools and Families in 1878. This hymnal contains forty-three hymns in English and nine in German. The music is partly arranged for one voice, partly for two and three voices. Twelve tunes are original compositions of S. Hecht, while the remainder were partly composed especially for that songster by local musicians in Evansville (M. Z. Tinker, P. Esser, Chr. Mathias, C. C. 
Genung), partly adapted from the German classic music of Mozart, Gluck, Mendelssohn. The two traditional tunes for Chanukah and Pesach are likewise given.

The most popular hymnal thus far was compiled by $\mathrm{R}_{\mathrm{ABBI}}$ IsaAC S. Moses of the Central Synagogue, New York (Posen, I847-New York, I926), in I894. In 1920 the fourteenth enlarged edition was put out. In addition to about two hundred fifty hymns in English, four Hebrew hymns are given (Adon Olam, Yigdal, En Kelohenu, and El Nora). There are likewise responses in Hebrew and English for Sabbath's and High Holiday's services for School and small congregations as well as some solos and traditional tunes with accompaniment. There are furthermore seven services for children, a Sabbath service for the home, a Flower service, a National service, a Harvest service, and a Chanukah and Purim service. The hymns are classified as: Songs of Praise and Prayer, Songs of the Sabbath Day, the Word of God, Festivals and Seasons, Patriotic Songs, and Songs of Duty. In the preface to his sixth edition the editor makes the following statement: "The improvement of this book will be found not only in the larger number of hymns but chiefly in its 'Jewishness.' It is eminently proper that hymn-books intended for Jewish worship should be Jewish in character, and that the hymns of prayer should be the products of Jewish authors. An exception to this rule may be made to hymns that are versifications of Psalms or of other portions of the Hebrew Bible. A collection of fine poems and melodies culled from the hymnals of the different Churches has no place in the Synagogue. Has the Jewish genius produced nothing of value that we must needs go begging at the doors of every denomination?" The editor was aware of the value of Jewish music for Jewish education and service, and he, therefore, did not fail to insert this element. "Many traditional melodies," says he, "have 
been utilized for hymn purposes for the first time." In this work Theodor Guinsburg, for over forty years cantor in the same temple (1844, Suvalk, Poland-1923, New York), contributed a considerable number of hymns and solos based upon traditional tunes. Likewise, Gideon Froelich, organist in that temple, furnished the Hymnal with an abundant number of tunes. But according to I. S. Moses "he (Froelich) has caught the spirit of Jewish melody, and the character of Jewish worship," though his tunes do not certify that statement, for they have the regular German melodic line. The editor, likewise, inserted original compositions by P. C. Lutkin, A. J. Davis, S. Sabel, as well as many tunes adapted from Mozart, Schumann, Beethoven, Mendelssohn, Rossini, Spohr, H. W. Hawkes, Weber, Schubert, etc. He also borrowed several hymns from Otto Lob's Hymnal. The general impression of the music is decidedly German, though a few Jewish modes and tunes were inserted.

Mention should be here made of a Hymn for Confirmation, No. IOI, composed by a Jewess, Mrs. S. E. Munn, of Newark, New Jersey. The text was written by Felix Adler, the founder of the Ethical Society in New York. This song became very popular in the Reform Synagogue.

Henry Gideon, the Jewish organist in Temple Israel, Boston, published in cooperation with L. WeINSTEIN (a chazzan) a hymnal for modern congregations, both Reform and Conservative (Bloch, New York, I919). The compiler follows the usual Church hymn-style and typical Church hymns such as No. 30 are inserted. A considerable selection of traditional tunes was added. Furthermore, various compositions in simplified form by Sulzer and Naumbourg, etc., are given, thus furnishing musical settings, in part at least, for the services of Sabbaths and the festivals.

A new and enlarged edition of the Union Hymnal, treated 
above, was published in r9r4. It was edited by a committee of rabbis, under the chairmanship of Rabbi Harry H. Mayer, Kansas City. The material of the first edition was retained only in part. Many new hymns were added, bringing the total to 226 numbers. Eleven of these numbers cover two tunes: "first" and "second." On the other hand about 12 tunes are repeated. The authors of the new texts are Jews and gentiles. About I 40 tunes are of non-Jewish origin-several of them adopted from Church Hymnals. Some melodies are popular in all Churches, such as No. 97, which was first introduced into the Reform Temple by Jacobson (Chapter XII). Forty tunes are marked "traditional," of which only I 6 really are so (Nos. I, 8, 4I, 55, 68, I00, I03, I36, I38, I62, I64, I 7 I, I 78, I86, I89, 2I7), the others being unknown tunes of recent date and have German features. Four of the 16 tunes (Nos. IOO, IO3, I 38 and I 86) are taken from the Jewish-Portuguese song, the rest are of Ashkenazic-German origin. Some of these melodies, as given in the Hymnal, are extremely modernized and partly corrupted, such as No. 68, the old form of which is given in Baal-Tefillah, No. I32I, I; No. I7I, which is to be found in table XXII, 7; No. I78, see table XXV, 4; No. I62, for the original form of which see Baal-Tefillah, No. I306; No. 217, compare Baal-Tefillah, No. 1467. The Hymnal contains over 50 tunes by Jewish composers, of which Two have Jewish flavor (Nos. 7 and 77). No. 77, the Yigdaltune by "Leoni," is given in the form as it occurs in the Christian Hymnals (Chapter XI), not in its Jewish version (see table XXVII, 6; L. Mombach's work cited in Chapter XIII, p. 76). Two hundred and fourteen tunes are in major and $\mathrm{I} 2$ in minor. In addition there are 22 Hebrew hymns and responses (No. 227-248), five children's services for week-days, one for Sabbath (without music), one for the Three Festivals, which utilizes none of the traditional tunes of these holidays, 
and one for Chanukah and Purim. The music supplied in the "Responses" and "Services" is restricted to such texts as Borchu, Shema, Mi-chomochoh, Kedushoh, which since the eighteenth century have been those habitually used for responses in the German Synagogue. Neither traditional modes nor motives of Jewish folk song have been utilized. The style of the hymns is that of the Protestant Hymn, both in its melodic line and in its harmonization in four-part choruses. This procedure adopted also by the other Hymnals is detrimental for congregational unison singing as well as for an appropriate instrumental accompaniment. It leaves a dull and choppy impression.

Almost all the congregations founded by Jewish settlers of Germany and Bohemia became Reform; whereas the Hungarian Jews and, especially, the great influx of Polish and Russian Jews in the last two decades of the nineteenth century increased the number of Orthodox congregations. "However, even many of these immigrants, often living in the country for some time, affiliate themselves with Reform congregations. The free spirit of American institutions is impatient of the restraints of rabbinical legislation as embodied in the Shulchan Aruk. The descendants of the immigrants, even in the first generation, are so affected by the free school, the free state, and the free atmosphere in which they live and move and have their being that they can impossibly entertain the religious views of their Orthodox forebearers. Frequently, they swing to the opposite extreme and become outspokenly irreligious and atheistic." 5 This statement of over twenty years ago holds true to the present day. Many of the so-called Orthodox congregations are so by name or in theory only, for in practical life very few of the members are strict observers of the Orthodox teachings and laws. The observance of Orthodoxy is for 
the most part restricted to the Synagogal service only, to the retaining of its traditional customs and ritual. Traditional music is retained; likewise the chazzan with the meshorerim in the old primitive style of bass and "singer" or in a modernized form of men and boys in four-part singing, as introduced by Sulzer and practiced in Eastern Europe. The chazzan is still the leader in the service, the central figure of the Synagogue and his chazzanuth; his musical art constitutes the chief purpose and attraction. As a rule, the existence and prosperity of an Orthodox synagogue depends upon the musical ability of the chazzan and upon his vocal artistry.

Frequently there are chazzanim with fine vocal ability and with marvelous chazzanic talent. They were all born and trained in Eastern Europe, in the "schools" of the prominent chazzanim of whom an account is given in Chapter XIV. Thus far no chazzan of note is American born. Moreover, the musically gifted sons of immigrant chazzanim choose to enter a secular musical career.

Several chazzanim gained a reputation of popularity, such as Joseph Rosenblatt (born I880 in Bielozerkov, Southern Russia), Mordecai Hershman (I886 (?) in Volhynia), Zavel Kvartin (born 1874 in a village in the government Cherson), and others. These gained their reputation and popularity not only because of their achievements in the Synagogue, but also because of their vocal performances in the concert house, and notably because of their phonograph records. By the latter means, they have popularized (and at times also vulgarized) the Synagogue song. Their strength lies in their rendition of the Synagogue modes in unrhythmical improvised form, with accompaniment likewise improvised, on piano or string-instrument. With respect to improvisation, these Orthodox chazzanim are in this country the only protagonists of the traditional Jewish-Oriental song. However, none of them 
have thus far created music of any originality. They continue to sing in the style of the Eastern European chazzanuth, and some of them, in order to attract the public, do not hesitate to sing arias of operas and musical selections of dubious sources set to prayers, as was customary among the chazzanim in the seventeenth and eighteenth centuries.

Apart from the groups thus far treated, there was organized about fifty years ago a third group, called "Conservative." Realizing, on the one hand, the impossibility of the retention of the Orthodox form of Judaism, but on the other hand, considering sudden fundamental changes dangerous, this group chose a slow and gradual process of reform. However, no platform nor unity of policy in achieving this aim has been observed. The Conservative congregations differ in their reforms. Some consider the organ, mixed choir, English prayers and sermon, and an abbreviated ritual within the frame of Conservatism; others, however, restrict their reforms to the English sermon and to the abolition of some medieval poems. Indeed, all Conservative congregations have thus far retained Hebrew prayers containing the idea of Resurrection, of the restoration of the Temple with its sacrificial cult in Jerusalem, and of a personal Messiah. Almost all the Conservative congregations insist, likewise, upon covering the head during worship and upon the retention of the chazzan. The music in the Conservative Synagogue is based on Sulzer's principle (Chapter XIII), though some chazzanim still use Eastern European chazzanuth, while others do not hesitate to employ arias and selections from operas as well as items from the Reform-music. No original features were thus far brought forth in the Synagogue music by this group.

Of the few attempts made by musicians belonging to this group we cite: 
Solomon BAUM, Friday evening and Sabbath morning service for cantor and choir with organ accompaniment, in which the Mogen-ovos and Ahavoh-Rabboh modes are employed for choral numbers.

M. HALPERN, Z'miroth Ut'filoth Yisroel, a Synagogal Hymnal for Sabbath and Festivals, The Boston Music Co., I9I 5, consisting of cantor solos and choruses (with exception of Nos. I06, I 10, I 2 I, I 23, I29, I30) without accompaniment. Several items are in the traditional modes and tunes. Many cantor solos have the unrhythmical modal form with embellishments. The material is partly Halpern's own compositions based on traditional modes, partly imitations of and adoptions from prominent Synagogue composers. The term "traditional" he uses so broadly as to cover even tunes which are apparently his own compositions. His collection supplies songs for the services of all Jewish festivals. In the section of hymns and songs the compiler threw together Christian hymns, such as "Oh, Paradise," with Jewish folk-songs, such as Cheder Koton (一Afn Pripitshok).

Louis M. IsaAcs and Mathilde S. Schechter edited a Hebrew Hymnal for School and Home (-Kol Rinnah) London, I9IO, containing 24 numbers arranged for four-part choir, in Hebrew with English translation. The material taken from Sulzer, Naumbourg, Lewandowski, Mombach and Adon Olom of Salomon Rossi (Chapter X), as well as from The Voice of Prayer and Praise (Chapter XIII), is often badly corrupted.

ISRAEL and SAMUEL E. Goldfarb are engaged in compiling songsters for the Hebrew Schools in America. The largest of their compilations is the Jewish Songster (Hamnaggen), Brooklyn, I925. It contains religious and secular songs for Sabbaths, the festivals and for various occasions. The musical material is partly their own, partly adopted from popular folk tunes, or from Jewish composers. The texts are mostly in Hebrew, and some in Yiddish and English. 
COLLECTIONS OF AND LITERATURE OF SYNAGOGUE SONG.

\section{Collections}

The compositions for the Synagogue service of the eighteenth and nineteenth centuries were mostly the creations of individual Jewish musicians, even when the works were constructed out of traditional material. Hence the ambition of the musicians to publish their products or, at least, to write them down! The effort to preserve works of unknown men, or merely traditional tunes, is not early met with. Indeed, we are informed that at the end of the sixteenth century the chazzan Abraham Sagri in Casale Monferrato in Italy prepared a collection of traditional tunes for Bible, prayers, and piyyutim, according to the Ashkenazic ritual for his pupil Jacob Finzi; ${ }^{2}$ but since only one page-that of the Psalm mode-remained of his manuscript, we cannot judge the nature of that collection; we cannot know whether it was of strictly traditional tunes throughout, or whether it was a mixture of his own compositions and reworked tradition (Chapter X). In the manuscripts of Ahron Beer and of the Bass Joseph Goldstein, at the end of the eighteenth century (Chapter XI), there are some traditional tunes which seem to be genuine, that is, without individual modifications. But from among all of his recorded compositions, these numbers are few. The first collection known which can be considered an objective copy of traditional tunes without personal additions is that of the Southern German chazzanuth which S. Naumbourg (Chapter XIII) wrote down according to the singing of L. Sänger ( $178 \mathrm{I}-\mathrm{I} 843$ ), Cantor in Munich, in 1839-40. For 337 
a long time no stress was laid upon the exactness of traditional tunes. It was counted permissible for every singer and chazzan to modify the traditional tunes in innumerable variations according to the taste and voice of each, as we so clearly see in all the published and unpublished works of the eighteenth and nineteenth centuries. While in the beginning, the Reform Movement regarded tradition as a valueless old burden from which it sought to release itself, Moderate Reform, little by little, came to exhibit the same degree of enthusiasm in retaining the old traditional tunes and chants as it had previously shown eagerness to forget them, for it is the nature of men to begin appreciating things after they are removed from them. Already in the first years of the appearance of the Allgemeine Zeitung des Judenthums (published from the year 1837) traditional tunes were occasionally printed. An earnest attempt at collection was made by a magazine called Liturgische Zeitschrift, which was devoted to liturgy and Synagogue song, started by the teacher and cantor Hermann EhrLich in the fifties of the nineteenth century in Berkach, Meiningen, and continued for about four years. In that magazine there was gathered a considerable number of traditional tunes and of their different variations. Prior to that attempt, a collection of Hebrew tunes had been published (London 1815) by $I$. NATHAN I 792-I864, and John BRAHAM, I774-I856, the son of Abraham Singer (Chapter XI), who was the most celebrated tenor in England in his time. The compilers harmonized and arranged the tunes for choir, and provided piano accompaniment. But the tunes, with the exception of those for Chanukah and Pesach, were not traditional at all. They were melodies created or adopted by various chazzanim. Of greater value is a collection of Portuguese tunes published by DE SoLA and Aguilar in London, 1857. These are mostly adopted tunes of Dutch origin from the seventeenth and eighteenth centuries, 
only less than half of them being traceable back to Spain. ${ }^{2}$ Of still greater value than the music of the last-named book is its introduction of which we shall speak later.

In 1868 a collection of Southern German traditional tunes was published by Katz and Talbott. ${ }^{3}$ This volume was really the first of its type, an objective rendition of traditional tunes as they lived in the Synagogue from the Middle Ages on; and it may be considered a trustworthy source-book of the Synagogue song in Southern Germany, even though some numbers invite suspicion as being the compositions of individuals. In I87r, the chazzan Moritz Deutsch published in Breslau his Vorbeterschule, a collection of traditional chants, modes, and solo tunes for the entire cycle of the year, as a guide and reference book for young chazzanim. That collection is based upon the Eastern German tradition, which embraces Moravia, Austria, Bohemia, and Silesia. Deutsch's purpose was to offer a refined form of the traditional tunes of the Synagogue. Hence, he did not care always to give the tradition in its originality where it failed to satisfy modern European taste. As he pointed out in his introduction to the collection, he did not regard the Synagogue song as original. Deutsch's volume does not provide traditional tunes for week-day services.

The greatest and most complete collection is that published in 1877 by ABRAham BAER, chazzan in Gothenburg, Sweden; it is called the Baal Tefillah. Baer utilized not only the abovementioned collections but also the works of Sulzer, Weintraub, Naumbourg, and Lewandowski, as well as the already mentioned collections of De Sola-Aguilar and Katz-Talbott. He, too, sought to prepare a guide for young chazzanim; but he likewise provided the simple reader in small congregations with every possible tune for all those texts of the prayer-book for the entire year, which were customarily sung. It was not his aim to give strictly traditional tunes, but rather to offer a 
great number of variations for every text, be the tunes modern or traditional compositions. $\mathrm{He}$ also gave the EASTERN European (called by him Polish) rite and the German rite, as well as the Old Tradition and the New Style. He selected some Portuguese tunes ${ }^{4}$ and inserted them into his collection. The volume contains about fourteen hundred numbers, and for this quantity alone it is very remarkable. Yet, for historic investigation, Baer's collection is of minor value, because he never indicates what is real tradition and what is innovation. From the practical point of view, his book filled a great need. It became so popular that in the course of twentyfive years it reached its fourth edition.

Under the influence of Baer, many other collections were published which were arranged according to his method. They are either of Southern Germany or Austria or even Eastern Europe. Especially noteworthy is Schir Lisch'laumau by Aron FrIEDMANN, in that it gives the scale of the mode in which the traditional numbers are written. He presents the Lithuanian tradition with German modifications.

Of far more scientific value, however, than the just-mentioned works are two collections which present with certainty their tradition and without individual additions. The one is Zemiroth Yisrael, Chants Hebraiques, Marseilles I 885, J. and $M$. CREMIEU containing the traditional tunes of the entire year of the Southern French Jews, the so-called Minhag Carpentras (Chapters VII, XIII). ${ }^{5}$ These Jews were partly of those descended from the ancient communities in Provence who remained in France after the expulsion of $\mathrm{I} 394$ because they were protected by the Pope in Avignon, and only a few of them were of the offsprings of the refugees from Spain in 1492 and $1496 .^{6}$ They did not mingle with German Jews; they even strongly opposed extending full rights to the German Jews in Paris in I79I-I810.7 Their traditional tunes differ to a great 
extent from those of all other Jewish communities. They contain elements of original Jewish modes intermingled with French chants of the Middle Ages. ${ }^{8}$ Peculiarly enough, these Jews accepted the German Ashkenazic Pessach tune of Addir $H u$ (o.c., p. I97). The collection contains three compositions for four-part choir, three solos, and one piece in three partsall with the accompaniment of organ, harp, and flute. The other collection contains traditional tunes of the Italian Jews or rather of the Italianized Spanish Jews, as explained in the preface by the author, the violinist and composer, FEDERICo Consolo (Chapter XIII), who says that he gathered the tunes in Leghorn, where the Spanish tradition was best retained. $\mathrm{He}$ himself claims to be a descendant of those Spanish refugees, and signs himself "Yehiel Nahmani Sefardi." His collection, called Sefer Shire Yisrael, Libro de Canti D'Israele, printed in Firenze, 189I, gives all traditional tunes as well as the beginnings of chants and modes. Most of them are similar to the Portuguese tunes in Europe and the Sephardic tunes in the Orient, and offer a valid proof of the antiquity of the song of the Spanish Jews who, though scattered over both hemispheres for more than four centuries, yet preserved the traditional tunes as they had them while still living in Spain. In a separate volume, Consolo published traditional tunes arranged either in four parts or in solo, with piano or organ accompaniment.

In the Prayer-book, "Order of Service according to the custom of the Spanish and Portuguese Jews of London," Shaar Hashamayim, edited by M. Gaster, London, I904 (five volumes), the traditional tunes for the entire cycle of the year were added by Jessurum, choir leader at the Portuguese Synagogue in London. With slight variations, several of these are the same tunes as those in the collection of De Sola and Aguilar. But Jessurum rendered a valuable service in giving psalms, 
prayers, and poems in their entirety as rendered responsively in the service by reader, choir, and congregation. Through this presentation, we gain a clear idea of the character of these ancient modes.

Of similar character is the publication of $M . A$. de Villers (published in Paris, I872), Recueil des chants trad. et liturgique composent les offices hebraiques du rite oriental.

Concerning the musical illustrations in the Jewish Encyclopedia, we must say that, despite the blunders and many fallacies, the work must be highly regarded as a laudible first attempt. On the one hand, the editors recognized the existence of and gave due space to traditional song. On the other hand, the author, though handicapped by his lack of information and material, succeeded in many articles in giving some valuable data.

There are the following collections of the Eastern European tradition: Hammithpallel by A. A. Nezwizsh KI, who was cantor in Ruzshani in the government of Grodno. This collection is printed in MS. form by lithography, Wilna, r903. It contains recitatives and traditional modes for the High Holidays, etc.

M. Wodax follows the same method in his collection Ham'natzeach-Schule des isr. Cantors, praktische und bewährte Methode zur gründlichen Erlernung aller Singund Vortragsweisen der gesammten Synagogen-liturgie mit besonderer Berücksichtung des Recitativ . . etc. et., Vienna, I90r. He presents the Eastern European, especially, the Hungarian tradition.

An ambitious attempt to offer something "scientific" was that of ABRAhAm EisenstadT, week-day cantor in Berlin, who published a collection called Alt-israelitische Gesänge $I$ and II in Berlin, 1897. In his preface he claims that this material was traditional in his family for many generations, and that many 
members of his family functioned as chazzanim in different cities in Poland. He further claims that his ancestors, coming from Jerusalem, settled in Worms before the destruction of the Second Temple. He makes the statement that the Jews settled on the banks of the Volga in the eighth century; and, establishing there a Jewish empire called Chazzarian Kingdom, they maintained in it their traditional song which subsequently spread throughout Eastern Europe. From this direct line his progenitors received the tradition. Eisenstadt succeeded in convincing of his contention a scholar like Oskar Fleischer and a musician like Joseph Joachim, both of whom recommended his collection. In spite of these important patrons, his material is nothing but a compilation of low-class chazzanic improvisation of the type current among the chazzanim in the small Lithuanian villages. The book is important only as a colossal monument to ignorance.

The writer of the present book published, in Leipzig in I914, the first volume of his Thesaurus of Hebrew-Oriental Melodies (German edition: Hebraisch-Orientalischer Melodienschatz; Hebrew edition: Otzar Neginoth Yisrael) entitled Songs of the Yemenite Jews (Gesänge der jemenischen Juden). It contains a collection of the traditional songs of the Yemenite Jews, with an introduction explaining the characteristics of the music; and it presents comparisons with the traditional song of other Jewish communities of the Diaspora. With several additions, the same volume was published in Berlin in 1923 in Hebrew, and it was translated into English in I925 (Benjamin Harz Verlag, Berlin). Volume two, Songs of the Babylonian Jews (Gesänge der babylonischen Juden), was published in Hebrew, German, and English in I922-1923. Volume three, Songs of the Persian, Bokharian, and Daghestan Jews (Gesänge der persischen, bucharischen, und daghestanischen Juden), was published in 1922 in Hebrew and German. Vol- 
ume four, Songs of the Oriental Sephardim (Gesänge orientalischen Sefardim), was published in Hebrew and German in 1923. The Hebrew edition has more folkloristic material, while the volumes in German and English present more musical research studies. Volume five, Songs of the Moroccan Jews (Hebrew edition), was published in 1928, and volume six, Songs of the Ashkenazim (German edition), is still in press. The entire collection is compiled by the method of recording traditional tunes phonographically, transcribing the music from the plates, comparing the phonographical records with the performance by various people of one and the same tune, in order to ascertain those characteristics of each tune common to all traditions. A synopsis of this work was published by the Vienna Academy of Sciences in 1917 in its proceedings, volume $17 \mathrm{I}$ : Phonographierte Gesänge und Aussprachsproben des Hebraischen der jemenitischen, persischen und syrischen Juden.

From the Christian side, attempts were made to collect and transcribe Synagogal songs: e.g., VIlloteau in Dissertation sur la musique des ancien Egyptians, in Description del "Egypt," Vol. I, p. 337 ff.; Dom J. PARIsot in Rapport sur une Mission scientifique en Turquie D'Asie, Paris, I899, p. 245, who collected in Jerusalem three Ashkenazic tunes: one for Kaddish for Musaph on the High Holidays, one for Hammelech, and a third for a Kinoh (Lamentation), the last named being a composition of Sender, cantor in Minsk (Chapter XIV). A fourth tune is for the hymn Bar Yochay which is used as a dancing song at the celebration for "Simeon the Righteous" on the thirty-third day of the Omer, and this tune is of Turkish origin. It is quite evident that these four tunes do not represent Jewish traditional song; and it may be readily understood why Dom Parisot himself did not consider them representative. His ignorance of Jewish ritual and tradition deprived him of the means of selecting and collecting the genuine material. 
Aside from the published works thus far named, several collections remained in manuscript form, such as the above-mentioned Naumbourg-Sänger volume, and that work of Maier Kohn which, although announced in his publication of 1839 , was really finished thirty years later (1870). The latter contains Southern German chazzanuth with several insertions of modern tunes (Chapter XIII). A collection which follows Baer's Baal Tefillah in giving German and Polish traditions is that of IsAAK LACHMANN, Avodath Yisrael, a small part (weekdays' service) of which was published in 1899. Lachmann tries to give tradition as truly as possible, according to his knowledge of it. Although a man of information, he blindly regarded the Eastern European tradition of the environs of Dubno, where he was born, and the Southern German tradition of the neighborhood of Hürben-Bavaria, where he spent half of his life, as the only standards.

We see that a number of the collections mentioned above cannot, from the scientific point of view, be considered authentic sources for the traditional song. It was this fact that induced EduARD Birnbaum to start collecting material free of all emendations and personal modifications. And, indeed, he succeeded in amassing a remarkable quantity, especially of German and Eastern European traditional songs. He was the first among the workers in the field of Synagogue song who perceived the necessity of possessing all sources, if the research was to be scientific. ${ }^{10}$

We should expect records of traditions of cantillation, because of the special stress always laid upon the chanting of the Pentateuch and the other books of the Bible. Already the punctuator and vocalizer, Ben Asher in Tiberias, of the ninth century tried to explain the tunes of the Bible in words (Chapter III). Since then many grammarians, such as Jehudah Hayyuj, Kalonymos (in Abraham de Balmes' Grammar, Mikne 
Abram, printed in Venice in I 523), Simon Duran (in his Magen Avoth, Livorno, I780, F. 55), and especially the physician Abraham ben David Portoleone in Italy (in his work Shilte Haggiborim, printed in I6I2, see Chapter X) followed along the same path of explaining in words the tonality of the Biblical modes. In this, of course, they did not succeed. The first who tried to set the Pentateuch tune, at least according to the tradition of the Ashkenazim, in music notes was the priest Johann Böschenstein, ${ }^{11}$ who prepared the writing for the Hebrew Grammar of Johannes Reuchlin which was printed in Hagenau in 1518 . Böschenstein, a Catholic priest and scholar, was very much attached to Jews, and he mingled with them. Since his time, different attempts have been made, mostly by gentiles, to consign to score from the Jewish Biblical modes. Such a publication was that of Athanasius KIRChER entitled Musurgia Universalis (Paris, c. I660), which gives the Sephardic tradition of the Pentateuch chant. There was also Julius Bartolocci's Bibliotica Rabbinica (Kiriath Sefer) (Rome c. I675-93), Vol. IV, pp. 429-40, Neginoth Ashken. for Pent. and Sephard. and Ital. for Pent. and Haftara in music notes. Of special interest, however, because the writer of the music was a Portuguese Jew, the physician David Pinna of Amsterdam, is his transcription of the Pentateuch and Prophet modes according to the tradition of the Amsterdam Portuguese Jews, printed in the preface to the Bible edited by JABLONSKI, Berlin, I699. The most complete presentations of the modes of the Bible according to the Ashkenazic tradition are given in the Baal Tefillah of Baer and in the Jewish Encyclopedia, sub-verbum "Cantillation," in both of which the examples of Portuguese and Moroccan traditions are copied from Naumbourg's Agudath Schirim (Paris, I874). The readings for Bagdad, the Orient, and Egypt in the Jewish Encyclopedia, s.v. "Cantillation," are all incorrect. 


\section{Literature}

The Jewish sages did not write theories of music like those of the Greek philosophers; they did not leave us descriptions of the nature and characteristics of ancient Jewish song. This statement does not mean to ignore the occasional comment on music, or the detailed descriptions of the song and musical instruments of the Temple in Jerusalem, or the many traditions of the manner of performance of the songs which have been preserved among the sayings of the sages in the Mishnaic, Midrashic, and Talmudic literature, as well as in the works of Josephus. Although in most cases exaggerations, these statements are, nevertheless, based upon some historical facts. They are scattered through all ancient Jewish literature, not only in the just-mentioned post-Biblical works but also in the Bible itself. Through an exhaustive search for and careful compilation of these references, we can accumulate material sufficient to reconstruct the musical conditions of the time of the Second Temple ${ }^{12}$ (Chapter XV).

Of a different type, however, is the description and interpretation of Israel's ancient music in the Medieval literatures, both in Hebrew and in the Vernaculars, for-under influence of mysticism-music, like other subjects, was removed from the sphere of reality into the realm of fantasy. Further damage was caused by astrology, for it attributed musical inspiration to the movements of the stars and planets. Material of great value for the history of Synagogue song and singers of the Middle Ages is to be found in the Responsa of the Gaonim and Rabbis in which records of actual problems in the form of decisions concerning definite issues give us a key to the understanding of conditions of the music of the Synagogue from the eighth to the nineteenth centuries. ${ }^{13}$ On the other hand, all the references to music in medieval philosophic 
literature are without any historical significance, because they are nothing more than a mere continuation of the philosophized interpretation of music of the Greek philosophers, exaggerated by the Sophistic and Scholastic fantasy of the medieval dreamers. ${ }^{14}$

Similarly valueless is the Christian literature on Jewish music and musical instruments. At the beginning of the nineteenth century, some Christian theologians still tried to ascribe musical value to the Hebrew vowels, and thus reconstruct an ancient Hebrew scale. ${ }^{15}$ Forkel in his history of music (I788-I80I) was the first to try to describe in a somewhat natural way the ancient Hebrew music, but his treatment is a construction in accord with his logic, rather than a reconstruction from authentic sources.

The first attempt to explain the musical instruments of the Bible in a manner approximating fact was made by Moses Mendelssohn and his collaborators in translating the Bible, at the end of the eighteenth century. ${ }^{16}$

The literature worthy of consideration started around the middle of the nineteenth century. In the above-mentioned magazine Liturgische Zeitung there was published some good material, such as contributions bearing upon the history of the chazzan, by Hecht. Furthermore, there are Weintraub's introduction to his work Schire Beth Adonai (Chapter XIII); Deutsch's introduction to his Vorbeterschule (1871); De Sola and Aguilar's introduction to the Portuguese songs (London, I857); Naumbourg's introduction to his Agudath Schirim (1874); and Baer's introduction to his Baal Tefillah (1877). In 1879 , there was organized a cantor association of Central Europe which started the publication of a weekly under the name of Der Jüdische Cantor, printed in Bromberg. This continued for twenty years. Soon after its beginning, another organ, Die Oestereichische-Ungarische Cantoren-Zeitung, was 
founded (I88I) which, likewise, continued till about I898, and which was later incorporated into the weekly Die Wahrheit, in Vienna. In those two organs there was accumulated rich material: research work, historical data, biographies, liturgies, music, general facts, and so on. For a long time both organs carried musical supplements. Both discussed many questions concerning Jewish music in general and chazzanuth in particular. Both included contributions from all the prominent chazzanim and investigators of that time. They reflect the life of the Synagogue of the last quarter of the nineteenth century. Another Jewish weekly, Das Hamburger Familienblatt, likewise offered a special supplement devoted to the interests of the chazzan from the beginning of the twentieth century. Likewise, Der Lehrer und Cantor, a monthly supplement to the Juedische Presse, Berlin; Ost und West, an illustrated monthly, Berlin, I90I-1922; Ungarische isr. KultusBeamtenzeitung, Budapest, I883-I892; Isr. Wochenschrift und freie Lehrer und Cantorzeitung, Berlin, contain valuable material. In I886, Josef Singer (Illinik, I84I-Vienna, I9II), the chazzan of Vienna, published a pamphlet on the scales of the traditional tunes of the Synagogue, which was a first attempt to force a path into the labyrinth of Synagogue song. His pamphlet aroused vigorous discussion in the press. In his book Cenni Sull'origine e Sul Progresso della Musica Liturgica con appendice Intorno, all'origine dell'organo (Firenze, 1897), Federico Consolo tries to give some historical and scientific surveys.

Ernest David (Nancy, I824-Paris, I 886), noted composer and author, wrote La Musique chez les Juifs, essai de critique et d'histoire, Paris, 1873. The first part of this book is devoted to an explanation of the Biblical instruments, the author merely repeating the hypotheses of others. The last part of his essay he devotes to the post-Biblical tunes of the 
Synagogue. He admits his inability to approach this problem properly, due to the lack of an authentic collection of traditional material.

In 1877, S. Naumbourg edited the Synagogue compositions of SALOMon Rossi, including the Hebrew and Italian letters of Rossi and Leon of Modena, as well as an introduction in French (Chapters X, XIII).

G. S. ENSEL, minister of Congregation Yeshurun in Paducah, Kentucky, made an attempt to explain the Ancient Liturgical Music in a "comparative and historical essay on the origin and development of sacred music of the Synagogue, Church, and Mosque," Paducah, I88 I, lithographed.

Emil Breslaur (Kotbus, I 836-Berlin, I899), musical director of the Reform Temple of Berlin, and noted musician, published an essay Sind originale Synagogen-und Volksmelodien bei den Juden geschichtlich nachweisbar? Leipzig, 1898, wherein he declares that music is only that which is rhythmical, and that the unrhythmical chant, therefore, does not belong to music. He further tries to deny to the Synagogue Song any originality.

EDUARD Birnbaum wrote many essays and articles in the above-mentioned papers, some of which are reprinted, e.g., Juedische Musiker am Hofe von Mantua von ${ }_{1542}$ bis 1628 , Vienna, I893 (Chapter X).

In the Souvenir Volume, a collection of traditional tunes with accompaniments, published by the National Council of Jewish Women, Chicago, r893, the editors, Alors KaISER (I840-1908) and William SPARger, cantor at Temple Emanuel, New York, provided an introduction comprising a compilation of statements previously made by others (Chapter XV).

Aron Friedman published a collection of biographies of prominent cantors Lebensbilder berïhmter Cantoren, Vols. IIII, Berlin, I9I8-I927, and a collection of essays on Jewish 
music in memoriam of Eduard Birnbaum, Berlin, 1922, which works contain valuable data and studies.

The number of pamphlets, lectures, and essays on the subject of Jewish music increased toward the beginning of the twentieth century. In English, Francis L. Cohen published a pamphlet on The Rise and Development of Jewish Music (printed in London, r888). He also wrote many articles on this subject in the Jewish Encyclopedia. More complete is the book by Aron Friedman (Berlin, 1904) Der Synagogale Gesang -Eine Studie. A. Ackermann, Rabbi in Brandenburg, likewise published a survey of Jewish music in WINTER UND Wünsche's Historic Anthology: Hebrew Literature, Vol. III, I 896. Aмвros, in his History of Music, Vol. I, third edition, 1887, p. 404 , gives a survey of ancient Hebrew music, without adding much to the before-mentioned chapter in Forkel's history. The general and the Biblical encyclopedias deal with ancient Hebrew music in the Temple, but they entirely ignore the post-Biblical times. Some brief surveys are to be found in the Judeo-Russian and the Hebrew encyclopedias, the author of the articles in both being Pinchos Minkowsky, late chazzan in Odessa, who unfortunately wrote from an exceedingly subjective point of view, without considering the researches of others. Popular and in journalistic style are the writings of Minkowsky in Hebrew, German and Yiddish in various magazines and pamphlets. An attempt was made in Russia by ABraham B. Birnbaum, chazzan in Chenztochow, to publish a magazine on Jewish music in Hebrew under the name Yarchon Lechazzanim, of which only four numbers appeared. The articles of A. B. Birnbaum in the Hebrew weekly Haolam ${ }^{17}$ and in some other Hebrew magazines provided much information, especially in regard to the characteristics and conditions of chassidic song. Aside from these, there are innumerable articles scattered in the Jewish and general press, the detailed men- 
tion of which is impossible. And finally there is the popular presentation of Jewish music, in the form of illustrated lectures, written in English by A. IRMA СоноN, and published by the National Council of Jewish Women, r923. The two-fold significance of this publication lies first of all in its attractive style-its writing breathing a love for the subject and inspiring the larger public; and secondly in the fact that it is the first attempt to cast the material into a popular form.

The "Jewish Ministers Cantors Association of America" (New York) published in 1924 the history of chazzanuth in Yiddish, Die Geschichte von Chazzanuth, issued on the thirtieth anniversary of the Association. It contains popular and folkloristic material, also biographical notes on contemporary cantors as well as on some East-European chazzanim of the last generation. The publication is bountifully provided with photographic illustrations.

Much information on the life of the chazzan and of the conditions of Synagogue song in the seventeenth and eighteenth centuries is to be found in the booklet Teudath Shlomo, Offenbach, I7.18, by Sнцомо Lifschüтz, chazzan in Prague and Metz (I675-I758) (Chapter XI). We note also the apologetic booklet Reach Nechoach, published in Fürth, I724, by JoEL, chazzan in Leipa. It is written in rhymes in Hebrew and Yiddish.

Jehuda Leb, chazzan of Zellichov, Poland, published a booklet Shire Yehuda, Amsterdam, 1697, in which very interesting details are given (Chapter XI).

In the book Noheg Katzon Yosef by Joseph HaHN NordIINGEN, published in Hanau, I7 I8, there appear several valuable notes on the Synagogue song of Southern Germany and on those in Frankfort in particular. Later, a complete description of the Synagogue Song in Frankfort was given by SALOMON 
Geiger, brother of the famous Rabbi Abraham Geiger, in his Hebrew work Divre Kehilloth, Frankfort, I862.

There are also books by non-Jews containing either descriptions of or research into Synagogue Song:

Franz Liszt: Die Zigeuner und ihre Musik in Ungarn, Leipzig, I883, pp. 20-68.

Franz Leitner: Der Gottesdienstliche Volksgesang im Jïd. und Christl. Alterum, Freiburg i/B, 1906.

Oskar Fleischer: Neumenstudien, II, Berlin, I 897, Chapters I-II.

Peter WAgner: Einführung in die gregorianische Melodien, I, Leipzig, I910, Chapter I, Vol. III, Leipzig, I92 I, pp. 240, 367 .

ROBERT LACH: Studien zur Entwicklungsgeschichte der Ornamentalen Melopoie, Leipzig, I913, pp. I6ff., I33-138, I 45, I 50, 197 .

Heinrich Berl: Das Judentum in der Musik, Berlin und Leipzig, 1926.

Besides the above-mentioned works, the writer of this book published a history of Jewish music in Hebrew: Vol. I, Dvir, Berlin-Tel Aviv, I924; Vols. II and III in press. He likewise published Parallelen Zwischen dem Synagogengesang und den gregorianischen Melodien in Die Zeitschrift der deutschen Musikgeselschaft, 1922; Der Missinaj Gesang der deutschen Synagoge, ibid., I926; also several essays in Hebrew, in the periodicals Hashiloah, Haolam, Jerushalaim, Reshumoth, Hatoren, etc.; in German, in the Monatschrift für die Wissenschaft des Judentums, Archiv für Musikwissenschaft, Ost und West, etc.; in English, in the Journal of the Palestine Oriental Society, Proceedings of the Music Teachers National Association, Hebrew Union College Jubilee Volume, etc. 

PART II FOLK-SONG 



\section{CHAPTER XVII}

THE FOLK-SONG OF THE ORIENTAL JEWS.

Every nation that possesses its own soil, that has made a history for itself and that has created an individual atmosphere must, according to the established premises in musical science, have its own folk-song. Inversely, a folk-song must spring from a nation. But are the Jewish people a nation? For two thousand years, they have been rent from the physical homeland that cradled their youth; they have been scattered over the entire earth; they have been influenced by almost every climate, culture, and nation, constituting a small minority in each country. On the basis of these determining factors, the Jews may hardly, in the commonly accepted sense, be adjudged a nation. And yet through circumstances peculiar to themcircumstances that know no parallel in history-the Jews have never been divorced from the land where they developed from nomadic tribes into a nation. The topography, the atmosphere, the very soil of Palestine, was molded into their faith, their thought, their spiritual culture, and folklore. Through these intangible, yet very real, roots, they never ceased to draw nourishment from the vale of Sharon, and to drink inspiration from the dews of Hermon. Of vastly deeper significance, however, is that power by which a nation survives: the power of the spiritual ideal incorporated, in the case of the Jew, into his spiritual culture-into Judaism. Wherever a Jew settled, whether in the North or in the South, in the desert of Arabia or in the plains of Siberia, in North America or in North Africa, he carried his spiritual home in his heart-the home of the Kingdom of God, of the optimistic belief in the final victory 
of righteousness and purity, of the staunch faith in the good and the true, and of the firm conviction that his ideal will become the ideal of mankind. Indeed, such a spiritual nationalityunique as it is among the races of man-has proved itself potent in the case of the Jew. Its power springs from a religion which means the sanctification of life, and in the light of which life means religion. Thus, life as the Jew visualized it, has no room for what is commonly denominated "secular."

This spiritual nationality brought forth a folk-song as distinctive as the people itself. Just as to the Jew religion meant life and life religion, so to him sacred song has been folksong, and folk-song, sacred song. In the folk-songs current among the Jewish people there are included tunes for Bible texts or tunes based upon Biblical themes, for prayers, for religious poetry, melodies for meditation, for the elevation of the soul to its Creator, for rousing the spirit to ecstasy, for joy in the moment in which the spirit becomes aware of the majesty and love of God, and, finally, melodies which express the innumerable struggles and pains the Jew has suffered. There are songs for the family-table on Sabbaths and holidays -songs which give those various holy days tonal expression and which aim to spiritualize the meals. Even those types of songs common to all peoples, which are designated as "secular," such as cradle and love songs, humorous songs and ballads, received in Jewish folk-song a different complexion; they received an impress of the religious life-concept that flowed in the blood of the Jew. And because of this conception, vulgar songs that sought to insinuate themselves never did become rooted in Jewish folk-song. If by folk-song we understand words and tunes of war and drink, of carnality and frivolity, then the Jews have no folk-songs. Jewish folk-song, like Jewish life in the last two thousand years, nestles in the shadow of religion and ethics. 
Indeed, in ancient Israel a "secular" folk-song flourished-a folk-song of war and carnality and lust inspired by wine and women-a folk-song against which the prophets and the sages carried on a battle for centuries. Still in his day BEN SIRACH, in Chapters XXX and XLIX, praises song at a wine-banquet and compares it with a diamond in a gold setting, or he likens it to a honey-cake. He warns the people, however, against associating with female singers (ibid., Chapter IX). Occasionally we hear echoes of the fight against secular song in the beginning of the Common Era through comments such as that of Elisha ben Abuya (see Chapters I, V), who relates that at a celebration the sages sang religious hymns, while the other guests intoned secular songs. We have already seen that this fight continued for a long period thereafter, as several references in Midrash and Talmud testify; and only through gradual religio-ethical education did the spiritual leaders check the secular folk-song and substitute songs with religious content. On the other hand, the "Destruction" and the "Exile" and the social and political misery in which the Jew lived for so many centuries tended to tear him away from the secular joy of life. "Rejoice not, O Israel, unto exultation, like the peoples" (Hosea 9: I) became the motto of the spiritual leaders after the Destruction; and they were on their guard to prevent the people from singing secular songs at joyous occasions (Chapter V). All folk-songs of a secular nature were suppressed. The Biblical Song of Songs, the secularity of which is so apparent, and which, inasmuch as it is a part of the Bible, could not be suppressed, ${ }^{1}$ was classified as "sacred" by ascribing to it an allegorical interpretation: the love between God and Israel. ${ }^{2}$ The sages tried to suppress the opinion that the Song of Songs was secular, and sought to prevent its use as a mere love-poem. ${ }^{3}$ The authorship of the Song of Songs was accred- 
ited to King Solomon, who was supposed to have written by holy inspiration. ${ }^{4}$

Thus, Jewish folk-song received more and more a religioethical character, interwoven with motives expressing national trouble and hopes, until it became a mirror of the spirit dominating Diaspora-Judaism. Abraham Ibn Ezra, the distinguished poet and scholar, writing eight hundred years ago, recognized the ethnological truth that every people fashions its song to suit its spirit, and reflects in its chant its inner mood and characteristics. Thus, he says in one of his Hebrew epigrams:

The Arabs sing of love and lust,

The Christians of war and revenge,

The Greeks of wisdom and cunning,

The Hindus of proverbs and riddles,

But Israel's song is to the Lord of Hosts.

Indeed, the efforts of the spiritual leaders were not always and in all countries successful in preventing the people from singing secular songs, as we shall see later on.

No post-Biblical texts of folk-songs were retained from before the paytanic period. From that time on, some songs created in Babylonia and Palestine as early as the tenth century spread throughout the Diaspora and became the standard songs of the Jewish home. They are all in Hebrew; most of them are in the form of alphabetic acrostics, and some are built in stanzas with a recurring refrain. Their contents is religionationalistic. The same ideas and hopes found expression in many songs. Thus, there are Elijah-songs, dealing with that prophet who became the legendary guard of Israel and who was expected to be the messenger of the Messianic era (Mal. $3: 23-24)$. Already in the eleventh century there were songs of Elijah sung by all Jewish communities on the outgoing of Sabbath. ${ }^{5}$ The oldest part of this group is the refrain "Elijah, the 
prophet, Elijah, the Tishbite, Elijah, the Gileadite, may he speedily come to us with the Messiah, the son of David." Another group has as its subject matter, "Sabbath, the bride, the queen." In the third century it was customary to receive the Sabbath with the refrain: "Come, let us go forth to receive the Sabbath the queen" and "Come, O bride!" * Beginning with Dunash ben Labrat (tenth century), many poets wrote poems glorifying the Sabbath which became popular as home-songs, called Zemiroth, which were sung at the meals on Friday evening, Sabbath noon, Sabbath afternoon, and on the night of that holy day. Both groups were later inserted into the Siddur, the prayer-book. This became not only a book for the Synagogue but also the Songster of the Jewish people for its daily life. A third group of popular songs is for the celebration of the Seder on the first two nights of the Passover Festival. Its oldest part, the Hallel (Ps. Ir 3-8), used to be sung in Jerusalem in every home before the Destruction. From the tenth century on, there were composed several songs in folk-character, such as Ki lo noé, Addir hu, Echod mi yodea, the latest (from the fifteenth century) being Chad gadyoh.

Apart from these groups, there were likewise composed songs for the Three Festivals, for Chanukah and Purim, for Circumcision and wedding ceremonies. All these popular folk-songs sprang forth in the East, in Palestine and Babylonia, and were carried over to the European and North African communities, where they were imitated in style and form, while they also served as a stimulus for further original creations. Only in rare cases were the tables turned-that is, European creations being adopted by the Oriental Jew. Oriental Jewry continued to influence Occidental Jewry in folk-song up to the seventeenth century. The last folk-singers, whose products were accepted throughout the Diaspora, were Solomon Alkabetz (c. I 505, Salonica-I580, Safed), the author of the famous Sabbath 
hymn Lechoh dodi, IsaAc Luria (I 544, Jerusalem-r 572, Safed), who wrote the famous cabbalistic songs in Aramaic: Azammer Bishvachin, Athkinu Seudathah, Benei Hechalah, which became popular among the chassidim (Chapter XIX), and IsRael NaJARA (Safed, I 550-Gaza, I620), the author of the popular Sabbath song Yah Ribbon alam. ${ }^{7}$ The Oriental poems remained the standard songs of all Jewish communities, and they are retained to the present day, although in the course of time local poets arose in various countries: Northern Africa, Italy, Spain, France, Germany, and Yemen-whose poetical productions overshadowed the Babylonian-Palestinian creations.

The interest in folk-song of the religio-national character increased in the Oriental communities, stimulated partly by inner religiosity, partly by the Arabic enthusiasm for popular song. The love for song called forth many folk poets in almost every community. Not only rabbis, but also laymen, well versed in Hebrew lore, composed songs and hymns in the adopted style for the above-mentioned ideas and occasions. Most of these poems did not spread beyond the immediate community; others gained more popularity and were adopted by other communities of the same country, at times even crossing the boundary of the country and becoming the favorite songs of Jewish settlements in foreign lands. Congregations used to collect, in Arabic manner, songs which had gained popularity among their members, and published these in Drwans which at times would be favored also by other congregations. But also individuals, popular poets, or singers would publish diwans of their own compositions, and some of these gained wide popularity. This diwan production-thus compiling communitysongsters or songsters of individuals-continued in the Orient till lately, and became an industry, especially since the establishment of printing-houses in various cities in Asia and Africa. In 1587 , Israel Najara published the first edition of his diwan 
Zemiroth Israel in the newly founded Hebrew press in Safed. This was the first songster published in the Orient. In 1599I600, he published in Venice a second and enlarged edition of the same diwan, which soon became the most popular song-book among all the communities in the Orient. A great number of the three hundred forty-six poems which the collection contains was adopted into other diwans and reprinted innumerable times. The success of Najara's songs lies, first of all, in their contents. Najara struck the Oriental-Jewish romantic note in a fascinating folk-manner, such as had not been done since Jehuda Halevi. The success is due, secondly, to the popular ingratiating style, which at times has a strong Oriental sensuous strain. This latter feature aroused the dismay of some rabbis. ${ }^{8}$ Thirdly, Najara's success should be ascribed to the music, for Najara had likewise musical ability and a sweet voice and was well versed in the popular songs of his day. He knew a great number of Arabic, Greek, Turkish, and Spanish songs, to the tunes and according to the rhythm of which he wrote his Hebrew lyrics, imitating even the sounds of the syllables of foreign texts. As he explained in the preface to his diwan, his imitation was consciously executed, with the intention of preventing the mob from singing profane and vulgar folk-songs in the above-named languages, and with the aim of winning over the people through the deceit of giving them their favorite tunes and even the sounds of the words they liked. ${ }^{9}$ For the same reason, Najara arranged his diwan according to the plan customary in the Arabic diwans, that is, the grouping of the songs according to the musical Makams (Chapters II, VII). This manner which Najara introduced into the Hebrew songsters was imitated by subsequent poets and editors of diwans in the Near East and in the Balkans. Najara's tunes, except for six for which he claims authorship, were all adopted. But long before him, non-Jewish melodies of the neighboring peo- 
ples had been borrowed either by the poets themselves or by the performers, as we have seen in Chapter VII. Hence, no claim to originality can be made in the case of the music of the Jewish Oriental folk-song. The tunes, being of Oriental origin, satisfied the musical taste of the Oriental Jew; and only in the SELECTION of the musical material was Jewish taste manifested. As we glance over the vast number of tunes adopted for the Jewish-Oriental folk-song, we notice a preference for melodies based upon the Makams that were related to the modes of the Synagogue, such as Bayati and Nawa, corresponding to the Prophetic, Mogen-Ovos, and Lamentations modes; for Siga and Irak, which correspond to the Pentateuch, Ruth, and Tefilla modes; for Hedjaz, which corresponds to the Ahavoh-Rabboh mode; and for Rehaw, which resembles the Job mode.

Of all the Jewish communities in the Orient, that of Yemen accomplished most in the creation of folk-poetry, some of the compositions reaching the rank of art. In the sixteenth century the poetic pulse of this severed member of the shattered body of Israel was quickened. A number of highly gifted and talented poets arose who enriched Jewish poetry with new artistic forms. This period reached its zenith in the ingenious poet Sholem Shabzi of the seventeenth century, who composed several hundred poems in various forms and of diversified contents.

What was it that moved the Jews of Yemen at that time to new life and increased activity, after they had been exposed to inhuman persecutions and oppressions for almost a thousand years following their complete subjection by Mohammed? Of a certainty it was not redemption from their social misery, for at that time the hatred of their Arabian oppressors vented itself in as bestial a manner as ever before. It seems that the spiritual fermentation of the cabbalists, who in the sixteenth 
century established a center in Northern Palestine (Safed) and aroused the dormant susceptibilities of the Orient, penetrated also into Yemen and had the effect of a messianic message to the languishing souls longing for redemption.

This cabbalistic-mystic movement called to new life by Isaac Luria, finding enthusiastic adherents in the Spanish refugees in the Orient, reaching its highest development in the pseudomessiah Shabbatai Zevi and through him finally carried to the grave-this fantastic movement gripped all Jewry in the Orient, as well as in the Occident. It called forth many dreamers and visionaries, each one of whom attempted to reproduce his feelings and illusions in verse and rhyme, probably after the manner of the saintly Isaac Luria, who himself, as mentioned above, had composed numerous poems.

Thus, at that time a new era dawned for Jewish poetry in the Orient. Indeed, after a close examination of the contents of Yemenite poetry, it becomes evident that it is saturated with the mystic spirit of that cabbalistic school.

The overwhelming majority of these poems consists of wedding-songs, intended for the various ceremonies of the wedding and the daily festivities of the first week after the wedding. But these are not wedding-songs in the ordinary sense. In them, the wedding is SYMBoLIzED. The poet speaks, indeed, of bride and bridegroom. But thereby he in no sense signifies the young human pair, but rather, true to cabbalistic implication, he intends the bridegroom to be God while the bride is the personified people Israel, an allegorical interpretation of old which was applied already to the Song of Songs, as pointed out at the beginning of this chapter. Almost all wedding songs deal with the same subject: on the one hand, with the tribulations and lamentations of the bride, Israel, and on the other, with the promises, the forgiveness, and yearning of the bridegroom, God. 
In addition, a third figure plays an important part in these songs, namely, Palestine or rather Jerusalem concentrated in the Temple. The train of thoughts is as follows: The pair, designated now as engaged and now as married, quarrels and separates. It goes without saying that in this conflict the bride, i.e., wife, is the guilty party. The result is that the bridegroom, i.e., husband, banishes his beloved from his housePalestine, especially the Temple. But now he feels unhappy to be alone in the house, and he, too, abandons his home, which thereupon remains desolate. However, as soon as the reconciliation between the angered husband and his beloved will take place, the pair will return to its old home. For the poetical expression of these fancies several forms were employed. Thus songs in which the longing and complaints of the bride are pictured, received the form Neshid; the love songs of the bridegroom were couched in the form Shira; the march toward reconciliation was treated in the form $Z a f a t$; and the joyful effusion after the reconciliation in the form Chidduyoth, while the Haleloth served as an interlude, overture, or postlude.

I. Haleloth. These songs have folk-character. Some of them are compilations of Psalm-verses; some have rhyme but no meter. They always begin with the word Wehaleluyoh"praise the Lord"; and they are rendered in unison in the Psalm-mode.

2. Zafát. This Arabic word signifies "wedding." The songs of this class are sung as the bridegroom goes in procession to the house of the bride. They commence either with "Come, O bridegroom, in peace," or "Be blessed at thy going out." All of them express the hope that through the reconciliation of the beloved, the Messiah will come to Zion.

3. Chidduyoth. The Yemenites explain this name to be derived from the Hebrew stem chada-songs of joy. These songs are sung immediately after the nuptial ceremony. They 
usually start with "I shall sing to the beloved one" or with "The beloved coming from the myrrh-hill"-meaning God descending on Mount Sinai.

The three classes of this poetry thus far explained are really nothing more than a preparation for the wedding celebration, an introduction to the festal song. Hence, the poems are few in number, for no great importance was attached to these songs which used to be sung on no other occasion than at the dressing of the bridegroom or during his passage (procession) from his home to the neighboring house of the bride. Poor in quality as are these classes, just so rich in the number of songs and melodies are the other groups which constitute the weddingsongs proper.

4. Neshid. The wedding dinner is ushered in through the singing of Neshid-songs. This class of songs has almost invariably the form of the Kasida, i.e., two-lined strophes. The number of the Neshid-songs may be estimated to be two hundred, and of these only a few consist of four- or five-line stanzas.

Neshid, plural Nashwad, signifies in Arabic "folk-song"; Anshada is the term for measured song, in contrast to Tartil, which stands for recitative. ${ }^{10}$ In the Yemenite interpretation, Neshid signifies "song of request." Hence, the bride chooses this type of song in which to address to her bridegroom her plea for his grace and love.

5. Shiroth. This class of poetry is the greatest achievement of the Yemenite muse. It is distinguished from the other poetical types, first, by its content. In it, with exultation and emotion, the bridegroom sings to the bride his extravagant praise and fiery love. But the Shirah is especially distinguished by its form. The greatest number of these songs is composed in the so-called girdle form, in Arabic taushich. With the Yemenites, Shirah poetry is identical with artistic 
poetry. The girdle-form is considered by Arabic singers as the acme of poetical achievement, wherefore it is styled MAsCULINE, inasmuch as the girdle serves as a symbol of masculine bravery.

The girdle-form takes its name from a variant meter introduced in the middle of the stanza. The Shirah stanza consists of three parts: (a) the chief part, which is usually a quatrain; (b) the GIRDLE consisting of three lines, all shorter than those of the presiding selection; and (c) the conclusion composed of two lines of the same meter and number of feet as part (a). The shortened lines give the reader the impression that part (b) girdles the body of the stanza. There are girdles of four or five lines, and sometimes two or three girdles in one stanza.

Apart from the wedding-songs, which, as stated above, constitute the greatest part of the Yemenite folk-songs, there are songs for Sabbath, likewise called Shiroth. While the festivals, too, are provided with songs, the Sabbath, having acquired a special sanctity, is far more richly adorned. The cabbalistic school gave the Sabbath a mystic interpretation. But to every Jew, oppressed as he was, tortured physically and morally, the Queen Sabbath became the divine dispenser of rest, bringing peace and bliss to his soul. On at least one day of the week the Jew could conjure up a Messianic era where he breathed freely and happily. This romanticism is voiced in the Sabbathsongs of the Jews throughout the Diaspora, and so also in those of the Yemenite Jews. Many of the texts of the Yemenite Sabbath-songs are taken from the Jewish-Spanish classics or are imitations of them.

The Yemenite poems for the festivals and for the ceremony of circumcision have no fixed melodies, but are sung to the tunes customary for Sabbath-songs, and they resemble the latter also in their forms. 
While the Synagogue song of the Yemenite Jews consists of the modal chants only (Chapter VII), their folk-song for the most part has strict rhythm and melodic form. It is true that the Haleloth and the Sabbath-songs are based upon the Synagogue modes and are generally without any rhythm. The reason for this exception lies in the fact that these lyrics are not accompanied by dance-the propelling force of rhythm. The other songs are, as a rule, sung to dancing and hand-clapping, and, consequently, they acquired fixed rhythmical melodies.

The Yemenite Jews entertain the opinion that the tunes of their folk-songs are their original creations and have no connection with the Arabic songs. However, this claim holds true in part only, for, according to their own statement, it is the tunes of townspeople only, principally of those in the capital San'a that are original; while the folk-song of the village Jews, who live in close contact with the Arabs, is strongly influenced by Arabic music. In some instances, entire melodies were borrowed. Hence, all melodies which are of doubtful and nonJewish origin the Jews in San'a call "village melodies." In San'a the Jews have been separated from the Mohammedan population for the last three hundred years, and closed up in a Ghetto apart from the main town. This seclusion has caused the development of specific Jewish folk-tunes which differ from all current Arabic melodies that are accessible.

Unlike its poetry, the music of the Near East retained its folk-character, artistic endeavors being confined to embellishment and subtle modulations from one Makam to the other. The other form of "art" consists in the PERFormance. The various types of the Yemenite poetry are, with the exception of Haleloth, sung in responsive and antiphonal forms, and are executed by a minimum of four singers divided into two groups, in one of which the chief singer functions as soloist and director. The partner of the director is called "colleague," or sec- 
ond singer; and the two in the second group are the third and fourth singers. Only the first line of the song is intoned by the first singer solo, whereupon his "colleague" joins the singing of the first stanza. The second group, i.e., the third and fourth singers, respond with the second stanza. The song usually ends in a coda without text, which is sung in unison by both groups, the singers carrying the melody either on the last syllable of the last word or with "ah." Assembled guests participate by clapping their hands to mark the rhythm. In rare cases, however, is the little drum duf or darbaka employed.

During the singing of Neshid and Shirah, dancing is obligatory. The dance is executed by one pair, sometimes two pairs, of men only; and it has the Arabic character. The dance starts with a slow tempo, but the more the excitement rises the quicker becomes the tempo, until finally it becomes a whirling prestissimo. There are among the Yemenite Jews very skillful and graceful dancers. Aged and worn-out men dance with an astonishing celerity and agility. Women are excluded from dancing; the festivities take place among groups of men alone.

In the chant each stanza is repeated. After the antiphonal response, the first singer is at liberty to introduce another melody for the subsequent stanza for the sake of variety. This process is known as "reversing." Skillful singers make several "reverses" in one and the same poem, in case it consists of many stanzas. Among the Yemenite singers "reversing" is considered the highest "art."

In addition to those in Hebrew, several songs were written in Aramaic, though more than a thousand years ago Aramaic ceased to be a spoken language. Through the influence of the cabbala, this tongue revived as a medium of expressing mysticpoetical sentiments. The above-mentioned poem of I. Luria as well as Yah ribbon alam by Najara are written in Aramaic. 
The Arabic language, which became the vernacular of the Oriental Jews, was, next to Hebrew, the chief vehicle of Yemenite poetry. Some lyrics peculiarly employ Hebrew and Arabic in alternating stanzas, or even within one and the same stanza; nay, even in one and the same line Hebrew and Arabic words are used promiscuously. Approximately one-fifth of the Yemenite poems is purely Arabic, and about half of them are Hebrew-Arabic. There are also trilingual poems, HebrewArabic-Aramaic, similar to the combination found occasionally in the poetry of Halevi, Alcharizi, and other Spanish-Jewish poets.

Table XXX illustrates the folk-songs of the Oriental Jews. Group $A$ indicates songs in Hebrew, the texts of which are of a religionational character. Numbers $I-6$ are of Babylonian origin. Example $I$ is a seder-song for the beginning of the ceremony. Its text is a mere list of the subdivisions of the service. The tune is in the Pentateuch mode. No. 2 is an Elijah-song sung at the outgoing of the Sabbath. The tune is in Bayati-Huseni, which resembles the Mogen-Ovos mode. No. 3 celebrates the famous revered saint Rabbi Simon bar Yochai, and it is sung on the thirty-third day of the Omer. The tune is in Bayati-Sabba, and it has the tetrachordal form in minor. While singing this song the people work themselves into an ecstasy which results in a whirling dance. No. 4 is a plea for redemption from the exile of Ishmael (Arabs). The tune is in Hedjaz. In the same Makam we have also No. 5, used for "Rejoicing with the Torah" (Simchath Torah). Both songs are stimulating dancing numbers. No. 6 is associated with the outgoing of the Sabbath. Its text, known throughout the Diaspora, originated in Babylonia.

The second group, Nos. 7-10 comprises songs of Sephardic-Syrian origin. No. 7 has the same text as No. 6. Its tune, which is in Bayati, is known also in Italy. ${ }^{11}$ No. 8 is a responsive song for the return to Zion, its tune being in Makam Nawa. No. 9 is a plea for the restoration of Galilee (North Palestine), most likely dating from the time when, under Joseph Nasi (sixteenth century), an attempt was made to establish a Jewish settlement in Tiberias. ${ }^{12}$ Its tune is in Hedjaz. No. 10, in the same scale, is used for the "Rejoicing with 


\section{TABLE XXX}

Folk-songs of the Oriental Jews

\section{$a_{\text {Hebrew songs }}$}

Babylonian
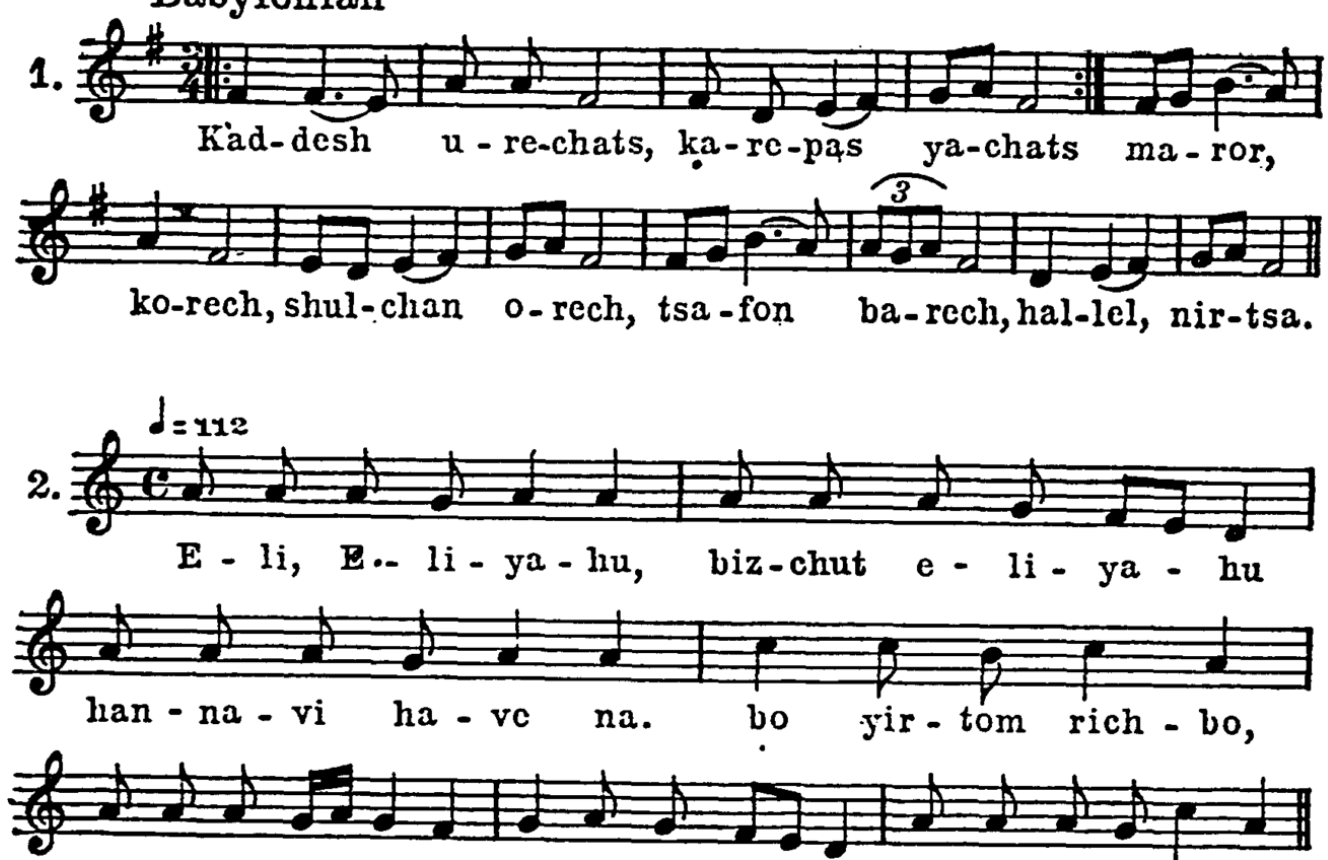

na ba-she-vi ki va, lo sha-chav lib-bo gam lo ra-a she-na.
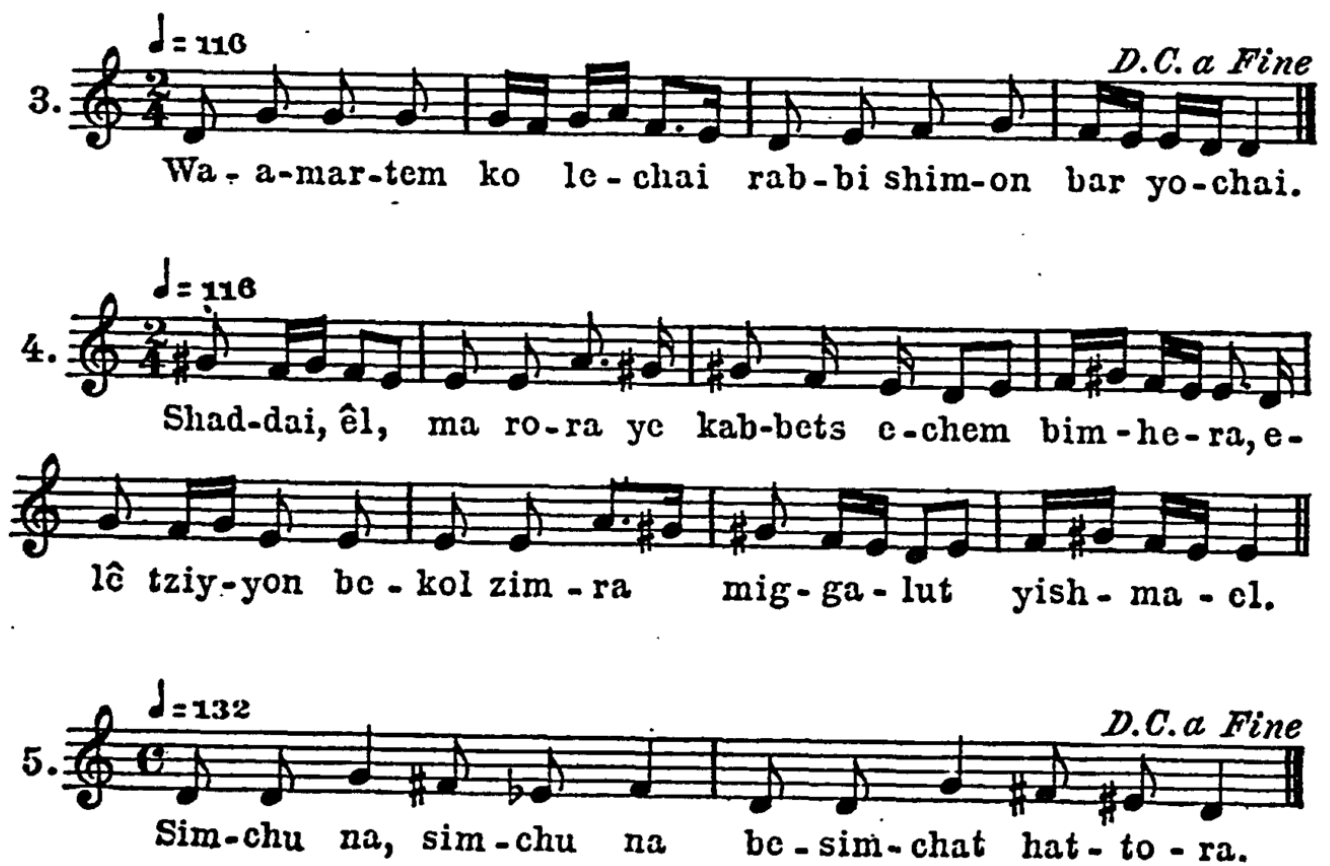
6
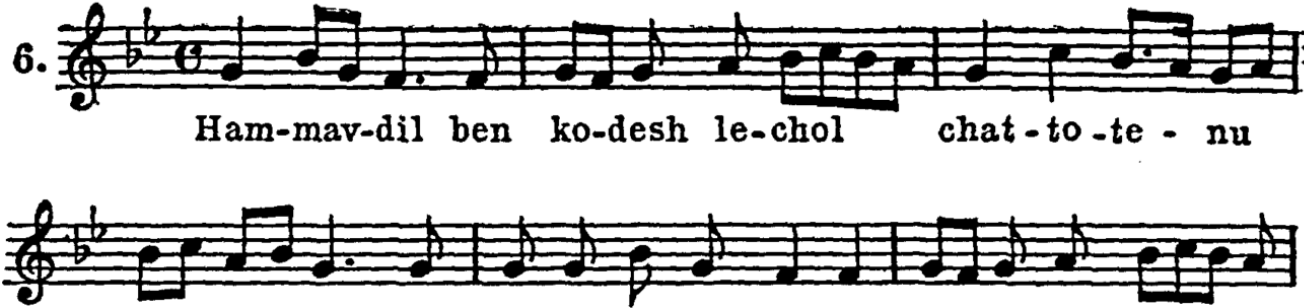

hu yim-chol, zar - e-nu wo-chas-pe-nu yar-be cha-chol we.
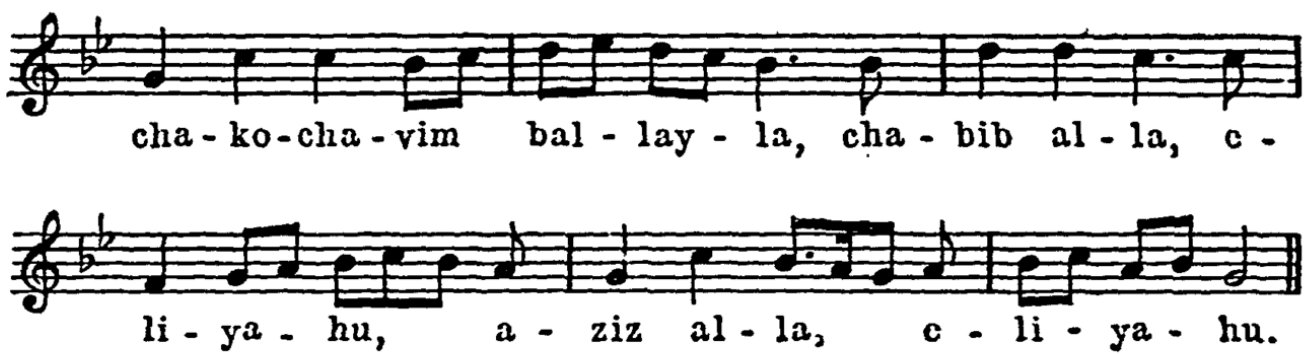

Sephardic-Syrian

Andante
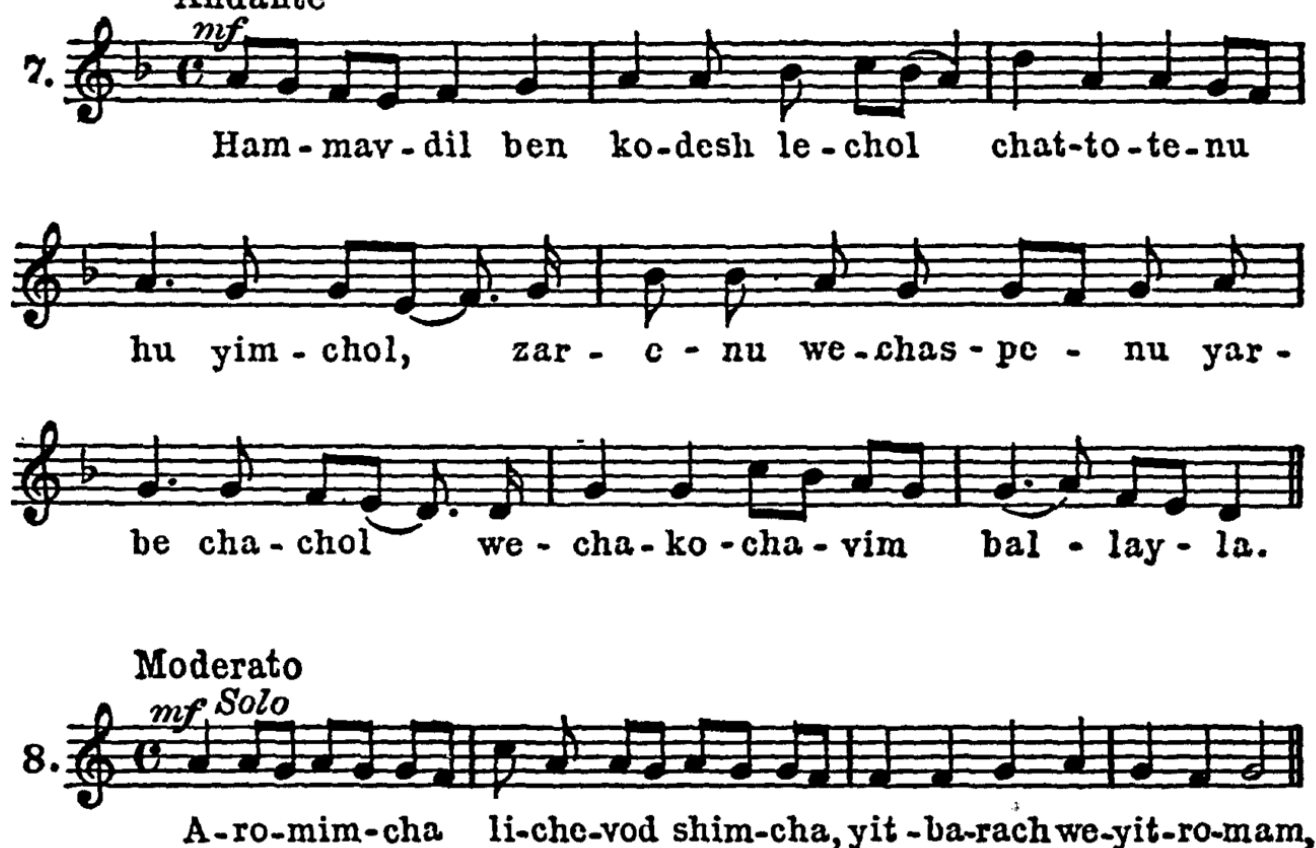

A-ro-mim-cha li-che-vod shim-cha, yit -ba-rach we-yit-ro-mam,

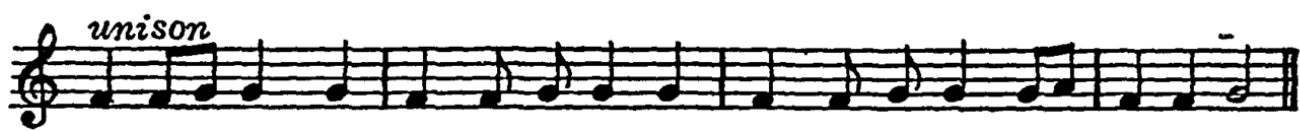

le-ir tziy-yon har ko-de-she-cho sham ni-se-mach we- na-a-le. 

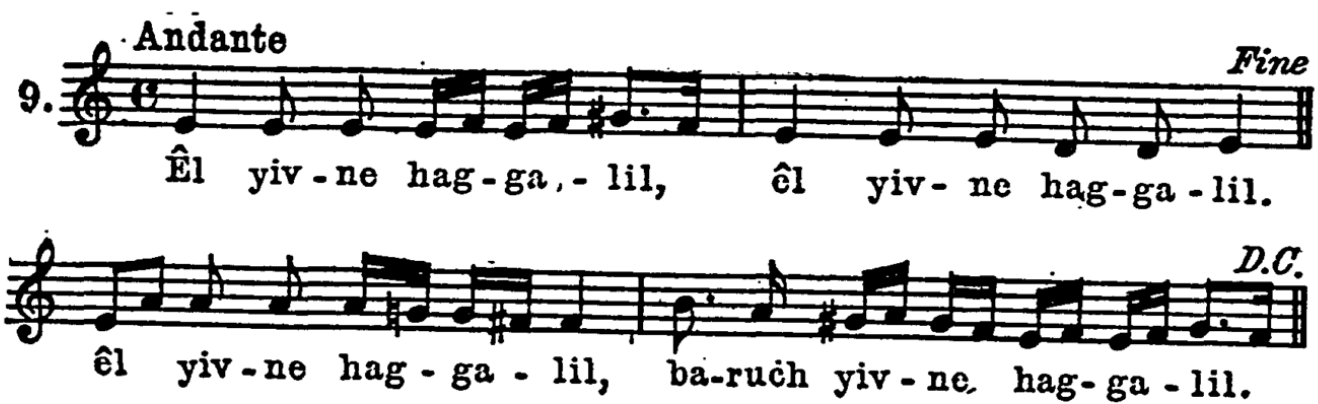

Largo

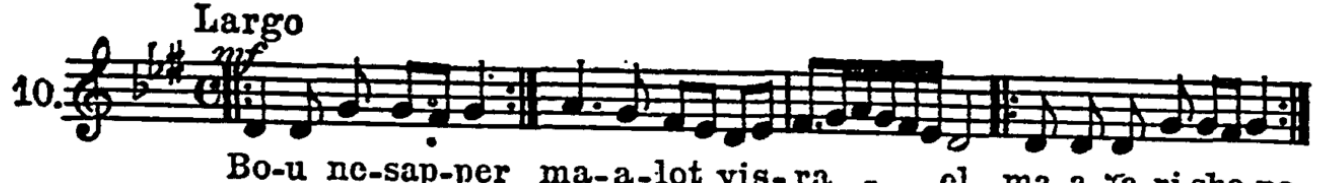

Bo-u nc-sap-per ma-a-lot yis-ra - cl. ma-a-ra ri-sho-na
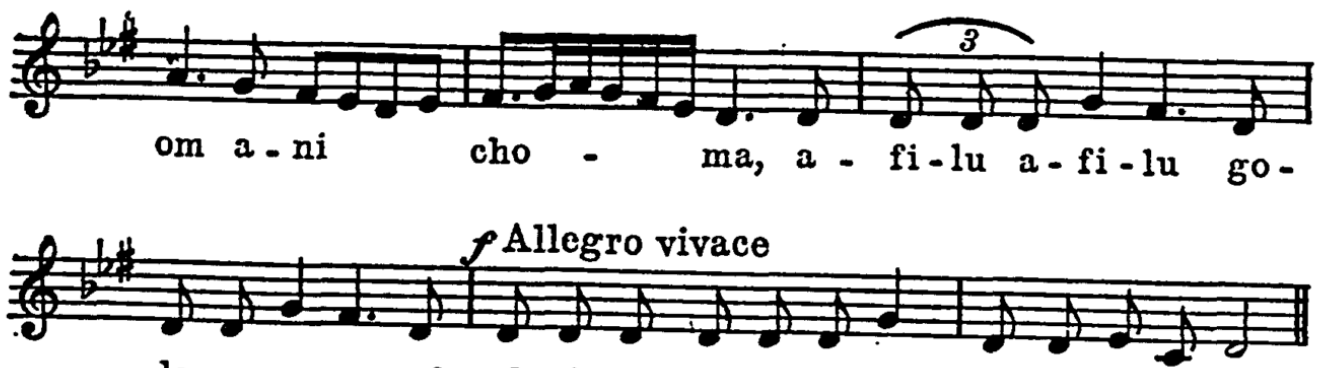

la we-su-ra, af al pi chen, af al pi chen dam-ta le-ta-mar.
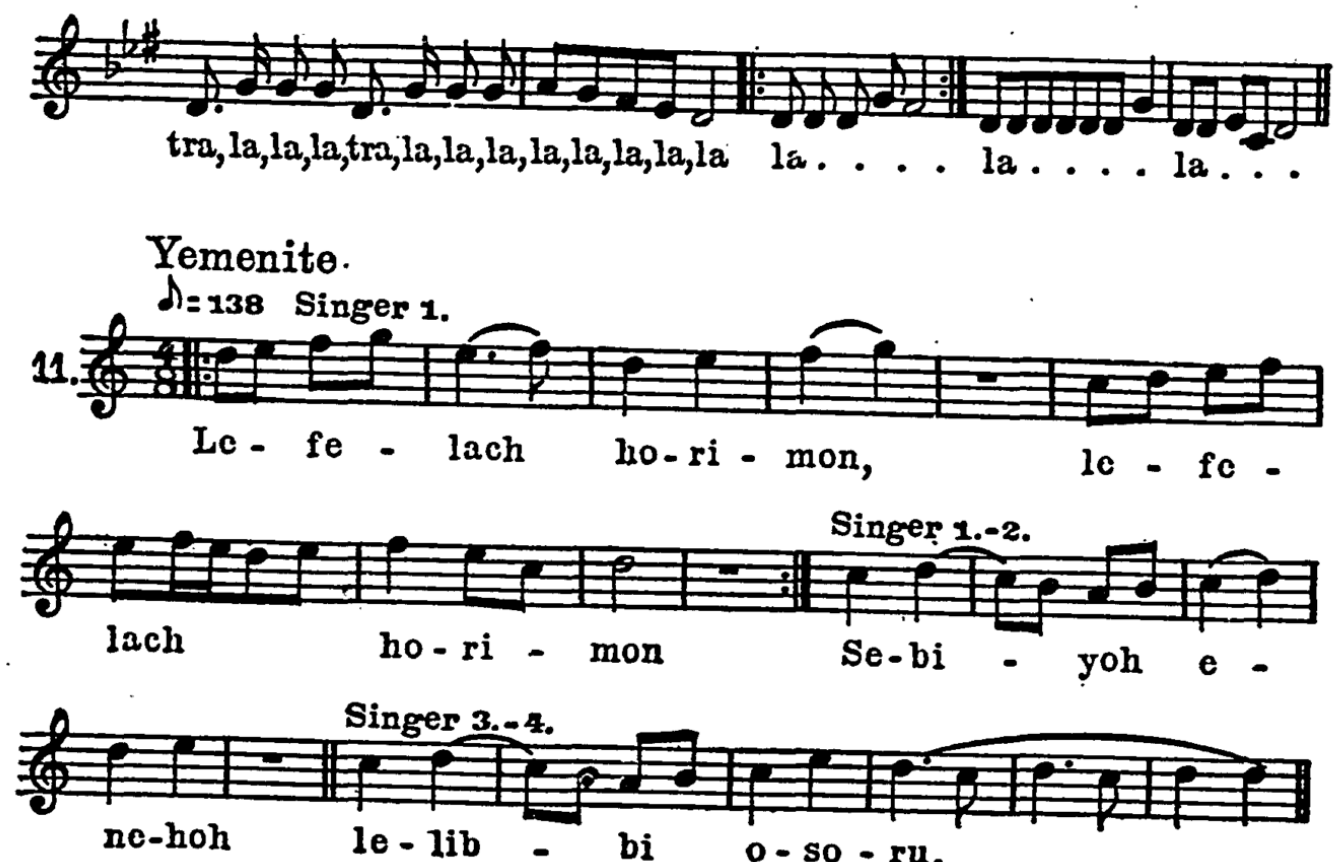
THE FOLK-SONG OF THE ORIENTAL JEWS

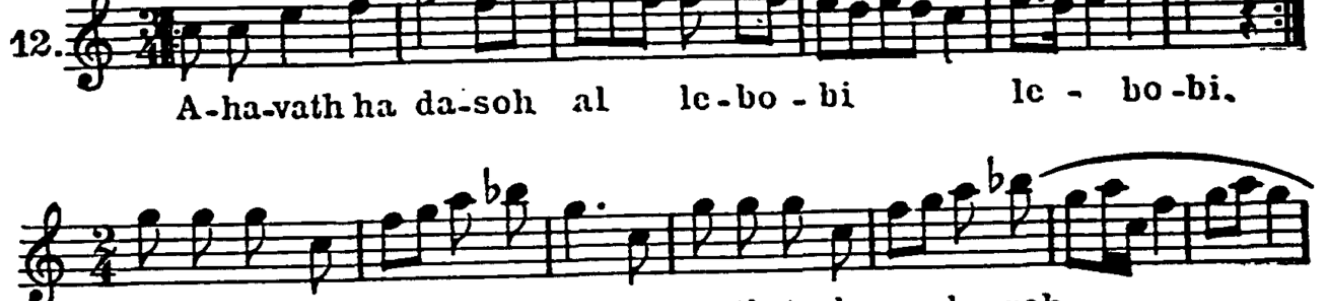

ta-a-wath le-bo-bo-m la-a-so-th to-b go-bc-roh.

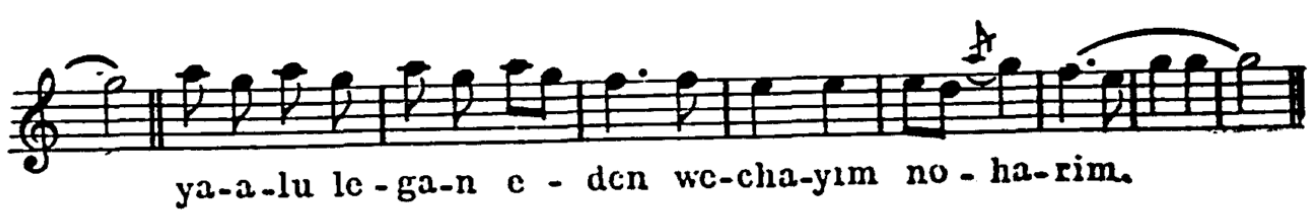

Singer 1.-2.
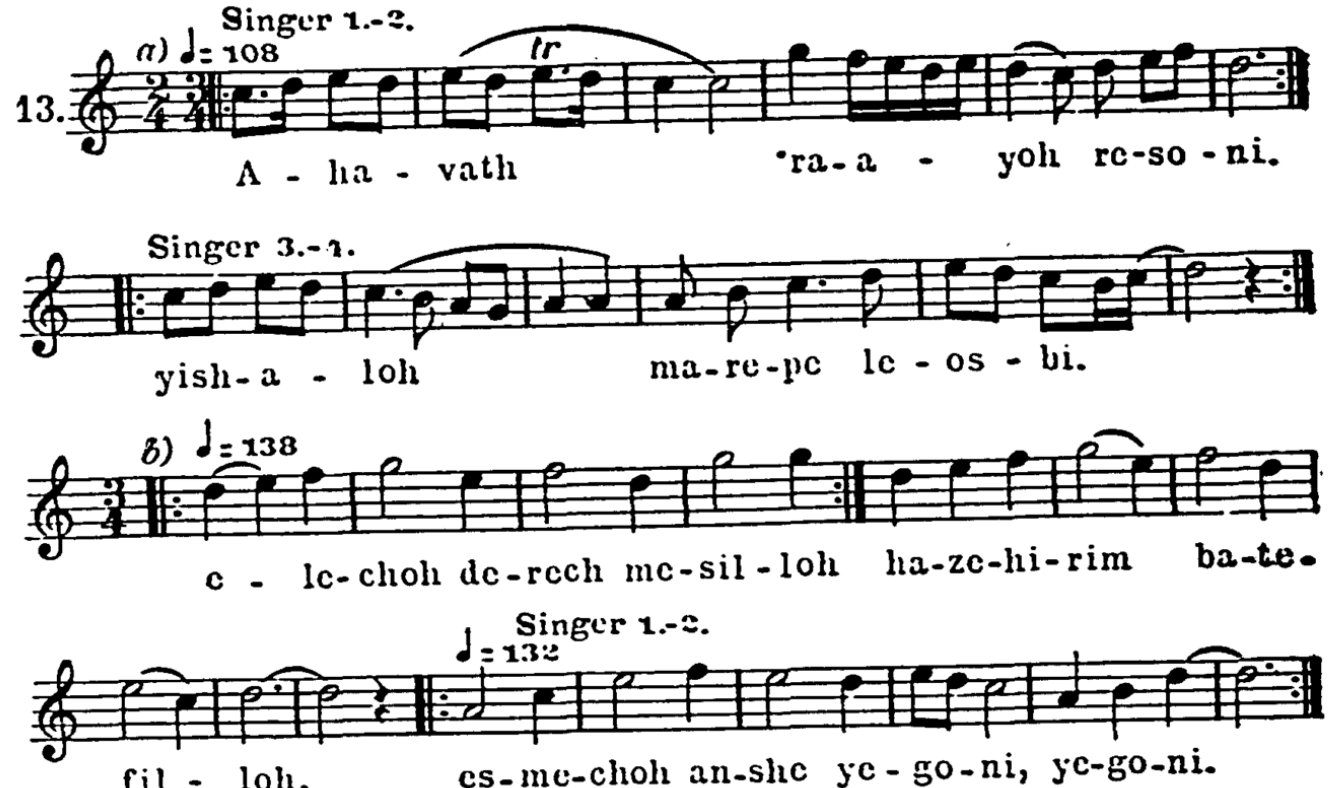

fil - loh.

cs-me-choh an-she ye-go-ni, je-go-ni.

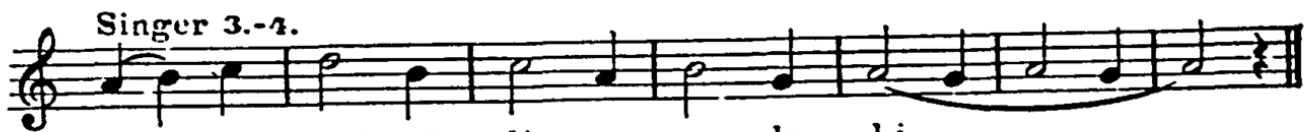

csh-kc-choh ul - li we-o-lc - bi.

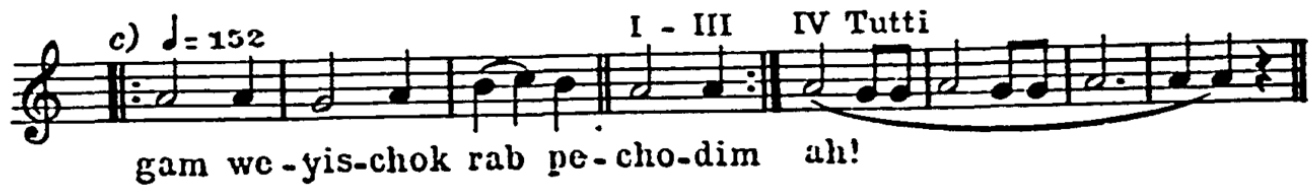


the Torah," the text being based on Hoshanah. It starts largo; but in the last part it changes to Allegro-vivace.

The third group, Nos. I I-1 3, consists of Yemenite songs. No. II belongs to the type Zafat. This poem praises the beauty of the bride in terms taken from the Song of Songs, such as "Thy temples are like a pomegranate split open; Thy height is like the height of the palace. ... O gazelle, her eyes captured my eyes." The tune is Hypo-Phrygian, which resembles the Prophetic mode; the melodic line has a tetrachordal curve and consists of four-bar periods with a coda of two bars. No. I2 is a Neshid-song. The tune is composed of three themes: the first of six bars repeated several times; the second and third of eight-bar periods. The tune is based upon the Makam Nawa. No. 13 illustrates a "girdle-song"-Shirah. The poem has the abbreviated Ramal meter (Chapter VII). The tune has three parts: (a) intones the first part of the stanza in six bars, (b) gives the girdle which consists of four bars, and (c) intones the concluding part of the stanza with an additional coda of four bars sung in unison. The scale is the Hypo-Phrygian in a tetrachordal melodic line.

\section{Judeo-Spanish (Ladino) Songs}

While still in Spain the Jewish people used to sing Spanish canciones and romances in the old Castilian dialect. These songs the Jews carried with them in their exile in 1492 and continued to sing in their new settlements in Northern Africa, in the Balkans and, until lately, in Turkey. ${ }^{13}$ The Oriental environment and the new conditions caused the creation of specific Jewish folk-songs in the Spanish vernacular which the Jewish refugees retained as their idiom. Already in Spain the Jews incorporated into their familiar dialect many Hebrew terms employed for religious subjects, until these words became an integral part of their Spanish idiom. Now in Greek, Turkish, and Arabic environment many idiomatic expressions of these languages crept into the Spanish, thus molding that language into a peculiar medium of expression of the Jewish population of Spanish extraction. This Spanish-Yiddish became known as 
b) Judeo - Spanish songs (Ladino) Songs

Moderato
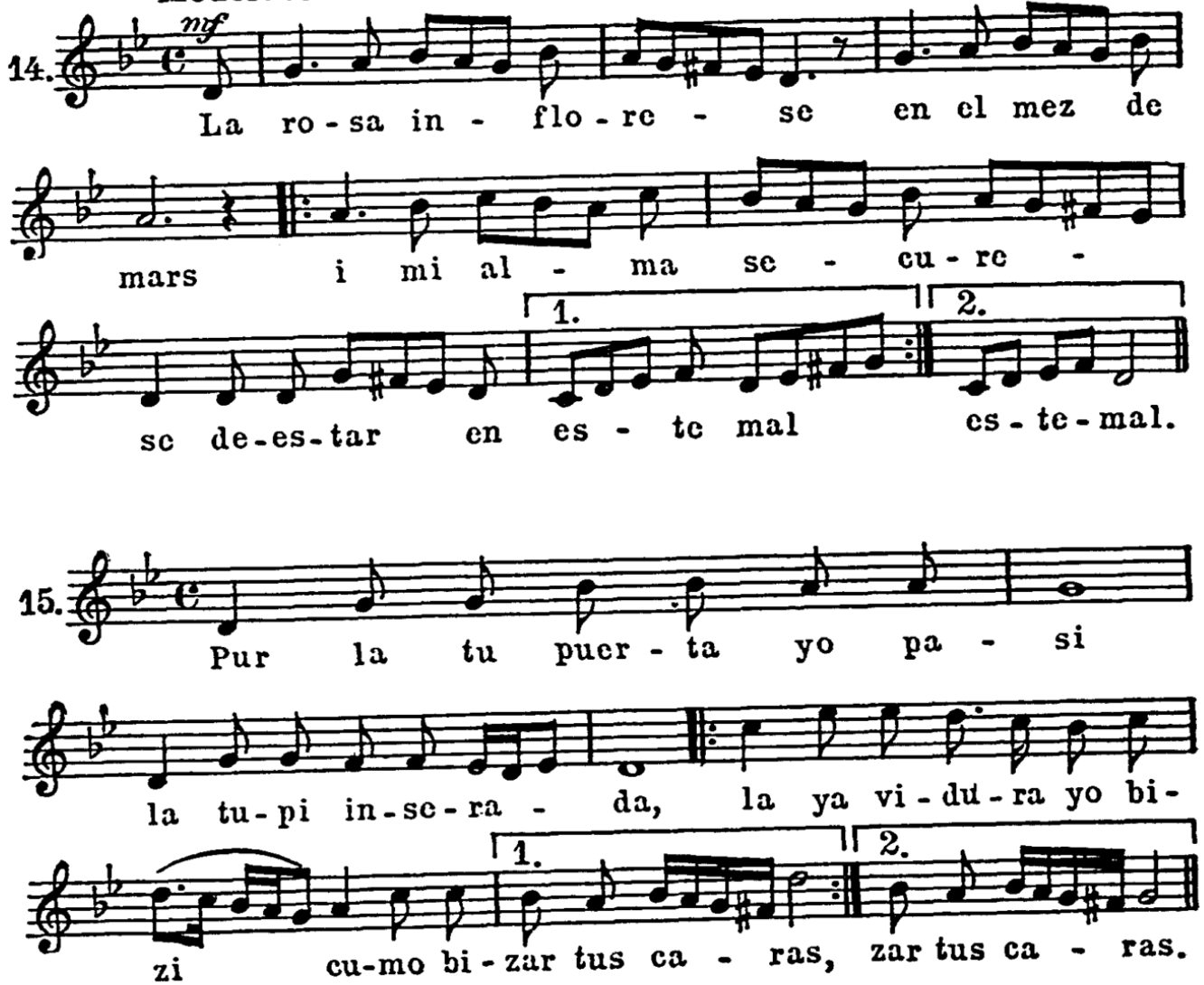

Adagio
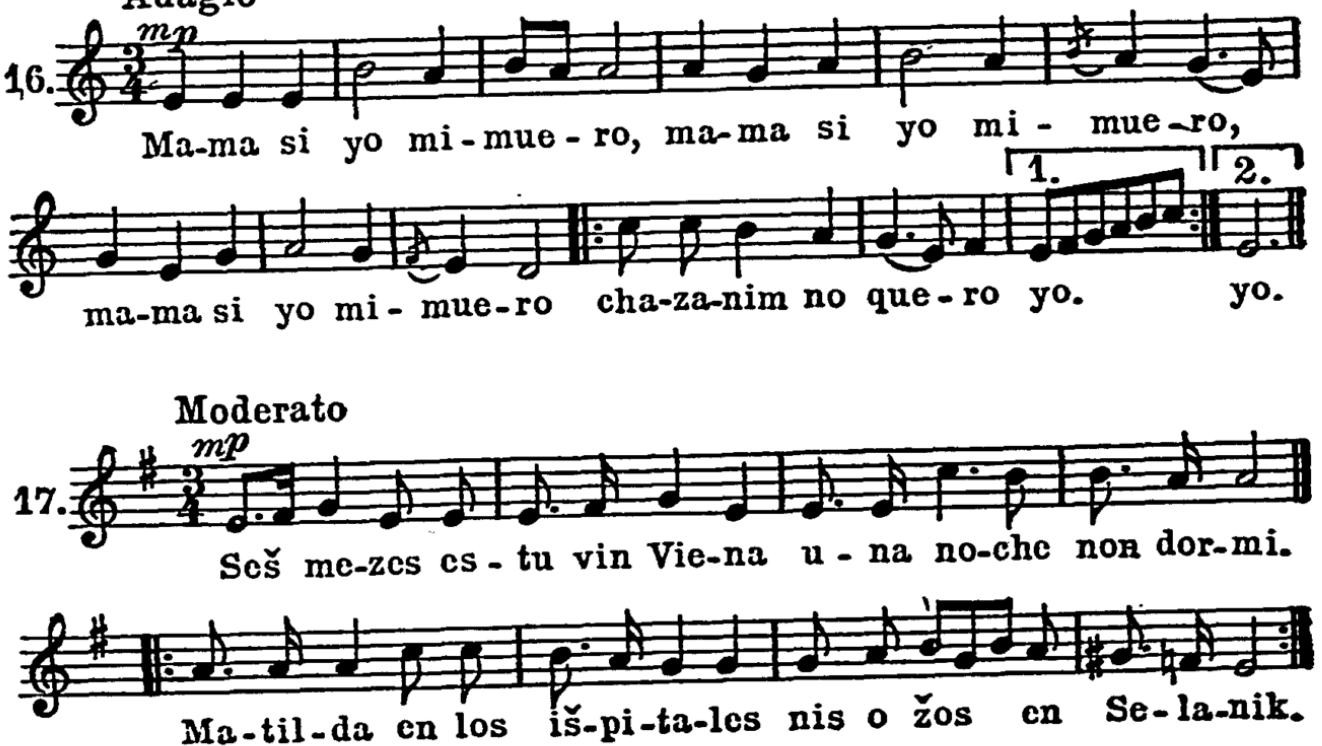
Ladino (corrupted from "Latin"). Religion and race as well as their superior culture separated them from their Oriental neighbors and caused the creation of their own cultural values. Thus, in the course of four hundred years, they developed a popular literature in Ladino, in which the folk-poetry occupies a prominent place. This folk-song is partly of a religious and partly of a secular character. ${ }^{14}$ The tunes have an Oriental color and are either adoptions or imitations of Greek-Turkish melodies.

Examples 14-1 7 in table XXX furnish some love-songs in Ladino. No. 14 speaks of the rose blooming, of the moon shining, while in the heart of the lover there is darkness. The tune starts in minor and ends in the fifth in Hedjaz. No. I5 says, "I passed thy door and found it locked; so I kissed the lock. It was as sweet as if I had kissed thy cheek." The tune is in minor. No. 16 expresses the last will of a girl, sick unto death, whose heart was broken by love. She importunes her mother, "When I die, I do not want chazzanim (to officiate at my funeral), but I want twelve boys led by my sweetheart to walk in procession." The tune is in the Dorian scale, and seems to be of Greek origin. No. 17 is obviously of the last century. In that song the sweetheart or young husband complains, "You have already been six months in Vienna, during which time I did not sleep a single night; for Mathilda is in the hospital (in Vienna) while my eyes are in Salonica." The tune starts in minor and modulates to Hedjaz on the same scale, a peculiarity frequently to be found in the Synagogue as well as in the Yiddish folk-song in Eastern Europe, as we shall see in the following chapters. 


\section{CHAPTER XVIII \\ THE FOLK-SONG OF THE ASHKENAZIM.}

(a) The folk-song of the Ashkenazim in Germany.

As their brethren in the Orient, the Jews in France and Germany cultivated a home-song, in Hebrew as well as in the vernaculars, French and German. The content of the Hebrew songs was of a religious nature. The texts of these were carried over from the Orient or written by local poets. The early songs of the vernacular were translations from the Hebrew songs, and, consequently, they had religious themes. No specifically Jewish secular songs are traceable in the early medieval centuries. As long as the Jews in Western Europe lived and mingled among the gentiles, they spoke the language of the nations and sang their secular folk-songs, so that there was no need for particular Jewish secular folk-songs. The cause of the creation of Jewish folk-songs of a secular nature was the expatriation of the Jews and their separation from the people in whose midst they dwelt. This exclusion from the life of their environment brought about peculiar modes of life for the Jew which found tonal expression in Jewish folksongs. Thus, with the erection of the Ghetto walls, we perceive the first sounds of original Jewish secular folk-songs in the vernacular. Beginning with the sixteenth century and down throughout the Ghetto period, Jewish folk-song was cultivated; and it discontinued with the readmittance of the Jew to the society of his neighbors, because his separate social life ceased then to exist. In Western and Central Europe Jewish secular folk-song vanished about the beginning of the nine- 
teenth century, while in the East European countries it continued until lately, and in some places it still lives.

But little is known of the Judeo-French folk-song. In I 874 M. Sabatier of Nîmes published Chansons Habraico-Provençals des Juifs Comtadins, ${ }^{1}$ containing three songs: (I) a translation of Chad Gadya (Un Cabri) for the Seder celebration of the Passover evening, which dates back to the sixteenth century; (2) the story of Abraham and Sarah; and (3) a Purim song. The tunes to these songs were taken from old French and Provençal folk-songs, ${ }^{2}$ as tunes for Synagogue hymns were often borrowed.

The oldest collection of texts of secular folk-songs in JudeoGerman thus far known was compiled by Eisik Walich of Worms in $1595-1605 .^{3}$ It contains fifty-four poems, fortytwo of which are of German origin, mostly popular love, dance, and humorous songs. The compiler changed in these songs all references to Christian beliefs and religious customs, substituting Jewish names and symbols. Many of these can be identified in collections of old German songs. Twelve texts in this collection are of Jewish origin, written by Jews on various Jewish subjects. In the last stanzas some of these authors mention their names. In addition to the compiler, there are "The Joyous Jew" Schlome of Prague, who apparently was a badchan (a merry-maker, see Chapter XX), and JosEPH THE sON of Benjamin. The texts of the Jewish songs are peppered with Hebrew words and phrases, and are either of a didactic or of a humorous character. Some of the latter were widely known, and their tunes were used also for other lyrics. One such favorite was:

\footnotetext{
"Jüdischer stamm, von echten art, Ich will euch singen von einem, der hat einen gruen bart.
} 
Eisak Stilingain ist er genant, er wont im Schweizerland. . . ."

This song is a satire on Jewish community life in Germany. Its tune was very much liked, and several texts were set to this melody.

The German verses of the collection, in most instances where the melody is named or can be traced, were sung to the German tunes. Similarly were German tunes adopted for the JEWISH texts. The source of the tune is sometimes indicated, as in the case of a bridal-song which is marked: beniggun-(in the tune of) "Es ist uf erden kein schwerer leiden." This German song was really the prototype of the Jewish song in form and meter. We give here the first stanzas of both songs:

JEWISH:

"Es ist kein grösser freud uf erden

als wen zwei lieb zusammen geben werden;

$\mathrm{Zu}$ dieser freud sol sich jederman sein bereit, knecht und maid,

Choson und kalloh zu eren."

\section{German:}

"Es ist auf erd kein schwerer leiden

(als) wen sich zwei herzlieb mussen scheiden.

Ja bitter tot, mit deiner not

und ganzen rat:

dir kan ich nichts vergleichen." ${ }^{3}$

We illustrate the Jewish version with the prescribed German tune in table XXXI, 19. This melody was well known at the end of the sixteenth century. ${ }^{\circ}$

In the verses of this collection there is no sadness nor lamentation over Jewish troubles. Later, in the seventeenth cen- 
tury, persecutions and massacres, conflagrations and expulsions of whole communities, or the misfortune of individuals became the themes of the Jewish popular and didactic songs. This collection, however, gives but a partial picture; for the greatest part of Judeo-German songs of its date, and the tunes before and after, were of a religious nature, and comprised translations or paraphrases in verse of Hebrew poetry or prose. Almost the entire Bible was translated. Of these endeavors, the "Book of Samuel" ranks highest in standard of poetry."

To all the poems and translations there were melodies adopted, which contributed much to the popularity of the texts. Tunes greatly favored by the public were sometimes employed also for other texts, in order that the popular melody might carry the text. Some of the tunes retained their popularity for a long time. Thus, for example, the melody of the above-mentioned Book of Samuel continued to be attractive to the people for over a century and a half, from the time of the publication of that book (Augsburg, I 544) up to the end of the seventeenth century. Likewise, the tune of the Bovo-book survived from 1507 , when that fascinating story appeared, up to the seventeenth century; and still in 1654 a eulogy on the death of Emperor Ferdinand was published in Prague to be sung to the tune of the Bovo-book. ${ }^{8}$

The poetical forms and meters used in the Judeo-German folk-songs were German. Some of the German texts were Judaized by making the subject matter Jewish. The tunes used for the songs up to the eighteenth century were forgotten, for they were not written down in musical notation by the Jewish singers. Only through the original names of the songs, the tunes of which were adopted, do we obtain a clue of their origin. From that source we learn that the tunes were taken partly from the Synagogue and partly from the German folksong. Synagogue tunes are marked by the name of a prayer 
or a hymn, as, for example: beniggun Ani hu hashoel, Eftechoh pi, Akeda, Eil mole rachamim, Adir oyom venoroh, Schochnei botei chomer, and so forth. German sources are such as Hoch rief der Waechter, Dietrich von Bern, Halb schwarz halb weiss, Das Pavierlied, Das Schloss in Oestereich, Vom jungen Grafen, etc. Besides these there are tunes mentioned the origin of which cannot be identified, such as the tune of Rabbi Simon of Prague, Gut Shabbos, Judischer Stamm, Wie in der Tora steht geschrieben, or the tune of Haman of the Ahashverosh-play. 9 Occasionally "special" tunes are mentioned, but there is no way of finding out whether these tunes were especially composed or especially adopted. In the adoption and selection of tunes in Germany, no other features than sweetness and popularity were considered, regardless of origin. This attitude was the cause of so many rebukes and complaints expressed by the rabbis on the use of Christian tunes for homesongs. Even the "Marseilleuse" was adopted for a satiric song which Amsterdam Jews wrote on the leaders of their community. ${ }^{10}$

The first collection with music was printed in Fürth in 1727. ${ }^{11}$ It is named Simchath Hannefesh-the delight of the soul-and it contains thirteen songs in Judeo-German written by Elchonon-Henle Kirchhain, who adopted tunes for his poems. The tunes were written down by a professional and expert musician, the author assures us. The songs have a religio-ethical content and are written for the following occasions: (I) Friday evening, (2) Sabbath morning, (3) Sabbath evening, (4) New Moon, (5) The High Holidays, (6) Tabernacles, (7) Chanukah, (8) Purim, (9) Passover, (10) Shavuoth, (II) Circumcision, (I2) Bridal-songs, and (I3) Daily songs. The texts lack poetical spirit. They are didactic, describing the ritualistic regulations of the holy days and the religious duties. They were written with the intent 
to prevent the people from singing secular and vulgar German songs, an effort made throughout the Middle Age by both Synagogue and Church. Thus, these songs have little or no claim to the title FoLK-songs; and were probably rarely used. The adopted or imitated tunes have the German melodic line of the seventeenth century. They are in the barock-style which flourished at that time. We give these tunes in table XXXI as an illustration of the type of melodies used for the Judeo-German songs. Nos. 7 and I 2 have a strong resemblance to the tune of the German song, Der Tod als Schnitter, which became popular after 1637 (XXXI, I4). ${ }^{12}$ Some of them, as Nos. I, 5, 6, have folk character, whereas Nos. 3, 7, 8,9, I 2 and I 3 have alterations which presuppose artistic influence. No. 8 has peculiar chromatic steps, which apparently are supposed to express a state of intoxication, because it is a Purim song, at which celebration banqueting was permissible (Chapter XX).

We can identify some of the tunes of the seventeenth century used by German Jews for their Zemiroth (Sabbath songs). For example, the tune of the Zemirah Kol mekaddesh shevii is designated as adopted for the song Mensch, gedenk. This tune resembles Bruder Veit's tune (XXXI, I 5 a-I6). ${ }^{13}$ The latter tune was very popular in Germany in the sixteenth and seventeenth centuries, and it appealed to the Jews because it had similarity to the Mogen-Ovos mode, (Chapter IV). In Eastern Europe the Kol Mekaddesh song is recited in the Adonoy-Moloch mode, as illustrated in table XXXI, I 5 b. In the Mogen-Ovos mode there was chanted another Zemirah, Sholom Aleichem (Peace unto you, $\mathrm{O}$ angels of peace!), which, too, as mentioned above, resembles Veit's tune (XXXI, I 7$)^{14}$

- Another Sabbath song, Ma Yofis, became popular in Ger- 
many and Poland in the seventeenth and eighteenth centuries. To the Polish "Pans" this song was the symbol of Jewish song, and they used to delight themselves urging their Jews to sing it accompanied by dances and comical gestures. In the middle of the nineteenth century the tune of $M a$ Yofis was adopted for a German Sabbath song, written by Rabbi Leopold Stein of Frankfort. In table XXXI, 18, we give the Ma Yofis song according to M. Kohn's version in his MS. from I870 (Chapters XIII, XVI). The tune is decidedly German. ${ }^{15}$

The songs of the German Ashkenazim thus far analyzed can by no means be considered "folk-songs" either in style or in content of the texts, for they bear the marks of artistic endeavors of individuals. Neither do the melodies show any Jewishness, for they are as a rule adopted from the German popular songs. Indeed, the home-song was Germanized long before this was done with the Synagogue song. Rich Jews used to engage Christian music-teachers to teach their daughters German vocal and instrumental music. Already in the seventeenth century the above-mentioned Joseph Hahn complains against this custom current among the wealthy families in Frankfort. ${ }^{16}$ At social gatherings and joyous occasions they would sing German folk and popular songs of vulgar contents, called Huren lieder, to the greatest chagrin of the rabbis. ${ }^{17}$. Thus, we see that the German Jews continued to be strongly influenced by German music, despite Ghetto-walls and social separation.

(b) The folk-song of the Ashkenazim in Eastern Europe. The folk-song of the Jews in the East-European countries took another course of development from that of the Jews in Central Europe. It is distinguished by its genuine folkcharacter. Created out of the people, it remained anonymous. 
Tunes of Ashkenazic songs in Judeo-German of the 17. Century

1. Friday ovening

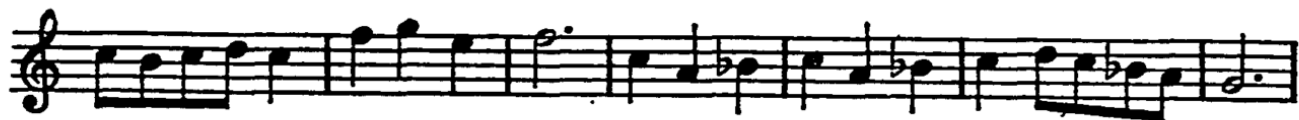

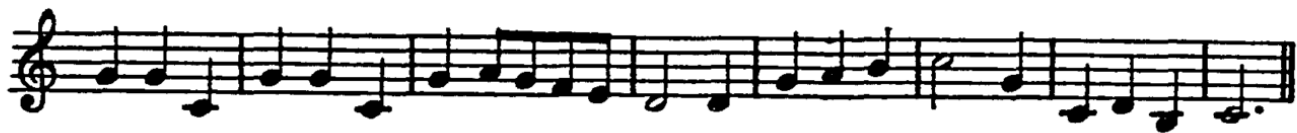
Sabbath

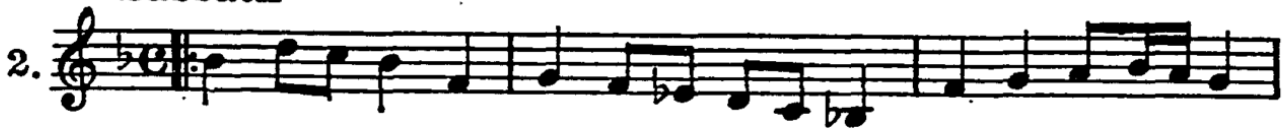

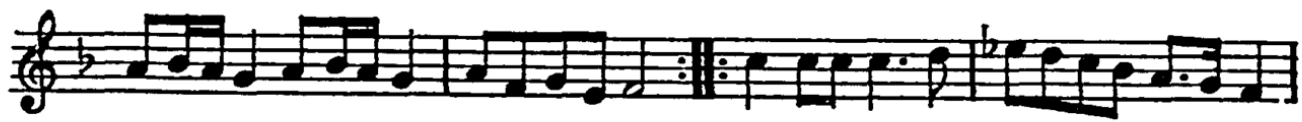
द

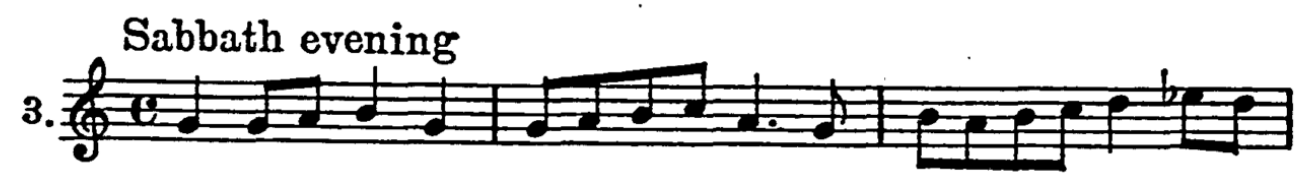
1. Now Moon

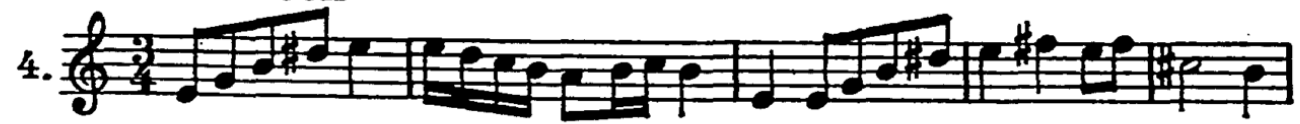

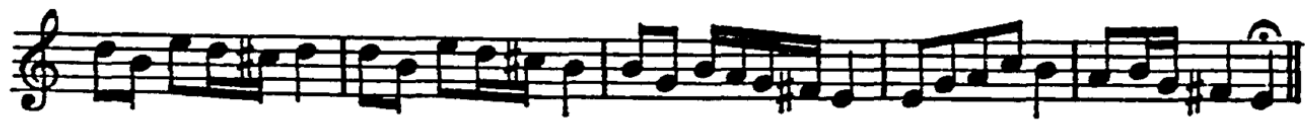



High Holidays

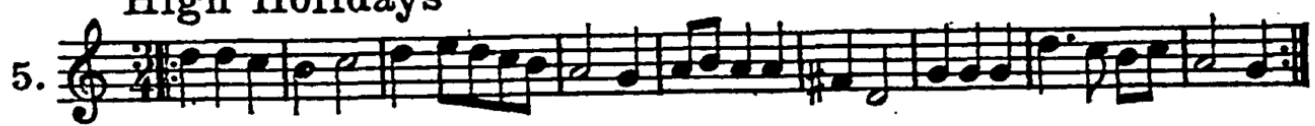
6. Tabernacles

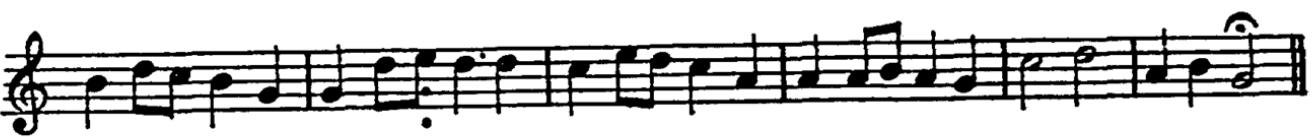
Chanukkah

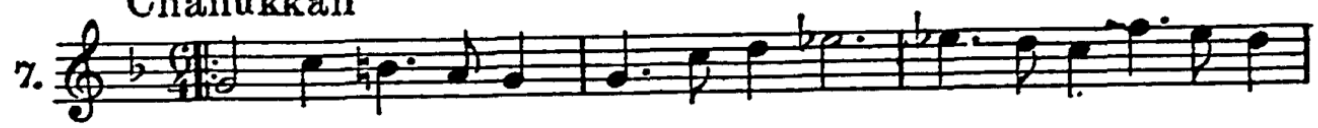

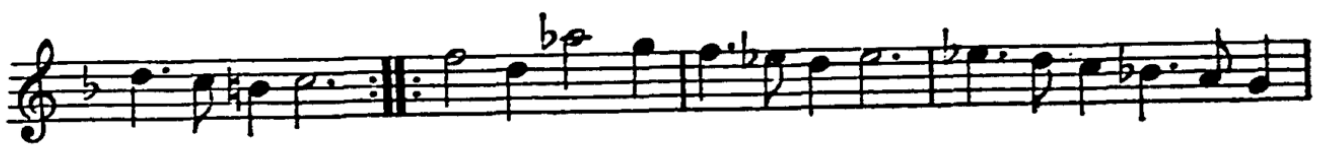

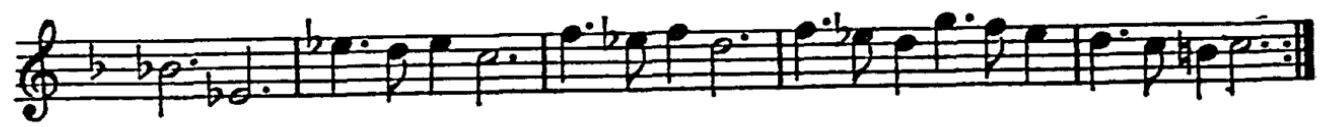
8. Purim

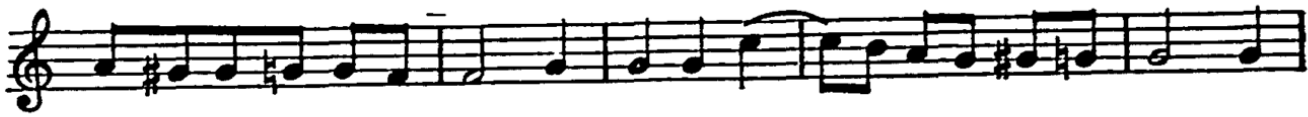

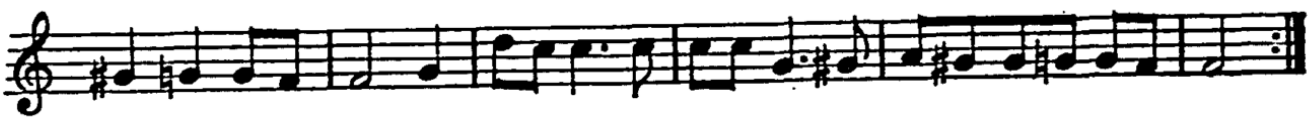
9. Passovor

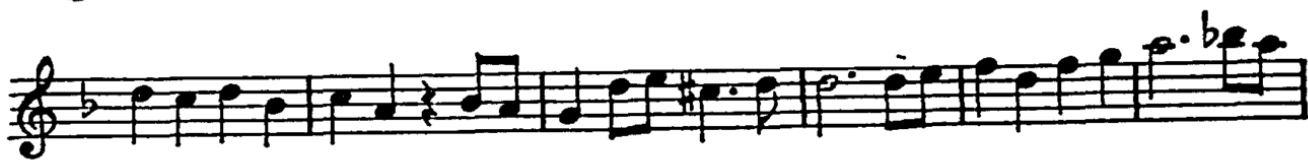

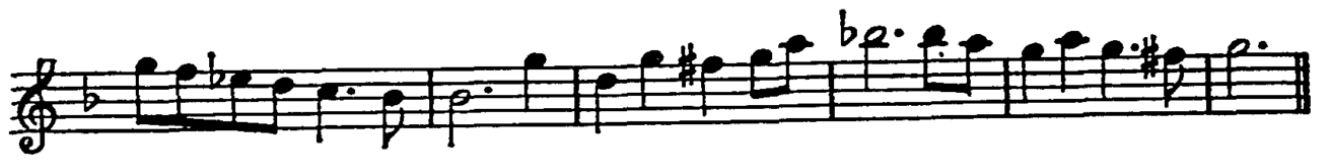


Shavuoth

10.

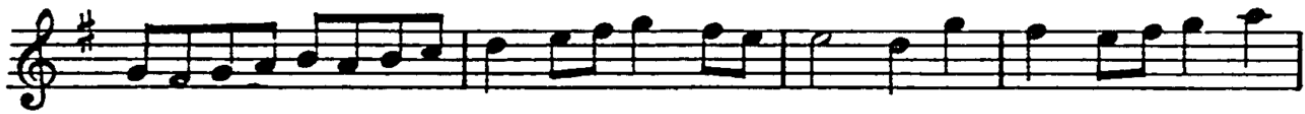

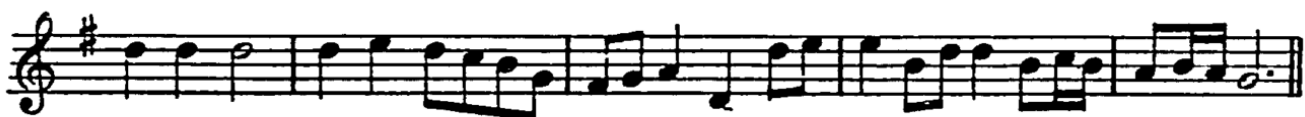

Wedding and circumeision

11. 琎

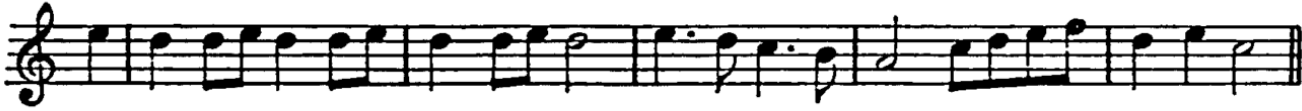

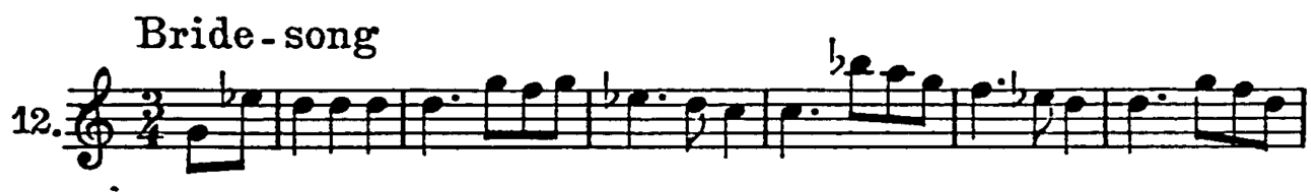

2)

Daily song

13.

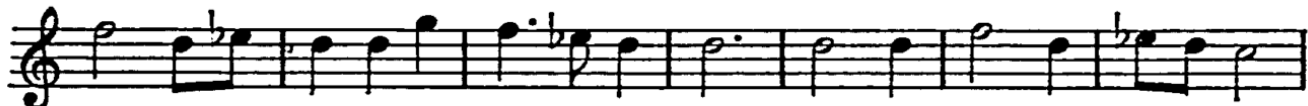

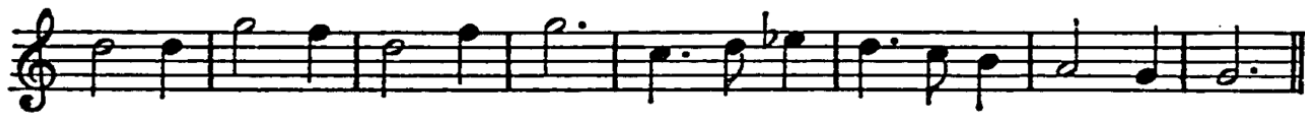


Der Tod als Schriitter

14.

एकo

20\%p

15.

Kol me-ka-desh shc-vi-i ko-ro-uy lo, kol sho-mer shab-bos ka-
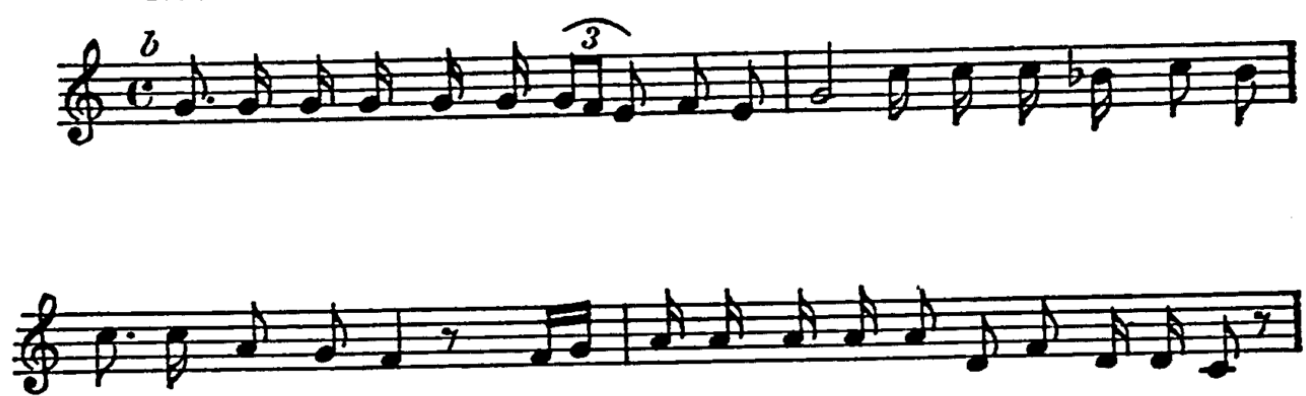

dos me-cha-le-10, sho - ro har-be me-od al pi fo-0-10,
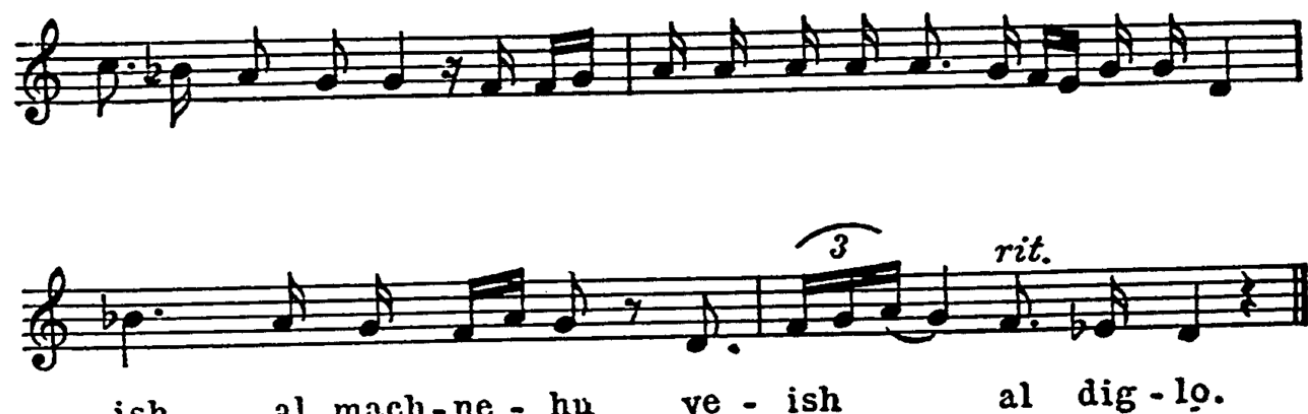

ish al mach-ne-hu ve - ish al dig-lo.

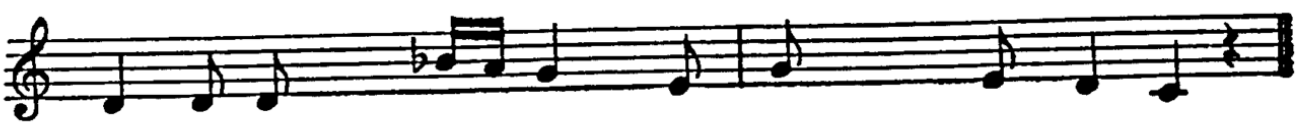


16. Bruder Veitston

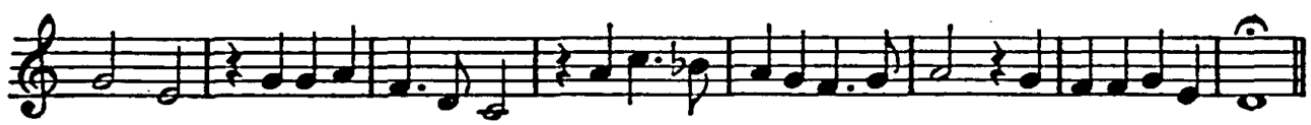

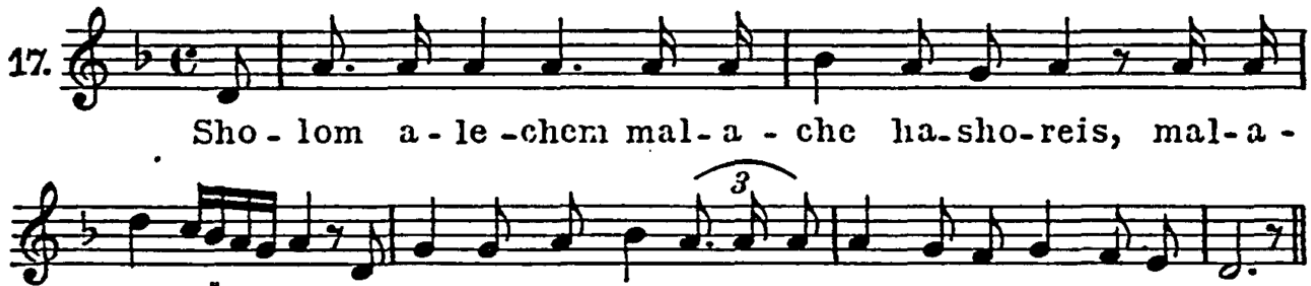
che $\mathrm{cl}^{\prime \prime}$ - yon, mi-me-lech mal-che ha-me-lo-rhim ha-ko-dosh bo-ruch hu.

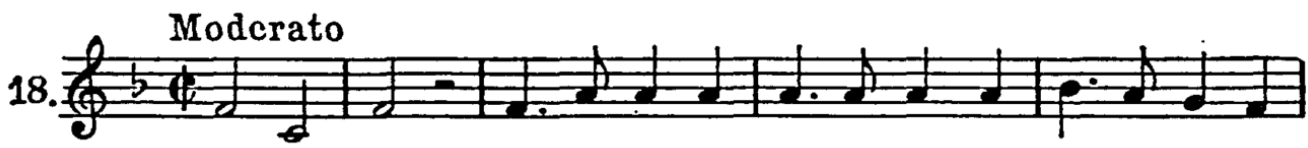

IIa jo-fis, ma yo-fis u - ma no-amt ah-voh bc-sa-nu-
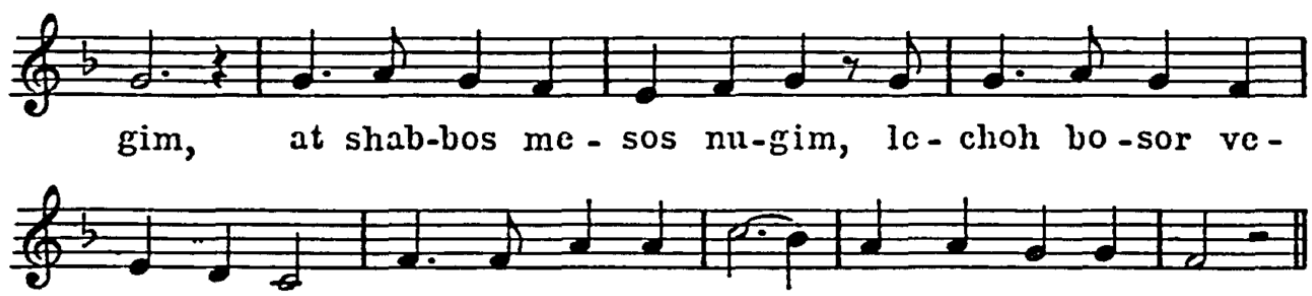
gam do-gim, ncho-nim mi-b'od yom, ncho-nim mi-b'od yom.

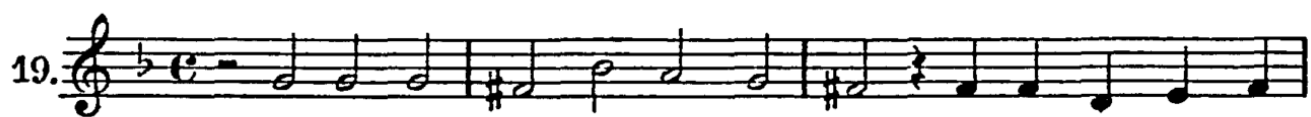

Es ist kcin grös-scr freud auf crd'n als wen zwei licb zu-

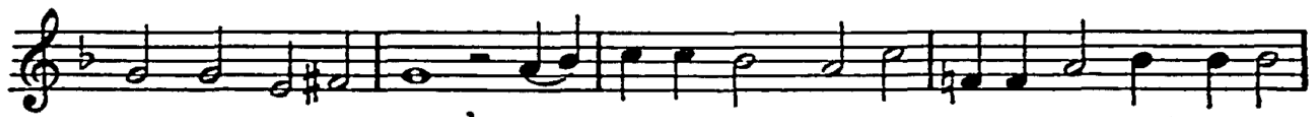
sam-men ge ben werd'n; zu dic-scr frcud sol sich je-der-man scin be-reit,

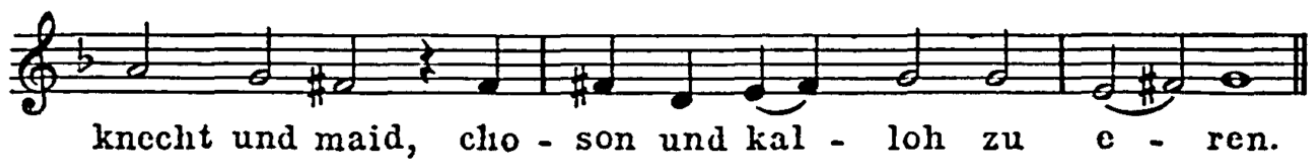


Neither can the time of the songs' creation be determined. They are simple and short in form and content, voicing the sentiments of the life of the people at large. The Eastern song consists not only of religio-ethical folk-songs in Hebrew and Judeo-German, but to a great extent also of secular songs of various types, as love, cradle, humorous, and satiric jingles, usually composed in the Judeo-German dialect which developed in the Eastern countries into a Jewish idiom, called "Yiddish," from the German Jüdisch.

In this song we again find the spirit of the Jewish people, of the masses, expressing itself. In the Eastern folk-song the life of the PEOPLE as a whole is reflected, but nonetheless are the sentiments of the individual voiced. Moreover, the Jewish woman, as a loving girl, as a married woman, and as a mother, found in it a channel for the outpouring of her heart. This song is no longer entirely governed and directed by the Synagogue and religious principles and doctrines, though in many folk-songs we find the influence of the Synagogue in both text and melody. At times we sense a heavy cloud of melancholy settling upon the spirit, as a result of century-long suffering under the pressure of the Golus. On the other hand, we miss the consideration of nature. No nature-songs are to be found in the folk-poetry of the Ghetto-dwellers, the urban inhabitants, who were forced to that life throughout many centuries. The same people who created the Song of Songs-that hymn on nature and love, saturated with the rays of the sun, with the morning dew and the fragrance of roses-were doomed to suffocate behind the mouldy walls of their environment, the Ghetto, or to rot in the mud of the "Jewish alley," the Jïdische Gass. "Centuries of city life have incapacitated them for any other occupation than commerce and artisanship, and have entirely estranged them from nature." ${ }^{18}$ However, this statement of thirty years ago no 
longer holds true, for the "back to the soil" movement which started recently among the Jews in Russia and Palestine gives evidence of the deeply rooted love for nature that has resisted nineteen centuries of privation.

The contents of the religious songs of the Eastern Ashkenazim is identical with that of the German Ashkenazim, notably, the Zemiroth in Hebrew which were taken over in toto. However, the texts alone were taken over, while the tunes were replaced by others with Jewish-Oriental flavor, as we shall see later on. In table XXXII, I-2, we give the song Eliyohu Hannovi in two tunes, both very popular; and in No. 3-a tune for Hammavdil, for the outgoing of the Sabbath. In addition, several new songs in Hebrew were created, usually in alphabetical acrostics and of folk-character, based on Biblical or prayer texts, as Omar Adonoy leyaakov, No. 4 .

As in the Orient, so also in Germany and Eastern Europe, there developed bi-lingual songs in Hebrew-Yiddish, mostly of a religious character. They are either in the form of translations, i.e., the Yiddish interpreting the Hebrew or alternately a line in Hebrew and one in Yiddish. For the first form, table XXXII, 4 may serve as an illustration:

Omar adonoy leyyakov: Said God unto Jacob:

Al tiroh, avdi Yaakov

Do not fear, my servant Jacob!

Hob nit kein forcht,

Mein knecht Yaakov!

Do not fear, my servant

Nein, Foterl, nein! Jacob!

Ch'hob nit kein forcht far I fear nobody, keinem.

Nor far dir allein! But Thee! 
No. 5 of table XXXII illustrates the second form:

Yovo addir veyigolenu,

Yovo eliyohu vivasrenu.

Un vos vet er uns mevasser sein?

Ki yovo moschiach tzidkenu,

G'vald, venn vet er kumen?! Sha, nit shrei, er vet shon kumen,

Venn zshe, vet dos sein?

Bimheroh veyomenu!

Un vos far a tog vet damals sein?

Yom gilloh, yom rinnoh, yom ditzoh,

Yom chedvoh.-Haleluyoh.
May the mighty one come and redeem us,

May Elijah come and bring us good tidings.

What message will he bring us?

That the Messiah our righteous one will come,

Alas! when will he come?!

Hush! Do not cry! He will come.

But when will that be?

Speedily in our days!

And what kind of day will that be?

A day of joy, a day of song, a day of rejoicing,

A day of happiness.-Haleluyoh.

Both examples have the alphabetical acrostic.

The greatest part of the folk-songs is in Yiddish, especially cradle and love songs, and songs relating to family life, for the simple reason that they were sung and probably likewise composed by women, who did not know any other language. Some of these songs are very popular, such as the cradle-song given in table XXXII, 6:

Unter dem kind's wigele Steht a waisse tzigele. Tzigele is geforen handlen, Rosinkes mit mandlen
Beneath the baby's cradle, There stands a white kid. The kid has gone a-bartering. Raisins and almonds 
Rosinkes mit mandlen

Is die beste s'choroh,

Mein kind vet kennen lernen toroh.
Raisins and almonds Are the best goods.

My baby will know the study of Torah.

It was the ideal of the mother that her boy should become a scholar in Jewish lore, and the next ideal was that her son should be a skillful merchant, since free trade was the only occupation left open to the Jew.

Both occupations were for the men only. Women were generally kept at home; excluded from instruction in Hebrew lore. They received their religious and ethical education orally from their mothers and from books in Yiddish, and awaited the ideal marriage to young men well versed in the Torah but utterly unprepared and ignorant in worldly matters. The bride knew that in most cases she would be doomed to help her husband earn a living. Besides so many calamities might strike her, as, for instance, the tyrannic law issued by Emperor Nicholas I, compelling Jewish youths to serve in the army for twenty-five years. Even later, after that law was abolished by Emperor Alexander II, the service in the Russian army was looked upon with terror. At the age of twenty-one the Jew was already married; thus, serving in the army meant to him leaving his wife and children without support, and sacrificing his best years for a government which refused to grant him full rights as a citizen. Furthermore, the suffocating restrictions against the Jew robbed him of all possibilities of making a living, and he was finally compelled to leave his native home and emigrate to another land, leaving his family in poverty. In order to help the young couple in their first steps on the path of life, one of the parents used to take them into his home and provide them with their necessities for a certain period. But family love was 
not always ideal, and the young woman had to suffer most, from the proverbial mother-in-law as well as from her own mother. At times, religious struggles caused the break-up of the family: A young man limited to the study of Hebrew lore was caught by the modern spirit. As a result, he could no longer get along with his "fanatic" wife, and left her.

All these bitter experiences of life struck the Jewish woman primarily, and found utterance in her song. Thus, we find bridal-songs, wedding-songs, laments of the young disappointed wife, of the young woman who had to stay with her mother-in-law. There are mother-songs, soldier-songs, grasswidow-songs, orphan-songs, woman's-trade-songs, accusations against and curses upon the heretic husband. These songs are in a pathetic style and in a desperate sadness.

Sad and sentimental as the songs of actual Jewish life may sound, they do not comprise the entire material of Eastern folk-songs, for there exists a considerable part of joyous songs. As soon as the subject matter is religious-the Torah, Messiah, Israel and its past, the festivals, etc.-the tone becomes brighter. Furthermore, we find a great number of humorous and witty jingles, at times of subtle satire and sarcasm against both Jew and gentile. At times, peculiar conditions of Jewish life find expression in biting irony in which tears mingle with laughter.

The forms of the songs are partly in the German fourfoot meter either in trochee or in dactyl; seldom, however, in the iambic meter. They have rhyme, and consist mostly of four lines to the stanza. Some are written in alphabetical acrostics without meter. The language of the humorous and satiric songs is interspersed with Hebrew terms and Biblical quotations, with prayers and post-Biblical literature. Often Hebrew poems are paraphrased or interpreted in Yiddish or in one of the Slavic languages. 
Aside from the Yiddish and Hebrew-Yiddish song, there developed a type of song composed of Hebrew-Ukrainian, Yiddish-Ukrainian or Russian, and Hebrew-Yiddish-Ukrainian, in similar manner as the Jewish-Oriental songs are composed of Hebrew-Arabic, or Hebrew-Aramaic-Arabic, as explained in the previous chapter. Those songs were composed by Jews who lived in a Slavic environment, or by those Jewish soldiers, who, cast away in the remote Russian districts, were Russified to the extent that their vernacular became more Russian than Yiddish. There are also imitations of Ukrainian folk-songs in a Judaized form, Jewish themes being inserted into shepherd and love-songs. The religious songs have the responsive form mostly, while the love-songs and those dealing with social problems are for solo-the outpouring of a single soul in solitude and despair.

The texts of the folk-songs, in so far as they have been retained, seem to be of no earlier date than the beginning of the nineteenth century, for the songs reflect events which occurred during that century. But no song is to be found, at least not in the material published, which refers to events of previous times, such as the Chmelnitzki pogroms or the pseudo-messianic movement of the seventeenth century. No doubt, there were folk-songs created which voiced those tribulations, but they were forgotten, or superseded by new poems bewailing new tragedies.

Following this survey of the texts, we turn to the musical part of the songs, to their tunes. Upon examination of the musical material employed in the Eastern folk-songs, we find these elements:

Group (A) Biblical and Prayer modes are employed either in their original unrhythmical form, or are shaped in rhythmical melodies. This type of music is usually employed for texts of a religious and serious nature, or for texts with 
humorous intent. Example 7 in table XXXII is a song in the three languages, in Ukrainian-Hebrew-Yiddish, called Cheshbon tzedek (the righteous account). ${ }^{18}$

\section{(UKRAINIAN)}

Hei, piv ya u niediliu

I propiv ya vsu nadiliu,

$\mathrm{Oj}$, treba znati yak huliati,

Yak boha pochvaliati.

(YIDDISH)

Iber hundert yor

(Ukrainian) Yak umirati,

(HEBREw)

cheshbon tzedek

(Ukrainian) otdavati,

(Ukrainian)

A mi piom tai huliam

\section{(HEBREW)}

Veatoh tishma min hasho- And mayest Thou hear from mayim.
I have drunk all week

And spent all my possessions,

One has to know how to rejoice,

How to praise God.

After one hundred years I will have to die,

And to give a righteous account.

But we drink and rejoice.

The tune is based upon the prophetic mode (table VII, 6), but finishes in the Ahavoh-Rabboh mode. Example 8 is a love-song, ${ }^{20}$ and it is based upon the mode of Lamentations (table VIII, 3); while No. 9 has the Psalm-mode modified for Akdomus (table XXIII, 7) ${ }^{21}$ No. Io ${ }^{22}$ has the Tal-Geshem tune (table XXIII, 4, II). No. II is the widely known humorous song A chazzandl auf Shabbos, based upon the Adonoy-Moloch Steiger (table XII, 4). No. 12 has the character of the Mogen-Ovos Steiger, as applied for the study of the Talmud (table XIV). The text is a parody on the superstitious beliefs of the chassidim. No. 13-a love-song ${ }^{23}$ and No. 14-the familiar "philosophical" song Fregt die velt an alte kashe, are based upon the Ahavoh- 
Rabboh steiger (table XV). On this mode there are likewise founded No. 3-Hammavdil-and No. 6-a cradle-song-and many other religious and secular folk-songs.

Group (B) The bulk of the folk-songs, however, is in the MINOR SCALE, partly with the minor and partly with the major seventh. Out of one hundred forty tunes in Kipnis' collection ninety-one are in minor, while in Cahan's collection one hundred twenty-eight out of one hundred sixty-eight melodies have this scale. As a whole, the minor tunes in the Eastern folk-song exceed the tunes in other scales (Hedjaz and major) by a great majority, while the greater number of tunes of the Slavic folk-song are in major or Church-Phrygian. ${ }^{24}$ On the other hand, the old Spanish folk-songs are mostly in minor. ${ }^{25}$ The same is true with the Arabic and the modern Greek folksong. ${ }^{26}$ This relation of minor and major changes entirely as soon as we turn to the German song. In the collection of German folk-song of the eighteenth and nineteenth centuries published by $\mathrm{F}$. Boehme, ${ }^{27}$ out of seven hundred eighty, only nineteen are in minor, all the rest being in major. Considering all these facts we are prompted to accept the opinion that the preference of scale is a RACIAL EXPRESSION rather than the result of conditions of life. In other words, the folk-psychology is voiced in the scale, not the economic and social conditions, be they miserable or favorable. Major for joy, Minor for sadness, is apparently a significance which the German nations read into these scales; while the Semitic, Latin, and Slavic nations do not share this conception. Therefore we find so many joyous dance and humorous tunes in minor among the folk-songs of these nations.

The minor tunes employed in the Jewish folk-song have kinship to the Slavic as well as to the Spanish-Oriental tunes in minor. The melodic lines of Nos. I, 2, 4, 5, I 5 and 16 (in 
table XXXII) resemble those of Polish, Ukrainian, Spanish, Arabic, and old French tunes. At times it is impossible to identify the source of a melody without words, to decide whether it be of Jewish, Spanish, French, Polish, or Ukrainian origin. Such examples as $28-3$ I stand as evidence that a melody can be found in any of the above-mentioned folk-songs, yet No. 28 is of Polish origin. ${ }^{28}$ Likewise can the origin of the melody No. 29 be argued, though it is a Portuguese folk-song. ${ }^{29}$ A motive like No. 30 is very familiar in the Yiddish folk-song. In Chapter XX we will meet it in a tune by E. Zunser; yet it is, nevertheless, in an old Spanish folk-song of the fifteenth century which was published in 1575 by Francesco di Salinas of Burgos, and which was set to a satiric text dealing with the expelled Jews from Spain in $1492 .^{30}$ No. 31 could be taken as a typical Russian dance-motive. Nobody would think it a folktune originated in Bretagne (Northern France). ${ }^{31}$

This kinship in scale, melodic line, and structure may account for the fact that it is difficult to distinguish between Jewish, Slavic, and Roman tunes, if there are no Synagogal motives interwoven in them which point to an ancient SemiticOriental origin. Thus, Nos. 2, 5 and I 5 may with equal justification be considered either Jewish creations or adoptions from the Slavic song. There are a great number of such tunes adopted from Ukrainian, Polish, and other Slavic sources of which Nos. 17-27 are further examples. Folk-tunes thus taken over show interesting changes. No. 17, a love-song, originated in the Slovak national anthem Over Tatra, as illustrated in No. $18 .^{32}$ A comparison of the two shows that in order to suit its iambic text, the Jewish version changed the rhythm of the tune to $3 / 4$, and extended the second period of it from three to four bars by creating a resting point on the fourth bar. In similar manner were Nos. 19-20 adjusted to text and taste. The latter is an Ukrainian folk-song, ${ }^{33}$ considerably abbreviated 
and reshaped. In Nos. 22-23 the original tune is developed by the addition of a sequence built on the first period. ${ }^{34}$ Nos. 2627 are Ukrainian tunes, embellished, arranged in $4 / 4$ rhythm instead of $2 / 4$, and concluded with a coda. ${ }^{35}$ Many tunes, suiting Jewish text and taste, were retained in their original form, as for example Nos. 24-25. Here, both the Yiddish and the Ukrainian texts are based upon four-feet trochee. ${ }^{38}$

Group (C) This group contains tunes in the Ukrainian "Dorian" scale. This scale, which first crept into Synagogue song (Chapter IX), entered to a small degree also into the folk-song of the Jews in the Southeastern districts. No. 2 I illustrates this type of tune. ${ }^{37}$ It has the typical Ukrainian melodic line.

Group (D) This group comprises a small number of tunes in major, all of which are adopted from German or Slavic sources, and they are all of recent date. They spring from the time when the Jewish population in the East came into closer contact with its surroundings.

The Jewish rhythmical folk-tunes are in $2 / 4,3 / 4,4 / 4$, and $6 / 8$ time. None of the intricate rhythms employed in the Oriental song are used; neither will $5 / 4$ or $7 / 8$ time be found. The structure, too, is simple, logical. The tunes consist of $I^{1 / 2}, 2,2 \frac{1}{2}$, or 3 periods, making $12,16,20$, or 24 bars.

In summary, Jewish folk-song in Eastern Europe is based primarily upon types (A) and (B). It developed a style of its own, influenced by that in Slavic song which is Oriental. This accretion strengthened the Oriental foundation of the Jewish music.

The most noteworthy collections thus far published are:

S. M. Guinsbourg and P. S. MArek, Yevreiskia Narodnia Pesni, Petersburg, I90r. This collection contains three hun- 


\section{TABLE XXXII}

\section{Tunes of the Eastern Ashkenazic folk-song}
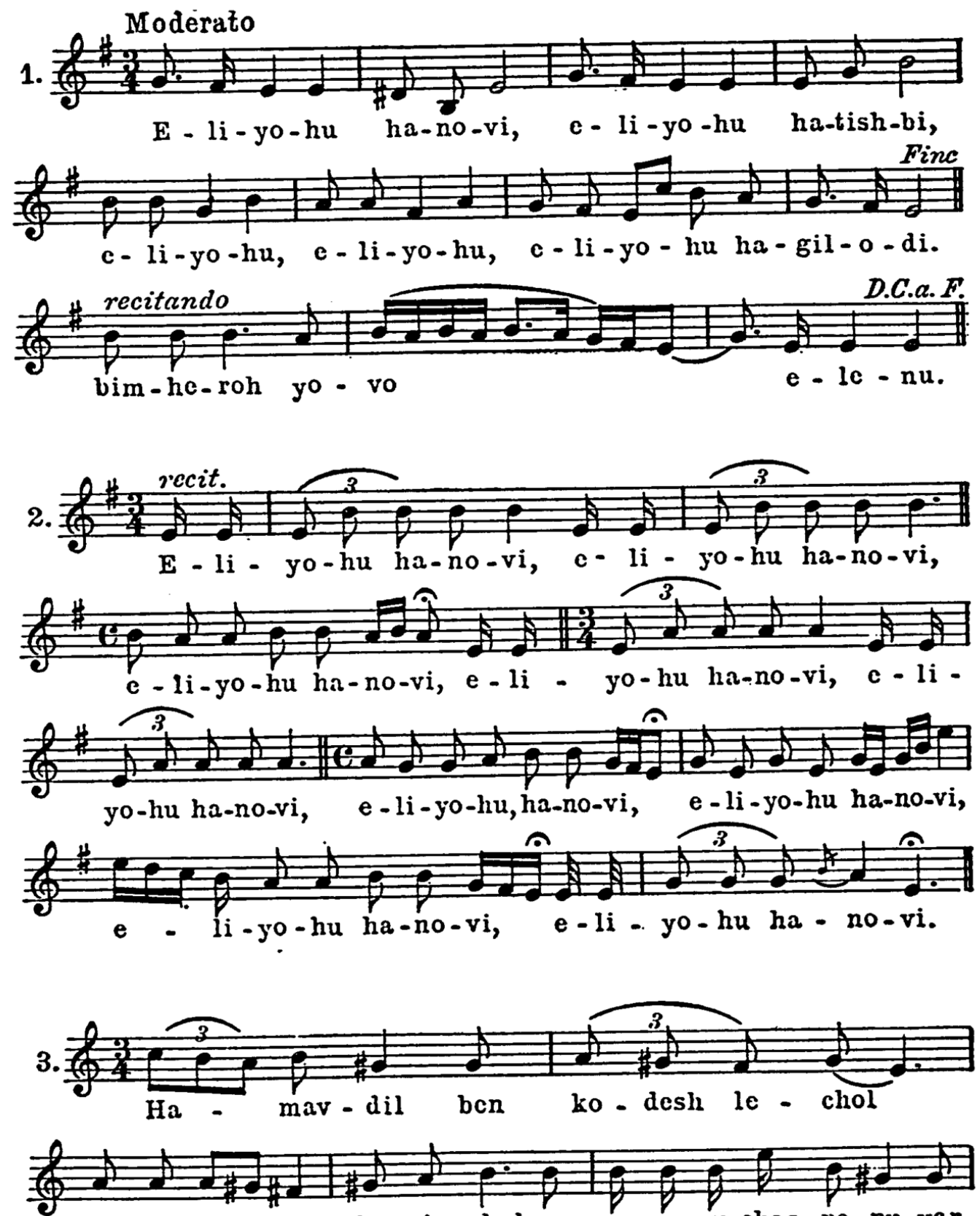

cha-to-sc - nu hu yim-chol, zar-e - nu ve-chas-pe-nu yar-

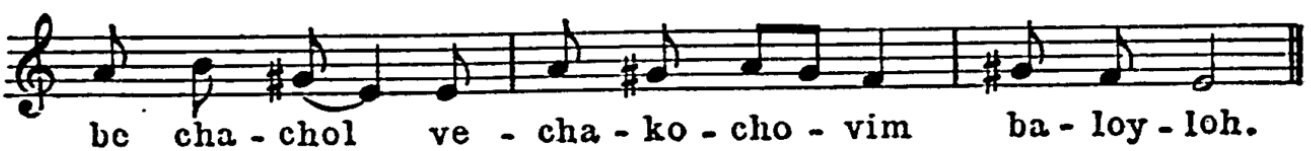




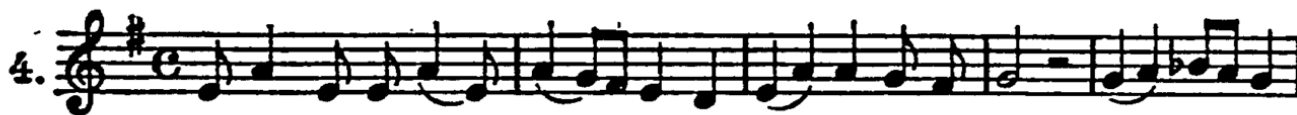

O-mar a-do-noy le - ya-cov,nein fo-te-rl, nein, al ti-roh

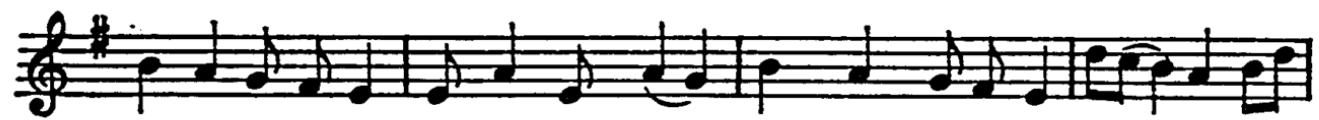
av-di ya-a-cov, hob nit kein forcht main knecht ya-a-cov,nein fo-terl,
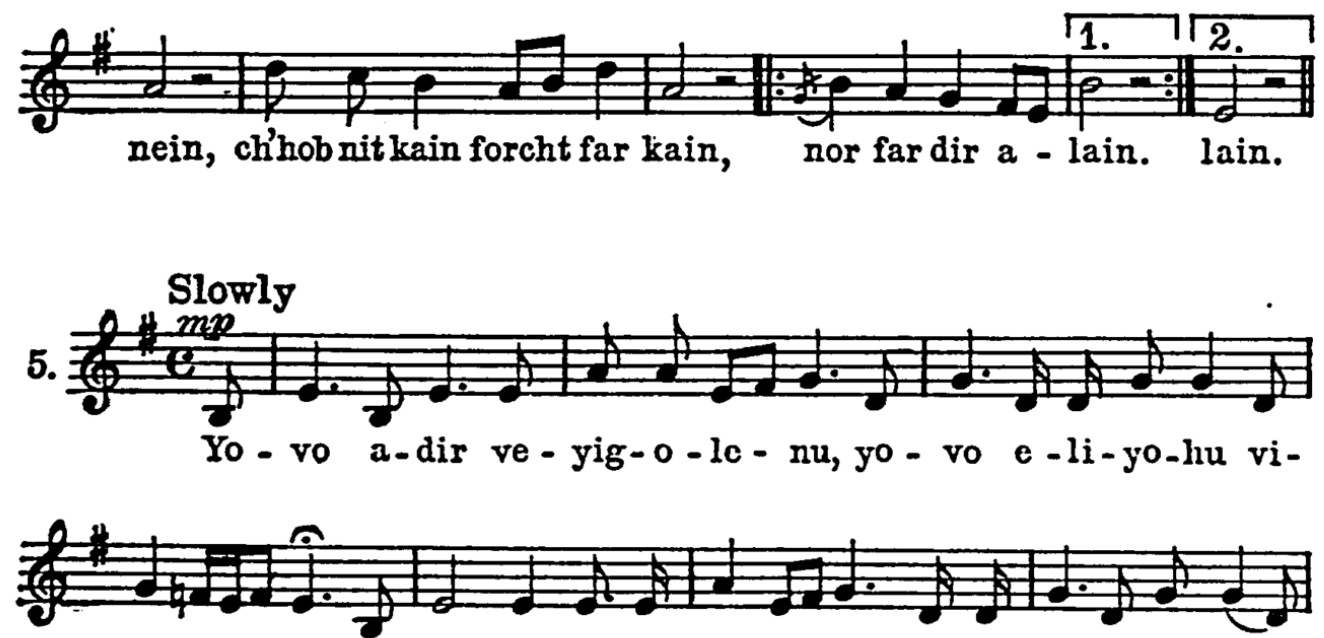

vas-re - nu. un vos vet er me-va-ser sein? ki yo-vo mo-shi-ach

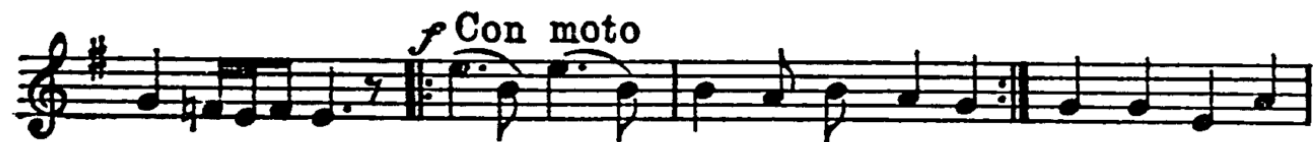

tzid-ke - nu. gvald, grald ven vot er ku-men, ven zshe,venzshe sha!nit shrei er vet shonku-men,

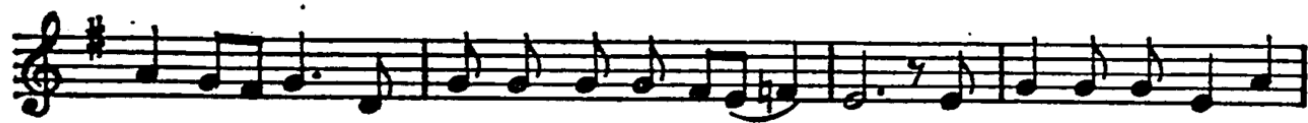

vet dos sein, bim-he-roh ve-yo-me - nu. un vos far a tog vet

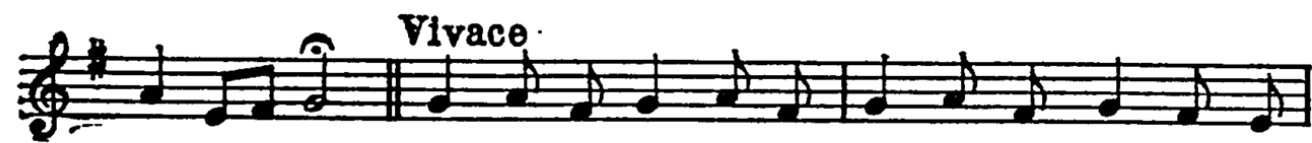

da mols sein? yom gi-loh, yom ri-noh, yom di-tzoh, yom ched-voh,

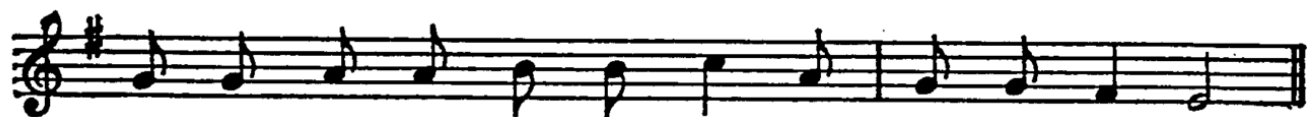

gi-loh, ri-noh, di-tzo ched-voh, ha-le - lu - yoh. 

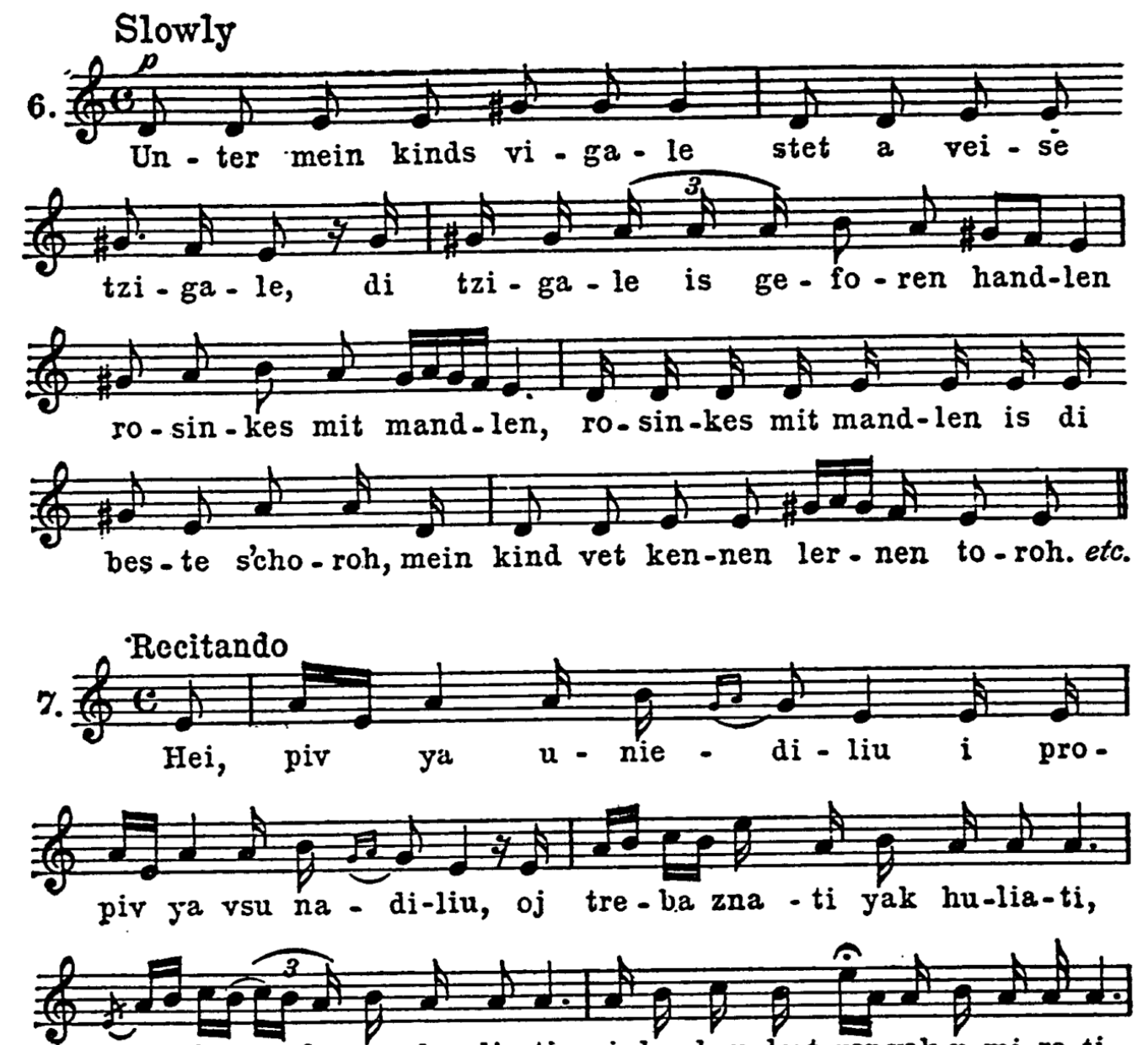
yak bo - ha po-chva-lia-ti, i-ber hun-dert yor yak u-mi-ra-ti
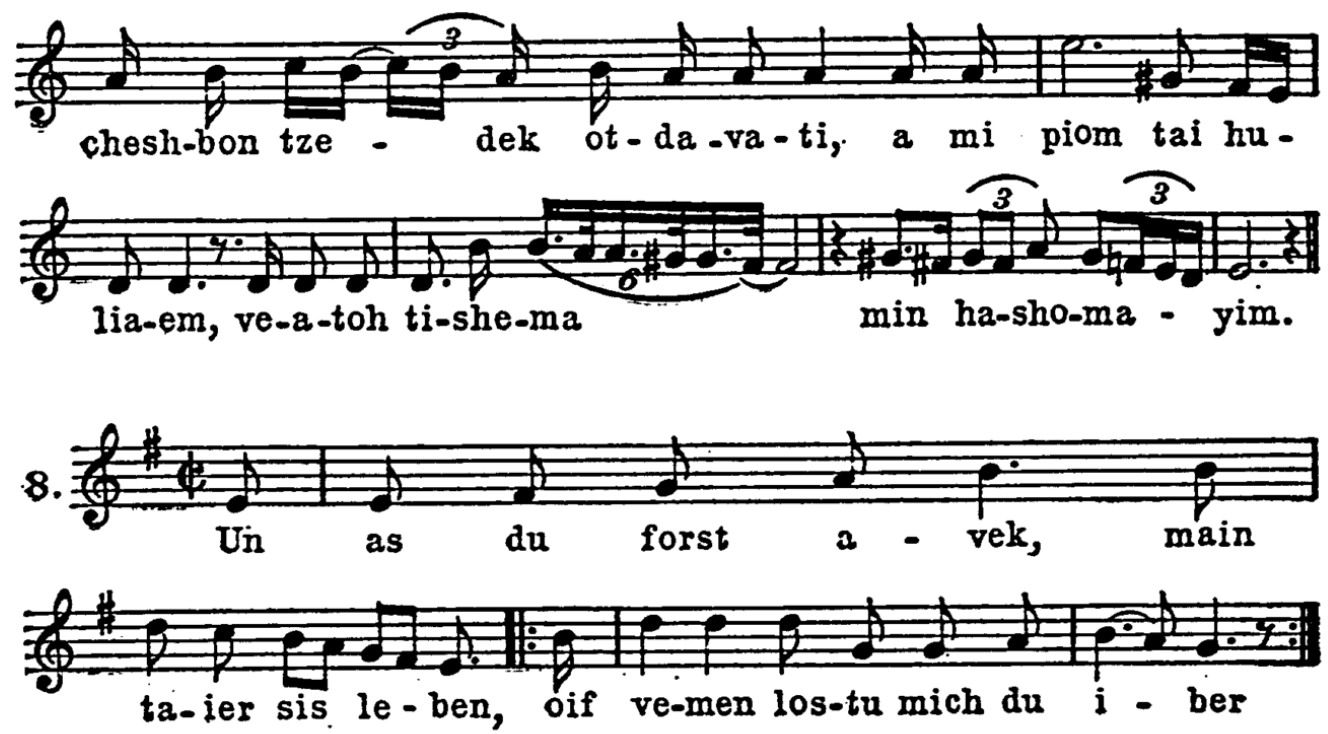

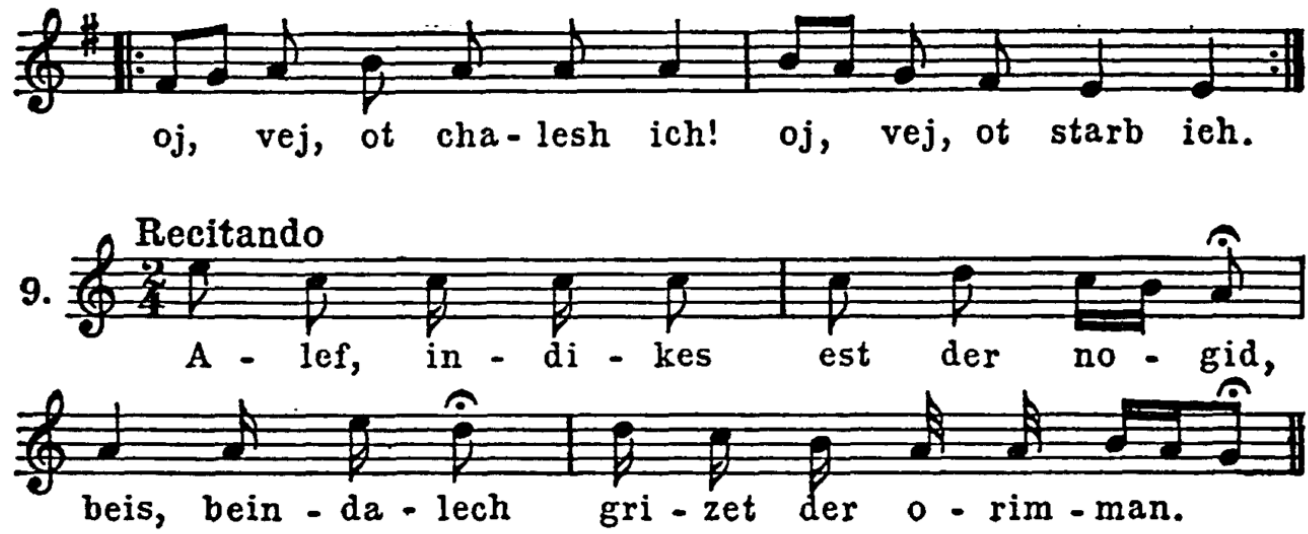

Recit.
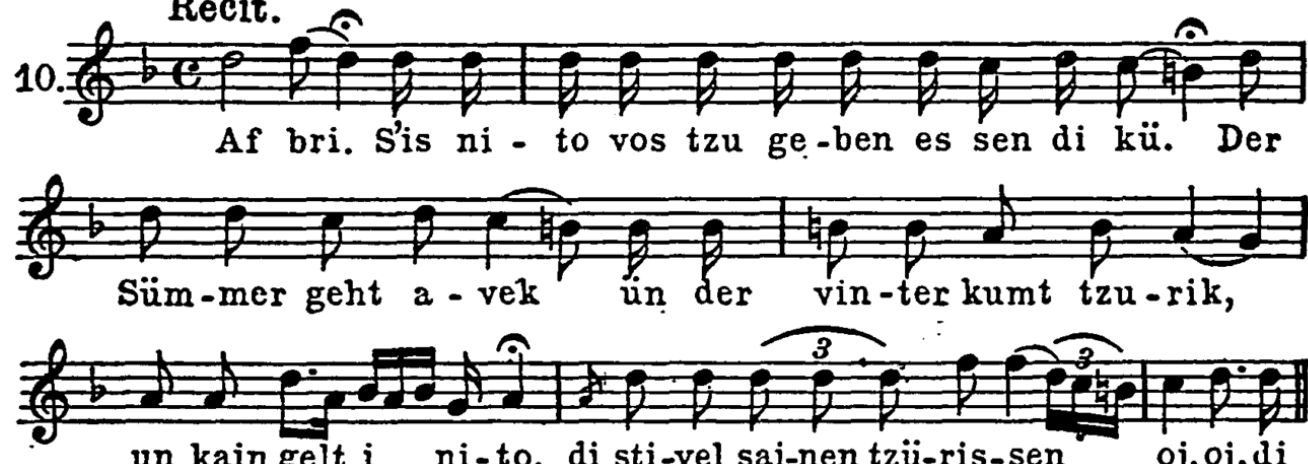
un kain gelt i ni-to. di sti-vel sai-nen tzü-ris-sen oj, oj, di
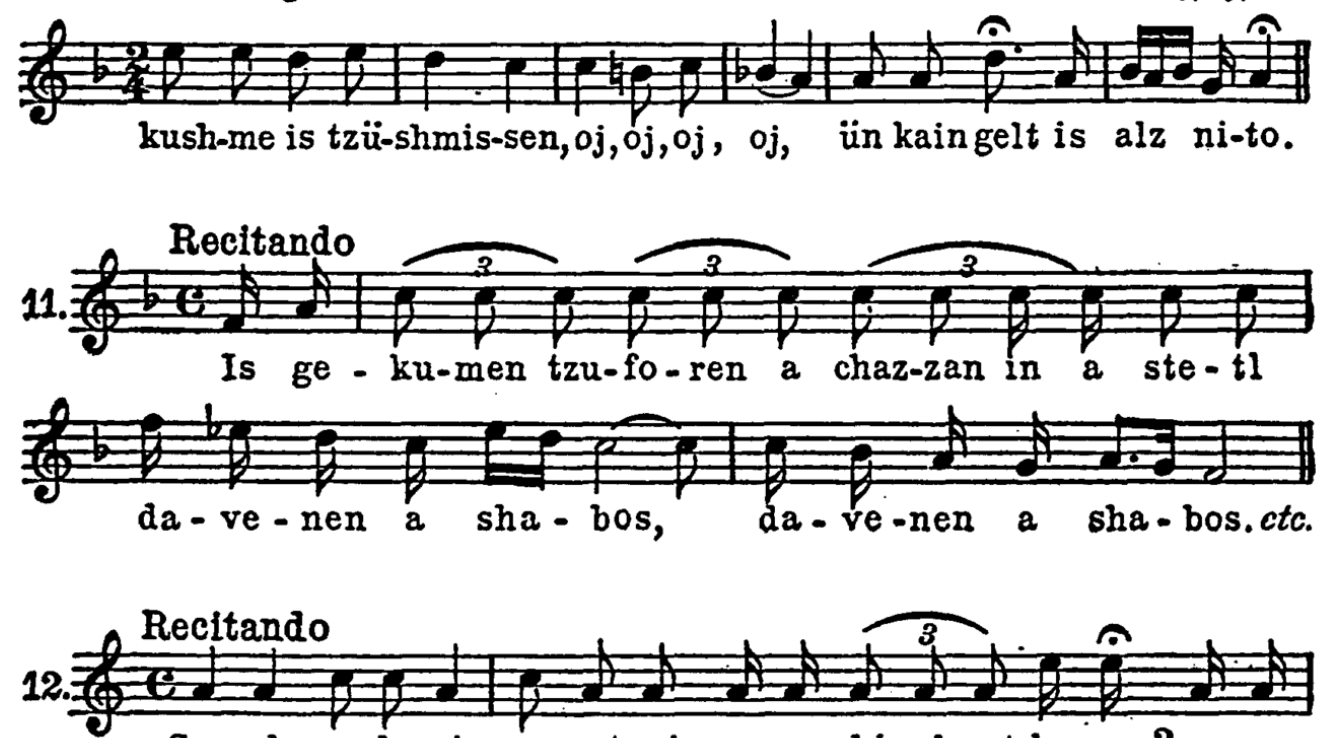

Sog zshe re-be-niu.vos vet sein as mo-shi-ach vet ku-men? as mo-

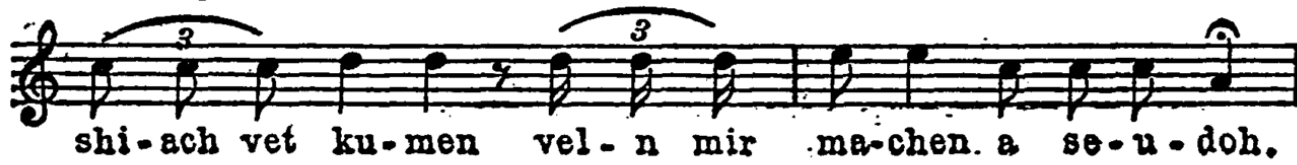



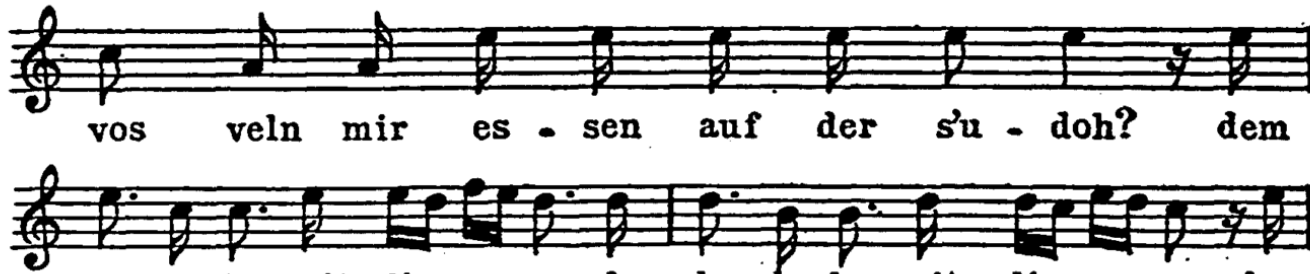

shor ha bar mitn liv-yo-son, dem shor ha-bar mitn liv-yo-son, dem

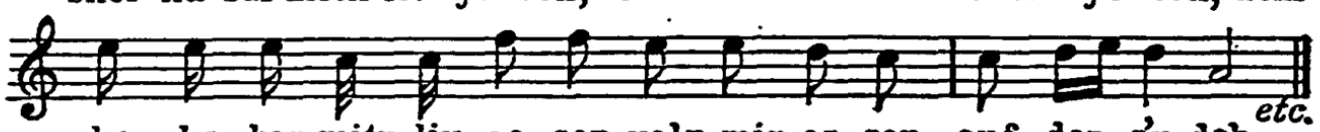

shor ha-bar mitn liv-yo-son veln mir es-sen auf der s'u-doh.
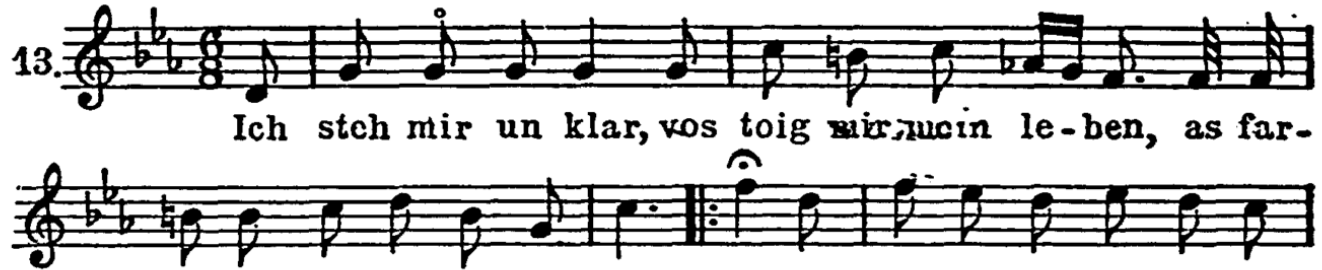

vo-gelt bin ich fun der velt, oj, ich seh far mir, veh is mir,

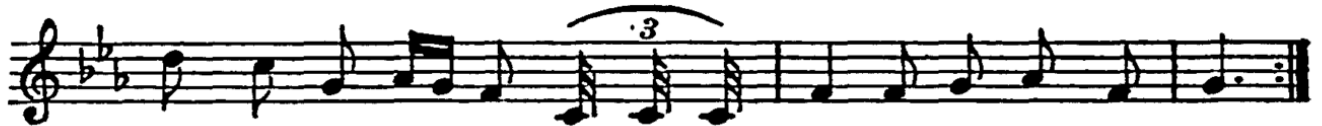

mein tai-cr le-bcn, as un-ser lie-bc is shon far-stert.

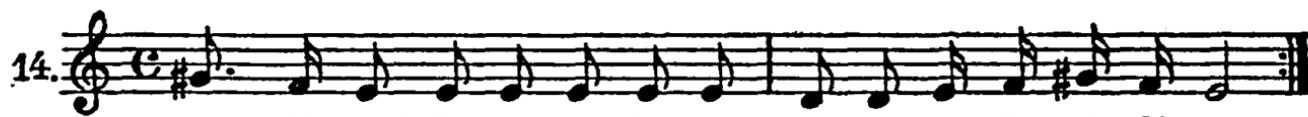

Fregt di velt di al-te ka-she: tra-la tra-di-ri-di-ra.

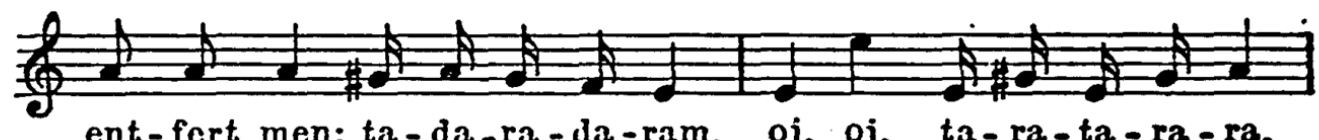

ent-fert men: ta-da-ra-da-ram, oj, oj, ta-ra-ta-ra-ra.

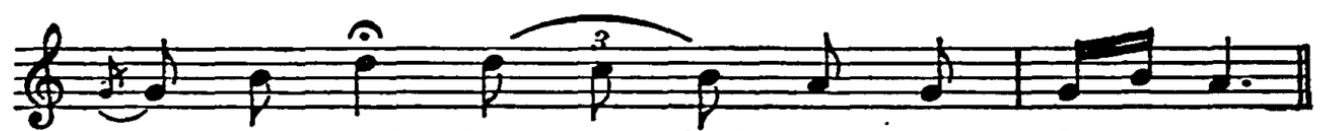
unas, men vill ken men doch so - gen: ta - ram.

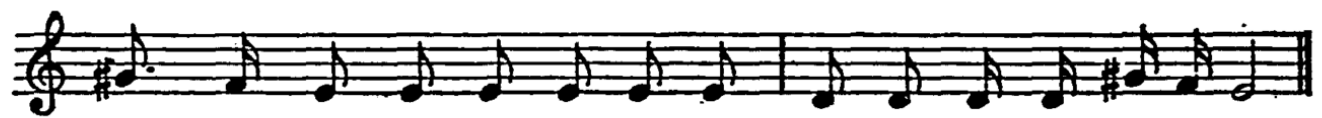

bleibt doch alz di al-te ka-she, ta-ra ta-da-ra-da-ram!

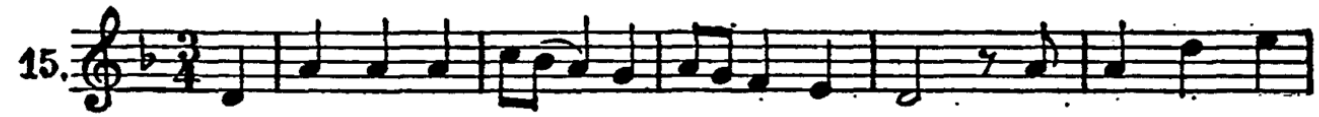

$\mathrm{Pa}$-pir is doch vais un tint is doch shvartz, tzu dir main sis 


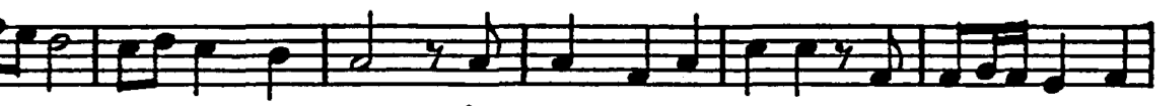

le-ben tzit doch main hartz! chvolt sten-digge - sc-sen drei tog noch a-

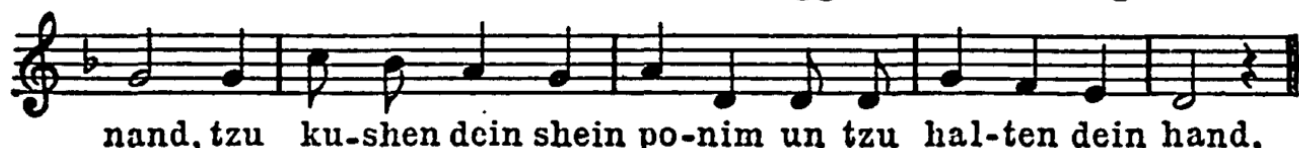

nand, tzu ku-shen dein shein po-nim un tzu hal-ten dein hand.
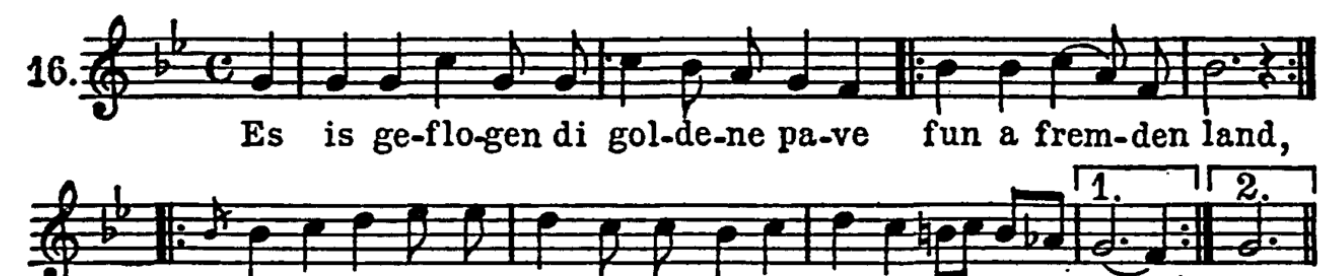

hot si far-lo-ren dem gol-de-nem fc-der mit a gro-ssen shand. shand.
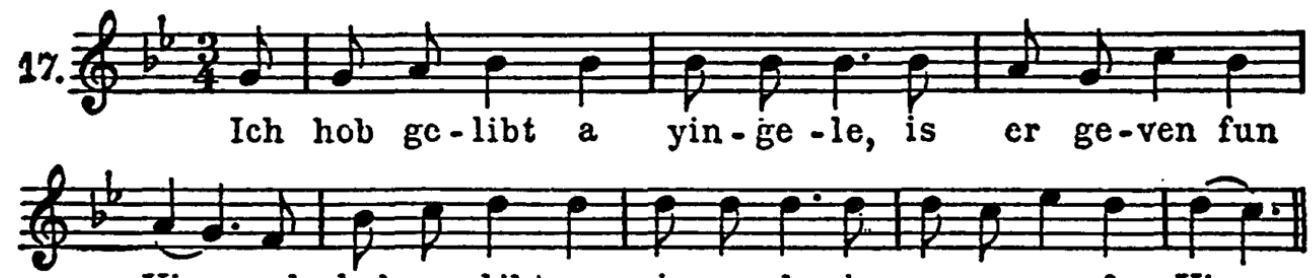
Vien, $2 \mathrm{ch}$ hob gc-libt a yin-ge-le, is er ge-ven fun Vien.

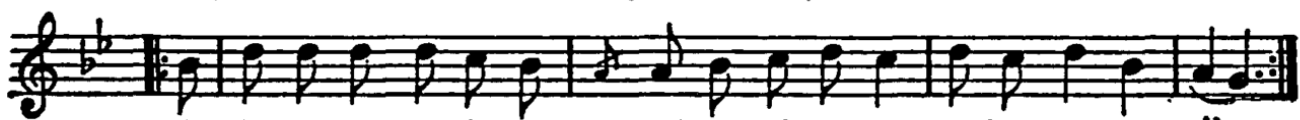

Er is a-vek ge-fo-ren tzu sei-ne el-ter-cn se-hen vos sei tün.

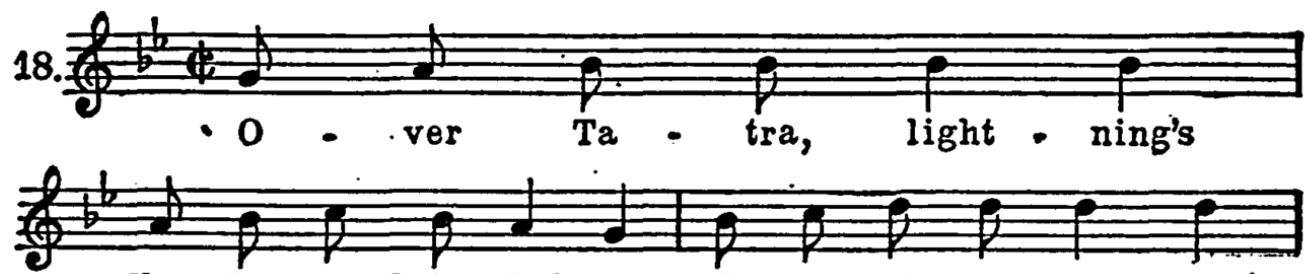

flam-ing sword is shak-en, 0 -ver Ta-tra, light-ning's
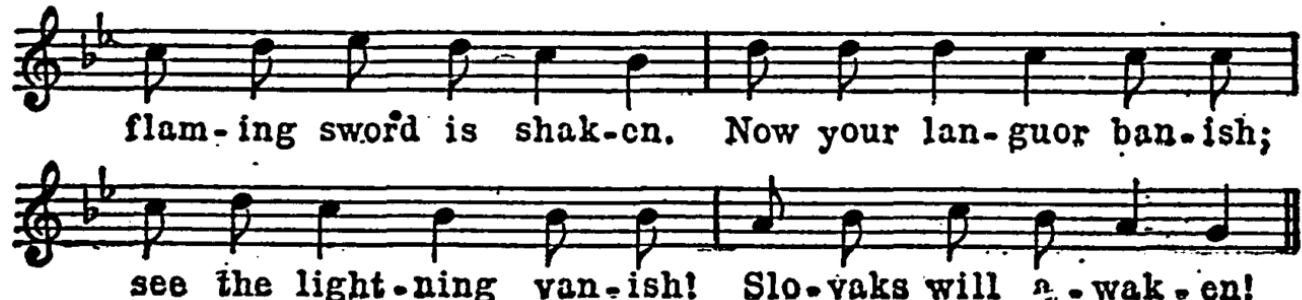

see the light,ning van-ish! Slo-vaks will s.-wak -en! 


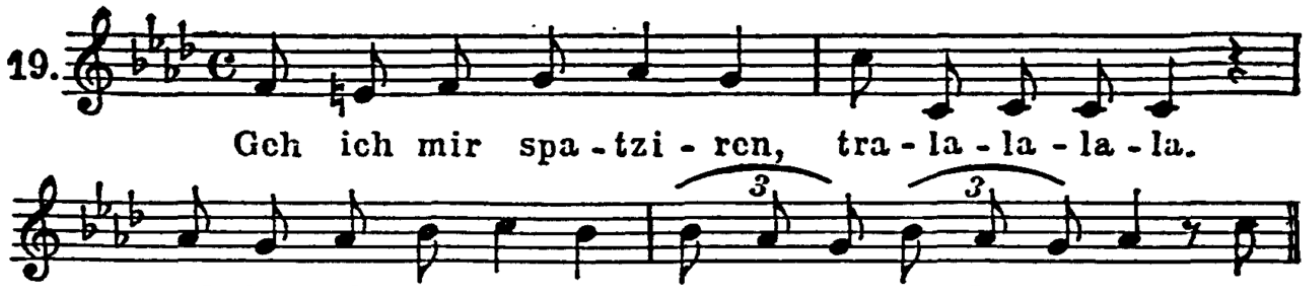

Gch ich mir sua-tzi-ren, tra-la-la-la-la-la-la, es

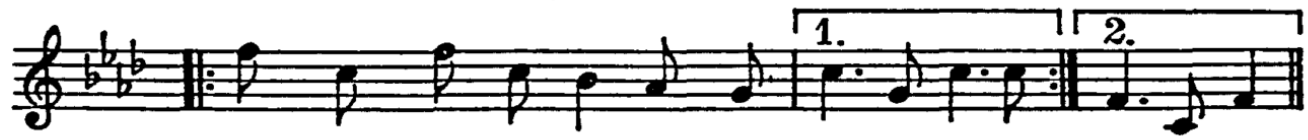

treft mich on a bo-chur, a - ha a-ha! es ha, a-ha!

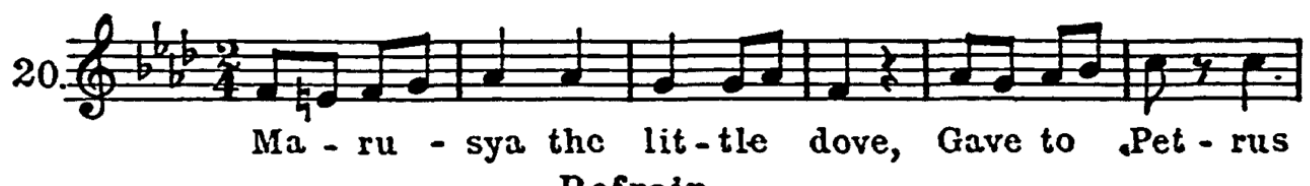
Refrain.

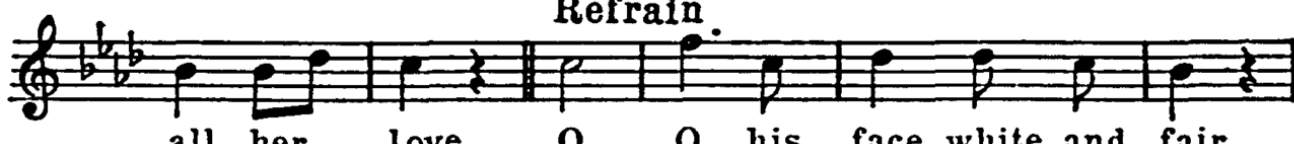

all her love. 0,0 , his face white and fair,
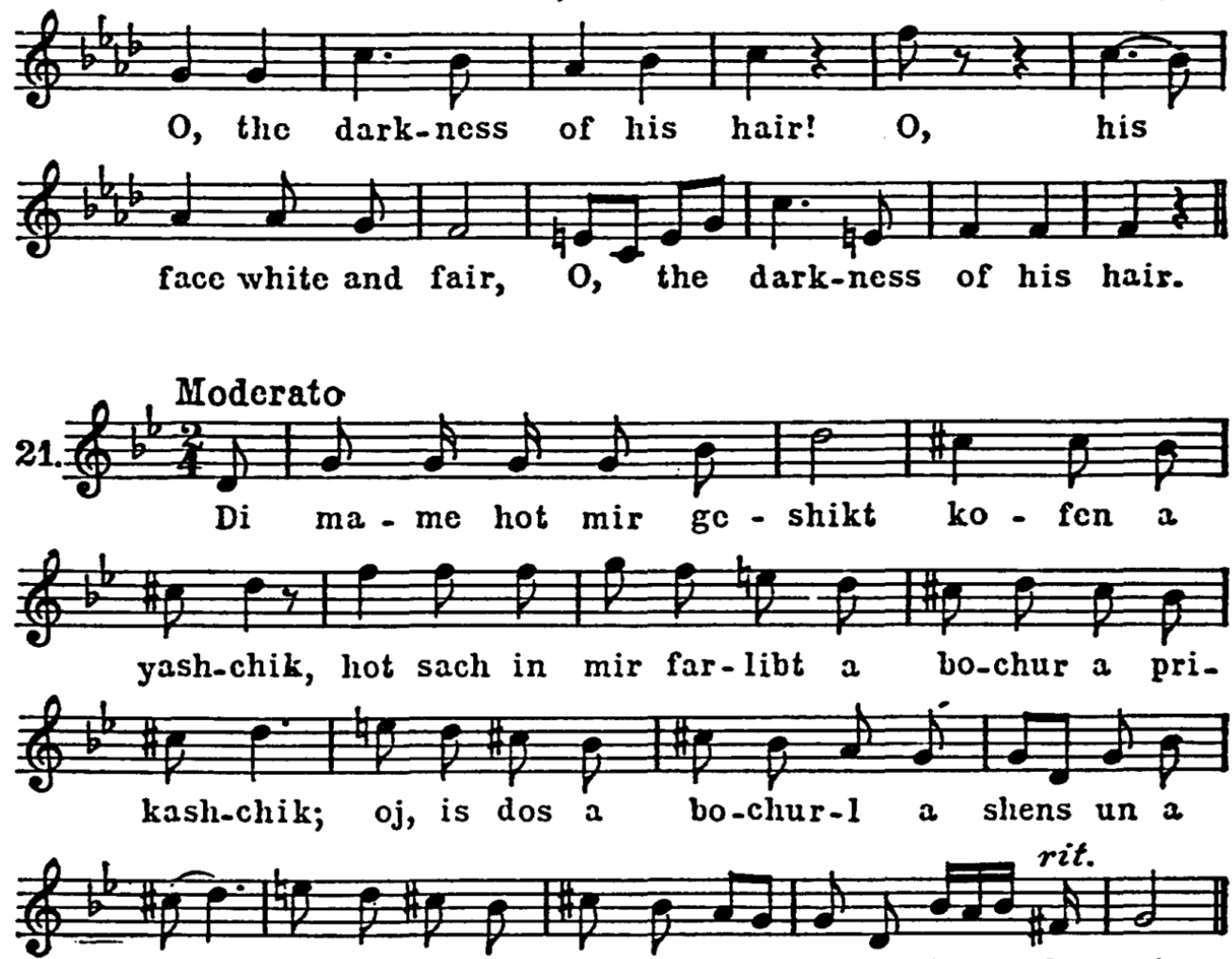

feins! mir far sei-ne bein-da-lach, ke-tze-le, du meins. 

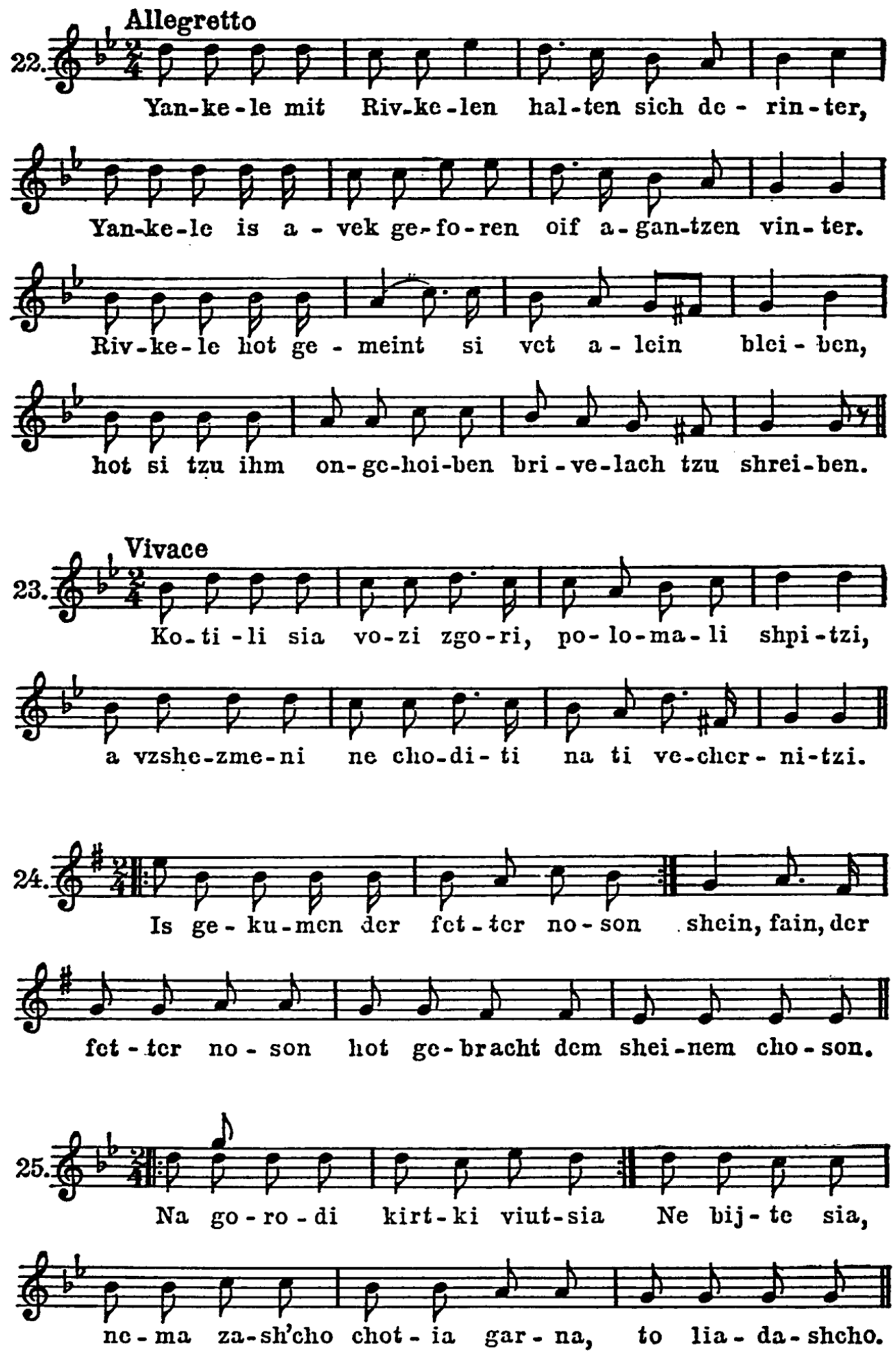

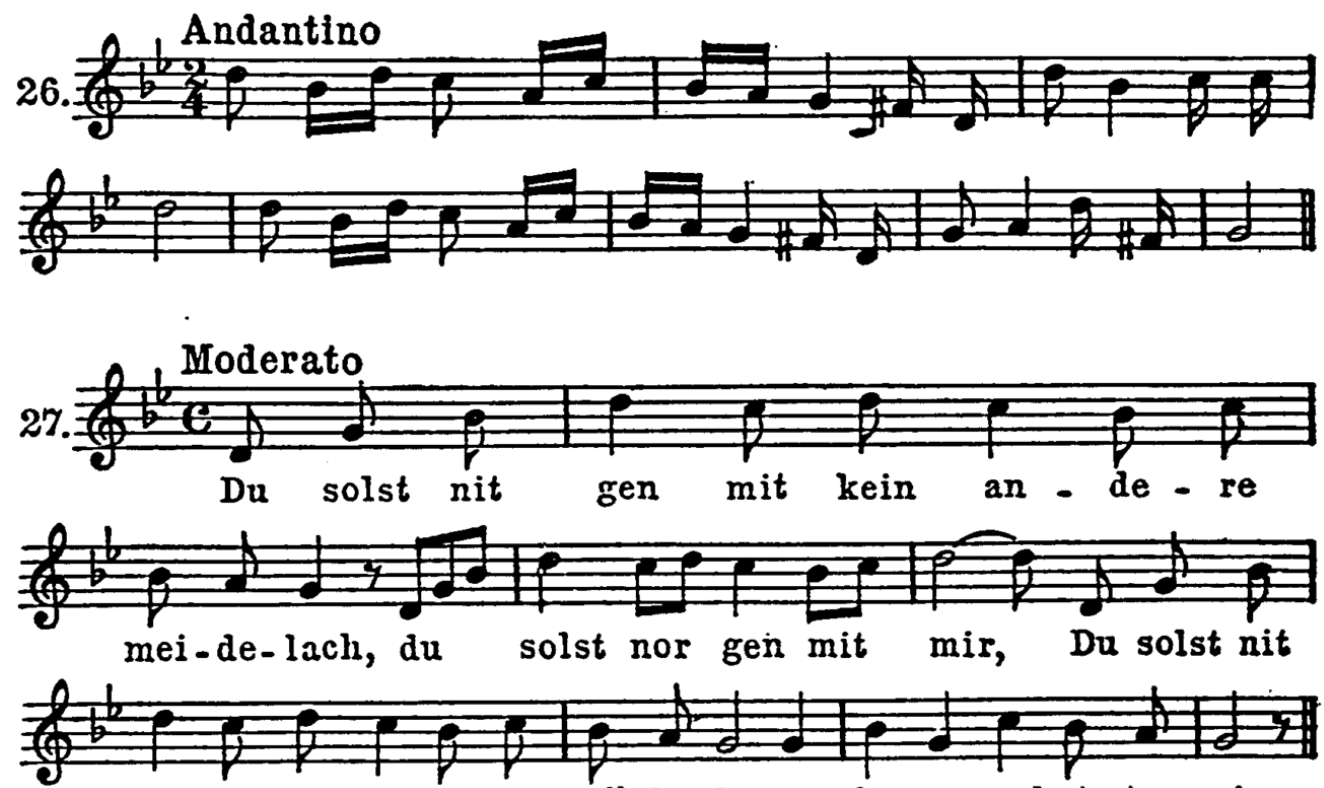
gen tzu dein ma-me in stü-be-le, nor ku-men sol-stu tzu mir.

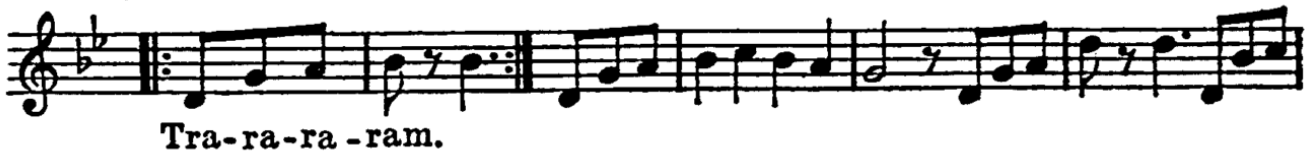

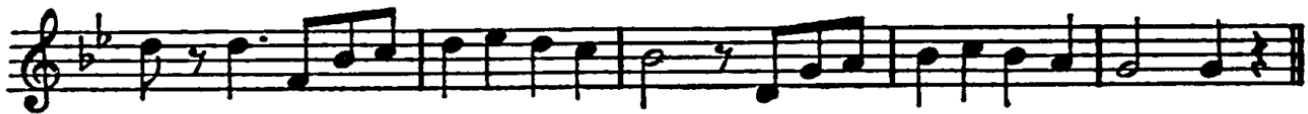

28. +
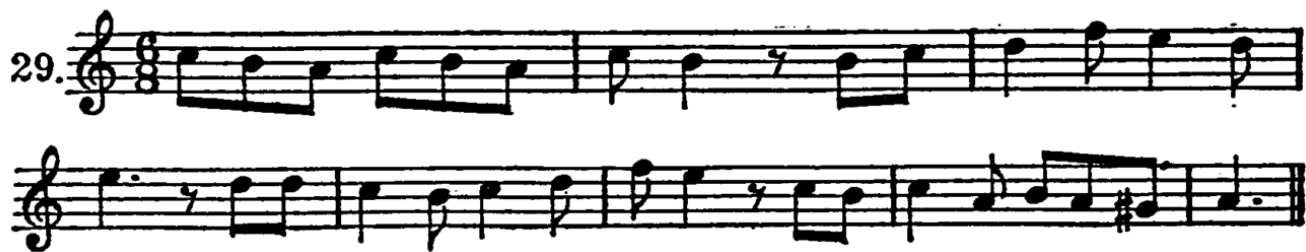

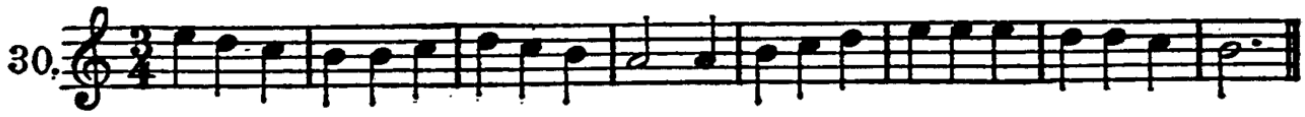

31. Allegretto

31. Allegretto 
dred seventy-six poems in Hebrew characters with Latin transliteration without music.

M. KIPNis, one hundred forty Folkslieder, Warsaw, in two volumes (without date of publication). Vol. I contains sixty songs and Vol. II eighty. The texts are printed in Hebrew characters; the melodies are given without accompaniment.

I. L. CAhan, Yiddish Folk-songs, in two volumes, New York, I9I2, containing three hundred twenty-four poems and one hundred eighty-six tunes. In a long introduction Cahan gives an interesting characterization of Jewish folk-song. A considerable number of songs of this collection are also incorporated in the two previous collections.

Fritz Mordechai Kaufmann edited Die schönsten Lieder der Ostjuden, containing forty-seven songs with a phonetical transliteration and explanations of each song. Jüdischer Verlag, Berlin, 1920.

Much material was published in various Jewish periodicals and magazines, especially in the proceedings of the ethnographical Mitteilungen für jüdische Volkskunde (editor M. GRUNWALD), Hamburg-Vienna, I898-I926.

Muzykaliszer Pinkos, Vol. I, a collection of two hundred forty-three Zemiroth and chassidic songs, edited by A. M. Bernstein, Wilna, I927.

Ganovim Lieder (Songs of Thieves) and love songs, a collection of one hundred thirty songs with music, edited by Samuel LeJMan, Warsaw, 1928.

In Chapter XXI account will be given of the collections and publications arranged for instruments. 


\section{CHAPTER XIX \\ CHASSIDIC SONG.}

In addition to its distinctive chazzanuth and folk-song, Eastern Europe made another contribution to Jewish music. The Jews in Poland and the Ukraine produced an original type of song which in its aim and composition has no counterpart elsewhere. It is generally called cHAssidic song, because it was created out of the spirit of Chassidism.

Chassidism is usually linked up with Cabbala, with mysticism. Indeed, Chassidism is a derivation of and a new phase in the development of the never completely lost mystic strain in the Jewish people. When we glance over the long history of Judaism, we become aware of the continuation of a hidden mystic stream flowing through Jewish life from ancient times on. And music is and always has been an important means wherewith to procure the mystic's inspiration and to express his ideas. The Neo-mystics in Safed, Palestine, under the leadership of the genius Isaac Luria-known by the abbreviation Ari (Chapter XVII) -made singing their duty and counted it a condition of inspiration and devotion. ${ }^{1}$ From that time onward the rivulet of mysticism pushed its way ahead without pausing, winding through many changing fields and emptying into the stream of Chassidism.

The mystic movement in Palestine created a special kind of cabbalistic song, peculiar not only in its text but also in its type of melody. These tunes have a taste of unearthliness-like a swaying mist which loses itself in infinity (en sof). ${ }^{2}$

We digress here for a moment to call attention to table XXXIII, I-3, presenting a few songs of the Palestinian cabbalists. No. $I$ is 
the intonation for Barechu for the Evening service of "New Year." We notice in this tune the long embellishment on the word Adonay (Yahwe, see note 2). The tune is in the Psalm-mode (Chapter III c). No. 2-Yedid Nefesh-is a poem by Eleazar Azkari, who was a disciple of Isaac Luria. ${ }^{3}$ This poem became very popular among the cabbalists and later among the chassidim. The tune is in modal form, in the makam Sabba (Chapter II). No. 3-Azammer bishvachin by Isaac Luria in Aramaic became likewise very popular. This tune has strict rhythm and is in the makam Nawa (Chapter II). ${ }^{4}$

Although this cabbalism was, as stated above, the basis of the later chassidic movement, yet it alone never became popular, in spite of efforts made to spread it among the people. It, therefore, remained only for world-forsakers in Palestine. But what the Palestinian mysticism could not achieve Chassidism did.

The code of the Shulchan Aruch, a program of Jewish life formulated for the purpose of keeping before the people through their daily practices the religious and ethical intent of the Commandments, had become in the course of time an end in itself, rather than a tool to achieve a spiritual goal; it had become a rigid system of laws and commandments. This decadent state roused emotional spirits among the Jewish people to infuse into Judaism new vision, or rather to re-awaken the dormant emotionalism and mystic strain.

The founder of this movement was ISRAEL BAAL-Shem-Tov, known by the abbreviation Besht. He lived in Galicia and Podolia (I700-I760). After his death, his disciples and followers continued his work, and at the end of the eighteenth century, through the influence of several prominent and inspired leaders, the movement reached its height. These leaders were called tzadikim-Righteous ones-in the sense of saints. The most outstanding among them were BER OF MESERITSH 
(I7IO-I 772), LeVI YitzchoK OF BeRditschev (I740-I8 IO), ShNeOR Zalman of Ladi (I747-I8I3), and Nachman of BRASSLAW (I772-I8II). The two latter, being fine thinkers, attempted to formulate the ideas of Chassidism into a philosophical system.

The tzadikim founded residences, called "courts" by their adherents, whereto the chassidim-the pious-ones-used to pilgrim in order to receive inspiration and salvation and to be instructed in the mysticism of the chassidic doctrine. Every chassid used to bring gifts to his tzadik, so that the earthly prosperity of the "saints" depended upon the number of their adherents.

Like other religious mystic movements, Chassidism is affected by and mixed with superstition. Its atmosphere is filled with good and evilspirits, with angels and ghosts, heaven and hell.

The tzadik is a thaumaturge and has exclusive access to the upper spheres. Only he, through his prayers, can obtain the things desired.

Throughout the nineteenth century this movement remained untouched by the realistic and materialistic Weltanschaunng of Central and Western Europe. Secluded from the outer world in remote villages, the tzadikim continued their mystic work amidst their pious-ones.

The chassidim were separated from the other Ashkenazic Jews by the establishment of their own synagogues in which they introduced the Sephardic ritual, according to the version sanctioned by I. Luria. ${ }^{5}$ They made some minor changes in Jewish religious customs. Their opponents, called misnagdim, fought them bitterly, accusing them of pantheism, even of paganism, excommunicating them, burning the books on Chassidism, ${ }^{6}$ and going to the extreme of effecting the imprisonment of one of their leaders, Rabbi Shneor Zalman of Ladi. Never- 
theless, the movement grew in Eastern Europe, and toward the end of the nineteenth century its adherents numbered from three to four million.

Chassidism set piety above learning and regarded the expression of exuberant joy as a chief religious duty. The chassidic leaders believed that vocal music is the best medium of rising to salvation. "All melodies are derived from the source of sanctity, from the Temple of music. Impurity knows no song, because it knows no joy; for it is the source of all melancholy." "Through song calamities can be removed." "Music originates from the prophetic spirit, and has the power to elevate one to prophetic inspiration." "

Song is the soul of the universe. The realm of heaven sings; the Throne of God breathes music; even the tetragrammaton Yahve is composed of four musical notes. "Every science, every religion, every philosophy, even atheism has its particular song. The loftier the religion or the science, the more exalted is its music." ${ }^{8}$

The tzadik, as the only representative of his flock, has sole admission to the heavenly spring of music. He receives the holy magic song from that source and uses it as a tool to purify the fallen soul, heal the sick, and perform all sorts of miracles. ${ }^{\circ}$ The tzadik receives the most exalted music of the Divine wherewith he destroys all songs of the pagan religions and of heresy. ${ }^{10}$ Some of the saints believed that they could achieve more in the heavens through the power of their song than through that of their prayers." "In the high spheres there exist temples that can be opened through song only." ${ }^{12}$ Some held that the sphere of music is near to the sphere of penitence. ${ }^{13}$

Since the tzadik was the only divine singer, it is evident that he was also the creator of the holy tunes by heavenly inspiration. Several melodies still circulate among the chassidim as 
compositions of tzadikim. It is, however, uncertain whether these are inventions of the sainted leaders or adopted tunes reshaped in accord with their emotions. Almost every "court" had its original style in music, its preferred mode, or at least a special tune, expressing the individuality and train of thought of the "reigning" tzadik. In case the tzadik lacked creative musical ability, he engaged a court-singer whose task it was to study the nature of the "saint," his feelings and ideas, and give them tonal utterance. The function of the court-singer was to sing tunes with or without words at the public Sabbath-meals in order to inspire the tzadik. But as soon as the singer dared to intone melodies belonging to another "court," i.e., to another tzadik, he was immediately dismissed, because in singing other tunes he desecrated the holy impulse of this tzadik. ${ }^{14}$ The tzadik also had his court-synagogue in which he frequently functioned as precentor. ${ }^{15}$ Because their song was largely inspirational and extemporaneous, chassidim paid but little attention to the musical tradition of the Synagogue. The tzadik of Gor, Isaac Meyer, used to say: "Were I blessed with a sweet voice, I could sing you new hymns and songs every day, for with the daily rejuvenation of the world new songs are created." 18 Some tzadikim opposed prayers and tunes "from yesterday." 17 Following their inspiration, they would invent new meditations and set them to tunes. Their texts were often a mixture of Hebrew and Yiddish, such as those of Levi Yitzchok of Berditschev, given in table XXXIII, 6. ${ }^{18}$ This procedure stimulated the antagonism of the misnagdim. ${ }^{19}$ Only Rabbi Jacob Joseph Katz, one of the outstanding disciples of Israel Besht (died I 782), favored traditional songs, at least those for the High Holidays. ${ }^{20}$

The songs were first rendered at the public-meals of the "court." The chassidim present would memorize them and carry them into their homes, teaching them to the pious-ones 
until the tunes became widely known. At least twice a year, on the High Holidays and Sharuoth, large pilgrimages to the "courts" were customary, on which occasions, as a rule, new melodies would be invented and sung. ${ }^{21}$

Israel Besht, so folklore has it, used to perceive words out of the tones of a melody. He was likewise able to follow the thoughts of the singer. Another saint believed that he could hear the confession of the singer, though no words were uttered. ${ }^{22}$ Shneor Zalman was of the opinion that melody is the outpouring of the soul, but that words interrupt the stream of the emotions. "For the songs of the souls-at the time they are swaying in the high regions to drink from the well of the Almighty King-consist of tones only, dismantled of words." ${ }^{23}$ A melody with text is, to his mind, limited to time, because with the conclusion of the words the melody, too, comes to an end; whereas a tune without words can be repeated endlessly. As a result of this attitude, most chassidic tunes are sung without words.

The characteristics of the early chassidic melodies were governed by the preferences of the tzadikim. Some delighted in lyric-sentimental tunes which voiced yearning and revery; ${ }^{24}$ while others liked subtle rhythms, syncopations and tempo vivace. ${ }^{25}$ Some would pour out their emotions in soft minortunes; others would give utterance to emotionalism and indulge in dance and march rhythms. Once the chazzan Nissi Belzer (Chapter XIV) gave a concert in the court of Rabbi Dovidl, tzadik of Talno. He selected his best compositions for the High Holidays in order to delight the Rabbi. But when the choir started to sing a touching tune, the tzadik interrupted the singing, exclaiming, "Oh, you want to move me to tears. Stop!" ${ }^{26}$

The material for their songs and melodies the chassidic singers drew from the Synagogue modes, from the Oriental 
elements in the Ukrainian or Slavic folk-song, and from Cossack dances and military marches. As a whole, we see here the same procedure of acquiring the material as we saw in the previous chapter. However, in the chassidic song the adopted melodies were reworked, for borrowed tunes, sprung forth in an entirely different milieu, could not satisfactorily express the chassidic spirit. Consequently, there developed gradually a typical style, a chassidic melodic line. This style branched itself out into subdivisions, in compliance with the spirit of the various "courts," voicing one or the other feature within Chassidism. But despite the emphasis laid by the tzadikim upon their individuality, they remained within the chassidic realm as it was framed by the first leaders of that movement.

Like the zealous Christians in the Middle Ages, some of the tzadikim considered it their holy duty to save secular tunes for sacred purposes. It is related of "Leib Sarah's" (I 730-I 79I) and of his disciple the tzadik of Kalif, Hungary, that they used to stroll through woods and meadows to listen to the songs of the shepherds and to rework these songs into religious meditations. Once, upon listening to the love-song of a shepherd, the tzadik of Kalif immediately copied the ditty and paraphrased it in Yiddish. Both versions are circulating among the people, the secular and the reworked religious one: ${ }^{27}$

\section{Secular}

Ros', Ros', wie weit bist du!

Wald, wald, wie gross bist du! Wolt die Ros' nit aso weit gewe'n,

Wolt der Wald nit aso gross gewe'n.

\section{Religious}

Shechina, Shechina, wie weit bist du!

Golus, Golus, wie lang bist du! Wolt die Shechina nit aso weit gewe'n,

Wolt der Golus nit aso lang gewe'n. 
Rose, rose, how far you are! Woods, woods, how large you are! The rose would not have been so far, Were the woods not so large.

The tzadik substituted Shechina (Divine Presence) for "rose" and Golus (exile) for "woods." In this sanctified form the song lived among the chassidim for about a century and a half, until lately, when it was written down and published. In table XXXIII, 4, this song is illustrated.

In the course of its development, the chassidic movement branched out in two directions: the one called "the system of Besht" with most of its adherents in Poland, Southern Russia, Roumania, and Hungary. The followers of this system claimed to be the real disciples of the founder, Israel Besht, and of his descendants. The other system was called Chabad, an abbreviation of $\dot{C}$ hochma-Wisdom, Bina-Insight, and $\dot{D} a$ ath -Knowledge. This system was founded by the above-mentioned Shneor Zalman of Ladi, with its adherents mostly in Lithuania and White Russia, ${ }^{28}$ and with its centre in Liubawitz, in the Government of Mohilev. Here the descendants of Shneor Zalman resided for about a century, establishing a dynasty of five generations, called "the Shneorsons." ${ }^{29}$ This system, although reaching toward the same purpose of attaining divine bliss, has another approach to the goal. It is impossible, the Chabad contends, to leap immediately from extreme melancholy to extreme joy. It is impossible for a human being to rise from the lowest to the highest degree without proceeding through the whole scale of the intermediate states of the soul. Great stress is laid upon each progressive stage of the development, as significant for the education of the soul and for the improvement of the spirit. It is, Chabadchassidism says, as if someone who had never seen the interior of a palace suddenly stepped into its bewildering splendor without having first passed through the corridors. Such a 
person will never be able to feel fully the glory of the palace. Therefore, the APPROACH to joy, the corridor of the palace, is very important. Every step must be achieved through deep meditation. These steps for the elevation of the spirit begin with the lowest, called hishtapchuth hannefesh-the outpouring of the soul and its effort to rise out of the mire of sin, out of the shell of the evil spirit, the klippah, and to reach the second stage, hithoreruth, spiritual awakening. Thence the devotee rises to hithpaaluth, a stage in which he is possessed by his thought; and from this state he reaches dveikuth, communion with God. Then he progresses to hithlahavuth, a flaming ecstasy; and finally he attains the highest step, hithpashtuth hagashmiyuth, a stage when the soul casts off its garment of flesh and becomes a disembodied spirit.

For this purpose the Chabad-chassidim, with even less success than the Besht sect, might seek tunes from without, because none of the gentiles has such a program underlying his folksongs. Therefore, they were compelled to create original tunes which express the meanings and the thoughts of all these stages in the elevation of the soul, tunes to be used as means for the attainment of their purpose. The founder of the Chabad system himself composed a tune, called Dem Rebbens Niggun - the Rabbi's tune-constructed to conform to his system. We give this popular melody in table XXXIII, 5 . The tune starts in largo and voices the first stage, the outpouring of the soul. With the fifth bar, con moto, the tune progresses to the second stage, the spiritual awakening. The third part, beginning with the ninth bar, aims to express the steps of hithpaaluth and dveikuth, until it reaches the stage of ecstasy. And the fourth part, from bar thirteen on, presents the stage of the "disembodied soul." According to a later interpretation, however, "the Rabbi's tune" gives tonal expression to the four realms of the universe. ${ }^{30}$ Starting at the bottom with briah- 
the creation of the lowest elements of minerals, the tune next voices the second higher realm, yetzirah - the creation of living beings. Proceeding to the third realm asiyah - the creation of man, the tune finally reaches the goal in the fourth realm, atziluth-emanation, the Heavenly region. Every Chabadtune aims to voice either all the stages of the elevation of the soul or only some phases of them. Thus, there are tunes expressing dveikuth, hishtapchuth hannefesh, hithlahavuth, hithoreruth, and so on. The latter two stages are also called Rikud -dance. The illustrations Nos. 4, 6, I4-1 8 in table XXXIII are dveikuth or hishtapchuth tunes, while Nos. 7-10, 19-22, 23-28 give tonal expression to the other stages. No. 23 consists of seven parts in Rondo-form and aims to express all the stages explained. The melodies voicing dveikuth, etc., have the free unrhythmical form, or are in a slow rhythm. The tunes for "awakening," etc., are built upon vigorous syncopated and dancing rhythms.

The melodies are based either upon the Ahavoh-Rabboh scale or upon the minor scale with minor or major seventh. Tunes based upon the major scale are very few and are adopted. In the AhavohRabboh scale are the tunes: Nos. 5, 7-13. In the minor scale are: Nos. 14-1 7, 19-23. Nos. 25 and 27 are in major.

No. 6 is attributed to the above-mentioned Levi Yitzchok of Berditschev. The tune is partly unrhythmical and partly rhythmical. Its text is mixed, Hebrew-Yiddish. The name A Dudule refers to the playing on the primitive shepherd's instrument, Dudelsack-bagpipe. Dudlen in German means "to tootle." Here, however, the name is used as a play upon the word $d u-d u$-le-Thou, Thou! The tzadik addresses himself to God with the endearing German diminutive "le." The contents of the text are as follows: "O Lord of the world, I shall sing to Thee a 'du-du-le'; where can I find Thee, and where can I not find Thee? Wherever I go Thou art present, 


\section{TABLE XXXIII \\ Cabbalistic and Chassidic Songs}
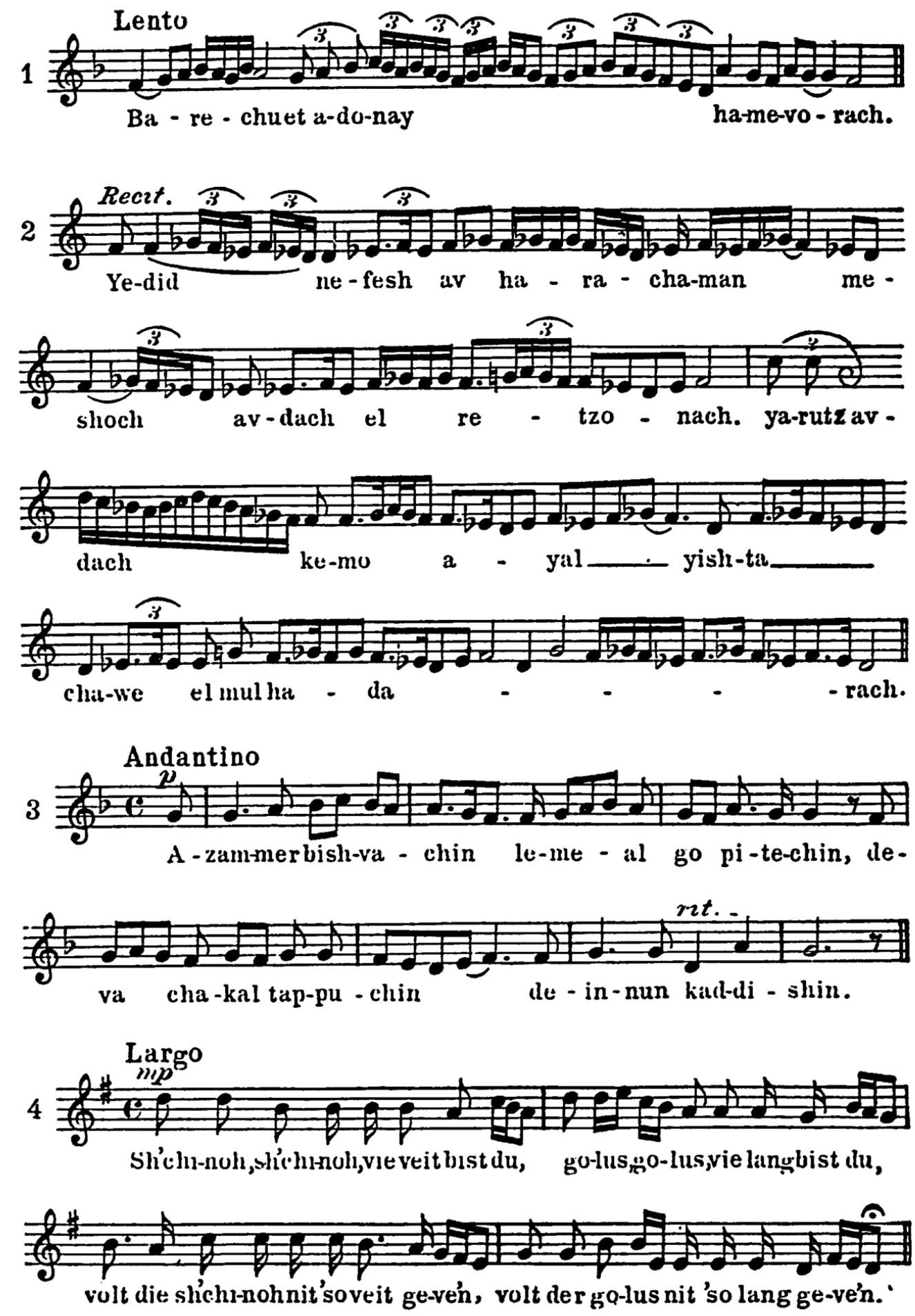


\section{a) Tunes in Ahavoh-Rabboh Mode}

5

Largo tror to 泉conmoto Andante
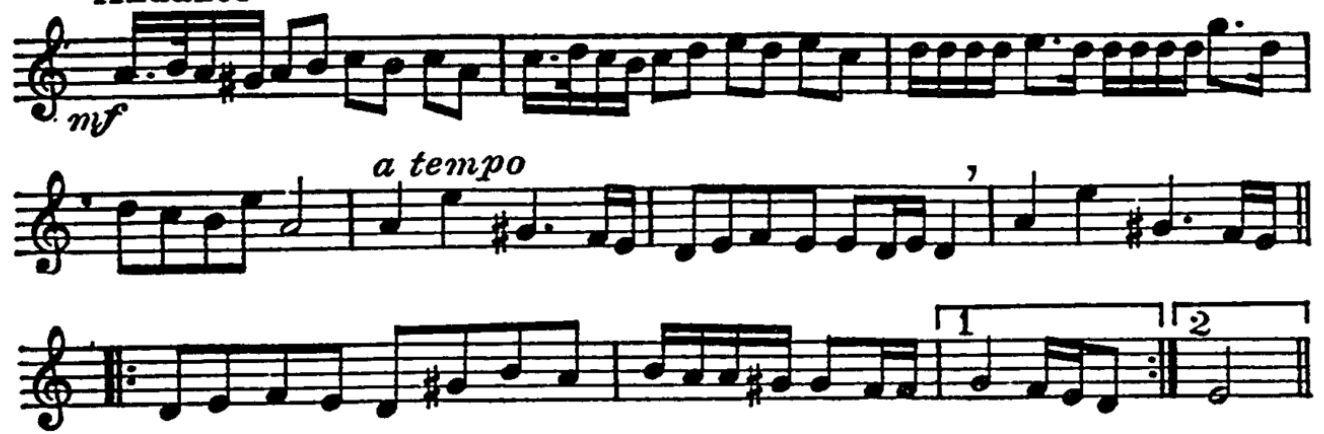

\section{A Dudele}

Andantè con moto. Recit.

6

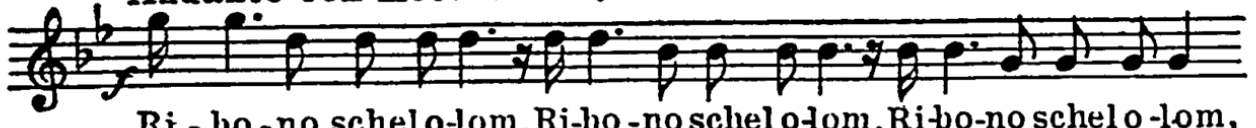

Ri - bo -no schelo-lom, Ri-bg -no schel otom, Ri-bo-no schelo-lom,
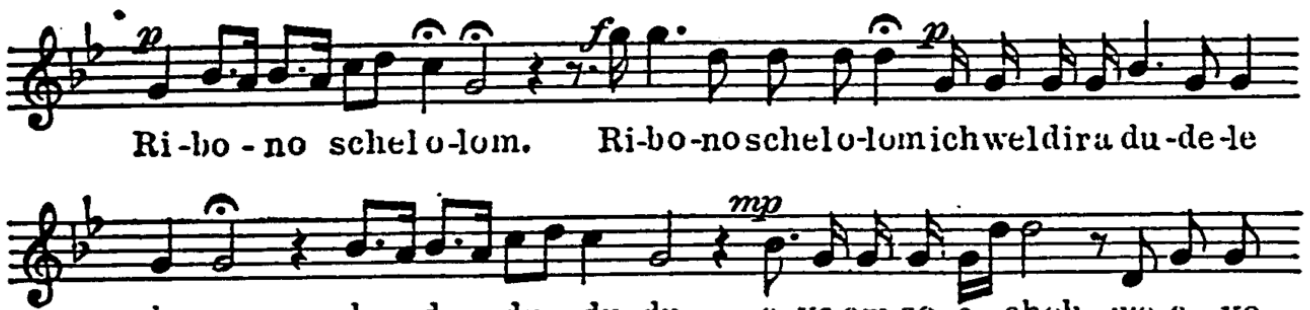

sin-gen, $\quad d u-d u-d u-d u-d u . \quad u-y e$ em-zo-e-choh we-a-ye
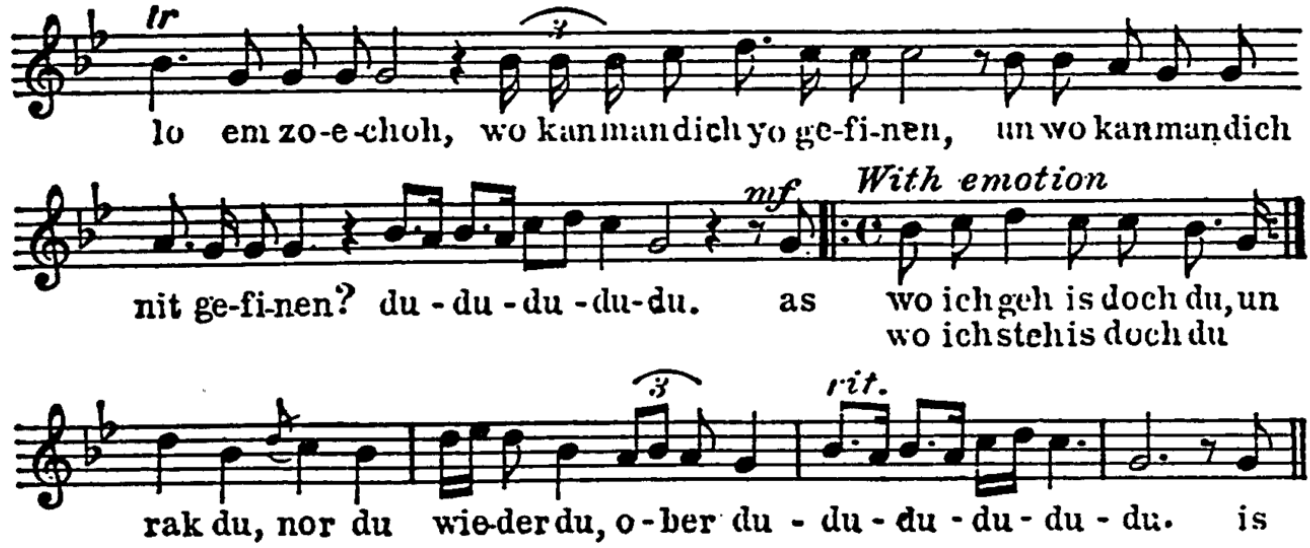
Recit.
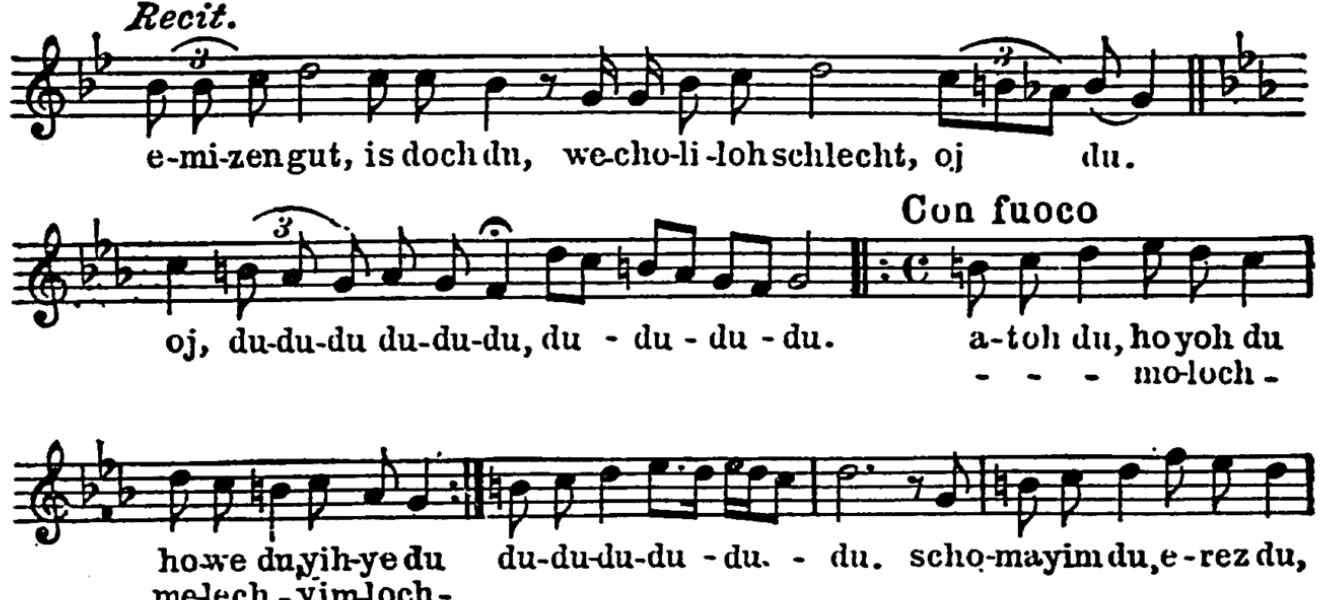
melech - yimloch -
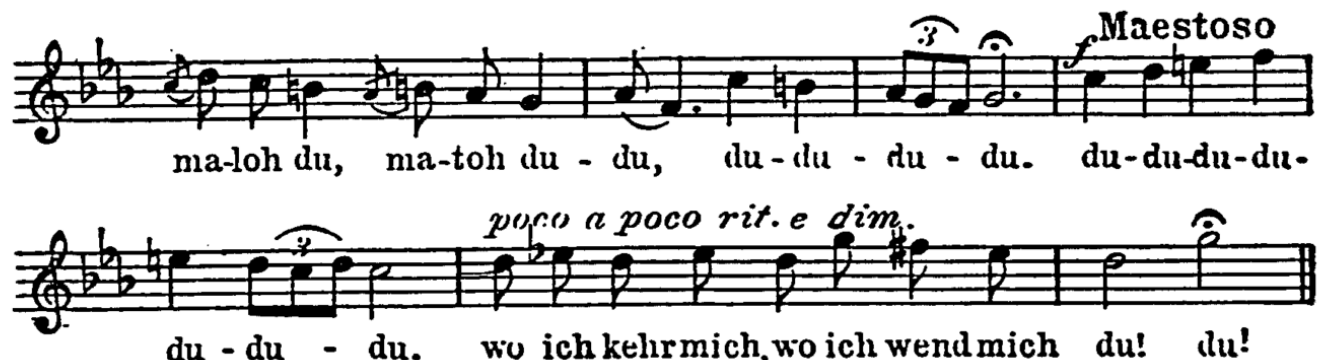

$d u-d u$ - du. wo ich kehrmich, wo ich wendmich du! du!
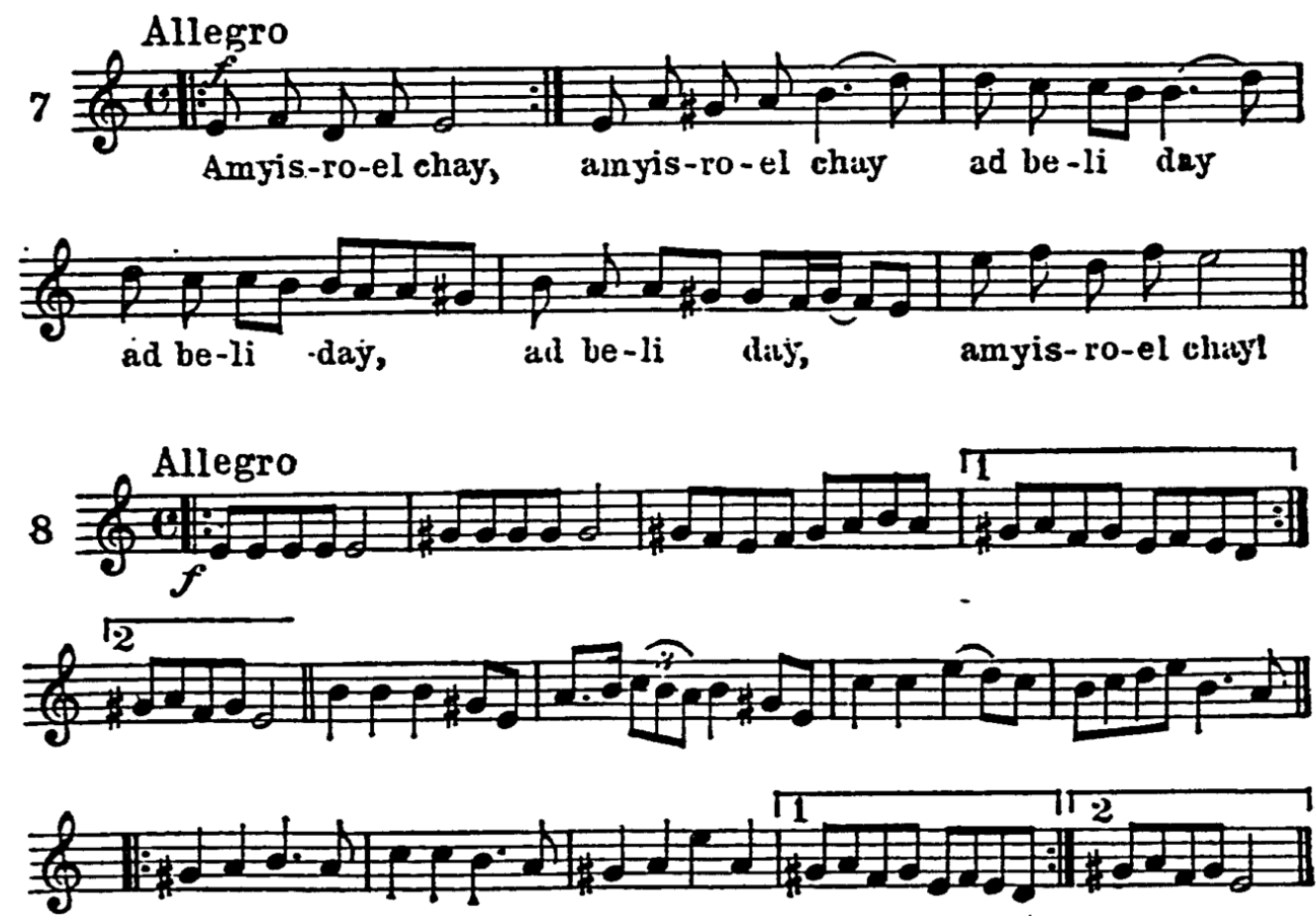
9 色过

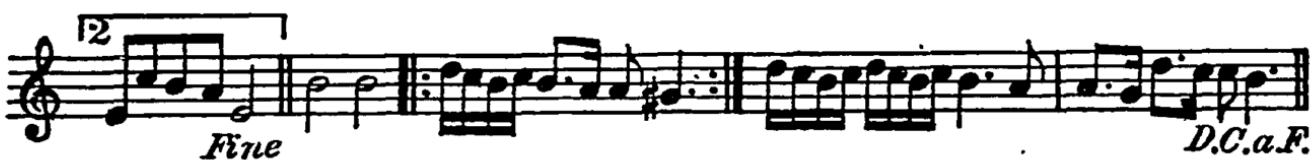
10 Allegro vivace

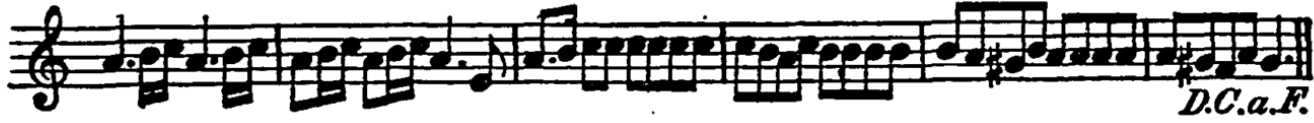

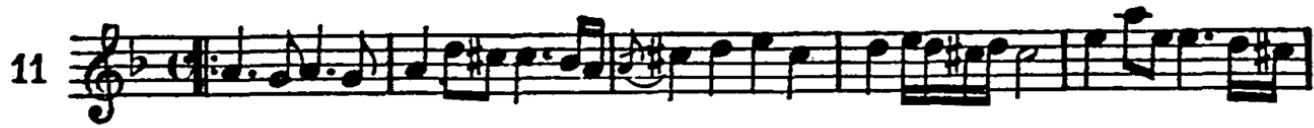

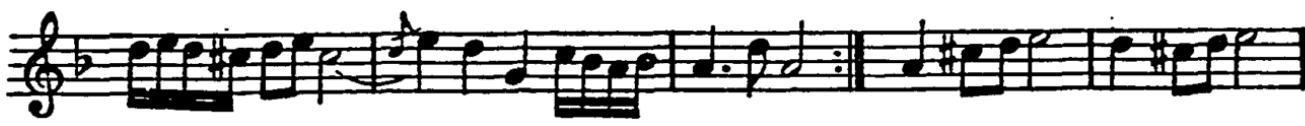

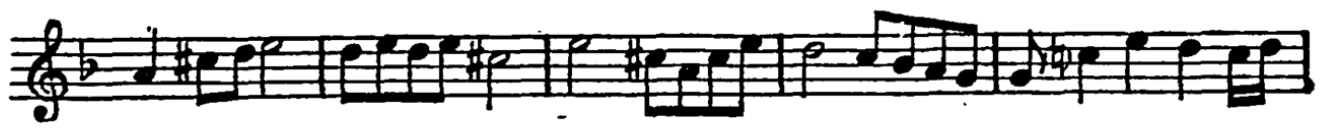

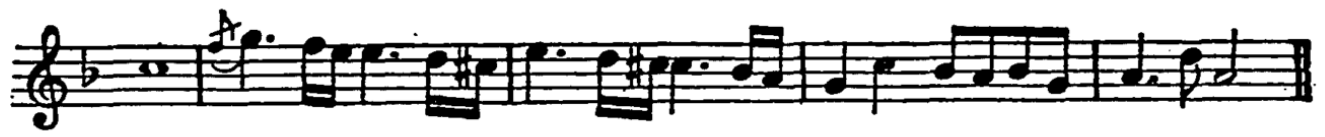
12 Polnisch

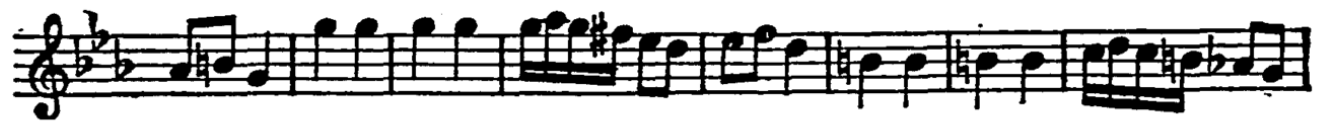

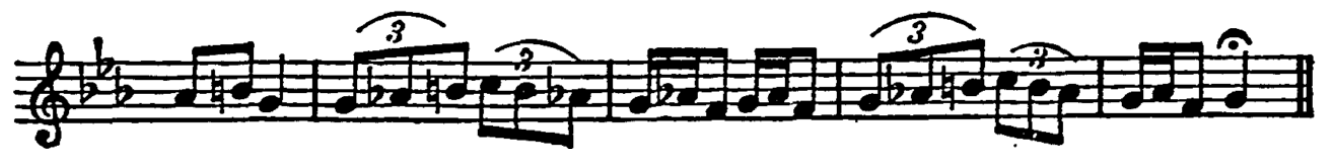


Rondo

13

Allegro moderato 1 (15:

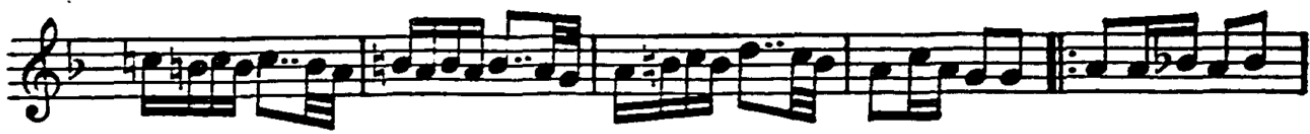

$\Rightarrow$ for

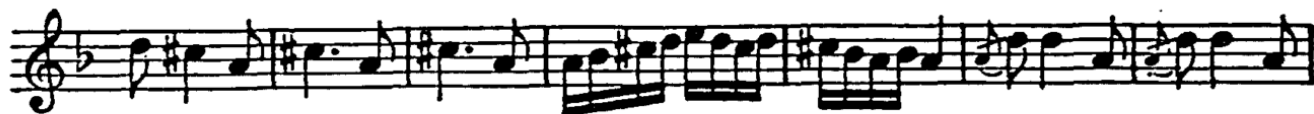

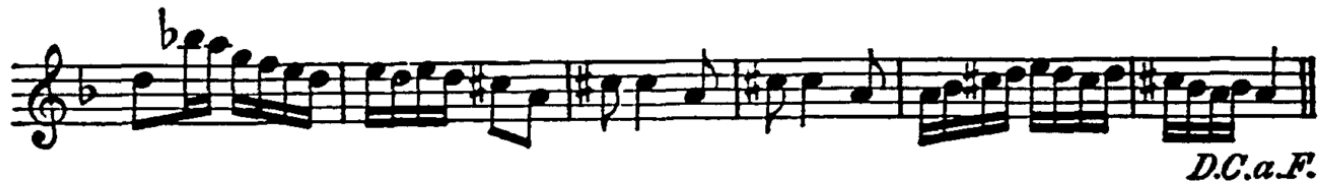

b) Tunes in Minor

Recit.

Con moto,mysterioso

142

Be-ne he-cho-loh dich - si-fin

le-nechzezivdiz-er an-pin

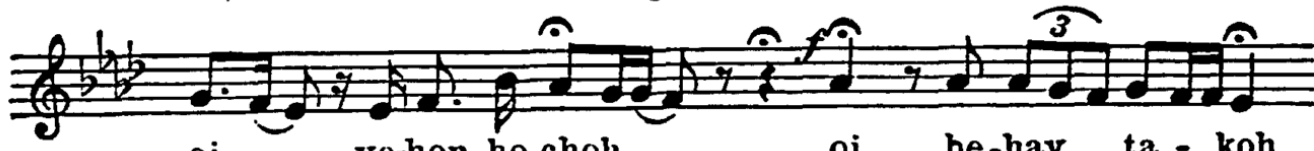

oj

ye-hon ho-choh

oj be-hay ta - koh

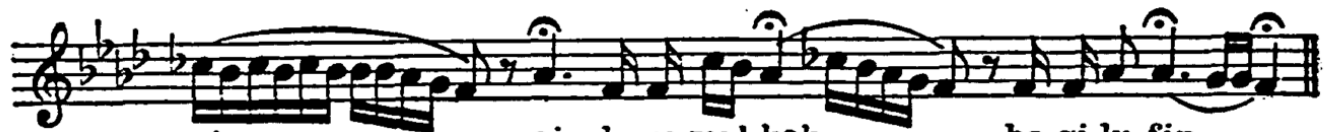

oj

oj de-ve mal-koh

be-gi-lu-fin.

Lento

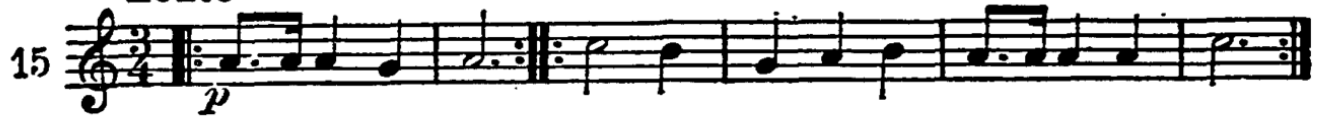

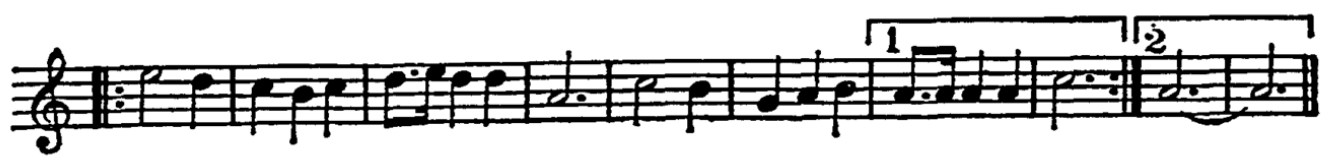


16 Lento \% 1 With emotion

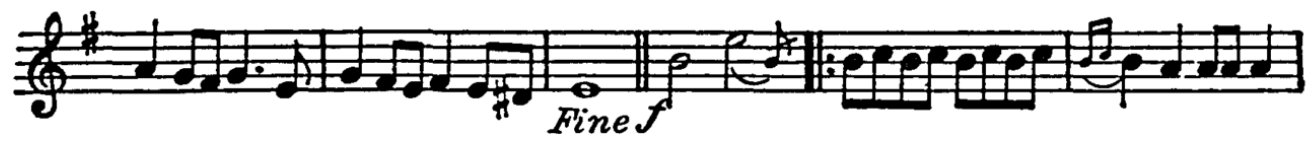

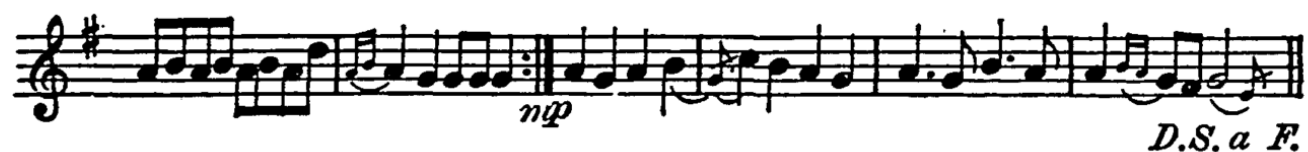

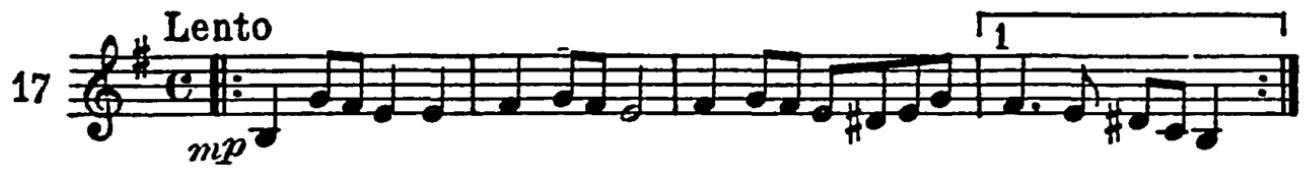
独 Do \%

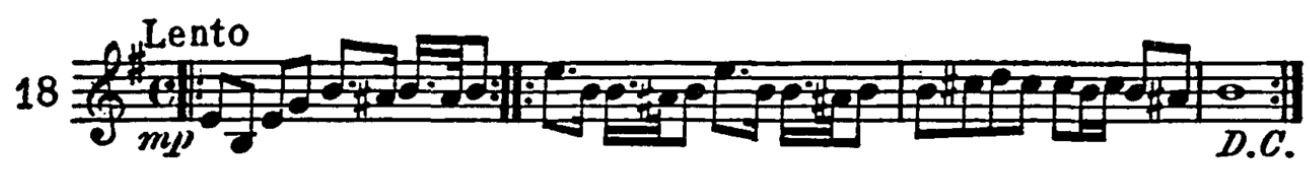

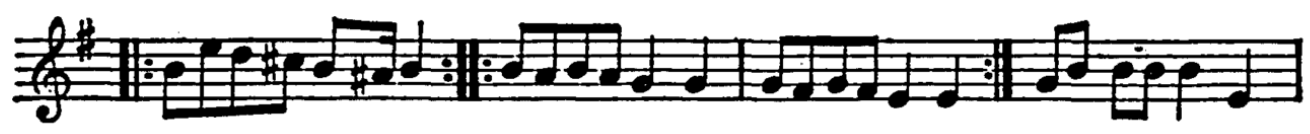

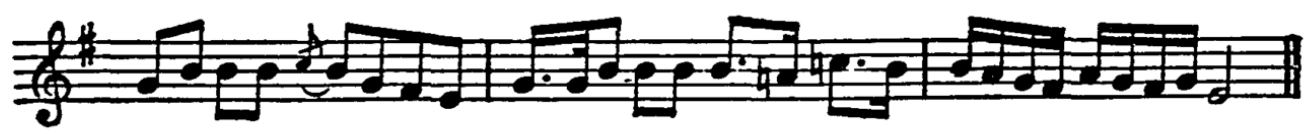




\section{Reçitando}

19 年3 Gott mus mandienen unmanwetihmdienen, obernitwie a-go-tom, haLento Andante
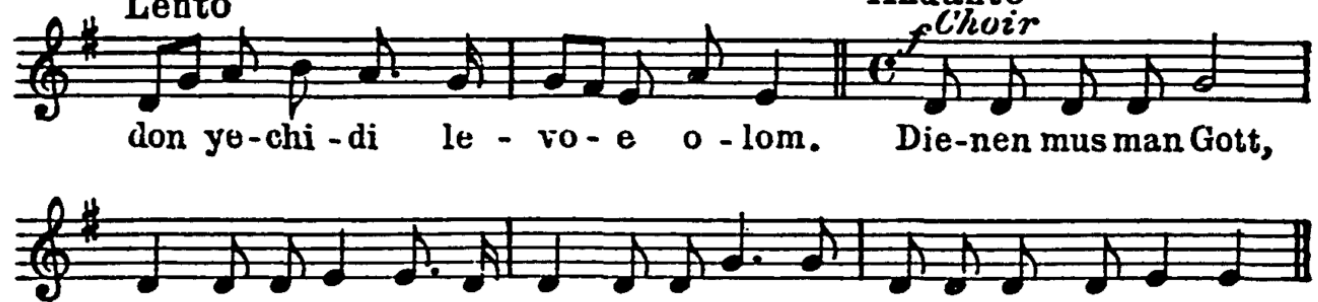
Gott musmandie-nen, der for wos er hot uns aus-ge-weilt zumdie-nen.

$20 \frac{b^{2} \text { Allegro }}{f^{\prime}}$

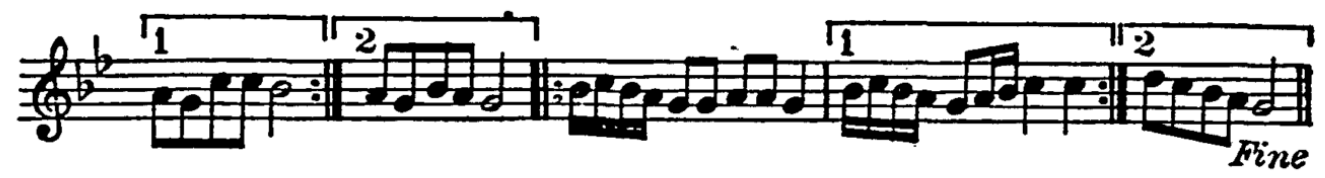

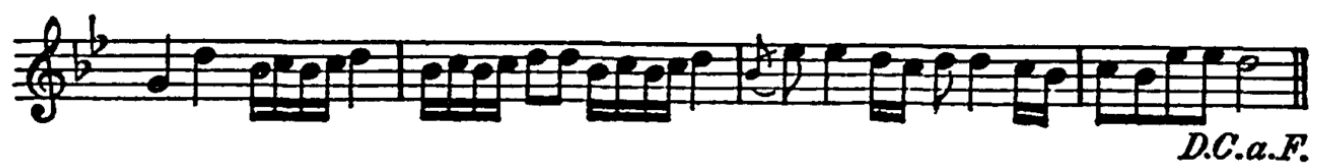

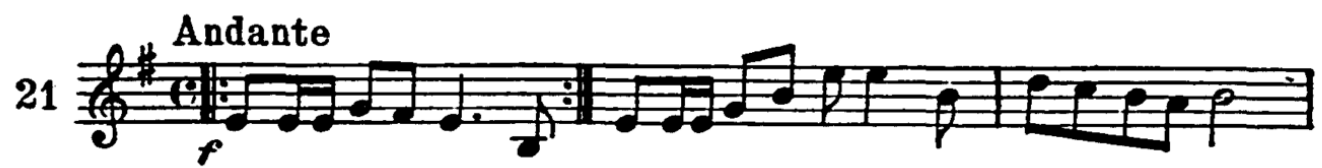
\%)

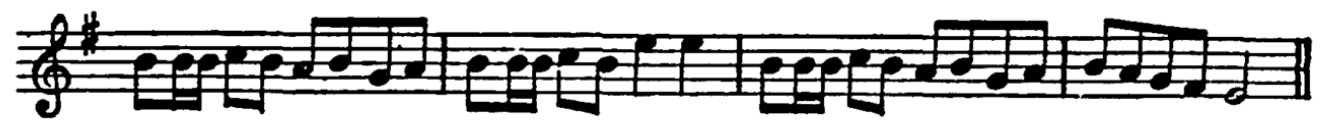
22 Andante with ecstasy

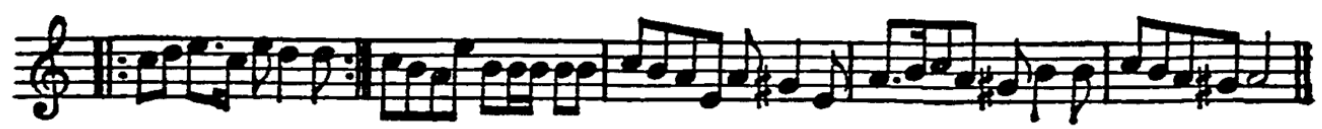




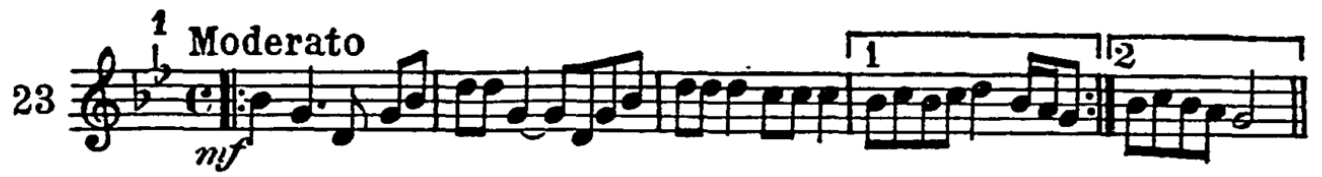

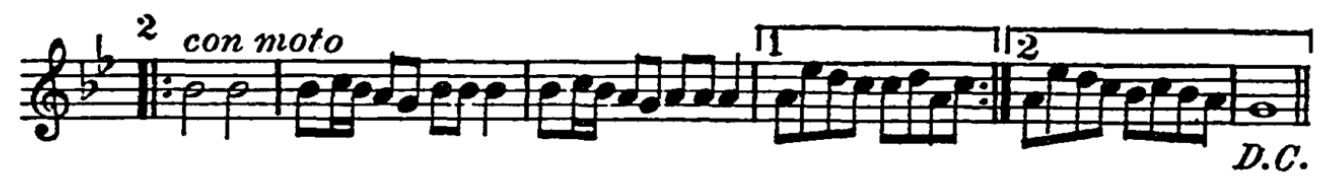
3.5 with increasing emotion

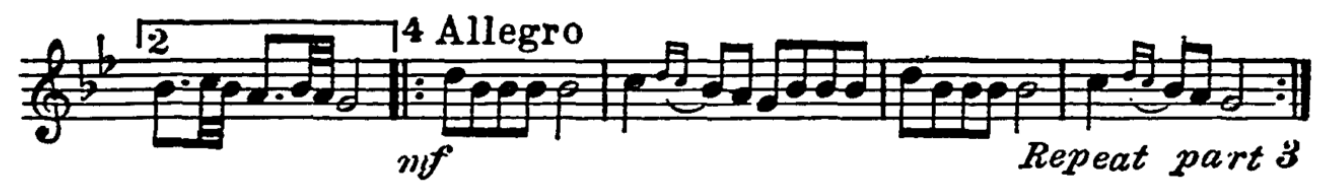
(2) Andante

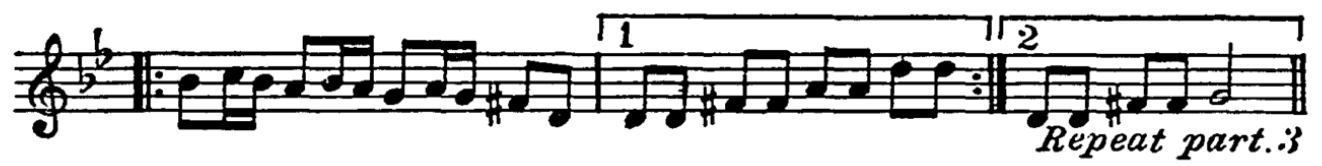

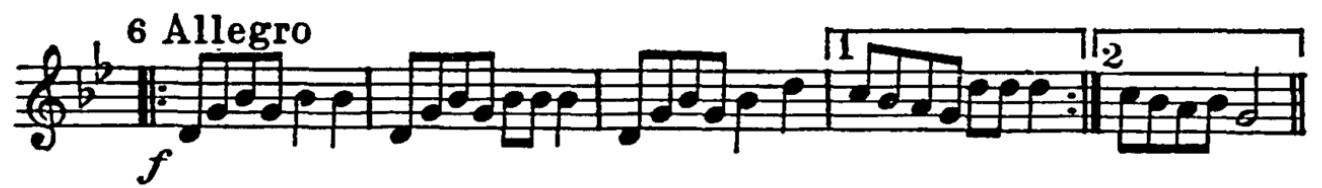
Allegro vivace 24 Allegro moderato

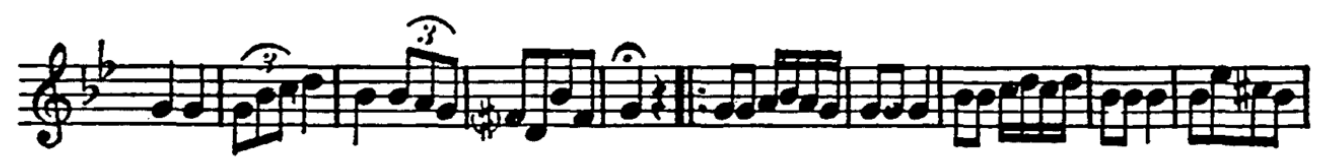
3 
c) Tunes in Major

25 Allegro moderato Ash-rechem, ash-rochem, ash-rechemyis-roel, ash-rechemyis-roel,

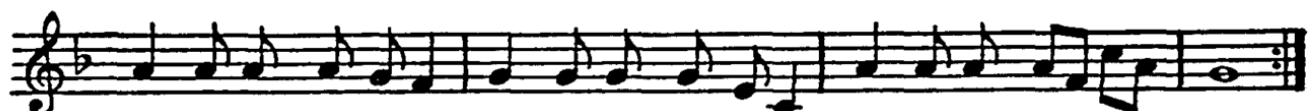
ash-rechemyis-roel, ash-re-chemyis-ro-el, ash-re-chemyis-ro - el.

26 1. Allegro Ash-rea-yinverhotdosge-sehn.

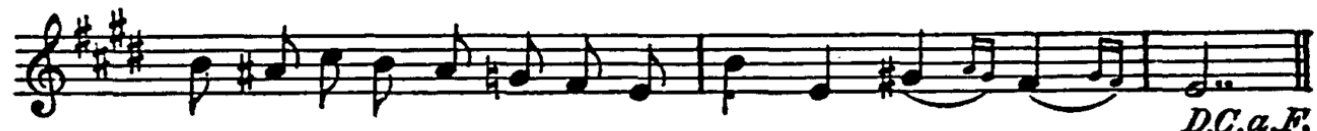

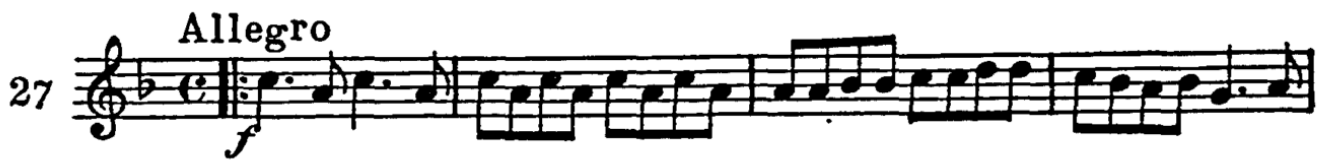

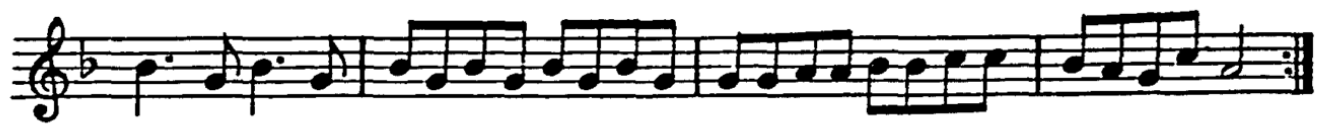

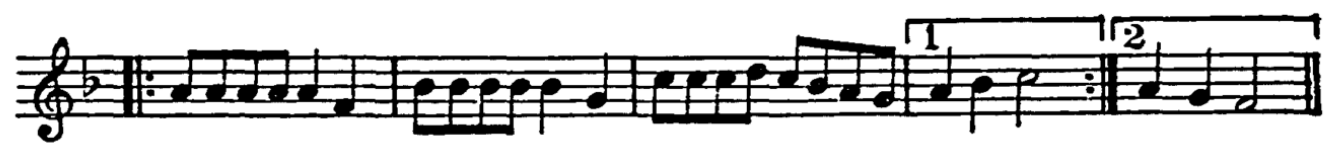

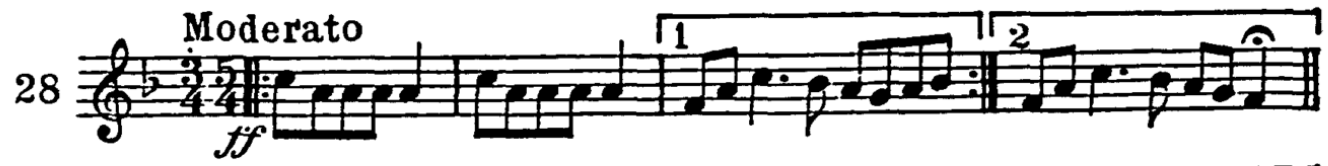
†ाँ. . 

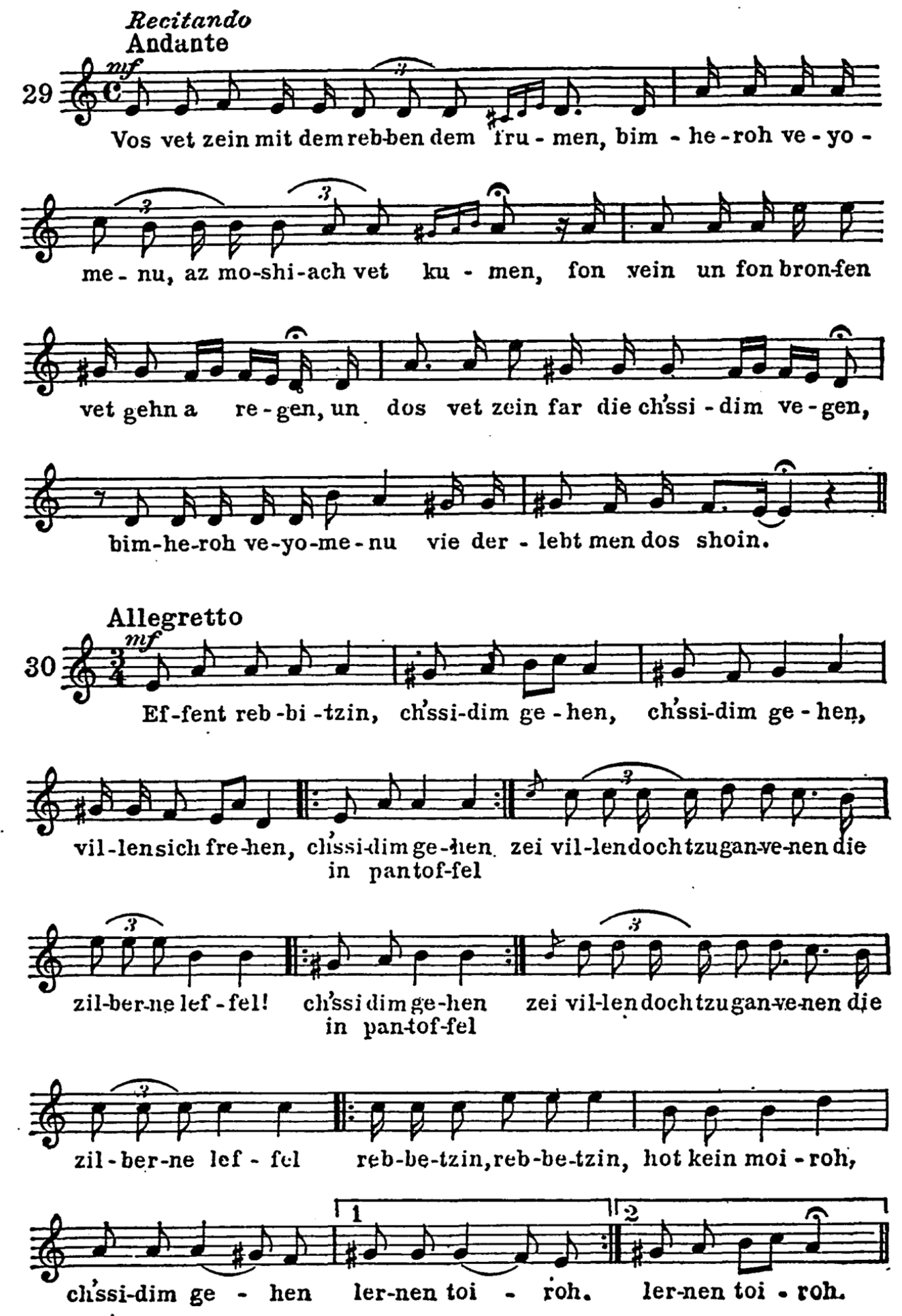
and wherever I stand Thou art present. Thou, only Thou, always Thou! Prosperity is from Thee; and suffering, oh, it, too, comes from Thee! Thou art, Thou hast been, and Thou wilt be! Thou didst reign, Thou reignest, and Thou wilt reign. Thine is Heaven, Thine is earth. Thou fillest the high and the low regions. Whithersoever I turn, Thou art there!"

The tune starts in minor $(\mathrm{g})$, modulates to Ahavoh-Rabboh $(\mathrm{g})$, turns toward the end to the major on the sub-dominant (c) and concludes in minor $(\mathrm{g})$.

No. 14 is by the above-mentioned Dovidl of Talno; it is a dveikuth tune in free modal form. Its scale is $f$ minor, though the fifth (c) is frequently diminished, in fashion similar to the Makam Mustaar ${ }^{31}$ which makes a mystical impression. The text is an Aramaic poem by I. Luria B'nei Hechalah for the third meal of the Sabbath, and is very popular among the chassidim.

No. 28 is a typical major-minor tune with no stable scale, beginning in major and finishing in minor. This type is known in the Oriental and in the Slavic folk-song. No. 26 starts in E major, modulates to the Adonoy-Moloch mode in $\mathrm{E}$ with the minor seventh, turns then to the Ukrainian-Dorian in $E$, and finishes in major. Only two bars have a text consisting of a few Hebrew and Yiddish words: Fortunate is the eye that has seen this (wonder). The remainder of the tune is sung without words.

In No. 18 only an inclination toward the Ukrainian scale is noticeable, while Nos. I 2 and 24 are based entirely upon this scale. These two tunes, as well as Nos. II and 13 were written down in 1809-10 in Berlin by I. Löb Wolf and in Amsterdam by Sholom Friede (Chapter XI), and they prove that chassidic tunes were spread all over Central Europe at the beginning of the nineteenth century.

We find a strict form in the rhythmical chassidic tunes, even as in the Yiddish folk-songs. The tunes have symmetrical structure of one to three periods, eight bars to the period. Some of them, such as No. 23, have larger forms: the compound Lied-form (A.B.A.; A.B.C.A.) and the Rondo-form. We also notice that the principle of modulating to the subdominant is observed. 
The rhythmical tunes are usually sung in unison by the groups, while unrhythmical songs are rendered by single voices.

The chassidic song, though religious in purport, is not used for the worship proper, but for inspiration and preparation of the "pious-ones" for worship. It aims to elevate the troubled soul to approach the Source of all goodness, happiness and joy, in prayer and in communion.

As long as the chassidic movement flourished its song naturally developed. But toward the end of the nineteenth century, Chassidism began to deteriorate, and as a consequence, its song likewise decayed. Hence, those chassidic tunes created in the last few decades sound like caricatures of the old and genuine ones. The opponents of Chassidism took delight in imitating and caricaturing chassidic song, setting to the garbled melodies satiric words. Two examples, Nos. 29 and 30 , illustrate that type of song. No. 29 recounts the miracles the tzadik will perform at the time when Messiah will come. The tune has the form of an unrhythmical dveikuth-melody in the Ahavoh-Rabboh mode. No. 30 is a dialogue between the chassidim who seek to enter the house of the tzadik in order to be instructed by the "saint," and his wife, who hesitates to let them in out of fear that they might steal the silver dishes.

Chassidic song exerted a strong influence upon the chazzanuth of Eastern Europe. Almost all the prominent chazzanim treated in Chapter XIV were reared in the chassidic atmosphere and were imbued with its mystical spirit and its emotionalism. These characteristics are reflected in their musical creations. Apart from those cited in Chapter XIV, we mention here some of the chazzanim who served at the "courts" or were for some time connected with them.

JoshUA Finesinger in Lontshitz gained much popularity 
for his compositions for the piyyutim for the Sabbaths between Passover and Shavuoth. Of great merit are his settings of Shechuloh achuloh, ${ }^{32}$ Yokush beonyo, Shviyoh aniyoh. LEIzER of LoDz (died I887) was a noted chazzan and likewise a great Talmudist. $^{33}$ IsRAEL JAFFA of Suvalk, later chazzan in Kalish, was also a remarkable Hebrew scholar. Moshe Michel EICHLER, chazzan in Praga near Warsaw is the composer of the tune in table XXXIII, 20. Hersh of Przshev (I798I892) served for seventy-seven years as chazzan at the courts of Gor, Kotzk, and Alexandria. Others of ability were ZALMAN of Poltosk, chazzan at the court in Kotzk; ChayYim Chaykl, a court-singer in Gor; Hershele Tolczyner, Yosele Dem Rebiins, both court-singers in Talno; and Jacob Telechaner, court-singer in Koydanov. ${ }^{34}$ RabBi Ber of Radoshitz, called "the Little Ber," in contradistinction to Ber of Mezeritsh, "the Great Ber," became a tzadik through the magic of his wonderful singing.

The most gifted chazzan who grew out of the chassidic environment is JacoB Samuel Margowsky, called "Zeidel Rovner." He was born in Radomishl, in the government of Kiev, in 1856 , and was destined early for the career of rabbi. $\mathrm{He}$ sang at various occasions to the delight of the chassidim in his native village. These admirers once took the youth to the tzadik of Makarov, asking that Zeidel be permitted to sing in his presence. This request the saint granted. After hearing the lad, the tzadik ORDERED him to officiate as chazzan in the synagogue on the High Holidays. Zeidel's pleadings and arguments that he had neither chazzanic training nor knowledge of the traditional tunes were of no avail. He officiated, and by merit of the tzadik, with great success. After that, Zeidel engaged himself in business and continued for many years to act as High Holiday-chazzan. He obtained rudimentary knowledge of music from the klezmer (instru- 
mentalists) (Chapter XX). Once, while he was visiting the tzadik, the latter suddenly ordered him to abandon his business and become a professional chazzan. This order Zeidel faithfully, though reluctantly, obeyed. Thereafter he occupied various posts and became famous through his compositions which follow the style of Nissi Belzer's creations in structure but which excel them in LENGTH. Seidel's compositions are markedly instrumental in character. Under other circumstances he might have become a prominent composer for the orchestra. In the Synagogue his orchestra was the a capella choir, and his singers, human instruments. Zeidel wrote voluminously. After officiating in Rovno, Kishinev, and Berditshev, he left for Lemberg. Later he traveled to London, and finally settled in New York. ${ }^{35}$

Chassidic song, like that of the Yemenite Jews (Chapter $\mathrm{XVII}$ ) is rendered exclusively by men. It is a masculine song. Thus, we see that Jewish folk-song has both a feminine (Chapter XVIII) and masculine song. They grew out of the circumstances of Jewish life. 


\section{CHAPTER XX}

BADCHONIM (MERRY-MAKERS) AND KLEZMORIM (MUSICMAKERS); SONG AND SINGERS IN FOLK STYLE. ${ }^{1}$

\section{A. Badchonim and Singers}

Jewish folksingers were called badchonim-merry-makers, also leitzim or leitzonim - comedians, jesters. In Germany they were also called marshalks, marshaliks. ${ }^{2}$ It was a custom of old that, though secular song and instrumental music were prohibited in Israel after the Destruction (Chapters V and VI), both were permitted at weddings and on Purim. It was even considered a merit to sing and dance and make merry in order to cheer the bride by praising her beauty and good qualities. Prominent Talmudists counted such conduct not beneath their dignity. It is reported of Rabbi Juda bar Ilai that he would dance and sing before the bride with a palm-branch in his hand -the refrain of his song being: "Oh, beautiful and virtuous bride!" The same is reported of the disciples of Hillel. The scholars would suspend their study to dance and sing at weddings in the presence of the bride. ${ }^{3}$

The people grasped this opportunity for rejoicing in order to give vent to their suppressed longing for music and amusement, song and dance. It became a hard task for the spiritual leaders to check this passion (Chapter V) and to direct the singers and merry-makers to songs of religious and ethical content. Hence, the singers and merry-makers used to interweave their couplets and jingles with Biblical phrases and Talmudic sayings.

Already in the first centuries of the Common Era there 435 
existed professional badchonim, whose task it was to cheer the sad and to make peace between enemies, ${ }^{4}$ an aim indicating the high conception that the badchonim had of their profession. They sought to elevate and to instruct the masses while entertaining them. This goal they attempted to achieve primarily through witty and subtle satire of which the Jewish people were always fond. Their songs, the badchonim invented extemporaneously according to the particular conditions at each wedding.

"In the Middle Ages we find among the Jews traveling merry-makers, who probably patterned themselves after the troubadours, and took the place of former voluntary entertainers at weddings. Their task was by jest, music, and humorous song to provoke joviality. The name given them originally in Jewish writing is leitzim, a term which occurs . . . in the early part of the thirteenth century. The jesters were obliged to possess not only comic ability, but also a certain deal of learning, since those jokes were appreciated most which were connected with Scriptural verses or Talmudic passages. Such scholarly comedians were in vogue largely in the Middle Ages. As the clouds of persecution, however, continued to gather round the Jew, merriment was discouraged. R. David Levy ( $\mathrm{I} 680$ ) ... inveighs against the fashion of engaging lezim for wedding festivities." ${ }^{5}$ In Germany and Poland the standard of the badchon deteriorated. Singing and merry-making at weddings instead of being counted a merit were considered unfitting for a scholar. Rabbi Yair Bachrach (seventeenth century) stigmatized the professional jester as "a man playing the fool in order to provoke laughter; such a wedding is called a seat of scoffers (leitzim, Ps. I: I), for it is not real rejoicing, but hilarity and folly." ${ }^{\circ}$

On Purim, song, merry-making, and rejoicing were permitted already in the Talmudic age. $\quad$ The celebration con- 
sisted of special humorous Purim-songs in the vernacular of each country. Many of these songs are still retained, in JudeoItalian, ${ }^{8}$ Judeo-Spanish ${ }^{9}$ and Judeo-German. Of the latter there are two poems in the collection of songs by $\mathrm{E}$. Walich, treated in Chapter XVIII, the one relating the story of Esther and the other, a merry song by Jewish Talmud-students, who would visit the Jewish homes in disguise and obtain food and gifts. $^{10}$

The Purim rejoicing brought about the creation of Jewish folk-comedies. While as a usual thing a dramatic performance was considered frivolous, an exception was made with regard to Purim. In Gaonic times the dramatization of the story of Esther was a well-established custom among the Jews in the Orient. The central figure of these plays was a dummy representing Haman, which was burned, while the spectators jested and sang. Similar amusements are reported of the Jews of other countries during the Middle Ages. ${ }^{11}$ The real Purim play, however, the Judeo-German Purim-spiel, did not make its appearance until the first decade of the eighteenth century. There were, it is true, some productions on the subject of the Book of Esther and the Feast of Purim long before that time, such as the drama Esther by Solomon Usque and Lazaro Gratiano ( 1567 ) - the first Spanish drama written by a Jew. But these dramas were probably intended for the general stage, since there is no record that they were ever performed by the Jews. ${ }^{12}$

The first Purim play intended for and actually performed on the stage during the days of Purim was the Ahasweros Spiel, published in Frankfort in $1708 .^{13}$ The play was performed with music and had a special tune which became popular. Apparently this was a tune of a serious character, for it was later (in I7 I2) set to a lamentation on the conflagration of Frankfort, written by David Saugers of Prag. ${ }^{14}$ 
In 1720 the play Acta Esther was performed on the stage by Talmud-students of Prague, "beautifully decorated with orchestral accompaniment." In I780 a tragi-comedy in five acts, called The Salvation of the Jews by Esther and Mordecai (in Yiddish), was published in Amsterdam by Jacob of Prague. In I 828 the play Esther or Belohnende Tugend was published in Fürth by Joseph Herz. ${ }^{15}$

The Purim-play was the beginning of the Jewish Theatre and melodrama, of which we shall treat later.

The badchonim were not solely merry-makers and jesters. Many a tear would mingle in the cup of joy that they presented to the young couples and the wedding-guests. They utilized this opportunity to keep before the eyes of their people the unpleasant conditions of the Jew as well as the Jew's inner troubles. But a tone of love was felt in the badchon's reproach, the challenge of a friend, of a true son of his people. This circumstance contributed considerably to the popularity of the badchonim and their badchonus-songs. Hence badchon became synonomous with folksinger.

Some singers published their poetry, or at least set it in writing, by reason of which circumstance their names and works were retained. Thus we hear of Eisik Walich, cited in Chapter XVIII, of Jacob Heilprin Dick in Frankfort in the sixteenth century, ${ }^{16}$ of Hershel Weinshenk-Tausik in Prague, who in 1655 wrote a necrology on the chazzan Lippman Popper, ${ }^{17}$ of Mose Stendal, who in I 586 translated the Psalms in verse, of Nathan Bach, the translator and publisher of the above-mentioned Book-Samuel. Jacob Kopelman of Brisk, Lithuania, paraphrased in verse the Aramaic translations of the five scrolls, to be sung to the Book-Samuel tune (Chapter XVIII); Elchonon Kohen paraphrased Judith in verse, under the name Dos Chanukah Büchel (Frankfort, I 7 I2). Leib Sofer of Posen paraphrased, in verse, the great poem Kether Mal- 
chuth by Solomon ibn Gabirol (Dessau, 1698). The Zemiroth were translated by Abraham Bookhandler (Basel, I600). In I6I4 Elchonon Heln wrote the Scroll Vinz, a narration of the expulsion of the Jews from Frankfort in 1614, to the tune of the Battle of Pavia. ${ }^{18}$ The above-mentioned scholar Eliyahu Bachur was likewise a prolific verse-writer. From among his many poems, his lamentation on the conflagration of Venice should be mentioned. Concerning a similar calamity which befell Frankfort, David Schweigers wrote an elegy "to the tune of Haman in the Ahashwerosh play" mentioned above; the destruction of the community in Worms, set to "the tune of Rabbi Simon of Prague" was elegized by Isaac Liberman of Worms (1696); the Chmelnitzki pogroms in Ukraine, Joseph Ashkenazi lamented to the tune of Adir oyom venoroh (Prague, 1648); on the expulsion of the Jewish community from Vienna, the chazzan Jacob Koppel wrote an elegy to the tune of the Akeda (Prague, 1670); of the plague in Prague Jacob Horvitz sang to the tune of Shochne bote chomer (I7I4); Jacob Tausik composed a poem about the pseudoMessiah Sabbathai Zebi (Amsterdam, r666). Solomon Singer Kristal wrote many songs, of which that concerning Emperor Leopold I was well known (Prague, 1658); Selig Chazzan sang a hymn about the same Emperor to the tune of $\mathrm{Halb}$ schwarz, halb weiss (Prague, 1678). Leib Walich composed a hymn about King Charles (Prague, I704). Wolf of Cracow wrote a song Conduct of Life to the tune of Ach Gott wie bin ich ein verirrter Mann (Prague, 1692): Another Solomon Singer of Prague sang a song of the fear of God to the tune of Was in die Tora steht geschrieben (1692). A special type of Torah-songs was developed, praising the Law. Noah Abraham Altshul published wedding and bridal-songs as well as Chanukah and Purim songs (Prague, 1676). Zalman Chazzan, Samuel Pifert and Elchonan Katz of Kremnitz likewise 
wrote Chanukah and Purim songs. Eliyahu Luanz wrote a song $A$ Dispute Between Wine and Water to the tune of Dietrich of Bern; Zalman Sofer and Menachem Alendorf composed jingles on the passion for money to the tune Hoch rief der Wächter. From Leib Kutner "who is famed throughout the countries" several popular verses were retained.

Among the folksingers also women appear who wrote and published several songs. We hear of Rivka Tiktiner, Taube, wife of Jacob Pan (Prague, I609); of Bela, wife of Joseph Chazzan Horvitz, who wrote Techinoth-supplications for women (Prague, I705); of Rachel, daughter of Mordecai Sofer of Pintshof (Frankfort, I723); of Seril, the daughter of Jacob of Dubno (1783); and of Friedchen, the wife of Mose Leib of Anklam (I 782). ${ }^{19}$

From the list we gather that the field of the badchonim was not limited to merry-making only. The songs reflected all phases and vicissitudes of Jewish life.

The badchon vanished in Central Europe after the middle of the nineteenth century, ${ }^{20}$ whereas in Eastern Europe he survived until recently. During the last century a few singers (badchonim) arose in the Eastern countries who were probably the most gifted of their guild, and who, before the disappearance of their profession, raised it considerably. We shall speak of but the most outstanding ones. They were at once poets and composers and performers of their own products, some of which became very popular and were published.

(I) Berl Margulies, called Broder. He was born in Brody, Galicia, in $18 \mathrm{I} 7$, studied Talmud and became a bristleworker. In 1857 he organized a troupe of badchonim and toured Southern Russia, performing his songs at weddings or in public gatherings. Later he returned to Brody and sang there in a coffee-house, accompanying his performance with mimicry. His themes were all taken from Jewish life and his tunes 
adopted from and based on Synagogue modes and melodies. Later he went to Bucharest, Roumania. He died there in 1880 . A collection of 30 songs in Yiddish he published in Lemberg in $1876 .^{21}$

(2) Benjamin Wolf Ehrenkranz, called Wölwel Zbarazer. This most talented Jewish singer of Galicia was born in 1826 in the little village Zbarazh. His father was a shochet (ritual slaughterer). He received a good Jewish education, acquiring the Hebrew language and Rabbinic knowledge. Especially was he imbued with Biblical poetry which aroused in him his own poetical instinct. He was early caught by the spirit of enlightenment that swept Galicia at that time. At the age of 18 he was married against his wish, and, as a consequence, disappeared a few days after his wedding. $\mathrm{He}$ escaped to Roumania, at that time the haven for all Jews of Galicia and Russia, who were not comfortable in their native places. There Ehrenkranz remained for 25 years, a wandering singer, performing his songs not at weddings, as had been customary, but in coffee-houses and at public gatherings, at inns and saloons before the mob. His songs are distinguished for their biting satire and humor. They are saturated with love for the singer's people and with a deep sorrow for their troubles and shortcomings. His greatest strength lay in his ability to extemporize on any theme given to him or suggested by the public. His satires on current events gained a wide reputation. Especially bitter was he against the chassidim and their tzadikim-cult. He was equally master of Yiddish and Hebrew, and wrote almost all his poems in both languages. At the urgent request of his friends, he published a selection of his songs in 1865, in Hebrew, under the name of Makkal Noam (The Staff of Pleasantness), and in Yiddish Makkal Chovlim (The Staff of Severity), names taken in altered meaning from Zechariah II, 7. His tunes he drew from the Syna- 
gogal modes. But since he was not a technically trained musician, he did not write his tunes, and, consequently, the most of them were forgotten. Only some of them were orally retained and written down. In table XXXIV, r, we give a song by Ehrenkranz, Moshiachszeiten (The Messianic Age), a satire on that orthodox belief. ${ }^{22}$ The tune is in the AhavohRabboh mode. According to his statement in the preface of his publication of 1865 , his activity as professional singer began in 1858 . After a sojourn of 25 years in Roumania, he returned to Galicia. However, he could not establish himself in his native country. The ultra-orthodox party considered him an Epykoros (heretic). He was pursued by the chassidim, while the "intelligenzia" saw in him a menace to their assimilative efforts. To them Yiddish was a handicap, a relic of medievalism, to be forgotten, and to be replaced with German and Polish. Only the masses, the artisans and laborers, clung to him and filled the coffee-houses where he performed his art. Soon Ehrenkranz had to realize that there was no future for him in Galicia, and he left for Constantinople. There he married a woman, who supported him during the last years of his life, to his death in I883. A tombstone with a dignified inscription in Hebrew marks his grave: "In the Hebrew tongue thou hast created glorious values, thy sweet songs captured all hearts; thou hast descended from the heights to the poor people, to enlighten their darkness, and by the whip of thy tongue many hypocrites were chastised." ${ }^{23}$ Those who witnessed his performances of his extemporized verses and tunes, and those who knew his songs, testify that text and melody constituted a unit. His tunes breathed a deep melancholy and were seldom brightened by even a feeble smile. His melody to his song The Nightingale used to draw tears from the people even 40 years after the death of the composer. ${ }^{24}$

(3) Elyokum Zunser was a native of the Lithuanian cen- 


\section{TABLE XXXIV MOSHIACHSZEITEN}

Passionate
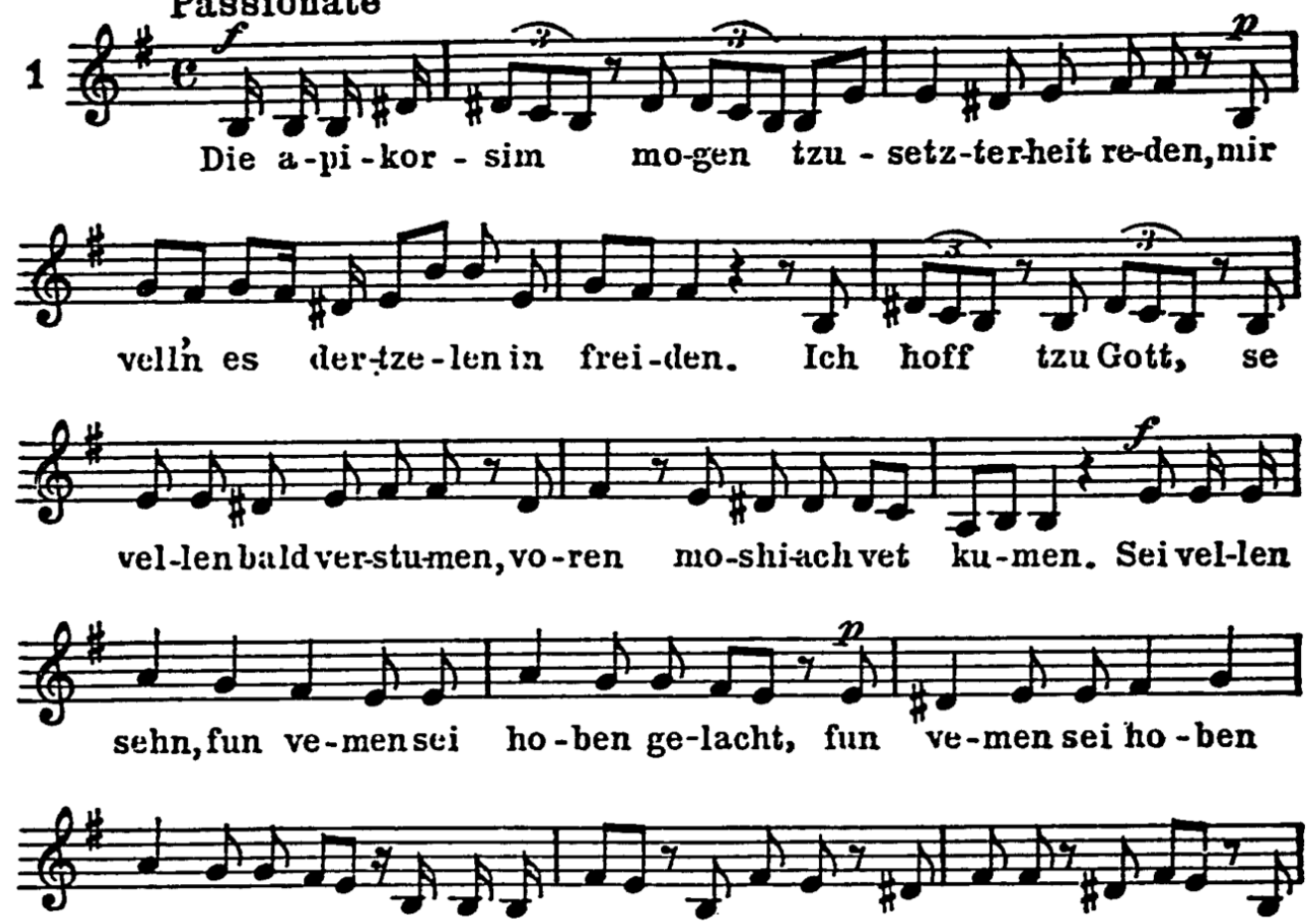

choi-zek ge-macht,sei vel-len sehn, fun ve-men sei ho-ben ge-lacht, fun

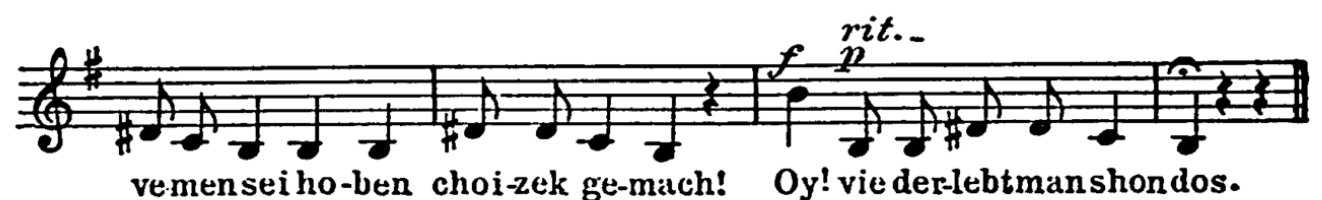

vemensei ho-ben choi-zek ge-mach! Oy! vie der-lebtmanshondos.
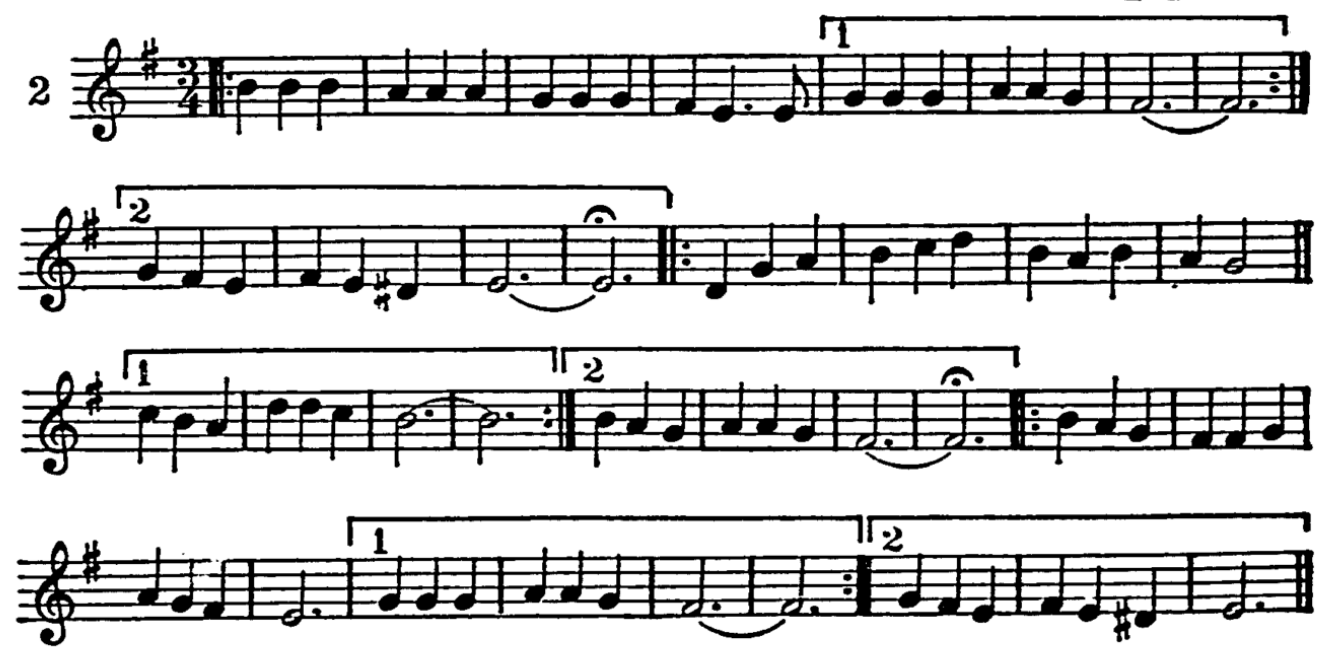
tre, Wilna, which during the eighteenth and nineteenth centuries brought forth a great number of sages and scholars, thinkers and leaders, poets and musicians and artists. Born in I 840 in poverty, son of a carpenter, Zunser had but little education. While still a boy, he lost his father and was compelled to abandon his study of Talmud for a trade. At times he sang with chazzanim. At the age of $\mathrm{I} 4$ he became private teacher to the children of a farmer, who instead of paying him his salary handed him over to the Russian "catchers," to be "trained" as a soldier, according to the iron régime of Nicholas I. He was confined in the army-barracks together with several other Jewish boys. During this imprisonment he composed his first song, both text and tune, and taught it to his fellow sufferers, arranging a choir of ten boys. Through an unexpected order of Alexander II, newly ascended to the throne, he was released from prison. He wandered to Kovno, where he engaged in the embroidery trade. From that time on his talent blossomed. Zunser was a very prolific composer. According to his statement, he wrote about 600 songs. One of the most popular, Die Blum (The Flower), he composed at the age of 15 . His songs became much liked by the masses in Kovno, so that in I86I he was encouraged to abandon his trade and devote himself to his muse. He became a badchon, returned to Wilna, and published a collection of New Songs (I86I). Zunser's popularity spread quickly, and he was invited to weddings, where he would sing his songs and improvise, to the accompaniment of the Jewish "music-makers" (klezmer), of whom we shall speak presently. His fame spread all over Lithuania and the North Russian districts, and he was called to weddings throughout the country. While Zunser had but a poor education, his striving toward self-education and enlightenment brought him into contact with the outstanding scholars of Wilna, under whose influence he studied 
Hebrew literature and history. He became an ardent Jew and later a nationalist. In 1862 he married, but in 1871 his wife and children died of the cholera. He then settled in Minsk, married again, and remained in that place until $\mathrm{I} 889$.

In addition to his songs Zunser wrote a drama Mechirath Yosef (The Sale of Joseph), based on the Biblical story. It was published in 1868 and was repeatedly performed. ${ }^{25}$ Zunser's popularity grew more and more, until he became a national figure among the Jewish people. By reason of this fame, he was suspected in governmental circles of being a disguised agitator of the revolutionary party. Becoming aware of his dangerous situation, he left Russia and settled in New York, where for a while he continued his profession. In his more advanced age he withdrew from public appearances and opened a printing-office on East Broadway, which he maintained until his death in 1913. In 1904 he published his autobiography. It was translated into English and published in 1905. A selection of his songs in three volumes was published in 1920 by his family.

His tunes are all for solo; some of them were arranged with a poor piano accompaniment. They have partly the Jewish folksong-character and partly the form of the German-French couplets. ${ }^{26}$ His melodic line is influenced by the Synagogue song from which source, according to his own statement, he first used to draw; but includes, also, German features, as felt in his songs Die Kontrasten, Nach dem neuesten Journal, Die Antwort, Ich bin schon sicher and Klug, edel und still. Some of his tunes show Slavic influence, for example, Die Socha. Some remain strictly faithful to genuine Jewish melodic line, such as The Lament on Lewando, which has similarity to the Spanish tune given in XXXII, 30. In XXXIV, 2, we give Zunser's tune. Genuinely Jewish are also Der Peddler, Das Neunzente Yahrhundert and Der Aristocrat. This last song 
became endeared to the Jewish masses in Lithuania, and was sung for many years.

Zunser was the first badchon who acquired some rudimentary knowledge of music. During his lifetime he published several of his songs, both text and music, for solo and accompaniment. From these we gain an idea of the nature of his music.

The themes of his poems are the same as those of Ehrenkranz, i.e., subjects from Jewish life, reflections on Jewish social and cultural conditions. He conceived of the Jewish people collectively. Never does he take moments of the individual's life for his subject matter. He never sang lovesongs or voiced private griefs or joys. But he always touches the problems of the House of Israel (Klal Yisroel). Superstition, abnormal political and cultural circumstances, are the main sources from which he draws his themes. He favors enlightenment, but criticizes assimilation. He pleads with his people to awaken from apathetic slumber and to become aware of their misery. He tries to awaken in them self-respect and reverence for their own spiritual culture; and last but not least, to turn back to their territorial home, to regain their lost independence and their country-Palestine. His language is simple; he employs the Lithuanian Yiddish idiom with some Germanisms, and uses modern European names of cultural achievements. At times he is compelled, out of fear of the Russian censor, to choose an allegorical form of presentation of his subject matter. Zunser, in contradistinction to Ehrenkranz and Margulies, always strikes a mild and noble tone. $\mathrm{He}$ is never harsh, satiric and sarcastic, he never mocks at the shortcomings of his people. With a fatherly, warm challenge he tries to instruct and to elevate his brethren to a better understanding. No wonder that he was so much beloved and greatly venerated during almost a half century. In the scale of art standard neither his verse nor his music reached any consid- 
erable height, and vocally he had but limited quality. But it is Zunser's intense Jewish sentiment that is his most striking characteristic. That wholesome sentiment is the magnetic power which, more than his poetic and musical talent, captured the hearts of his people.

Through his personal qualities, Zunser raised the low level of the badchon to the dignified standard of a singer to the people, of the people's life and struggle. He was the last JEWISH BARD of note.

(4) Abraham Goldfaden (originally Goldenfodim) was born in Altkonstantin, Wohlynia, in 1840 . His father, a watch maker, was a liberal-minded man. When Tzar Nicholas I issued the order that those Jewish children who attend the public schools, established especially for them, should be exempted from army service, his father was one of the first to make most of the alternative, and sent him to school. From this elementary school, his father sent him in 1857 to the Rabbinical Seminary in Zhitomir, from which institute he was graduated in I 866. While still a student Goldfaden started his activity as popular poet-singer. In his reminiscences he relates how he used to compose songs which the students eagerly sang. His first publication was a collection of Hebrew songs (Zhitomir, 1865) Tzitzim Ufrachim ("Blossoms and Flowers"). Not being rabbinically inclined he became a publicschool teacher first in Simferopel and later in Odessa. In 1868 he published a collection of Yiddish songs, Dos Yuedele. Although he occasionally has recourse to the style of Ehrenkranz, in striking the satiric note, or, forshadowing his future career, even descending to the use of theatre couplets, yet most of his poems have an individual character, distinct from those of his predecessors. ${ }^{27}$ A year later he published another collection Die Yuedene (The Jewess), touching the problems of the Jewish woman. For these lyrics he adopted melodies. With- 
out any technical knowledge of music, he merely marked the names of the adopted tunes to be sung: popular Russian lullabies, Ukrainian melodies or Jewish folk-songs. In 1875 he quit his post as teacher and went to Lemberg, where he started publishing a humorous journal, Yisrolic, for Russian Jews. But after half a year the Russian Government prohibited its circulation, and as a consequence the paper ceased to appear. He then went to Tschernowitz and started a Folksblatt. Upon the advice of a friend he transplanted his paper to Jassy, Roumania. "At that time," Goldfaden narrates in his reminiscences, "the Jewish public used to be entertained by popular singers-jesters, who performed their songs in saloons. They had in their repertoire also my songs, which became very popular. Once, while listening to these singers for the first time, the idea flashed in my mind to combine these songs of mine by the connecting links of prose into a tale that would make a theatrical piece. I immediately set to work and on the Feast of Tabernacles I laid the cornerstone of the Jewish Theatre." ${ }^{28}$

The Jewish population in Roumania at that time, in great part refugees from Russia, stood on a low cultural level. Young boys were sent over the borders by their parents to rescue them from the tyrannic army-law of Nicholas I. These grew up in ignorance, without Jewish or general education, and were employed as laborers and artisans. For entertainment they frequented saloons where Jewish singers, badchonim, delighted their public with trivial jingles and jests. "My heart was filled with pain," Goldfaden says, "to see my people in such a low state of spiritual development and in such vulgarity. . . . I realized that it was utterly ignorant of the holy spark of its nationality, which I had thus far tried to infuse in its hearts by my songs. . . . The people needed a school! They needed to understand their own life. They needed a 
means by which their own life with all its deficiencies should be reflected and brought before their eyes. . . . Historic pieces should be given that they learn their history . . . and find out who they were. ..." This was Goldfaden's train of thought when he conceived the idea of creating a Jewish theatre for melodrama or operetta.

Indeed, the Jewish play is not Goldfaden's innovation, for, as we have already seen, centuries before him there existed not only Purim plays but also dramas on other subjects such as the story of the sacrifice of Isaac (Akedath Yizchac), the story of Joseph, by Leb Ginsburg, published in Frankfort in I712. Its performance on the stage attracted attention on account of the satire on the Catholic clergy. There were further The Action of King David and Goliath, published in I II I in Hanau; The Greatness of Joseph (Gedulath Joseph), I801; Jonah in Nineveh (MS.); Rabbi Henich by Isaac Eichel, a satire on educational conditions at the end of the eighteenth century; Leichtsin und Fromelei (Frivolity and Hypocrisy) by Wolfsohn, published in Breslau, r786; The Wedding at Heichelheim, MS. written in $18 \mathrm{IO}^{20}$ These plays are all provided with songs and couplets. Finally there was already Zunser's Mechirath Yosef mentioned above.

Neither was the Jewish theatre Goldfaden's innovation. Already in the sixteenth and seventeenth centuries permanent stages existed in the Ghetto of Venice, for which Leon of Modena wrote plays and of which he was the director (Chapter X). Likewise in Frankfort and in other Ghettos Jewish plays were frequently performed in the "Dance-houses." Jewish professional actors and singers distinguished themselves throughout the Middle Ages in European and Oriental countries. $^{30}$ Even organized troups were acting in Germany in the seventeenth and eighteenth centuries. We mention the troup of Süsskind of Offenbach and his wife Michaele, the daughter 
of the chazzan Salmele of Frankfort and the mother of the famous Joseph Süss Oppenheim. ${ }^{31}$

However, in Eastern Europe there was no trace of all this, and when Goldfaden started, he had at hand neither actors nor stage. The first actor-singer at Goldfaden's disposal was Yisroel Grodner in Jassy, a badchon, his second, Sochor Goldstein, a harness-maker by profession, who, disguised as a young Jewish girl, played the part of the wife of a chassid in a concoction which Goldfaden manufactured in the form of a comedy in two acts, a caricature of the meanest order. He did it with reluctance, as he later confessed, in order to attract the Roumanian Jewish public to his ideal. He descended to them in order to elevate them gradually. Goldfaden recounts in his reminiscences his hardships and troubles in acquiring dramatic and musical talent and in training it, in constructing stages and screens, in procuring stage directors and prompters, and above all, in training the Jewish public - the mob as well as the "intelligenzia." The latter opposed the idea of a Jewish theatre as a breeding place of frivolity, joviality and blasphemy, and as an agency of reactionary nationalism, medievalism and so on. "I came to Jassy," he says, "from the big world, well acquainted with the classic literature, the drama and the opera. I already knew Meyerbeer's, Halévy's and Verdi's operas, and had heard the greatest artists. Jewish history and literature were open before me; my mind was filled with subjects such as King Solomon, the Maccabees, Yehuda Halevi, David Al-roi, Rabbi Akiba, Bar-kochba and others. Nonetheless I had to descend from my height, compelled by sheer necessity, to themes such as $N i$-be-ni-me, Shmendrik and the like, appearing heedless of the scoffing of antagonists, who pointed to these products as proof of my ignorance of better subject-matter."

After many disappointments and failures, Goldfaden succeeded in organizing a troup of actor-singers, and above all in 
engaging some Jewish actresses. These were a real innovation in Eastern Europe, the first since the time of "Madam Europe," the sister of Salomon Rossi (Chapter X), and the above-mentioned Michaele. At that time the Russian-Turkish war started, and Bucharest became the seat of the Russian staff, surrounded with Jewish agents, contractors and traders. The invasion of this swarm of fortune-seekers stimulated Goldfaden's ambition. With their easy gotten gains the transients sought amusements, and the coffee-houses were crowded by Jews who came to listen to the songs of ballad singers. Reckoning with the Jews' fondness for music, Goldfaden abandoned for the time his ideals of historic dramas and started writing light burlesques, mostly imitation of French originals, in which the songs written and set to music by him were the most important things. "There is no other merit whatsoever in the plays, as their Jewish setting is merely such in name, and as otherwise the plot is too trivial. But the songs have survived in the form of popular ballads." ${ }^{32}$ After the conclusion of the war, in 1878 , Goldfaden returned to Odessa, where he established a regular Jewish theatre and from where he toured the country, playing in every large city.

Finally he began to near his goal, the creation of historical melodramas. He wrote Shulamith, a romantic melodrama of the last period of the Second Temple; Bar-Kochba, based on the story of the Jewish revolt against the Roman Empire in c. I35 C.E., and Doctor Almosado, a tale of the Jewish life in Palermo. These plays are in the style of the operetta, though they are more serious than the German Sing-spiel. Due to his lack of musical training, Goldfaden really wrote dramas with interspersed songs, in the form of couplets, arias and choruses, with primitive orchestral accompaniment. The number of the songs he used to increase or reduce, according to the vocal ability of the actors. The tunes Goldfaden drew 
from all sources procurable; from the Synagogue, from the Jewish, Ukrainian and Roumanian folk-song, taking also snatches from French, Italian and Russian couplets, marches, operas and potpourris.

The motley origin of the music is best understood through detailed analysis of the operettas. On examination we find that Shulamith, according to the latest edition, consists of twenty-five music-pieces. ${ }^{33}$ No. I, "The March to Jerusalem," is taken from Naumbourg's Zemiroth 1srael, p. 79 (Lechoh adonoy). No. 2 is likewise from Naumbourg, ibid., p. 196 (Mi hu ze melech). No. 3 is in the MogenOvos mode with the ending motive of the traditional tune of Ledovid boruch (Chapter VIII), while the motive which Goldfaden uses for the word darkechoh in this song is similar to a Yemenite folk motive. ${ }^{34}$ No. 5 is a typical Italian "aria." No. 6 is a Jewish folktune, and became very popular in Goldfaden's words and setting. No. 8, too, seems to be taken from an Italian source, while Nos. 9-10 were adopted from Schestapol's setting of Psalm II4 (Adonay Zechoronu), who on his part adopted the aria of Verdi's La Traviata, No. 6 (The Aria of Violetta). Of Italian source, likewise, No. I I appears. No. 12, a "Ballet," is an imitation of a Mazurka. No. 13 is Ukrainian, while No. 14 is a chassidic dance in Adonoy-Moloch mode, and No. 15 is chassidic in the Gipsy-scale. It became very popular. In No. 16 we recognize an imitation of Eleazar's famous aria in La Juive beginning "Recha, when God." No. 17 is the Ukrainian tune given in table XXXII, 24-25, and discussed in Chapter XVIII. Nos. 18-19 are a compilation of German and Ukrainian motives. No. 20 is a typical Turkish Hedjaz tune. Nos. 21-22 are a popular Jewish folktune with another text, No. 23 is a chassidic tune of the type called dveikuth (Chapter XIX), No. 24 is in the Ukrainian Dorian scale, and No. 25 is a Russian march or an imitation thereof.

The latest edition of Bar-Kochba contains seventeen musical numbers. $^{35}$ No. I is a chassidic dveikuth melody with a touch of chazzanic flavor. No. 2 is a very popular Jewish folk-song. No. 3 is a duet and solo adapted from French or Italian sources. Of the same source apparently are No. 4 and No. 5, while No. 6, a charming march, shows the Ukrainian scale. Nos. 9-10 are a concoction of chazzanic motives of Schestapol and others. No. II starts in the 
usual German march-style and modulates to the Hedjaz scale. Nos. 12-1 3 are in the mixed Ukrainian scale, and became very popular. No. 14 is a bravura-aria in Italian style. No. 15 is in the style of Jewish folk-song, and became a favorite of the people, while No. 17 is a chassidic tune.

Though Goldfaden cannot be credited with original creations of music in these two operettas analyzed, he showed much dramatic skill and musical taste in adopting fascinating tunes which would appeal to the Jewish masses. The tunes are well chosen, also with regard to their dramatic effectiveness. It goes without saying that the accompaniment is very primitive, and that there is no musical style, with exception of that of a potpourri. Upon the more developed taste of the present Jewish public, Goldfaden's operettas do not make much impression, but a half century ago his plays were a revelation to the people in Eastern Europe and caused a furor throughout the Jewish settlement in Russia. The two melodramas were even translated into Polish. The officials of the Russian Government became suspicious of that institution which seemed to strengthen nationalistic sentiments among Jews, and in 1883 all Jewish theatres were closed. The troup had to leave Russia for Galicia. From there it proceeded to London and finally settled in New York. Goldfaden continued to compose and compile dramas and musical plays. $\mathrm{He}$ is accredited with 26 pieces, of which, however, only eight are of any value. Never did he again reach the climax of the two pieces discussed.

Apart from his dramatic creations, Goldfaden was a prolific song writer, composing both text and tunes. Some of his songs gained wide popularity and were published in sheet form. We name only Yankele geht in Shul arain, Dos pintele Yüd, Yisrolik kum ahaim. He died in New York in r908.

Of later composers of Jewish musical plays we mention Joseph Rumshinsky (born in Wilna in 1879), who gained 
popularity in New York. His music is based upon folk motives and influenced by "Jazz" rhythms and melodic curves.

(5) MaRK WARSChawski was a lawyer by profession and a folksinger by nature (Zhitomir I845-Kiev I907). Many of his songs became real folk-songs, especially Aufn Pripitshok, in the Mogen-Ovos mode. His tunes were partly composed, partly adopted, by him. Some of them are genuine Jewish melodies. A collection of 25 of his poems, Jïdische Volkslieder, was published in I900 (second edition, New York. I918). Some of his tunes were published in sheet form and in various magazines.

The last few decades continued the creative stream of Jewish song that gained popularity. In most cases, the composers of these songs, in true folk-style, remained unknown. Such anonymous pieces are Dos Talissl (The Prayer-Shawl), Gott und sein Mishpot ist Gerecht (God and His Judgment are Righteous) and especially Eili, Eili, which became so widely known in the last fifteen years. The tune of the latter is in the Ahavoh-Rabboh mode, expressing deep Jewish emotions. In content and character these songs are a continuation of the Jewish folk-song of Eastern Europe, though more intricate. We may classify them as songs in FOLKSTYLE (Volkstïmlich).

Of quite another character are the songs in modern Hebrew which sprang forth in the last forty years. Their content is nationalism, the call to rejuvenation, to the rebuilding of the Jewish people as a nation in Palestine. They were created by the Zionist movement, and voice its ideals. Of these songs Hatikvah (The Hope) became the Zionist national anthem in I897. The text was written by Naftali Herz Imber (I856I9II) and was published in a collection of his poems called Barkai (The Morning Star) in Jerusalem, I886. The tune is similar to the Dew-tune of the Portuguese Jews given in table XXVIII. Another famous song is Birkath Am which is by 
Ch. N. Bialik. The tune has Slavic flavor. Some songs were created in Palestine, such as Shir Avoda (Labor Song), the text by Bar-Nash of Jerusalem, the tune of Arabic origin. The tunes are, in general, adaptations from Jewish Ashkenazic, Arabic or Sephardic-Oriental and Slavic originals; yet a Jewish spirit has been breathed into them, and they are distinguished by a vigorous, hopeful note.

\section{B. Klezmorin $=$ Music-makers}

This word is a corruption of the Hebrew kle-zemer-musical instruments.

Already in Chapters I and V we saw that after the destruction of the Second Temple in Jerusalem music-making on instruments was restricted to weddings. Exception was made in the case of those poor people who earned their livelihood by making music for Gentiles. ${ }^{36}$ Instrumental music was allowed at the celebration of the dedication of a synagogue or of a Scroll. In the Orient it became customary to sing hymns with musical accompaniment in the synagogues on the intermediary days of Pesach and Sukkoth. This custom was in practice already in the twelfth century ${ }^{37}$ and has continued until the present day.

During the Middle Ages music-making became a standard profession among the Jews in the Orient as well as in the Occident. In almost every city there were professional Jewish klezmorim. We hear of musicians who gained fame and were court-musicians of sultans and caliphs, of dukes and kings and even of Popes (Chapter X).$^{38}$ In some places the Jewish musicians were the main music-suppliers, and functioned even in Christian religious ceremonies.

Thus, we hear, for example, that in Constantinople there were 500 Jewish musicians toward the middle of the nineteenth 
century. ${ }^{39}$ In the fifteenth century there were in Europe organized Jewish music bands in which also women were active. ${ }^{40}$ These bands traveled throughout the country, concertizing at Christian festivities, and were often preferred to Christian musicians on account of their art and because of their modesty and sobriety. This preference combined with prejudice caused the issuing of restrictions with regard to the Jewish musicians and the laying of heavy taxes upon them. Hence, after the sixteenth century no Jew was allowed to perform his art as a profession without a permit of the local governmental authorities, and since such governments were as many as there were cities in Germany, the hardships these musicians had to bear are easily imaginable. ${ }^{41}$ Further restrictions were issued as to the days on which the Jews were permitted to make music even in their family celebrations, such as weddings. We hear already in the fifteenth century of cases in which Jews were punished for having made music at weddings on days prohibited to them. Many Jews were compelled to celebrate their weddings in other districts, where these prohibitions were not effective. Rabbi Jacob Mölin (Maharil), considering instrumental music essential for the wedding ceremony, ordered such temporary removals in cases of local restrictions. ${ }^{42}$

Even at times when music was permissible, the government set limits to the NUMBER of the musicians that might be employed. For quite other reasons Jewish religious authorities, too, restricted the size of the orchestra. They sought to erect a "fence" against hilarity and gaiety, out of respect for their ever remembered "Destruction." After every new disaster and each renewed outbreak of persecution Jewish authorities would reenforce interdictions against music-making. We hear, for example, that in Worms, or Brest-Litowsk, Selz and in many other communities, music-making, even at weddings, was forbidden on account of calamities. ${ }^{43}$ In Metz, only three 
musicians as a rule-for weddings a quartet-were permitted, but those without legal right of residence in Metz might employ only one even for a wedding. In Frankfort a quartet was permitted, but the klezmer had no permission to play after midnight. In Fürth, the number was restricted to three instruments, and similarly in many other cities.

Nevertheless, the organized Jewish bands developed more and more. In some places there were no other musicians but Jews. $^{44}$ We hear of a large Jewish guild of klezmorim in Prague, whose emblem was a violin. They would volunteer their service for religious celebrations in the synagogue at the regular Friday evening service, before the traditional ritual would start (Chapter XI). They volunteered, also, at celebrations which the Jewish community arranged in honor of the reigning Emperor. Of one such celebration in 1716 a detailed description has been preserved. ${ }^{45}$ There is a description for the same year of a celebration in Offenbach in the synagogue which reports the accompaniment of Jewish klezmorim, and another detailing a similar performance in Worms in $1790 .{ }^{48}$

There are also many descriptions caricaturing the nature of the music performed by the Jewish musicians and casting aspersion on their musical ability. ${ }^{47}$ A description of a Jewish band of five, in I800, in a small German town, seems to be objective. According to this description the five musicians engaged in other trades in addition to their playing. Two of them were violinists, one played the clarinet, one the violoncello and one the Hackbrett (Dulcimer). "Only the first violinist played from written music, the others following by ear. The cellist, an old man, played with especial skill. He knew nothing of notes, but had an excellent ear, observed each turn of the leading melody and was able to add accompaniment in perfect harmony." ${ }^{48}$ The Hackbrett was very much in favor with the Jewish klezmorim. Already in 1694 
this instrument was used by travelling Jewish music-makers. ${ }^{49}$

Next in skill to those of Prague and Fürth were the klezmorim of Frankfort and Berlin. They used to tour the country despite heavy taxes, visit fairs, such as the "masses" in Leipzig, making music in inns and wine-saloons, and would perform at summer resorts. These bands, however, vanished gradually with the emancipation of the Jews in Central Europe, while in Eastern Europe the klezmorim continued as a guild until lately.

Many distinguished Jewish musicians and virtuosos of the nineteenth century were descendants of these music-makers. But some of the klezmorim gained reputation and fame even as klezmorim. One of these was Michael Joseph Gusikow. He was born in Shklow in 1806, in a family of klezmorim, and learned the profession of his father, the playing of the flute. Defective lungs forced him to abandon the flute in I83I for the Hackbrett. Out of this he constructed the socalled "straw-fiddle." In a very short time he gained a marvelous virtuosity on this invention of his. He left his home, and toured the principal cities of Russia (in the beginning on foot). In Kiev he gained the admiration of musicians. In Odessa he gave a concert in the Italian Opera house, in 1832. His reputation spread rapidly after his appearance in Vienna. Prominent journalists, such as Saphir, described Gusikow's unique art with great enthusiasm. "See this man," writes Saphir. "Here he appears in the national costume of his Polish coreligionists, wrapped in a black 'talar,' with his black hair and the two curis peios (side locks), his head covered with a black cap. He relates to us a touching elegy through his features, and this elegy he sets to music. . . . Out of wood and straw he charms forth tones of deep melancholy, of profound emotion. Out of wood and straw he knows how to produce the finest vibrations, sounds of most 
tender softness. How painful and tender sound his national tunes." In 1836 he gave a concert in Leipzig. Felix Mendelssohn-Bartholdy, who attended, wrote to his mother thus: "I am curious to learn whether Gusikow pleased you as much as he did me. He is quite a phenomenon, a famous fellow, inferior to no virtuoso in the world, both in execution and facility. He, therefore, delights me more with his instrument of wood and straw than many with their pianofortes, just because it is such a thankless kind of instrument. . . . It is long since I so much enjoyed any concert as this, for the man is a true genius." " ${ }^{\text {so }}$ After his tour of Germany and France his malady, consumption, overpowered him and in I 837 he died in Aix-la-Chapelle. A tune of his for Psalm I26, in the Ahavoh-Rabboh mode, is still preserved. ${ }^{51}$

A similarly gifted musician was the klezmer MORDChele Rosenthal, whose name was later changed to Rozsavölgyi Mark (I787-I 848). He was the creator of the Gipsy-Hungarian national music and the composer of the Hungarian Rakoczy march. Joseph Schlesinger (born I 794), in order to escape the occupation his father had selected for him, fled to the just-mentioned Rosenthal and became a flutist in his "Gipsy-band," which consisted entirely of Jews disguised as Gipsies. ${ }^{52}$

Some of the artists among the klezmorim communicated their art to gentile musicians. ${ }^{53}$

Among the Jews in Poland, too, music was much cultivated. Reports of the sixteenth century inform us of talented Polish artists who came to Silesia and were recommended to the German nobleman. ${ }^{54}$ Occasionally Jewish klezmorim served in military bands of the German armies. A certain Chayyim Cimbalist of Poland served in Wallenstein's army, and died in the war in $1637 .{ }^{55}$ The influx of Jewish musicians from 
Poland into Germany continued throughout the last three centuries. $^{56}$

The music which the klezmorim used to perform was of Jewish as well as of non-Jewish origin-music of all the various styles, according to the demand of their audiences, from elegiac tunes to frivolous dances. Especially were their stirring and subtle rhythms much liked by their gentile employers. ${ }^{57}$ The competition of the Jews raised the wrath of the Christian musicians, and in Bohemia they petitioned the authorities repeatedly, in $I 64 I$ and $I 65 I$, to prohibit the Jewish musicians from playing at Christian festivities, "because they confuse the music in that they are incapable of keeping strict rhythm or tempo, and vulgarize our noble and graceful music." The Jewish musicians were likewise accused of possessing no music of their own, but only imitating Christian music in a miserable manner. In their reply, the Jewish musicians attempted no vindication of their musicianship, but only appealed to the human sentiments of the authorities, declaring that inasmuch as they had no other profession by which they could earn their livelihood, the interdiction to practice their music would cause their ruin. ${ }^{58}$

The prejudice seems to have been one-sided, for we find that Jews employed Christian musicians not only on Sabbaths and festivals, when music-making was forbidden to Jews ${ }^{59}$ (Chapters I and V), but even on week-days Christian musicians were invited to play together with the Jewish klezmorim. Christian musicians were known to come to Jewish weddings uninvited. ${ }^{\text {Bo }}$

Thus, we see that the klezmorim in Central and Eastern Europe were the forerunners of the host of musicians of Jewish extraction, both composers and performers, who, from the beginning of the nineteenth century on, contributed enormously toward the upbuilding of European art-music. 


\section{CHAPTER XXI}

\section{ARTISTIC ENDEAVORS.}

Almost a century after European artistic achievements in the field of music had been employed for the song of the Synagogue, these were applied also to the Jewish folk-song. Though, occasionally, Jewish folk motives had been utilized for artistic works, as, for example, by Anton Rubinstein in his opera The Maccabees (in 1875), it was only toward the end of the nineteenth century that some Jewish musicians, trained in European art-music, discovered artistic possibilities in the folk-song of their people, and set themselves to systematic artistic endeavors. These young men were of East European origin, educated in a Jewish atmosphere, saturated with the sounds of Jewish folk-song. They were stimulated by the newly revived Jewish national movement which strired up their Jewish self-consciousness, and turned their interest to their people's song. They devoted themselves to cultivating Jewish folk-songs: first, in ARRANGING them mostly for solo with piano accompaniment; but also for choir or for instruments-and, secondly, in utilizing folk motives and tunes for ORIGINAL compositions in the classic forms of European music. The creations of the second type are both vocal (for solo or choir) and instrumental (for violin, violoncello, piano; duets, trios, quartets and for small orchestras).

The new undertaking involved difficulties of technique and spirit not apparent on the surface. Artistically successful arrangement of folk-song depends not merely upon faithful adherence to the melody-vitally important as is this care of 
the tune's genuineness. The musician must have absorbed the spirit of the tune, and be moved by the emotions which gave it birth, so that, instead of caricaturing the melody by reason of unsuited harmonization, he give it fuller expression through instrumental accompaniment. He needs must preserve the simplicity of the folktune, must subordinate the instrument to the melody, and must employ only such modulation, progressions and harmonic combinations as spring from the character of the song. The value of all artistic labor in the realm of folk music rests with the composer's regard for and preservation of the song's own character.

If with mere "arrangement," when guided by the established melody, the musician face so complicated a problem, how much more intricate, how much greater, the hazards of creating original compositions in which folk motives are utilized as themes. The artist is not free for a moment to forget the source of the theme, to violate the atmosphere that there surrounded it and gave it color; he is never privileged to abduct it to realms of foreign emotions. So imbued must he be with the spirit of the song from which his theme sprang, that his artistic product breathe forth the atmosphere of that theme's origin, and that from the theme in its new setting there flow the expression of the sentiments and emotions of the people who conceived it.

\section{Arrangements}

In 1887 H. B. Golomb, a music-teacher in Wilna, published ten Jewish folk-tunes for weddings, arranged for piano, under the name Kol Yehuda-Klänge der Juden. Bogumil Zepler: (Breslau, I858-Berlin, I9I8), after considerable success as operetta-composer and writer on music, took to cultivating Jewish folk-song. Several of his arrangements were 
published in sheet form and in the monthly Ost und West in Berlin. Julius (Yoel) Engel (I868 Verjansk, TauriaCrimea-died, Tel-Aviv I927), was music teacher and music critic in Moscow and an ardent cultivator of Jewish song. He composed and published several collections of songs for children and adults with piano accompaniment, in Hebrew and Yiddish, also numbers for piano and choir. He also attempted solo and piano arrangement for Yemenite songs, ${ }^{1}$ but being unacquainted with their Oriental atmosphere, gave to their accompaniment an inappropriate harmony. Platon BrouNOFF (I868 Russia-r924 New York) in I9I I published in New York a volume of 50 Jewish folk-songs with piano accompaniment. This collection contains valuable material. His accompaniment is in the routine style. Brounoff likewise published several original works based upon Jewish motives, in which he tries to give Oriental color.

In the above-mentioned Ost und West about 70 songs for voice with piano or for violin and piano were printed during the existence of this monthly: I90I-1922. Among the contributors ARNo NADEL was the most productive (born in Wilna 1878 . Is now choir leader at a synagogue in Berlin). $\mathrm{He}$ further published a few collections of folk-songs with piano accompaniment: Juedische Volkslieder and Jonteffieder, Juedischer Verlag, Berlin.

In I908 a "Society for Jewish Folk Music" was organized in Petersburg, with the aim of collecting folk-songs and arranging them in artistic forms. The founders and coworkers were trained musicians. In I9I I this society published $A$ Collection of Songs for School and Home. The songster includes 62 Jewish songs for solo and three-part chorus with simple but appropriate piano accompaniment; and 23 songs selected from German and Russian classical music. ${ }^{2}$ In an appendix some examples of the Biblical and Synagogal modes 
are given. The same society published several songs arranged for voice with piano accompaniment and some for choir or for instruments, by M. Gnessin, M. Milner, S. Kisselgof, P. Lwow, I. Achron, L. Saminsky, M. Schalit, A. Schitomirsky, L. Zeitlin, S. Gurowitsch, I. Schulman, E. Sklar, I. Kaplan and H. Kopit.

The activity of this society was cut short by the World War. With reestablished peace some members of the original group organized the Juwal Publishing Company for Jewish music in Berlin; and since I 922 have put out several works among which is a number of folk-songs in arrangements.

In I9I 8 a "Chamber-Music-Ensemble"-Zimro ("Song") was organized in Petrograd by G. Mistechkin (first violin), G. Besrodney (second violin), K. Moldavan (viola), I. Cherniavski (cello), S. Bellison (clarinet) and L. Berdichevski (piano), trained at the conservatories of Petrograd and Leipzig, with the following objects in view:

“(I) To propagate Jewish Folk Music artistically cultivated.

(2) To collect means by subsidy and percentage from income of concerts, for the fund which the 'Zimro' Ensemble established for the purpose of building a Temple of Art in Palestine.

(3) To unite all Jews, who are active in the field of art and literature, in one common bond under the name of Omonuth (Art), in order that they may contribute potentially to the revival of the Jewish Nation and cooperate in the development of Jewish Art in Palestine.”

To materialize their ideal they started out on a concert tour through Siberia, China, Japan, via America to Palestine. After concertizing in all these countries the troup published a book- 
let relating its aims and activities (New York, 1919). Some of the members of this "Ensemble" arranged Jewish folksongs for quintette (string-quartette and clarinet), and solos for cello, clarinet and violin.

Many more workers are now collecting and arranging: JANOT S. Roskin, Berlin, has given a considerable number of songs in sheet form. Henry Gideon published From the Cradle to the Chuppe, Boston, I923, containing I 5 songs; and LaZAR SAminsky, Ten Hebrew Folk-songs and Folkdances, New York, 1924. SARAh Pitkowsky-Schack collected 50 Yiddish Folk-songs which were arranged for piano by ETHEL Silverman Cohen, New York, I924, 2nd edition 1927.

Zavel Zilberts (Pinsk, I88I), the violinist EFrem $Z_{\text {IM- }}$ balist (Rostov-on-Don, i889), Joseph Cherniavsky and A. W. BINDER, all living in America, arranged several folksongs and utilized folk motives in their compositions.

Among the songs favored with several arrangements are Dem Rebbins Niggun (table XXXIII, 5), Kaddish and $A$ Dudule (ibid., 6), Alte Kashe (XXXII, I4), A Chazzandl auf Shabbos (ibid., ii) and Eili, Eili.

Occasionally musicians of European reputation interested themselves in the arrangements of Jewish folk-song, as in the instance of MAx BRUCH's Hebräische Gesänge or MAURICE RavíL's Deux Melodies Hebraiques, Paris, I91 5, containing Kaddish (table XXIII, 4) and An Alte Kashe. In most such cases the composer's lack of familiarity with the spirit of the songs and the atmosphere out of which they sprang precluded the possibility of his offering appropriate arrangements.

\section{Original Compositions}

A classic illustration of the use of Jewish motives without the production of a Jewish composition is the Kol-nidré con- 
certo for cello and orchestra, op. 47, by Max Bruch. In Chapter XIII (note 22) it was related that Bruch became interested in Jewish songs through the chazzan Lichtenstein. Bruch utilized the Kol-nidré theme to create a fine piece of music but one that is German-European in spirit and style. $\mathrm{He}$ did not express as a background of the tune the milieu out of which it sprang, the religious emotions which it voices: awe, repentance and hope. In Bruch's conception the melody was an interesting theme for a brilliant secular concerto. In his presentation, the melody entirely lost its original character. Bruch displayed a fine art, masterly technique and fantasy, but not Jewish sentiments. It is not a Jewish Kol-nidré which Bruch composed.

Quite different are some of the artistic endeavors by Jewish composers of Eastern Europe. Out of the nucleus of the motive, they develop an artistic composition. Saturated with Jewish sentiments, they feel the emotions which gave birth to these tunes with the intense and profound sense of artists; and they try to pour these sentiments into artistic moulds.

The above-mentioned J. Engel composed 50 children-songs with piano accompaniment, utilizing folk motives. In his accompaniment he breaks with the routine manner of applying arpeggio-figures, passages and runs, and adheres to the harmonic support of the melody. His accompaniment, while it gives primarily a basis for the tune, has an expression of its own through modulative and rhythmic combinations.

Solomon Golub (born in Russia I888-now living in New York) in some of his published Yiddish songs with piano accompaniment has succeeded in creating artistic music based upon the genuine Jewish folktune. His songs Tanchum, in the mode of Talmud-study (Chapter XIV), "The Old Watchman," "The Cup," "A Cradle Song" and Burikes af 
Pessach rank as successful achievements in the field of Jewish art-songs in folkstyle. Golub certainly absorbed the spirit of Jewish song, in the motives, melodic line and in the modulations he employs. In the accompaniment of "The Old Watchman" and Tanchum he displays original features. In his later publications, however, his attempt to compose in EUROPEAN style led him to imitate in melody and in form the German Lied, notably such songs as those of Schubert, Schumann, Franz and Wolf. The compositions are consequently weak. Among many songs of Jewish value we mention In Cheder by M. Milner. The tune is in the mode of the Talmudstudy, worked out in a dramatic manner.

In the field of instrumental music Joseph Achron (I 886 in the Government of Suvalki-now lives in New York) was successful with his "Hebrew Melody" for violin and piano, published by the above-mentioned Petersburg Society in I9I4. This composition is based upon a folk-tune in minor, with the Ukrainian augmentation on the 4 and 6 toward the end. $\mathrm{He}$ developed this melody in the violin and the piano part according to Jewish ways: by the sudden transferring of the tune to the upper third, giving vent to the outburst of suppressed pain and emotion, and then, toward the end, falling back exhausted to the first state of depression. His "Hebrew Dance" is another solo for violin and piano, based upon a chassidic tune in the Ahavoh-Rabboh mode. In this piece the Jewish-Oriental fiery temperament is expressed in masterly fashion. The same feature is to be found in Märchen (Fairy tale) for violin and piano.

Of a similar character is a "Fantastic Dance" of the Chabad chassidim (Chapter XIX), for piano, violin and cello by SoloMon Rosowsky. The tune is based upon the Gipsy-scale explained in Chapter IX, which is seldom used in Jewish music. 
On the other hand there are some works, such as "Variations on a Jewish Theme, for String Quartet" by M. GNessin and a "Romance for Violin and Piano" by I. Weinberg, which do not show Jewish characteristics.

These endeavors are but a beginning in the building up of a Jewish art-music, in which the vibrations of the Jewish pulse will be reechoed. 
PART III 



\section{CHAPTER XXII}

\section{THE JEW IN GENERAL MUSIC.}

We have thus far treated Jewish music created by Jews for Jews. But apart from the musicians who served the Jewish cause in creating Jewish music, the Jewish people produced throughout the ages hosts of professional musicians, who were active in the music of their gentile neighbors. The question naturally arises as to whether or not Jewish musical sounds vibrate in their compositions or in their performances; whether they brought to the music of the general world a distinctively Jewish contribution.

It is generally known that a composer creates his music on the established premises of the music prevalent in his immediate environment. His tonal elements he instinctively chooses from the folk- and art-music with which he is filled from his childhood. Since every historical nation has its peculiar folk-song, and, to a certain degree, also its original style in art-music, the new composition generally makes an additional contribution toward the music of the artist's nation. Despite the professed tendency in the classical music of Europe toward INTERNATIONALISM, toward a European music for all European peoples and for those of European extraction, the classic music created by Germans has the imprint of German folksong and character; while the Russian music unmistakably bears the marks of Russian folk-song and character. We find, likewise, Anglo-Saxon and Gaelic folk-song features in English music, and in Scandinavian music its people's folk-motives. We know of many cases in which musicians of one nation were 
attracted to the musical style of another people and sought to create in that adopted style. The result, however, was different from what they had originally anticipated. Handel, Gluck, and Mozart, despite being enamored of Italian music, created German music with some Italian flavor. ${ }^{1}$ Verdi, in his Ä̈da, made an effort to introduce Wagner's style into Italian music. The result was an Italian opera with some German flavor. In either case childhood training and environmental influence proved to be stronger than foreign models and personal effort.

Musicians of Jewish origin, due to their scattered places of residence and the often preponderant influence of the nonJewish majority, present a phenomenon apparently unique but genuinely in line with the facts just presented. They created or performed music in the style of their neighbors and were considered good composers in the field of their neighbors' music. The participation of the Jews in European music increased tremendously since the beginning of the nineteenth century after their admittance into the social and cultural life of Europe. An innumerable host of musicians filled the musical world, creators and especially performers-virtuosos on various instruments, but notably on the violin. They cultivated all styles and branches in music: opera, oratorio, concerto, symphony, sonata, vocal and instrumental music from sacred Church-music to the comic opera and Jazz-hits. They became distinguished theoreticians and teachers, musical critics and essayists, directors, publishers and promoters of music. The following list of the most important and successful musicians of Jewish extraction, who contributed enormously toward the upbuilding of European classic and popular music, may suffice to illustrate their activity during the last century up to the present day: Jacob (Giacomo) Liebmann Meyerbeer (Berlin I79I-Paris I864); Jacques Fromental Halévy (Paris 
I799-Nizza I862); Felix Jacob Mendelssohn-Bartholdy (Hamburg I 809-Leipzig I847); Ignaz Moscheles (Prague I794-Leipzig I870); Jacques Offenbach (Cologne I8I9Paris 1880); Sir Michael Costa (Naples I810-Brighton I884); Ferdinand David (Hamburg I8 Io-Switzerland I 873); Ferdinand Hiller (Frankfort I8I I-Cologne I885); Anton Rubinstein (Wechotynetz 1829-Peterhof I894); Karl Goldmark (Hungary 1830-Vienna 1915); Joseph Joachim (Kitsee, near Pressburg, I831-Berlin 1907); Leopold Damrosch (Posen I832-New York 1885); Gustav Mahler (Kalischt I860-Vienna I9II); Hermann Levy (Giessen I839Munich 1900); Adolph Bernhard Marx (Halle I795-Berlin I866); Salomon Jadassohn (Breslau r831-Leipzig I902); Leopold Auer (Vesprem, Hungary I845- ); Arnold Schönberg (Vienna I874 ); Ernest Bloch (Genf r880 ); Ignace Friedman (Cracow, Poland $\mathrm{I}_{82}-$, is living in New York); Irving (Israel) Berlin (Baline) Russia r888- ); George Gershwin (Brooklyn I898- ); Erich Korngold (Brünn I897- ) and Jascha Heifetz (Wilna r90I- ); Mischa Elman (Talnoje, Russia I89I- , lives in New York). All these musicians created or performed European music for the European people. Almost none of them had been reared in a distinctly Jewish environment, or had been given a positive Jewish education and knowledge. As a result several of these musicians became converts to the dominant Christian faith; some attempted assimilation in the society they had adopted. Indeed, Mendelssohn's and Rubinstein's parents had carefully kept them away from Jewish influence, and educated them in the culture of their Christian environment. There were musicians of the younger generation whose only knowledge of their Jewishness was the bare fact of their extraction. In any case, very few knew anything of Jewish Synagogue and folk-song. The most conscious Jew among the earlier of these musicians, 
Halévy, only once (for the aria of Eleazar, in his La Juive, Act IV) utilized a Jewish motive, while Goldmark and Offenbach-both sons of chazzanim-never employed Jewish motives in their compositions. These Jewish composers drew their material from the wells of the music of their adopted peoples.

On examination of their creations we discover not a single element that bears Jewish features that might be reckoned a distinctly Jewish contribution. Of them all, it was Rubinstein who occasionally and with conscious intent used Jewish motives in connection with Jewish or Oriental episodes in his operas and in his songs. But he, likewise, utilized other Oriental material, such as Persian and Tartaric motives. Some claim that a certain inclination toward melody-lyricism-is a pronounced feature in the music of Jews. ${ }^{2}$ But the music of Mozart, Haydn and Schubert has also the same feature. There is no standard or measure by which we can distinguish a German song by Mendelssohn from hundreds of other German songs; or a jazz-song by Berlin from the other innumerable modern Anglo-Saxon popular "hits." Neither by their motives and form, nor by their style and spirit, can they be identified.

Ernest Bloch's music is designated "Jewish." Its Jewishness, however, consists in an abundance of augmented steps, and, according to the opinion of some, in a certain heavy melancholy. But, these characteristics are not exclusively Jewish, for all the Semitic and Tartarian peoples have the same characteristic step, and as to the melancholy impression Oriental music makes on the Occidental hearer, we have seen in the course of our discussion that such an impression is based upon the difference of taste of Orientals and Occidentals. At best, Bloch's music may be said to have a touch of Orientalism. A. Einstein says of him: "Determined to create Jewish music, he does not turn to the real Oriental or Jewish music for themes, 
but tries to construct the character and spirit of his race out of himself." ${ }^{3}$ In a similar way an Englishman, German or Russian, born and reared in the Orient in an Arabian atmosphere, would try to compose English, German or Russian music, without actual knowledge of his people's song. In music such as Bloch's, we find the refutation of the lightly conceived and unthinkingly accepted present-day opinion that the musician, unconscious and ignorant though he be of his people's music and folklore, yet instinctively manifests these racial expressions. Seductive as is the theory, for rational nationalists, there is in music not only no tangible proofs of it, but positive evidence against it. Not through composers withcut Jewish background, and without being imbued with their people's folk-song, has Jewish music left any unique impress upon general art-music. For the Jew his lore and his faith substitute national atmosphere. ${ }^{4}$

We shall not discuss all the arguments and accusations brought forth in the course of the last century as to the genuineness of the creation of Jewish composers. Opinions of that type are created out of subjective impressions, without any real basis, and are often in line with the cheap and malicious attacks of Richard Wagner, which sprang forth not out of analysis and conviction, but out of bitterness and envy. $\mathrm{He}$ obviously had forgotten the enthusiastic laudations of Meyerbeer, Mendelssohn and Halévy which he had written when he was in need of their support. At that time he had proclaimed Meyerbeer and Mendelssohn the greatest and purest German composers. ${ }^{5}$

Nor can we give more than passing attention to another opinion expressed lately, that the Jews are revolutionaries in music, that they destroy established forms and are the protagonists of all that is new and ultra-modern. ${ }^{\circ}$ As examples we are shown: Schönberg, Korngold, etc. However, but a 
glance through the above list suffices to prove the superficiality of such a viewpoint. Alongside of the few musicians who became adherents of the revolutionary music doctrines of modern times, we find the majority of Jewish composers holding to the established principles of classic music without admitting any sidestep. Were not Mendelssohn, Halévy, Goldmark, Joachim, Moscheles, Rubinstein and others strict classicists? Did not the latter, in his zeal for classical forms, make the statement that after Schumann and Chopin there are no new creations worthy of the name "music." "Finis musicae!" he exclaimed. Were not the great theoreticians, Marx and Jadassohn, pious adherents of the style established by BachMozart-Beethoven, recognizing no later innovations in harmony and form? For about eighty years these two men taught nothing but the classic music of the eighteenth and of the beginning of the nineteenth centuries.

Jewish musicians did contribute much toward the internationalization of art-music. Since Meyerbeer, the Jewish composer has learned to merge different styles into a composite one, and the virtuoso has rendered Italian, German or Russian music in the genuine temperament of each people, giving expression to the spirit of the people whose music he presents, penetrating into the very core of that people's scale of emotions. Further, the Jewish musicians contributed NumBERs. The list of Jews among the great in general music is out of all proportion to the comparative numbers of the Jews and gentiles of the nations whose songs we have considered. Musical talent is undoubtedly a pronounced feature of the Jewish people.

Verily, history teaches us that RACE alone does not make for originality in music. It serves merely as fertile soil which, when sown with seeds of the spiritual culture of that race, bears distinctive fruits. The Jew in general music has written 
not as a JEw, but has produced out of and contributed to the culture in which he happened to be reared.

The place for an evaluation of the musical creations of these Jewish musicians is, therefore, not in a treatise on JEwISH music, but in the history of GENERAL art-music. Indeed, such evaluation has been repeatedly made. Here we need only demonstrate the fact that music composed by Jews is not always JEwish music. 


\section{CHAPTER XXIII}

HARMONY.

More than two centuries (from Salomon Rossi to Salomon Sulzer) were required to stabilize harmony in the Synagogue song of Europe. Almost three centuries passed before this art was applied to Jewish folk-song. Apparently insurmountable obstacles stood in the way of employing harmony for a song, the primary features of which sharply contradicted the established principles of classical harmony. First in importance stands the problem of the scales. As explained in Chapter II, and frequently discussed in this book, Synagogue song is based upon THREE principal scales.

First, the tetrachord $\mathrm{e}-\mathrm{f}-\mathrm{g}-\mathrm{a}$, conjunctively repeated: $\mathrm{e}-\mathrm{f}-$ $\mathrm{g}-\mathrm{a}-\mathrm{b} b-\mathrm{c}-\mathrm{d}$ becomes a heptachord, while disjunctively: $\mathrm{e}-\mathrm{f}-$ $\mathrm{g}-\mathrm{a}+\mathrm{b}-\mathrm{c}-\mathrm{d}-\mathrm{e}$ constitutes an octachord. Out of this scale the Ashkenazim developed the scale of the Adonoy-Moloch mode, by adding two tones below the tonic $(\mathrm{d}-\mathrm{c})$ and by lowering $\mathrm{e}$ in the octave $\left(\mathrm{e}^{\mathrm{b}}\right)$, thus creating the following succession of notes: $c-d-e-f-g-a-b b-c-d-e b$. The second scale consists of the minor tetrachord $\mathrm{d}-\mathrm{e}-\mathrm{f}-\mathrm{g}$, which, if conjunctively repeated: $\mathrm{d}-\mathrm{e}-\mathrm{f}-\mathrm{g}-\mathrm{a}-\mathrm{b}-\mathrm{c}$, produces a heptachord, and by its disjunctive repetition: $\mathrm{d}-\mathrm{e}-\mathrm{f}-\mathrm{g}+\mathrm{a}-\mathrm{b}-\mathrm{c}-\mathrm{d}$, forms an octachord. The third scale: $\mathrm{d}-\mathrm{e}-\mathrm{f} \#-\mathrm{g}+\mathrm{a}-\mathrm{b}-\mathrm{C}-\mathrm{d}$, the basis for the Ahavoh-Rabboh mode, is formulated of two disjunctive tetrachords.

None of the scales has the elements requisite for the accepted system of harmony. The basic variances are six, designated (a through f) as follows: (a) The scales of Jewish music have no "Leading-note" in the seventh (i.e., a semi-tone between 7 and 8), and in their heptachordal form have no octave at all. This circumstance precludes the 
forming of a major triad on the fifth tone. (b) In none of the scales is the fifth dominating, the classical importance of the dominant being transferred to the sub-dominant, the fourth, because the SCALEs, and as a consequence, the melodic line of the modes have the tetrachordal form. (c) In scale $I$, in its heptachordal form, the fifth (bb) is diminished, thus preventing the forming of a common triad upon the tonic (e). (d) The second in the scales $I$ and 3 being minor, semitones, makes the forming of a triad upon the fifth a diminished cord. Thus, for example, in scale I the triad upon the fifth will be $b-d-f$ and that of scale 3 will be a-c-eb. (e) The second in scale. 3 is augmented $\left(e^{b-f} \sharp\right)$, a step which is forbidden in classic harmony. (f) The third in the scale of the Adonoy-Moloch mode is, in its octave, flat $\left(E-e^{b}\right)$, and the sixth in scale 3 is major below the tonic and minor above it $(B-b b)$. Both cases make a permanent system of diatonic harmony impossible.

The tetrachordal character of the ancient part of Synagogue song, in giving the fourth the dominating rôle calls not only for the plagal cadence, but causes a change in the whole system of modulation. The tendency toward the TETRACHORDAL CIRCLE involves departure from the circle of the fifth and its related keys, and makes a system of modulation to the related keys of the sub-dominant. Thus, scale 3 has the following modulations: the sub-dominant minor or major, or Ahavoh-Rabboh; the upper-mediant (flat) major or minor; the subsecond minor and major; the sub-mediant major. Scale 2 has: The sub-dominant minor; the fifth Ahavoh-Rabboh; the upper-mediant major; the sub-mediant major; the sub-second major; the upper-second Ahavoh-Rabboh. Scale I in the Adonoy-Moloch form has: the subdominant major; the fifth minor and Ahavoh-Rabboh; the tonic minor; the upper-mediant Ahavoh-Rabboh. In the original form of scale $I$ the nearest modulations are: to the upper-mediant in minor; to the sub-mediant major; to the sub-dominant in the same scale, and to the tonic in Ahavoh-Rabboh.

These obstacles faced the first harmonizers of Synagogal song. The problem was the same as that of the first harmonists of the Gregorian chant three or four centuries earlier, except that the workers in Synagogue music had the more dif- 
ficult task of coping with scale 3, which has no counterpart in the eight old Church-modes. The Church-musicians, as is known, cut the Gordian knot: reduced the eight scales to two, Major and Minor; and reshaped the latter by creating in it the "leading-note" of the major seventh. Needless to comment, in so doing, they violated all that was unique in the Church-song, sacrificing its character to the rules of the science of European music. What they intended was the beautification of a revered inheritance. What they did was to lop off the individualities of their chants to fit the Procrustean bed of accepted classical harmony. They lacked the knowledge, the art and the daring to recast the technique of harmony to conform to the artistic demands of another song.

The first harmonists of the Synagogue fell into the same manner of meeting their difficulty. The structure of Oriental song succumbed to the rules of harmony. The Adonoymoloch scale they reshaped to major; and scale 2 to minor in its "harmonic" and "melodic" succession; scale 3 appeared too "exotic" for the application of harmony; therefore, they often employed for that scale harmony of the major scale. Had they been fully aware of the affront to the integrity of the Synagogue song, some among them might have preferred violating the rules of harmony. As it was they (Jew and gentile alike) believed that they were "modernizing" the traditional scales and modes.

We shall now examine the harmony of the first prominent composers for the Synagogue. Their work was of two-fold character: the creating of new compositions for choir and solo, and the harmonizing of old modes and tunes. Their new creations were based entirely upon European music, in melody and in harmony, without the employment of any Jewish material whatsoever. The only problem of which they were at all conscious was the harmonization of traditional material. 
On examination of the Schir Zion by S. Sulzer we find that he has turned the Adonoy-moloch mode into major (Nos. 19-38), and the Ahavoh-Rabboh, likewise, to major (Nos. 56-75, 82-92). He harmonizes the responses for the three festivals in major (Nos. 164174; 237; Anhang I, No. 21). The test of the man's ability to utilize harmony in accord with the character of Jewish song would have been the $A$ havoh-Rabboh mode. But not a single item did Sulzer compose in the Ahavoh-Rabboh in harmonic setting. He uses minor as a basis and modulates occasionally to the Ahavoh-Rabboh. The minor he employs for short items in which, however, no tetrachordal melodic line is utilized. The old traditional tunes, with but two exceptions, Sulzer gave either in solo or in unison, without any harmony. These exceptions are: No. 435 , in Adonoy-moloch mode, in which Sulzer retained the minor seventh and added organ accompaniment "ad libitum," and No. 46r, a minor tune, the tetrachordal line of which Sulzer retained. Sulzer's harmony expresses depth and exaltation. In it he voices his Jewishness only through his inclination toward interrupted ("deceptive") cadences, through modulations in minor, and the avoiding of too frequent modulations to the dominant.

S. NAUmbourg's harmony is inferior in depth and in originality to that of Sulzer. The Ahavoh-Rabboh he did not use at all. Scale I he, like Sulzer, "modernized" to major. In his harmonization of traditional ancient tunes he not always preserved their integrity, as proved by these numbers from his Zemiroth Israel: Nos. 136, 148, 169, 182, I 83, 226, 229, 233, 246, 282, 292, and these from his $A$ gudath Schirim: Nos. I, 3, 7, I 1, 13, I4, I5, 27, 42, 48, 50, 52. He generally selected those tunes the scale and melodic structure of which were easily adjustable in the major or minor key. Most of the other tunes he rendered as Sulzer did, without harmony. In some items in his A gudath Schirim Naumbourg succeeded in giving harmony not discordant with the characteristics of the Jewish melodic curve. For example, there are No. $3 \mathbf{I}$, in which modulations to the second in Ahavoh-Rabboh, and to the upper mediant are made; and No. 35 (Adonoy, Adonoy), in which the turn toward the sub-dominant is noticeable.

After this scrutinizing search through the entire works of the two most prominent first Synagogue composers for the 
few harmonical progressions that merit attention as adjustments to the character of the song, we conclude that the most that these men achieved even in these rather insignificant exceptions was the avoidance of jarring modulations; and that through their work they nowhere deviated from the strictest adherence to classical harmony.

The first who met the problem, first as a Jew and secondly as a harmonist, who either by conscious planning or by an inspirational leap (We shall never know which.), devised a system of harmonization for Jewish modes, was H. Weintraub (Chapter XIII). Rooted deeply in Synagogue song, technician and artist enough to manipulate with freedom the tools of the science of harmony, he turned to the advantage of Synagogue song, his acquaintance with the work of J. S. Bach, with the classics of Church and secular music. The soundness of his knowledge of classical forms and usages he evidences in his employment of the "Cantus Firmus" with contrapuntal embellishments, which he was first to introduce into Synagogue: song, and further in his composition of fugues (see his work Tempelgesänge, Nos. 3I, 8I, II9). Strongly influenced by Sulzer, he follows his prototype in the harmonization of simple responses in major. But in his handling of scales $I$ and 3 he demonstrates his mastery, his bold independence. In his harmonization of the Synagogue modes he leaves Sulzer behind, he breaks the fetters of classical harmony, and strikes out, forcing for himself a new and untried path. Note numbers $33,35,38,134,145,182,183$ in his above-mentioned work. But Weintraub's crowning achievement is the creation of a harmonic system for the Ahavoh-Rabboh mode.

He sanctioned the augmented second as a DIATONICAL STEP, and set the perfect cadence of that mode in two forms: (I) by means of the sub-dominant, and (2) by the sub-second, or by the diminished fifth in its first inversion (table $X X X V, I$ ). He gave ample illustrations of 
ways the Ahavoh-Rabboh mode should be harmonized, such as Nos. 163, I72, I83, 185, 186, 187, I91, 192, 193, 194, 195, 196, 201, 202, 219-223, 229-231, 236-239, 241. Even his numbers in the minor modes, in the Selicha or Mogen-ovos modes are interspersed with modulations into Ahavoh-Rabboh, such as numbers 188, 189, 190, 197, 198, 199, 200, 207, 209, 210, 211, 213, 216, 232, 234. He was first to introduce the system of transcribing the Ahavoh-Rabboh scale in the key of its sub-dominant minor as, for example, for Ahavoh-Rabboh in "e" the "a" minor key, with individual marking of sharps for the third tone: g\#; for "g" Ahavoh-Rabboh the "c" minor key, with the separate marking of $\mathrm{b} h$ for the third, etc. Similarly he applied for Adonoy-moloch the key of its sub-dominant, as, for instance, for Adonoy-moloch in "c" the key of F Major; for Adonoy-moloch in "d" the key of G Major is employed, etc. Weintraub was the first to render the Adonoy-moloch mode in harmonic setting, retaining in its scale the minor seventh (Nos. 215, 217).

Extracting Weintraub's harmonic scheme from his published work and preserved MSS., we may formulate thus its progressions, combinations and modulations.

(a) Ahavoh-Rabboh or Hedjaz, or Phrygian as Weintraub wrongly called it: (1) 1. Hedjaz-4 minor-1. Hedjaz. (2) 1. Hedjaz-4. Hedjaz-I. Hedjaz. (3) r. Hedjaz-sub-second minor, then Dorian-I. Hedjaz. (4) I. Hedjaz-3. major-4. Hedjaz-I. Hedjaz (see No. 186). (5) 1. Hedjaz-3. major-3. Dorian-4. Hedjaz4. major-4. minor-I. Hedjaz. (6) I. Hedjaz-I. minor-I. Hedjaz-2. major-2. Dorian-3. Hedjaz-3. major-sub-second Dorian-1. Hedjaz. (7) I. Hedjaz-4. Hedjaz-6. major-4. Hedjaz. (8) I. Hedjaz-3. major-4. Hedjaz-5. Hedjaz-4. minor (see No. 193). (9) I. Hedjaz-4. minor-4. Hedjaz-6. Dorian -sub-second minor+Hedjaz+minor-I. Hedjaz (see No. 201). (I0) I. Hedjaz-4. minor-sub-second minor +major-3. majorsub-second major+minor-r. Hedjaz. (II) I. Hedjaz-sub-second major-3. major-4. minor-6. Dorian-6. major-4. minor-4. Hedjaz-I. Hedjaz (see No. 20I). (12) I. Hedjaz-4. minor-6. major-4. Hedjaz-4. minor-sub-second Hedjaz+minor-4. Hedjaz-I. Hedjaz (see No. 24I).

(b) MINoR, or Eolian as Weintraub called it: (I) I. minor4. minor-4. Hedjaz-1. minor. (2) 1. minor-3. major-1. minor. 
(3) I. minor-5. Hedjaz-3. major-I. minor. (4) I. minor-3. major-sub-second major-4. major (see No. 206). (5) I. minor5. Hedjaz-3. major-sub-second major-5. major-1. minor (see No. 195). (6) I. minor-3. Dorian-4. Hedjaz-4. minor-3. major-sub-second major-1. minor. (7) I. minor-3. major-5. Hedjaz-1. minor-5. Hedjaz-1. minor-3. Dorian-5. Hedjaz1. Hedjaz-4. minor-1. minor-3. major-1. minor (see No. 197). (8) I. minor-5. Hedjaz-sub-second major-3. major-4. minorupper-second Hedjaz-3. Dorian-3. Major-I. Dorian-I. minor (see No. 198). (9) 1. minor-3. major-1. Hedjaz-sub-second major-3. Dorian-I. Hedjaz-3. Dorian-3. minor (see No. 200).

(c) Adonoy-moloch, or Mixolydian according to Weintraub: (I) I. A.M. -4. major-5. minor-1. minor-4. Dorian-1. A.M. (2) I. A.M.-I. minor-I. Dorian-I. A.M.-5. minor-1. DorianI. A.M.-4. major-I. A.M.-sub-second major-I. A.M.-I. Dorian-2. Hedjaz-I. A.M.-I. Dorian-2. Hedjaz-sub-second major-2. A.M.-5. minor-4. major-I. A.M. (see No. 205). (3) I. A.M.-4. major-5. major-5. minor-4. minor-5. major-4. major-sub-second major-5. major-I. A.M.-4. major-5. major -I. A.M. (see No. 215).

Weintraub's compositions in the old Synagogue modes are all for cantor solo and choir, so that a good part of the modulations are executed by one voice. Weintraub's harmonic art has not been superseded by any subsequent composer.

L. Lewandowski had no more Jewishness in his harmony than had Sulzer or Naumbourg. True, he succeeded in creating some fine Jewish items, like No. 9I in his Todah Wesimrah I, which he developed out of the traditional Ledovid-Boruch tune. Likewise, No. I 98 Zocharti loch and No. 202 for Psalm I 50. In his harmony he was an adherent of Mendelssohn's school, whose oratorio-style for vocal music he adopted. His music is based, as already pointed out in Chapter XIII, on the German Lied of the nineteenth century and is, therefore, in major with German harmony. The latter feature is expressed in the preference for the progression 
of major chords and modulation into major keys and in an avoidance for minor chords and modulations. Furthermore, there is the predominant striving toward the major dominant. In minor, Lewandowski composed but a very few numbers, while in Ahavoh-Rabboh he has but one composition (No. 218). Noteworthy are his fine organ accompaniments of some traditional tunes, such as Nos. I09, I20, I22, I64, I8I, 222,244 in his above-quoted work. As a whole he adopted the policy of Sulzer, to give traditional tunes and modes without harmony. The other Synagogal composers in Central and Western Europe stood entirely upon the basis of European harmony, and in only very rare cases we find harmonic progressions of Jewish character.

For this artistic Jewishness we have to turn to the works of East European chazzanim. In the collections of E. GERowITscr (Chapter XIV) there is a wealth of Jewish harmony. Both his treatment of traditional material and his original compositions in the Synagogal modes are remarkable for their genuineness and their fine artistic conception. The same holds true with regard to the works of David Nowakowsky, $P$. Minkowsky, A. M. Rabinowitz (Wilna, 1855-Cantor in Libau), and several others. They evolved either through Weintraub's influence or independently, the same manner of harmonic treatment of the Ahavoh-Rabboh, Mogen-ovos and Selicha modes, a system unlike anything to be found in European music.

In table XXXV several examples of harmonic progressions are given. No. 2 is from a composition by D. Nowakowsky. ${ }^{2}$ This selection is in the Ahavoh-Rabboh in "g" and modulates to the sub-second in major $(F)$. No. 3 is by Weintraub from his work No. 220. It modulates into the sub-dominant (c), to the third flatted (bb) and to the sub-second in major, and finishes on the tonic $(\mathrm{g})$ in AhavohRabboh. No. 4 is from Gerowitsch's work Shire Tefilla No. 36, in 
which the same progression is observed, namely, the turn toward the sub-dominant and the cadence with the sub-second in minor.

The same system was later applied for the harmonization of folksongs in Ahavoh-Rabboh. No. 5 furnishes an example of the harmonization of the tune Alte Kashe by A. Shitomirski, given in table XXXII, 14. ${ }^{2}$ The same tune was harmonized by Maurice Ravél in ultra-modern style, without regard for its scale and the nature of the mode. $^{8}$

Among the latest composers S. Alman, in his above-mentioned work for the Synagogue (Chapter XIV), does justice to the AhavohRabboh mode in numbers $25,26,32$. In the latter he modulates to the sub-dominant in minor and in the Ahavoh-Rabboh scale; to the sub-second in minor, to the sixth in major, and finishes on the tonic in Ahavoh-Rabboh. In No. 47 he modulates into the 6th and $3^{\text {rd major. }}$

In a period of 80 years (the oldest composition by Weintraub dates from I 842) the Jewish composers of East European extraction developed a system of harmonization of the Ahavoh-Rabboh mode, which is based on the tonality of its scale and accords with the characteristics of its melodic curves. The consistency with which they have adhered to the system gives us the possibility of establishing certain rudiments of harmony for that mode.

\section{(A) The Harmony of "Ahavoh-Rabboh"}

In $\mathrm{XXXV}, 6$, we give the chords applied in the diatonic scale. In this example we find three major chords upon the first, second and sixth degrees; two minor chords upon the fourth and the seventh, and two diminished chords upon the third and the fifth degrees. The third is at times altered to major, in lowering it a semi-tone (II), while the sixth is, as a rule, applied in major only, taking the third or its octave (tenth) flat. The triads are used in the first and second inversions. The seventh 7 th chord, in all inversions, is the one most frequently used. Next in order come the third 7 th and the fifth 7th (No. 7). Also on the first and on the fourth degree, the chords of seventh are built, while on the second and sixth, seventh chords 
occur but seldom. As has been explained above, the leading-note of the Ahavoh-Rabboh mode is not a semi-tone from the seventh to the eighth. Its leading-tones are the sub-second (a whole tone) ascending, or the upper second (semi-tone) descending to the tonic.

\section{(B) The Harmony of the Minor Modes}

The modes in minor are harmonized in two forms, ( 1 ) in the harmonic minor, and (2) in the Æolian minor. In the first case the harmonic progressions are like those used in classic harmony. The exceptions lie in the modulations. These never occur to the dominant major or minor, but to the dominant Ahavoh-Rabboh, to the subdominant minor and major, to the upper mediant major and minor, to the sub-second major, to the upper second and sub-dominant $A$ havohRabboh. The cadence is effected through the dominant chord. In the (2), Æolian form, the dominating power is given to the subdominant, through which cadences and modulations occur. Cadences are effected also by the major chord on the seventh, as, for example, in Sulzer's Mogen-ovos (No. 43). The use of that form of minor is extensive both in the Synagogue and in folk-songs. We give two examples of harmonization in the Æolian minor scale. One is No. 8 in XXXV, a lullaby arranged by P. Lwow. ${ }^{4}$ The second is No. 9, which is a harmonization of XXXIII, 15. In both examples we clearly see the predominance of the sub-dominant and the lack of the semi-tonal leading-note. In No. 8 the cadence occurs through the subsecond major mentioned above.

At times minor tunes end in the Ahavoh-Rabboh scale on the tonic of the minor in which they begin. In this instance the harmony at the end is in accordance with the Ahavoh-Rabboh.

\section{(C) The Harmony of The "Adonoy-moloch"}

This mode has been comparatively seldom set to harmony. In addition to Weintraub, Gerowitsch, in his above-mentioned work, p. 61, made use of it. XXXV, No. Io affords an example. Here we see the seventh consistently minor. However, the dominant is regularly applied as leading major chord, owing to the fact that the seventh is major when BELOW the tonic. Thus the harmonization leaves the impression of a major scale in which modulation is continuously made to 
the sub-dominant, rather than of the Adonoy-moloch scale with the lowered seventh a regular diatonic step.

The chords are, as furnished in No. II, three major-chords upon the first, fourth and seventh; three minor-chords upon the second, fifth and sixth, and one diminished chord upon the third degree. The seventh, when occurring below the tonic, is major and the chord upon it is a diminished triad. In this case the seventh serves as leading-note and as third in the chord upon the fifth, which chord in this case receives the major dominant character. From all described we see that the chords upon the fifth and the seventh are applied in twofold manner, and these, if properly employed, add a great deal of color and variety to the harmony. The modulations are: to the sub-dominant major, to the fifth minor and Ahavoh-Rabboh scale, to the tonic in Ukrainian Dorian (see S. Alman, No. 7 in his above-mentioned work), and to the sub-second major.

Harmony has adapted itself to Jewish song. Not only has a beginning been made, but a complete system lies before us, the success of which is best attested by the character of the works from which the formula have been extracted. Masters have blazed a path. They employed the IDEA of harmony rather than its established RuLEs. For what they laid the foundation must depend upon the knowledge and the art of those who now approach Jewish music, upon the degree to which composers will remain faithful to the unique character of Synagogue and folk-song.

\section{CONCLUSION}

As a result of our treatise, we see that the Jewish people has created a special type of music, an interpretation of the spiritual and social life, of its ideals and emotions. In this music we find the employment of particular scales, motives, modes, rhythms, and forms, based on definite musical principles. These run through the music like a golden thread. Ele- 


\section{TABLE XXXV}

Harmony

a) Ahavoh-Rabboh
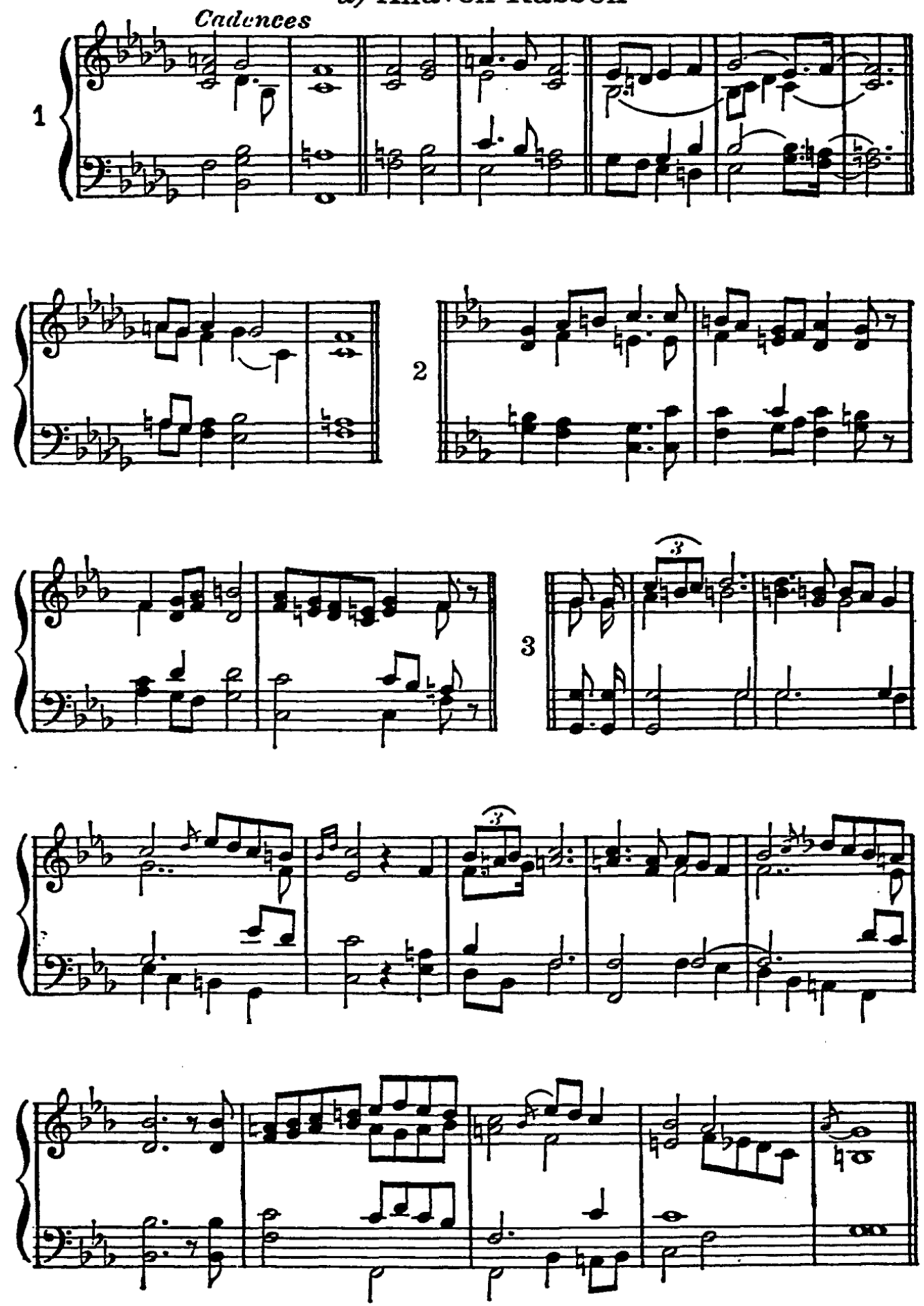

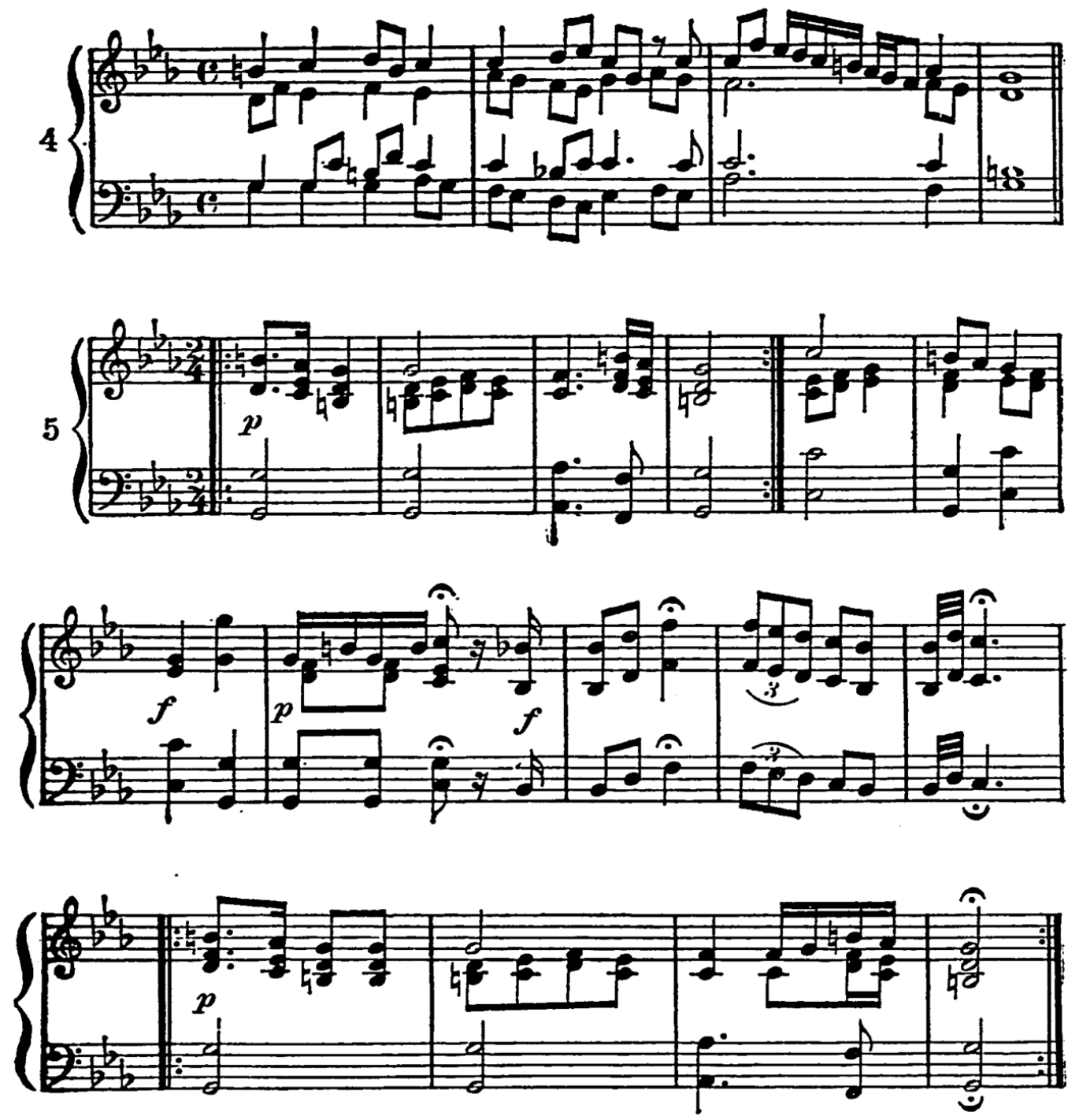

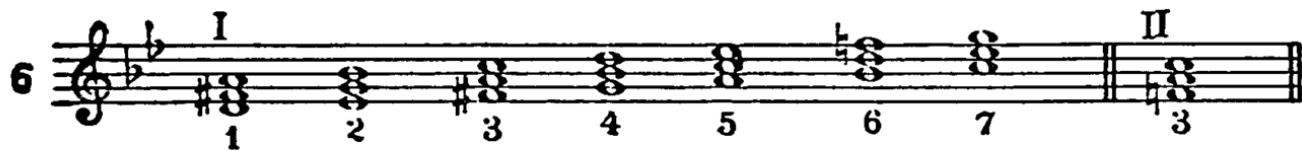

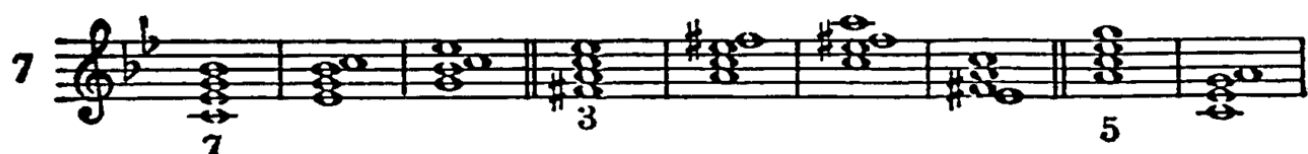

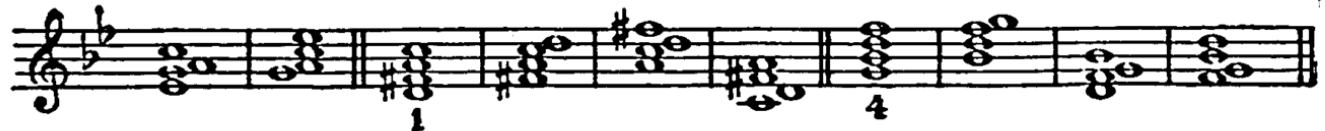



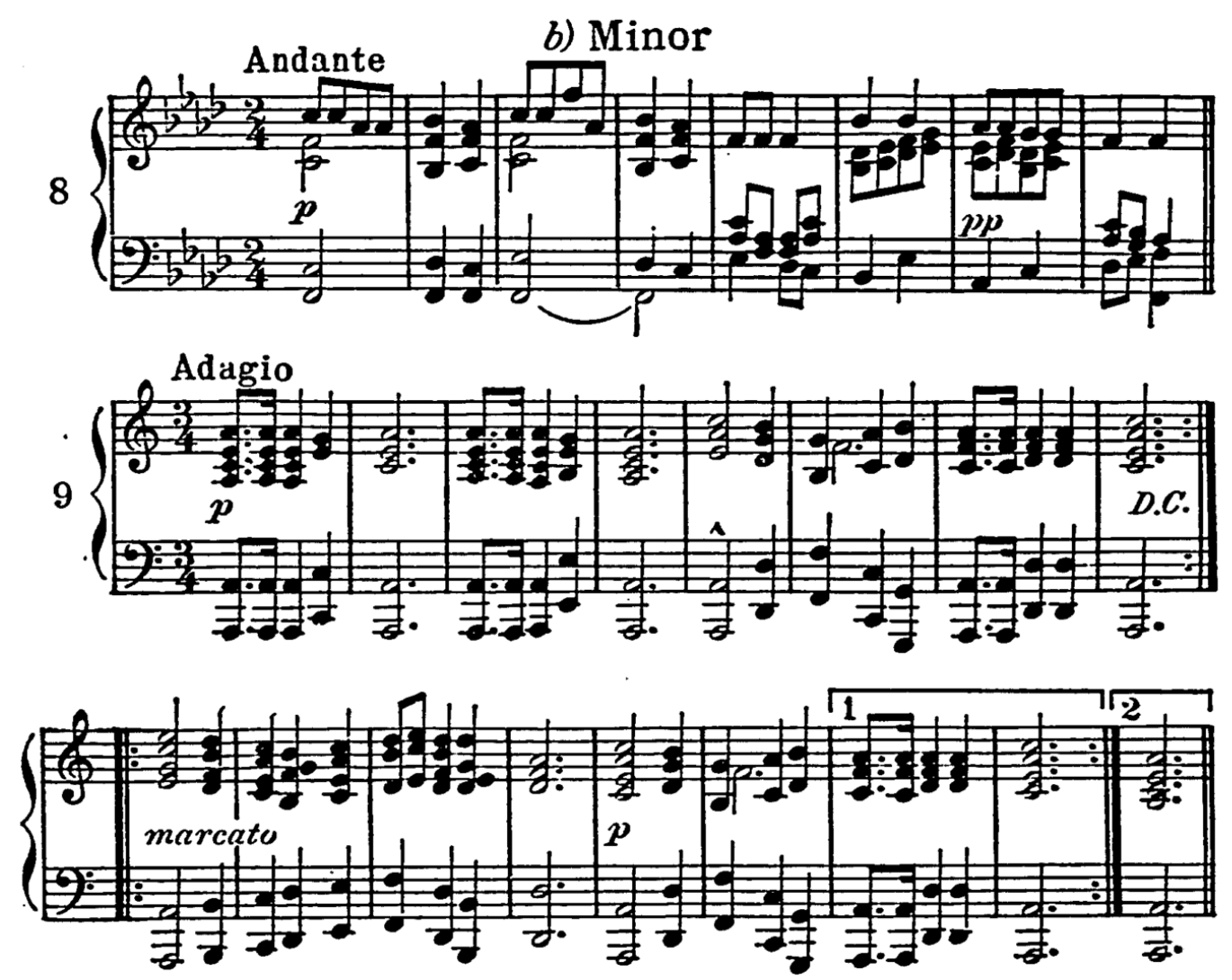

c) Adonoy Moloch
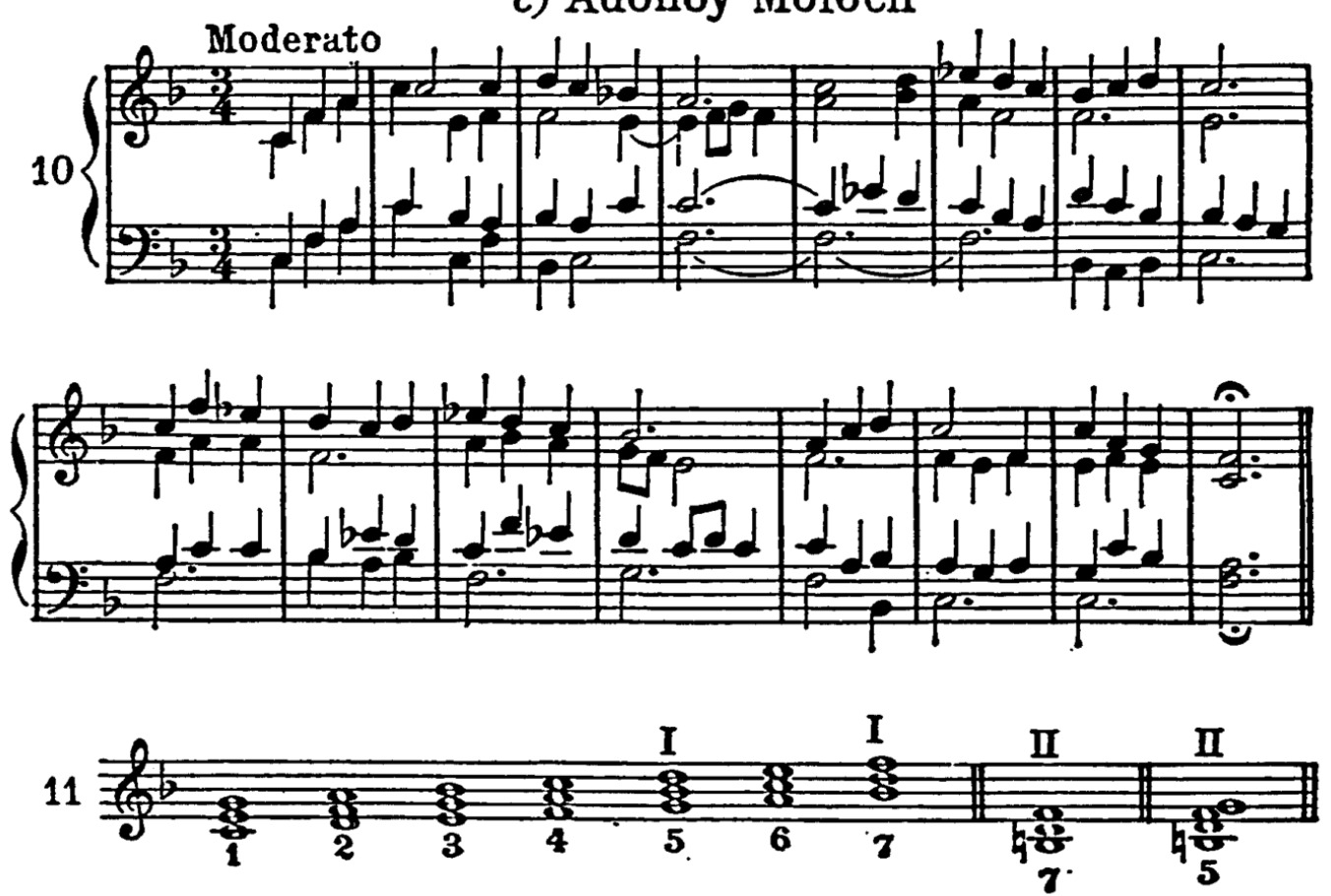
ments which do not conform to them have no hold on the music and consequently vanish from the body of that song.

Jewish song voices the spirit and the history of a people who for three thousand years has been fighting bitterly but hopefully for its existence, scattered in thousands of small groups among the millions having diverse tongues, cultures, and creeds. Its history has shown Jewish music always to be a genuine echo of Jewish religion, ethics, history, of the inner life of the Jews and of their external vicissitudes.

Wherever a Jewish group maintained Jewish spiritual culture, there Jewish song was cultivated. Wherever the group upheld its historic integrity, Jewish song flourished. It is a song created by the people of Semitic-Oriental stock, the same who created the other Jewish spiritual values and upheld them. It is the product of those imbued with the fundamental and genuine elements of that song. Often have our pages recounted of musicians of foreign origin as well as of Jews without knowledge of Jewish music, who were unable to create music genuinely Jewish. That great song, born of Jews, preserved by them, and in the course of centuries developed by them, can continue to grow only through musicians, born Jews, reared in Jewish environment, steeped in Jewish folklore and folk-song, vibrant with Jewish emotion, sensitive to Jewish sorrows, joys, hopes, and convictions-faithful sons of Israel. 
NOTES 



\section{NOTES TO CHAPTER I}

I. Ambros, A. W., Geschichte der Musik, Vol. I, 3rd edition. Leipzig 1887, p. 365 .

2. Ambros, o.c., p. 347-8.-Ambros' presumption that Herodotus referred to a folksong cannot be correct, because the song being a lamentation had a religious character.-Maneros was the only son of the first Egyptian king. On the instruments of the ancient Orient see Curt Sachs, Reallexikon der Musikinstrumente, Berlin 1914; Handbuch der Musikinstrumente, Berlin 1920.

3. Ambros, o.c., p. 388; Chayne, Encycl. Biblica s. v. Music.

4. B. Sabbath, 56 b.

5. Jer. Sukka V, 6. Maimonides, Kelé Hamikdash.

6. Midrash Shocher-tob, Ed. S. Buber, p. 406.

7. Josephus, Antiquities of the Jews, VII, I2, 3.

8. Muss-Arnold, Assyrisch-Deutsches Handwörterbuch, Berlin 1905, p. 1093.

9. B. Rosh Hashanah, 34 b; 16 a.

10. Saadiah, quoted by Abudraham, Ed. Warsaw 1878, p. 145.

II. Maimonides, Hilchoth Teshuvoah, Chap. III, IV.

12. B. Rosh Hashanah, 34 a; Jewish Encycl. s. v. Shofar. The form of blowing explained is the Sephardic-Oriental, whereas the Ashkenazim changed the terua to a short staccato note, and the shevarim to three long abrupt notes. Up to the present day Arabic shepherds in Palestine call their sheep and cattle with a tekia-terua-tekia sound of a Shofar, in Arabic also Shafur.

13. Ambros, o.c., p. 389.

14. How much of exaggeration there is in that number we cannot determine.

15. Josephus, o.c., III, 12, 6.

16. Mishna Rosh Hashanah, III, 3-4.

17. The list of instruments is given in Mishna Arachin II.

18. Targum Onkelos to Genesis 4, 21; Targum Jonathan to Psalms 150, 4.

19. B. Arachin, ro b; Jer. Sukka, V, 6.

20. Mishna Arachin, II, 3.

21. 1.c.

22. B. Arachin, ro b; Jer. Sukka, V, 6.

23. For list of instruments of the First Temple see I Chronicles, 15, 16, 25; II, $5 ; 29,25-30$.

24. Mishna Sukka, V, I; B. Sukka, 50 b.

25. Mishna Bikkurim III.

26. Mishna Kethuboth IV, 4 .

27. Maimonides' commentary to Mishna Arachin II.

28. Rashi's commentary to Arachin II, io a, gives for Halil the French chalumeau which was the ancestor of the present oboe. The origin of chalumeau is the Latin calamus-reed. In Babylon the Aulos was known and called malilu, and was considered a lamenting instrument par excellence. See M. 
Jastrow, Die Religion Babyloniens u. Assyriens, II, I. Giessen 1912, p. 4. Halil, from halal-to hollow out, may have a relation to the Assyrian chalalu-flute, from which muttachalilu-the flute player is derived. See Muss-Arnold, o.c., p. 314. The Greek name Aulos may be borrowed from the Semitic halalu, by dropping the " $\mathrm{h}$ " and adding the Greek suffix "os." It is agreed that the Aulos was brought to Asia Minor from Assyria, from where Olympus introduced it into Greece about 800 B.C.E. Ambros, o.c., pp. 388, 399, 401; H. Abert, in G. Adler's Hdb. M. G. 1924, pp. 44, 47.

29. $M$. Tamid IIII, 8. In like manner it is reported in the same place that the tone of the Magrepha, of the Cymbal, of the Levitical song, of the Shofar, of the voice of the High Priest when he chanted his confession on the Day of Atonement, and of the call to service, that all these voices were heard in Jericho.

30. Writers like Dio Cassius (born 155 C.E.) stated the fact that the tetrachordal system was borrowed by the Greeks from Asia. Even the halftone system was not of Greek origin, but was also taken over from the Egyptians, who knew it as early as I 200 B.C.E. According to H. Abert, 1.c., it was most likely imported into Egypt by the Semites.

31. In Arabic Alama means "open lips," "parted lips," figuratively for teacher, orator, or sage.-On elymos see Abert, o.c., p. 4r.

32. On Magrepha see Mishna Tamid V, 6; B. Arachin, 1o b.-Magrepha is derived from the Hebrew "grophith"-reed.

33. B. Arachin, 1.c.; Jer. Sukka, V, 6.

34. Mishna Tamid VII, 3.

35. Mishna Arachin II, 5 .

36. Ambros, o.c., p. 364 .

37. Mishna Sukka V, 4. Rabbi Simeon ben Gamaliel, who was killed during the fall of Jerusalem, is reported to have been a skillful dancer. See $B$. Sukka, 53 a; Jer. Sukka, V, 4 .

38. Mishna Sukka, IV, 5 .

39. Alamoth is translated "soprano" or "falsetto," and in conjunction with our explanation of Alamoth (double-pipe) it may refer to a soprano pipe instrument. We know that the Greeks had Aulos of soprano, alto, tenor, and bass register. See H. Abert, 1.c.

40. Already around roo C.E. Rabbi Meir explained that the female singers mentioned in the Bible referred to the women of the Levites, whereas Rabbi Simeon entertained the opinion that they were "talented women" in general. Pirke R. Eleazar, Chap. XVII.

41. Jeremias, A., Das Alte Testament im Lichte des alten Orients, Leipzig 1906, p. 527.

42. Mishna Kethuboth IV, 4.

43. Mishna Arachin II, 3; Sukka IV, V.

44. Mishna Sukka V, 4.

45. Mishna Arachin II, 6.

46. B. Chullin 24.

47. Arachin, l.c.; B. Arachin, 13 b, tells that the boys caused embarrassment to the adults on account of their sweet voices, and were nicknamed "pain causers"- "Tsoare" instead of "assistants"- "Soade."

48. Mishna Arachin, II; B. Arachin, I I a.

49. B. Sukka, 5o b-5 I a; Arachin, I.I a.

50. Mishna Yoma III, I1. He used to press his thumb in his mouth; while 
his fingers he pressed "between the voice-chords," i.e., on the Adam's apple. On the Assyrian bas-relief, quoted above, we see a female singer in like manner pressing her hand against her cheek and neck. The same is to be seen on the Egyptian wall-pictures.

51. Mishna Tamid V.

52. Deut. 32, I-43; B. Rosh Hashanah, 31 a; even the laymen read from the Pentateuch. Mishna Taanith, IV, 2-3. Baraitha Yoma, vii a; $B$. Yoma, $69 \mathrm{~b}$; Mishna Sota VII, 7-8.

53. According to tradition there were 480 synagogues in Jerusalem at the time of its conquest by the Romans. Jer. Megilla III, I; while according to another tradition there were 390 . B. Kethuboth, 105 a.

54. Mishna Taanith IV, 2. The Anshe Maamad were selected from the different districts of the country as representatives of the people to be present at the offerings and pray for their people. They were divided into 24 groups, each group serving two weeks a year in turn, or rather one week each half-year. See Elbogen, o.c., pp. 237, 553. During the week that their representatives were on duty in Jerusalem, the congregations of the respective districts used to gather, hold public services, and read from Genesis I.

55. B. Sota, 30 b; Tosefta ed. Zuckermandel, p. 303; Jerus. Sota, V, 4 ; Mechilta, ed. I. H. Weis, p. 42; Maimonides, Hilchoth Megilla, etc. Chapter III. § I 2-I3.

56. Hasting, Encyl. of Religion \& Ethics, Vol. X, p. $160 \mathrm{ff}$.

57. Mishna Sota VII, 5 .

58. Josephus reports that Herod introduced in Jerusalem Greek musicians for the theater. Ant. Jud. XV, 8, I.

59. Midrash Ruth Rabba, 6; B. Hagiga, 15 b, reports about Elisha ben Abuya called "Acher," who was fond of Greek song.

6o. L.c., Midrash Shir Hashirim Rabba, 8. end.

6x. All the traditional material of the song of these communities I have collected and explained in my Thesaurus of Hebrerw-Oriental Melodies.

\section{NOTES TO CHAPTER II}

I. On Semitic-Oriental music see Thesaurus, etc., o.c., Vol. IV, German edition, Berlin 1923, pp. 52-112.

2. The creation of compositions of European folk-song and even art music is essentially also an arrangement and variation of motives traditional in a folk-song of a certain people or race. Many motives are common to the musics of the different European peoples. Not only are the creations of the classics based upon melodies or motives which the composers have consciously taken from their folk-song, but they have likewise been unconsciously influenced by the motives of the music of their people. The fundamental difference between the manner of composition in the Orient and in the Occident is that in the Orient a motive is employed in its mode and in a customary position with relation to the other motives of that mode; whereas in Occidental music, a motive is a unit unbound to mode, scale, or position.

3. A detailed account of the various modes and scales is given in Thesaurus, etc., o.c., IV, pp. 53-112. 
4. Thesaurus, 1.c.

5. Thesaurus, 1.c.

6. The illustrations in table I are taken from Thesaurus, o.c.

7. The illustrations $x-7$ of table II are taken from Der Kirchengesang der Jakobiten by A. Z. Idelsohn, published in Archiv fuer Musikwissenschaft, Berlin 1922, III; No. 8 from D. J. Parisot, Rapport sur une mission scientifique, etc., Paris 1899 , No. 62.

8. The illustrations of table III are from J. B. Rebours, Traité de Psaltique, Jerusalem-Paris 1906, pp. 148-163.

\section{NOTES TO CHAPTER III}

I. B. Megilla, 32 a.

2. B. Sanhedrin, rо г a.

3. Luke 4:17; Elbogen, o.c., p. 176; J. E. Haftora VI, p. 136.

4. Elbogen, Der Jïd. Gottesdienst, etc., 1913, p. 533; Tosefta Megilla, 1-6, quotes a decision regarding the reading of Esther on Purim in the name of Rabbi Zacharia, the Priest, who lived long before the destruction of the Second Temple. See J. E. Megillot, the five X, p. 43I. Purim is mentioned in the second book of Maccabees XV: 43 .

5. Though the usage of their public reading is mentioned only in the late source of Soferim XIV: 18 .

6. D. Pinna's notation was printed in the introduction to the Bible. Ed. Jablonsky, Berlin 1699 .

7. The notation was prepared by J. Boeschenstein, who was a pupil of a Jewish scholar and mingled with Jews (1472-1540); and was printed in Reuchlin's De accentibus et Orthographia Hebrcorum, Hagenau 1518 . - All other oriental examples are taken from my Thesaurus, Vols. I-V.

8. These communities are remnants of the old Jewish settlements in Provence and France. At present only sixty families survive in Avignon and twenty in Carpentras, many of them having moved to Marseilles, where they established a community. In 1885 , they published their traditional tunes and modes, called Chants Hebraiques (Zemiroth Israel) by Jules and Mardochee Cremieu. The example 6 is taken from that collection, p. 153.

9. For example, R. Gershom, "the light of the exile," who was a native of Norbonne and settled in Mayence toward the end of the tenth century.

10. Such as the Kalonymos family, originally from Luca, which settled in Germany about 870 or 970 .

II. See for example P. Wagner, o.c., I, Chapters I-III.

12. About the way in which the Biblical modes could be made attractive and palatable for modern taste, see Chapter XXIII. 13. The Ashkenazim chant the Song of Songs, Ruth, and Ecclesiastes in the
same mode.

14. B. Megilla, $16 \mathrm{~b}$; Soferim, Chapters XII and XIII. However, Deut. 33 is

15. L.c. considered a song only in the Yemenite tradition.

16. See illustrations in table II; Gardiner, W. H. T., Egyptian Hymn-tunes. London, No. 43; Der Kirchengesang d. Jakobiten, o.c., No. 32.

17. The Arabic Dictionary, Muchit-il-Muchit, s. v. Rehaw.

18. P. Wagner, o.c., III, Leipzig 1921, p. 236 .

19. According to P. Wagner, o.c., I, Chapter I. 
20. P. D. Johner, Neue Schule d. Greg. Choralges., Regensburg 1913, II, p. 154.

21. P. Wagner, o.c., I, p. 36.

22. More details about these local modes are given in my Thesaurus, Vols. I-V, o.c.

23. On the cheironomia compare P. Wagner, o.c., II, Chapter I, Leipzig rgr2.

24. B. Berachoth, $62 \mathrm{a}$, for which the second finger was used. The statement is reported in the name of Rabbi Akiba (40-135 C.E.).

25. Rashi's commentary to $B$. Berachoth, 1.c.

26. In the ninth century only nineteen accents were known, twelve disjunctives and seven conjunctives. Compare Dikduke Taamim, S. Baer and H. Strack, Leipzig 1879.

27. P. Wagner, o.c., p. 18.

28. P. Wagner, o.c., Chapter II.

29. Neumos = sign in Greek, seems to have relation to the Hebrew Neima= tune (sweetness), mentioned in B. Megilla, 32 .

30. A detailed account of the accents, as well as all Hebrew sources referring to their description, is given in my Hebrew History of Jewish Music I, Berlin 1924, pp. 95-1 17 .

3 I. See my Hebrew History, o.c., J. E. Accents, cantillation.

32. The system of accents for chanting was employed also for the Mishna and Talmud, accentuated parts of which are retained in MS. in several libraries. Compare J. E., o.c.; my Hebreso History, o.c. On the system of accents of Job, Proverbs and Psalms, compare History, o.c., and Thesaurus II, p. 13.

\section{NOTES TO CHAPTER IV}

I. Mishna Tamid, V; Mishna Berachoth, I; B. Berachoth, 12 a.

2. The introductory six Psalms 95-99, 29, for the Friday evening service as well as the hymn Lechoh dodi were introduced into the service by Isaac Luria in Safed (Palestine) about 1570 and became generally used at the beginning of the seventeenth century. Up to that time the service started with Psalms 92-93.

3. P. D. Johner, Neue Schule des Greg. Choralgesanges, Regenburg 1913, I, p. 46. In the English transl., I, pp. 56, 217.

4. B. Sabbath, $24 \mathrm{a}-\mathrm{b}$; $119 \mathrm{~b}$.

5. Hammanhig, Lemberg 1858 , Sabbath, 7. See also Machsor, Vitry, Berlin 1893, pp. 82-83.

\section{NOTES TO CHAPTER V}

1. Ben Sira IX, 4; "The hearing of a woman's voice is indecency." B. Berachoth, 24 a.

2. B. Chagiga, 15 b.

3. Ruth Rabba, Chapter VI.

4. Yalkut Mishle, $\$ 932,3$.

5. Psikta Rabbathi, Chapter XXIII; Tanchuma, Reé, § 9.

6. Shir Hashirim Rabba, Chapter VIII end.

7. L.c. 
8. B. Gittin, 7 a; Orach Chayyim, $\S 560$.

9. All quotations cited are from $B$. Sota, 48 a. See M. Jastrow's Dictionary, p. 9 19.

10. (I quote from the English translation by G. M. Butterworth.) The Instructor, Book II, Chapter IV. According to H. Windisch in Zeitschrift für Palestina Kunde, 1925, p. 152, Clement had a Jewish teacher during his sojourn in Palestine about $180-200$.

Ix. In the Egyptian cult, too, after its destruction by Cambyses of Persia, instrumental and choral music were interdicted. The song was limited to one soloist-a priest. Ambros, o.c., p. $38 \mathrm{r}$.

12. P. Wagner, Gregorianische Melodien, I, p. 16. Havelock Ellis in his The Dance of Life II, "The Art of Dancing," is entirely on a wrong track in stating that Christianity and Judaism retained dancing at worship. $\mathrm{He}$ either fails to take account of or ignores historic facts. Not only was it the tendency of Synagogue and Church to abolish all bodily motions, but this reform was actually carried out in practice. Only here and there in provincial places, as a remnant of paganism, dances occasionally accompanied worship. Similarly reads a Jewish source of the preference of vocal music. Midrash Thilim, ed. Buber, p. 204.

13. B. Sota, 1.c.

14. Though the origin of that custom may be rooted in the superstitious belief of frightening away evil spirits. Compare $B$. Berachoth, 30 b- 3 I a.

15. B. Berachoth, 30-31. At the same place it is related that upon the request of the guests of Rab Hamnuna Zuta to sing, he started to eulogize, "Woe unto us, we have to die," and he taught his guests the response, "Study and obeying the commandments will protect us."

16. B. Gittin, 1.c.

17. Shir Hashirim Rabba, Chapter VIII end, in the manner of the singing of which, God finds great delight and he says, "Oh, let me hear thy voice for it is sweet" (Canticles 2, 15), but when they sing in confusion in shouting one before the other, then God says, "Let us run away."

18. P. Wagner, 1.c.

19. H. Burgess, Selected Metrical Hymns, etc., of Ephraim Syrus, London 1853, gives in his introduction a detailed description of Ephraim's poetry.

20. Thus do we notice a meter of 3-4 words in Genesis 49:2-26; Exodus 15: 1-1 9; Deuteronomy 32; Judges 5:2-31; 1 Samuel 2:2-10; 2 Samuel 22: 2-5I, etc., besides, of course, the poetical books Psalms, Proverbs and Job.

\section{NOTES TO CHAPTER VI}

1. On Babylonian liturgy, see M. Jastrow, Die Religion der Assyrier und Babylonier I, 1.c., Chapter XVII, "Gebete und Hymnen."

2. "We have no one on whom to rely but our Father in Heaven," B. Sota, $49 \mathrm{a}-\mathrm{b}$.

3. Such as Honi Hammaagal, B. Taanith, $23 \mathrm{a}-\mathrm{b}$; his grandson Abba Hilkia and his wife; Rabbi Akiba, o.c., 25 b; Rabbi Chiya, 0.c., 24 a, and many others, on whose power in prayer many legends are related in the Talmud Taanith, 23-25.

4. "Those who write down prayers are like those who burn the Scripture." Tosefta Sabbath, Chapter XIII; Tania Rabbathi, Warsaw 1879, 7 . 
5. Tosefta Megilla, Chapter IV; Sofrim, Chapter XIV; Pesikta, Ed. Buber F. 22 ; Pirke R. Eleazar, 44; Jerushalmi, Megilla, Chapter IV.

6. L.c., the assistants were also called Mutznafim-Aramaic, assistants, Pachad Yitzchak, letter "shin," p. 223. In the Machzor Sepharad, Livorno 1822, I, $8 \mathrm{I} \mathrm{b}$, there is still the regulation that beginning with Nishmath the precentor must have two assistants, somchim.

7. B. Taanith, 16 a.

8. Pesikta Rabbathi, Chapter XXIII; Tanchuma, Reé, § 9.

9. B. Megilla, 24 .

10. Tosefta, Megilla, 4.

I1. L.c.; Siddur, Amram Ed. Koronel F. 35; Meyer of Rothenburg in Yam Shel Shlomo to B. Chullin, Chapter I, $\$ 48$.

12. B. Berachoth, ro b.

13. Jerus. Yebamoth, Chapter XII; B. Sukkah, 5 I b; Jer. ibid., V, I.

14. On the origin of chazzan: Jewish Encycl., VI, p. 284; B. Kethuboth, 8; Tosefta, IV; B. Makkoth, 23; Mishna Tamid, V, 3; B. Joma, 7 a; Jerus. Berachoth, V, 3; B. Taanith, 16; Tanchuma, Jethro; Wayyikra Rabba, 6; Tosefta, Bikkurim, II; B. Sota, 5 b. Already around 200 C.E. some communities were compelled to engage a permanent chazzan who was able to render also other communal services. Jerus. Yebamoth, Chapter XII, reports that the community in Simonia asked Jehuda Hannasi to recommend them a man who should be capable of functioning as Judge, chazzan, and Scribe; and of performing all communal tasks. And he sent Levy ben Sisi.

15. The chazzan had no right to read the portion of the Pentateuch without special permission from the elders of the Synagogue, Tosefta, Megilla III, and only at a later time he became the permanent reader or lektor, Sofrim ii. He likewise became the instructor of children in the Mishnaic time, Sabbath I, 3. On the custom of appointing two precentors B. Megilla, 24; M. Rosh Hashanah IV, Teshuvoth Hag'onim, Lyck 1864, § 9.

16. Jerus. Berachoth IV a.

17. Jerus. Berachoth, III a; Sofrim XIII.

18. Midrash Tehillim, ed. Buber F. 29.

19. Siddur Amram, o.c., F. ii.

20. M. Taanith I.

21. Maimonides, Hilchoth Tefilla VIII.

22. W. Oesterley, The Jewish Background of the Christian Liturgy, Oxford 1924.

23. P. Wagner, o.c., I, pp. 16-1 7, 19-20.

24. O.c., pp. 20, 29-30, 81-87, 95 .

\section{NOTES TO CHAPTER VII}

I. W. Bäumker, o.c., I, pp. 6-7, etc.; P. Wagner, o.c., I, p. 30, etc., is of the opinion that rhythmical singing in the Church was practiced already in the fourth century. H. Riemann goes further and decides that the Church hymns were based upon Greek art and had strict rhythm, Hdb. M. I, 2, Chapter VIII; he finds also rhythm in the "Sequences" (Prosae), o.c., $\S_{3} 6$. Indeed, being aware of the fact that the Sequences have modal structure, he compromises in saying that only the older ones have rhythm, while LATER, rhythm and form were neglected. O.c., pp. 124-125.-The Lais of the 
French and the Leiche of the Germans are products of Gregorian song intermingled with folk-elements. Riemann, o.c., § 37 . The same is true of the Minnesong and of the song of the Troubadours, compare H. Riemann, o.c., Chapter XV.

2. Franz M. Boehme, Altdeutsches Liederbuch, 2 Ed., Leipzig 1913, p. lxvii.

3. M. Berachoth IV; B. Berachoth, 29 b; M. Aboth II, 18.

4. Compare my Thesaurus I: "The Song of the Yemenite Jews," I925. Ibid., II: "The Songs of the Persian," etc. Jews, 1923.

5. On Arabic meter compare Martin Hartmann, Metrum und Rhythmus, Giessen 1896, p. 4, etc.; on the different metrical forms, his Das Arabische Strophengedicht, Weimar 1897, pp. 200-201.

6. S. Duran, Magen Aboth, Livorno I785 F. 55; S. Archevalti, Arugoth Habosem, Venice 1602, F. 100. M. Lonsano, Sheté Yadoth, Venice 1617, F. 140 .

7. J. Elbogen, o.c., pp. $283-4$.

8. Tachkemoni (Makames) XXIV Ed. A. Kaminka, Warsaw 1899, pp. $220-27$.

9. Hay Gaon, Responsa of the Gaonim, Ed. Miller, p. 208. Isaac Alfasi, Responsa, § 281 . Jehuda of Barcelona, Sefer Haitim, F. 173, p. 253.

10. Maimonides, Responsa, Pe'er Hador, Lemberg 1849, § 129.

11. Kusari II, § 70-78.

\section{NOTES TO CHAPTER VIII}

1. Zunz, Ritus, Berlin 1858, p. 66; Jewish Encycl., II, pp. 191-3.

2. Graetz, Geschichte der Juden, 2 edition, Leipzig $187 \mathrm{I}$, Vol. V, p. $195 \mathrm{ff}$.

3. Ibid., Gross, Galia Judaica, Paris 1879, p. 401.

4. B. Megilla, 17 b; Matzref Lachochma, Warsaw I890, p. 64.

5. D. Kaufmann in Monatschrift f. W. J. 1896 s. v. "Achiamaaz."

6. Zunz, o.c., p. 67 .

7. B. Taanith, ro a.

8. Agobard's letters were translated from Latin into German by Emanuel Samostz, Leipzig 1852, which translation I used here. The same fact is stated in Hebrew sources of the twelfth century. Shibbole Halleket, Ed. Buber, Wilna 1887 F. I13.

9. Ibid.

10. Reissmann, Das Deutsche Lied, Cassel 1862, p. 2.

11. W. Bäumker, Das katholische deutsche Kirchenlied I, Freiberg i/B., 1886, p. 6.

12. Ibid.

13. M. Güdemann, Geschichte des Erziehungswesens u. der Kulturr, etc., I, p. 14 (Hebrew).

14. Sefer Chassidim, Ed. Freimann, Frankfort 1924, p. 332.

15. Ibid., p. 106.

16. O.c., Berlin, p. 85 .

17. A. Epstein, Die Wormser Minhagbücher (reprint) Breslau 1900, p. XXII. On hymns on "Maria Magdalena" of the twelfth century, see Boehme, o.c., Nos. 560,618 ; p. 654 .

18. Epstein, o.c., p. XXIV.

19. Yosef Ometz, Frankfort 1727 F. 77 .

20. Mose ben Ezra (eleventh century) in his work on Hebrew poetry makes the 
statement that in Arabic poetry each poem has a tune, but not each tune a separate poem. Shirath Israel, Leipzig 1924, p. 110. (Hebrew translation by B. Halper.)

21. Sefer Chassidim, $\S 302$, interprets the phrase in Exodus 19: 19, "And God answered him by a voice"-God taught Moses the Biblical modes.

22. The term Steiger may be interpreted either with the German Weise (way, wise, mode) or as a derivation from steigen-ascending, i.e., scale or curve or succession of tones.

23. The sharp on the $\mathrm{f}$ being an alteration, influenced by the $A$ havoh-Rabboh mode.

24. Boehme, o.c., No. 513 .

25. H. Riemann, o.c., I, 2, p. 29.

26. V. d. Hagen, Der Minnegesang, Hannover 1841, Vol. IV, p. 792. The rhythmization is mine.

27. W. Bäumker, 1.c., II, p. 203.

28. F. Pedrell, Cancionero, etc. Cataluna 1920, introduction.

29. F. Consolo, o.c., No. 17.

30. P. Wagner, 0.c., III, pp. 140-141.

3x. Ibid.

32. This change caused the medieval theoreticians to identify this mode with the fifth Gregorian mode which corresponds to the Lydian. However, the artificial classification of Semitic-Jewish modes according to the scheme of the Greek scales killed their vitality by this Procrustean procedure.

33. A. Schubiger, Die Sängerschule St. Galleus, 1858, p. 3; P. Wagner, o.c., I, p. 164. Illustration 8 is taken from H. Riemann, o.c., I, 2, p. 27.

34. V. d. Hagen, o.c., p. 826; Die Jenaer Handschrift, Leipzig 1901, ed. E. Bernoulli and Saran II, p. 42.

35. These special modes are mentioned in Siddur Rashi, Machzor Vitry, Shibbole Halleket, Rokeach, Sefer Chassidim, etc.

36. Emek Habbacha, Leipzig i 858, p. 8 (Hebrew) and p. 31 (German). The translation cited is by K. Kohler in Jewish Encycl. s.v. Alenu.

37. In his prayerbook, Malëa Haaretz Dea, Thiengen, 1560, F. 172 a. R. Mordecai Jaffa in Prague (1530-1612) explains the reason why the Olenus should be sung on these days in a solemn tune, in his work Lewush, Prague 1622-24, § 133. In like manner another author in Frankfort of the seventeenth century, Joseph Nordlingen, in his work Noheg Katzon Josef, Hanau $1718 \mathrm{~F} .72 \mathrm{ff}$. reports of that tune.

38. Tashbetz, § 245; Machzor Maagle Tzedek, Venice 1568 I, F. 22.

39. Compare my essay, Der Missinai Gesang der Deutschen Synagoge, in Z. M. G. 1926, p. 466.

40. Maharil, Rosh Hashanah, ed. Warsaw 1874, F. 38 b.

41. Machzor Maagle, etc., o.c., Purim.

42. Nolieg, etc., F. 52 b. The tune for the verse in Esther is retained in MS. L. Sänger.

43. Tashbetz, 1.c.

44. Noheg., etc., 1.c.

45. Tashbetz, 1.c.; Maharil, o.c., F. 38 b; Siddur Troyes, in Bloch's Jubilee Volume, Budapest 1905, P. 97 ff.

46. Noheg, etc., F. 63 .

47. Chibbure Likkutim, Venice I715, F. 4; Reshith Bikkurim, Frankfort 1708, F. 29. 
48. Shire Yehuda, Amsterdam 1697, introduction.

49. Chorgesänge der Synagoge in München, 1839, No. 74.

50. Baal Tefillah, Frankfort 1901, No. 1442, P. W.

51. Ahron Beer and Goldstein use it for Vechach hoyoh omer.

52. MS. Goldstein, while others used a part of the Kol-nidre tune. Baal Tefillah, No. $85 \mathrm{I}$, W. 1 .

53. Machzor Vitry, o.c., p. 388; Raban (thirteenth century), Prague 1610, F. 70 testifies to the same usage customary in the Slavic countries.

54. Machzor Nürnberg, ed. B. Ziemlich, Berlin 1886, p. 50.

55. Maharil, o.c., F. 45 b: "Yaarich bo beniggunim."

56. Lewush, o.c., § 619.

57. Sefer Chassidim, o.c., §414; Machzor Vitry, p. 210.

58. Compare my Thesaurus II, pp. 71-72; IV, p. 157.

59. Machzor Vitry, p. 154.

6o. Maharil, Sabbath.

61. S. Geiger, Divre Kehilloth, Frankfort 1862 , p. 67; Baer, Baal Tefillah, No. 504 .

62. Maharil, 1.c.

63. Rokeach, Lemberg $1858, \S 49 ;$ Maagle Tzedek, o.c., II; Noheg, etc., F. 57.

64. Noheg, etc., F. 72 .

65. Siddur Troyes 1.c.; in B. Rosh Hashanah, 32 b, Rabbi Abbahu of Cesarea (fourth century) states as the reason why on the High Holidays no Hallel (Laudation Ps. $113-118$ ) is recited, that Israel stands trembling on trial on the Day of Judgment, in which state of mind the joyous singing of laudation is impossible.

66. Maharil, Rosh Hashanah; Noheg, etc., F. 76.

67. Maharil, 1.c.; Maagle II, 1.c.; Noheg, etc., 1.c.

68. Baal Tefillah, No. 713 W. 2 ; Jewish Encycl. s. v. Ledavid.

69. F. Consolo, o.c., No. 143 .

7o. Zunz, Lit. d. syn. Poesie, Berlin 1865, p. 240.

7 I. Volume IV, p. 86, Psalm 21.

72. Nos. 3, 4, are taken from J. Zahn, Die Melodien der deutschen evangelischen Kirchenlieder, III Güterloh 1890, Nos. 4533-4.

73. Bäumker, o.c., I, p. 496.

74. F. Pedrell, Cancionero, etc., No. 46.

75. J. Malát, Chzechische und Moldaische Gesänge, Prague 1871 , Vol. I.

76. Compare W. Tappert's interesting study Wandernde Melodien, Berlin 1890.

77. The chorale was composed in 1523 and published in Wittenberg in 1524 . Boehme, o.c., Nos. 623, 635 .

78. Boehme, o.c., No. $38 \mathrm{r}$.

79. Ha-asif, Warsaw 1885, p. 298.

80. Responsa Charwoth Yair, § 238.

81. Vol. III, p. xii, Psalm I5.

82. The illustrations in example II are taken as follows: I from the Hagada of Johann Stephan Rittangel, Koenigsberg i/P. 1644; II from the Hagada Zewach Pesach by Friedrich Albrecht Christian, Leipzig 1677. He was chazzan in Bruchsal, his Jewish name having been Moshe of Prossnitz; III from the periodical Der Jude published by the convert Gottfried Selig, Leipzig I 769; IV from M. Kohn MS., written probably about 1840 .

83. Boehme, o.c., No. 521 a; 569 a.

84. Bäumker, o.c., II, p. 133 ; No. 363 . 
85. Ibid., IV, p. $48 \mathrm{I}$; No. 79 .

86. Ambros, o.c., II, p. 5 16, etc.; ibid., III, p. 477; H. Riemann, o.c., II, 2 ; pp. 329-339 ff.

87. From the many references collected in my Hebrew history II, Chapter XIII, but a few sources shall be given, such as Shire Yehuda, o.c., F. 5; Reshith Bikkurim, o.c., F. 29; and in the Judeo-German Songster Simchath Hannefesh, Fürth 1727 .

88. Responsa, Jacob Weil, Venice 1549, § 140, § 147, §152; Pachad Yitzchak, letter Mem, F. I37.

89. Eckstein, Geschichte der jüdischen Gemeinde in Bamberg, p. 149.

90. Responsa, Mose Minz, Salonica 1615, §81.

9x. Yosef Ometz, o.c., F. 87 b.

\section{NOTES TO CHAPTER IX}

1. Philaret Kolessa, Phonographierte Melodien der Ukrainischen rezitierenden Gesaengen (Dumy), in Beitraege zur Ukrainischen Ethnologie B. XIII, Lemberg 1910, introduction, p. lxxv.

2. O.c., part II, Lemberg 1913, p. xxix.

3. O.c.

4. O.c., part II, p. xxxi-ii.

5. O.c., part I, p. lxxxi.

6. The Ukrainian examples are taken from Kolessa, ibid., as follows: No. 1part I, No. 21; 3-No. 15; 4-pp. 91, 102; 5-part II, 57; 6-part II, No. Io; 7-part II, No. II. The Jewish example 2 is taken from E. Schnipelisky Tefillat/2 Eliyahu, New York 1924, p. 38.

7. Kolessa, 1.c., part I, p. Ixxvi.

8. Béla Bartók, Volksmusik der Rumaenen von Maramures, Munich 1923, Drei Masken Verlag.

9. Ibid., p. xxix.

10. Ibid., p. xx. The Roumanian examples in table XXVII are taken from Bartók's collection: 8-21 e; $11-52 ; 15-23 \mathrm{a} ; 16-23 \mathrm{c}$.

11. Bartók in his Das Ungarische Volkslied, Berlin 1925, p. 24, denies the existence of this scale in the Hungarian folk-song.

12. F. Liszt Die Zigeuner und ihre Musik, Leipzig 1883, pp. 20-81. More on this subject in Chapter XIII.

13. The example of Dovidl Brod is taken from the musical appendix to Oester. Ungar. Cantoren Zeitung, 1886, No. 17.

14. Kolessa, 1.c., Bartók, o.c., p. 22.

15. A. P. Berggreen, Folkivisor, Folkesange og Melidier, 2nd Ed. 1864, Vol. 1o.

16. Bartók, o.c., p. x; Kolessa II, p. xxxii.

17. Example 17 is taken from Tefillath Eliyahu, o.c., No. 19, with some changes.

18. We meet such orders in the community of Brisk in 1623 : "No chazzan shall sing on Sabbaths more than three selections, and on distinguished Sabbaths no more than four tunes, and this not before 'Shema' in the morning service." In Selz after the persecutions of 1650 it was agreed that in no Jewish home should there be heard music except at weddings (see Chapter V): "In 1655 the rule was accepted to mourn the destruction of our country, that no music should be heard in Jewish homes, not even at weddings, for a period of a year." Ha-asif VI, p. 172. 
19. Nathan Hanover, Yevén Metzula, Cracow 1896, p. 9.

20. In his book Chibburé Likkutim, Venice 1715, F. 4-5.

21. J. G. Frazer, The Golden Bough, part IV, Adonis Attis Osiris, I, London 1914, Pp. 53-54.

\section{NOTES TO CHAPTER $\mathbf{X}$}

1. See Ed. Birnbaum, Jüdisclie Musiker am Hofe von Mantua von 1542-1628, Vienna 1893. Reprint of the Kalender fïr Israeliten für das Jahr 5684. Already at the court of the art-loving Pope Leo X (1513-1521) two Jewish musicians were much in favor. The one was Jacobo Sansecondo, who stood as a model in Raphael's "Apollo on Mount Parnassus." The other musician was Giovani Maria, who in honor of the Pope adopted the name "de Medicis," and who was the model of the "Violinist" by Sebastiano del Piombo. Among the oldest theoreticians of the dance was Guglielmo da Pesaro, who at the end of the sixteenth century was considered foremost. "His treatise Trattato del arte del ballo is the basis upon which all the choreographical works are founded." Paul Nettl, Alte jüd. Spielleute und Musiker, Prague 1923, pp. 4-5.

2. Birnbaum, o.c., p. 14. The title page reads as follows: Premite armoniche a tre voci de Davit Civita Hebreo. Al Serenissimo Signor Signor, e Patron mio Collendissimo il Sig. D. Ferdinando Gonzaga Duca di Mantova di Monte ferato, etc. In Venetia, Appresso Giacomo Vincenti MDCXVI. The sheets are marked: Madrigali Ebrei.

3. The Hebrew name of Allegro was, according to Birnbaum, o.c., p. I6, note 23, Simcha.

4. Grove's Dictionary of Music, s. v. Rossi.

5. H. Riemann, o.c., II, 2, p. 88.

6. Idem., o.c., pp. 94-95.

7. Birnbaum, o.c., pp. 19-34, gives a detailed list of his works.

8. The title of the opera is Musiche de alcuni eccellentissimi Musici, composte per la Maddalena, sacra Rapresentazione de Gio Battista Andreini, Fiorentino, Venice 1617 , with a Balleto a tre, vá contato $\&$ Sonato con 3 Viole da Braccio. The last item was by Rossi. See P. Nettl, o.c., p. 14.

9. Birnbaum, o.c., p. 22, gives the ducal order verbatim. Grove, 1.c.

10. In his autobiography Chaye Yehuda, Kiev 1912, p. 64.

II. The verbal translation of the Hebrew reads "in the arrangement and according to the relation of voices to each other, based on THAT SCIENCE."

12. The Responsa on that controversy were published by Modena, and republished several times. Compare Teudath Sh'lomo, by the chazzan Sh'lomo Lifshitz, Offenbach I718 F. I3 ff.

13. L.c.

14. The Sullam family was one of the most cultured Jewish families in Italy at that time. The daughter-in-law of Mose Sullam, Sara Copia Sullam, was a highly educated and gifted woman (d. 1641 in Venice), musician, poetess, and renowned writer. She knew Italian, Hebrew, Spanish, Latin, and Greek. She fought for her religion, and was very active as an author. S. Naumbourg in his introduction, o.c., p. 16.

15. The collection of Madrigals for five voices is drawn in part from R's Madrigals Libro I (II numbers) and in part from his Libro II ( 1 I num- 
bers). As an appendix, d'Indy gave R's song Spazziam pronto o vecchia velle.

16. Naumbourg, o.c., p. 16.

17. In order to prove his innocence, that man, Nehemia Cohen, published an apology in Hebrew Metzitz Umelitz, Mantua 1715, where he states all details.

18. See Catalog Halberstam Kehillath Sl'lomo, Vienna 1890, No. 227. From that collection only one page has been preserved. It contains the mode of Psalms.

19. Divre Agor, Venice 1603 .

20. J. Moscato devoted his first sermon to music. The collection of his sermons is called Nefutzoth Yehuda. Porteleone published his work Shilté Haggibborim in Mantua 1612, in which he devoted several chapters to the music of the Temple.

21. This Hebrew theory is but a fragment in MS. in the Bibliotheque Nationale in Paris. A copy of it is in the H. U. C. Library in Cincinnati.

22. His description of his travel was published in the Israelit. Letterbode in Amsterdam I 884.

23. B. Marcello's Psalms Esto poetico-armonico were published in eight volumes in Venice 1724-1727. On the Jewish tunes chosen by $\mathbf{M}$. Josef Singer gives a detailed account in his article "Marcello Benedetto" in the Kalender für Israeliten, Vienna igoo.

\section{NOTES TO CHAPTER XI}

I. In his above-mentioned (Chapter VIII) commentary to the prayer-book Diengen 1560; preface to the Kaddish.

2. H. Riemann, o.c., II 2, p. $239 \mathrm{ff}$.

3. Sabbathai Bass, Sifthei Yeshenim, Amsterdam 1680 end; A. Levy's Travels in Israel. Letterbode, 1.c.

4. Bikkure Haitim, 1824, p. 257 ; Nettl, o.c., p. 39.

5. A. Levy's Travels, 1.c.

6. Shivche Ari.

7. Kevod Chachamim, Venice 1700, Chapter VIII, F. 15; Noheg, etc., f. 39.

8. Grove I, p. 457 ; H. Riemann, o.c., II 2, p. 308 ; II 3, p. 5 ; Ambros IV, p. 218.

9. Meharil, Ed. Warsaw 1874, p. 64.

ro. More in detail compare Albert Wolf, Falirende Leute bei den Juden, in Mitteilungen Z. Jüd. Volkskunde XI, Leipzig 1908, 3 .

11. Josef Ometz, F. $1_{3}$ b; Yoel Sirkish in his responsa $\S$ ro3 reports of a certain Chayim Cimbalist of Turbin (Poland) who served in Wallenstein's army in 1637 as cymbal player, and who embraced Christianity.

12. Sefer Chassidim reports of a Jewish musician who would play and sing Christian music while among Christians. Ed. Freimann, Frankfort 1924, p. 85 .

13. P. Nettl, o.c., p. 33 .

14. P. Nettl, o.c., p. 39. The bass singer Isaac composed a German song in 1716.

15. Ibid., pp. 41, 64-65. 
16. Éle Divre Habrith, Dessau 1818, F. 5.

17. Wagenseil in his work Sota appendix, p. 85 ; on the chazzanim in Prague compare my essay in Reshumoth V, pp. 354-6; further below.

18. Schudt, Jud. Merkwïrdikeiten II, pp. 51, 284, 323. Süss is the hero of the famous novel Power by L. Feuchtwanger.

19. In a pamphlet called Shloshoh Tzoakim, see note 46 , Chapter IX.

20. V. Sluys: De Oudste Synagogen der Hoogduitsch-joodsche Gemmente Te Amsterdam (1635-1671), Amsterdam I921, p. 27.

21. Mitteilungen, etc., 1903. Jahrbuch der Jïdischen Literatur-geselschaft VI, p. $18 \mathrm{ff}$., concerning the minutes of the Portuguese community of the year 1652 .

22. V. Schudt: Merkwürdichkeiten der Juden 1714, part IV.

23. V. L. Geiger: Geschichte der Juden in Berlin I, Berlin 1871, pp. 45, 68.

24. Michael of Kempen was appointed chazzan in Prosnitz 1764. His agreement (Chazzanuth-brief) is still preserved in the archives of that community. Therein it is stated that the bachelor Samuel was appointed bass on the salary of one-half Taler per week; the community had to supply him with Sabbath meals, while the chazzan was to provide his food for the week-days. V. Oest. Ung. Zeit. 1894, No. 26.

25. The "Great Singer," Rabbi Josef of Bixheim was appointed chazzan in Hildesheim in 1780 . In the still retained agreement the community urges him to have a bass singer, for whose salary the community and the chazzan are responsible.

26. Community regulations (Tekanoth) of Worms from 1641 ; Blätter für Jud. Gesch. u. Lit., Mayence 1903, No. 10, §§ 31 , 33.

27. Mitteilungen, etc. M. Grunwald, 1923, p. 231; idem., 1903, VII, p. 13.

28. There is a legend about evil spirits which were called forth by the bass during his singing in the Synagogue in Izborz. Compare A. Kahana, Sefer Hachasiduth, Warsaw i 922, p. 40.

29. Reshith Bikkurim, Frankfort 1708, F. 29.

30. Cantor in Osterode, Minden in Western Germany, then in Altona and Hamburg, originally from Poland. His book Shire Yehuda was published in Amsterdam I 697, XIV.

31. In his book on the conduct of the chazzan, Teudath Sh'lomo, Offenbach, 1718, F. 20.

32. Responsa (Bach Yeshanoth) Frankfort 1697 , § 127 .

33. Shtei Yadoth, Venice $1618, \mathrm{~F} .142$.

34. Yosef Ometz, Frankfort 1627, F. 77 .

35. Reshith Bikkurim, 1.c.

36. The custom of singing Boruch Sheomar was an old one. V. Tur O. CH., $\S 5$ I, v. also Machzor Maagle Tzedek, Venice 1568, Vol. I. Introduction. Already Reb Samson ben Eleazar the Scribe was called Boruch Sheomar and that same name he gave his book, Shklow 1805 . He lived in the fourteenth century. In his introduction he tells that, as a boy of eight, he was brought from Saxony to Prague, where he lost his parents and remained an orphan. There, every morning, in the Synagogue, he used to sing Boruch Sheomar with a loud and sweet voice. Every Synagogue in Prague had a special society called Mezamrei $B$ 'sh. On the tombstones of the members of those choral societies is marked Mezamrei B'sh, v. Hock: Epitaphs of Prague, ed. D. Kaufmann, Pressburg 1892. There were also orchestral societies which played in the Synagogue before the beginning of 
the Friday evening service. Abraham Levy, in his Reisebeschreibungen, speaks of Prague thus: "In Prague are famous chazzanim. Among them I found one who is a great artist and famous throughout Europe. His name is Yokele Chazzan. The chazzanim use 'singers' and also flutes and organs and violins and cymbals and various instruments of percussion for every Friday to receive the Sabbath. With the help of these instruments, they sing not only Lechoh dodi, but after they finish that poem, they continue to sing several sweet tunes for about an hour's time." See Ant. Margarite's (born 1500) report in Mitteilungen, etc., 1909, p. 60; also Elbogen, Der juid. Gottesdienst, etc., p. 506. Of the famous chazzan Lipman Poppers (d. 1649 ) it is reported in the Necrologue of Hirschele Tausig Weinschenk, which was printed in the introduction to Sota, Wagenseil $16 \times 4, \mathrm{p}$. 83 ff.; Von Schnitzen und Mahlen will ich schweigen still, dazu alle Seitenspiel Schalmeien und Tromete.

37. Riemann, o.c., II 3, p. 7 I.

38. L.c.

39. Idem., p. 78.

40. Bäumker, 0.c., II, p. 5 .

4r. Idem., III, p. II.

42. L.c.

43. Idem., III, p. 144 .

44. O.c., II, p. 5.

45. O.c., III, p. II.

46. First in MS. found in a book (Klei Yakar) published 1602 in Lublin, then printed in Amsterdam as a placard (1709?). Heb. Bibl. II, pp. 155-158.

47. Chibbure Likkutim, 1.c.

48. Levy's Travels, 1.c.

49. In the memoirs of Glickel von Hammeln, Ed. D. Kaufmann, p. 325; Benjamin Kreilsheim in his pamphlet, Chelkath Binjamin, Berlin 1722.

50. Jacob Emden, Megillath Sefer, Warsaw r903, p. 27 ff.; Sluys, De Oudste Synagogen der Hoogduitsch-joodsche Gemeente Te Amsterdam (16271671), 1921, p. 27.

51. Hammaor Hakkaton, Fürth, 1679, by Meier Tarnopol, who was rabbi in Oettingen, and whose father-in-law, Chayim Zelig, was chazzan in Fürth. The latter was originally chazzan in Lemberg in Poland, and in 1660 was compelled to emigrate by reason of the Chmelnitzki pogroms. The author states also that all the Polish rabbis and their disciples emigrated to Moravia and Southern Germany. P. Ch. Kirchner, Jïdisches Ceremoniel, etc., Nürnberg 1724, p. 177, tells that the chazzan sings with four singers; p. 189 speaks of ten singers not less than thirteen years of age.

52. MS. copied by Birnbaum.

53. V. Memoirs in Oesterreichisch-Ungarische Cantoren-Zeitung. Jhrg. 3, Nos. 6-8.

54. The traditional tune of the so-called Sefira Lechoh-dodi is claimed to be an imitation of an aria in Mozart's "The Wedding of Figaro," No. 3. In reality the tune of Lechoh-dodi has also very much similarity to a German folk-song of Paderborn of the year 1765 (v. W. Bäumker, Das KatolischeDeutsche Kirchenlied, Vol. III, No. I2r). The basis seems to be an older German folk-song, utilized both by Mozart in the aria mentioned and by some chazzanim. That the chazzanim did not take the tune from Mozart is evident from the fact that Mozart composed his Figaro in 1785, while 
the Lechoh-dodi tune was well known a long time before that, as proved by the manuscripts.

55. James Piccioto, Sketches of Anglo-Jewish History, London 1875, pp. 147-8.

56. Jewish Chronicle, 1873: 642. The Leoni tune is to be found in the Church Hymnal ... of the Protestant Episcopal Church, Boston 1925, No. 460, and in The Hymnal ... of the Protestant Episcopal Church, New York 1916, No. 253.

57. F. Pedrell II, No. 186.

58. Noskowski, S. Piessn Ludu, 1892, p. 218.

59. Salaberry, J. D. J., Chants populaires du Pays basques, Bayonne 1870, pp. 236-238, 260.

6o. Kirchner, o.c., pp. 177,189 . See note $5 \mathrm{I}$.

61. A. Levy's Travel, o.c., 1884, No. 10, P. $148 \mathrm{ff}$.

\section{NOTES TO CHAPTER XII}

1. David Friedländer published a circular in 1799 addressed to Oberconsistorialrat Teller, in which he together with several Jewish families "agreed to accept Christianity and even baptism, if they were not required to believe in Jesus and might evade certain ceremonies."-In 1813 he proposed a plan by which he intended "to reduce Judaism to a mere colorless code of ethics." Jewish Encycl. V, p. 515.

2. Bäumker, o.c., III, p. 12.

3. Idem., III, p. 15 ; idem., p. 160.

4. Hebräische und Deutsche Gesänge zur Andacht und Erbauung, zunächst für die neuen Schulen der Israelitischen Jugend in Westphalen. Kassel 1810. This Hymnal contains 26 German and 4 Hebrew hymns to be sung according to 17 Church-tunes.

5. See note 14, Chapter XIII.

6. The title of the collection is Gesaenge fuer Synagogen. It became very popular and experienced several enlarged editions.

7. Allg. Zeit. d. Judenthatms, 1842, p. $412 ; 680$.

8. Nos. I and 3 are taken from W. Bäumker, o.c., III, pp. $285-6$; No. 2 from J. Zahn, o.c., III, No. 3495 .

9. Of Ashkenazic origin are: Nos. 6, 20, 24, 25 a-b, 27, 28 b, 34, 39, $42 \mathrm{c}$, $44,48,52,53,54,55,56 \mathrm{~b}, 57,58,59,60,63$ (Kol Nidré with the German text $O$ Tag des Herrn). Of Sephardic origin are: Nos. I1, 12, $14 \mathrm{~d}$, $16,18,19,21$ a, 26, 33, 35, 42, 49, 50, 51. The "Chorale-book" entitled Gesänge und Melodien für die Jacobson Schule in Seesen was reedited later in Wolfenbüttel without date of print. In addition to the ro6 tunes Iro new chorales and 20 traditional melodies were added, making a total of 236.

10. This was not the first Jewish-German Hymnal, for the Songster of Cassel Religiöse Lieder und Gesaenge für Israeliten, 1816 , preceded it.

11. Festschrift zum hundertjährigen Bestehen des Israel. Tempels in Hamburg, 1918, pp. 68-70.

12. L.c.

13. O.c., pp. 68,84 .

14. In his letter to the author dated $7 / 15 / 27 /$ he says, "When I was appointed in 1913 successor to $M$. Henle, $I$ had no interest to republish the chorale- 
book (referring to the Hamburg songbook originated by Kley and in 1887 republished by Henle), because my intention was to abolish entirely the "chorale singing, i.e., to create a Jewish musical service. I succeeded in overcoming the strong opposition. And now for several years no chorale is sung with the exception of 'My soul, why art thou cast down' for the Memorial service, which became traditional." This song was composed by the organist I. H. Stoewing, o.c., P. 69. The text has been paraphrased in English in the U. P. B. II, p. 327. In the Union Hymnal, No. 184, this hymn is set to the "EI nora" tune.

15. See the Hymnal ... of the Protestant Episcopal Church, New York 1916, No. 158.

16. F. Boehme, o.c., No. 622; Hymnal . . o.c., No. 424-

17. The reports and discussions of that fight have been published in Hebrew: Éle Divré Habrith and Noga Hatzedek, Dessau 1818 .

18. Protokolle der 2 Rabbiner Versammlung in Frankfurt, 1845, p. 149; 354, 360.

19. Idem., p. 133 .

20. I. Nathan, Musurgia Vocalis, London 1836, p. 102. The traveller was Thomas Rees (1777-1864), who wrote about his travels in $1800-1810$.

21. An attitude again and again expressed at the Conference at Frankfort in 1845 , o.c.

\section{NOTES TO CHAPTER XIII}

1. Born in Nikolsburg, 1769. He continued later as second chazzan with Sulzer. Died 1848 . See G. Wolf, Wiener Friedhof, p. 33, Vienna 1879.

2. Moscheles was born in Prague. His grandfather was Isaac Schulhof Moscheles. His great-grandfather, Zalman Schulhof, Dayyan in Prague, was burned in 1689 . He composed a cantata for the Vienna Congregation in $1814 ;$ and on the occasion of the victory over Napoleon, he conducted a thanksgiving service of which this cantata formed a part. His wife was of the Emden family in Hamburg. His son Felix, named after his godfather, Felix Mendelssohn-Bartholdy, was a painter in London. See Aus I. Moscheles Leben, Leipzig 1872, v. I, p. 16;254;261 ff.

3. Paul Nettl, Alte jüd. Spielleute u. Musiker, Prag, 1923, p. 43, says: "Emil Breslaur (Sind originale Synagogen-und Volks-Melodien bei den Juden Geschichtlich nachweisbar? Leipzig 1898, p. 35), discovers a remarkable similarity between the Kol Nidré and the beginning of Beethoven's Quartet in C\# Minor, opus $13 \times$ (Movement 6. Adagio quasi un poco andante, measures $1-5$ ). I wish to add the following remark, in order to set forth the relation of Beethoven to the Synagogue: Beethoven composed his abovementioned quartet in 1826 . In the previous year (1825), Beethoven was asked by the Israelitic Community (in Vienna) to compose a cantata on the occasion of the dedication of the new Temple. As a matter of fact, Beethoven was considering complying with the request. Finally, it was not Beethoven who wrote it, but Drechsler." Nettl presumes that Beethoven might have occupied himself with Synagogue tunes in order to become acquainted with the style. It is noteworthy that at one time Beethoven was near to Jewish atmosphere, for in 1792 he fell in love with Rachel Löwenstein, whose Jewish faith prevented her acceptance of Beethoven's offer of marriage. Wahrheit, Vienna 1901, No. 21. 
4. Noah Mannheimer (1754-1824) was originally from Hungary. He had been for a certain time chazzan in Mannheim, from where in 1795 he went to Copenhagen, remaining there until his death. In Copenhagen he arranged a somewhat modernized musical service. Mannheimer composed some numbers for the Synagogue, one of which was adopted by Lewandowski in his Todah Wesimral I, No. $5 \mathrm{I}$, without mention of Mannheimer's name. See also the biography of his son by M. Rosemann, Vienna 1922, p. 22.

5. Of these composers, Franz Schubert, the most distinguished, contributed one number, Psalm 92, while Seyfried, Drechsler, etc., were the main collaborators with Sulzer.

6. Part I of the Schir Zion was published in 1840 , though the preface was written in 1838 ; Part II in 1866 . The compositions of the Christian musicians were not specified in Part I, apparently to avoid arousing the antagonism of the Orthodox party. Part II does not include non-Jewish contributions. Herein we see that Sulzer later somehow considered Christian participation inappropriate. A second edition in 1905, with some eliminations and some additions, was published by Sulzer's son Joseph (1850-1927), who was the musical conductor at the Temple in Vienna for many years. In this edition, the names of the Christian contributors to Part I are given.

7. French 1859. Quotation from the German edition: Die Zigeuner und ihre Musik in Ungarn, translated by L. Ramann, Leipzig 1883, p. 51 ff.

8. See the above-mentioned second edition of the Schir Zion.

9. P. Wagner, Gregor. Mel. I. Leipzig IgII, p. 30 ff.; R. Lach, Studien zur Entwickelungsgeschichte der ornamentalen Melopöie, Leipzig 1913, p. 195.

10. He utilized recitatives and themes of Bezalel Schulsinger of Odessa, of Dovidl Brod, and H. Weintraub.

11. A title adopted from the Church. However, already at the beginning of the eighteenth century the chazzan used to be called so, compare Kirchner, o.c., p. 209.

12. Algemeine Zeitung d. Judenthums I 865, pp. 620, 635.

13. H. Graetz, Geschichte d. Juden (German), Leipzig 1870, V. XI, p. 239 ff.

14. Kindergebet, published by Schlesinger, Berlin. Meyerbeer, as far as is known, never wrote for the Synagogue. L. A. Frankl, secretary of the Vienna Community, asked Meyerbeer to compose a special number on the occasion of the dedication of a Temple in Vienna, which request Meyerbeer refused on the ground that, inasmuch as they had Sulzer, they should not approach him. At the same time, Meyerbeer added the hope that no organ would be installed in the new synagogue, because it is a "pure Christian instrument: and I consider it my merit that, in accordance with Mendelssohn-Bartholdy, I arranged in Berlin an a cappella choir only. The praying man should approach his God without any intermediary. The Jews have maintained that opinion since the destruction of the Temple, and we should not introduce any innovation. But, if any music is required, thenaccording to my opinion-flutes and horns should be used, similar to those used in Solomon's Temple. However, the human voice is the most moving." Der Jïd. Cantor, Bromberg 1879 , No. 26. The musical service to which he referred was most likely the attempt made by Meyerbeer's father, J. H. Beer, who arranged such a service in his private home in $1815-17$. Surely the opinion of Felix Mendelssohn-Bartholdy, in the earlier years of that 
service, when Mendelssohn was a boy of seven or eight years, could not have been of great value.

15. That valuable manuscript prepared in $1839-40$ is still preserved; and $I$ am publishing it in the second part of the sixth volume of my Thesaurus of Hebrew Oriental Melodies.

16. In his pamphlet, Das Judentum in d. Musik, 1850, Wagner's Gesam. Schriften, Hesse and Becker, Leipzig V. XIII. To Wagner's anti-semitic attitude, which, as is generally known, sprang from envy, his writings testify: Über Meyerbeer's Hugenotten, Ibid., V, VIII,-in which these Jewish composers are considered by Wagner as great geniuses; Meyerbeer and Mendelssohn especially as pure and genuine Germans! In V. VIII, p. 86, he protects the Jews against the attacks of Rossini in Paris.

17. As an item in operatic style, Seu Sheorim, Zemiroth Yisroel v. II., No. 162. Uvnucho Yomar, according to Meyerbeer's tune in Zemiroth Yisrael v. II, No. 166.

18. Recueil de Chants Religieux et populaires des Israelites. See Group I.

19. H. Steinthal, Ueber Juden und Judentum, Berlin 1925, p. 284.

20. H. Weintraub's biography of his father, Hammagid, Lyck 1875.

21. Der Jïdische Cantor 1882, p. $18 \mathrm{ff}$.

22. Extracts from Max Bruch's letter to E. Birnbaum: Breslau $4 / 12 / 8 g / \ldots$ "Ich habe schon als junger Mann, namentlich in den Jahren $1861-63$, Volkslieder aller Nationen mit grosser Vorliebe studiert, weil das Volkslied die Quelle aller wahren Melodik ist-ein Jungbrunnen, an dem man sich wieder erfrischen und erhaben muss-wenn man sich nicht zu dem absurden Glauben einer gewissen Parthei bekennt: Die Melodie sei 'ein überwundener Standpunkt.' So lag denn auch das Studium Hebräischer Nationalgesänge auf meinem Wege-Kol Nidre und einige andere Lieder (u. A. 'Arabiens Kamele') habe ich in Berlin durch die mir befreundete Familie Lichtenstein kennen gelernt. Obgleich ich Protestant bin, habe ich doch als Künstler die ausserordentliche Schönheit dieser Gesänge tief empfunden und sie desshalb durch meine Bearbeitungen gerne verbreitet. . . .

"Ihr ergebener

23. Preserved in the Hebrew Union College Library.

"MAX BRUCH."

24. Zunz, Gesam. Schriften. Vol. II, Berlin 1870 , p. 135 ff. Speaking of Lewandowski's endeavor to give new form to old songs, Zunz makes the following statement (p. 142): "Ist Israel's Geschichte unbekannt, bleibt jüdische Literatur vernachlässigt, wird die hebräische Sprache vergessen und das Judentum geringgeschätzt, so helfen weder alte Texte noch neue Melodien. ..."

25. Sulzer originally had the idea of compiling a handbook for chazzanim, of which he speaks already in the preface to his Schir Zion I, in 1838 ; but he never carried out his intention.

26. Kirschner in his above-mentioned work, Vol. II, $S h^{\prime} m a$.

\section{NOTES TO CHAPTER XIV}

1. An account of his rendition of the service at the dedication of the BrodySynagogue in Leipzig in 1818 was given in the newspaper Weimarische Zeitung, May 14, 1818 . 
2. Oester. Ungar Cantorenzeitung 1883, Nos. 6-8. Dovidl Brod's biography was written in Hebrew by his son, entitled Zecher Olam, Lemberg 1849.

3. The description is given by Wolf Privin, cantor in Graudenz (1843-1895), who for twelve years sang with Sender, in Der Jüdische Cantor 1886.

4. The agreement (Ksav-chazzanuth) made with the Wilna community was published in the Hebrew magazine Talpiyoth, Berditschev 1895, by Hillel Noah Steinschneider, who also gave a short biography of Yoel Dovid of Wilna.

5. Ibid., the name of his father-in-law was Mordecai Strashum (Raines). Compare Ir Hatzedek, p. I go.

6. On Stanislaus Moniuszko compare the Musical Quarterly, 1928, No. I, G. Schirmer, New York.

7. The author of an important collection of Synagogue tunes frequently quoted in this book.

8. Der Jüdische Cantor, 1892, p. 75.

9. Some of his tunes were printed, as Vahavienu and a tune for Chanukah in Golomb's Zimrath Ya, Wilna 1885 ; Habbet mishomayim in Grunwald's Mitteilungen, etc., 1923, p. 244 and in my Manual, etc., 1926, No. 104.

10. A vivid description of Boruch Karliner is given in the Hebrew annual for ethnology and folklore Reshumoth, Vol. II, pp. 71-74.

I1. A detailed characterization of Nissi Belzer as well as of the prominent chazzanim in Southern Russia in the nineteenth century is given by P. Minkowsky in the above-mentioned Reshumoth, Vols. I, II, IV, V.

12. Its first chazzan, Schpitzberg, was a disciple of Sulzer who served him as prototype. P. Minkowsky, ibid.

13. His biography was published in the History of Chazzanuth (Yiddish), New York 1924, pp. 89-91.

14. On this scale compare Thesaurus, Vol. IV, p. 69 (German).

15. This statement in the biographical sketch in the publication of his compositions edited by his son is incorrect since Tschaikowsky was from 1866 engaged as teacher of Theory at the conservatory in Moscow, and during his stay in Petersburg in 1868 he was already starting his career as composer. Compare Grove's Dictionary of Music s.v.

\section{NOTES TO CHAPTER XV}

I. I. M. Wise in his Reminiscences, Cincinnati $190 \mathrm{I}, \mathrm{pp} .2 \mathrm{I}-23$, describes the condition of the Synagogue Service in America at the time of his arrival in the United States in 1846 .

2. Compare D. Philipson, The Reform Movement in Judaism, New York 1907, p. 468.

3. Ibid., p. 478.

4. According to the statement of Rabbi A. S. Moses, Mobile, in a letter to the author, dated February 21, 1928.

5. D. Philipson, 1.c., p. 474. On the history of the Orthodox congregations in New York compare I. D. Eisenstein, "The History of the First Russian American Jewish Congregation," in the Publications of the American-Jewish Historical Society, Vol. 9, 1901, pp. 63-74. 


\section{NOTES TO CHAPTER XVI}

I. Catalogue Halberstam, Vienna, 1890 , No. 227.

2. Of the Spanish period we may consider the numbers: $6,8,9,11,12,14,16$, $18,27,28,30,31,32,33,34,36,42,51,54,56,59,62,68$. The collection contains seventy numbers.

3. Published in Emmerich, 1868 . It contains: (a) material of the eighteenth century, as, e.g., in Part I; p. 9, p. 15, p. 17, p. 18, p. 19, p. 24, p. 25, p. 27 , p. 28, p. 31 , p. 37 , p. 39 , p. 41 , p. 43, p. 48 , p. 5 I. In Part II: p. 24, p. 53, p. 60, p. 87, p. 88 ; (b) compositions or adaptations by the compilers. In Part I, p. 46, p. $5 \mathrm{I}$; in Part II, p. 6, P. 37, p. 39-45, p. 60, p. 63 , p. 64, p. 29 , are of Sephardic origin. See De Sola-Aguilar, ibid.; Machsor H. Gaster, London 1904, Vol. III, p. 273.

4. Portuguese tunes are Nos. 937-943. The last edition: Leipzig 1901. I. Kaufmann, Frankfort A/M.

5. On the history of this community see I. Loeb, Les Juifs de Carpentras, D. d. E. J. Vol. XII, Paris 1886; I. Cohen in B'nai B'rith Magazine, Cincinnati, 1927 , Nos. 5-6.

6. Ibid. However, the Sephardic songs had but little influence upon them. See my History of Jewish Music (in Hebrew), Vol. II, Chapter IX.

7. Graetz, Gesch. d. Juden, Leipzig 1900, Vol. XI, Chapter VI, pp. 46, 146 (Hebrew translation, Wilna 1900); S. M. Dubnow, Die Neuste Geschichte des Jïd. Volkes, Vol. I, Berlin, 1920, pp. 93-97.

8. On the origin and originality of their Syn. songs, see my above-mentioned History, Chapter IX.

9. There are some other collections to be mentioned, e.g., S. ScheuermanN, Frankfort A/M., I912; JACOB RosenhaUPT, Schiré Ohel Yaakov, I-III, 1879-1886. In Vol. II a tune for the chanting of Vechoraus is given, which according to tradition dates back to Maharil.

ro. Birnbaum's collection consists of musical material in MS., mainly Ashkenazic Synagogue songs of Europe of the eighteenth and nineteenth centuries. Of Portuguese origin, his collection contains a MS. of Rome of the early part of the eighteenth century, another MS. of Amsterdam by Abraham Caceres written in 1739, and one of Bayonne in Southern France. A detailed description of Birnbaum's musical MSS. is to be found in the abovementioned H. U. C. Jubilee Vol., in my essay, "Songs and Singers of the Synagogue in the Eighteenth Century." A considerable number of Birnbaum's MSS. are inserted in the sixth volume of my Thesaurus mentioned above. His collection is now in the possession of the Hebrew Union College Library, Cincinnati.

II. Boeschenstein was teaching Hebrew in various Christian institutions in Germany. See Jewish Encyclopedia III, s. v. Compare also Chapters III, VIII. Bäumker, o.c., III, p. 348 .

12. Partly collected in the Pachad Yitzchak: zemer, chazzan, Naggen, Shirah, Shaliach tzibur; in my Hebrew History, etc., Chapters VI-XVII.

13. Pachad Yitzchak, 1.c., History, etc.; Hachazzan Beyisroel in the Hebrew monthly Hatoren, New York, 1923-5.

14. See A. W. Ambros, Musikgeschichte, Vol. I, Leipzig, 1887, p. 425 ff.; J. Moscato in his work, Nefutzoth Yelutda.

15. Such as Arthur Bedford, The Temple Musick, or an essay concerning the method of singing the Psalms in the Temple before the Babylonian captiv- 
ity, wherein the music of our Cathedrals is vindicated. London, Motlock, 1706. An account of these theories is given in A. Baer's Baal Tefillah, mentioned above. See, The Occident, vol. XIII, pp. 373-38r.

16. In the introduction to Psalms, though it is to a great extent based on the explanation of A. Porteleone in his quoted work.

17. Haolam, Berlin, 1908.

\section{NOTES TO CHAPTER XVII}

I. Aboth de'rabbi Nathan, I, Ed. S. Schechter, Vienna 1887, p. 2.

2. M. Yadayim III, 5; B. Megilla, 7 a; Midrash Shir Hashirim I, Verses I I12 ff.

3. B. Sanhedrin, ror a.

4. Midrash Shir Hashirim, I, 8.

5. Hammanhig, Sabbath, § $7 \mathrm{I}$.

6. B. Sabbath, I1 9 a.

7. For more detail concerning those poets, see Thesaurus, Vol. IV.

8. O.c. (Hebrew edition), p. $19 \mathrm{ff}$.

9. O.c., pp. 19-28.

10. Nashad is the name given in Yemen to a certain type of beggars who acquire their alms by singing. They are popular singers and fortune tellers, and exert a great influence chiefly on the women. Hence their songs are sung with predilection. For this reason, the Neshid poetry has come to be accredited to the feminine muse. For more detail about the Yemenite poetry and music, see Thesaurus, Vol. I.

11. F. Consolo, o.c., No. 142.

12. Thesaurus, Vol. IV, p. 29 (Hebrew), p. 14 (German).

13. Some of these old Castilian songs current among the Jews were recently collected and published by various Spanish authors. Compare, for example, Manuel L. Ortega, Los Hebreos En Marruecos, Madrid 1919, where 22 old "Romances" are given.

14. In Thesaurus, Vol. IV, Nos. 476-500, 25 Judeo-Spanish songs of religious and secular nature are given.

\section{NOTES TO CHAPTER XVIII}

1. A second edition was published by Libraire Lipschutz, Paris, 1927.

2. Ibid., p. 16, a list of the adopted French tunes is given.

3. This collection, a manuscript in the Bodleiana, Oxford, was treated by F. Rosenberg in his essay Ueber eine Sammlung deutscher Volks- und Gesellschafts-lieder in hebräischen Lettern, published in L. Geiger's Zeitschrift für die Geschichte der Juden in Deutschland, Berlin 1888-1889. See Neubauer, Catalogue of Hebrew Manuscripts, No. 2420.

4. F. Rosenberg, o.c., No. 46.

5. F. Boehme, o.c., No. 266.

6. F. Boehme, o.c., p. 697 .

7. Similarly in Persia Mula Shahin of Shiraz translated the Pentateuch into Persian in verse and rhythm. This translation became popular among the 
Persian and Bokharian Jews to such a degree that it was and still is sung every Saturday to a special tune. Compare Thesaurus, Vol. III (German), pp. 7, 45-46.

8. The Bovo-book was translated by Eliyahu Bachur Ashkenazi, a distinguished Ashkenazic scholar who lived in Italy. His translation he prepared from an Italian translation of the English story Bevis of Hampton, which in Italian became Bovo d'Antona, and in Judeo-German it was changed to Bovo-or Baba-book, i.e., "Grandmother's tales." E. Bachur, according to his own statement, adopted a "Welshtune," i.e., an Italian melody.

9. The names quoted are gathered from A. Schulman's treatise on Judeo-German Literature from the sixteenth to the end of the eighteenth centuries (Hebrew), Riga, 1913.

1 o. A. Schulman, o.c., p. 20 r.

I.I. A copy of this rare print is preserved in the H. U. C. Library. A photostatic copy with an introduction was published by J. Schatzky, New York, 1926.

12. Example 14 is taken from F. Boehme, o.c., No. 650.

13. F. Boehme, o.c., No. 399 c.

14. Rabbi Joseph Hahn of Frankfort, in the first half of the seventeenth century, opposed the custom of singing Zemiroth and especially Kol Mekaddesh to the tunes of the gentiles. Yosef Omets, o.c., $\S 602$, F. 77.

15. The tune with Stein's German text is to be found in Baer's Baal Tefillah, No. 4 I7.

16. Yosef Ometz, o.c., $\S \S 603,619$.

17. Shire Yehuda, introduction, 1.c., Simchath Hannefesh, 1.c.

18. L. Wiener, The History of Yiddish Literature, etc., New York, 1899, p. 53.

19. M. Kipnis, Volkslieder, Warsaw, Vol. I, p. 131.

20. L. Cahan, Jüdische Volkslied, New York, 1920, Vol. I, p. 93.

2 I. M. Kipnis, o.c., Vol. II, p. I 19.

22. L. Cahan, o.c., Vol. II, p. 270.

23. Ibid., I, p. 189.

24. In my Thesaurus, Vol. IV (German), p. I18, a detailed account of melodies in major and minor of the Slavic folk-songs is given from which we may deduce that the minor scale is by no means predominant. Thus, out of 1600 Southern Slavic folk-tunes in the collection published by Kuhac, c. rooo are in major; out of 700 Czechoslovakian tunes edited by J. Malat, 387 are in major; and out of 300 Ukrainian rhythmical tunes in the collection of F. Kolessa, o.c. (Chapter IX, note 1 ), over a half are in major.

25. In the Cancionero Musical, published by F. Pedrell (Chapter VIII, note 28) 160 are in minor and 96 in major.

26. In the collection of 260 Greek melodies published by G. D. Pachtikos, Athens, 1905, 145 are in minor, 38 in Hedjaz, 13 in the Third Churchscale, and 23 tunes have the Lydian scale.

27. Leipzig 1882 .

28. No. 28 is taken from the collection Folk Songs of Many Peoples, The Womans Press, New York 1921, Vol. I, p. 73.

29. No. 29 is taken from Cancionero Salamantino, etc., Madrid 1907, p. 60.

30. Compare F. Pedrell, Folk-lore Musical Castillan du XVI siècle, in I.M.G., Vol. I, pp. 372-400. 31. Chants Populair de la Bretagne, by H. de la Willemarqué, Paris 1867,
Appendix. 
32. No. 18 is taken from Folk Songs of Many Peoples, o.c., Vol. I, p. 150. No. 17-from L. Cahan, o.c., Vol. I, p. 231 .

33. Folk Songs, etc., o.c., I, p. I 10.

34. No. 22 is taken from L. Cahan, o.c., I, p. 5 I. No. 23 from F. Kolessa, o.c., III, Lemberg 1916, No. 127 .

35. No. 26 is taken from F. Kolessa, ibid., IV. No. 70, No. 27 from L. Cahan, Vol. I, p. 27.

36. No. 24 is from L. Cahan, II, p. 50 . No. 25 from Kolessa, o.c., No. II2.

37. M. Kipnis, I, p. 38.

\section{NOTES TO CHAPTER XIX}

I. In Shivche Ari it is related that "once on the eve of a Sabbath the Rabbi (I. Luria) went out of the city of Safed, followed by his disciples . . . to receive the Sabbath, and started singing special Sabbath songs in sweet tunes." Compare also Sefer Charedim, Venice 1601, Chapter VII.

2. A remainder of that Palestinian cabbalistic movement still persists in Jerusalem in the Synagogue Beth $\mathrm{El}$ as a special congregation, called Mechavnim -The Meditators. According to their doctrine, every law or custom should be observed not in meaningless manner, but with devotion, accompanied by thinking upon its religious and ethical purpose and upon its additional mystic meanings introduced by these cabbalists. In the reading of the daily prayers, the worshipper must think not only upon the meaning of every word, but must likewise recall an entire historic event, or a complete cabbalistic or ethical meditation. The greatest stress is laid on the name Yalve. Whenever this name occurs during the prayers, it has a certain shade of meaning which must be thought over. During this contemplation of the meaning of the word, its pronunciation must be prolonged until the meditation (kavanah) is finished. And naturally, this prolongation is executed through melodic curves, through tunes.

3. This poem was first published in his work Sefer Charedim, 1.c.

4. The three examples are taken from Thesaurus IV, Nos. 188, 363, 377 .

5. The most important prayer-book was edited by Shneor Salman, called Dem Rebbins Siddur, and was published by his son Ber, Kopust 1830 (?).

6. Rabbi Elija of Wilna (1720-1798) ordered in 1772 the excommunication of the chassidic sect, and in 1777 the burning of their books. He repeated his orders in 1781 and in 1797 . V. M. Teitelbaum, The Rabbi of Ljadi (Hebrew), Vols. I-II, Warsaw r9i3.

7. Likkute Moharan, a collection of sermons by Nachman of Brasslaw, Jerusalem 1874, F. 54 a ff.; 62 b.

8. Likkute, etc., F. 18 a, 79 a.

9. Ibid., F. 79 a.

10. Ibid., F. 79 b.

11. A. B. Birnbaum in his essay "The song in the courts of the tradikim in Poland" (Hebrew), Haolam, 1908.

12. Teitelbaum, 0.c., I, p. 19.

13. Attributed to Rabbi Pinchas of Koretz, Birnbaum, 1.c.

14. Birnbaum, 1.c.

15. L.c., such as Rabbi Shlomele of Radomsk, who used to sing accompanied by a choir of his adherents, or Rabbi Meirl of Apta, and Rabbi Avrohom Moshe of Prshischa. 
16. Birnbaum, 1.c.

17. This saying is attributed to Rabbi Mendell of Kotzk, ibid.

18. Nachman of Brasslaw in his above-mentioned work Likkute, etc., II, F. 23 a, says: "Seclusion is the highest stage in which man can attain divine inspiration, where he can pour out his heart to his God in a free and intimate way, and in the language familiar to him, in his native tongue. In our country this is Yiddish, for Hebrew is little known to the average man, and consequently it is difficult for him to express himself in it fluently. Therefore, whenever Hebrew is used as a medium of prayer, the ears do not hear what the mouth utters."

19. Among the reasons for the issuance of an excommunication of the chassidim in Cracow in 1786 was also the accusation that they changed the traditional form of the ritual and disregarded the traditional tunes. Wetstein, Kadmoniyoth, etc., Cracow 1892, p. 62.

20. Toldoth Yaacov Yoseph, quoted by A. Kahana, o.c., p. I39. However, al-

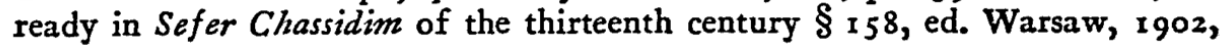
the advice is given that if one cannot invent new prayers or meditations, he should choose the tune which appeals to him most and chant in it his prayers. In so doing his heart will be filled with meditation. Soft-minortunes should be selected for supplications, while for laudations joyous ones should be chosen.

21. Birnbaum, 1.c.

22. A statement of the Maggid (preacher) of Koznitza, Birnbaum, 1.c.

23. Kontros Hahithpaaluth, Warsaw 1876, F. 5; Teitelbaum, o.c., I, p. 19 ff. The same opinion was expressed by Anton Rubinstein: Die Musik und ihre Musiker, Leipzig I 891, pp. 2-3.

24. To that type belonged the "court" of Borka, Birnbaum, 1.c.

25. This type of song was cherished in Talno, Kotzk, and Gor.

26. P. Minkowsky in Reshumoth, o.c., I, p. I14.

27. Kahana, o.c., pp. 284-286.

28. The best work on the founder of the Chabad system is by M. Teitelbaum, cited in the text.

29. The last living Rabbi of Liubawitz and the sixth generation of Shneor Salman was forced by the Bolshevik Government in 1927 to leave his residence and to emigrate. He settled in Riga, Latvia.

3o. A. S. Rabinowitsh, Derech Haruach, in Hashiloach, Vol. XXI, Odessa 1909, p. 468.

31. Compare Thesaurus (German), Vol. IV, p. I05.

32. This composition, however, is by others attributed to Joshua Feinsinger, chazzan of Wilna (1839-1872). Printed in my Manual, etc., No. 103.

33. Kneseth Israel, II, Warsaw i 887, p. 359.

34. Some of his tunes are printed in Der Kuzykaliszer Pinkos, Wilna 1927.

35. Die Geschichte fun Chazwanuth, 1.c., pp. 92-93.

\section{NOTES TO CHAPTER XX}

I. "Songs in folk style" is here used for Volkstïmlich in German. According to Grove, o.c., IV, p. 608, "This term defies exact translation; but, speaking broadly, it means a simple and popular form of the art-song. . . . The Volkstiimliches Lied is, in short, a combination of the Volkslied and the 
Kunstlied, and its area of capacity is a very wide one. It may rise to a high level of poetic beauty, and may descend to low depths of stupidity or triviality without ceasing to be volkstïmlicl." -The form of Volkstümliches Lied became very popular in Germany since the seventeenth century, and many of them were converted into folk-songs. Of many songs the authorship is wholly unknown. Some composers wrote nothing but volkstïmliche Lieder. Grove, ibid., p. 609.

2. Compare Jeswish Encycl., II, p. 427.

3. In Palestine, the popular wedding song was: "Precious without powder or rouge, or hair dye."-Rav Acha used to dance with the bride on his shoulders. When questioned by his disciples as to whether they should do the same, he answered: "Only if you can withhold yourselves from base thoughts." B. Kethuboth, I 7 a; Aboth de Rabbi Nathan, § 4 .

4. B. Taanith, 22 a.

5. In his commentary Ture Zahav to Orach Chayyim, §560, 3. See also I. Abrahams, Jewish Life in the Middle Ages, Philadelphia 1898, pp. 135, 197. Jewish Encycl., II, p. 427.

6. Jewish Encycl., o.c., A. Schulman, o.c., p. viii. Noheg, etc., F. 17 calls Klezmorim the Letzanim. Albert Wolf, Falirende Leute bei den Juden, in M. Grunwald's Mitteilungen, etc., 1908, p. 151 ff.

7. B. Megilla, 7 b.

8. Mitteilungen, etc., o.c., 1901, p. 156.

9. Thesaurus, Vol. IV, No. 491.

Io. F. Rosenberg, o.c., pp. 278-281. A long Purim song is also printed in Mitteilungen, etc., o.c., 1909, pp. 33-36.

11. Abudraham, Warsaw 1878, p. I1 2; Jewish Encycl., X, p. 279.

12. Jewish Encycl., 1.c.

13. I. Abrahams, o.c., pp. 265-6.

14. Beniggun Haman of the Ahashverosh-Spiel, A. Schulman, o.c., p. 133.

15. On Purim celebration in Italy see M. Güdemann, Leben und Erziehungswesen, etc., Vol. II, Chapter VII; III, Chapter III. I. Abrahams, o.c., p. 254, Chapter XIV.

16. Yosef Ometz, o.c., F. 45 b.

17. Published by Wagenseil in Sota 1674, p. 85 ff.

18. Megillas Vinz was first printed in Frankfort 1696, 2nd edition Berlin 1916, Louis Lamm, publisher. On the event of Vinz (Vincenz Fettmilch) compare Yosef Ometz, o.c., § 953; J. E., V, pp. 378-79.

19. Compare A. Schulman, 1.c.

20. A. Wolf, o.c., Mitteilungen, etc., rgog, p. $40 \mathrm{ff}$.

21. On his biography in details and on his poetry see Mitteilungen, etc., 1913, III, pp. 1-8, IV, pp. 1-12.

22. G. Dalman, in his Jïdische Melodien aus Galizien und Russland, Leipzig, No. 3 .

23. His biography was written by $M$. Fried, Mitteilungen, etc., 1917, pp. 1-25. A characterization of his poetry is given in Mitteilungen, etc., 1909, pp. 65-89, 103-121, by $M$. Weissberg.

24. M. Weissberg, o.c., p. 73 ; p. I1 5 .

25. A list of his publications is given by Guinsbourg and Marek (Chapter XVIII), appendix pp. ix-xiii. A new edition of 49 of his songs is now in press in New York.

26. In French and German, the term couplet signifies a type of song dealing in 
a satiric manner with topics of current events. V. Brockhaus' Konversations Lexikon, item "couplet."

27. L. Wiener, o.c., p. 87 .

28. A selection of his reminiscences was published in Jewish Forward (Vorwärts), New York 1927, April 24.

29. A. Schulman, o.c., pp. 76-77.

30. A. Wolf, o.c., p. 40 ff., 1909.

31. A. Wolf, o.c., p. 57.

32. L. Wiener, o.c., p. 237 .

33. Published by the Hebrew Publishing Co., New York, arranged for piano by H. A. Russotto.

34. Compare Thesaurus, Vol. I, No. I9I end.

35. According to A. Garfinkel's arrangement, R. Mazin Co., London 1904.

36. Noheg, etc., o.c., F. 17, quoted from Yosef Ometz.

37. Sibbuv Rabbi Petachya, ed. Grünhut, Jerusalem 1905 (Hebrew), p. 24 (German), p. 33 .

38. A detailed account is given by A. Wolf, o.c.; Paul Nettl, Alte Jiidische Spielleute und Musiker, Prag 1923, pp. 49-55.

39. A. Wolf, o.c., p. 53 ff., 1909.

40. Ibid., p. 93, 1908 .

41. Compare A. Wolf and P. Nettl, 1.c.

42. Maharil, ed. Warsaw 1874, F. 3 I b.

43. See Chapter IX, note 18 .

44. A. Wolf, o.c., p. 154 .

45. A. Wolf, o.c., 1908, p. 93 ff.

46. Ibid.

47. Ibid., P. Nettl, o.c., p. 64, gives caricatured Jewish dances of the sixteenth century.

48. A. Wolf, o.c., p. $: 54$.

49. Ibid., p. 155 .

50. Mendelssohn's Letters from 1833 to 1847 , English translation by Wallace, Boston 1863, pp. 98-99. On Gusikow in details compare Mendel's Mus. Conver. Lexicon, Vol. IV, p. 460.

51. Allgemeine Zeitung d. Judenthums, October 1837 . His tune for Psalm 126 was published in Muzykaliszer Pinkos, o.c., No. 114.

52. A. Wolf, 0.c., I909, p. 6. Grove, Vol. III, p. 27, discussing the Rakoczymarch does not mention Rozsavölgyi's name. W. S. Pratt, in The New Encycl. of Music and Musicians, New York 1924, p. 703, quotes his name as the father of Julius Rozsavölgyi, the founder of the Royal Music Publishing House in Pest.

53. We hear, for example, of a blind Jewish violinist, Löbel, in the eighteenth century who was the teacher of the famous violinist Franz Benda. The latter was grateful to the Jewish klezmer all his life for the perfect and wonderful production of tone he taught him. Compare Mendel's Lexicon, Vol. I, p. 537. However, the later encyclopedists, such as Grove and Riemann, omit the story of his blind Jewish teacher. A Bohemian poetess used this episode as a subject for the novel Judith-Mary, published 1867 .

54. A. Wolf, o.c., 1909, p. 19.

55. Responsa Bach (Yoel Sirkish) § ro3.

56. In 1842 a Jewish family, Kantorowitz of Grodno or Wilna, came to Berlin and concertized at the royal court. A. Wolf, o.c., p. 57. 
57. P. Nettl, o.c., p. 37 , cited a statement of 1580 by Wenzel Brezam that a Jewish band played at a Christian wedding and delighted the people with its music.

58. P. Nettl, o.c., p. 38 .

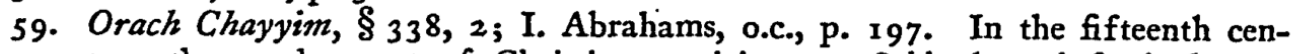
tury the employment of Christian musicians on Sabbath and festivals was already customary. See Maharil, o.c., F. 31 a.

60. Radbaz, Responsa, § 132; Magen Abraham to Orach Chayyim, §338, 2; I. Abrahams, ibid.

\section{NOTES TO CHAPTER XXI}

1. Selected from Thesaurus, Vol. I, Nos. 155, 74 .

2. Fourth edition Berlin Juwal Publishing Co., 1923.

\section{NOTES TO CHAPTER XXII}

A. Rubinstein, Die Musik und ihre Meister, Leipzig 1891, pp. 64-65.

2. Heinrich Berl, Das Judentum in der Musik, Berlin und Leipzig 1926.

3. Alfred Einstein, Das Neue Musiklexikon, Berlin 1926, p. 58 .

4. Richard Wagner's Gesammelte Schriften, Hesse \& Becker, Leipzig. On Meyerbeer compare Vol. VII, pp. 48-58; Vol. XI, pp. 83-97. On Halévy and Mendelssohn, Vol. VIII, pp. 65-96. Wagner's well-known attack on these Jewish composers Das Judentum in der Musik and Aufklärungen über das Judentum in der Musik, see in Vol. XIII, pp. 7-50. In this connection the opinion of Friedrich Nietzsche may be quoted according to which Wagner was strongly influenced by French music and folklore. Compare Friedrich Herz, Rasse und Kulture, Leipzig 1925, p. 367.

5. Compare Max Brod and F. Weltsch, Zionismus als Weltanschauning, 1925, pp. 96-107.

6. H. Berl, o.c.

7. A. Rubinstein, o.c., p. 92.

\section{NOTES TO CHAPTER XXIII}

1. Published in Avodas Habore, Wilna 1914, p. $15 \mathrm{ff}$.

2. Published in Lieder-sammelbuch, etc., cited in Chapter XXI, No. 50.

3. Deux Melodies Hébraïque, avec accompagnement de Piano, par Maurice Ravél, A. Durant \& Fils, Paris 1915.

4. Lieder-sammelbuch, o.c., No. 19. 


\section{INDEX}

Aapid, tune of, 170

Abahu in Cæsarea, ro

Abba Areka (Rab), 93

Abbub, Abobas, II

Abelov, Jacob Moshe of Trocki

(J. M.), 150,158

Abert, H., 496

Abobas, 6

Abraham (bar) ben Ezra, 126, 360

Abramino dall' Arpa Ebreo, 196

Abrass, Osias (Joshua), 289

accents, 68; Greek-Byzantine, 68 ;

Hebrew, 69

A Chazzandl auf Shabbos (song), 397

Acher. See Elisha ben Abuya

Achron, I., 464; Joseph, 467

Ackermann, Aron, 294, 35 I

acutus, 67, 68

Acta Esther (play), 438

Addir bimluchoh, 188

Addir hu (tune of), 168, r74, 341, 36r

Adon olam (tune of), II6

Adonoy beckol Shofar (music), 122 f., 127

Adonoy-Moloch mode, Steiger, 73, 285, 478 ; scale, 480

$A$ Dudule, 420

Eolian, 483

Af bri (music), 404

Agada, 105

Agades (Hagros), 18

Agala, 70

Agathon, 113

Agobard of Lion, bishop, 130

Agudath Schirim, 265, 346, 348

Aguilar, Emanuel Abraham, 292-3, 338,348

Ahasweros spiel, 437

Ahavoh-rabboh, 88; mode, 84 ff., 285 , 478 ; music, 90 f., 422 ff.; scale, 26

Akdomus, .160; tune of, 156

Akeda, $\mathbf{1 7 0}$

Akiba, Rabbi, 20

Alamoth, 13, 496

Alcharizi, 37 I

Alef indikes (music), 404

Alendorf, Menachem, $44^{\circ}$

Alfasi, Isaac, 125

Alkabetz, Solomon, 126, 36r

Allegro Porto Hebreo, 196
Allgemeine Zeitung des Judentums, 338

Allmächtiger Gott (Baugesang), 174

Alman, Samuel, 3r3, 486, 488

"Alt-Neu-Schul," 205

Altshul, Joseph (Yoshe Slonimer), 299

Ambros, A. W., 4, 7, 35x, 495

Amen, $2 \mathrm{r}$

Amida, 78, 108

Amran Gaon, 108

Am Yisroel chay (music), 423

Ancient Liturgical music, $35^{\circ}$

anenu, $2 \mathrm{x}$

Anglo-Saxon song in the Synagogue, 316 ff.

anshada, 25, 367

Anshe Maamad, 20, 497

antiphonal singing, 21

anudata, 67

Aolodia, I3

Arabic melodies in the Synagogue, 125; meter, I13, I15, 124

Arabic Tunes, secular, 29; religious, 30

Ari. See Isaac Luria

ariach all gabbe levena, 50

Armianus Mercelinus, I3r

ars nova, 162, 201, 210

artistic endeavors, $46 \mathrm{I}$ ff.

Asaf, 15

Asher, Aaron ben, 68

Asher, Simon, 314

Ashkenazi, Joseph, 439

Ashkenaz, 129

Ashkenazic Modes in Major, $145 \mathrm{f}$; in Minor, $138 \mathrm{ff}$.

Ashkenazic-Pentateuch for the High Holidays, 59

Ashkenazic Song of the Synagogue in the seventeenth and eighteenth centuries, 204 ff.; song, 133

"Ashkenazi," Synagogue song of the, r29 ff.

Ashkenazic tunes for individual poetical texts, $166 \mathrm{ff}$.; prose, $148 \mathrm{ff}$.

Ashrechem (music), 429

Asia Minor, 87

Asor, 8

Assyria, music of, 7

Athanasius, bishop of Alexandria, 6o 
Athkinu seudathah, 362

Athnah, Ethnachta, 67, 68

Auer, Leopold, 473

Aufn Pripitshok, 454

augmented second as a Diatonical step, 482

Aulos, 4, 12, 26, 87

Av-horachamim Steiger, 185; (music), 186

Avignon, 43

Avoda, 159

Avodath Yisrael, 345

Azammer Bishvachin, 362, 412

Azkari, Eleazar, 412

Baal-Shem-Tob, Israel (Besht), 412. See Besht I.

Baal Tefillah, 307, 339, 346, 348

Babylonia, 23, 97; Babylonian, 43; music, 7

Bach, Johann Sebastian, 235, 476, 482

Bach, Nathan, 438

Bachmann, Jacob, 290

Bachrach, Rabbi Yair, 436

Bachur, Eliyahu, 439

badchon, badchonim (merry-makers), 380,435 ff.

badchonus, $43^{8}$

Baer, Abraham, 292, 339, 348

baith, 28

Balkan, 87

de Balmes, Abraham, 345

bands, Jewish music, 456

Bardaisan of Edessa, 99

"bards," 125

Bar Kochba, opera, 45x

Bar-Nash of Jerusalem, 455

barock style, $\times 65,213,384$

Bartók, Béla, 190, 505

Baruch of Kalisch, 194

Bashraw (Pashraw), 27

Basit meter, $\mathrm{II}_{4}$

Bass, Lipman, 215

Battle of Pavia tune, 439

Bauer, Jacob, 294

Baum, Solomon, 336

Bäumker, W., 2ro, 50 r

Bayat-Huseni, 84; -Nawa, 84

Bayati (makam), 29, 34, 50

Bedford, Arthur, 515

Beer, Ahron, in Berlin (A.), 148,149 , $154, x_{57}, 158,159,193,217,218$, 236,278

Beer, Jacob Herz, 236, 512

Beethoven, L., 247, 33x, 476; Quartet in C\# Minor, 5 II

Belzer, Nisson Spivak (Nissi), 275, $303,306,313,314$
Bema, 106

Ben Asher, 345

Ben Azra, 19

Benda, Franz, 521

Benjamin ben Yerach, $x 70$

Ben Naftali, 68

Benei Hechalah, 362, 425

Benzenauer, I7I

Berdichevski, I., 464

Ber of Meseritsh, 412

Ber of Radoshitz, Rabbi, 433

Berggreen, A. P., I9I

Berl, Heinrich, 353

Berliyn, Anton (Ahron Wolf), 289

Berlin, Irving (Israel), 473

Bernstein, A. W., 4rI

Berthold von Regensburg, 164

Besht, Israel, 41 5, 416, 418

Besrodney, G., 464

Beth-Hak'neseth, I9

Bethuel, 240

Bevis of Hampton, 5x7

Bialik, Ch. N., 455

Biblical and Post-Biblical, 35 ff.; modes, 38

Bibliotica Rabbinica, 346

bi-lingual songs, 392

Binder, A. W., 465

Birkath am, 454

Birnbaum, Abraham Ber, 294, 35r

Birnbaum, Eduard (Asher Ensel), 293, 350; collection, $5^{\times 3}$

Blaustein, Abraham, 294

Bloch, Ernest, 473 ; music, 474

Blumenthal, Nisson, 307

Boehme, Franz M., III, 390

Bokharian, 43

Book-of-Samuel tune, 382,438

Bookhandler, Abraham, 439

Borchu tune, 158, 161

Boruch-sheomar tune, I70; custom of singing, 508

Böschenstein, Johann, 346

Bovo-Book, tune of the, 382, 517

Braham, John, 226, 338

Breslaur, Emil, 350

Brod, Dovidl, 216

Brunoff, Platon, 463

Bruch, Max, 276, 465; Max Bruch's letter, 513

Bruder veit's tune, $384 ;$ music, 390

Butstedt, 2 ro

butu, 67

Byzantian system, 69

Cabbala, 412; cabbalistic movement, Palestinian, 518; song (music), 421 ff. 
Cahan, I. L., 4 II

calamus, 495

canciones, 376

cantor, 109

cantus firmus, 201

Caceres, Abraham, 515

Carian muse, 94

Carpentras, 43

Castilian dialect, 376

Cenni Sull'origine, 349

Chabad songs, 418

Chad gadyoh, 36r

Chalumeau, 495

"Chamber-Music-Ensemble," 464

Chanukah tune. See Mooz tzur, hymn, I7r

Chants Hebraique, 340

Charlemagne, 129, 131

Chassidic singers, 416 ; song, $412 \mathrm{ff}$.; (music), 42I ff.; style, 230; tunes in Major, $429 \mathrm{f}$; ; in Minor, $425 \mathrm{ff}$.

Chassidim, 4r9, 467; tune, 420

Chassidism, 4 I2

Chatzotzera (Trumpet), ro, Ix

Chaykl, Chayyim, 432

chazah, 106

Chazzan, Origin of, 50r; Rise and

Development of the, ror $\mathrm{ff}$.

Chazzanim, 133; and Chazzanuth in

Eastern Europe, $296 \mathrm{ff}$.

Chazzanuth-brief, 215

Chazzanya, 125

Chazarian proselytes, 87

cheironomia, 67

Cherniavsky, I., 464

Cherniavsky, Joseph, 465

chidduyoth form, 366

Chmelnitzki pogroms, 195, 213

Chopin, 476

chor-chazzanim, 306; -schul, 306, 307

chorus (employed in the Temple), 17

chromatic, 13, 34; -harmonies, 95

Chronicles, 38

Chronoi (ta'amim), 68

chronos protos, 28

Church style, 244

Cimbalist, Chayyim, 459, 507

circumflex, 67, 68

City-chazzan, 305

classical style, I65

Clement of Alexandria, 93

Coblentz, Meier, 219

Cohen, Elkan, 215

Cohen, Ethel Silverman, 465

Cohen, Francis Lyon, 291, 293, 351

Cohen-Linaru, M., 292

Cohon, A. Irma, 352 comparative table of accent motives for the intoning of the Pentateuch, 44 ff., 70

congregational singing, 98

conjunctives ( $\left.t^{\prime} a m i m\right), 38,70$

Consolo, Federigo, 202, 293, 341, 349

Costa, Sir Michael, 473

Cremieu, Jules Salomon, 293, 340

Cremieu, Mardochee, 293

cymbal, 17

couplet $(s), 45 x, 452,520$; GermanFrench, 445

Damrosch, Leopold, 473

dance, 15; dancing at worship, 500; religious, 16

Daniel, 6r

darbaka, 370

darga, 70

Das Hamburger Familienblatt, 349

Das Pavierlied, $3^{83}$

Das Schloss in Oestereich, 383

David, Ernest, 349

David, Ferdinand, 473

David (son of Jacob), Futeralmacher, 217

David, King, 9, 14, 15, 192

David, Samuel, 290

Davis, A. J., 328, $33 \mathrm{I}$

Davit da Civita Hebreo, 196

Day of Atonement, 57

Dem Rebbins niggun, 419

Der Jïdische Cantor, 348

Der Lehrer und cantor, 349

De Sola, David, 292, 338

Der Synagogale Gesang, 351

Der Tod als Schnitter, tune of, 384; (music), 389

Deutsch, Moritz, 288, 292, 339

Diaconus, John, 131

Diaconus, Paulus, 144

Dick, Jacob Heilprin, $43^{8}$

Die Geschichte von Chazzanuth, 352

Die mame hot mir geshikt (music). 407.

Dietrich von Bern, 383, 440

d'Indy, Vincent, 199

diminished fifth, 482

Die Wahrheit, 349

Die Oestereichische-Ungarische Cantoren-Zeitung, 348

Dio Cassius, 496

Disjunctives (ta'amim), 38, 70

Doctor Almosado; 45I

Dorian, 47, 56, 60; (Greek), 25; scale, 43

Dort vo die zeder, 221

Dos Tallis'l, 454 
double-flute, 4, I3

double-pipe, I4

Dovidl of Talno, $43 \mathrm{r}$

Dovidl, Rabbi, 416

drong, 216

Dudaim, 255

duf, 370

Dukes in Mantua, 196

Dulcimer. See Hackbrett

Dunash ben Labrat, .36r

Dunham, Arthur, 328

Duran, Simon, 346

Du solst nit gen (music), 409

dveikuth, 419; melody, 432

ear-marks, 27

Eastern Europe, 23

Ecclesiastes, 36, 38, 47

Echod mi yodea, $36 \mathrm{r}$

Eder vohod, I70

Effent rebbitzin (music), 429

Egypt, 87; song of the Copts in, 56; Egyptian music, 3

Ehrenkranz, Benjamin Wolf (Wölwel

Zbarazer), 44 r

Ehrlich, Hermann, 294, 338

Eichberg, Salmon, 248

Eichel, Isaac, 449

Eichler, Moshe Michel, 432

Eisenstadt, Abraham, 342

elamu, 13

Eliazar, Rabbi (son of Joseph Hagalili), 20 .

Eliezer ben Meshullam "the Great," I6I

Elijah of Wilna, Rabbi, 518

Elijah-songs, 360

Elisha ben Abuyah, 92, 359

Eli tziyon, tune of, $168,17 \mathrm{I}$

Eliyohu Hanovi, tunes of, 392 ; music, 401

Ellis, Havelock, 500

Elman, Mischa, 473

El Mole Rachamim, 194

Elymos, $I_{3}$

Emechoh nososi, 165

Endel, Edmond Sereno, 328

Engel, Julius Yoel, 463, 466

En kelohenu, 238; (music), 239

Ensel, G. S., 350

Ephraim of Nisibis, 99

Es is geflogen (music), 406

Es ist kein grosser freud (music), 390

Esoh dei, tune of, 167,170

Esser, P., 329

Esther, 36 ; the Book of, 38 ; mode of, 65; (music), 66

Ethnachta, athnah, 70
Eth shaare ratzon, 127

Ett, 262

Etz Chayim, melody, 24r; tune for, 239

European art-music, 46r; folk-song, 497; music, 47I; style, 467

Ezra, 38

fa-i-lan, Ir4; fa-i-la-tun, Ir3; fa-ulun, 114

Feinsinger, Joshua, 164, 432

female singers, 496

Finzi, Jacob, 20r, 337

Fisch of, 249

Fisk, Frank T., 327

Fleischer, Oskar, 353

Folk-character, 27

Folk-song of the Ashkenazim, $379 \mathrm{ff}$.; in Germany, 379 ff.; in Eastern Europe, $385 \mathrm{ff}$; tunes of the Ashkenazic, $40 \mathrm{rff}$.

Folk-song in the Biblical and Prayer modes, 396; in Minor scale, 398

Folk-song, Jewish, 50; "secular," 435

Folk-song of the Oriental Jews, 357 ff.; Hebrew-Yiddish, 396; Ukrainian, 396; Hebrew-Yiddish-Ukrainian, 396

Folk-songs in Arabic, 37x; Aramaic, 370; Hebrew-Arabic, 37x, 396; Hebrew-Aramaic, 371, 396

folk-style, 467 ; motives, $47 x$

Foot, Arthur, 328

Forkel, 348; Forkel's history, $35 \mathrm{I}$

form, 27; in which the Psalms and prayers were rendered, 20

Fraenkel, Jacob, $\mathbf{3 2 2}$

Frankel, Isaac Seckl, 240

Frankl, L. A., 512

Franz, 467

Frazer, J. G., 195, 245

Fregt di velt (music), 405

Freudenthal, Julius, 238

Friedchen, wife of Moses Leib, 440

Friede, Sholom, 229, $43 x$

Friedländer, David, 235, 5 ro

Friedman, Ignace, 473

Friedmann, Aron, 286, 293, 350

galchish, 254

Gamaliel in Jamnia, Rabban, ro7, 129

Garte tarzunae (music), I73

Geh ich mir spatziren (music), 407

Geiger, Abraham, 242

Geiger, Salomon, 352-3

General art-music, 477

Genung, C. G., 329-30

gereshin (see Tarsa), 70 
German Jews, 23; Lied, 467, 484; music, 133; song, 13r

Gerovitsch, Eliezer, 310, 487, 485

Gershwin, George, 473

Gervelyn, Meister, 142

Gibraltarian, 43

Gideon, Henry, 331, 465

Ginsburg, Leb, 449

Gipsy music, 190, 19r

girdle-form, 368

Glogow, Yitzchok, 226

Gloria patri, etc. (music), 146

Gluck, 330, 472

Gnessin, M., 464, 468

God of Abraham, Praise," "The, 220

Goldberg, Hirsch, 238, 289

Goldfaden, Abraham, 229, 449, 453 ; operettas, 453

Goldfarb, Israel and Samuel E., 336

Goldmark, Karl, 473, 476

Goldstein, Joseph H., I51, 153, I59, 230, 290, 337

Goldstein, Morriz, 323

Golomb, H. B., 462

Golub, Solomon, 466

Gott mus man dienen (music), 427

Gott un sein mishpot is gerecht, 454

gova, 68

Grauman, M., 327

gravis, 67,68

Greek art-music, 96

Greek Churches, 96; tunes, 33

Greek Dorian, 39

Greek song, 92 ; penetrated into Palestine, 22

Gregorian chant, 56, 6r, Ixr, $x_{32}$; Lamentations, $4: 16,55, x: 59,5: 1$, 59; (Prima lectio), 55

Gregorian mode, 47; and Minnesong, Motives of the, I63; song, 42, 47, 73, 2 10

Gregory I, 177

Grimm, Carl, 328

Groenland, F. J., 240

Grodner, Yisroel, $45^{\circ}$

Grünzweig, Adolf, 29I

Guido of Arezzo, 69

Guinsbourg, S. M., 400

Guinsbourg, Theodor, $33 \mathrm{r}$

Gurowitsch, S., 464

Gusikow, Michael Joseph, 458

Gut Shabbos, 383

Haarbleicher, M., 24r

Hackbrett; 457,458

Haftara, Haftora, 38, 51

Hagada, I74
Hahn, Joseph, 132, 180, 209, 385

Hakkol Yoduchoh, 160

Hakofoth, 137

Halaka, 105

Halb schwarz halb weiss, 383, 439

Halévy, Jacques Fromental, 262, 263, 473,475

Halevi, Jehuda, 126,363

Halil, Chalil, 11, 12, 17, 495; Halilim players, 12

Hallel, 20, 73, 36r

Haleloth, 366

Halleluyah, $2 \mathrm{x}$

Halpern, M., 336

Hamavdil (music), 402

Hamburg Temple, 246; Reform, 252, 320

Hammelech, r48, I 57, 158

Hammithpallel, 342

Hamshorer Hagodol, 217

Hamishoyoh (mode), 3r

Handel, G., 472

Hand-marks, 67

Haolam, 35I

Happakoli, Simeon, 129

Harmony, 26, 478 ff.; (music), 489 ff.; classical, 482 ; harmonists of the Synagogue, 480; harmonizers of Synagogal song, 479

Harmony of the modes, Adonoy Moloch, $487 \mathrm{f}$; (music), 49r; Ahavoh Rabboh, 486 f.; (music), 489; Mogen-ovos, 486; minor, 487

Hashirim asher Lishlomo (S. Rossi), I99

Hashkivenu, tunes for, $1 \times 6$

Hassler, Hans Leo, 24I

Hast, Marcus, 286, 291, $3 I_{4}$

Hatikva, Zionist hymn, 221, 454

Hausman, Rosalie, 329

Hawkes, H. W., $33 \mathrm{I}$

Haydn, 474

Hay Gaon, 125

Hayyuj, Jehudah, 345

hazağ (meter), Ir4

Hebräisch-Orientalischer Melodienschatz, 343

Hebrew songs, Babylonian (music), 372 f. Sephardic-Syrian, 373; Yemenite (music), $374 \mathrm{f}$.

Hecht, Rev. Simon, 329, 348

Hedjaz (mode), 30, 34; scale, 88

Heifetz, Jascha, 473

Hei piv ya (music), 403

Heine, Salomon, 246

Heinroth, J. A. G., 240

Henle, Elchonon, 439

Helfere, Marx, 328 
Heller, Josef, 29r

Henle, Moritz, 240, 292

heptachord, 478

Herodotus, 5, 495

Hersh of Przshev, 432

Hershman, Mordecai, 334

Herz, Joseph, 438

Hessel, David, 26r

Hiller, Ferdinand, 240, 473

Hirsch, S. R., 284

Hirsch of Ziviotor, 194

Hisda, Rab, 97

hishtapchuth hannefesh, 50, $4 \times 9$

hithlahavuth, 419

hithpaaluth, 419

hithpashtuth hagashmiyuth, 4r9

Hoch rief der Wächter, 383, 440

Horace, 6

Horvitz, Jacob, 439

Hoshanah Rabbah, 159

Hoshianah, 21

Huna, Rab, 97

Hungary, 87; Hungarian Rakoczy march, 459

Hurenlieder, 385

Huseni, Bayat-Huseni (makam), 30 ,

Hypodorian, 50, 51, 56, 61, 73

Hypolydian, 6r

Hypophrygian, 6r

Ich hob gelibt (music), 406

Ich steh mir un klar (music), 405

Idelsohn, A. Z., 498

Imber, Naftali Herz, 454

Immanuel of Rome, 181

Improvisation, 26

In cheder (song), 467

Influence of Moderate Reform upon Synagogal Song, $246 \mathrm{ff}$.

Influence of the Reform Movement on the Synagogal Song, 232

instruments employed in the Temple, I 6

interrupted ("deceptive") cadences, $48 \mathrm{r}$

Introduction of Harmony and Polyphony into the Synagogue in Italy, $196 \mathrm{ff}$.

invitatorium, 144

Ionian, 56

Isaac of Prosnitz, 226

Isacchino or Jacchino Massarano, 196

Isaacs, Louis M., 336

Is gekumen der fetter (music), 408

Is gekumen tzuforen a chazzan (music), 404

Israel Baal Shem-tob, 208. See Besht I., Baal-Shem-Tob
Isr. Wochenschrift und freie Lehrer und Cantorzeitung, 349

Isidor of Sevilla, 6I

Iste confessor, 146

Italian, 23

Italy, 43

Jablonski, 346

'Jacob of Prague, Rabbi, 438

Jacob the son of Peretz, 217

Jacobite, 96; Church-song, unrhythmical, $3 \mathrm{I}$; rhythmical, 32

Jacobson, Israel, 235, 236, 240; reform of, 24r ; Songbook of, 24I

Jadassohn, Salomon, 473, 476

Jadlowker, 312

Jaffa, Israel, 432

Jaffa, Rabbi Mordecai (M.), of Prague, 159

Japhet, Israel Meyer, 284 ff., 289

Jazz-hits, 472 ; song by Berlin, 474

Jehuda of Barcelona, 125

Jellinek, A., 259

Jessurum, $34 x$

Jesus, 38

Jew in General Music, The, 47x ff.

Jewish dance music, 206

Jewish Encyclopedia, 346

"Jewish Ministers Cantors Association of America," 352

Jewish Music, Rise and Development of, $35 \mathrm{I}$

Jewish Song, Oldest Unrhythmical elements of, $35 \mathrm{ff}$., $72 \mathrm{ff}$.

Jewish theatre, 449

Jischac, Jehudah ben, 202

Joachim, Joseph, 473, 476

Job, 36; (music), 59; "Job-mode," 57; mode of, 56

Joel, Chazzan in Leipa, 352

Johlson, Joseph, i4r

Jokele of Rzeszow, chazzan, 213

Jonas, Emile, 290

Joseph, Rab, 93

Joseph of Bixheim, 508

Joseph the son of Benjamin, 380

Josephus Flavius, 8, II

"Jubilation," r47; (chants), r3

Judah bar Illai, Rabbi, I05, 435

Judeo-French folk-song, 380

Judeo-German song, I33, 380; Ashkenazic of seventeenth century ( $\mathrm{mu}$ sic), $386 \mathrm{ff}$.

Judeo-Italian song, 437

Judeo-Spanish song (Ladino), $376 \mathrm{ff}$.; (music), 377

Juedische Musiker am Hofe von Mantua, 350 
Juedische Presse, 349

Julianus, Emperor, r3r

Kaddiah, $15^{8}$; tunes for, 116, 151, 152

Kadma, 67, 68, 70

kadmoyoh (mode), $3 \mathrm{I}$

Kahal-singers, 207

Kaiser, Alois, 322, 350

Kallir, Eleazar, Ir3, 170

Kalonymos, I34, 345; family, 129

Kamil (meter), II4

Kanun, 25

Kaplan, I., 464

Karliner, Boruch, 302, 303

Kashtan, Nochum Leb, 298

Kashtan, S'alomon, 193, 266, 267, 27I, 297

Kasida, 367

Katz, Elchonon, 439

Katz, Rabbi Jacob Joseph, 4r 5

Katz, N. H., 292

Kaufmann, Fritz Mordechai, $\mathbf{i}^{\mathrm{x}}$

Kedusha, musaf, 88

kelei-chomos, 207

kelim, 192

kiddush, 160

$K i$ lo noe, $36 r$

kina, 73

Kinnor, 5, 8, 12, 16

Kinnura, 5

Kipnis, M., $4 \mathbf{r}$

Kircher, Athanasius, 346

Kirchhain, Rabbi Elchonon-Henle, 227, 383

Kirschner, Emanuel, 286, 29r, 324

Kithara, 4

Kitzinger, Fred E., 327

Kley, Israel Eduard, 236, 238

klezmer, klezmorin (music-makers), 435 ff., 455 ff.

klippah, 4 r9

Kobsari, r85; Ukrainian, 297

Kohn, Maier (M.), x 59, 174, 260 ff., 288

Kohen, Elchonon, 438

Kolessa, Philaret, 185, 505

Kol mekadesh shevii (music), 389; tune of, 384

Kol-Nidré, I, II, III, IV, I 54-r 55 ; tune, I6o, 226; Max Bruch's, 276

Kopelman, Jacob, 438

Kopit, H., 464

Koppel, Jacob, 439

Kol Rinnah, 160, 281; Utefillah, 276

kore, 104

Korngold, Erich, 473

Kornitzer, L., 24r

Kotili sia (music), 408

Krebs, T. L., 328
Kristal, Solomon Singer, 439

Kunstlied, 520

kurr, 67

Kutner, Leib, 440

Kvartin, Zavel, 334

kyrie eleison, 42, 47, 131

Lach, Robert, 353

Lachmann, Isaak, 286, 292, 30r, 345

La Juive, 474

Lamentations, 36, 38; (music), $54 \mathrm{f}$.

La Traviata, 309

Lazaro Gratiano, 437

Leb, Jehudah, 352

Leb, Chazzan Nahum, 219, 267

Lebensbilder Berühmter Cantoren, 350

Lechoh dodi, 116, 362 ; Sefira, 509

Ledovid boruch, 170

Legarme, 70

"Leib Sarah's," 4r7

Leitner, Franz, 353

Leitzim, Leitzonim, see badchonim

leitzim, leitzonim, 435

Leizer of Lodz, 432

lektor, rog

Lejman, Samuel, 4rx

Leon of Modena, 198, 205, 265, 350

Leon, Meier, 220

"Leoni," 220

Lern-steiger, rgr

Levi, Hirsch Bochur, 299

Levinsohn, Yoel Dovid, 299

Lewandowski, Louis (Eliezer), 155, r6o, 269 ff., 276, 288, 324, 484

Levy, Abraham (of Amsterdam), 202

Levy, Heniot, 329

Levy, Hermann, 473

Liberman, Isaac, 439

Libro de canti D'Israele, etc., 34X

Lichtenstein, Abraham Jacob (chazzan) $, 275,276,466$

Lied-form, 43I; -style, German, 275

Lifshitz, Moses, 215

Lifshitz, Salomon, 209, 2x5, $2 \times 7$

Lifschutz, Shlomo, 352

Linos, 5

Lion, Asher, 236, 269

Liszt, Franz, r91, 253, 265, 353

Liturgische Zeitschrift, 338, 348

Lob, Otto, 329

Löbel, a blind violinist, 521

Lobt Gott den Herrn (music), 172

Loewe in Strassburg, chazzan Karl, 262,276

Louis the Pious, r3o

Lovy, Israel (I. Levy, Lowy), 219, $226,255,287$

Löwenstamm, Max G., 289 
Löwit, I., 295

Luanz, Elijahu, $44^{\circ}$

Lucian, 6

Liubawitz, 418

Luria, Isaac (Ari), 126, 205, 362, 365, 412

Luther, Martin, 17 I

Lutkin, P. C., 33 I

Lwow, P., 464, 487

Lydian scale, 56, 6r ; Greek, 26, 43

Maarich, 70

Maccabees, The (opera), 46r

Machbaroth. See Imanuel of Rome

Machir, Rabbi, 129

machol, $x 5$

Machzor, Ashkenazic, Sephardic, 57

Mackfarlane, W., 327

Madama Europa, r97, 45I

mafsikim (ta'amim), 39

"Magdala," the tune of, 132

Magrepha (pipe-organ), I4, I9, 496

Maharil, Jacob Levi (Segal) Mölin, I70, 177, 206, 456

Mahler, Gustav, 473

Mahler, Maier, 205

Maimonides, M., ro, I2, 126

$\operatorname{makam}(s), 24,34,363$

Maneros, 5, 495

Mannheimer, Isaac Noah, 246, 247, 249, 512

Marcello, Benedetto, I67, I71, 202; Marcello's Psalms, 202

Marchettus of Padua, 202

Marek, P. S., 400

Margolis, Rabbi Selig of Kalish, I94, 213

Margowsky, Jacob Samuel ("Zeidel Rovner"), 433

Margulies, Berl (Broder), 440

"Maria's cradlesong," I74

Maria, Giovani, 506

Marien ward ein bot, 146

Markbreiter, Koppel, 247

Maronite song, 32

"Marseilleuse," 383

Marshalik, marshalk. See badchonim, 435

Mar Ukba, 98

Marusya (music), 407

Mathias, Chr., 329

Marx, Adolph Bernhard, 473, 476

Mayence, I 58

Mayer, Rabbi Harry H., 332

Mayer, L. M., 226

$M a$ yofis (song), 384 ; tune of, 385 ; (music), 390

Megilla, see Esther, 65
Meier ben Yitzchak of Worms, 159

meinyana, 60

Meldola, David, 240

melisma, 258

melody, melodies, III; in the Hazagr meter, $\mathrm{II}_{7} \mathrm{ff} . ;$ in the kámil meter, I20; in the Major and Minor, 517 ; in the Mutakarib meter, 120, in the Rağaz meter, I20

melos, 192

mena'anim, I5

Menahem de Lonzano, 209

Mendell of Kotzk, Rabbi, ${ }^{1}$ g

Mendelssohn, Moses, 330, 331, 348

Mendelssohn-Bartholdy, Felix Jacob, $247,459,473,474,475,476$

Mensch gedenk, 384

mesayim, ro4

mesharethim (ta'amim), 39

meshorer, meshorerim, 204

Meshullam ben Kalonymos, 134, 165

metrical poetry, roo

Methfessel, A. G., 240, 24I

metziltayim, $\mathrm{I}_{5}$

Meyer, Joachim, 2 ro

Meyer, Isaac, 4I 5

Meyer of Rothenburg, Rabbi, I 57, 158

Meyerbeer, Jacob Liebmann (Giacomo), 236, 264, 472, 475, 512

Michael Chosid, 218

Michael ben Nathan of Lublin, 213

Michael of Kempen, 508

Mi Chomochoh, r6o

Milner, M., 464, 467

Min Hametzar, by Halévy, 263

"minhag," 180; minhag Carpentras, 340

Minkowsky, Pinchos, 293, 351, 485

Minnesinger, Minnesong, 125, 132 , I47, 175

Minz, Rabbi Moses, I79

Mirkin, 272

Misheberach Steiger, 185

misnagdim, 413

Missinai melodies, tunes, $\times 36, \times 77,312$

Mistechkin, G., 464

Mixolydian (scale), 73, 286

mithpallel, mithpallelim, 102, 104

Mitteilungen fur jüd. Volkskunde, 4II

mode, modal, 24, 28; modes of the Bible, 35; modes or Steiger in Major, 143f.; in Minor, 137; for Sabbath Mincha, 137

modulations in minor, $48 \mathrm{x}$; to the dominant, $48 \mathrm{r}$

Mogen-Ovos, 285 ; mode, 78,483 ; (music), 85-6

Moise, Penina, 320 
Moldavan, K., 464

Mölin, Rabbi and chazzan, 157, 159

Mombach, Israel Lazarus, 286, 288, $3{ }^{1} 4$

mono-au!os, 12

Moniuszko, Stanislaus, 300

Mooz tzur, tune of, 168, 171

Moravia, 22I

Moroccan, 43

Moscato, Jehuda, 20r

Moses ben Ezra, 126, 502

Moses de Lion, 57

Moses, Rabbi Isaac S., 330

Moscheles, Ignaz, 247, 285, 473, 476, 5 II

Moshe of Prshischa, Rabbi Avrohom, 518

Moshiachszeiten, song, 442

Mosley, B. L., 291

motive (s), 24; and tunes of German religious and secular folk-song, $172 \mathrm{f}$.

Mozart, 330, 33I, 472, 474, 476

Muezzin, 28

$m u-f a-i-l u n, \mathrm{I}_{3}, \mathrm{Ir}_{4}$

music, sacred, 21 ; secular, 21

musical performances at the Temple service, 18

Musaf, ro8; Kedusha, 159

mustaar (makam), $43 x$

mus-taf-i-lun, II4

Musurgia Universalis, 346

mutakarib (meter), II4

Muzmar, 12

Nabla, 4; Sidonian, 5

Naboth, 92

Nadel, Arno, 463

Nachman of Brasslaw, 413, 519

nagen, 9

naghana, 24

Na gorodi (music), 408

Najara, Israel, 126, 362

nashwad (plu.) neshid, 367; form, 366 ; songs, 367

nashad, 516

Nasi, Joseph, $37 \mathrm{r}$

Nathan, Isaac, 338

Naumbourg, Samuel, 199, 229, 230, 260 ff., 280, 288, 292, 337, 348, 350; Naumbourg's harmony, 481

Nawa, 29, 34, 4r2

neginoth, 69

Nehemiah, 38

Nehemiah, Rabbi, 2I

Neidlinger, W. H., 328

Neila, 308 ; Kaddish, tune of, 170

Ne'im Zemiroth, I92
Neo-mystics, 4 r2

Nestorian, 96

Nettl, Paul, 506, 5ix

Neuberger, 26I

Neumeister of Weissenfels, Erdman, 210

Nevel, 5, 8, 12, 16

Nezwizshki, A. A., 342

Ni-be-ni-me, 450

Nicholas I, Emperor, 394

Noheg Katzon Yosef, 352

Nordlinger, Joseph Hahn, 352

North Africa, 23

Northern European music, rro, III

Northern Germany, 87

Nowakowsky, David, 308, 485

Nun freut Euch Ihr lieben Christen, I71; (music), r73

Nun wend is horen (music), 173

Occident, Jews of, 26

Ochiloh loel, 170

octachord, 478

Odessaer, Bezalel, 298, 303

Odo, Archbishop, 132

Offenbach, Jacques, 473

Olenu (tune), $147, x_{4} 8,157$

Olivers, Thomas, 220

Olympus, 13, 87

Omar adonoy leyaakov, tune of, 392;

(music), 402

Oppenheim, David. 2r 5

organ-builder, Jewish, 205

"Organ" congregations, 244

ornament, oriental, 25

Ortega, Manuel L., 516

Oschoh edrosh, tune of, 165

Osisi, tune of, 170

Ost und W est, 349, 463

Ottenhofer, 327

Otzar Neginoth Yisrael, 343

Over Tatra, 399; (music), 406

Ovos (tune), 149,150

Owst, W. G., 328

" $O z$ shesh meos," 159

Paamonim, I 5

Pachtikos, G. D., 517

Palestine, 87

Pan, Moshe, 219

Papir is doch vais (music), 405

Parisot, Dom J., 344

Pashraw, 27

Pashta, 68

paytanim, 134

Pazer, 70

Pedrell, F., $5 \times 7$

pentameter, $5 \mathbf{I}$ 
Pentateuch, 36; mode, 39 ; reading of the, 38 ; (music), $40 \mathrm{ff}$.

pentachordal, 25

percussive instruments, 14

Perl, Joseph, 245

Persia, Persian, 23, 43

Phœnicians, music of the, 5

Phrygian (Greek), 25, 483

Piccioto, James, 220

Pifert, Samuel, 439

Pilpul, pilpulistic, 184

Pindar, 13

Pinkos, Muzykaliszer, $4 \mathrm{II}$

Pinna, David, 39, 346

Pitkowsky-Schak, Sarah, 465

piyyut, 87, ro6

"Plain Chant," 47

Plutarch, 15

Pneumata (ta'amim) , 68, 70

Poetical Portions of the Pentateuch, modes of the, 47

Poetry of the Pentateuch, tunes for the, 49

Poland, 87

Polatshik, Sender, 298; "Sender Minsker," 302

Polnisch, 182

Popper, Lipman Katz, 207, 21 7, 438

Portuguese songs, $34^{8}$

Porush, 30r

Porteleone, Abraham ben David, 20r, 346

Prayers, the modes of the, $72 \mathrm{ff}$.

precentor (in the church), rog; Rise and Development of the, ror $\mathrm{ff}$.

pronunciator psalmi, 109

Prophets, 36; mode of, 50; (music), $52 \mathrm{f}$.

prosodia, 68

Provence, 47

Proverbs, 36, 6r

Psalms, 36; modes of the, 58; (music), 62 ff.

Purcell, Henry, 234

Purim-Spiel, spieler (play), 437

Purim songs, 437

Pythagoras, 5

quarter-tone system, 25, 26

Raba, 93

Rabbi Henich, 449

rabbis-chazzanim, 135

Rabinowitz, A. M., 485

Raff, Moshe, 230

rağaz (meter), $\mathrm{Ir}_{4}$

ramal (meter), ri4

Rashi, r30
Ravél, Maurice, 465, 486

Rebia, 70

"Reform Society of Israelites," 320

Reform Temple in Seesen, 96

rehaw (makam), 57

Renaissance in Italy, 196

responsive form, 7

Reuchlin, Johannes, 43, 346

rhythm, 28

rhythmical music, 100, 124; set to unmetrical text, I2r; song, I 10 ff.

rhythmical music, Oriental, 25

Ribono schel olom (music), 422

Riemann, H., $x 97$

Rikud, 420

Rimsky-Korsakow, 254

Rittangel, J. S., I74

rococo style, 272

Rogers, James H., 327

Romanos (of Homs), roo

rondo-form, $43 \mathrm{I}$

Rosenblatt, Joseph, 334

Rosenthal, Mordchele (klezmer), 459

Rosenstein, Gerson, 238

Rosh Hashana, 57

Roskin, Janot S., 465

Rosowsky, Boruch Leib, 3 II

Rosowsky, Solomon, 3r2, 467

Rossi, Anselmi, 196

Rossi, Salomon, 196, 197, 265, 336, 350,478

Rossini, 33 r

Roumania, 87; Roumanian folk-song, r90; (music), $187 \mathrm{ff.}$

Rubin, David, 290

Rubinstein, Anton, 3Ir, 46r, 473, 476 rum, 68

Ruth, 36, 38; mode of, 47; (music), 48

St. Jacobs-tune, I $_{43}$

St. Jerome, 60

Saadia, ro

"Sabba" (mode), 26, 4r2

Sabel, S., 33I

Sachs, Curt, 495

Sagri, Abraham, 20r, 337

Saint-Saëns, 254

di Salinas of Burgos, Francesco, 399

Salman in Frankfort, 207

Salmele of Frankfort, chazzan, 450

Salue mundi (music), 172

Saminsky, Laza r, 464, 465

Sänger, Loew, I48, I 50, 158, 230, 260, 264, 337

Sangers of Prague, David, 437

Sanseconda, Jacobo, 506

saria (meter), Ir4 
Sasgar (makam), 29, 34

scales, minor, 27; major, 27; problem of the, 478

Schalit, M., 464

scarbove, $\mathrm{I}_{3} 6$

Schaz, Rabbi Meir, 22r

Schechter, Mathilda S., 336

Scheuermann, S., $5 \times 5$

Schink, 240

Schir Zion, I, 250, 255, 257; II, 25I, 258, 48I

Schire Beth Adonai, 348

Schir Haschirim asher lischlomo, 265

Schitomirsky, A., 464

Schlesinger, Joseph, 459

Schlesinger, Sigmund, 325

Schlome of Prague, 380

Schönberg, Arnold, 473

Schorr, Boruch, 286, 290, 309

Schorr, Israel, 3 Io

Schubert, F., 249, 331, 467, 474

Schulman, I., 464

Schulsinger, Bezalel of Odessa, 267, 298

Schumann, 33r, 467, 476

Schwartz, Joseph, 312

Schweigers, David, 439

Schwenke, I. F., 240, 24 I

Scroll Vinz, 439

Seder service, I74, 36r

Sefer shire Yisrael, $34 \mathrm{I}$

Selicha, 73; mode, comparative table of, $79 \mathrm{ff}$.

Selig, Chazzan, 439

Semetic-Oriental characteristics, 24; song, 24 ff., 38

Sender Polatschik, "Minsker," 298, 344

Sephardic in Amsterdam, 43; in France, 43; in Egypt, 43 ; in Palestine, 43 ; Sephardim, 23

sequence (chants), 147

Seril, daughter of Jacob of Dubno, 440

Seyfried, 249

Shabbatai Zevi, 365, 439

Shabzi, Sholem, 364

Shachrith, 108

shafur, 495

Shahin, mula, 5 I 6

shaliach-tzibur, 102

shalishim, I5

shalsheleth, 70

shapparu, 9

shechitah, 182

Shechina, wie weit bist du, 4r7

Shechuloh achuloh, 432

Shefal berech, 127

shehiya, 68

shekalim, 160
Shema, 18, 21, 103, 108

sheminith, 8

shesht, 67

Shestapol, Wolf, 308

shira, shiroh, Yemenite song, 367; form, 366; stanza, 368

Shir avodah, 455

Shire Yehuda, 352

Shitomirski, A., 486

Shlomele of Radomsk, Rabbi, 518

Shmendrik, 450

shofar, shofaroth, 9, ro, Ir, 495; mehuppach, 70; munach, 70

Shofet kol hooretz, tune of, r67, 202

sholom aleichem, 384; (music), 390

sh'titoyoh (mode), $3 x$

shuar, 125

Shulchan Aruch, 333, 412

Shulamith, 309, 45I, 452

Shoiyoh aniyoh, 433

Siddur, ro8, 36r

siga (makam), 29, 34

silluk, 70

Simchath Hannefesh, 227, 383

Simchath Torah, 137

Simeon the Great, Rabbi, 132

Simon bar Abbun, 134, 165, 170

Simon bar Yochai, $37 x$

Simon of Prague, tune of rabbi, 383 , 439

Sind originale Synagogen-und Volksmelodien, 350

Singer, Abraham, 226, $33^{8}$

Singer, Josef, 292, 349

Singer, Leon, 220

Sirkas, Rabbi Joel, 209

Sistrum, 4, I5

Sklar, E., 464

skolion, 95

Slavs, Southern, Irr

Smetana, 22 I

"Soade," 496

"Society for Jewish Folk Music," 463

sof, 67, 68; -passuk, 70

Sofer of Pintshof, Mordecai, 440

Sofer, Leib, $43^{8}$

Sofer, Zalman, 440

sofer, ro3

sogachts, 183

Sog zshe rebeniu (music), 404

Solomon of France, $17 x$

Solomon ibn Gabirol, r26, 439

Solomon Usque, 437

Songs of the Ashkenazim, 344

Songs of the Babylonian Jews, 343; Moroccan Jews, 344; Persian, Bokharian and Daghestan Jews, 343; Yemenite Jews, 343 
Songs of the Oriental Sephardim, 344

Song of the Sea, 124; Song of Songs, 36,38 ; intonation of, 48

song and singers in Folk-style, $435 \mathrm{ff}$.

Souvenir Volume, 350

Sparger, William, 324, 327

Spicker, M., 327

Spivak, Nisson, 303

Spohr, 33 I

Stadt-chazzan, 182

Stark, Edward, 326

Stark, Joseph, 326

Stendal, Mose, 438

Stein, Rabbi Leopold, 385

Steinthal, Hyman, 265

Stoewing, I. H. G., 240

"straw-fiddle," 458

Strelisker, Dovidl Brod, $297 \mathrm{f}$.

String instruments, 8

Sullam family, 506; Mose, r98, 506; Sara Copia, 506

Sulzer, Salomon, 246 ff., $287,324,478$, 481 ; music, 279 ; style, 327

Süsskind of Offenbach, 207, 449

suz-nak (makam), 3 10

swarita, 67

Synagogue 'Song after the Destruction of the Second Temple, a historical survey of the, $92 \mathrm{ff}$.; Eastern European, 18I ff.; Collections of and Literature of, $337 \mathrm{ff}$.; in the United States, $316 \mathrm{ff}$.

Syria, 87; Syriac, 93; church, 99; Syriac, 43

syrinx, 14

Ta'amim, the (musical notation) of the Bible, 35, 65, 69

Tachanun, 73

Tal-and-geshem mode, I37; tune, 24r

Talbott, L., 292

talsha, 70

tarsa (gerishin), 70

Tartaric-Altaic, I3 $_{3}$ T Tartaric Oriental mode, 88

Tartil, 25

Taube, wife of Jacob Pan, 440

taushish, 367

Tausik, Jacob, 439

tawil (meter), Ir4

tebir, 70

Techinna, Techinnoth, 73, 440

Tefilla, 73; mode, 73; (music), for the High holidays, $75 \mathrm{f}$., 137

tekia, ro

Telechaner, Jacob, 433

Teller, Oberconsistorialrat, 5 ro

Temple in Jerusalem, music of the, 7
"Temple Verein," 238

terua, 9

tetrachord, tetrachordal, 25, 39, '478; circle, 479; form, 479

Teudath Shlomo, 352

Thatcher, Howard, 328

Thesaurus of Hebrew Oriental Melodies, 343

tifha, 67, 68, 70

Tinker, M.Z., 329

Tochter Zion, 210

Todah Wesimrah, 227, 282

Tof, $x_{4}$

Tolczyner, Hershele, 432

tomechim, ro4

tonality, 8, 26; in Oriental music, 25; scales and modes of ancient Jewish song, 22 tonoi (ta'amim), 68, 70

Tosefta Megillah, 498

tradition, musical, 22

Treves, Herz, 176, 204

Trobadors, Troubadours, I25, 132

trumpet, 4

Tumas tzurom, tune of, 167

Tunes for Individual Texts, $144 \mathrm{ff}$.

Tylor, Abram Ray, 328

tzadik, tzadikim, 4I2, 4I3, 4I5

Tzadik of Kalif, the, $4^{\mathrm{r}} 7$

Tzadik of Makarov, 433

tzalzal, tziltzal-cymbal, ${ }_{5}$

Ud, 25

uaiata, 67

Uggav, Ir, 12

Ukraine, Ukrainian, 87; “Dorian," 3r4, 400; folk-song, 184, r85, 399; Gipsy-scale, 298; motives in Dorian ending on the second, $x 86$; (music), r $86 \mathrm{f}$.; song, $\mathrm{r}_{3}$

Ultra-Reform, 246

ultra-reform movement, 244-5

Un as du forst (music), 403

Ungarische isr. Kultus-Beamtenzeitung, 349

Union Hymnal, $33 \mathrm{I}$

Unison singing, 21

Unrhythmical (elements), 25; music set to metrical text, $\mathrm{x} 2 \mathrm{I}$

Unter dem kinds vigele, tune of, 393; (music), 403

Van der-Stucken, Frank, 327

Vaychullu, 84

Vehakohanim, 159; (tune), I, 153, II, I53, III, $x_{53}$

Venite exultemus, 146

Verdi, 254 
Vetaher libenu (music), 424

Viddui, 73; comparative table of -mode, 78, 82-3

de Villers, M. A., 342

Villoteau, 344

vocal music, I7, 19; song of the

Temple, 20

"voice-chords," 497

Volhynia, 87

Volkstümlich, 454

Vom jungen Grafen, 383

Vorbeterschule, 339,348

Vos vet zein mit dem rebben dem frumen (music), 430

Vrowenlop, Heinrich, I64

Vulpius, M., I7x

Wachenheimer, Abele, 221

wafir (meter), $\mathrm{II}_{4}$

Wagenseil, 217

Wagner, Peter, 353, 500

Wagner, Richard, IIr, 265, 475, 476; attack on Jewish composers, 522

Wald, Franz, 327

Waley, Simon, 29x

Walich, Eisik, 380,438

Walich, Leib, 439

Warschawsky, Mark, 454

Wasserzug, Chaim, 289

"water libation," I6, I7

water-organ (organon hydraulium), $x_{4}$

Weber, 33 1

Weinberg, I., 468

Weinshenk-Tausik, Hershel, $43^{8}$

Weinstein, L., $33 \mathrm{r}, 348$

Weintraub, Hirsch (Alter), $266 \mathrm{ff}$., 271, 286, 288, 482, 486, 487; chazzanuth of, $3 \times 1$; harmonic scheme, 483

Weiss, Jacob Leopold (Leib), 290

Welsch, Samuel, 323

"Welwele Chersoner," 308

Wie in der Tora steht geschrieben, 383

Wilnaer Baalhabessil (Yoel Dovid Levinsohn), 299

de la Willemarque, $\mathrm{H}$., $5^{\mathrm{I}} 7$

Wimmelbacher, 26r

Wind instruments, 9; musical, Ir

Wodak, M., 342

Woelfin von Locham, 206

Wolf of Cracow, 439, 467

Wolf, I. Löb, 43I

Women in religious music, 27; in the Temple choir, 16
Yah Ribbon Alam, 362, 370

Yankele geht in Shul arain, 453

Yankele mit Rivkelen (music), 408

Yarchon Lechazzanim, 35x

Yedid Refesk, 412

Yehudah Charizi, 125

Yehudah Leb ben Moses, 209

Yekel Bass, Singer (I. Lehman), 22 I

Yekuthiel ben Moshe, r7o

Yemen, Yemenite, 23; folk-song of Jews, 364

Yeruchom Hakoton, Blindman, 302, 303,314

Yeshivah, 215

Yesli te (music), r73

yethib, 70

Yigdal, tune, 22r; Table of Folk-songs compared with the, $222 \mathrm{ff}$.

Yisrolik kum ahaim, 453

Yisroel in Prosnitz, 215

Yitzchok Chazzan, 219

Yitzchok of Berditschev, Levi, 413, 420

Yokush beonyo, 432

Yoreisi, r70

Yosef of Bicksheim, chazzan, $2 \times 5$

Yossele dem Rebbins, 432

Yotzer, 160; mode for the three Festivals, 142

Yovo addir, tune of, 393; (music), 402

Zafát form, 366

Zakef, 67, 7o

Zalman of Ladi, Shneor, 413,416, 418

Zalman of Poltosk, chazzan, 432, 439

Zarfati, Rabbi Benzion, 198

Zarka, segol, 70

Zeidel Rovner. See Margowsky, J. L.

Zeitlin, L., 464

Zemiroth (songs), 73, 36r, 384; in Hebrew, 392 ; Israel, 263, 363; Yisroel, 340

Zenon, Rabbi, 107

Zepler, Bogunil, 462

"Zevach Pesach," 174

Zilberts, Zavel, 465

Zimbalist, Efrem, 465

Zimro (organization), 464

Zoelner, H., 327

Zohar, the, 57

Zunz, L., 279

Zunzer, Elyokum Badchan, 399, 442; (music), 443; popularity of, 444 